\title{
ILANT ANALYSIS:
} QUATITATIS \& QUANTLTATTVE DRACENDORAB.

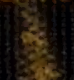


Med

K13632 
thike the Irmoneators Compto

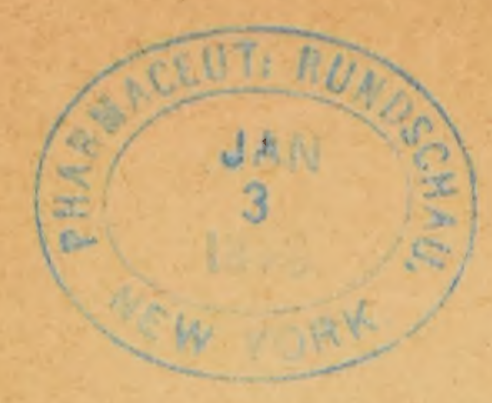

$$
\text { L. } x x x i x
$$

$19 / d$ 


\section{PLANT ANALYSIS:}

QUALITATIVE AND QUANTITATIVE.

BY

G. DRAGENDORFF, Рн.D.,

PROFESSOR OF PHARMACY IN THE UNIVERSTTY OF DORPAT, RUSSTA,

\section{Tramslated from the German}

BY

HENRY G. GREENISH, F.I.C.

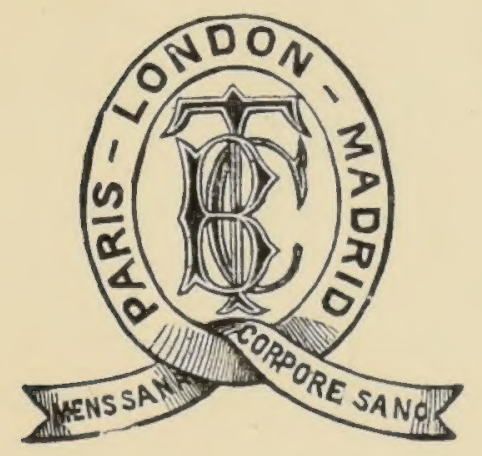

LONDON :

B A I L L I E R , T I N A L L, A N D C OX, 20, KING WILLIAM STREET, STRAND.

1884.

[All Rights Reserved.] 


$$
92133
$$

3802206

\begin{tabular}{|l|l|}
\hline \multicolumn{2}{|c|}{ WELCOME INSTITUTE } \\
\hline COIl. & Well \\
\hline Call & \\
\cline { 2 - 2 } No. & QU \\
\hline & \\
\hline & \\
\hline
\end{tabular}




\section{TRANSLATOR'S PREFACE.}

Soon after the publication in German of Professor Dragendorff's 'Pflanzenanalyse,' it was suggested to me that an English translation of the work would supply a want keenly felt by both English chemists and English pharmacists.

A thorough knowledge of the German language and a practical acquaintance with many of the processes described, gained whilst a pupil in the author's laboratory, would, it was thought, enable me to offer a translation of trustworthy accuracy; and this has been my endeavour. Such alterations or additions as have been considered needful have been made in the text, the proof-sheets of which have been submitted to the author.

Most of the references have been checked, as accuracy in this particular was deemed very important. To many of them, however, access could not easily be had; but it is hoped that even in these cases very few will be found to be incorrect. To secure to English readers the usefulness of the numerous quotations, reference has been frequently made, in brackets, to abstracts or translations that have appeared in English journals.

One word has been employed in a somewhat unusual sense. The solution obtained by treating a substance with spirit is called a ' tincture,' with cold water an 'infusion,' and so on. All such solutions have been included in the general term 'extract;' the latter will not, therefore, necessarily mean the dry residue commonly called 'extract.'

The name 'petroleum spirit' sufficiently indicates the origin of 
the liquid. A petroleum spirit boiling above $60^{\circ} \mathrm{C}$. should not be used. Benzene should boil at $80-81^{\circ} \mathrm{C}$. ('Die gerichtlichchemische Ermittelung von Giften,' Dragendorff, 1876.)

The index will be found more copious than in the original; it has been compiled from the English text.

The high reputation of the author and the favourable reception accorded to his 'Pflanzenanalyse' are a sufficient guarantee for the value of the work.

THE TRANSLATOR.

Losinon, October 1st, 1883. 


\section{AUTHOR'S PREFACE.}

WHILST engaged in collecting the material for my ' Ermittelung von Giften,' I formed the intention of utilizing the knowledge then acquired of the alkaloidal and other constituents of plants to improve and extend the present methods of plant analysis. In accordance with this intention I subsequently discussed in my 'Chemische Werthbestimmung' the detection and estimation of the active principles of some powerful drugs, and at the same time promised further communications on allied substances.

In the meantime, I gradually became convinced of the need of devising a process of analysis that should include as many as possible of the more important constituents of plants. Such a process was, I thought, a desideratum, as I had frequently observed that the methods of examination published in some of my researches were adopted by other chemists in cases in which I myself should have deviated from them.

This consideration was mainly instrumental in inducing me to carry my plan into execution more rapidly than was originally contemplated. No one can be more thoroughly aware than I am myself of the insufficiency of the material at present available for the construction of a systematic process of analysis, nor can anyone be more conscious of the necessity for sifting and improving the contents of the following chapters. I may, however, be permitted to remark that in proposing to my pupils subjects for scientific investigation, I have never lost sight of the plan I had formed, and I have been able to benefit by the results of upwards 
of one hundred dissertations or communications published by myself or by my scholars.

Comparatively few chemists will have learnt, as I have done, that nothing can tend so much to the end aimed at as increased activity in this much-neglected branch of chemistry; and it was the hope of stimulating young chemists to steady, persevering work in testing the methods now placed before them, and devising better ones, that finally decided me. I doubt the possibility of making, without assistance, such progress as I think necessary; and I trust, therefore, that the publication of this little work will be followed by an increase in the number of my fellow-workers.

As will be explained in the introduction, I have endeavoured to construct a method that shall comprise at once both the qualitative and the quantitative, micro- as well as macro-chemical analysis of plants and their constituents. All widely distributed vegetable substances are to be included, the detection of rarer ones facilitated, and the method so arranged that other principles not hitherto observed shall, if present, attract the attention of the investigator.

An exhaustive treatise on all the known constituents of plants would naturally have obscured the method of examination. This result I have endeavoured to avoid by compressing the method of examination proper (Part I.) into the smallest possible limits ; and by following it up with further observations (Part II.) on the characters, etc., of the substances there mentioned. Numerous notes and a systematic, as well as alphabetical, index will guard the reader from confusion.

I have been compelled to restrict myself to the treatment of the more important constituents of plants, that is, those that are of importance to the plant itself, or that play an important part in its economical application. The extracts in which rarer or less important substances are to be looked for have been pointed out, but it has been left for the reader himself to gain further information about them from other sources. Numerous references will aid him in his search, and also direct his attention to a number of analyses that may be of service to him in modifying or extending the process here recommended. 
I have assmencl in my remler's an acpuaintance with the leading principles of general and analytical chemistry, and have, therefore, passerl over parts of the latter, such as ultimate and ashanalysis, since these have been fully treated of elsewhere. Sul,jects that have been discusser at length in my 'Elmittelung' von Ciften,' and 'Chemische Werthbestimmung' starkwirkender' Drogutuen, have been referrel to as briefly as possible. An ultimate analysis is, of course, frequently necessary in order to demonstrate the illentity of a substance isolated during the investigation with some other known body. I have, therefore, collected analyses of the constituents of plants, and have arrangerl them both alphabctically and according to the percentage of carbon they contain.

THE AUTHOR. 



\section{SYSTEMATIC INDEX.}

\section{INTRODUCTION}

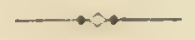

§1. General Remarks, p. 1.—§ 2. Object of the Work; Division of Matter, p. 2.- $\$ 3$. Leading Principles in the Analysis of Plants, p. 3

IETHOD OF EXAMINATION FOR THE MIORE IMPORTANT CONSTITUENTS OF PLANTS

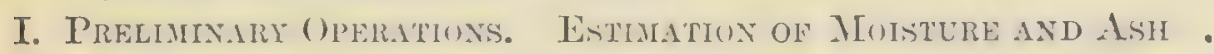

$\S 4$. Drying the Materials, p. 5. - \$5. Treatment of Fresh Plants, 1. 6.-\$ 6. Pulverization, p. 6.—§7. Estimation of Ash, p. 7

II. Examixation of the Substayces Soluble ix Petroleum Spirit; Ethereal and Fixed Oils, Wax, etc. .

§ 8. Value of Petroleum Spirit in the Analysis of Plants, p. 8. § 9. Methods of Extraction, p. 8. $-\$ 10$. Treatment of Fresh Aromatic Vegetable Substances, p. 10

Examination of the Fixed Oil

$\S 11$. Macroscopical and Microscopical Detection; Total Estimation, p. 10.-\$ 12. Composition, Qualitative; Oleic and Linoleic Acids, p. 11.-§. 13. Quantitative; Estimation of Glycerine, p. 12. - \$14. Cetyl-, Cerotyl-, Melyl-Alcohol, p. 13.$\S$ 15. Volatile Fat-Acids, p. 13.—§ 16. Non-volatile FatAcids; Separation, p. 14. $-\S 17$. Determination of Melting. Point, p. 14.-§ 18. Melting-Points of the more important Fat. Acids and Mixtures of the same, p. 15.-§ 19. Further Remarks on Oleic, Ricinoleic Acid, etc., p. 18.

Chlorophyl and Alkaloing Extracted Surultaneously with THe Frxed OrL.

§ 20. Optical Properties and Detection of Chlorophyll, p. 19.$\S 21$. Influence of Fixed Oil in Determining the Solution of Alkaloids, p. 20.

Examination of the Ethereal Oil

$\S$ 22. Detection and Estimation, p. 21.- $\$ 23$. Estimation in the Presence of Fixed Oil and Resin, p. 22.--\$24. Distillation of Larger Quantities of Ethereal Oil, p. 23.-\$25. Examination of the Aqueous Distillate for Volatile Acids, Formic, Acetic, Acrylic, 'Toxicodendric, Salicylous Acid, p. 23.—\$26. Salicylic, Benzoic, Cinnamic Acid, Styracin, Cinnameïn and Aldehydes of above Acids, p. 24. - $\$ 27$. Physical Properties of Ethereal Oils ; Umbelliferone, p. 25.-§ 28. Reactions, p. 26.-§ 29. Ethereal Oils contrining Nitrogen and Sulphur, p. 26. - $\$ 30$. Constituents of Ethereal Oils, p. 27.- $\$ 31$. Hydrocarbons and Oxygenated Constituents, Stearoptenes, p. 2S. -\$ 32. Other 
Constituents, p. 28. - $§ 33$. Aldehydes, p. 29.-§ 34. Volatile Acids, p. 29. - $\$ 35$. Ethereal Salts and the Alcohols contained in them; Primary, Secondary, and Tertiary Alcohols, p. 29.

III. Examination of the Substances Solubie in Ether: Resins and their Aluies

§36. Methods of Extraction ; Fixed Oil, p. 31.—§37. Chlorophyll, p. 32. - $\$ 38$. Portion of the Ethereal Extract Soluble in Water; Hæmatoxylin, Gallic Acid, Glucosides, Alkaloids, etc., p. 32.$\S 39$. Portion Soluble in Alcohol, p. 33. - \$ 40. Microchemical Examination; Treatment of the Substances dissolved by Ether with various Solvents; Crystallization, etc., p. 33. - $\$ 41$. Behaviour of Resin to Aqueous and Alcoholic Potash, Sulphuric Acid, Nitric Acid, Bromine, etc., p. 34.-§ 42. Action of fused Potash, Resorcin, Phloroglucin, Pyrogallol, Protocatechuic and Paroxybenzoic Acids, p. 34.-\$ 43. Dry Distillation of Resin; Umbelliferone, Pyrocatechin, p. 36.-§44. Examination of that Part of the Ethereal Extract dissolved by Alcohul; Pæoniofluorescin, Chrysophanic Acid, etc., p. 36.-\$ 45. Acids produced by the Action of Alkalies on Anliydrides; Santonin, etc., p. 36. - $\$ 46$. Direct Extraction with Ether, p. 36 .

IV. Examination of the Substances Soluble in Absolute Alcohol; Resins, Tannins, Bitter Principles, Alkaloids, Glucoses, etc.

\$ 47. Methods of Extraction; Estimation of Total Substances dis: solved, p. 38. - \$ 48. Estimation of the Portion Soluble in Water ; Phlobaphenes, Alkaloids, etc., p. 38.

Examination of Tannin

$\S 49$. Detection, p. 39.- $\$ 50$. Detection continued, p. $39 .-\$ 51$. Reactions of most Tannins ; Microchemical Detection; Alcohol more suitable for their Extraction than Water, p. 40.-\$ 52. Methods for their Estimation: I. Acetate of Lead, p. 41; Ir. Acetate of Copper, p. 42; III. Stannous Chloride; p. 42 ; IV. Tartar Emetic, p. 42; V. Acetate of Zinc, p. 43 ; VI. Ferric Acetate, p. 43 ; VII. Permanganate of Potassium, p. 43 ; VIII. Chlorinated Lime, Iodic Acid, Iodine, p. 45; IX. Caustic Potash and Atmospheric Air, p. 45 ; X. Cinchonine, p. 45 ; XI. Hide, p. 46; XII. Gelatine, p. 46.-\$ 53. Tannic and Gallic Acid, p. 47

Examination for Glucosines, AlKalords, etc.

\$54. By the Nethol of A ritation, 1). 48. - \$55. List of Bitter Principles, Acids, etc, removable from Acid Solution by Agitation with Petroleum Spirit, Benzene, Chloroform, p. 49.-\$56. Extraction of Alkaloids from Ammoniacal Solution, p. 49.- $\$ 57$. Direct Test for Glucosides, Alkaloids, etc., p. 50.-\$ 58. Isolation and Purification of Substances not removable by Agitation; Separation from Glucose, etc., p. 51.-\$59. Separation of certain Glucosides and Bitter Principles from Tannin, etc., p. 52. - $\$ 60$. Decomposition of Compounds of Lead with Bitter Principles, etc., p. 52.- $\$ 61$. Detection of the Glucosidal Nature of a Substance, p. 53.- $\$ 62$. Other Reactions of Gluco-

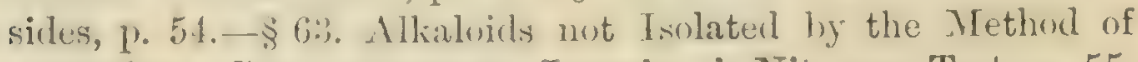
Agitation; Group-reagents; Lassaigne's Nitrogen Test, p. 55. -\$64. Isolation by Precipitation with Potassio-mercuric Iodide, etc., 1) 57.- $\$ 65$. Estimation, 1. 58.—§66. Estimation 
of Theine, p. 62.-\$ 67. Estimation of 'Total Alkaloids in Cinchona, p. 62.-\$ 68. Acidimetric Listimation, p. 63.-\$69. Separation of Alkaloids from one another, 1.63. - \$70. Glucoses Soluble in Alcohol, p. 64.

V. Examination of Substances Soluble in Water: Mucrlage, Saponin, Actid, Glucoses, Saccharoses, etc.

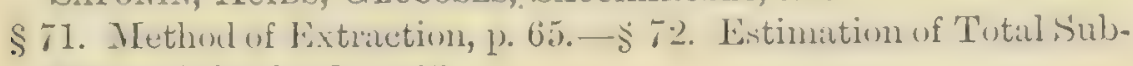
stances Dissolved, p. 65.

Examination for Vegetable Mucilage, Dextrix, Levulix, Tritioin; Stnistrin . . . . .

$\$$ 73. Detection and Estinnation of Mucilage, p. 65.-\$ 74 . Vegetable Albumin and Tarsoates Present in Mucilage-precipitate, p. 66. - 75 . Inulin, p. 66.— $\$$ 76. Dextrin, Levulin, Sinistrin, Triticin; Estimation, p. 67.

SAPONIN AND its Alites

§77. Separation from Dextrin, etc., p. 67.-\$78. Estimation, p. 68. - $\$ 79$. Digitonin, p. 69.

Examination for Acios.

§ 80. Precipitation with Acetate of Lead, p. 69.-§ 81. Malic, Fumaric, Oxalic, Racemic, Citric, Aconitic, 'Tartaric Acid; Narattin, 1. 70.- $\$ 82$. Volumetric Listimation of the foregoing Acids. Free and Combined Acid. Mineral Acids, p. 71.

Examination for Glucoses, Saccharoses, etc.

\$ 8:). Volumetric Extimation of Glucose with Fehling's Solution; Gravimetric Estimation with Copper, p. 72.—§ 84. Knapp's Method; Sachsse's Method, etc., p. 73.-§ 85. Influence of Saccharoses, p. 75.- $\$ 86$. Estimation of Saccharose in presence of Glucose, p. 75. - $\$ 87$. Estimation of Saccharose alone; Inversion, p. 75.- $\$ 88$. Distinguishing Tests for Saccharose and Glucose, p. 76. - \$ 89. Distinctive Characteristics of the Various Saccharoses and Glucoses; Purification, p. 76. - $\$ 90$. Soluble Modification of Arabic Acid; Albuminous Substances not precipitated by Alcohol, p. 76.-\$ 91. Mannite and its Allies, 1. $7 \%$.

Examination for Albumions Soluble in Water, Amonia, Amides, Nitric Acid

\$92. Detection and Estimation; Microchemical Detection; Protoplasm, Cell-nucleus, Crystalloids, p. 78.—§93. Estimation of Legumin, Globulin, and Allied Substances, p. 79.—§94. Vegetable Albumin, p. 79. - $\$ 95$. Estimation of Total Albuminoids Soluble in Water; $(\alpha)$ By Precipitation with Tannin, p. 80.$\S 96$. (b) From the Nitrogen, p. 80.-\$97. Estimation of Ammonia, p. 81.—§98. Amido-compounds, p. 82.—\$99. Estimation of Nitric Acid (a) by Schulze's Method, p. 83.-\$100. (b) By Wulfert-Schloessing's Method, p. 85. -\$ 101. Sclerotic and Cathartic Acid, etc., p. 86.

Examination for Inulin

§ 102. Characteristic Properties of Inulin and Inuloid, p. 86.

VI. Examination of the Substances Soluble in Druete Soda: Metarabic Acid, Albuminoids, Phiobaphene, etc.

$\$ 103$. Wethod of Extraction, 1. \$8.-\$10\%. Detection and Estimation of Albumen, p. 88. - $\$ 105$. Estimation, p. 88.—§ 106. Nitrogenous Substances not dissolved by Dilute Soda, p. 89.- 
\$ 107. Mucilaginous and Albuminous Substances, Phlobaphene, etc., not Precipitated by Acids, p. 89. $-\S 108$. Phlobaphene, Polyporic Acid, Humus, etc., p. 90.

VII. Examination of Substances Soluble in Dilute Hrdrochloric Acid ; Starch, Pararabin, Oxarate of Calcium, etc.

$\S 109$. Extraction, p. 91.- $\$ 110$. Estimation of Oxalate of Calcium, p. 91.- $\$ 111$. Estimation of Oxalate of Calcium and Pararabin, p. 92.-\$ 112. Estimation of Pararabin, p. 93.-\$ 113. Estimation of Oxalate of Calcium and Starch, p. 93.-§ 114. Estimation of Oxalate of Calcium, Starch, and Pararabin, p. 93.$\$ 115$. Estimation of Starch, p. 93.

VIII. Estidation of Lignin and its Allies, and of Cellulose .

$\S 116$. Lignin, Incrusting and Cuticular Substances, Suberin, p. 95. - $\$ 117$. Estimation of Cellulose, p. 96.

Concluding Remarks

$\S$ 118. Remarks on the Method of Analysis recommended, p. 97.- $\$ 119$. On the Object of Plant Analysis, p. 97.

SPECIAL METHODS ; SUPPLEMENTARY NOTES, ETC

Fats and their Constituents, Cholesterin, Fulicin, etc.

$\$ 120$. Estimation of Fat in General; Apparatus for Extraction, p. 99. $-\$ 121$. Resinification, p. 101.— 122. Elaidin-test, p. 101. - $\$ 123$. Behaviour to Sulphuric Acid, p. 102. - 124. Behaviour to other Reagents, p. 102.-\$125. Detection and Estimation of Free Fat Acids contaminating Fixed Oils, p. 105. - $\$$ 126. Detection and Estimation of Cholesterin, Phytosterin, Filicin, Kosin, Euphorbon, Lactucon, Lactucerin, Echicerin, Cynanchocerin, Helenin, Coumarin, Melilotic Acid, Styrol, Myroxocarpin, Diosmin, Kämpferid, Asaron, Angelicin, Anemonol, Capsicin, Capsaicin, Amyrin, Bryoïdin, p. 106.$\$ 127$. Caoutchouc, p. 109.- \$128. Estimation of Glycerine, p. 109.— $\$ 129$. Cetyl-, Cerotyl-, Melyl-alcohol; Cerotene; Vegetable Wax; Microchemical Detection of Wax, p. 110. $\$ 130$. Estimation of Oleic Acid, Linoleic Acid, Lauric Acid; Separation of the latter from Oleic and Myristic Acid; of Oleic from Stearic Acid, p. 111. - § 131. Separation of Fat. acids from Resin-acids, p. 112.

Chlorophyll and its Allies

$\S 132$. Remarks on the Chemistry of Chlorophyll, p. 113.$\S 133$. Possibility of Estimating, p. 115.- $\$ 134$. Erythrophyll and Chlorophyllan, etc., p. 115. - $\$ 135$. Xanthophyll, Hypo. chlorin, Etiolin, Anthoxanthin, p. 116.

Ethereal Oils, Votatide Acids, etc.

§ 136. Examples of Extination, 1) 117.-\$ 1:37. Fimation with Bisulphide of Carbon, p. 118. - $\$ 138$. Mixtures of Fixed and Ethereal Oils, Resin, etc, p. 118.— 139. Volatile גcids : Angelic, Methylcrotonic, Capric, Caprylic, Enanthic, Caproic, Valerianic, Butyric, Propionic, Acetic, Formic Acids and their Separation, p. 119.— $-\$ 140$. Identification of Volatile Acids by Saturating Power, ctc., p. 120.- $\$ 141$. Optical Tests for Ethereal Oils, Solubility, p. 120. - $\$ 142$. Colour-reactions of Ethereal Oils, p. 121.-\$ 143. Tractional Distillation, p. 124. - \$144. Examples of Analyses, p. 125. 
Resins, Anthraquinone-Derivatives, Galitc Acid, Bitter PrixCIPLES, ETC.

\$145. Coniferous Resin-Acids; Podocarpic Acid, Phyllic Acid, Mongumic Acid, Pronia acid, Chrysin, etc.; More important Methods of Isolating Resin-Acids, p. 127.-\$ 146. More important Commercial Resins; Estimation of Ethereal Oil, Mucilage, etc., p. 129.-§ 147. Pæonio-fluorescin, p. 131.$\$$ 148. Anthraquinone-derivatives, Chrysophanic Acid, Chrysarobin, Emodin, Frangulic Acid, Alizarin, Purpurin, Sclererythrin, Ruberythric Acid, Rhinacanthin, Alkannin, Bixin, Curcumin, etc., p. 131.- $\$ 149$. Recognition of Anthraquinonederivatives, p. 136.-§150. Hæmatoxylin, Brasillin, Santalin, p. 136. - $\$ 151$. Gallic Acid, Catechin, Pyrocatechin ; Detection, Estimation, etc., p. 137.-\$152. Quercitrin, Quercetin, Thujin, Rutin, Robinin, Luteolin, Gentisin, Constituents of Podophyllin, p. 138. - $\$ 153$. Jalapin and Allied Resin-glucosides; Convolvulin, Tampicin, Turpethin, etc., p. 140.— $\$ 154$. Santonin ; Estimation, p. 141.- $\$ 155$. Picrotoxin, Digitalin, Digitoxin, Digitaleïn, Digitonin, Digitin, Coriamyrtin, Ericolin, Vanillin (Estimation), Ostruthiin, Peucedanin, Oreoselon, Athamanthin, Laserpitin, Cubebin, Betulin, Anacardic Acid, Cardol, p. 142. $\$ 156$. Other Bitter Principles Soluble in Ether; Absinthiin, Elaterin, Hop-Bitters, Meconin, Meconic Acid, Methysticin, Quassiin, etc., p. 146. $-\S$ 157. Lichen Acids and their Allies: Roccellic, Lecanoric, Orsellinic, Gyrophoric, Parellic, Patellaric, Evemic, Everninic, Usnic, Carbusnic, Vulpic, Lrythric, Beta-erythric, Cetraric, Lichenostearic, Stictic, Lobaric, Atranoric Acid; Ceratophyllin, Picroerythrin, Picrolichenin, Variolinin, Zeorin, Sordidin, Calycin, etc., p. 149.-\$158. Orcin and Betaorcin; Estimation of Orcin, p. 152.

TANNTS

\$159. Constitution, p. 152.— $\$ 160$. Glucosidal Nature or otherwise Decomposition-products, Phlobaphene, etc., p. 153.-§ 161. Proneness to Decomposition, p. 154.- $\$ 162$. Preparation in a State of Purity, p. 155.-\$ 163. Tannic Acids sparingly Soluble in Water: Tannins of Alder and Hops, p. 156.- $\$ 164$. Occurrence of two different Tannins in the same Plant, p. 156.$\$ 165$. Notes on the more important Tannins; Tannic Acids from Catechu, Rhatany, Kino, Tormentilla, Bistort, Horsechestnut, Sumach, Myrobalans, Divi-divi, Bablah fruits, Pomegranate, Tea, Coffee, Oak, Willow, Elm, Fir, Birch, Acacia, Male-fern, Cinchona, Cinchona-nova, Ipecacuanha, Mate and Celastrus; Morin-tannic, Gallo-tannic, Leditannic and Nucitannic Acid, p. 156.

OTHRr GuUcosides

$\$ 160$. Cyclopin, Rhinanthin, p. 16\%, - $\$ 167$. Solubility; 1)escription of the more important Glucosides. Amygdalin and Laurocerasin, Estimation; Myronic Acid, Estimation; Sinalbin (and Sulphocyanate of Sinapine), Menyanthin, Pinipicrin, Coniferin, Arbutin, Daphnin, Salicin, Populin, Benzohelicin, Philyrin, Phlorrbizin, Asculin, Fraxin, Syringin, Globularin, Pittosporin, Samaderin, Colocynthin, Bryonin, Ononin, Apiin, Datiscin, Physalin, Dulcamarin, Hesperidin, Crocin, Glycyr- 
rhizin, Panaquillon, Thevetin, Chamælirin, Gratiolin, Paridin, Convallarin, Convallamarin, Helleborin and Helleborein, Scillaïn, Saponin, Digitonin, Senegin, Melanthin, Parillin, Sapogenin, etc., Indican, Indigo-blue, p. 164.-\$ 168. Nonglucosidal Bitter Principles, Cusparin, Chinovin, Cnicin, p. 175. — 169. Aloins, p. 176. -\$170. Carthamin, p. 178.

AlKAlOIDS . • . . .

$\S 171$. Colour Reactions of the more important Alkaloids, p. 178. - $\$ 172$. Identification, p. 181.—§ 173. Double Chlorides with Gold and Platinum, p. 181.—§ 174. Further Remarks on Titration with Potassio-mercuric Iodide; Atropine, Hyoscyamine, Coniine, Strychnine and Brucine, Morphine, Narcotine, Chelidonine, Veratrine, Sabadilline and Sabatrine, Calabarine and Physostigmine, p. 182.—§ 175. Estimation of Coniine with Phosphomolybdic Acid; of Pilocarpine; Application of Phosphotungstic Acid, Tannic Acid, Picric Acid in the Estimation of Alkaloids, p. 184.- $\$ 176$. Determination of Alkaloid in Tea, Coffee, Guarana; Lieventhal's and Claus's Methods, p. 186. - $\$ 177$. Estimation of Theobromine in Cacao; Methods of Trojanowsky and Wolfram, p. 187.-_ 178. Estimation of Piperine, p. 188. $\$ 179$. Volumetric Estimation of Nicotine, p. 188. - $\$$ 180. Estimation of Coniine, p. 189.$\S 181$. Separation of two or more Alkaloids from one another ; Jervine and Veratroidine, Paricine, Narceïne and Narcotine, Morphine and Codeine, Morphine and Narcotine, Strychnine and Brucine, p. 189.— $\$ 182$. Separation by Solvents; Strychnine and Brucine; Colchicine and Colchiceine; Cinchonine and Amorphous Alkaloid; Delphinine and Delphinoïdine; Morphine and Narcotine; Morphine, Codeïne, and Thebaine; Delphinine, Delphinoidine and Staphisagrine, p. 191.—§183. Separation of Quinine and Cinchonidine from other Cinchona Alkaloids; of Quinidine from Cinchonine; of Quinine from Cinchonidine; of Strychnine from Brucine: of Calabarine from Physostigmine; of Chelidonine from Sanguinarine; of Muscarine from Amanitine; Paytine, etc., p. 193.—§ 184. Separation of the more important Cinchona Alkaloids from one another, p. 194.— $\$ 185$. Estimation of Cinchona-Alkaloids by Polarization, p. 198.—§ 186. Rarer Cinchona-Alkaloids; Aricine, Cusconine, Quinamine; Paricine, Paytine, p. 198. - $\$ 187$. Estimation of the more important Opium-Alkaloids, p. 199. — $\$ 188$. Methods of Procter, Prollius, Fliickiger, p. 200.$\S 189$. Other Alkaloids; Ergotinine and Picrosclerotine; Curarine, Erythrophlœine, Lobeliine, Conessine, or Wrightiine, Harmaline and Harmine, Surinamine, Aribine, Atherospermine, Rhoadine, Violine, Beberine, Belladonnine, Cocaine and Hygrine, Chlorogenine and Porphyrine, Corydaline, Cytisine, Ditamine, Geissospermine, Aspidospermine, Dulcamarine, Glaucine, Fumarine, etc., p. 201.-\$190. Amanitine, Muscarine, Choline, Betaine, 1) 205.-\$191. Asparagine, Glutamine and Lstimation of the same, p. 206.— $\$ 192$. Leucine, Chenopodine, Tyrosine, Rhatanhin, p. 207.

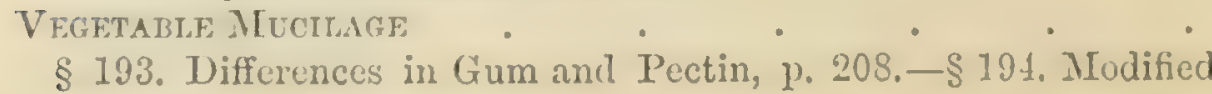


Method of Examination for Gum, p. 209.- $\$ 195$. Characters of Soluble Vegetable Mucilage (Arabin, Arabic or Gummic Acid); Metarabic Acid, p. 210.—§196. Behaviour to Reagents; Commercial Varieties of Gum-arabic, p. 211.- $\$ 197$. Separation of Arabin from Dextrin, Glucose, Saccharose, etc., p. 212.

Dextrin, Triticin, Levulin, etc. - •

$\S$ 198. Distinctive Characters, p. 212.—\$199. Formation of Alcoholates; Composition; Estimation by Titration and Polarization, p. 213.

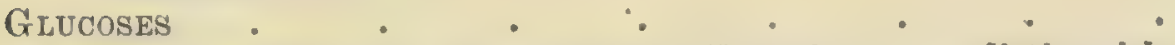

\$ 200. Detection of Grape-sugar; Reactions to distinguish Grape-sugar from Cane-sugar, Milk-sugar, Mannite, etc., p. 214.- $\$ 201$. Detection and Estimation in Presence of Dextrin, p. 215.- $\$ 202$. Detection of Dextrin in Presence of Cane-sugar, p. 215. - $\$ 203$. Estimation of Glucoses in Presence of Cane-sugar, p. 215.- $\$ 204$. By Fermentation; Influence of Substances retarding Fermentation, p. 216.-§ 205. Characteristic Properties of Grape-, Fruit-, Invert-, Salicin-, and Caragheensugar; Phlorose, Arabinose, Galactose, p. 217._\$ 206. Inosite Sorbin, Eucalyn, Nucite, p. 219.-\$207. Cane and Milk-sugar; Maltose, Melitose, Melezitose, Mycose, p. 220._§ 208. Estimation of Glucoses and Saccharoses by Polarization, p. 221. $\S 209$. Estimation of Two Glucoses by Titration and Polarization, p. 222. - \$210. Estimation of Cane- and Invert-sugar, p. 223. - §211. Estimation of Three Sugars in Solution together, p. 224.—§ 212. Mannite, Dulcite (Melampyrite), Isodulcite (Rhamnodulcite), Hesperidin-sugar, Sorbite, p. 224.§ 213. Mannitan, Quercite, Pinite, Abietite, p. 225.

ACIDS

§ 214. Reactions of Malic Acid; Separation from Oxalic, Tartaric, Citric, Succinic, Gallic, Tannic, Benzoic, Acetic, Formic Acid, p. 214.- $\$ 215$. Estimation of Citric Acid as Barium-salt, p. 206. - $\$ 216$. Reactions of Citric Acid; Aconitic Acid, p. 227.- $\$ 217$. Estimation of Tartaric Acid as Acid Tartrate of Potassium, p. 228.- $\$ 218$. Estimation of Tartaric and Citric Acid when present together; Separation from Malic, Oxalic, Phosphoric, and Sulphuric Acid; Racemic Acid, p. 228. -\$219. Oxalic Acid; Separation from Tartaric and Citric Acid; Isolation from Oxalate of Calcium, p. 230.$\S 220$. Succinic Acid; Separation from Oxalic, Tartaric, and Citric Acid, p. 230.-§ 221. Fumaric and Maleï Acids; Kinic Acid; Rubichloric Acid, p. 232. —§ 222. Lactic Acid, p. 232.-§ 233. Glycolic Acid, p. 233.

Alibuminolds, ETc. • • • • • • $\S 224$. Calculation of Nitrogen into Albuminoids, p. 234.-§ 225 . Repetition of Estimation of Legumin, p. 234.- $\$ 226$. Caseïn, Glutencaseïn, Fibrin; Globulin, p. 235.-§ 227 . Vitellin, p. 236. - $\$ 228$. Myosin, p. 236. - $\$ 229$. Estimation of Albuminoids by Titration with Tannin, p. 236. - $\$ 230$. Comparison of Results with those of the Estimation by Coagulation; Ferments ; Diastase, Invertin, Emulsin, Myrosin, Papayotin, etc., p. 237. - $\$ 231$. Estimation of Albuminoids with Acetate of 
Copper, p. 238. - $\$ 232$. With Acetate of Lead, p. 238. - 233.

Estimation of Albuminoids Soluble in Dilute Acid; Albuminoids capable of being assimilated, p. 240. $\$ 234$. Albuminoids Soluble in Spirit; Glutenfibrin, Gliadin, Mucedin, p. 241.$\$ 235$. Properties of the same, p. 242. - $\$ 236$. Gluten ; Estimation, p. 243.-\$237. Albuminoids precipitated simultaneously with Metarabic Acid, etc., p. 243.-\$238. Nitrogenous Substances Insoluble in Water, Dilute Acid, and Dilute Alkali, p. 244.

Ame Compoustos . . . . . .

$\S 239$. Distinctive Characters of Monamines, Diamines, etc., p. 244. $\$ 240$. Separation of Ethyl-and Methyl-amine from the corresponding Di-and Tri-amines, p. 244.-\$ 241. Approximate Estimation of Amides, p. 245. - § 242. Cathartic Acid, Sclerotic Acid, Scleromucin, Assay of Rhubarb, p. 247.

Staroh, Lichenix, Wood-gum, ettc. .

$\S 243$. Constituents of Starch, p. 249.- $\$ 244$. Constituents of the Cell-wall that turn Blue with Iodine; Lichen-starch, p. 250.$\$ 245$. Lichenin and Gulose, p. 251.--\$246. Wood-gum, p. 252.

Cellulose, Lignix, and Allied Substances

\$247. Researches of Frémy and Terreil on Composition of Woodytissue; Cuticular and Incrusting Substances; Modifications of Cellulose, Iignin (Vasculose, Incrusting Substances), Suberin, Glyco-lignose, Glyco-drupose, p. 252.-\$248. Composition of Cellulose, p. 256.- $\$ 249$. Properties of the Various Forms of Cellulose, p. 256. - $\$ 250$. Crude Fibre ; Estimation, p. 257.

PERCENTAGE COMPOSITION OF THE CONSTITUENTS OF PLANTS REFERRED TO

COMPOSITION OF THE MORE JMPORTANT CONSTITLENTS OF PLANTS ARRANGED ACCORDING TO THE PERCENTAGE OF CARBON 


\section{PLANT ANALYSIS:}

\section{QUALITATIVE AND QUANTITATIVE.}

\section{INTRODUCTION.}

\$ 1. AN accurate qualitative and quantitative analysis of a plant or vegretalile substance is not unfrequently referred to as one of the nost difficult tasks that a chemist may be called upon to undertake. Attention is very properly directed to the great number of species of plants that occur in nature, to the great abundance and variety of their chemical constituents, and to the circumstance that almost every skilful amalysis of a plant that has not previously been examined yielis new, hitherto unknown products. Prominence is also justly given to the fact that the analysis of regetable substances differ's from that of minerals, inasmuch as the elements present in the latter hare in many instances only to be seprarated and weighed or measured, either as such or in the form of certain of their simpler, more easily recognisable compounds, whilst in the anilysis of plants it fin more frepuently occurs that the proximate principles themselves must be first separated before they can be examined or weighed. These reasons are all admissible; we are, moreover, justified in pointing out, amongst other numerous difficulties encountered in the analysis of plants, the great proneness to recomposition of many of the constituents of regetable substances and the errors that may arise therefrom, not only in the estimation of these bolies themselves, but also of such suhstances as may accompany them. But surely these considerations should not tend to prevent investigations from leeing carried ont which are equally important for scientific hotany and chemistry, for medicine, pharmacy, dictetics, agriculture, etc. By systematically arranging 
the methods of examination hitherto deviserl, either for the estimation of a single constituent or for the separation of several substances contained in a plant, I hoped to succeed in inducing other's to conduct investigations in a department of chemistry at present so much neglected; and it was in that hope that I decided upon the compilation of this work. In it I trust to be able to show that for the separate estimation of many substances we have methods at our disposal which, in point of accuracy, are nearly abreast of the processes employed for the determination of mineral constituents, and that we can often obtain results really serviceable in the investigation of the more important component substances contained in a plant. I especially hope to succeed in showing that analyses of plants possess in one respect an advantage over the analyses of minerals, inasmuch as it often happens, in examining mixtures or conglomerates of several chemical individuals, that in the latter case a much less satisfactory insight into the constitution can be obtained than in the former. The elements, for instance, of which a granite is composed can easily be determined by inorganic analysis, but it is exceedingly difficult to ascertain with exactitude in what quantity each separate mineral occurring in the granite is present. But in the analysis of vegetable substances the endeavour is made from the outset to separate the different chemical individuals from one another, and by the use of various solvents this is frequently possible. In this respect, therefore, the analysis of a plant can often he made more complete than that of a mineral.

\$2. The object that I have sought to attain in this work was the compilation of a methor of analysis applicable to the qualitative and quantitative examination of regetahle sulsstances of both known and unknown composition, and of an introduction to the qualitative and quantitative determination of the rarious more important constituents of plants with which we are at present acquainted.

I need scarcely observe that I have given the fullest possible consideration to the question as to which tissues of the plant contain the various constituents, and have therefore, for that purpose, made use of microchemical analysis.

With reference to the arrangement of the matter in the work, I would remark that in the method of analysis contained in 
Part I., I have not separated the qualitative and the quantitative determinations of the more important substances from each other. I have made the method of separation serve as is leading principle, and have therefore grouped together the constituents of plants in such a manner that all those may be considered together that are isolated by the same means. I have then placed in sub-divisions of the principal groups such substances as may be isolated by special methods, and these latter are also discussed.

The more important peculiarities of the various bodies belonging to the different groups, as well as special methods for the estimation of some of them, have been placed in Part II., which has been so arranged as to follow closely on Part $I$. in the form of a supplement. In this way I hope to be more easily able to avoid repetition, and especially to facilitate investigations in which the substances that may be found are unknown. Thus a method of analysis, taking account of the more important constituents of plants, may be traced through the work.

\$3. It has always been accepted, as an important principle, by those who have been engaged in plant analysis, that the constituents present should be separated as far as possible by means of different solvents. I have also followed this plan, which has in many instances proved itself adapted to the attainment of the object in view, and I concur with those chemists who recommend the use, as far as practicable, of the most indifferent solvents. If, in the analyses of vegetable substances I have alrearly made, I have deviated from the course followed by my predecessors, ${ }^{1}$ I have done so, first, in increasing the number of solvents; and secondly, in varying the order in which those solvents were allowed to act upon the substances under examination. I shall subsequently show that this may have a great influence on the result of the analysis.

${ }^{1}$ I draw particular attention here to Rochleder's 'Anleitung zur Analyse von Pflanzen und Pflanzentheilen' (Wiirzburg, 1858), which I regard as opening up new ground in this subject. See also Wittstein, 'Anleitung zur chemischen Analyse von Pflanzentheilen' (Nördlingen, 1568), and an Finglish translation of the same by Baron von Mueller, 'The Organic Constituents of Plants and Vegretable Substances and their Chemical Analysis' (ALelbourne, 1878); Arata, 'Guja Paralel Análysis immediato de los Vejetales' (Buenos Aires, 1869); and a paper by Parsons in the American Chemical Joumal, vol. i. No. 6 . 
It will be seen from the foregoing that the principal groups into which I have divided the matter to he treaterl are formed by the behaviour of the plant constituents to solvents.

In a chapter preceding the method of examination proper, I have given a few general rules for plant analysis. 


\section{METHOD OF ANALYSIS FOR THE MIORE IMPORTANT CONSTITUENTS OF PLANTS.}

I.

\section{Prelininary Operations. Estumation of Moisture AND AsH.}

\$4. Drying.-In the majority of cases the parts of plants at our disposal for analysis have already been dried, and we can only take-account of the small amount of moisture that has been albsorbed from the air in consequence of the hygroscopic nature of the vegetable tissue in contact with it. I can only recommend that the estimation of moisture, for which a temperature not exceeding $110^{\circ}$ will as a rule suffice, be made with a small quantity of the substance. I should not advise the drying of the material intender for use in the investigations to be discussed in the following chapters, because, even at a temperature of $100^{\circ}$ to $110^{\circ}$, a number of constituents prone to decomposition undergo chemical change. It will be sufficient if the moisture be estimated in about 2 to :) grams, that is, if that quantity be kept at the temperature inclicated till it ceases to lose weight. By means of this determination the results of all other estimations can be calculated to the dry substance. ${ }^{1}$

${ }^{1}$ An apparatus for drying material for agricultural (chemical) analysis has been described by Hugo Schulz (Landw. Versuchsstat, vol. ix. p. 213) ; one for the rapid estimation of water in organic substances by Gawalovski in the Zeitschrift f. anal. Chemie, xiii. 267 (1874). For the determination of moisture in fruits rich in sugar, such as apples, etc., Tschaplowitz (ibid. Jg. 19, p. 243, 1880), recommends the slices to be first extracted with absolute alcohol containing 10 to 20 per cent. of ether, and then dried at $100^{\circ}$ to $110^{\circ}$, the ether-alcohol solution to be evaporated, the residue heated to $85^{\circ}$ to $90^{\circ}$ and then added to the dry substance. See also Reischaner in the Jahresb. f. Pharm. Jg. 1867, p. 8 (Amer. Journ. Pharm. xxxviii. 74); Schoonbroodt, 
That portion which has served for the determination of the moisture can subsequently be used for the estimation of the total ash.

\$ 5. Treatment of Fresh Plants. - If fresh plants or parts of the same are to be examined it will be advisable in many cases, at least if a quantitative examination is to be made, to first dry the material, or it will at any rate be necessary for those portions which are subsequently to be treated with petroleum spirit, ether, alcohol, and similar menstrua. Here, too, it will be desirable to make an accurate estimation of the moisture, and in doing so it is advisable to allow the temperature to rise very gradually to $100^{\circ}$ or $110^{\circ}$. The greater part of the material can as a rule be dried at a temperature under $30^{\circ}$ till in a condition suitable for powdering, and the amount of moisture still retained in it can be determined in a small portion by a separate estimation. In drying fleshy fruits or roots care should be taken not to reduce them to too fine a state of division. Leaves which are not too fleshy do not require any preparation at all. It is very desirable that as little of the cell-tissue as possible should be depriver of its natural covering, as by doing so the action of the air on the decomposable constituents is only facilitated. With substances which are very rich in sugar it is better not to dry the portions destined for the estimation of the saccharine matter at all, but to examine them in the fresh state. The same holds good for such substances as are very rich in ethereal oil, or contain volatile acrid compounds; I shall sulsequently show that such compounds may be easily isolated from, and determined in, the fresh plants. Of course the amount of such rolatile substances as may be found by other means must be deducted from the result of the determination of moisture.

\$6. Powdering.-It is of the greatest importance that the material for the various estimations should he uniformly mixed and reduced to the very finest powder possible. It may be asserterl that the greatest errors marle in the analysis of plints are due to the material not having been reduced to a sufficiently fine state of sublivision. Estimations of oil made with ether or petroleum spirit often show differences of several mits per cent.,

ibid. Jg. 1869, p. 9. (Pharm. Journ. Trans. [2], xi. 84). In the latter work illustrations are given of the difference in composition that may be met with in fresh and dried, and in quickly and slowly dried, vegetable substances. 
because these solvents do not penetrate into the cells, lut only dissolve that which is adhering to the exterial surfices of the object. It must be admitted that it is often very difficult to reduce a vegetable substance to an impalpable powder, but the necessity of sparing no trouble in this respect must be most strongly urged. It may sometimes be expedient to dry very hard substances, such as seels, etc., at $100^{\circ}$ to $110^{\circ}$ before powdering them. Coffee-seeds may thus be reduced to quite a fine powder, especially if triturated in an agate mortar with a known quantity of powdered glass or sharp sand (that has been previously treated with hydrochloric acid). Somewhat hard substances may occasionally be grated upon a fine grater with advantage, and then powlered as above. Tough material, too, and such as is to be examined in the fresh state, may loe generally prepared in this way. In working with substances containing: much fixed oil it is sometimes expedient to dry the residue after the first extraction with petroleum spirit, etc., powder it again and repeat the extraction.

$\$ 7$. Estimution of Ash. - With regard to the total ash, which is usually estimated in plant analysis, reference may be made in the majority of cases to the generally known methods of procedure. For vegetable substances that are rery difficult to incinerate, it is adrisable, after carhonization, to cool, powder as finely as possil,le, and continue the heating, placing a cylindrical tube vertically alove the platinum clish, so as to create a current of air. Or the incineration may he conducted in a Hempel's jacket with access of air. If easily fusible salts are present and prevent complete incineration, the admixture of about an equal weight of nitrate of ammonium with the cooled mass, and repeated ignition, may reuder good service. Or the carbonized mass may be mixed with a weighed quantity of oxide of iron, and the incineration continued. ${ }^{1}$

After weighing the ash the quantity of carhonic acid present in it is to be determined and dediucted from the total weight. The carbonic aciel is simply a part of the organic matter, the rest of which has been burnt off, and is to he determined in other ways. It is also desirable to test the ash for sand, and finally, if a complete analysis is not required, to estimate at least the total quantity of phosphoric and sulphuric acid and potash. (See also \$82).

${ }^{I}$ Compare also Borntrïger, Zeitschr. fo anal. Chemie, B. xvii. p. 440 (1878). 
II.

Examination of the Substances Solubie in Petroleuni SPIRIT.

ETHEREAL AND FATTY OILS, WAX, ETC.

\$8. Petroleum Spinit.-I have proposed the use of petroleum spirit in the analysis of plants on account of its being a relatively good solvent for most ethereal and fatty oils, but not for the majority of resins and allied substances which would have been simultaneously brought into solution had ether been.used. We have therefore in this liquid a means of more accurately estimating ethereal and fitty oils than was formerly possible with ether. Another arlvantage which petroleum spirit possesses over ether is that it does not, like ether, cause a coagulation of soluble albuminous compounds in substances rich in such bodies. As it is desirable to deprive the material of fat before extracting the soluble albuminous substances for their quantitative determination, the whole or part of the residue after treatment with petroleum spirit may be very well employerl for this purpose. A chief comlition for the suceessful application of petroleum spirit is that it be very volatile. It must therefore be purified by repeated fractional distillation, and care taken that it contains no compound boiling above $45^{\circ}$. It is, moreover, desirable to distil it over fat (lard) to free it from some of the impurities of more powerful odour.

\$ 9. Extraction with Petroleum Spirit.-It has already been mentioned in $\$ 6$ that vegetable substances to be extracted with petroleum spirit must be reduced to the finest powder possible. $\mathrm{ft}$ is advisable in such extractions to employ a known quantity of petroleum spirit-say five to ten times that of the substance to be treated; or, better still, for every gram of the latter $10 \mathrm{cc}$. of the former. A small narrow cylinder with glass stopper may 
bo user for this purpose. It should be weighed immediately after the introduction of sulsstance and menstruum; or, if graduated, the rolume only oecupied by both need he noted. They may be macerated for about eight days, shaking several times daily, and then made up to the original volume or weight by the ackition of petroleum spirit, to replace any that may have been lost by evaporation. This having been done, it is sometimes only necessary to eraporate an aliquot part of the solution, and calculate from the residue the weight of the substances which have been brought into solution. ${ }^{1}$

The supernatant liquid frequently becomes so perfectly clear on standing, that all trouble of filtration may be avoided by removing with a pipette a definite volume, which may then be evaporated and weighed.2 ${ }^{2}$

This method of procedure is especially to be recommended if the object under examination contains ethereal oil, in which case all washing of the residue, or any dilution whatever of the petroleumspirit solution, should be carefully avoirled. The more concentrated the petroleum-spirit extract is, the more accurate will be the gravimetric estimation of the ethereal oil. If, however, the petroleum-spirit solution is to be filtered off and the residue on the filter washed, care should be taken that a funnel with ground edges be employed and kept well covered.

For the evalporation of the petroleum-spirit solution no porcelain basin or round-bottomed platinum or glass dish should be used, on account of the loss easily caused by the capillarity of its sides. It is expedient, as a rule, to use a flat-bottomed glass dish with vertical sides and well-ground edges, a ground-glass plate acting as a cover. If the presence of a rapidly resinifying oil is suspected, the petroleum-spirit solution may he evaporated in a tared flask by passing a current of carbonic acid gas through it whilst kept surrounded with warm water. (See also § 138.)

${ }^{1}$ In this case, a slight error is introduced into the calculation, by the increased volume of the petroleum spirit clue to dissolved oil. But this will, as a rule, be so small that it may be entirely neglected; or, if desirable, a correction may be made after weighing the residual oil, since we know that the specific gravity of the fatty oils hitherto examined ranges from 0.91 to 0.925 .

${ }^{2}$ Even when the petroleum-spirit solution does not become quite clear on standing, as is often the case when seeds are under examination, it is better to measure off a quantity with a pipette, filter it, and wash the filter and the mouth of the funnel (on the outside) with petroleum spirit, than to filter off the whole of the liquid and measure off a quantity for evaporation. 
Shallow evaporating dishes, which can be enclosed hetween clamper glasses and weighed, may also be used if ethereal oil is present; but they must be placed in other larger dishes during the evaporation of the petroleum spirit. It is, however, preferable even in these cases to use the glass dishes with vertical sides previously described.

$\$ 10$. Treutment of Fresh Plants.-Fresh, very aromatic parts of plants may be examined as stated in $\$ 5$, without being previonsly dried.' 'They should be as finely divided as possible by pressure and trituration, then packed in a small percolator, and the moisture present displaced by the smallest passible quantity of petroleum spirit or ether; the latter is, perhaps, in this case to be preferred. The menstrum itself must subsequently be displaced by water. The liquids may be received in a graduated burette fitted with a glass stop-cock and long fine point; in this the ether or petroleum suririt may be allowed to separate, and an aliquot part measured off for evaporation. (See also \$22 and following.)

\section{EXAMINATION OF THE FIXED OIL.}

\$ 11. Detection and Estimation.-We will first consider the simpler case in which the petroleum spirit (or ether) dissolves fixed but not ethereal oil. The absence of the latter may be recognised by the light colour of the petroleum-spirit solution and its residue after evaporation, and by the alsence of any aromatic orlour which would otherwise be given off during the evilporation of the last traces of solvent, the operation being conducted at the ordinary temperature. That we really have a fixed oil to deal with may be shown by the uniform character of the spot left on evaporating a drop of the petroleum-spirit solution on a sheet of blue notepaper.

On examining vegetable sulstances under the mirrosenpe, fixed oil is seen in the form of small globules of high refracting power, which dissolve in petrolemu spirit, ether, and lisulphide of carbon, and are saponified by a dilute solution of soda. If the objects examined are fresh it is advisable to treat the section with a relatively large quantity of water. Concentrated solutions of sugar and similar sulsstances have the power of dissolving oil, which is, however, again separrated on the addition of a large

i For information concerning the so-called dietheralysis, see Legrip, Union Pharm. V. vi. p. 65 (1876). 
quantity of water. I lo not think it improbable that in the juice of fresh plants oil is held in solution by carlohydrates and does not show itself until separated by dilution with water. And in examining the expressed juice of fresh plants, or concentrated infusions of the same, it is well to bear this peculiarity of oils in mind.

To determine the totul amount of fixed oil, the residue from the evaporation of part or all of the petrolem-spirit solution is dried at $100^{\circ}$ till the weight remains constant, which may then be noted. For further information respecting the estimation of fixed oils, and especially the apparatus to be used, see \$120. Compare also § 36 .

The fatty residue so obtained may be kept for some time, to observe whether partial or complete solidification does not gradually take place. The solubility in absolute alcohol, spirit of 95 and 90 per cent., may also be tested, to ascertain whether free fatty acids, cholesterin, resinous bodies, caoutchouc, or such compounds, can be isolated. (Cf. $\$ 125,126,127,130$.) It may also be olserved whether the oil is easy or diflicult to saponify, whether the soap is soft or hard, colourless or coloured, whether glycerine is separated during saponification, and the fat consequently contain glycerides (ef. § 13), and whether the oil resinifies readily on exposure to the air (\$ 121). Finally, the melting and solidifying points may be taken. Concerning this determination see $\S 17$.

\$ 12. Composition.- - If a further insight into the composition of the fixed oil is required, larger quantities must be prepared either by extraction, or by expression followed by extraction, according to the nature of the material and the quantity of oil it contains.

A few quulitutive experiments may first be male with a portion of this oil. If it remains fluid at ordinary temperatures the action of nitrous acid may be tried. The solidification of the oil would prove the presence of oleic $(\$ \$ 19,130)$ or an allied acid capable of conversion into elitidin (\$ 12\%). In this case, on mixing the oil with about one-fifth of its volume of concentrated sulphuric acid, but little heat will he evolverl, whilst comprounds of the drying linoleic acid (\$ 130) and its allies generally canse a considerable rise in temperature $(\$ 1:: 3)$. For comparison parallel experiments maly be marle with linseer and almond or 
olive oil. Any colouration produced by the first drops of sulphuric acid should be noted, and the experiment repeated with a small quantity of the oil, adding a little syrupy phosphoric acid. The hehaviour of the oil to syrupy chloricle of antimony, nitric acid (from $\frac{1}{3}$ to 1 volume) of specific gravity $1 \cdot 3$, alone or combined with a little powdered sugar, may be tested. The action of concentrated solution of bisulphide of calcium, borax, and chloride of lime may also yield reactions characteristic of certain oils. (See \$ 124.) It may finally be ascertained whether the oil combines quickly with oxide of lead, and whether the plaster so produced is soft or hard, soluble or insoluble in ether.

If the fatty oil is solid at ordinary temperatures, a portion may he melted, and the above tests with acids, etc., applied. The solulility in ether should be trierl, and note taken whether a solution in two parts of warm ether deposit sulid matter on cooling.

If the fixed oil from a regetable substance partially solidifies after standing several days, the liquid part may be separated from the solid by filtration and expression, and each treated separately.

§ 13. Composition; Estimation of Glycerine.-It is well known that natural fats are almost invariably mixtures of different slycericles or ethereal salts. If the various constituents of which a fixed oil is composed are to be ascertained, larger quantities (250 to 500 or 1000 grams) must he saponified with a solution of caustic soda of specific gravity 1.25 to $1 \cdot 3$; and after complete saponification, as shown by the soap dissolving in water warmed on the steam bath without the separation of undecomposer oil, the soap so formed may be thrown out by the addition of a concentrater solution of salt. The separation may be performed with advantage in tall beakers, which should be placed on the waterbath until the soap has assumed such a condition that on cooling it can be removed as a solid cake. (See also § 15.)

A measured portion of the arpenus liquil, after the removal of the soap, may be concentrated on the water-hath, or preferalbly at a temperature of $70^{\circ}$ to $80^{\circ}$, and the residue treated with absolute alcohol, or better with a mixture of about three rolumes of absolute alcohol to one to two of ether, which dissolves the glyerim: liberated hy the decomposition of the oil. On evaporating this solution the gryeerine remains hehind as a sweet syrupy 
liquid. It is optically inactive, and yields acrolein when heaterl with acid sulphate of potassium. If the soip), after removal from the liquid, is washed several times with solution of salt and the washings added to the liquid in the beaker, then the glycerine obtained as described may be weighed. The estimation is not free from error, but it permits of an approximately correct idea being formed of the quantity of glycerine contained in the fat. (See $\$ 128$.)

\$ 14. Cetyl-, Cerotyl-, Melyl-Alcohol.-In solid fats, especially in the so-called regetalle wax, cetyl, cerotyl, or melyl may be present as bases instead of glyceryl, in which case the fat is much more difficult to saponify than it otherwise would have been and there is formed, in addition to the soap, a lind of alcoholate of the fatalcohol. If to such a mixture of soap and alcoholate solution of chloride of barium is added, a barium soap insoluble in alcohol and ether is generally precipitated, whilst cetyl-, cerotyl-, or melylalcohol is liberated and may be extracted with ether. Or the precipitation may be accomplished with acetate of lead (in the ahsence of oleic acid), and the wax-alcohol extracted by ether from the dried mass. (Cf. $\S \S 126,129$.$) The melting-point (see$ $\S 17)$ and the ultimate analysis will show which of these alcohols has been isolated (\$ 129).

Vegetuble wu. frequently dissolves in boiling absolute alcohol, but separates out again on the addition of a little water, as a rule before the resins ( $\$ 145)$.

$\$ 15$. Volutile Fut-Acicls.-In prosecuting the examination of the fat-acids the soap obtained in 13 is warmed and again decomposed with excess of hydrochloric acid, the mixture of fat-acids separated from the aqueous liquil, and washed repeatedly with water. If the odour of the mixture points to the presence of a rolutile uriel, this latter must be separated from the less volatile hy distillation. The distillate should be saturated with soda, evaporated, the resillue again decomposed with hydrochloric acid, and the fatty acills separated from the aqueons liquid. The possible presence of valerianic, caproic, caprylic, pelargonic, capric, and lauric (\$ 1:30), also angelic and methyl-crotonic acid must be borne in mint. They may be identified by their boiling-points, saturating power' for bases, and composition. Of course the acil must be tested to ascertain if it is a mixture or not of several volatile acids separahle by fractional distillation.

(Cf. § 25.) 
§ 16. Less-rolatile Fat-Acids. - If no volatile acids are present, or after their separation by distillation, as directed in $\$ 15$, the less rolatile fat-acids may be dissolved in alcohol and sul,jected in alcoholic solution to a fractional precipitation with acetate of magnesium. This salt precipitates members of the fat-acid series more easily thin it does oleic acid and its homologues, and of the fat-acids proper of the $\mathrm{C}_{n 1} \mathrm{H}_{2 n} \mathrm{O}_{2}$ series, those standing highest in the series (i.c. containing the largest number of carbon-atoms) are precipitated first. The magnesium precipitates appear at first as soon as the acetate has been added, and in that case, after having been well shaken for some time, they may soon be filtered off. But subsequently it becomes necessary to add strong solution of ammonia, as well as the magnesium salt, to produce precipitation, and to allow the mixture to stand twelve to twentyfour hours in a cold place before filtering. The fractional precipitation is so contrived that each precipitate shall weigh about 1 to 5 grams, and this is continued till the tolerally strongly ammoniacal liquid yielels no further precipitation on the addition of alcoholic solution of acetate of magnesium. Each precipitate must be well washed with alcohol and decomposed with hydrochloric acid. The fat-acid must be washed with water, driecl, and crystallized once from hoiling alcohol. After carefully drying the crystals the melting-point of each fraction must be taken. The acids are then recrystallized repeatedly from alcohol, and the melting-point again determined. (Cf. $§ \S 130$ to 131.)

$\S 17$. Determination of Melting-Point.-The following is the method I adopt when I have only a small quantity of the substance at my disposal. I place a minute portion on the surface of mercury contained in a small beaker. This is then introduced into a small cylindrical copper air-oven in such a way that it does not rest on the bottom, but remains three or four centimeters from it. To allow of careful observation of the substance during the experiment, I use as a cover for the airoven an ordinary bottle the bottom of which has been cut off. A cork, perforated for a thermometer, is then fitted into the neck. The thermometer is now introduced through the perforation into the mercury contained in the beaker placed just beneath, until the bull, is completely covered. In cloing so it is desirable that some of the minute fragments of fat-acid, or other sulbstance, be as near the bulb as possible. The whole is now heated over 
a small flame, so that the temperature rises about $1^{\circ}$ erery two minutes. ${ }^{1}$

\$ 18. Melting-Points of Fut-Acills. - The melting-points of the several fractions before and after purification are noted. If in the same fraction the same melting-point is observel on both occusions, or if the estimations show a difference of only $0.5^{\circ}$, the conclusion may be drawn with tolerable safety that the precipitate under examination contains only one fat-acid. The observer melting-point is then compared with those of the more important fat-acils, and the result arrived at confirmed, if possible, by ultimate analysis.

Experiments that have hitherto been made assign to capric acid a melting-point of $30.0^{\circ}$; lauric, $43 \cdot 6^{\circ}$; myristic, $53.8^{\circ}$; palmitic, $62 \cdot 0^{\circ}$; stearic, $69 \cdot 2^{\circ}$; arachic, $75 \cdot 7^{\circ}$.

Mixtures of two of these acids in certain proportions possess, as the investigations of Heintz ${ }^{2}$ have shown, a lower melting-point than either of the constituents. Heintz has also noticed that the mixture, on solidifying, crystallizes in a characteristic form, or remains amorphous, according to the proportion in which the two constituents are present.

tearic Acid. Palmitic Acid. Melts at Solidifies at

90

80

70

60

50

40

30

20

10

0

Mixture of

Palmitic Acid. Myristic Acid."

$\begin{array}{rr}100 & 0 \\ 90 & 10 \\ 80 & 20\end{array}$

$69 \cdot 2^{\circ}$

$67.2^{\circ}$

$65 \cdot 3^{\circ}$

$62.9^{\circ}$

$60.3^{\circ}$

$56 \cdot 6^{\circ}$

$56.3^{\circ}$

$55^{\circ} 1^{\circ}$

$57 \cdot 5^{\circ}$

$60 \cdot 1^{\circ}$

$62 \cdot 0^{\circ}$

$62 \cdot 0^{\circ}$

$60.1^{\circ}$

$58.0^{\circ}$

\section{$62 \cdot 5^{\circ}$ \\ $60 \cdot 3^{\circ}$ \\ $59 \cdot 3^{\circ}$ \\ $56 \cdot 5^{\circ}$ \\ $550^{\circ}$ \\ $54.5^{\circ}$ \\ $54 \cdot 0^{\circ}$ \\ $53.8^{\circ}$ \\ $54 \cdot 5^{\circ}$}

\section{$557^{\circ}$}

$53 \cdot 5^{\circ}$
Manner of Solidification. Crystalline scales.

Delicate crystalline needles.

Amorphous, lumpy.

Large crystalline lamellæ.

Amorphous, "vavy, dull.

Very indistinct needles.

Fine crystalline needles.

Crystalline scales.

Crystalline scales.

Scaly" and indistinct needles.

${ }^{1}$ For further information about this determination see also Pohl, in Polyt. Centrbl. Jg. 1855, p. 165 ; Bergmann, in Kunst und Gewerbebl. f. Bayern. Jg. 1867, Januarheft; Buis, in Annalen d. Chem. und Pharm. xliv. p. 152; Wimmel, in Annal. der Physil. xxxiii. 121 (Am. Journ. Pharm. xli. 22, 430); Redwood, in Pharm. Journ. and Trans. [3], vi. 1009 (1876).

2 Annal der Physik. xcii.p. 588 (Pharm. Journ. and Trans. [1], xv. 425); cf. ibid. Ixxxiv. 226.

3 For particulars of the examination of a fat in which stearic, palmitic, and myristic acids were found, see Greenish in Pharm. Journ. and Trans. [3], x. 909. 


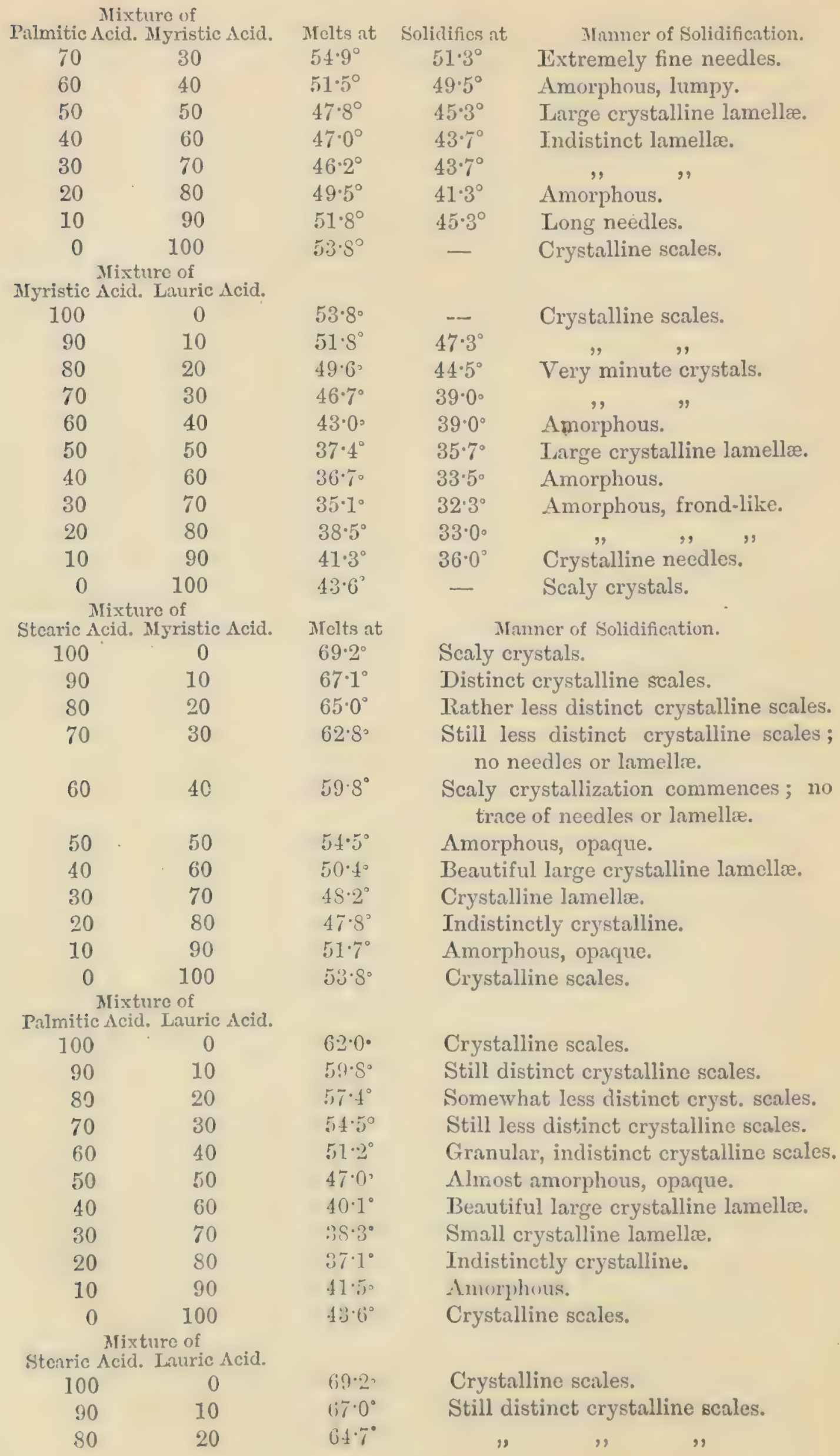


sixture of

Stmric Acid. Lamric Acid. Melts at

70

60

30

40

$62^{\circ} 0^{\circ}$

$59^{\circ} 0^{\circ}$

$\begin{array}{lll}50 & 50 & 55.8^{\circ} \\ 40 & 60 & 50.8^{\circ} \\ 30 & 70 & 43.4^{\circ}\end{array}$

20

10

0
80

90

100
$43 \cdot 4^{\circ}$

$38^{\circ} 5^{\circ}$

$41 \cdot 5^{\circ}$

$43 \cdot 6^{\circ}$
Manner of Solidification.

Distinctly granular and scaly.

Granular; commencement of scaly crystallization.

Almost amorphous, slightly granular.

Amorphous, warty.

On the surface shining faces of small crystals.

Amorphous, rvarty.

Amorphous.

Crystalline scales.

Heintz also noticel that a mixture of three fat-acids could melt at a still lower temperature, even if the third fat-acid added possessed a higher melting-point than either of the others. A mixture of 30 parts of palmitic and 70 of myristic acid melts at $46 \cdot 2$, and solidifies amorphous. To 20 parts of this mixture stearic acid was adled in the following proportions, and meltingpoint and manner of solidification observed:

$\begin{array}{cc}\text { Stearic Acid. } & \text { Melts at } \\ 1 & 45 \cdot 2^{\circ} \\ 2 & 44 \cdot 5 \\ 3 & 44 \cdot 0^{\circ} \\ 4 & 43 \cdot 8^{\circ} \\ 5 & 44 \cdot 6^{\circ} \\ 6 & 45 \cdot 6^{\circ} \\ 7 & 46 \cdot 0^{\circ} \\ 8 & 46 \cdot 5\end{array}$

Manner of Solidification.

Amorphous.

To 20 parts of a mixture of 30 parts of myristic with 70 of lauric acil, melting at $35 \cdot 1^{\circ}$, palmitic acid was adeded, and the following observations made :

$\begin{array}{cc}\text { Palmitic Acid. } & \text { Melts at } \\ 1 & 33 \cdot 9^{\circ} \\ 2 & 33 \cdot 1^{\circ} \\ 3 & 32 \cdot 2 \\ 4 & 32 \cdot 7^{\circ} \\ 5 & 33 \cdot 7^{\circ} \\ 6 & 34.6^{\circ} \\ 7 & 35 \cdot 3^{\circ} \\ 8 & 36^{\circ} 0^{\circ} \\ 9 & 37.3^{\circ} \\ 10 & 38.8^{\circ}\end{array}$

Manner of Solidification. Amorphous.

These tahles show clearly that it is important to cxamine the fractions.; in the succession in which they were mepared. For instance, supposing the first precipitate to have yielded a fatacil melting at $68^{\circ}$, which might consequently be considered as stcan ic acid, the following precipitates fat-acids melting at about 
$56 \cdot 6^{\circ}$, and suldserquently one melting at $62^{\circ}$, the conclusion to be drawn is that the last is palmitic acid, and that the fractions with lower melting-points consist of mixtures of stearic and palmitic acids. According to Heintz's table a mixture of equal parts of stearic and palmitic acid should melt at $56 \cdot 6^{\circ}$, and assume on cooling a lamellar crystalline structure. Should no palmitic acid have been found, but in its stead a fat-acid melting at about $53^{\circ}$ to $54^{\circ}$, the presence of myristic acid is to be inferred and the mixture naelting at $56.6^{\circ}$ would contain about 55 parts of stearic to 45 of myristic acid.

It is easy therefore to understand that if these obserrations be correctly interpreted a rough judgment may be formed of the rmount of the separate acids present in the fat.

At the ordinary temperature pure stearic acil dissolves in ahout 40 parts of absolute alcohol, but in much less ether. When suspended in water it may easily be collected and removed by agitation with the latter solvent. The barium and calcium salts are soluble in boiling alcohol, but the major part separates out again on cooling.

Palmitic acid dissolves much more easily in warm and cold alcohol, and is very soluble in ether. It may also be collected when suspended in water by shaking with ether.

§ 19. Uleic Acid, etc.-The alcoholic liquid from $\S 16$, which gives no further precipitate on the addition of acetate of magnesium and ammonia, may be freed from alcohol by distillation under diminished pressure. That may be accomplished, both in this and many other cases, in the following manner: A retort is charged with the liquid, into which a few pieces of scrap platimum may with adrantage be introduced, and attacherd to a Liebig's conlenser provided with a tubulated receiver, care heing taken that all comnections are air-tight. The exhausting tuhe of a Bunsen's air-pump is then introduced into the tubulure of the receiver. Even if the evacuation be carried to only one-half an atmosphere, aqueous infusions, etc., may be rapidly concentrated on the water-bath and decomposition thus aroided which would otherwise easily be camsed hy overheating, or by the action of the air, etc.

After the recovery of the alcohol by distillation, the residue is poured from the retort, which may be rinsed with a little water, and acidulated with hydrochloric acid. The fat-acid which collects on th": :urace of the liquid may le removerl mechanically, 
a)r by agitation with ether. In examining these acids attention must be paid to the possible presence of members of the oleic-ucint series (s 130, 1:31) and of the allied ricinoleic arid. (See also \$ 12.) As a preliminary operation an ultimate analysis may be made; and if this, as well as the reactions of the oil already observed, does not point directly to a particular acid, an attempt must be made to accomplish a separation either by treating the plaster olstained by heating the fat-acid with oxide of lead, with ether (which dissolves oleate of lead) or absolute alcohol; or by fractionally precipitating an alcoholic solution of a soda-soap with acetate of barium, or acetate or chloride of calcium (\$ 130, 131).

CHLOROPIYLL AND AIKALOIDS FXTRACTED SIIULTANEOLSLY WITH THE FIXED OIL.

§ 20. Chlornhyll. - The petroleum-spirit extract of vegetable substances often shows a green colour by transmitted light. This is generally due to chlorophyll. Such solutions are usually fluorescent, and appear blood-red by reflected light. Pure chlorophyll is only slightly solubic in petroleum spirit, and its presence in this extract is accounted for by the influence exercised upon its solubility by the fixed oil. That the green colour is really due to chlorophyll mat easily he shown by spectroscopic cxamination. White light, on passing through a solution of this substance, undergoes a change in various of its constituent colours, as shown by the alsorption bands in the spectrum. If the Fraunhofer line $A$ correspond to 17 on the scale, $B$ to 28, $\mathrm{C}$ to $34, \mathrm{D}$ to 50 , and $\mathrm{F}$ to 90 , there are observable in the spectrum (compare Table I. to $\S 148$, Nos. 13 and 14) $)^{1}$ four absorption bands situated hetween $B$ and $F$, the darkest of which extends from 30 to 42 , and the remaining three from 44 to 50,52 to 56 , and 58 to 60 respectively. From 80 to the end the spectrum gradually darkens. Of these ahsorption bands only the first two can be observed in dilute solutions, and the relutire amount of chlorophyll dissolved may he jurlgerl from the presence or absence of the others. It would he scitreely possible to obtin absolute values for the amount of chorophyll puresent, as liquirls containing but very small qumtities of that borly are comparatirely deply coloured. Norcover, $n n$ methor has hitherto been found available

I In examining a fresh leaf, only the most marled line between $\mathrm{B}$ and $\mathrm{C}$ is seen. Compare Vogel, Ber. d. d. chem. Gus. B. xi. pp. 623, 1367 (1878). 
for separating chlorophyll from the substances that accompany it. But if series of analyses are to be made with the same plant, to determine the changes it undergoes under the influence of the seasons, or certain conditions of cultivation, etc., the relative quantity of chlorophyll may he estimated by the ontical (colorimetric) methoul. It is better, howerer, to use alcohol or ether instead. of petrolemm spirit, as the latter does not usually extract the whole of the chlorophyll present. Admixture of foreign colouring matter may be avoided by first extracting the material sereral times with water, and drying the residue at the lowest temperature possible. whe chlorophyll may then be dissolved out by alcohol or ether. (See further in $\$ \S 37,132$.)

Under the microscope chlorophyll is seen to be associated with semi-fluid substances allied to protoplasm, often in the form of sminll granules (the so-called chlorophyll-granules), from which it may be extracted by alcohol. It is more rarely found equally distributed throughout the whole of the protoplasm corering the inner surface of the cell wall. It is bleached by chlorine and ean de Labarraque; the green colour is changed to yellow by dilute acids, and blue by concentrated hydrochloric acid.

\$21. Alliculoids extrected by Petroleum Spirit.-Parts of plimts containing alkaloid may, when extracted with petroleum spirit, yield some of the allialoid, together with fixer oil, to that menstruum, even when the pure alkaloid is insoluble in it. Here, too, it is the fixer oil that determines the solution of the alkatoid. The presence of the latter may be detected by evaporating the petroleum-spinit solution, shaking the residue with water acidulated with sulphurie: acil, and separating the aqueous from the oily liquid. Should an 'mulsion have been formed, separation may be induced by allowing the mixture to stand at a temperature of $40^{\circ}$ to $50^{\circ}$. The last traces of suspended fat may be removed from the aeid liquid by shaking with petroleum spirit, and the presence of alkaloid demonstrated by the usual reagents. (Cf. \$ 63.) The amount will not often be large cnough to cause a perceptible error in the determination of the fixer oil. But in dealing with very small quantities of alkaloid the estimation of the latter may, under these circumstances, be appreciably affected; cases occur in which even the whole of the alkaloid present passes into solution with the oil, and would be overlooked if attention were not paid to this projerty of fixerl vil. On that ancount the petrolem-spirit solution. 
must he treated as alowe rricribed, and the alkaloid so isoliated adderl to the extracts in which vegetable hases are to be lookerl for.

\section{EXAMINATION OF THE ETHEREAL OIL.}

\$22. Detection and Estimation.-Here, as in \$11, we will first discuss the simpler case, viz, that in which the petroleum spirit has removed ethereal, but no fixed oil, or at least only a very small quantity.

Like fixed oil, ethereal oil may also he frequently recognised under the microscope as highly refracting globules, or drops of irregular shape, which are soluhle in cold alcohol (fixed oil dissolves usually in war'm spinit only, if indeed it is solulle at all) and insoluble in water. Sume of them yield even under the microscope several of the characteristic colonr seactions describal in $\$ 14$.

We have now to estimate the amount of ethereal oil present als accurately as possible, without using any rery large guantity of material. From experiments mate ly Osse ${ }^{1}$ the following method would appear to be the best. A quantity of the petrolem spirit solution is aceurately measured on to a carefully tared sliss dish, which can he closerl air-tight. (Cf. \$ 9.) If 5) ('e. of the solution correspond to 1 gram of substance, 1 to 2 ec. will he found to be sufficient. The glass dish continining the petroleumppirit solution is then pilued under a tulbulated glass hell-jar

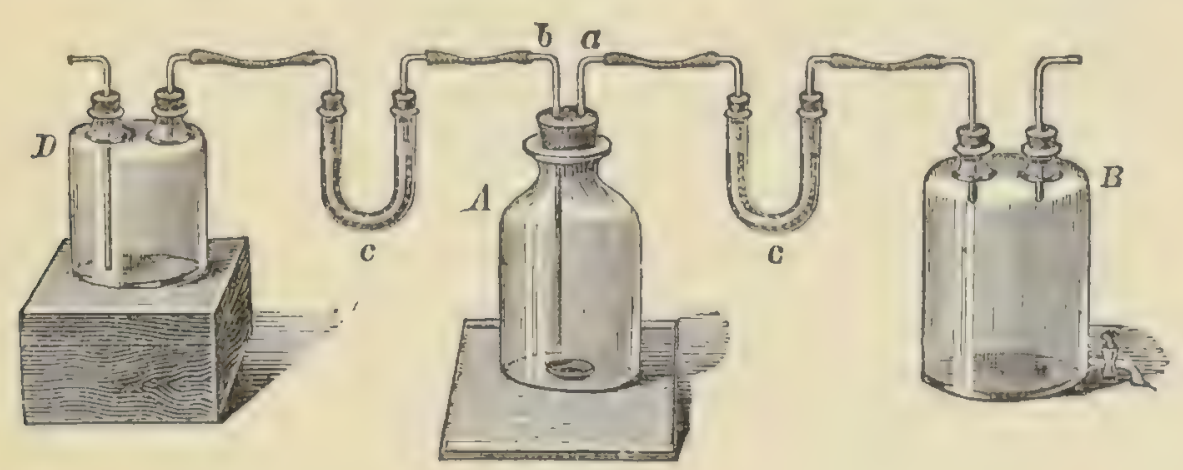

Fig. 1.

(Fig. 1), A, with gromul mlges resting on a gromel-glass plate. I'wo glass tules are then introulneed throush the tulunlure; one of them (b) reaches nearly to the surface of the liquid to be craporated, the other (11) is cut off close below the cork, and connected with an aspirator $(B)$, so that a current of dry air may be

${ }^{1}$ Archiv d. Pharm. [3], vii. 104 (1575) (Year-book Pharm. 1876, 302). 
drawn through the apparatus, entering by the tube $b$, and passing out through ". A chloride of calcium tube (c) is placerl before $b$, and another between (c and $l$, the former to dry the air entering the apparatus, the letter to prevent moist air from the aspirator passing into $A$. These precautions are necessary, for if the atmosphere in which the evaporation of the petroleum spirit is to take place be not completely dried, moisture may be deposited on the glass dish containing the solution, in consequence of the cold produced by evaporation, thus causing, of course, an increase of weight. It is alvisalle, therefore, to connect the first chloride of calcium tulse (c) with a Wolff's hottle one-third full of concentrated sulphuric acid. A current of air is then passed through the apparatus and the petroleum spirit allowed to evaporate at the ordinary temperature until the operation appears complete; that is, until the residue has only a slight smell of petroleum spirit. The glass dish is then closed and weighed. After the weight has been accurately taken, it is, again opened, exposed for one minute to the air, closed and again weighed, and the alternate exposine and weighing repeated until the same loss in weight is observed twice in succession. This loss is then assumed to be the amount of ethereal oil that diffuses into the air per minute. It is also assumed that during every previous exposure of one minute the same weight of ethereal oil has evaporated, so that to the quantity of oil as found by the last weighing there has to be added the 'co-efficient of evaporation,' multiplied by the number of minutes the dish has been exposed. (Compare the examples of estimation in §136.) If the coefficient of evaporation is less than one milligram this correction may be omitted. Perhaps it would be advantageous to pass a current of carbonic acid through the apparatus during the evilporation of the petrolem spirit, as many ethereal oils diffise much more slowly into that gas than into atmospheric air.

\$23. In Presence of Fat and Resin.-After thus determining the weight of the substances dissolved in a known quantity of petroleum spirit, it must be ascertained whether the residue after evaporation is completely volatile at $110^{\circ}$, or leaves a non-rolatile residue of resinous or fatty matter. In the latter case the weight must be determined and deducted from that obtained in $\$ 22$. (See $\$ 138$.) If the non-rolatile part constituties the majority of the dissolved substanees it may be ascertained, after the removal 
of the ethereal oil hy evaporation, whether the residue is now still completely soluble in petroleum spirit. liesins which, in a state of purity, are not dissolved by petroleum spirit, mily he taken into solution hy means of ethereal oil, just as fixed oil carries with it allisloids and chlorophyll ; they are left undissolved on agrin treating with petroleum spirit the resiche freed from ethereal oil. After having remover by this solvent the fixerl oil, etc., that has lreen simultineously extracted, the resin may be weighed alone (\$ 146).

Of course it is alvisable to repeat the experiments deseribed in $\$ \$ 2,23$ sereral times, and take the mean of the results. I need scarcely saly that this method of determining the total ethereal oil does not guarintee any alssolute accuracy, but as it is the only one we have at our disposition it might, for the time at least, be deserving of some notice. With less rolatile oils, cimnamon, clove, etc., it has yiehled rery satisfactory results, but less so with terpenes, such as oil of lemon and turpentine.

$\$ 24$. Distillution of Lenger Quentities of Oil. - If a further insight into the composition of the ethereal oil is desired, a larger quantity must be prepared from so 100 kilograms of material. For this puppose distillation in a current of superheated steam is to be recommended, the material having been if necessary previously comminuted and soaked in water. In order that the steam may thoroughly penetrate it the apparatus should he packed with alternate layers of material and straw. A distillate consisting of essential oil and water will be obtained which may be separated from one another in burettes or Florentine flasks. It should not, howerer, be forgotten that many ethereal oils are tolerahly easily soluble in water, and a small quintity of petrolemm spinit of low hoiling-point should therefore le shaken with sucessive portions of the aqueous distillate. The petroleum spirit is allowed to craprolate in a current of carbonic acid in the apparatus described in $\$ 2.2$, and the residue arded to the oil separated from the distillate $(\$ 137)$.

\$ 25. Examination of Aqueous Distillate-After separation of the oil, the action of the watery liquid on litmus should be tested. It will be frequently found to possess a distinct acid reaction, and contain formic, acetic, or other volatile acids of the fat-acid series. In such a case the higher acids in the series maty he remover hy shaling with ether or petroleum spirit. To 
obtain all, inchuding those standing lower in the series, the aqueous distillate may lo saturated with soda, concentrated and acidified with sulphuric acid (1.5). If an oily acid separates from the aqueous liquid, angelic or valerianic acid, or an acid higher in the scries, may be looked for. (The test of smell, boiling-point, ete., may be applied, and the nItimate analysis made.) Further information on this point may he found in $\$ 139,140$. If the acid liberated is soluble in water, an attempt to separate it by the addition of chloride of calcium may meet with success. Should that not he the case, formic and acetic acids may finally be tested for (behaviour to mercuric chloride, ferric chloride and nitrate of silver, the latter also reduced by acrylic acid) as well as salicylous acid. The last-namerl acid strikes a violet colour with ferric chloride. (See also \$33.) Salicylous acid may likewise be separated from its aqueous solution hy shaking with ether. For hydrocyanic acid see $\$ 34$.

Toxirodentrie acid, to which Maisch partly attributes the poisonous properties of Rhus toxicodendron, appear's to possess great similarity with formic, acetic, and acrylic acid. It may be isolated by distillation, and like formic acid reduces nitrate of silver and chloride of gold slowly in the cold, quickly on warming. But it does not reduce mercurous nitrate or chromic acid as formic acid does, nor does it yicld the iron reaction characteristic of acetic acid, etc.; the mercuric salt dissolves with difficulty in water ${ }^{1}$ (formic acid reduces mercuric to mercurous chloride).

\$26. Salicylic, Benzoic Acid, etc.-It must also be borne in mind that some of the aciels of the aromatic series, such as sulicylic and benzoic acid (\$55), are volatile with the vapour of water at temperatures as low as $100^{\circ}$, and may therefore be carried over with the steam in distilling the ethereal oil. On shaking the ristillate with petroleum spirit small quantities of sulicylic uciul are removerl, hut ether and chloroform may be more adrantageonsly employed; the latter liquid is also adapted for the isolation o benzoic acid. On evaporating the ethereal or chloroformic (or petroleum spinit) solution, loth benzoic and salicylic acid are obtained as crystalline residues diffieultly soluble in cold water (salicy lic acid about 1 in 300$) 0^{2}$ The two acids may be dis-

${ }^{1}$ Conf. Amer. Journal of Pharmacy, xxxviii. 9 (1866).

2 For particulars of the detection of salicylic acid in Viola tricolor by Mandelin in my lab oratory, sce Sitzungsber. d. Dorpater Naturf. Gesellsch. Jg. 1879, p.77, and Diss. Dorpat., 1881 ; also Pharm. Journ. and Trans. [3] xii. 627. 
tingruished by their behaviour to ferric chloride, with which salicylic acid strikes the well-known violet colour. Benzoic ariel may be easily sublimed between watch-glasses. Dissolved in a drop of ammonia, the excess of which is allowed to evaporate by exposure to the air, a drop of ferric chloride produces a brownish tinge.

Cinnemic ucil may also be similarly distilled orer, and seprarated from the distillate. It may be distinguished from both the foregoing acids by its behaviour to oxidizing agents such as lermanganate of potassium, with which an aqueous solution yiclels on warming oil of bitter almonds, whereas benzoic acid yields the same product when acted upon by a reducing agent such is sodium-amalgam. (See also § 38 .)

Any cinnamic acid present might in certain cases have been produced from ethereal salts, such as, for example, styracin (cinnamate of cinnamyl), or cinnimeïn (cinnamate of henzyl). Both of these compounds are soluble in petroleum spirit, and are resolved, by decomposition with an alkali, into cimnamic acid and the respective alcohol. Styracin crystallizes in needles, which, according to Scharling, ${ }^{1}$ melt at $44^{\circ}$. Cinnamein is liquicl at the ordinary temperature. The former has an odour resembling vanilla, the latter a faint smell of balsarn of Peru.

If one of the three acids mentioned has been isolated, special care should be taken to ascertain whether the corresponding wldchyle is also present in the aqueons liquid, viz., salicylie, henzoic (nil of bitter almonds), or cinnamic aldehyde, and whether the acid has not been produced from the aldehyde ly absorption of oxygen during or after distillation ( $\$ 33$ ).

$\$ 27$. I'hysicul I'roperties. - The principal part of the oil olytained by distillation should be completely freed from moisture, filtered and tested with regard to its consistence. If, on standing some time in a freezing mixture, a crystalline constitnent he deposited it should be scparated and examined hy itself. The action of the oil on polarized light should be observed (\$111), and fluorescence looked for ; if present, it should be ascertained whether warm water will remore a substance fluorescent either alone or on

${ }^{1}$ Annalen d. Chemie u. Pharm. Ixviii. 168. See also Rügheimer Dissertation, Tübingen, 1873; Kraut, Annalen der Chemic u. Pharm. clii. 129 (1869); (Amer. Joum. Pham. xlii. 2:36); and Von Muller, Ber. d. d. chem. (xes. Jg. $1576,274$. 
the actdition of caustic potash. Any resin that may have been obtained in the cuntutitative estimation of the oil (\$23), should be tested for a fluorescent substance by treating with distilled, or, if necessary, allialine water ; mmelliferone should be specially borne in mind ( $\$ 43)$. The resinous constituents, which will be subsequently isolated according to $\$ 36$, et sey., may be eximined for umbelliferone hy mixing with sand and submitting to destructive distillation, or ly heating in sealed tubes with alcoholic solution of hydrochloric acid.

Further, the specific gravity of ethereal oils should be taken. Westphal's specific-gratrity balance may be arlvantageously employed for this purpose, especially if the quantity of oil at disposal is rather small. (Cf. $\$ 141$.

It should also be ascertained what percentage of pure alcohol a spinit must contain to be miscible with the oil in all proportions. A drop only of spirit is first added to the same quantity of oil, and if the resulting mixture is perfectly clear, note should be taken whether the further addition of spinit cause a cloudiness or not. It is, however, only with freshly-prepared oil that such reactions can be considered as characteristic of the oil. Many oils undergo a change on keepring for any length of time, lecoming more or less soluble in alcohol, or forming clear mixtures with small proportions, but cloudy with larger (\$ 141).

\$28. Reactions. - It is, moreover, desirable to make qualitative experiments with small quantities of the ethereal oil, in order to become acquainted with their behaviour to some few re-agents. For this purpose I have recommended sulphuric acid, alone or applied in combination with sugar, nitre, or ferrice chloride; nitrice acid, alcoholic hydrochloric acid, solution of bromine in chloroform, picric acid, etc.

For the results which I mysclf, and some of my pupils, have obtained with the more important ethereal oils, see $\$ 142$.

\$29. Detection of Sulphur.-Some ethereal oils contain sulphur, which may be detected by mixing a few drops of the oil with carbonate of soda and nitre, and introducing it into a piece of combustion tubing, about $15 \mathrm{ctm}$. long, sealed at one end. The upper part of the tube is then charged with a similar mixture of soda and nitre, and the whole ignited as if it were an ultimate analysis in miniature. About one-third of the mass from the bottom of the tube upwards is then dissolved in a little water, 
heated with excess of hydrochlorie acid as long as nitrous fumes are erolved, and then tested for sulphuric acid ly chlorite of barium.

Warming a small quantity of an ethereal oil containing sulphur with a solution of canstic potash of specific gravity $1: 3$, and arding nitro-prusside of sodium, after diluting with water, often suffices to show the presence of sulphur by the sulphicle of potassium formed striking a bluish-violet colour with the nitro-prusside.

Some ethereal oils contain nitroyen, and many of these are resimled as nitriles. This element may be detected by heating a drop of the oil with metallic sodium, dissolving the coolerl mass in water, adding a drop of solution of ferric and ferrous salt, and, after a few minites, acilifying with hyclrochloric acid, when a precipitate of Prussian blue makes its appearance if nitrogen is present.

If the ethereal oil contains a sulfhorymide (oil of mustard or horse-radish), both the sulphur and nitrogen test must yichl a positive result.

\$ 30. Constituent:-Ethereal oils distilled from regetable sub. stances are generally mixtures that can he separater into their constituents. If this is to he attempted we must, from the first, admit that, in the present state of our knowledge, an exact quantitative separation is not to he thought of. The principal reason for this must be sought for in the ease with which ethereal oils undergo decomposition, and the great disposition many of them show to form polymers. In the majority of cases only one method of separating the constituents of an oil is feasilule, viz., that of fructionel distilletion, which must be repeater until prorduets of constant boiling point lave heen oldained. But it is in this rery distillation that a change in the oil often takes place, either by the formation of polymers of the original oil with higher boiling-points, or hy the production of hydrocathons hy the liberation of the elements of water from constituents of the oil containing oxygen.

An important improvement in these operations might perhaps lie marle in conducting the distillations muler liminisherl pressure. In order to make this morlification arailahle, the temperatme must first be ascertained at which the more commonly occurring eomstituents of oils can be ristillerl. Nany of the terpenes present in ethereal oils maty be distilled muler the ordinary presure at $155^{\circ}$ to $157^{\circ}$; many of their polymer's at about $190^{\circ}$; others at 
albout 250. This knowledge forms, of course, a good basis on which a separation may be attempted.

For these and other fractional distillations which may have to be performed in the analysis of plants, small flasks prorided with the dephlegmator's recommended by Limueman may be used. (Cf. $§ 143$.

\$31. Stearoptenes, etc.-The following are the more important constituents of ethereal oils that have up to the present time heen ohserved: Terpenes of the composition $\mathrm{C}_{10} \mathrm{H}_{16}$ often boiling at $155^{\circ}$ to $157^{\circ}$; polymers of the same, of the formula $\mathrm{C}_{15} \mathrm{H}_{24}$ and $\mathrm{C}_{20} \mathrm{H}_{32}$, boiling frequently at about $190^{\circ}$ or about $250^{\circ}$; vxygenated compounds of the formula $\mathrm{C}_{10} \mathrm{H}_{20} \mathrm{O}, \mathrm{C}_{10} \mathrm{H}_{15} \mathrm{O}, \mathrm{C}_{10} \mathrm{II}_{10} \mathrm{O}$, $\mathrm{C}_{10} \mathrm{H}_{14} \mathrm{O}, \mathrm{C}_{10} \mathrm{H}_{12} \mathrm{O}, \mathrm{C}_{14} \mathrm{H}_{12} \mathrm{O}$; ; hydrocarbons of the formula $\mathrm{C}_{10} \mathrm{H}_{14}$ are more rarely to be found; still less frequently those of the $\mathrm{C}_{n} \mathrm{H}_{2 n}$ series. Of these constituents of oils, it is noticealle that those containing oxygen crystallize in the cold more readily than hydrocarbons of the formula $\mathrm{C}_{10} \mathrm{H}_{10}$, and to the former, therefore, our attention must be specially directed in the examination of the crystalline 'stearoptenes' ol,tained liy cooling the oils (with the exception of otto of roses $=\mathrm{C}_{n} \mathrm{H}_{2 \mathrm{n}}$ ).

If such a stearoptene has been isolated, its purification should be attempted by repeatedly crystallizing from alcohol or ether, pressing the crystals each time between hlotting-paper. The coefficient of refraction may then le ascertained in the alcoholic solution of the pure substance; the melting-point, boiling-point, and rapour-density determined; and, finally, an ultimate analysis marle. It should also be ascertained whether hydrocarbons can be obtained by distillation over phosphoric anhydride or chloride of zinc.

The liquicl portions of the various fractions should he sulijected to similar experiments, with the exception of the last. It will frequently be found that ethereal oils containing oxygen, as well as those containing hydrocarbons, of the formula $\mathrm{C}_{15} \mathrm{H}_{24}$ and $\mathrm{C}_{20} \mathrm{H}_{32}$, yield very characteristic colour reactions with the reagents detailed in . 28,142 ; whilst oils consisting principally of terpenes of the formula $\mathrm{C}_{10} \mathrm{H}_{10}$ show less inclination to give marked reactions. These litter oils may often be purified for ultimate analysis by distillation over metallic sodium.

\$3:. Other Constituents. - Besides the constituents alrearly mentioner-which indecel, although frepuently agreeing in their 
composition, have, when prepared from different plants, somewhat dissimilar properties (odour, behaviour to polarized light, etc.) some ethereal oils contain other substances which may belong to. toleribly distant groups. Aldehydes, ethereal salts, alcohols, acids, etc., have been found in various oils.

§33. Aldehydes.-If an aldehyde is to be looked for in an ethereal oil, it must first be ascertained whether that oil precipitates. metallic silver from an ammoniacal solution of the nitrate. ${ }^{1}$ If this is the case, it must be shaken with a concentrated solution of acid sulphite of soda. The majority of aldehydes are dissolved by acid sulphite of soda, and may be separated from other constituents which do not enter into such combination by removing the aqueous liquil. The aldehyle may then be liberated from combination by neutralizing with caustic sodiu or decomposing with dilute sulphuric acid, and, when thus separated, should be testerl as to its physical properties, odour, ctc. It should also be ascertained if it produces a crystalline precipitate in ethereal solution of ammonia. Finally, an ultimate analysis may be made.

Of the aldehydes to which particular attention should bo directed, I may mention those of pelargonic, capric and methylcapric acid, of angelic, cimnamic, salicylic, and benzoic acid (\$\$ 25, 26). Many, perhaps all, vegetable substances containing chlorophyll, when distilled in the fresh state, appear to yield a substance with the characters of an aldehyde. ${ }^{2}$

\$31. Folutile Acids.-Acids may be removed from the ethereal oil by shaking with dilute solution of potash or sorla, and may be liberated, after eraporation of the solution, by the ardition of dilute sulphuric acicl. (Cf. 25, 139.) Besides the rolatile acids already mentioned, the possible presence of hydrocyanie acid, which is partially converted into formic acid hy shaking with sodia, is not to be forgotten. It may best be looked for in the aqueous part of the distillate (\$25), and recognised by the well-known silver precipitate and sulphocyanide and Prussianblue tests.

\$35. Etherenl Sults. - If an essential oil is to be eximined for ethereal salts that may be mixerl with it, it should be remembered that such silts mary be decomposed by heating in antoclaves with

1 See Tollens, Ber. d. d. chem. Ges. xv. 1635 ; Sallkowski, ibid, 1739 (1882).

${ }^{2}$ See Ber. d. d. chem. Ges. xiv. 2144, 2508, for an account of this most interesting observation. 
solution of caustic soda or with baryta-water, yielding a salt of the acid, and the alcohol corresponding to the basic radical contained in them. This latter body may be scparated by distillation. ${ }^{1}$ Acetate of octyl, which occurs in the oil of Heracleum, would thus yield an acetate and octyl alcohol. Certain substitution acids, such as methyl-salicylic acid, might be similarly decomposed; this, for instance, would yield a salicylate and methylic alcohol. The latter class of compounds would split up on treatment with hydriodic acid; methyl-salicylic acid would thus yield iodide of methyl and salicylic acid.

If the alcohols and iodides thus liberated are tolerably freely solulle in water, and therefore not mechanically separable, they must be removed by fractional distillation, in which chloride of calcium and other hygroscopic substances may be often used with success. $^{2}$ Their identification should rest upon the determination of boiling-point and vapour-density, and the ultimate analysis. The same applies in the case of an ethereal oil containing an alcohol a priori.

Of the alcohols that may be more commonly separated from ethereal oils, methyl alcohol boils at $58 \cdot 6^{\circ}$, ethyl at $78 \cdot 4^{\circ}$, propyl at $96^{\circ}$, isopropyl at $83^{\circ}$ to $84^{\circ}$, butyl at $116^{\circ}$, isobutyl at $109^{\circ}$, amyl at $130^{\circ}$, pseudo-amyl at $120^{\circ}$, hexyl at $157^{\circ}$, heptyl $175.5^{\circ}$ to $177.5^{\circ}$, octyl at $196^{\circ}$ to $197^{\circ}$.

To distinguish between a primary, secondary, and tertiary alcohol, $\mathrm{r}$. Meyer and Locher recommend conversion into iodide. This is mixed with twice its weight of nitrate of silver and a little sand, and distillerl, the distillate shaken with strong solution of canstic potash and nitrite of potassium, and then acidified with rilute sulphuric acid. If a primary alcohol is present the mixture will turn red, if a secondary, blue (which may be removed by shakingr with chloroform), whilst tertiary alcohols give colourless products of decomposition. In the series of secondary alcohols the reaction succeds as far as amyl alcohol, in the series of primary alcohols as far as octyl alcohol (Gutknecht). ${ }^{3}$

The acirls separated from the ethereal salts, obtained by decomposing the alkali or barium salt with sulphuric or phosphoric acid, may be examined according to the directions given in $\$ 5.5,34,130$.

1 Cf. Wanklyn, Chem. News. xxvi. 134.

2 If the ethereal salt yield ethylic alcohol as a product of decomposition, the amount may be directly estimated from the specific gravity of the distillate.

3 See also Heil and Urech, Ber. d. d. chem. Ges. xv. 1249 (1882). 
III.

Examination of tile Substances Soluble in Ether.

\section{RESINS AND THEIR ALLIES.}

\$36. Extraction.-After the eximination of the substances dissolved in petroleum-spirit has been carried as far as possible, the residue (ef. \&9), thoroughly washed with the menstrumm, should be removed from the filter (which is to be kept) dried at the ordinary temperature, and then macerated for seven to eight days with pure ether. It is advisable to use the same ressel that has been employed for the treatment with petroleum spirit. If it has been well washed there is no necessity for being minutely particular to bring the whole of the resilue on to the filter. The same vessel should, if possible, be reserved for the extraction with alcohol, to be described in $\$ 47$, and the filtration effected through the same filter that has alrealy done duty for the petroleum spirit and ether extracts. I allow the ether destined for this purpose to stand for several wecks over porous chloride of calcium, and then rectify it after carefully separating the calcium salt. To obtain constant results in such analysis it is necessary to have the ether as free as possible from water and alcolul. Ordinary commercial ether would, for instance, extract i portion of the tannin (sometimes more, sometimes less) from parts of plants containing that sulstance, whilst ether, purified as described, loes not usually jroduce this effect. As it is not well possible to remove the whole of the tamin with commereial ether, I prefer to refrain from extracting any of it with that menstruum, and remore the whole subsequently with aleohol. To attain this end I avoid the employment of a high temperature in extracting with ether. Inrlecl, I am of opinion that in the course of the andysis of plants, it is better in the majority of cases to 
allow the solvent to act at the ordinary temperature. Some instances of special estimations may be excepted in which separate portions of the material may be extracted warm.

After allowing the maceration with ether to proceed for about eight days, the first estimation to be made is that of the totul. substances dissolved, which may be effected by evaporating an aliquot part, or the whole of the extract, in a flat-bottomed glass dish. I usually employ a measured quantity of ether, say 5 to $10 \mathrm{cc}$., for every gram of substance under examination, macerate in a well-closed flask, and replace any ether that may have been lost by evaporation during the process. After well shaking I take a certain number of cc. of the clear or (cf. § 9) filtered liquid for evaporation. The residue must be dried at $100^{\circ}$ to $110^{\circ}$, till the weight is constant, and this then noted. It should be ascertained whether any fatty matter which has escaper extraction with petroleum spirit is mixed with the residue, and if this is the case it should, if possible, be removed by washing with the latter liquid, its weight noted, added to the amount, found in $\$ 9$, and sulutracted from the sulbstances dissolved by ether. It must also be borne in mind that all fats are not necessarily soluble in petroleum spirit. It is well-known that castor oil forms clear mixtures with certain, but not all proportions of that solvent. ${ }^{1}$

The remainder of the ethereal extract is filtered from the residual powder, the latter washed, and extract and washings allowed to evaporate at the ordinary temperature. The residue of the substance is freed from ether at the same temperature as speedily as possible.

\$37. Chlorophyll.-The ethereal extract may also be tested hefore evaporation for chlorophyll, as described in $\$ 20$, 132, et se\%. I have already obscrved that this substance is more easily and completely removed by ether than by petroleum spirit.

\$38. Portion Soluble in Water.-That part of the ethereal extract which has heen evaporated at the ordinary temperature may, if possible, be powdered or brought into as fine a state of divisjon as practicable by triturating with washed sand or pure silicenus carth (Kieselguhr), and treated with cold water. In the arpurous solution substances soluble in water, such as heenatorylin, gallic acid, catechin, pyrocatcchin, salicylic acid, benzoic acid, ${ }^{1}$ Jahrb. f. Pharm. 1876, p. 369 (Year-book Pharm. 1876, p. 356). 


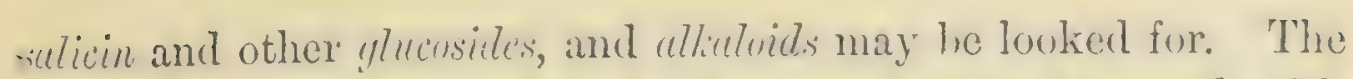
datter, however, may, as a rule, be more easily extracted with water containing acetic or sulphuric acid. A measurerl portion of the aqueous liquid may be eviporated, and the residue weigherl. For the detection of hematoxylin and allied sulstances see $\$ 150$; of gallic acid, etc., $\$ 151$; of salicylic and benzoic acill, $\$ \$ 26,34$; of glucosides, ss 54 et seq., 165 et ser. ; of allkaloids especially, s.: $6: 3$ et seq., 171 et seq.

\$39. Portion Soluble in Alcohol. - The part insolul,le in water should be again dried and extracted in a similar manner with absolute alcohol. If the plants under examination contain much resin it will often be olserved that a part only of the resinous constituents, etc., dissolves in alcohol. The amount of matter soluble in alcohol, as well as in ether, must then be determined by evaporating the alcoholic solution and weighing the residue.

We have thus determined (a) the total substances dissolved by ether, $(b)$ any fat that may have been extracted, $(c)$ the substances solul,le in ether and water, (l) sulistances insoluble in water, soluble in ether and in alcohol, and (e) substances extracted by ether insoluble in water and alcohol.

The next step is to obtain a further insight into the nature of the resinous substances soluble in ether alone, as well as those soluble in ether and alcohol.

\$ 40. Hicrochemical Exuminution.-The microscopical examination shows that the resins are present partly in the cell will, saturating it as it were, and partly in the form of exurlations either within or upon the cells. Special attention should be paid to their insolubility in water, soluhility in alcohol or ether, to the rerl colour which, according to Miiller, is produced with resins by alcoholic tincture of alkanna, violet or line (Hanst, in) by aniline. Some of the reactions entmerated in $\$ 146$ might also he made available for microchemical analysis.

In the macrochemical examination it should first he ascertained whether the resin cannot be separated into different component parts by the use of other solvents, such as chloroform, henrene, hisulphice of carhon, acetone, acetic ether, or boiling alsolute alcohol, or finally ly precipitating the concentrated ethereal solution with alcohol, petroleum spirit, or other suitable liquicl. Similarly, if a substance soluble in ether has not from the tirst been obtained in crystals, slow evaporation of the solution in the 
last-named solvents (prepared warm if necessary) should be resorted to in the attempt to crystallize the substance, or to separate it into a crystalline and an amorphous portion.

If the endearour to obtain crystals be successful, the crystalline form should if possible be determiner, and care should be taken to observe whether different erystalline forms can be distinguished under the microscope, rendering it probable that the substance under examination is a mixture. ${ }^{1}$

\$41. Behaviour of Resins to Reagents.-It will further be of special interest to learn whether the substances soluble in ether, insoluble in alcohol and water, are dissolved by alcoholic or arneous solution of caustic potash, in which case there would be reason to suspect the presence of an acid resin (\$145). If insoluble in these liquids it might be assumed that the body under examination is an indifferent resin, or a resin-enhydricle not. easily susceptible of decomposition. These and the following experiments should be conducted with larger quantities of the substance solul,le in ether, specially prepared for this purpose.

If an indifferent resin or stable resin-anhydride were present it might first be purified by recrystallization or reprecipitation, etc., and then an ultimate analysis made. It should be tested for colour-reactions with concentrated sulphuric acid alone and in conjunction with sugrar. If ethereal solution of bromine yield a substitution prorluct, its composition should be ascertainer. It should also be noticed whether the resin-anhydride is easily oxidized and dissolved by nitric acid, or whether that takes place only with difficulty; whether water precipitates the unchanged resin after the action of the acid, or whether oxidation products are formed ; ancl if so, what is their nature, as, for instance, picric ${ }^{2}$ or oxalic acid (\$§ 81, 219), succinic acid (\$220).

\$ 42. Action of F'used P'otesh. - It is further importint to hecome acpuainterl with the products formed under the influence of fused calustic potash or sodil." The fincly powdered sulstance, in quan-

1 For particulars of a case of this lind, viz. the separation of a mixture of resins obtained from larch-fungus, see Masing, Pharm. Zeitschr. f. Russland, Jg. 9, p. $394(1870)$.

2 Isittur yellow crystals belomging to the rhombic system sparingly soluble in cold water, more freely in boiling, soluhle in alcohol and ether. It stains skin and wool yellow, and yiches a blent-red liquid when an alkaline solution is warmed with cyanide of potassium, sulphide of potassium, or grape sugar.

${ }^{3}$ Cf. Hlasiwetz and Barth, Anualen der Chemie und Pharm. cxxxiv. 265; cxxxviii. 61 ; cxxxix. 77 . 
tities of not much more than 10 grams at one operation, is mixer with 6 to 8 parts of caustic alkili, and introduced in successive portions into a previously heated silver crucible, and the heat continued, stirring occasionally with a silver spatula until the mass is in a uniform state of fusion. After cooling the contents of the crucible are dissolved in watel, and a slight excess of sulphuric or hydrochloric acir added. The decomposition products, which are specially to be looked for, are butyric and valerianic acid (cf. §§ 2.5, 34, 139), pyrogallol, phloroglucin, and resorcin, benzoic $(\$ 26)$, paraoxybenzoic, and protocatechuic acil. The majority of these substances may be removed by ether after acidifying. Volatile fatty acils might be previously extracted by shaling with petroleum spirit.

Revincin.-After the fatty acids have been remored by petroleum spirit, resorcin may be extracted from the aqueous liquid by shaking with ether and distilling the ethereal solution after separation. It forms crystals melting at $99^{\circ}$, has a sweetish taste, and strikes a dark riolet colour with solution of ferric chloride, violet with chloride of lime, and rose-red with ammonia. It redizces ammoniacal solution of nitrate of silver.

Phloroglucin is also very sweet-tasted, and resembles resorein in many of its reactions, but is coloured redulish-violet with ferric chloride, and trinsient reddish-yellow with solution of chlorinated lime. The anhydrous crystals melt at $220^{\circ}$.

I',roygllel tastes bitter, is soluble in water, alcohol, and ether', melts at $115^{\circ}$, reduces ferric to ferrous salts, colours the latter bluc-black, and separates gold, silver, platinum and mercury from solutions of their salts. An allialine solution exposed to the air rapidly assumes first a red, then a brown colour; with lime-water it passes through a transient violet and purplish-red tint.

I'rotocatechuic Acid has an acil reaction, is sparingly soluble in water, strikes no colour with pure ferrous, but yields a dark-green solution with pure ferric salts. With mixtures of both ferric ani ferrous salts a violet tint is produced. The green liquid obtained by the action of ferric chloride is turned red by potash, and then assumes a violet tint on addition of hydrochloric acil. It reduces the metal from an ammoniacal silver solution, but is distinguished from the three foregoing sulsstances by not reducing alkaline tartrate of copper. With acetate of leal it yields a precipitate soluble in acetic acid. 
Parcoxybenzoic Acid melts at $210^{\circ}$, dissolves with difficulty in cold water, and gives, with ferric chloride, a yellow precipitate easily soluble in excess.

For Orcin and Betaorcin see $\$ 158.1$

$\$ 43$. Dry Distillation of Resins. - It has already been mentioned in $\$ 27$ that the dry distillation of part of the resin may lead to useful results. Besides the umbelliferone mentioned in that section, pyrocatechin ( $\$ 151$ ), pyrogallol, etc., should be borne in mind. The first of these substances is fluorescent, and dissolves in boiling water, alcohol, and ether; the second strikes a green colour with solutions of ferroso-ferric salts.

\$4. Examination of Portion Soluble in Alcohol. - The remainder of the mixture of resins extracted by ether--that is, the part soluble in alcohol-may be tested as directed in $\$ \$ 40$ to 43 . Acill resins will be found here more frequently than in the portion insoluble in alcohol. If the resin soluble in alcohol dissolves either partially or wholly in an aqueous solution of potash as well, the solution in the latter liquid may be shaken with ether to ascertain if any substance can be removed by that solvent. It was by this means that $I$ isolated pcconiofluorescin from peony-seed (\$ 147). Chrysophanic acid and allied substances ( $\$ 148,149)$ should also be tested for, as well as quercitrin, quercetin ( $\$ 152$ ), and the bodies discussed in $\$ \$ 150$ to 158 .

$\$ 45$. Acids Produced by Action of Alkalies.-Attention must further be paid to the fact that the action of caustic alkalies on certain anfyddrides nearly related to the resins-as, for instance, scntonin-may result in the formation of alkali salts, which are not of necessity, on the aldition of excess of acetic or hydrochloric acid, instantly decomposed with reproduction of insoluble anhydride. In the case of santonin, santonic acid is liberated on acidulating the alkaline aqueous solution. Any ordinary acid resin mixed with it may be removed by precipitation with hydrochloric or acetic acid and immediate filtration. The santonin is deposited only after standing several days, but can be extracted at once by shaking with chloroform. A method that I have proposed for the estimation of santonin is hased upon this fact, and will be described in $\S 154$.

16. Direct Eitruction with Ether.-A portion of the powdered material may, without further treatment, be extracted with ether,

${ }^{1}$ For ferulic acid compare Jahrb. f. Pharmacie, 1866, p. 95. 
and the substances thus dissolved estimated. In the majority of cases the weight will be the same as the sum of the substances extracted by petroleum spirit according to $\$ 9$, and ether according to $\$ 36$. If there is a deficiency, the residue should be treated with petroleum spirit, in which case attention would be directed to a substance other than an ethereal or fixed oil. The residue after exhaustion with ether, and, if necessary, petroleum spirit, may be dried and boiled with chloroform or bisulphide of carbon, to ascertain if such substances as caoutchouc, etc. can be extracted (§127). 
IV.

\section{Examination of the Substances Soluble in Adsoltte ALCOHOL.}

RESINS, TANNINS, BITTER PRINCIPLES, ALKALOIDS, GLUCOSES, ETC.

\$47. Extraction.-The residue of the substance under examination after exhaustion with petroleum spirit and ether (cf. $\$ 36)$ is remored from the filter, dried at the ordinary temperature, and treated with $10 \mathrm{cc}$. of absolute alcohol for every gram of original substance. After the lapse of five to seven days the alcohol lost by volatilization is replaced, and the whole well shaken. It is then filtered through the same filter that has been used for the previous operations, any evaporation of alcohol being prevented as carefully as possible. A measured quantity of the filtrate is next eraporated in a tared platinum dish and dried until the weight noted is constant. It is then incinerated, and the ash deducterl from the weight of the dry substance. After having thus estimated the total organic matter insoluble in petroleum spirit and ether, but soluble in alcohol, the residue on the filter may be washed with absolute alcohol, and the washings, with the remainder of the filtrate, concentrated. This may best be done by distilling in a flask, under diminished pressure. The liquid remaining after distillation is poured into a glass dish, and allowed to evilporate, at the ordinary temperature, over sulphuric acid.

$\$ 48$. Estimation of Portion Soluble in Water.-The dry residue thus obtained is first treated with a measured quantity of water. To ascertain the amount soluble in this menstrum, as well as in alcohol, a measured quantity of the solution is similarly eraporated, dried at $110^{\circ}$, and weighed.

The remainater of the aqueous extract is reserved for the experiments detailed in $54,50,70$; that which is insoluble in 
Water is treated with water containing a little ammonia ( 1 in 50$)$ ats long as anything is removel. The ammoniacal extract may be evinorated with a slight excess of acetic atcil, the residue riment on to a filter with a little water, washed, drich, and weighed. The brownish mass thus left on the filter is, as a rule, to be regarled as phlobaphene (\$108; see also $\$ 160,163)$, resulting from the decomposition of tannin. The portion of the aqueors extract insoluble in ammoniacal water may be again chied orer sulphuric acil, and then suljected to similar treatment as the resin soluble in ether (cf. 39 to $45 ; 145,146$ ). If there is reason to suspest the presence of an allkaloid soluble in alcohol, lut insoluhle in ether, the resilue, after treatment with ammoniacal water, may he digested with water containing a little sul phuric acil. (For alkaloids see s.5.5, et seq.; 63, et seq.; 171, et ser.)

\section{EXAMINATION OF THE 'TANNIN.}

5 49. Detection.-If the aqueous solution obtained from the evaporation residue of the alcoholic extract is coloured blue-b) ack by a ferroso-ferric salt and precipitated by gelatine, solution of acetate of learl is to be arder in slight excess. The resulting precipitate is immediately collected on a tarred filter, washed with water (not too long, three or four times, with 3 to $5 \mathrm{cc}$.), dried, and weighed (52, I.). It is then removed from the filter, which is burnt in a procelain crucible with a little nitrate of ammonia; the precipitate itself is next incinerated, and the whole finally ignited in the lilow-pipe fiame until the weight is constant. This is then derlucted from the weight of the precipitate, and the remainder noted as tamnic acid, or bitter principle precipitater by oxile of learl, or regetahle acids precipitated hy lead (\$80). The filtrate from the learl precipitate is treated according to $\$ 70$.

50 . Detection continued.--The same treatment is repeated with in similar quantity of the watery extract ohtainer in $\$ 48$, sulstituting acetate of copper for acctate of learl $(\$ 52$, II.). Here, too, the amount of oxide of copper in the precipitate is to he retermined by following the sime directions and deducted from the weight of the precipitate. If the estimation with the coprere silt yichls the same result as that with the loud, it is tolerahly certain that only tamic acis has heen precipitater. Inut if leal throws down more matter than colper we are generally justified in assuning that the fonmer precipitates sulstances other than 
tannin, such as other acids, or bitter principles, the amount of which may be approximately determined by deducting the weight of the organic matter contained in the copper precipitate from that contained in the lead. Under these circumstances the weight of the organic sulnstances precipitated by copper sometimes represents approximately the tamnin contianed in the material (\$5 5, 80). It must, however, be admitted that the great difference in the tamnins occurring in nature prevents such a result being looked for in every case.

: 51. Reactions.-The following reactions are common to all tamnins : they are precipitated from aqueous solution by gelatine, hy many" albuminous substances, by acetate of lead and copper, stannous chloride, etc. ; they reduce, at least when warm, alkaline solution of copper as well as solutions of gold and silver salts; they strike an inky or dirk-green colour with ferroso-ferric salts and transform skin into leather. Some tamnins are precipitated by mineral acids, by tartar emetic and by alkaloids, but it is frequently olservalble that an alkaloid and tannin which occur together in the same plant do not form an insoluble compound.

For the microscopic detection of tannin the reaction with iron salts may be made use of. Cells containing tamnin are moreorer coloured reddish-brown with bichromate of potash, violet-recl with aniline and reddish or violet with dilute solution of chloride of zine and iodine. (See note to $\$ 249$.)

The great difference shown by the various tamnins ( $\$ 159$ et seq.) makes it exceedingly difficult to give any general rules for their estimation. Some of my pupils ${ }^{1}$ have therefore at my instance tisted the behaviour of the more important tamnins to the reagents that have been recommended for their quantitative estimation. Before I give a short résumé of the results they have obtainerl I should like to olserve that, in my opinion, the estimation of the tannin in the alcoholic extract, preprared as I have described, is preferable to the determination in the aqueous extract, provided of course that the material is very finely powdered, that the tannin is insoluble in ether free from alcohol, and that the alcoholic liquid has been evaporated under diminished pressure

${ }^{1}$ Compare Günther, Pharm. Zeitschr. f. Russland, Jg. 1870, pp. 161, 193, 225, and 'Beiträge zur Kenntniss der in Sumach, Myrobalanen etc. vorkommenden Gerbsäuren,' Diss. Dorpat, 1871, and other Dorpat dissertations subsequently referred to. 
and rlied as directed in $\$ 4 \%$. One advantage in employing alcohol to extract the tamin, as alrealy recommended by Loewe, is the exclusion of the vegetable mucilage (so-called pectin) and similar substances which may under certain conclitions introduce a rery great error into the estimation. Another reason in favour of the use of alcohol is to be found in the fact that, if the material contains a large quantity of albuminous matter, water will frequently only partially remove the tannin, and that many tannins are much mole easily decomposed by evaporation in an aqueous than in an alcoholic solution. It may happen, it is true, that cold absolute alcohol will not in some cases extract the whole of the tannin from vegetal)le substances that are very rich in albumen, but even in such cases I would prefer treating the residue, after extraction with ether, with boiling alcohol to exhausting it with vater. (See also $\$ \$ 95,162$.

Special emphasis must, however, be laid on the importance of getting rid of the whole of the alcohol by distillation, if that menstruum has been employed, as almost all the following determinations of tannin are made in aqueous solution, and the admixture of even small quantities of alcohol might cause great error.

$\$ 52$. Let us now review the more important methods that have been recommended for the estimation of tannin.

I. Acetate of Lead.-Pribram ${ }^{1}$ has proposed precipitation with neutial acetate of lead. If care be taken not to introduce too great an excess of the precipitant, the precipitation of most tannins is tolerably complete, and it is only in the case of gallotannic acid, catechu-, kino-, and caffeo-tannic acid that part remains in solution on account of the slight solubility of the lead salt. But as the precipitates are not invariably of constant composition it is difficult to estimate the tannin by titration with lead solution. Some of the precipitates (tannic acids from oak-and willow-bark) are decomposed by prolonged washing with water, the tammic acid partly passing into solution and undergoing change. It was for these reasons that I have recommended the precipitation to be male in not over-dilute solutions, and directed that the washing should not be continued too long, and that the tammin should be deter-

1 Zeitschr. f. anal. Chemie, v. 455 (1866). Compare also Jacobson, Chem. techn. Repert. 1866, ii. 85 ; Stein, Schweiz. polyt. Zeitschr. ii. 169; Gietl, Zeitschr. f. anal. Chemie, xi. 144 (1872); and Schmidt, Zeitschr. d. österr. Apothekervereins, xii. p. 374 (1874); (Am. Journ. Pharm. 1874, 427). 
mined from the organic matter in the dried precipitate. In this way the tannin in rhatany, tormentilla, sumach, divi-divi, myrobalans, knopper-galls, oak-bark, and willow-bark may generally he satisfactorily estimated. Gallo-tannic acid at times also yields good results.

II. Acetate of Copper has been suggested by Sackur ${ }^{1}$ as a precipitant for tannin. The composition of the precipitate is, howerer, seldom constant even when working with the same tannic acid; and here, too, it has proved advisable to precipitate in tolerably concentrated solutions, not to wash too long, and to estimate the tannin gravimetrically, as above described.

III. Stannous Chloride and Ammoniucul Stannous Chloride, which have been recommended by Risler-Bemnat ${ }^{2}$ and Persoz, ${ }^{3}$ for the estimation of tannin, precipitate most tamnic acids less completely than the two foregoing reagents. The precipitates moreover form slowly, but are in the majority of cases tolerably constant in composition. On account of the solulility of the precipitate in Water, the estimation will here, too, be most accurate when the washing is not continued too long, the precipitate dried, impregnated with nitrate of ammonia, ignited, and the resulting oxide of tin weighed. The loss by ignition gives the weight of the tamnin. But since the advantage in obtaining precipitates of constant composition cannot compensate for the deficiencies of the method alleady mentioned, I have not further thought of employing the precipitation with stamnons chloride for the purposes we have now in view.

IV. Tertar Einetic, which has been recommended by Gerland4 and Koller ${ }^{5}$ for the rolumetric estimation of tamin, will yield

1 Gerberzeitıng, xxxi. 32. See also Wolff, Krit. Blätter f. Forst und Jagdwissensch. xliv. 167 ; Fleck, Wagner's Jahresber. f. techn. Chem. Jg. 1860, p. 531; Hallwachs, Zeitschr. f. anal. Chem. v. 234 (1866).

2 Zeitschr. f, anal. Chem. ii. 287 (1863).

3 Traité de l'Impression des Tissus, i. 282. 'The results obtained by the method recommended by Persoz, in which the amount of tannin is calculated from the volume of the precipitate, are, according to Gauhe (Zeitschr. f. anal. Chem. iii. 130, 1864) and Cech (Stud. iiber quant. Best. der Gerbsäuren, Inaugural Dissertation, Heidelberg, 1867), too high. I avail myself of this opportunity to draw attention to the works of the two last-named authors, which are intended as a critical review of the more important methods of estimating tannic acid. (See Procter, Pharm. Journ. Trans. [3], vii. 1020 ; Allen, Commercial Organic Analysis, London, 1879.)

${ }^{4}$ N. Jahrb. f. Pharm. xxvi. 20 (1866) ; (Amer. Journ. Pharm, xxxv. 519).

5 Foller employed this method in estimating the tannic acid in orange-peel (N. Jahrb. f. Fharm, xxv. 206, 1866). 
satisfactory results in some few cases only, hecause, even if the solution be mixed with chloride of ammonium, it is difficult to ascertain when a sufficient quantity of the reagent has been acled, and because some of the tamnin precipitates so produced are rapidly decomposed. Some tannins (rheo-tamnic acid) are not precipitated at all by tartar emetic.

V. Ammoniacal Solution of Acetate of Zinc.-This reagent should, according to Terreil, ${ }^{1}$ Carpené, ${ }^{2}$ and Barbieri, ${ }^{3}$ he used in the following manner for the estimation of tannic acid. The liquid to be precipitated is brought to the boiling-point, an excess of the zine solution added, and, after concentration by evaporation, the mixture is cooled and filtered. The precipitate is then dissolved in sulphuric acid, and the tannin estimated by titration with permanganate of potassium. I must admit that some tannic acids may be determined in this manner, but I must also draw attention to the fact that all tannins occurring in vegetable substances do not exercise the same influence on permanganate of potassium; that is, one tannic acid may differ from another in the amount of permanganate a given quantity can decolourize, and this value of the tamnin in terms of permanganate must in many cases be first determined. It is partly on this account that the estimations of the tamnin in wine, made accorting to this method, are of but little value.

VI. Ferric Acetate, in conjunction with acetate of soda, has been used by Handtie ${ }^{4}$ for the estimation of tamnic acid in oak-bark, ralona, divi-divi, sunach and catechu. He found the reagent unsuited for the precipitation of the tannin present in Rheum, various species of Filex, coffee and other plants; and even with the firstnamed substances it was only when the concentration was such that the precipitate contained $45 \cdot 8$ per cent. of oxide of iron that the estimation yielded satisfactory results.

Still less feasible is Wildenstein's ${ }^{5}$ colorimetric examination, which is based upon the intensity of the colour preduced by the solution on paper impregnated with ferric citrate.

VII. Titration uith Permangunate of I'otassium. - MIonier, ${ }^{G}{ }^{C} \mathrm{ech},{ }^{7}$

1 Zeitschr. f. anal. Chem, xiii. 243 (1874).

Ibid. xv. 112 (1876).

${ }^{3}$ Ibid. xvi. 123 (1877). See also Kathreiner, ibid. xviii. 113 (1879).

${ }^{4}$ Journ. f. pr. Chem. Lxxxi. 345.

5 Zeitschr. f. anal. Chemie, ii. 13 (1863).

${ }^{6}$ Compt. rend. xlvi. $44 \%$.

7 Loc. cit. 
Löwenthal, ${ }^{1}$ and others, have shown that the tannin contained in many vegetable substances may be estimated with sufficient accuracy for technical purposes by titrating with solution of permanganate of potassium. In dealing with regetalle infusions, however, almost all authors agree that if a satisfactory result is to be obtained the solution to be titrated must be very dilute (about 1 in 400), and the oxidation incomplete. Löwenthal and others have found the following to be the most advantageous method of procedure. The liquid under examination is mixed with a measured quantity of solution of indigo-carmine, the value of which, in terms of permanganate, has been previously determined. The permanganate solution is then run in till the blue colour changes to green. The value of the pure tannin in terms of the reagent must have been previously determined by experiments with weighed quantities of the same. By such experiments Günther ascertained that 16 parts of oxygen from the permanganate oxidized 32.5 parts of gallo-tannic acid, 33.0 of sumach-tannic acid, $25.0(5.54)$ of catechu-tannic acid, $24 \cdot 0(5 \cdot 32)$ of catechuic acid, $228 \cdot 0$ of kinotannic acid, 34 to 37 of rhatania-tannic acid, 35 of tormentillatannic acid, 34 of caffeo-tannic acid, and 32 of oak-bark-taunic acid.

Neugebauer ${ }^{3}$ estimated the tannic acid in oak-barks with permanganate by taking advantage of the power possessed by animal charcoal of absorbing tannic acid, and thus removing it completely from its aqueous solution. He divided the infusion to be examined in two equal parts. The one was titrated direct with permanganate, the other after the absorption of the tamic acid by animal charcoal. The amount of tamin present was then calculated from the difference, the assumption being made that the substances which acted upon permanganate in the liquid after treatment with animal charcoal were foreign bodies. Lïwenthal (see below) titrates a part of the tannin solution direct, another part after precipitation with solution of grelatine(XII.). From the difference in the quantity of permanganate used the tamnin is calculated.

1 Journ, f. pr. Chem. lxxxi. 150.

2 Owing to a mistake in the calculations, the figures here given for catechutannic acid and catechuic acid are much too high. The correct numbers are placed in brackets after them. Lehmann, in checking the experiments ( $V$ ergl. Unters. einiger Catechu- und Gambier-Proben. Diss. Dorpat, 1880), found that $16 \cdot 0$ parts of oxygen were equivalent to $5 \cdot 14$ parts of catechu-tamic acid and 4.84 catechin.

${ }^{3}$ Zeitschr, f. anal. Chem. x. 1 (1871). 
If a solution contain both gallic and tannic acid, or catechin and catechu-tannic acid, both may be approximately estimated by Löwenthal's method. (See also \& 164, et seq.) The addition of gelatine as directed by him introduces only a slight source of error, which may be generally neglected.

VIII. Chlorinuted Lime.Löwenthal ${ }^{1}$ has titrated with chlorinated lime in the presence of indigo carmine in the same way as with permanganate of potassium, but the estimations generally yicld too high results in consequence of the impurities present.

Cech" has already expressed an unfavourable opinion of the propositions of Commaille ${ }^{3}$ and Millon ${ }^{4}$ to make the separation of iodine from iodic acid by tannin the basis of a method for its quantitative estimation. The decolourization of a solution of iodine by tannic acid in the presence of carbonate of sorla has been recommended by $\operatorname{Jean}^{5}$ for the quantitative estimation of tannin. He states that 1 part of gallo-tannic acid decolourizes 4 parts of iodine, and reserves to himself the determination of the value of other tamnins in terms of iodine. He admits that gallic acid also acts upon iodine, and advises, when both are present, first to make a total estimation, and then determine the gallic acid alone in a second portion of the liquid, after the tannic acid has been removed by gelatine or hide. The solution of tannic acid for standardizing should contain 1 part in 1,000 of water. Before titrating, 2 cc. of a 25 per cent. solution of cryst. carbonate of solla should be added for every $10 \mathrm{cc}$. of tannic acid solution. It must be observed that here, too, many organic compounds would act in a similar manner to tannin.

IX. Oidution.-For the estimation of tamnin Mittenzwey ${ }^{6}$ has availed himself of the fact that an alkaline solution of tamnic acid rapidly absorbs oxygen from the air. In the analysis of plants this methorl will seldom be of any value. Cech has alrearly shown that it yields unsatisfactory results with the tannins usually employed.

X. Titration with Cinchonine.-Wagner 7 has proposed titration with sulphate of cinchonine, using acetate of rosaniline as an

1 Loc. cit. ${ }^{2}$ Loc. cit. $\quad{ }^{3}$ Compt. rend, lix. 599 (1864).

4 Annales de Chimie et de Phys. [3], xii. 26.

5 Zeitschr. f. anal. Chem. xvi, 123 (1877).

${ }^{6}$ Journ. f. pr. Chemie, xci. 81, and Zeitschr. f. anal. Chemie, iii. 484 (1864). Sce also Terreil, Zeitschrift des isterr. Apothelervereins, . .g. xii. 376 (IS7.).

7 Zeitschr. f. anal. Chem. v. 1 (1866). See also Salzer, ibid. vii. 70 (1868); Buchner, ibid. 139 ; Clark, Amer. Journ. Pharm. xlviii. 558 (1876). 
indicator. But the majority of those who have worker the process have failed to obtain good results. Almost all of them have found that the assumption that rosaniline would not colour the liquid until all the tannin had been precipitated by the cinchonine, was true of certain tannins only, and not of all. It has been shown that, with some tamuins, the appearance of a red tinge in the solution, which is said to indicate the end of the reaction, may be noticed long before all the tannic acid has been precipitated. In many cases better results might be obtained with cinchonine if the tannic acid were precipitated by an excess, the liquirl filtered and the excess of cinchonine in the filtrate determined by titration with potassio-mereuric iodide. This method has been adopted by Clark in estimating the tannic acid in tea. (See $\$ 65$. )

XI. Gelatine and Hide.-The behaviour of gelatine and hide to tannic acid is often made use of in the estimation of tannin. The estimation may be made either by determining the increase in weight of a piece of hide, previously freed from substances soluble in water and petroleum spirit by digestion in those solvents, when allowed to lie for some time in the solution of tannin, or by ascertaining the specific gravity of the solution before and after the absorption of the tannic acid, and calculating the amount from the difference. Hammer ${ }^{1}$ has constructed a table for gallo-tannic acid, from which the amount of tamnin can be directly read off. If this method of estimation is to be adopterl, a sinilar table would have to be constructed for other important tamic acids, showing the relation between the difference in specific gravity and the amount of tannin present.

XII. Gelutine: Grarimetric Process.-Precipitation of the tamin by gelatine, and calculation of the amount present from the weight of the precipitate, has also been tried. But the disadvantages which present themselves here are that these precipitates are neither sufficiently insoluble nor constant enongh in composition to allow of their being male the basis of a gravimetric estimation; especially in washing the precipitate with pure water, considerable quantities of tannic acid are removed.

It is, therefore, most advantageous to apply the precipitation

1 Journ. f. pract. Chem. clxxxi. 159. See also Löwe, Zeitschr. f. anal. Chem. iv. 365 (1865), and Hallwachs and Cech (loc. cit.). Davy has already entimated tamic acid gravimetrically by cmploying hide (Chem. News, 156:3, p. 54, and Zeitschr. f. anal. Chem. ii. 419). 
with gelatine in the following mannel: A solution of that sul). stance-the value of which, in terms of the tamic acid to be estimated, has been previously ascertained - is run into the solution in which tannin is to be determined as long as precipitation occurs. The gelatine solution should be mixed with some salt, diminishing the solubility of the tannate of gelatine. For the latter purpose the addition of alum has been recommended (Miiller ${ }^{1}$ ). The proposal of Schulze ${ }^{2}$ to use chloride of anmonium, or of Löwenthal to add common salt and $\frac{1}{10}$ vol. of hydrochloric acil (specific gravity 1.12), appears better. A solution of gallotannic acid may be saturated with these salts; but in the case of other tannins (from oak, willow, and elm bark) a smaller quantity might be preferable. If Lüwenthal's modification be adopted, it is advisable to stir the liquid vigorously for five minutes after each addition of the gelatine solution. It has already been determined by Günther that the various tannins differ in the amount of gelatine they are capable of precipitating. He found that 100 parts of gelatine precipitate, in the presence of chloride of ammonium, 77 parts of gallo-tannic acid (according to Johanson 120 parts of dry tannic acid), 132 (Lehmann, 139) of catechu-, 130 kino-, 130 to 132 rhatania-, 130 oak-lark-, and 168 of tormentilla-tannic acid. As is well-known, gallic and catechuic acids do not precipitate gelatine.

5.5. Gallic and Catechuic Acids.--If one of these two substances is to be looked for, the tannic acids should be first precipitated by gelatine, the excess of gelatine by alcohol; and after the alcohol has been removed by distillation under diminished pressure, gallic or catechuic acir may be isolater by shaking with ether or acetic ether. If care has been taken to avoid using a large excess of gelatine, the treatment with alcohol might be omitted; and in many cases it would be possible to agitate even the ayueous solu-

1 Archiv d. Pharm. xxxviii. 147 (1845). Gauhe did not succeed in his endeavour to find an indicator (iodide of starch) to show the final reaction in titrating. Compare Zeitschr. f. anal. Chem. v. 232 (1866). Neither was Cech quite satisfied with an iron solution used for the same purpose. See also Hallwachs (loc. cit.).

2 Zeitschr. f. anal. Chem. v. 455 (1866). Compare also Salzer, ibid. vii. 70 (1865), and Johanson, 'Beitr. z. Chemie der Eichen, Weiden, und Tlmenrinche, Diss. Dorpat, 1875, pp. 72, 76. Also Lehmann (loc. cit.). A more recent critical review of the more important methods for estimating tamnic acid by Löwenthal will be found in the Zeitschr. fo anal. Chemie, xvi.33, and 201 (1877), and $x x .91$ (1881). 
tion $(\$ 48)$ directly with ether, renewing the solvent four or five times. On evaporating the ethereal solution, both gallic and catechuic acids remain behind in a crystalline form, generally needles felted together. (Cf. $\$ \S 151,165$.

The weight of the dried residue frecuently indicates with tolerable accuracy the quantity of the substance present; but if the residue be mixed with much colouring or amorphous matter, so as to cause some hesitation in accepting the weight as correct, the result obtained may be verified by titration with permanganate of potash. (See above.) If the material has been extracted with ether previous to treating with alcohol, gallic and catechuic aciils will he found in the aqueous solution from the ethereal extract. (Cf. $\$ \S 38,151$.

For the free regetable acids which may occur in the alcoholic extract see $\S 82$. (See also in $§ 159$.)

\section{EXANINATION FOR GLUCOSIDES, BITTER PRINCIPLES,}

ALKALOIDS, ETC.

§ 54. Extraction by Agitation.-If no tannic acid or allied substance has been found in the aqueous liquid ( $\$ 48$ ), lut by the bitter taste or other properties the presence of a bitter principle, slucoside or alkaloid insoluble in ether but soluble in water is suspected, the watery solution prepared from the eraporation residue of the alcoholic tincture may be sulvjected to consecutive treatment with various liquirls which, being themselves insoluhle in water, are adapted for removal of substances in solution by argitation and separation. The aqueous solution from the ethereal extract (\$38) may also be treated in a similar manner. 'The use of petroleum spirit, henzene, and chloroform may be especially reconmended for this purpose; they should he employed in the order in which they are named, and the liquid should be rendered finst slightly acid with sulphuric acid, and sulsequently alkaline with ammonia; I have spoken at length on this sulject in my ' E'rmittelung der (iifte.' $\Lambda$ fter each agitation, the solvent should be separated, washed once by shaking with pure water, again scparated, evaporated to dryness, and the residue examined. If a solvent, as for instance petroleum spirit, remores any apprecialile quantity of a sulustance, the agritation with this liquid should be

${ }^{1}$ P. 119. Compare also Russ. Archiv für gerichtl. Med. J. i. und Pharm. Zuitschr.f. Russland, v. 85 ; vi. 663. 
repeated until only traces of the substance are dissolved. Then, and not till then, the same treatment is repeated with the next solvent, and so on. All liquids employed for agitation must be rectified shortly before being used. Petroleum spirit must be as rolatile as possible; benzene should boil constantly at $81^{\circ} \mathrm{C}$, and yield nitro-benzene when treated with fuming nitric acid.

55. Froin Acill Solution.-Of the better-known bitter 1ninciples, acids and alkaloids removed by petroleum spirit from an acid solution, the following may be mentioned:

Salicylic acid (cf. § 26). Pungent principles of capsicum, etc. (S 126). (Both of these would have been already detected in the ethereal extract. Salicylic acid may be more casily removed by benzene or ether.) Piperin - the majority of this principle will be found in the part of the alcoholic extract insoluble in water (compare further $\$ \S 171,178$ ). Absynthin cannot be completely remored by petroleum spirit (\$ 156). Hop-resin (s 156).

Benzene remores from the same solution santonin (cf. \$151); rerryophyllin (\$156); cubebin (\$155); digitatin (remaius principally in that part of the ethereal extract which is insoluble in water (cf. $\$ 155)$; grativalin (\$165); cascarillin (\$156); eluterin (\$156); 2ululin (\$167); colucynthin (\$ 167); alsynthin (\$ 156); quassin (\$ 1.56); menyenthin (\$ 167); cricolin (\$ 155); dephnin (\$167); bitter principle of Cnicus benedictus (\$ 168); caffeine (\$S 171, 176); piperin (see alove); colcliceine (S 171); berberine is dissolved by benzene in small proportion only (compare $\$ 171$ ).

Besides the substances already named as being dissolved by petroleum spirit and benzene, chloroform removes also among sthers: Bensoic acid (cf. \$20); digitalein (sparingly soluble in ether, 155$)$; convallamerin (\$167); saponin (insoluble in ether, rifficultly soluble in absolute alcohol, \$ 77 et seq., 167); senegin (the same); physsutin (\$167); syringin (\$16 $\$$ ); asculin (\$167); jucrotorin (\$ 15.5); helleborien (\$ 167); cinchonine (is insoluble in ether, $\$ \$ 171,182,184)$; theobromine (\$ 177); papaverine (\$ 171); narceine (\$ 171). Colchicine, solanidine, quebrachine, geissospermine.

\$56. From Alkuline Sulution.-After the last aritation with chloroform the aqueous liquid should be shatien whilst still acid with petroleum spirit. This removes the small quantity of hloroform remaining dissolyed by the watery liquid. An error 
might be made in omitting this treatment, since on rendering alkaline and shaking with petroleum spirit this solvent would take up a little chloroform and would consequently be no longer pure. After, therefore, the remainder of the chloroform has been remored by petroleum spirit, the liquid may be marle alkaline with ammonia, and the argitation with the same solvents repeated in the same order. In addition to these three liquids I have, however, after agitation with chloroform, employed amylic alcohol for detecting certain poisons. It removes morphine, solanine, (\$171), salicine ( $\$ 167$ ), and some other substances from their aqueous solutions with special facility.

It is principally alkaloids that are removed by petroleun spirit, etc., from ammoniacal solution. Petroleum spirit dissolves, for instance, traces of strychnine, brucine, emetine, veratine, sabadilline, and subutrine. All these substances are, however, more easily and completely taken up by benzene and chloroform.

But petroleum spirit is specially valuable in the examination for the so-called rolatile and, at ordinary temperatures, liquirl alkaloids, such as coniine, methylconiine (and contydrine), nicotine, lobetiine, sparteïne, alkaloids in pimento, capsicum and Sarracenia purpurea. Aniline, trimethylamine, and allied substances are also dissolved by it (\$ 171, 239). In examining for volatile alkaloids I have advised agitation of the aqueous liquirl with petroleum spirit, and eraporation of the solvent, after separation, at a temperature of about $20^{\circ}$, on glass dishes previously moistened with strong hydrochloric acid, on which the hydrochlorides of the alkaloids will partly, at all events, remain behiml. A freshly-prepared dilute solution of hydrochloric acid gas in ether may be advantugeously substituted for the usual aqueous acid.

lienome removes from ammoniacal solution, in addition to the alkaloids alreadly mentioner, atropine, hyoseycmine, fhysostigmine, pilacurpine, yelsemine, turine, quimitine, nurcotine, codeine, thebaine, delphimine and delphinsidine, aconitine, "spidospermine, pereirine, and a trace of cinchonine. (Cf. $\$ 171$.

In addition to these, agrain, chlornform dissolves from ammoniacal solution cinchonine, puluteriur, nurceine, minhurine, the allaterids of celandine, and small quantities of morphine (\$171).

$\$ 57$. Ilirect Tests for Cituresides, Allectoids, etc.-The number of acids, glucosides and alkialoids (cf. \$21) that may be isolated hy 
this method of agitation is doubtless very large, and by making the required experiments the list given in the preceding section might be rendered far more complete. It is this rery fact that renders the method so suitable for the qualitative examination of those plants and parts of plants the constituents of which are at present unknown. Of course, it is possible to employ infusions which have been prepared by digesting the material under examination with water on the water-bath, instead of aqueous solutions from the ethereal or alcoholic extracts. This would especially be the case if acids, bitter principles and glucosides are to be looked for. Alkaloids may likewise be tested for by digesting the material with water acidulated with sulphuric: acil ( 1 in 50). In both cases, however, it must be remembered that by thus directly extracting the substance with aqueous liquicls many bodies, such as mucilage, etc., are dissolved, and that this is avoided by treating them according to the method first described. The presence of such substances is disadvantageous, inasmuch as they sometimes render the extraction of a principle from aqueous solution by the method of agitation more difficult, and always act injuriously in rendering the separation of the two liquirls after shaking almost impossible. It is therefore advisable to remove all matter tending to increase the viscosity of the aqueous infusion loy concentrating to a syrupy consistence (if necessary, after haring previously nearly neutralized with ammonia or masnesia), precipitating with about three rolumes of spirit, filtering after standing twelve to twenty-four hours in a cold place, and distilling off the alcohol.

\$ 58. Alkaloids, etc., not liemoruble by Agitution.-Some bitter principles, glucosides and alkaloids cannot, however, be remored from solution by agitation, either because they have less tendency to pass into any other known liquid than to remain in aqueous solution, or hecause they are insoluble in water. The latter is the case, for instance, with the grlucosidal resins which occur in the convolvulacex. Such substances are generally isulated with the resins. (Cf. § 153.)

The purification of bitter principles and glucosides that are soluble in water, but cannot be removel by shaking, may he effected by evaporating the aqueous solutions prepared from the; ethereal or alcoholic extracts, and repeatedly dissolving the sub)stance in chloroform, alcohol, or ether. It will be found easier to 
purify a bitter principle dissolved by water from the ethereal extract, than one obtained in a similar manner from the alcoholic extract, since the latter contains glucoses and tannins, which are insoluble in ether. Apart from the treatment with chloroform and other solvents which I have just described, another method of purification may in this case be adopted-viz., evaporation of the aqueous solution, extraction with the smallest possible quantity of absolute alcohol, and precipitation of sugar, etc. with ether.

\$59. Separation of Tannin.- - Tannic acid, when present in solution, together with bitter principles, etc., may frequently be removed by digesting the aqueous infusion with oxide or hydrate of lead. If salicine (cf. $\S 167$ ), for instance, is to be separated from tannin, the aqueous infusion may be mixed with oxide of learl, evaporated to dryness on the water-bath and extracted with alcohol. Basic acetate of lead may also be occasionally userl, when a bitter principle is to be separated from tannin, vegetable acids, albuminous matter and the like. Of course, it must have been previously ascertained that the bitter principle in question is not precipitated by lead; should that be the case, it may sometimes he isolated by decomposing the lead compound with sulphuretted hydrogen. By combining a bitter principle with lead a separation may sometimes be effected from sugar, etc. This method is, however, inapplicable if tannic acid be present, when it will often be found advisable to precipitate regetable acids, tamin, etc., by neutral acetate of lead before throwing down the bitter principle, etc., with the basic salt ( $\$ 51,162)$.

\$ 60. Seprarution of Lead Precipitute. - If such compounds of lead with hitter principles, glucosides, etc, are to be washed with water, it is very advisable to effect this as rapidly as possible by decantation. Such precipitates often block a filter, or form, by contraction, channels through which the wash-water runs off without penetrating the precipitate. If the use of a filter is necessary, repeater suspension in water and filtration is advisable. The washing of such precipitates should not be continued too long, as they nsually undergo decomposition during the process and yield the hitter principle to the wash-water. The presence of carbonic aceil in the water used for washing is specially to be avoided.

Decomposition.-The decomposition of those precipitates is usually effected ly sulphuretted hydrogen, which, howerer, does 
not act well if the learl compound has been previously dried. It is a well-known fact that, in the course of this operation, the bitter principle may be mechanically retained by the sulphide of lead formed. To aroid loss in this way the sulphide may loe filtered off, washed, dried, powdered, and boiled with alcohol. In evaporating the alcoholic extract care should be taken not to confound crystals of sulphur with the bitter principle, etc. It will often be found advantageous to decompose the lead precipitate in alcohol insteal of water. The surface-attraction of the sulphide of lead will, nevertheless, be frequently found useful in retaining foreign bodies, such as colouring matter and the like, whilst bitter principles, etc., pass into solution.

The directions given for the decomposition of the lead precipitates may also be followed in isolating tannic and regetable acids from such compounds. (See also $\$ 162$.

\$ 61. Glucosides; liecognition.--In proving the glucosidal nature of a substance advantage may be taken of the influence exercised by ferments (saliva, emulsin, myrosin), etc., or dilute acids (accompanier by heat) on glucosides, which, under such circumstances, split up and yield sugar as one of the products of decomposition. It is a(visal)le to ascertain whether the substance itself, in as pure a state as possible, reduces an alkaline solution of copper, either at the ordinary temperature or on boiling. If no reduction takes place the further examination for glucose is much facilitatecl. It is customary to boil the substance under examination with water containing 1 to 2 per cent. of sulphuric or hydrochloric acid, and test the liquirl for sugar from time to time. The rapillity with which decomposition may be thus effected varies very greatly. Some glucosiles yield a sugar reaction after boiling for a few minutes only; other's require several hours. In some cases it is preferable to allow the acid to act under pressure, or in alcoholic instead of aqueous solution.

(Cf. $\S \S 153,160$.

The decomposition-products which are formed, together with glucose, from glucosides, are not unfrequently insoluble in water, and therefore render the liquid turbid in proportion as the reaction procecls. This peculiarity may be often male use of as proof that decomposition has commenced, especially in those cases in which the glucoside itself reduces Fehling's copper solution. After the completion of the reaction and the cooling of the liquid, the decomposition-product may be filtered off and further 
examined. If, on the other hand, this substance be soluble in water, its isolation may be attempted by the method of agitation.

An experiment should also be made to ascertain the action of the glucose thus produced on a ray of polarized light, as well as its behaviour with yeast-that is, its capability or incapability of entering into fermentation. For this purpose it is best to decompose the glucoside with sulphuric acid, which may be subsequently removed by carbonate of barium. The filtrate from the sulphate of barium, which should be faintly acid in reaction, should be mixed with a little yeast, introduced into a eudiometer over mercury, and olservation made whether, under these circumstances, carbonic-acid gas is evolved. Many glucosides yield, hesides glucose, prorlucts of decomposition which are antagonistic to alcoholic fermentation; these are, if possible, to be removed.

This fermentation experiment will have a particular value in all cases in which the glucoside itself reduces alkaline copper solution. Proof of the glucosidal nature of the substance may then be found in the experiment yielding a negative result before, but a positive one after, the action of the dilute acid, especially if the substance be soluble in ether or cold absolute alcohol. Saccharoses and other carhohyclrates, which would yield similar results, are thus excluded, they being insoluble in the liquids named.

It is hardly necessary for me to point out the desirability of estimating, hy means of Fehling's copper solution, the sugar proruced by the decomposition of a glucoside. (Cf. \& 83, ct seq.; $\$ 200$, et seq.)

Some bodies which are usually treated of with the glucosides yield, when acted upon by acids, not glucose, lut sulstances allied to sugar or mannite, which, like isodulcite, are unfermentable. (Cf. $§ 212$.

\$62. Sulphuric Acid Group-recetion.-Many glucosides are capable of acting like sugar when mixed with bile and sulphuric acidthat is, of producing a red colour. This reaction has been described as to a certain extent characteristic of the whole group of glucosides; but it should be remarked that among them there are many which are rertidenerl by sulphuric acirl alone, whilst some cannot replace sugrar in the test for bile; and others, when mixed with sulphuric acirl, assume such characteristic colours that the bile reaction is quite undistinguishable.

For further information concerning gheosides, compare $\$ 165$, et seq. 


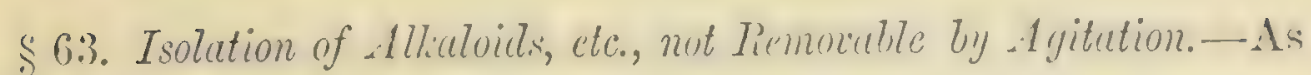
stated in $\$ 58$, there are some allarloids which, for the reasons. there given, camnot be isolated by the method of argitation. To separate these in a state of purity the extracts prepared according to $\$ 57$ should be exhausted as far as possible hy shaking with pet!oleum spirit, etc., and then evaporated to dryness. The dry residue should be finely powdered (if necessary, with the addition of washed sand or siliceous earth) and treated with alcohol, ether, chloroform, ete. The exhaustion, however, with these solvents will be incomplete if the resiche be not recluced to a very fine powder. (See also $\$$ 65, 66.)

Detection by Gioup.reagents. - Before proceeding to this extraction it may appear desirable to ascertain whether an alkaloid is present at all. To that end the liquid obtained in $\$ 57$, containing sulphuric acid but no alcohol, may be tested for alkaloids hy precipitants which have been introduced as group-reagents for that class of substances. The following may be especially recommended :

Tri-iodicle of potussium - that is, an aqueous solution of iodine in iodide of potassium-gives, with aqueous solutions of most alkaloicls, amorphous precipitates of a dark-brown or kermesmineral colour, and is one of the most delicate reagents. An alcoholic solution of an alkaloid frequently remains clear on the ardition of the tri-iodicle; or if a precipitate is formed, it differs in properties from that produced in aqueous solutions. For example, berberine and narceine would under these conditions yield crystalline precipitates.

Trillumide of potassium, prepared in a similar manner, also precipitates some of the alkaloils from very dilute solutions, but, in arlition, forms yellowish compounds with 1henol, orcin, and many allied bodies ( $\$ 158)$.

Potussio-mercuric iodide, obtained by decomposing mercuric hhloride with an excess of iorlicle of potassium, yiclds with most alkaloids, white, flocculent precipitates, which sometimes griulually assume a crystalline character. (See also\$65.) The presence of free acid may sometimes cause a lifference in the precipitate obtained from one and the same alkaloid.

Potussio-tismuthic iodide, prepared by dissolving iodide of bismuth and iodide of potassium in water, yields, even in highly dilute solutions, precipitates which are very sparingly soluble, 
and resemble orange sulphide of antimony in colour. It should not, howerer, be forgotten that albuminous ant other similar substances are also precipitated by this reagent. (Cf. $\$ 232$.)

Potussio-curtmir iodide, obtained in analogors mamner from iorlide of cadnium, gives white precipitates, which, like those yielder by potassio-mercuric iodide, sometimes become crystalline. They are mostly rather more soluble than those produced with the latter reagent.

Phosphen-molybulic acid (a solution of the sodium salt in nitric acid) Jields with most alkaloids yellowish precipitates, which are in certain instances rapidly reduced, and assume a bluish or grecnish colour. Ammoniacal salts and less complex amidecompounds are also precipitated by this reagent.

Metatungstic acid gives similar precipitates (\$17\%).

chloride of gold yields yellowish precipitates with rery dilute solutions of many alkaloids. Sometimes a rapicl reduction takes place, and the yellowish colour changes to a reddish-brown, the liquicl itself occasionally assuming at the same time an intense recklish tint (\$186). I consider this reagent especially ralualle for our purpose, as ammoniacal salts and the less complex amides are not precipitated by it.

Perchloride of platimum forms brownish-yellow precipitates with most alkaloids (not all), but is less valuable than chloride of gold, because the precipitates are mostly more soluble, and hecause it forms sparingly solul,le compounds with ammonium and potassium salts, etc. The precipitates obtained with this reagent also sometimes show a disposition to decompose.

Nercuric shloride. - The white precipitates which this salt yiclds with alkaloids are not rery sparingly soluhle, hut it possesecs some ralue, as it cloes not precipitate ammoniacal salts, etc. The same is the case with

Picric acid, which gives yellowish precipitates.

Tannic "cid, the conpounds with which are usually of a grerishyellow or greyish-brown tint, and

Bichromute of potesh, which yichls yellowish and occasionally crystalline salts. ${ }^{1}$

1 For group-reagents for alkaloids see further in my Ermittelung von Giften, 2nd edition, 123 ; also Selmi, Jahresb. f. Pharm. 1874, 480; 1875, 341; 1876, 628 (Year-book Pharm. 1876, 110). For behaviour of cinchonaalkaloids to sulphocyanide of potassium compare Schrage, Arch. d. Pharm. 
To confurm the presence of an alkaloil, advantage may also be taken of the fact that they all contain nitrogen, and, therefore, yield Prussian hlue with Lassaigne's test (heating with metallic solium, etc.). 'This test will be specially valuable if another' peculiarity of most, but not all, alkaloids-viz., the alkaline reaction towards litmus and capaloility of forming salts-be not well defined (colchicine), or if a compound be obtained which must be referred to the group of amilo-acids (colchicine) or glucosilal alkaloids (solunine). It must not, however, be forgotten that some of the glucosides already mentioned contain nitrogen ( 167 ). For tables of the colour-reactions characteristic of many alkaloids see $\$ 171$.

\$6t. Allulloids not Isolated by the Method of Agitation; Purification.-In cases in which an alkaloid is present that camnot be separated in this way or purified as recommended in $\$ 63$, the following method may be tried. The alkaloid is precipitated by potassio-mercuric iodide from its solution in water acidulated. with dilute sulphuric acid, the precipitate filtered off, washed, suspended in water and decomposed by sulphuretted hydrogen. On filtering off the sulphide of mercury, a solution of the hyclriodate of the alkaloid togrether with free hydriodic acid is obtained. Sulphate of silver is then added as long as it causes a precipitate, and the iodide of silver filtered off. After remoring the sulphuric acid by addition of caustic baryta and filtration, a solution of the alkaloid may be obtained by freeing the filtrate from cxcess of baryta by carbonic-acid gas. The last separation of baryta, however, is not always quite complete. It might he hetter therefore in many cases to remore the sulphuric acil lyy carbonate insteal of hyrlrate of barium. The former, moreover, would be less likely to decompose the alkaloid.

In following this methor, inconvenience is occasionally experiencer in filtering off the sulphide of mercury, which sometimes separates in a very fincly-divider state. To obtain a clear filtrate,

clxxiv. 143; [3], v. 504; xiii. 25; Hesse, ibid. xii. 313; xiii. 481; Godeffroy, Oesterr. Zeitschr. f. Pharm. 1878, Nos. 1 to 12 (Am. Journ. Pharm. 1878, 178). For the action of silico-tungstic acid on allialoids see Godeffroy, Archiv d. Pharm. ix. 434; chloride of antimony and stannous chloride see Godeffroy, ibid. 14\%, and Smith, Jahresb. f. Pharmacie, 1879, 166 ; arseno-molyblic acid, selenic and telluric acid, Drandt, .Tahresl. f. I'harmacie, 1875, 311. Smith heats trichloride of antimony and projects the alkaloid into the fused mass. DInrphine and codeine produce a greenish, narcotine olivegreen, thebaine, brucine and veratrine, red colouration. 
eraporation with white hole and re-solution in water may be tried. The iodide of silver and sulphate of barium are also at times very difficult to remove, ancl clear liquids can only be obtained by repeated filtration through double filters.

Should the alkaloid, after liberation with caustic baryta, be sparingly soluble in water, it may be precipitated simultaneously with the sulphate of barium. In this case it may be extracted from the dry precipitate by treatment with alcohol or other suitable solvent. But those alkaloids that resist extraction by the method of agitation are generally freely soluble in water.

Iilny alkaloids, too, are easily attacked by alkalies, splitting up, on boiling, into acids and new complex amides. Atropine under such circumstances yields tropine and tropic acid; hyoscyamine is resolved into the same two substances. (Cf. \$ 65.) How easily errors are thus caused may be seen from the number of alkaloidal substances that have been described in text-books as special alkaloids, and which are in reality nothing but products of decomposition (acolyctine and napelline = aconine; lycoctonine = pseudaconine). ${ }^{2}$ Curarine is another alkaloid easily decomposed by allkalies. C'ertain members of this class are also decomposed by boiling with dilute acids.

If the alkaloid under examination is not easily attacked by baryta or lime, it may be precipitated by phospho-molyldic or whospho-tungstic uciel (\$63), and separated from its combination with either of these acids by baryta or lime, the excess of alkalline earth being removed by carbonic acid. These methods, which are sometimes of use in the quantitative estimation of certain alkaloids, will be discussed in detail in $\S 177$.

\$6.5. Estimation.--For the quantitative determination of allialoids, one of the following methods may be feasible:

1. The alkaloid obtained in $\$ 64$ may be dried and weighed.

2. The sulstance removed by agitation according to 355,56 , may be weighed, care being taken to avoid loss. ${ }^{2}$

1 I avail myself of this opportunity to draw attention to the more recent researches of Wright and Luff on the aconite-alkaloids. See Jahresb. f. Pharm. 1873,$131 ; 1874,135 ; 1876,169 ; 1877,434 ; 1879,189$; and in Pharm. . Tourn. and Trans. On atesin of Aconitum heterophyllum see Wasowicz, Archiv d. Pharm. xiv. 193 (1879) (Pharm. Journ. and Trans. [3], x. 310). See papers by Wright and Luff, etc., in Pharm. Journ. and Trans. [3], vols. ix. x. and xi.

2 Compare the methods I have proposed for the quantitative estimation of trychnine, brucine, and veratrine, in $\$ 174$. Guinther has successfully em- 
3. The alkaloid may be precipitated from its aqueons solution by certain reagents, and estimated gravimetrically.

Chloride of gold, or sometimes perchloride of platinum (\$173), znay be advantageously used as precipitant in the last case, as the amount of alkaloid and chlorine present may be approximately calculated from the amount of gold or platinum contained in the precipitate. Alkaloids may often be estimated gravimetrically and volumetrically by precipitation with potassio-mercuric iodide (\$ 174).

I have discussed this subject fully in my 'Chemische Werthbestimmung starkwirkender Droguen,' ${ }^{\prime}$ where I have shown that many alkaloids may thus be accurately estimated. I found, howerer, that the precipitates produced were not always analogous in composition, and that therefore the precipitating power or value of the unit-quantity of reagent must be determined for each single allkaloid. The composition of the precipitate yielded by one and the same alkaloid may vary with the concentration of the solution, and a difference in the amount of sulphuric acid present may sometimes influence the result. A large excess of acid is incomjatible with the accurate estimation of certain alkaloids, such as Irucine and coniine, whilst in other cases (nicotine, colchicine) it is necessary. The latter alkaloid, together with atropine and others, requires a considerable excess of the reagent for complete precipitation, and in its gravimetric estimation therefore this condition must obtain; on the other hand, the precipitate first produced is sometimes redissolved on the addition of an excess of the precipitant. With regard to the reagent itself, I may observe that, according to Nayer, it is not advisable to prepare it by dissolving iodide of mercury in iodide of potassium, the best method being to mix 13.546 gram of perchloride of mercury with $49 \cdot 8$ gram of iodide of potassium and water to make one litre.

For details of experiments I refer to the work already men-

1) lnyed the methed of agitation for the estimation of atropine. Compare Pharm. Zeitschr. f. Russiand, 1869, p. 89 (Year-book Pharm. 1872, 236). In colchicum also it would be more advisable to determine the alkaloid by shaking with chloroform than by precipitating with potassio-mercuric iodide. The material should be extracted with pure water, and the solution made acid rather than alkaline before shaking with chloroform.

${ }^{1}$ St. Petersburg, 1874. Schmitzdorff. 
tioned, and will only remark here that, as a rule, the material may be extracted with water acidulated with sulphuric acid, ancl that in many cases the estimation may be made in this liquicl without further treatment. But if the presence of mucilaginous substances, etc., prevent this, and their partial remoral by alcohol be necessary, the solution must be completely freed from spirit before titrating. The termination of the reaction is usually found by a lrop of the filtered solution yielding no precipitate with a drop of the reagent.

Aconitine and Nepaline.-1 cc. of potassio-mercuric iodide solution of the above strength indicates 0.0269 gram of aconitine, and the precipitate (if the estimation be made gravimetrically) has the composition $\mathrm{C}_{27} \mathrm{H}_{40} \mathrm{NO}_{10} \mathrm{I}_{2}+\mathrm{HgII}_{2 \cdot}{ }^{\circ}$ In the latter case a correction of 0.00005 gram of aconitine must be made for every cc. of solution.

1 cc. of potassio-mercuric iodide indicates 0.0388 gram nepaline (pseudaconitine).

Atropine. - 1 cc. is equivalent to 0.0097 gram atropine if the solution contain about 1 in 200 , but in solutions containing 1 in 330 it is equivalent to only 0.00829 gram. The precipitate obtained by adding an excess of the precipitant to a solution containing about 1 in 200 to 300 has the composition $\left(\mathrm{C}_{17} \mathrm{H}_{24} \mathrm{NO}_{3} \mathrm{I}\right)_{2}+\mathrm{HgI}_{2}$. In working with solutions containing 1 in about 3.50 to 500 a correction must be macle of 0.00005 gram of atropine for every cc. of filtrate ( $\$ 174)$.

Hyoscyamine. $-1 \mathrm{cc}$. of the mercury solution is equivalent to 0.00638 gram hyoscyamine, the concentration being about 1 in 200 . According to the more recent researches of Ladenburg henlsane contains two alkaloids, one of which is isomeric with atropine, and identical with daturine and duboisine. Compare Berichte d. d. chem. Ges. xiii. 909, 10\$1, 1340, 1549 (Pharm. Journ. and Trans., [3], x. 759, 789, 790). [Ladenburg distinguishes hyoseyamine from atropine by the melting-points of the alkaloids and their gold salts. In belladonna a sccond allaloid at least is present, which is possibly identical with hyoscyamine.? The second alkaloid in henbane has been named hyoscine by. Ladenburg. This must not, however, be confounded with

1 For the present I make use of the old formula for aconitine, as the new does not agree so well with the volumetric determinations.

2 Compare Kraut, Ber. d. d. chern. Ges. xiii, 165. 
the hyoscine of Höhn and others. Its gold salt melts at a higher. temperature than that of atropine or hyoscyamine.] (See further in $\S 174$.

Emotine.-1 cc. of the potassio-mercuric iodide precipitates 0.0189 gram emetine. The precipitate has the composition $\mathrm{C}_{20} \mathrm{H}_{3.2} \mathrm{~N}_{2} \mathrm{O}_{5} \mathrm{I}_{22}+\mathrm{HgI}_{2}{ }^{1}$

Coniine. - 1 cc. indicates 0.0125 gram. coniine provided that the solution contain $\frac{1}{4}$ to 1 per cent. of the alkaloid, as little free acid as possible, and, in addition, 3 to 4 per cent. of chloride of potassium. If these conditions are complied with the composition of the precipitate will be $\left(\mathrm{C}_{18} \mathrm{H}_{10} \mathrm{NI}\right)_{2}+\mathrm{HgI}_{2}(\S \S 174,180)$.

Nicotine. - 1 cc. indieates 0.00405 gram nicotine; the composition of the precipitate is $\mathrm{C}_{10} \mathrm{H}_{10} \mathrm{~N}_{2} \mathrm{I}_{2}+\mathrm{HgI}_{2}$.

Strychnine and Brucine.-1 ce. precipitates 0.0167 gram strych-

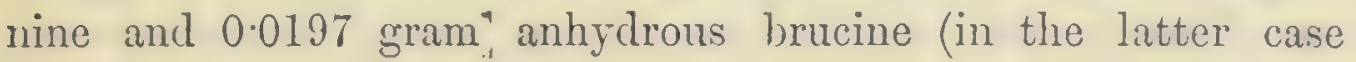
as little free acid as possible should be present). The precipitates have the composition $\mathrm{C}_{21} \mathrm{H}_{22} \mathrm{~N}_{2} \mathrm{O}_{22} \mathrm{HI}+\mathrm{HgI}_{2,}$, and $\mathrm{C}_{23} \mathrm{H}_{26} \mathrm{~N}_{2} \mathrm{O}_{4} \mathrm{HI}+\mathrm{HgI}_{2}(\S \S 174,180)$.

Colchicine. - 1 cc. precipitates 0.0317 gram colchicine, the concentration being about 1 to 600 , and the solution containing $r$ to 10 per cent. of sulphuric acid. The precipitate appears to contain four equivalents of colchicine to one of $\mathrm{HgI}_{2}$.

Morphine and Narcotine. - 1 cc. corresponds to 0.02 gram crystallized morphine2 and 0.0213 gram narcotine. (See also \$ 17t.)

Terutrine, subudilline, and sabatrine.-1 ce. indicates, according to Masing, ${ }^{3} 0.0296$ gram veratrine. Little sulphuric acid only. should be present and a correction of 0.000068 gram veratrine made for every cc. of liquid. According to the same chemist, $1 \mathrm{cc}$. of the potassio-mercuric iodide is equivalent to 0.0374 gram sabarlilline and 0.03327 gram sabatrine. Correction for every ce. 0.0000.) gram of the former and 0.0000108 gram of the latter (\$ 174).

I'hystigmine -1 ce. precipitates 0.01375 gram physostigmine (Masings). Correction for erery cc. 0.000105 gram. The composition of the precipitate is assumed to be $\mathrm{C}_{1 j} \mathrm{H}_{22} \mathrm{~N}_{\mathrm{j}} \mathrm{O} \mathrm{O}_{2} \mathrm{HI}+\mathrm{Hg}_{\mathrm{g}} \mathrm{I}_{2 .}$ (Sec also § 174.)

\footnotetext{
1 This formula, also, will have to be altered as soon as analyses of the pure emetine prepared by Podwissotzki are published.

- For the application of potassio-cadmic iodide to the quantitative determination of opium alkaloids see Lepage, Repert. f. Pharm. 1\$75, 613.

${ }^{3}$ Archiv d. Pharm, ix. 310 (Journ. Chem. Soc, xxxii. 369).
} 
Berberine.-1 cc. indicates 0.0425 gram berberine (Beach). ${ }^{\text {T }}$ The precipitate is stated to contain almost exactly half its weight of pure berberine.

Quinine.-According to Prescott ${ }^{2}$ the double salt of quinine with iodide of mercury contains 34.5 per cent. of alkaloid, and is almost insoluble in water. From the recent researches of Hielbig: it would appear that no special adrantage is to be looked for in the application of potassio-mercuric iodide to the quantitative estimation of quinine.

Chelidonine and Sanguinarine.-From some experiments made by Masing I anticipate that 1 ce. of potassio-mercuric iodide will be found to indicate 0.01675 gram of the former and $0.0148 .5 \mathrm{gram}$ of the latter. ${ }^{4}$ (Compare also § 174 et seq.)

$\$ 66$. Estimation of Theine, etc.-The quantitative determination of some alkaloids may be made as follows: The material is hoiler with water, either pure or containing a little sulphuric acid, the filtered or strained decoction eraporated with magnesia or lime," and the residue finely powdered with sand or some other inert sulsstance. It is then extracted with ether, chloroform, or other suital,le solvent, the filtered solution evaporated and the residuc weighed. ${ }^{6}$ I have found this method well adapted for estimating the alkaloid in tea (without the addition of acid).

Similar methods have also been proposed for the estimation of the total alkaloid in cinchona-bark, but the long-continued action of the dilute acid necessary to dissolve the alkaloid appears to decompose part of it and renders the estimation inaccurate. (Compare $\S 176$.

$\S 67$. Extraction of Cinchona Allaloids.-In a series of experiments in my laboratory the following methor was found by Hielbigi to be the most advantageous: 25 grams of powdered bark are digested with 100 grams of 1 per cent. sulphurie acid at the ordinary temperature for twenty-four hours, care being taken to ex-

1 American Journ. Pharm. xlviii. 386.

2 Ibid. xlix. 482.

${ }^{3}$ Kritische Beurtheilung, etc. Diss. Dorpat.

1 Compare my Chemische Werthbestimmung, p. 101. Also Naschold, Journal f. prakt. Chem. cvi. 385 .

${ }^{5}$ Compare Cazeneuve, Jahresb. f. Pharm. 1875, 342.

${ }^{6}$ Compare also Lösch, Pharm. Zeitschr. f. Russland, xviii. 545, and my remarks on his method, Jahresb. f. Pharm. 1879, 165 (Year-book Pharm. 1880,60).

${ }^{7}$ Loc. cit. 
clude direct sunlight; 500 cc. of spirit are poured in, and after two hours 2.) grams of slaked lime are added to the mixture. The whole is then macerated for two days, and finally boiled for half an hour on the water-bath. To the filtrate, together with 100 cc. of wash-alcohol, the results of two following extractions, each with $250 \mathrm{cc}$. of spirit and $100 \mathrm{cc}$. washings, are adderl. The mixture is neutralized with 25 drops of dilute sulphuric acid (1 to 7 ) or more if much cinchonine is present. After standing twenty-four hours the spirituous solution is filtered, and the alcohol recovered by distillation, the process being stopped as soon as the liquil becomes cloudy (about $200 \mathrm{cc}$ ) ; 15 cc. of 2 per cent. sulphuric acid are then adcled, and the eraporation continued on the water-bath, carbonization being carefully avoider. The residne is treated with water, the resin filtered off and washed with a little dilute sulphuric acid. The alkaloil is then precipitated by carbonate of soda, and the whole evaporated on the water-hath to about $20 \mathrm{cc}$. After cooling, the resinous precipitate is filtered off, rubbed down to a powder in a mortar with water, retransferred to the filter, washed, dried, and weighed. From the filtrate and wash-water the alkaloid is extracted by chloroform, and the weight thus found added. For the separation of the more important bark alkaloids from each other, see $\S \S 183,184$.

§68. Listimation by Titratiun.-If the alkaloid under examination has a powerfully alkaline reaction, it may be separated by the method of agitation, or according to $\$ \S 66,67$, and estimated by titration with $\frac{N}{10}$ acid. A method of this kind has been proposed by Schlössing and others for the quantitative determination of nicotine in tobacco. ${ }^{1}$ (See $\$ \S 179,180$. )

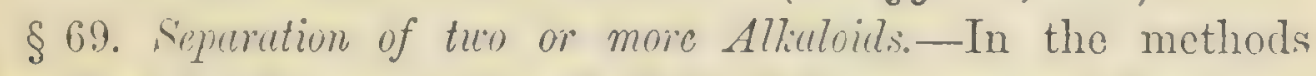
describel for tho estimation of alkaloids it was assumed that only one was present. But two or more may le met with in the same plant. In attempting their separation their behariour to solvents should be ascertained. Ether, for instance, may be used to separate quinine from cinchonine, narcotine from morphine, delphinine from delphinoidine.

1 Annales de Chim, et de Phys. xix. 230 (Am. J. Pharm. xix. 68) ; also Wittstein and Brandt, Vierteljahresschrift f. prak. Pharm, xi. 351, and xiii. 322 ; Liecke, Zeitschr. f. anal. Chem. iv. 492; Kosutany, Anal. Best. einiger Bestandth. d. Tabakspflanze. Diss. Altenburg in Hungary, 1873. 
This method is not, however, always successful, and compounds of the alkaloids differing considerably in solubility, etc., must be looked for, applicable to the separation to be effected. Quinine may be separated from quinidine by precipitation with Rochelle salt, quinidine from cinchonine by iodide of sodium, etc. Use may also be made of the difference in equivalent weights. (Compare the estimation of brucine in presence of strychnine in $\S 174$.) See also $\S \S 180$ to 183.

\section{EXAMINATION FOR GLUCOSES SOLUBLE IN ALCOHOL.}

\$70. Detection and Estimation of Glucoses soluble in Alcohol.Both glucoses and cane-sugars may be present in that part of the alcoholic extract $(\S 48)$ which is soluble in water, but the amount can be but small, since the material is macerated at the ordinary temperature. It must, however, be taken into account, in order to avoid error. If the alcoholic extract contain no tannin or bitter substance, the aqueous solution may be tested for glucose with Fehling's solution ( $\$ 83$ ) without further treatment; if found it may be determined quantitatively.

Sugar may also be qualitatirely tested for by adding to the liquid under examination first potash and then dilute solution of sulphate of copper, as long as the cupric hydrate first formed is redissolved. Excess should be avoided. The liquid may now be divided into two portions, one of which may be warmed and the other allowed to stand in the cold in order to ascertain whether reduction takes place at the ordinary temperature, as well as on heating.

If the glucose is accompanied by such substances as tannin, ctc., the filtrate olntained after addition of acetate of lead in their 'puantitative estimation ( $\$ \$ 49,52$ ), or after precipitation of a separate quantity with hasic acetate, may be treated, together with the washings, with a slight exeess of sulphuric acid, filtered, washed and made up to a known rolume. The sugar may then be estimated (puantitatively with Fehling's solution. The result must be added to the amount found in the aqueous extract ( $\$ 83)$. Part of the solution may be hoiled for half an hom with 1 to 2 per cent. of sulphuric or hydrochloric acid in a flask fitted with an upright condenser. If more sugar be found after such treatment, the difference is to be calculated as saccharose $(\$ 85)$. 
Examination of Substances Soluble in Water.

MUCILAGE, ACIDS, GLUCOSES, SACCHAROSES AND OTHER

CARBOHYDRATES, ALBUMNOUS SUBSTANCES, ETC.

\$71. Treatment with Wuter:-The residue of the material after exhaustion with alcohol ( $\$ 47$ ) is dried at a temperature not above $40^{\circ} \mathrm{C}$, and transferred to the vessel previously used, which should likewise be dried. Water is then added in the proportion of at least $10 \mathrm{cc}$. for every gram of original substance, and the whole frequently shaken during twenty-four hours. The liquid is now filtered off through the same filter that has already served for such operations, and the filtrate set aside for examination. The residue is washed by repeated maceration and filtration, the washings being reserved for treatment as directed in $\$ 194$. The insoluble substance is not dried (\$\$ 92, 102, 105 et seq.; 193 et seq.).

\$72. Totul Solid Residue.-10 cc. of the filtrate are evaporated in a tared platinum dish, dried at $110^{\circ}$ and weighed. The residue is then incinerated and the ash deducted. It should be ascertained if the ash is rich in carbonic, sulphuric, or phosphoric acid, chlorine, lime, magnesia or potash; and if large quantities of sulphuric or phosphoric acid are present they should be estimated (\$82).

If the filtrate contain much sugar, moisture may easily be retained by the residue. In such cases Serrurier ${ }^{1}$ advises the addition of $\frac{1}{2}$ per cent. of alcohol before evaporation. It is claimed that the residue is then porous and easily dried.

\section{EXAMINATION OF MUCILAGINOUS SUBSTANCES, DEXTRIN AND} ALLIED CARBOHYDRATES PRECIPITATED BY ALCOHOL.

\$73. IIucilaginous Substances.-10 to $20 \mathrm{cc}$. of the aqueous extract (\$r1) are mixed with two volumes of absolute alcohol, and

1 Zeitschr. f. anal. Chemie, x. 491. 
allower to stand for twenty-four hours in a cool place in a wellclosed vessel. The precipitate is collected on a tared filter, washed with 66 per cent. spirit, dried and weighed. Both filter and substance are then incinerated and the ash weighed, that of the filter being declucted. If the precipitate itself possess the characters of vegetible mucilage (\$195, 196) and contain not more than 5 per cent. of ash, it may be assumed the latter corresponds to the lime and potash usually found in such mucilages. But if the percentage of ash be liurger, and it contain much carbonate of lime or potash, attention should be paid to the possible presence of salts of vegetable acirls with these bases, such as acid tartrate of lime or potash, etc. (\$ 74 ).

That the precipitate really contains vegetable mucilage may be prover by its dissolving in water to a mucilaginous liquid which rloes not reduce Fehling's solution until after it has been boiled for some time with dilute hydrochloric acil. Its concentrated solution is precipitated by basic acetate of lead. It is also occasionally precipitated hy ferric chloride and thickened by solution of borax or soluble silicate of soda. See also $\$ 193$ to 196.

5 7. Vegetulle Albumen.-Incomplete solubility of the mucilage precipitate would indicate the presence of allumen, but, by the method of eximination adopterl, the quantity will nsually he so small that it may be neglected. (See also $\$ 92$ et seq.; 95 et seq.) If, however, Lassaigne's test show that the precipitate contains much nitrogen, the results of the estimation of legumin and albumen, which will be sulssequently marle, must be declucted from the weight of mucilage, etc. If, on treating the mucilage precipitate with a little water, a difficultly solulle crystalline substance be observed, examination should be made for tartrate of lime or acid tartrate of potash, which, if present, should be estimater by precipitating with nentral acetate of lear and should be reducted from the weight of the mucilage.

\$75. Inulin.-If subterranean parts of plants belonging to Compositæ or allied order's are under examination, they may, even though previously dried, yield a little inulin to water. After precinitation with alcohol it is not renlissolven by water at the ordinary temperature, lut is freely soluthe when warmed to $5 f^{3}$. It is lasvo-rotatory, is converterl ly treatment with dilute acirl into levulose, and may lee estimated hy determining the 
amount of sugar thus produced. The majority of the inulin is, however, left in the residue insoluble in water, from which it may be extracted as directed in $\S 102$.

$\$ 76$. Dextrin, etc.-The filtrate and wash-alcohol from the mucilage precipitate (\$73) are evaporated as rapidly as possible, at a temperature of $70^{\circ}$ to $80^{\circ}$, to a syrupy consistence and again precipitated with 4 volumes of alsolute alcohol. Certain carbohydrates soluble in dilute alcohol, such as dextrin, levulin, sinistrin and triticin, are thus thrown down and should be filtered off as rapidly as possible.

These carbohydrates may be distinguished from mucilage by their being more easily convertible into sugar and by their not being precipitated by hasic acetate of lead. Dextrin is dextrorotatory in aqueous solution, and yields grape sugar on boiling with a dilute acid. Levulin, sinistrin, and triticin yield levulose. The first of these three is optically inactive; sinistrin and triticin are lævo-rotatory $\left(\alpha_{\mathrm{D}}=-32.456^{\circ}\right.$ and $-43.579^{\circ}$ respectively). None of the four are coloured either blue or red by iodine. ${ }^{1}$ Sinistrin and triticin are precipitated by caustic baryta from solution in 40 per cent. alcohol. Carbonic acirl liberates the carbohydrate from the compound thus produced (\$198).

Quantitative Estimation (S§ 199, 201 to 204).-The carbohydrates mentioned in the preceding paragraph are best estimated by boiling with a dilute acid and determining the amount of sugar thus produced by titrating with Fehling's solution. The barium precipitates of levulin, triticin and sinistrin may be treated directly with acid.

If dextrin and glucose are present together, the results yielded by the estimation are as a rule somewhat too high, as a little sugar is precipitated with the dextrin.

It should, however, be ascertained whether the dextrin-precipitate contain much nitrosen, and, if this is the case, whether the amido-acids discussed in $\$ 101$ and 242 are present.

\section{EXAMINATION FOR SAPONIN AND ALLTED SUBSTANCES.}

\$7. Ertraction of Supmin.-If the precipitate obtained with alcohol in 56 is rapidly filtered off, the majority of the saponin

It was formerly thought that dextrin was coloured red by iodine. This c.)louration was (lue to an impurity (soluble starch-erythodextrin) contained in the dextrin examined. 
remains in solution, and is left behind on evaporating the alcoholic filtrate. It is soluble in hot 83 per cent. spirit and deposited again on cooling; but in absolute alcohol it is almost insoluble. Baryta-water precipitates it from aqueous solution; after washing with saturated baryta-water the saponin may be liberated from the compound by carbonic acid gas; a few per cent. of baryta, however, always remain associated with the saponin thus obtained. It also forms an insoluble compound with basic acetate of lead. Its solutions have an unpleasant acrid taste, froth on shaking, emulsify oils, etc. On agitating with chloroform it is taken up by that solvent and may be obtained in an amorphous condition by evaporating the chloroformic solution. (Cf. §55.) The residue, moistened with a few drops of concentrated sulphuric acid and exposed to the air, gradually assumes a reddish or reddish-violet colouration. It is a glucoside, yielding sapogenin as a resinous decomposition product sparingly soluble in water.

\$ 78. Quantitative Estimation.-Christophsohn ${ }^{1}$ and Otten ${ }^{2}$ have adopted the following two methods for the determination of saponin :

A. 10 grams of the powdered substance are boiled three times in succession with distilled water, the decoctions strained (they filter very slowly), evaporated to a small bulk, precipitated with alcohol and filtered. The precipitate is exhausted with boiling alcohol ( 83 per cent.), and the spirituous solution added to the filtrate. After recovering the alcohol by distillation the residue is dissolved in water, concentrated and precipitated with saturated baryta-water. The precipitate is collected on a tared filter, washed with saturated baryta-water till the washings are colourless and dried first at $100^{\circ}$, subsequently at $110^{\circ}$. After weighing it is ignited till the ash is white, the baryta estimated as carbonate in the usual way, calculated into oxide and deducted from the weight of the saponin-baryta, the difference being the weight of saponin from 10 grams of substance. For the seeds of Agrostemma githago the following morlification must be adopted on account of the large amount of starch rendering the extraction with water very tedious. A weighed quantity of ground air-dry seeds are

1 'Vergl. Unters, uiber das Saponin, etc.' Diss. Dorpat, 1874, and Archiv d. Pharm. vi. 432, 481.

${ }^{3}$ Histiol. Unters, der Sarsaparillen. Diss. Dorpat, 1876. 
exhausted by hoiling with alcohol and filtering whilst hot, the alcohol being recovered from the filtrate by distillation. The residue is freed from fatty oil by ether, dissolved in water and the saponin in it precipitated with baryta as before.

b. The saponin-baryta obtained by the previous method is dissolved in water with the aid of hydrochloric acid and freed from baryta by the cautious addition of dilute sulphuric acid. The filtrate and washings from the sulphate of barium are boiled for an hour; the sapogenin which has separated out is filtered off, washed, transferred together with the filter to a small flask and exhausted by boiling with 83 per cent. of alcohol. On cvaporating the filtered alcoholic solution and drying at $110^{\circ}$ the weight of the sapogenin is ascertained and may be calculated to saponin, 100 parts of the latter yielding on an average 35.8 parts of the former.

Christophsohn obtained the following results in a series of comparative experiments with both methods. The seeds of Agrostemma githago were treated as directed in $A$.

\begin{tabular}{|c|c|c|c|c|}
\hline 1. & & $\begin{array}{c}\text { A. } \\
8 \cdot 67\end{array}$ & $\begin{array}{c}\text { B. } \\
8 \cdot 82\end{array}$ & $\%$ Saponin. \\
\hline 2. $\mathrm{G}$ & & $14 \cdot 59$ & $15 \cdot 0$ & , \\
\hline 3. & & $13 \cdot 31$ & $13 \cdot 2$ & $"$ \\
\hline 4. Saponaria officinalis (root) & & $4 \cdot 78$ & $5 \cdot 09$ & , \\
\hline 5. Agrostemma githago (ripe seeds) & & $6 \cdot 67$ & 6.51 & 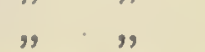 \\
\hline
\end{tabular}

In the various sarsaparillas Otten found, by method $A$, from 1.21 to 3.43 per cent. of saponin. (See also $\$ 167$. )

$\S 79$. Digitonin, which is allied to saponin, may be distinguisher by its assuming a fine red colour when heated with dilute sulphuric or hydrochloric acid. Lilie saponin, it is easily soluble in cold water, sparingly in cold absolute alcohol. (C'f. $\S \S 155,167$.

EXAMINATION FOR ACIDS, ETC.

$\$$ 80. Estimation of Totul Organic Acils.-Part of the filtrate obtained in $\$ 3$ and 76 is concentrated and, after complete dissipation of the alcohol, precipitated with neutral acetate of lead, avoiding an excess. After standing from twenty-four to forty-eight hours the precipitate is filtered off and treated as directed in $\$ 19$. The organic matter present is noted as organic acids and allied substences. If the presence of tamnic acid, which has escaped removal by the previous treatment with alcohol, is suspected, it 
should be estimated in a portion of the filtrate from $\$ 73$ or $\$ 76$, by precipitation with acetate of copper (cf. $\$ 50)$, and deducted from the total organic acids.

$\$ 81$. Qualitative Separation. - If the learl precipitate is at first amorphous, but becomes crystalline on standing, mulic or fumaric acidl may be present. (See also $\$ \S 214,220,221$.)

The acids thus precipitated may be further qualitatively examined by suspending the moist precipitate obtained as directed in $\$ 80$ in pure water and decomposing with sulphuretted hydrogen. The filtrate from the sulphide of lead is evaporated on the water-bath to a small bulk and, when the odour of sulphuretted hydrogen has disappeared, lime-water is added to the cooled liquid till the reaction is alkaline. If a precipitate is produced which dilute acetic acid fails to dissolve completely, oxalic acid is probably present. $^{2}$ (See also $\$ \$ 214,218,219$. ) If, on the other hand, it is entirely soluble in acetic acid, a fresh portion should be tried with solution of chloride of ammonium. Turtrute of calcium $(\$ 217)$ dissolves, rucemute (\$218) does not. In the latter case care should be taken not to mistake phosphate for racemate of calcium.

If lime-water has caused no precipitate in the cold the solution should be boiled. Any turbidity that may now occur would indicate citric acid. $\quad(\$ \$ 215,216,218$.

Aconitic acid is not thrown down by lime-water even on boiling, but it is characterized by the slight solubility of its acid ammonium salt in 50 per cent. alcohol. The liquid to be tested is divided into two portions, one of which is neutralized with ammonia and added to the other. Any crystalls of acid aconitate of ammonium which separate out should be washed with 50 per cent. alcohol. From this salt the acid may be isolated hy adding a slight excess of sulphuric aciel and shaking with ether. Its identity may be established by the ultimate analysis of the calcium, silver and ammonium salts. (See also \$216.)

I think it is very probable that the so-called Muruttin is aconitate of calcium $(10 \%)$. Sphero-crystals of this sulsstance were

${ }^{1}$ For the solubility of malate of lead in warm dilute acetic acid, and the deposition of a crystalline salt on cooling, see Hartsen, Zeitschr. f. anal. Chemie, xiv. 373 (Journ. Chem. Soc. xxix. 375).

2 Oxalate of calcium $(\$ \S 100,219)$ often settles slowly and on filtration passes through the pores of the filter. Muck has shown ('Zeitschr. f. anal. Chemie, ix. 451) that the precipitate is much easier to manipulate if small quantities of aluminium salts are present. 
observed by Russow in the stems of species of Marattia which had been kept in alcohol.

If the presence of an oxalate has been inclicated by the action of acetic acil, the acid solution should be filtered off and supersaturated with lime-water, which would re-precipitate tartaric, citric, racemic acid, etc. Citric acid may be detected by boiling the filtrate. Citric and tartiric acids may be separated quantitatively by Allen's method. ${ }^{1}$ The acils are dissolved in 20 volumes of spirit, and a concentrated solution of acetate of potassium added. After standing twelve hours the acil tartrate of potassium is collected and estimated either gravimetrically, or by titration with normal solution of sodia. (See also 214 et sey; 217 et ser.) \$ 82. Vul. Estinution; Mineral Aciels; Free and Combined Acid. -If only one of the non-volatile acids mentioned can be detected, the estimation male in $\$ 80$ may be checked by decomposing the lead precipitate from a known fraction of the aqueous extract with sulphuretted hydrogen, eraporating the filtrite and titrating the residue dissolved in water. But in this case the phosphoric and sulphuric acils previously estimated in 5 must be deducted (\$214).

Mincial aciels maly be tested for qualitatively by adding a drop of an alcoholic solution of nethyl-violet. Mineral acids change the colour to bluish-green.

The amount of fiee ucid present in fruits, etc., may be estimated in the aqueous extract by titration with normal alkali. A similar determination may be male in the alcoholic extract ( $4 \overline{7})$. Any excess of acid found in the first estimation over that in the second may generally be ascribed to the acid salts present.

If an extract from a vegetable substance is to be specially examined for free tartaric acid in the presence of acid tartrates (of calcium and potassium), the liquid mily be evaporated to a syruny consistence and the tartaric acid extracted with ether or alsolute alcohol." The alcoholic or ethereal solution is evaporaterl, the residue dissolved in a little spirit and the tartarie acid separater by the addition of alcoholic solution of atectate of potassium. ${ }^{3}$

1 Zeitschr. f. anal. Chemie, xvi. 251 (Pharm. Journ. Trans. [3], vi. 6).

${ }^{2}$ Cf. Claus, Zeitschr. f. anal. Chemie, xvii. 314.

${ }^{3}$ See also Nessler, Zeitschr. f. anal. Chemie, xviii. 230 (Journ. Chem. Soc. xxxvi. 981). 
EXAMINATION FOR GLUCOSES, SACCHAROSES, ETC.

\$ 83. Glucoses. - The alcoholic extract may, as mentioned in $\$ 70$, contain a small amount of glucose which, if present, should be quantitatively estimated. But, as was there observed, the whole of the glucose is not usually removed by cold alcohol, and the remainder must be looked for in the aqueous extract. If no tannic acid or other substance that reduces Fehling's solution is present, the glucose may be estimated in part of the aqueous extract in $\$ 71$ by direct titration. ${ }^{1}$ But if the glucose is accompanied by other substances that also reduce the salt, these must be removed before the estimation can be made. They may be avoided by using the filtrate from the mucilage precipitate (\$ 73), or from the dextrine group (\$76); the alcohol must be removed by evaporation, the residue dissolved in water and made up to a known volume. (Cf. § 197.) If such substances as tannic acid, etc., have to be removed, it is best to precipitate a portion of the aqueous extract with basic acetate of lead and remove the excess of lead with sulphuric acid before determining the sugar.

Instead of keeping the alkaline copper solution recommended by Fehling ready for use, I keep separate solutions of the three salts of which it is composed, viz., 34.639 grams of crystallized sulphate of copper, 173 grams of Rochelle salt, and 120 grams of caustic soda, each in a litre of water. $10 \mathrm{cc}$. of each of these solutions with $20 \mathrm{cc}$. of water represents $10 \mathrm{cc}$. of alkaline copper solution diluter with 4 volumes of water as recommended by Fehling. Of the three solutions the sulphate of copper alone requires to be accurately measured.

The titration is marle as follows: the alkaline copper solution is brought to the boil in a white porcelain clish and the sugar solution (previously made up to a known rolume) added from a burette until the blue colour has completely disappeared. $10 \mathrm{ce}$. of copper solution indicate 0.05 gram grape-sugar. Should the final disappearance of the blue colour be concealed by dark colouring matter, etc, in the solution, a few drops may be rapidly

1 On the estimation of sugar with copper solution, see Fehling, Annalen d. Chem. u. Pharm. 1xxii. 106, cvi. 75 (Pharm. Journ. Trans. [1], ix. 419); Graeger, N. Jahr. f. Pharm. xxix. 193 ; O. Schmidt, ib. 270 ; Stæedeler u. Krause, Annalen d. Chem. u. Pharm. Ixix. 94 ; Pellet, Journ. de Pharm. et de Chimie, 4 te Série, xxvii. 460 (Journ. Chem. Soc. xxxiv. 612). 
filtered off and tested for copper hy the addition of acetic acir and ferrocyanicle of potassium. But a slight reaction will generally be obtained as traces of copper remain in solution and the absence of any reddish-brown precipitate after the lapse of a few minutes must be taken as sufficient indication of the termination of the reaction.

It is well known that the sugar solution should be very dilute; the best strength is about $\frac{1}{2}$ per cent. If a preliminary experiment shows it to be more concentraterl, it should be diluted to about this strength. ${ }^{1}$

The estimation may also be make gravimetrically, by quickly filtering off the cuprous oxide, washing with water, drying and converting into cupric oxide. This method is advisable if, in titrating, the final reaction is obscured, or if the amount of sugar solution available is not sufficient to complete the reduction of the copper-salt taken.

But it must be borne in mind that by drying the cuprous oxide on the filter and weighing incorrect results would, as Brunner ${ }^{2}$ has shown, be obtained, since the alkaline copper solution dissolves cellulose and the filter accordingly loses weight. It is better, therefore, to dissolve the cuprous oxide and determine the copper by the usual methods, or to estimate the excess of copper in the filtrate. ${ }^{3} 317$ parts by weight of copper, 357 of cuprons oxide or 397 of cupric oxide indicate 180 of glucose, 171 of saccharose or 162 of starch, etc. $(\$ 200)$.

\$.t. Other Nethods of Estimuting Glucose.-Glucose may also be estimated by Knapp's reagent, ${ }^{*}$ which consists of 10 grams of

I Soxhlet-Zeitschr. f. anal. Chemie, xviii. 348 (Pharm. Journ. Trans. [3] xi. 720)-has shown that the reducing power of the glucose varies with the concentration of the solutions. In making estimations the sugar solution should therefore be of as nearly as possible the same strength as that used for standardizing. According to Soxhlet the gravimetric estimation in presence of an excess of copper may be attended with considerable error. But Maercker has shown that satisfactory results may be obtained by this method also, if the same conditions are always observed. See also Ulbricht, Chem. Centralblatt, $1878,392,584$.

2 Zeitschr, f. anal. Chemie, xi. 32 (Journ. Chem. Soc. xxv. 928).

${ }^{3}$ Compare also Weil, ih. 284 ; Mohr, ih. xii. 296 ; Jean, ih). 111 ; Lagrange, ib. xv. 111; Brieke, ib. 100 ; MLaschke, ib. xvi. 4iź. (Sce Joum. Chem. Soc. xxv. 1121 ; xxvii. 292 ; xxxi. 805 , ib. 116 ; xxxii. 930.)

4 Annal. d. Chem. u. Pharm. cliv. 252 (1'ham. Journ. Trans. [3] i. 301). See also Mertens, Zeitschr. f. anal. Chemie, xiii. 76; Brumme, ib. xvi. 121. Knapp's reagent keeps considerably better than Fehling's. 
mercuric cyanide and $100 \mathrm{cc}$ of caustic soda (sp. gr. $1 \cdot 145)$ in a litre of water; $0.4 \mathrm{gram}$ of the cyanide $=40 \mathrm{cc}$. of solution indicate $0 \cdot 10$ gram glucose. Knapp determines the end of the experiment by touching a drop of the solution on filter paper with a drop of sulphide of ammonium. An excess of mercury would produce a brown colour (\$200).

Insteal of Knapp's solution an allialine solution of potassiomercuric iodide maly be employed for estimating glucose, as recommended by Sachsse. The sugar solution for this reagent may be preparerl as directed in $\$ 83$. 'The reagent as first recommended by Sachsse ${ }^{1}$ contained a large excess of alkali, which rendered the estimation of dextrose and levulose in the presence of saccharose inaccurate. Heinrich ${ }^{2}$ therefore altered the composition by reducing the amount of alkali to a minimum, and directed that a litre should contain 18 grams of mercuric chloride, 25 of iodide of potassium and 10 of caustic potash. 40 cc. indicate 0.1342 gram glucose. The titration is made in the same way as with Fehling's solution, and the end of the experiment determined by testing a drop with stamnous chloride, which should not throw down a grey precipitate, showing that no excess of mercury remains in solution. The presence of ammonium salts does not interfere with the reaction. Nessler's reagent for ammonia has a composition similar to Heinrich's modification of Sachesse's solution, lut contains a far larger quantity of caustic alkali, which is necessary for the detection of ammonia (\$97).

The appearance of the final reaction is retarded if the solution contains lut very small quantities of invert-sugar. It is advisable to make the mereurial solution of such strength that 5 ce. indicate 0.0168 gram of invert-sugar.

Glucose may also be estimated grecimetricully by using an acid solution of a mereuric salt. The reagent recommended contains in a litre :30 grams of mereuric oxide, 25 of concentrated acetic acid and 30 of chloride of sorlium. On boiling with sugar the mereury is reduced and may be weighed as mereurous chloride. ${ }^{3}$ 5.88 parts of calomel indicate I part of glucose.

1 Jahresb. f. Pharm. 1876, 375 (Journ. Chem. Soc. xxxii. 226). See also Strohmer u. Klauss, Chem. Centralblatt, 187\%, 697, 713 (Journ. Chem. Soc. xxxiv。246).

${ }^{2}$ Chem. Centralblatt, 1878, 409 (Journ. Chem. Soc. xxxvi. 180).

3 Jahresb. f. Pharm., 1877, 340. 
The reagent is said to be without action on cane-sugar, glycerin, arabin and dextrin.

\$ 85.-Influence ererted by Sucrhuroses. - If the glucose in the liquid under examination is not accompanied by saccharose, or other carbohydrate not precipitable by alcohol, fairly accurate results may be obtained by the methods detailed in $\$ \$ 83,84$. But saccharoses influence the estimation by their uresence to an appreciable extent, although they do not themselves, when pure, reduce Fehling's or Sachsse's solution.

The same applies to the determination hy fermentation (\$204); saccharoses may be partially converted by the yeast into fermentable glucose.

It cannot be said that we are in a position to estimate with exactness in every case the proportion of glucose and saccharose in mixtures. Sometimes, it is true, the accuracy of the estimation leaves little to be desired-as, for example, mixtures of ilextrose or invert-sugar with cane-sugar. Solutions of such mixtures may be examined in the polariscope, in adulition to being tested chemically. But many instances occur in which the necessary conditions do not obtain. (Cf. $\$ \S 208,209$.

$\$ 86$. Estimation in Presence of Saccharose.-In such cases the only method we can adopt is, first, to remore the carbohydrates precipitable by alcohol ( 53,76 ), estimate the glucose with Fehling's solution, and then repeat the estimation after acidifying with 1 per cent. hydrochloric acid and boiling for 15 to 20 minutes (or several hours if the presence of mycose he suspected) in a flask provided with an upright condenser. If the two determinations yield fairly concorlant results, it may be assumed that no saccharose is present; on the other hand, any excess that the second may indicate over the first may be noted as 'saccharose or allied carbohydrate.' 'The possibility of error must, however, be admitted (\$207).

\$87. Estimution of Succhurese alone.-If the solution contains a saccharose alone, with the exception of milk-sugar or maltose, it will not reduce Fehling at all. Althongh, therefore, no recluction may be observed, the inversion with acid should not on any account be omitted, as the solution may contain a saccharose. (Cf. $\$ 07$.)

According to Pillitz, ${ }^{1}$ cane-sugar may be casily inverted by

1 Zeitschr. f. anal. Chemie, x. 456 (Journ. Chem. Soc. xxv. 329). See also Nicol, ib. xiv. $17 \%$ (Journ. Chem. Soc. xxv. 329). 
heating a solution of 1 part in 12 or 13 of water with 1.5 to 2.0 parts per mille of sulphuric acid (specific gravity $1 \cdot 12$ ), in sealed tubes, to $130^{\circ}$ or $135^{\circ}$. The estimation of sugar by the fermentation of such solutions is said to yield numbers that are rather too low. That is not the case with determinations by Fehling's or Knapp's method.

I am, on the whole, more inclined to use hydrochloric acid for inverting; but if the acid is to be subsequently removed, I must acknowlerlge that sulphuric is to be preferred, as it is easily precipitated by carbonate of barium.

\$8. Büttger's Test.- The above tests also suffice for the detection of glucose and saccharose. Böttger's bismuth test may be employed as confirmatory of the presence of the former. It consists in warming the liquid with a solution of carbonate of soda, together with oxynitrate or hydrate of bismuth; if sugar be present, grey suboxide of bismuth is formed. (See also $\$ 200$.)

\$89. Distinctive Characteristics. - The chief marks of distinction between the various members of the glucose or of the saccharose group are to be found in the difference in crystalline form, etc., and in the action on polarized light. In the cases here alluded to, use may sometimes be made of these characters, especially if the solution contains only one carbohydrate and no other substance that might influence the crystallization or optical activity. But these conditions are seldom fulfilled, and in the majority of cases we must, therefore, forego an exact identification of the particular glucose and saccharose present, unless we have a considerable quantity of the substance under examination at our disposal. (Cf. $\$ 205-207$.

If we have command of a large quantity of material, it would be best to endeavour to effect the separation of the carbohydrates by treatment with different solvents, decolourization with animal charcoal and crystallization. The crystallization of glucose is favoured by direct sunlight; the presence of a small quantity of a mineral (hydrochloric) acid may also prove advantageous. (Sce also $\$ \$ 205-207$.

\$90. Suluble. Alodification of Arubic Acirl. Albuminoids not Precipituted by Alcohol.--In almost every plant-analysis the sum-total of the separate estimations of the substances soluble in water (mucilarge, etc.) will be found lower than the estimation of the totial solicls in solution. One or more sul)stances must, therefore, 
generally be present that are soluble in water, not precipitated by alcohol or neutral acetate of lead and have up to the present time eluded investigation. It might appear hazardous to make conjectures as to the nature of these substances, but I cannot help remarking that in some cases a substance seemed to me to be present which, after evaporation of its alcoholic or aqueous solution, did not again dissolve completely in either of those liquids. It appeared to agree in some of its properties with that form of vegetable mucilage that is obtained by dialyzing acidified solutions of gum, etc., which sometimes remains in solution on the addition of alcohol. When I have met with a substance agreeing with mucilage in this peculiarity, I have spoken, it is true, of a 'soluble modification of arabic acid,' but I have not omitted to place a query after it. ${ }^{1}$ The further investigation of this substance is a desideratum for plant-analysis.

But in thus assuming the presence of such an 'arabic acid,' account must be taken of the results of the nitrogen determinations to be described in $\$ 96$. By deducting the nitrogen in the residue of the material after extraction with water from that in the original substance, the amount in the sulstances soluble in water is ascertained. If, now, the amount of nitrogen present as albuminoids, nitric acid, ammonia and alkaloid is calculated from the separate determinations and found to be much smaller than the estimation by difference, it should be remembered that under certain conditions water may dissolve albuminoids which alcohol fails to precipitate.

\$91. Mamite.-Another substance, however, which is of not unfrequent occurrence in the vegetable kingdom, would similarly elude detection by the foregoing experiments with the alcoholic and aqueous extracts, as it is almost insoluble in cold absolute alcohol but is not precipitated from its aqueous solution by the addition of either spirit or lead salts. The substance reforred to is mannite. If present it would he included in the deficit mentioned in $\$ 90$, but would be easy of detection, as it crystallizes with great facility in long prisms and needles and is somewhat sparingly soluble in cold spirit. It may be approximately estimated by precipitating the aqueous solution with alcohol and basic acetate of lead,

${ }^{1}$ Compare rny 'Chem. Beitriige z. Pomologie,' Dorpat, 187s; Verlag d. Dorpater Naturforscher Gesellsch.; and Pfeil, 'Chem. Beiträge z. Pomologie,' Diss. Dorpat, 1880. 
removing the lead by sulphuretted hydrogen and any glucose that may be present by rapid fermentation. The residue may be exhausted with boiling 90 per cent. alcohol and allowed to crystallize in the cold. But an accurate result cannot be expected, since, in addition to other errors, mannite may be produced in considerable quantity by the fermentation of cane-sugar. ${ }^{1}$ For particulars of some substances allied to mannite see $\$ 212$.

The method of examination for bitter principles, glucosides, and alkaloids has been described in $\$ 58$ to 69 . (See also 165 et seq.; 171.)

EXAMINATION FOR ALBUMINOIDS SOLUBLE IN WATER, AMMONIACAL SALTS AND NITRIC ACID.

\$92. Extraction of Alluminoids. - It has already been observed in $\$ t$ that if the residue, after extraction with ether and alcohol, be exhauster with watel the estimation of albuminoids in the aqueous extract thus prepared will generally sive inaccurate results. A fresh portion of material should therefore be directly exhausted with water, or, if much fixed oil is present, the extraction with water may be preceded by treatment with petroleum spirit. After having removed the fixed oil (if necessary) from about 10 grams, the residue is dried at $40^{\circ} \mathrm{C}$., macerated with 100 cc. of water, with frequent agitation, for 4 to 6 hours, and filtered as described in $\$ 71$. If thought desirahle the maceration may be conducter at a temperature not exceeding $35^{\circ}$ to $40^{\circ}$. (Compare also §2 225 et seq.)

Detection.-With a portion of the filtrate qualitative experiments should be made. Among the reagents used for the detection of albumen, iodine and mercuric nitrate (containing as little free nitrie acid as possil,le) may be mentioned ; the former colours it brown, whilst the latter produces a yellow colour, changing, on the arlition of a trace of nitrous acid, to a splendid red. The ardition of canstic potash to alhumen, previously moistened with solution of sulphate of copper, is followed by the appearance of a bluish-violet colour. If the amount of albumen present be rather small, these experiments may he marle with the precipitates obtainer by the addition of an acid to the arneous solution (\$93).

Alicrochemienl. - These reagents also serve for the microchemical detertion of albumen. The latter sulsstance possesses, moreover,

${ }^{1}$ Archiv d. Pharm, xv. 47 (Journ, Chem. Soc, xxxviii, 100). 
the property of absorbing aniline-riolet (protoplasm generally assuming a bluish-violet, the cell-nucleus a reddish tint), carmine, cochineal, picro-carmine, etc. Note should also be taken of the form in which the albumen occurs, whether crystalline or amorphous, etc. (See also $\$ 74,90,95,194$. )

Protoplasm is coagulated by absolute alcohol and by glycerine. It becomes clear with solution of caustic potash, cloudy with acetic acid. Nuclei are generally stained more deeply than protoplasm by aniline-violet, etc, and hy iodine. They are coloured deep blue by a solution of hrmatoxylin $(1: 30)$ and alum $(1: 10)$; the former alone also produces the same effect if the section has been previously treated with picric acid and the excess of the latter completely removed (Schmitz). Crystalloils dissolve in dilute potash, ammonia, and acetic acid.

Precipitation.-Albuminous substances are precipitated by ferrocyanide of potassium and acetic acid, ly aqueous solution of trichloracetic acid, and by solution of xanthogenate of potassium. The precipitate produced by the last reagent becomes flocculent on heating to $30^{\circ}$ (Zöller). (See also $\$ \$ 95,231,232$. )

\$93. Estimation of Legnmin and Globulin.-Part of the filtrate (2.5 to $50 \mathrm{cc}$.) is acidified with hydrochloric acid in the cold. By this means such substances as legumin are precipitated; they should be collected on a tared filter, washed first with water acidified with hydrochloric acid, then with 40 per cent. spirit, dried and weighed, deducting ash (\$225et seq.). If hydrochloric acid has caused a precipitate, a fresh portion of the filtrate should be tested for globulin by saturating with carbonic acicl. It should also be ascertained microscopically whether the precipitate (if any) is crystalline or amorphous. (Cf. $\$ 226,227$.)

$\$ 94$. Estimation of Allumen.-To the filtrate from the legumin (without the spirit-washings), 5 to $10 \mathrm{cc}$. of a concentrated solution of chloride of sodium are added, together with enough acetate of soda to remove all the hyilrochloric acid, and the whole raised to the boiling-point. If flocks of albumen separate they must be collected, washed first with boiling water, afterwards with 40 per cent. spinit, dried and weighed, deducting ash.

In the absence of legumin 25 cc. of the aqueous extract may be mixed with $5 \mathrm{cc}$. of a concentrated solution of chloride of sodium and a few drops of acetic acid and treated as described in the foregoing paragraph. (See also $\$ 230$.) 
\$95. Estimation of Total Allumen. (a) Precipitation with Tannin.-Another portion (25 cc.) of the aqueous extract is mixed with half its volume of a concentrated solution of salt and a solution of tamnin and acetic acid in dilute alcohol (20 grams tannin, $37.5 \mathrm{cc}$. glacial acetic acid, $400 \mathrm{cc}$. spirit made up to a litre with water) added as long as a precipitate is produced. This is then rapidly filtered off, washed with water and dried. The albumen contained in it may be determined by estimating the nitrogen and multiplying by 6.25 (see $\$ 224$ ), or by extracting the tannin from the powdered precilitate by boiling with alcohol, collecting and weighing the residue. (Cf. \$229.)

This estimation of albumen should be compared with the previous estimations of legumin (\$93) and albumen (\$94). If the determination by tamin yields a higher result, the difference may be taken to represent albuminous substances not precipitated by hydrochloric acid or by boiling with acetic acid. (Compare also the remarks on peptone in $\$ 232$.

As already observed in $\$ 51$, in working with substances containing a large quantity of tannin, the results obtained by proceeding as directed in $\$ 92, c_{t}^{t} s e q$. , cannot be quite accurate, as part of the albuminous matter is retained by the tannin in the residue insoluble in water. This undissolved albumen may be determined as directed in $\$ \$ 96,224$.

Amongst the sulistances which facilitate the solution of albumen we may include arabin. Güusbergs ${ }^{1}$ has proved that albumen, of animal origin at least, is precipitated by gum from slightly acid solutions, hut redissolved hy an excess. Dextrin is said to differ from gum in not redissolving the precipitated allumen when added in excess.

\$96. Totul Nitrogrn.-It is arlvisable to determine the total nitrogen in the sulsstance mrler examination before and after exhaustion with water; the difference represents the nitrogen in the substances removerl by that menstrumm. If from this difference the nitrogen contained in the albumen estimated according to 5.93 to 95 is derlucter, the remainder will he nitrogen that has been rissolved by water in the form of ammoniacal salts, amides, alkaloids, nitrates, etc. The following estimations should be marle with the olject of determining as far as possible in what state this remaining nitrogen exists.

I Journ. f. pract. Chem. Ixxxviii. 239. 
\$97. Ammonia. ${ }^{1}$ - A portion of the aqueous extract (\$ 92) is mixed with two volumes of alcohol and filtered. To the filtrate and washings calcined magnesia is added, and the ammonia distilled off into a receiver containing a measured quantity of normal sulphuric or hydrochloric acid, every precaution being taken to avoid loss of ammonia and spirting of the magnesia mixture into the receiver. The apparatus I use is represented in Fig. 2. The flask $A$ should not be more than half full of magnesia

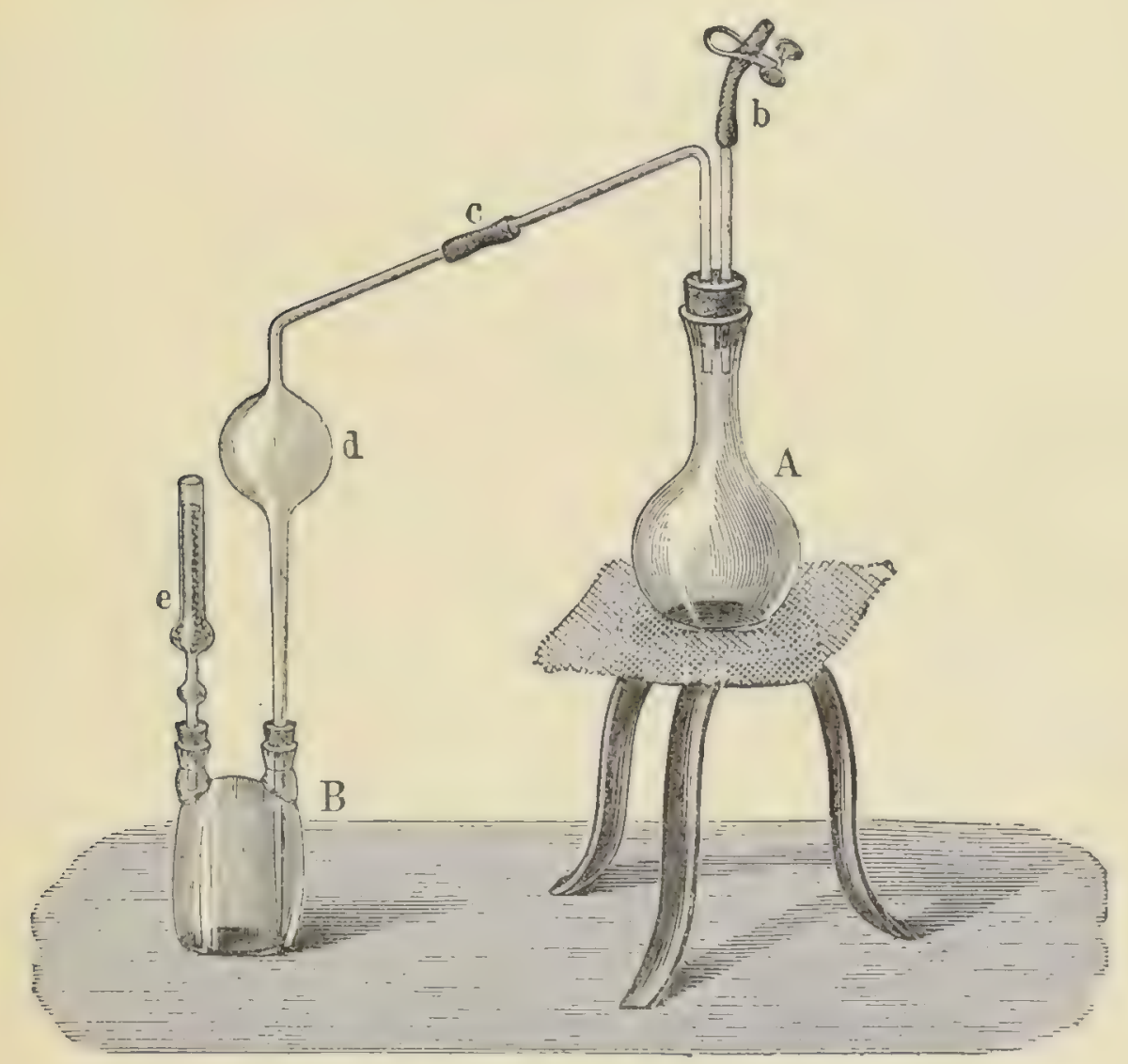

Fig. 2.

mixture, and a plug of glass wool should be inserted in the neck. The small tube $e$ contains glass heads, which are moistened with part of the acid. The distillition is complete when the rapours that issue on opening the clip $b$ are free from alkaline reaction. The estimation may he completed in either of the two following ways :

(a) The excess of acid in the receiver is determined rolumetrically and deducted from the quantity talien. From the differ-

${ }^{1}$ Compare also Morgen, Zeitschr. f. anal. Chem. xx. 37 (1881). 
ence the amount of ammonia may be calculated in the usual way.

(b) The ammonia may be distilled into hydrochloric acid, the liquid eraporated to dryness, the residue alternately moistened and dricd two or three times, and the chlorine estimated volumetrically by nitrate of silyer and chromate of potash. From the chlorine found the amount of ammonia may be calculated.

Another method for the estimation of ammonia is that proposed hy Schloessing. A few grams of the material made into a paste with water, or better, a concentrated aqueous extract, is mixed with milk of lime and placed over a measured cuantity of volumetric sulphuric acil under a bell jar. The ammonia liberated by the lime is alosorbed by the sulphuric acid, and after standing two or three diass at a temperature as nearly constant as possihle $\left(8^{\circ}\right.$ to $\left.10^{\circ}\right)$, the amount of acid thus neutralized may he ascertained by estimating the excess with volumetric solution of soda, and from this the ammonia may be calculated.

It must be admittell that in all these experiments the action of the lime or magnesia on albuminous sulstances may result in the formation of ammoniat. It is advisable, therefore, to remove such sulsstances by precipitation with basic acetate of lead before distilling. (flutamine and asparagine, howerer, remain in solution. These substances, when pure, are not acted upon by either lime or masnesia, but Schulze believes that they under'go a partial decomposition in mixtures, and therefore recommends boiling with hydrochloric acid for one to two hours (compare remarks on asparagine, \$191), by which they are completely resolved into the corresponding amido-acids and chloride of ammonium. The estimation of ammonia now includes the total ammonia derived from the asparagine and grlutamine. These two substances may, however, be determined by Sachsse's method, and the ammonia they yield calculated and deducted.

If the precautions mentioned have been observed, the first method $(a)$ will generally yield satisfactory results.

\$98. Amitn-Compounds, etr.-The foregoing estimation will be inaccurate if the material under cxamination contains amido-compounds, etc., or volatile alkaloids, as the former yield ammonia and the latter ciistil over and saturate part of the acid. Many amines,

1 Compare E. Schulze, Zeitschr, f, anal. Chem. xvii. 1 t1 (1878); Journ. Chem. Soc. xxxiv. 308. 
etc., thus liberaten, yield with perchloride of platinum rouble salts (s) that are soluble in ether-ialcohol, and error maty therefore he frepuently aroiled by precipitating a second portion of the distillate with excess of perchlorile of platinum, eraporating on the water-bath, extracting the residue with ether-alcolol, rrying and weighing instear of titrating the excess of acid with an alliali. If both experiments yicld the same result it may he concluded with tolerable certainty that no amiles, or only traces, are present. If the estimation by the first method gives a higher result than that by the second, the former is to be regarded as the more accurate, and the excess noted as amido-compounds, etc. If, on the other hand, the estimation by platinum is higher than that by titration, the juesence of an anile forming a double platinum salt insolutile in ether-alcohol and of a higher molecular weight than ammonia would be indicated. In the method of determining ammonia described in $\$ 97, \gamma$, certain chlorides of amines and alkaloidal substances, as for instance conine and nicotine, would be almost completely volatilized, and thus escape estimation.

The separation of ammonia from many amines may frequently he effected by taking artrintage of the difference in solubility of the chlorides, sulplates, and oxalates of the respectire bases in alcohol. In prepuring latrer quantitics of the base for closer investigation, the material might he distilled with masnesia or lime $(97$ (1), the distillate received in one of the abore-mentioned acills, and eraporated to dryness on the water-bath. The residne might be extracted with alcohol, the solution again evitpolated to dryness, and the clistillation with alliali repeated, if possible, in a current of hydrogen. (Cf. $\$$ 239.)

59. Nitric Acil.-For the estimation of nitric acid another portion of the alyucous extract of $\$ 1$ is taken and treated by Schulze's ${ }^{2}$ or Wulfert's ${ }^{2}$ method.

Schulze directs the liquid to he treated furst with pure potash, as long as ammonia is evolver, then with permanganate of potassium (free from nitrate) till the colom is perinanent after ten minutes' boiling. Fxcess of permanganate is remover by formic acil, the solution neutralized with pure sulphuric acid and evaporated to about $10 \mathrm{cc}$. This is then introluced into the flask $A$ of the

1 Zeitschr. f. anal. Chem. vii. 392.

${ }^{2}$ Landw. Versuchsstationen, xii. 164. 
apparatus recommended by Schulze ${ }^{1}$ (Fig. 3), a weighed quantity of powdered aluminium added, and solution of caustic sola slowly I'm in; from the deficit in the amount of hydrogen yielded the

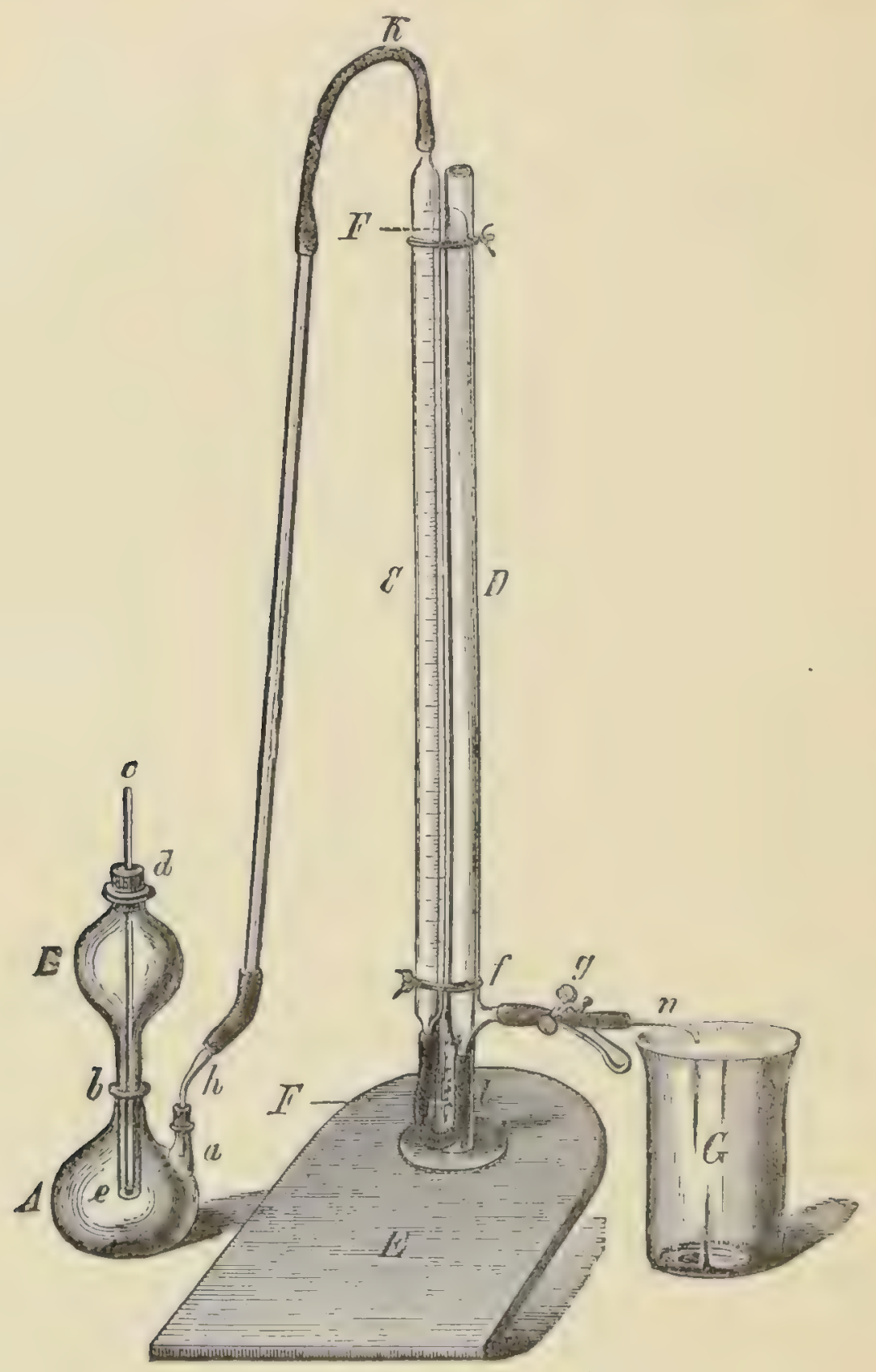

Fis. 3.

nitric acid present may be calculater. The following are the details of the operation:

$\Lambda$ measured quantity of solution of canstic soda is introduced into the pear-shaperl flask $B$. The end of the glass-rod $c$ is accurately ground into the delivery-tube of $D$, so that no soda can escape into $A$ until the rod $c$ is raised. The tube $C$ is

1 Zeitschr. f. anal. Chem. ii. 379, and vi. 379. 
graduated, and communicates with $D$ by means of an indiarubber tube. Both $C$ and $I$ ) are filled with water till the zero in $C$ is reached, the water standing at the same height in $D$. The solution of soda is then allowed to flow slowly into $A$ (which already contains the liquid and powdered aluminium), so that the experiment may last from two to three hours. The hydrogen evolved causes i rise of the water in $D$, but by occasionally opening the clip at $g$, it may be maintained at about the same level in both tubes. Care must be taken at the end of the experiment that the level is cxactly the same before the final realing is taken. From the volume of gas thus found the volume of the caustic sodia introduced from $I 3$ must be deducted, and the remainder corrected for temperature,

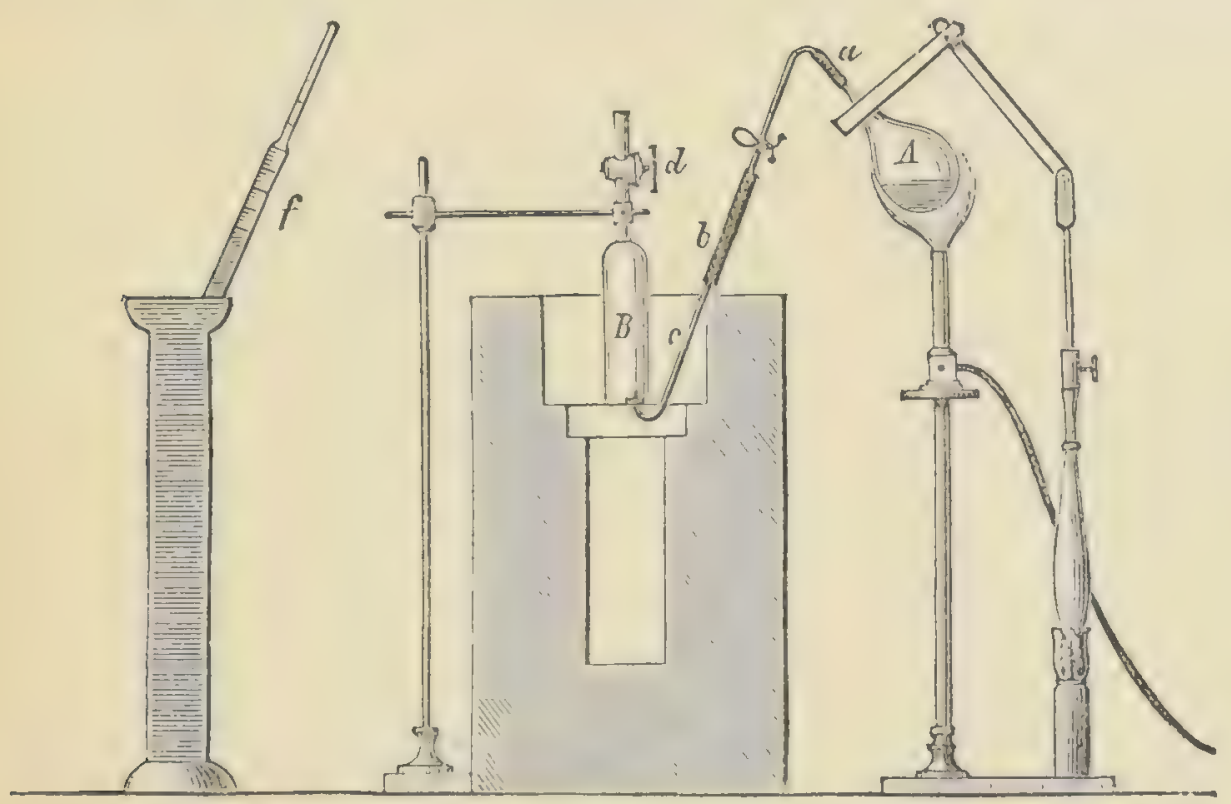

Fig. 1.

pressure, and tension of water-rapour. A previous blank experiment having shown the amount of hydrogen obtilinalile from the "lluminium taken, the nitric acil mily be calculated from the deficit, 4 molecules of hyrliogen corresponding to 1 of nitrie acid or nitrate of potassium.

$\$ 100$. Wulfert's method is a modification of Schloessing's deviserl by Schulze: 0.5 to 1.0 gram of the powlered sulustance is boiled with water to which a little milk of lime has been arlded, filtered and washed; the filtrate and washings are then evilporated to 30 or $10 \mathrm{ce}$, and again filtered. The filtrate is neutralized with hydrochloric acid and introduced into the flask $A$ (Fig. 4), the neck of which has been cliawn out so as to admit of connection 
by means of an indiarubber tube with the bent gliss tube ". The longer leg of the latter is similarly connecter with a second bentglass tube c, communication being regulated by a clip at $b$. The clip heing opened, the atmospheric air in the flask is completely expelled by boiling the liquid down to at least one-fourth of its original bulk. The end of the glass tulse $c$ is then introduced into a precipitating glass containing about 30 ce. of a concentrated solution of ferrous chloride, and, after allowing a little steam to escape, the elip at 7 is closed and the lamp removed. As soon as a partial vacuum has been produced in $A$, the clip is cantionsly opened, and about $20 \mathrm{cc}$. of the iron solution allowed to enter. The precipititing glass is then filler with hyrlrochloric acid (sp. gre. 1.12), and 25 to $40 \mathrm{cc}$. introducerl in a similar manner, sn as to sweep the iron solution out of the tubes into the flask. After closing the end of the tube $c$ with an indiarubber stopper, it is introduced into a mereury-bith and brought under a cylinder $D$, previously filled with mercury. The stopper is now removed, and the flask again heated until the pressure in the interior is nearly equal to that of the atmosphere. By opening the clip b, and regulating the pressure with the finger and thumb, the mercury is allowed to rise in the tube so as to drive most of the hydrochloric acid into the flask; it must, however, itself be carefully prevented from passing into the latter. After the external pressure has been overcome, the heat is so regulated that half the liquicl in the flask distils over in eight to ten minutes. It is then certain that all the nitric oxide that has been formed has been driven into $B$. The latter is provided with a glass-tap $d$, and can be connected air-tight with a measuring tube $f_{0}$ After cooling, the measuring tulse fillex with mereury is fitter on to the cylinder, and the nitrie oxide transerred to it hy opening the tap and sinking the cylinkler. The amount of nitrie acisl may then be calculated from the volume of nitric oxide found. ${ }^{1}$

\$101. Sclerotic, Cathartic Acid, etc.-If the total amount of nitrogen in the aqueous extract ( $\$ 96$ ) is now found, on comparison, to be larger than that present as albuminoids, alkaloids, ammonia and nitrates alrearly estimated, the excess may be reasonably ascribed to certain alluminons substances not 1re-

1 On the estimation of nitric acid in cultivated plants, see also Schloessing, Journ. f. pract. Chem. lii. 142; Fruhling und Grouven, Landwirthsch. Versuchsst. ix. 9, and 150 (1867) ; Reichardt, Zeitschr. f. anal. Chem. ix. 21 (1870) (Journ. Chem. Soc. xxiv. 439). 
cipitated in 93,94 , or certain amido-acids, such as sclerotic or cathartic acid, etc. (For the latter see $\$ 24 \%$.)

\section{EXAMINATION FOR INULIN.}

$\$ 102$. Entraction and Estimation. - It has allearly been mentioned in $\$ 75$ that in dried drugs the majority of this carbohyclrate is present in the form of an insoluble modification; in fresh it is always dissolved in the cell-sap. Dried druss may accordingly be treated first with cold water as directed in $\$ 971,92$, and the residue digested for some time with water at $55^{\circ}$ to $60^{\circ}$ (not higher). At this temperature inulin passes into solution. From a measured volume of the aqueous extract it may lo precipitated by the adlition of three volumes of alcohol; and if for every 100 cc. of mother liquor a correction of 0.1 gram of inulin is made, it may be thus estimated with tolerable accuracy. ${ }^{1}$

Charucters. - Inulin is not precipitated in a gelatinous or curdy form, but in a pulverulent condition. It has already been obscried that an aqueous solution is lievo-rotatory, and that boiling with a dilute acid converts it into levo-rotatory fruit-sugar (!evulose). Inulin may be satisfactorily estimated loy converting it into lerulose and tirrating with Fehling's solution. Of course, the above mentioned correction must be made.

I should not, however, procecel to the extraction with water at $55^{\circ}$ to $60^{\circ}$ unless a preliminary experiment had indicated the probable presence of inulin.

Inicroscopical.-In dricd drugs inulin usually appenrs, under the microscope, in the form of agglomerated masses in the parenchymatous cells. If fresh parts of plants that contain inulin are allowed to stand for soreral days in strong spirit, it is deposited in very characteristic sphero-crystals, which clissolve in acid and alkali without swelling.

Inuloid, which is said to occur in spring in the rhizomes of 11:unts of the natural oriter Compositie, may also form similar sphero-crystals, as do also marattin and a sulstance found in Acetabularia meeliterranea which has not yet been clusely investigated. (Cf. § 81.)

Inuloid is said to be distinguished from inulin lyy its somewhat greater solubility in water. ${ }^{2}$

\footnotetext{
I Compare my 'Materialien zu einer MIonographic des Inulins.' St. Petersburg, 1870.

${ }^{2}$ Compare Annal. d. Chem. u. Pharm. clvi. 190.
} 
VI.

\section{Examination of Substances Soluble in Dilute Caustic Sona; Mletarabic Acid, Albuminous Substances, Phloba- PHENES, ETC.}

$\$ 103$. Eutruction. - The resitue insoluble in water (\$r 51 ) is suspended, whilst still moist, in water containing a known quantity (about 0.1 to 0.2 per cent.) $)^{1}$ of caustic soda in solution, using about $10 \mathrm{cc}$. of alkaline liquid for every gram of original substance. After standing for about twenty-four hours, with frecunent agitation, the mixture is filtered. From $20 \mathrm{cc}$. to $50 \mathrm{cc}$. of the filtrate are acidified with acetic acid, mixed with 3 rolumes of 90 per cent. alcohol, and allowed to stand for twenty-four hours in a cool place. The precipitate is then collected on a tared filter, washed with is per cent. alcohol, dried, and weighed, deructing ash. This precipitate usually consists of mucilaginons sulbstances (pectin) and albuminoils. The former generally corresponds to Scheibler's metarabic acid (\$195).

$\$ 10$ t. Intertion and Listimulion of Allmu, On. - If Lassaigne's test shows the presence of a consilerat)le cluantity of alluminous sulhstances, these should be estimated and deducted. 'To this ond another portion of the filtrate is precipitated as in $\S 103$, the nitrogen in the precipitate estimater and calculated into allonminoirls (224). This amome is then derlueted from the weisht of the precipitate in $\$ 103$. (See also $\$ 226$ ct seq; 236 to 238.)

10.). Listimution.- - Iint the amount of albuninous sulustancess insoluble in witer thus found camnot he noted as snch in the smmmary of results menless it contesponds to that calculated from the nitrogen in the residue insoluble in water, as directed in $\$ 96$. If the latter is lower, it is to lie regareded as the more accurate of the two; the

1 Not more, otherwise starch is attacked. 
explanation of this is to be found in the fact alluded to in $\$ 9.5$ et se'., viz., that the material treated according to $\$ 103$ has loen exhimusted with ether and alcohol previous to being extracted with water, and that therefore the quantity of albuminoids taken into solution is smaller than that extracted according to $\$ 92$. But since the soluble albuminoids are determined in material that has not been subjected to the action of ether, etc., it follows that the nitrogen in the residue after exhaustion with water should guide us in estimating the insoluble albuminoids.

It should be observed that one extraction with dilute caustic soda is often insufficient to remove all the substances soluble in that menstrum. The treatment should therefore be repeated a second and, if necessary, third time.

$\$ 106$. Alluminoids not Vissolved by Dilute Solla.-There still remains the question whether the assumption is admissible that all albuminoids insoluble in water are clissolved by the dilute caustic soda used in $\S 103$. I can only reply that in a large number of experiments male by Stackmamn, Loroll, and C'ramerDolmatoff, ${ }^{1}$ the residue after extraction with water, alcohol, and soda was always tested for nitrogen, with the result that in none but substances very rich in suberin could it be said that a little was often present. Of course, it would be possible to apply Lassaigne's test to the residue after extraction with dilute soda; if evidence of nitrogen be obtained, the amount should be estimated and calculated as "allouminoils insoluble in dilute soda." In experiments made by Treffner ${ }^{2}$ on mosses in my laboratury it was foumd that the amount might occasionally be very considerable. At all events, if nitrogen is present, the quantity should be determined. (Cf. $\$ \$ 232,238$.)

$\$ 107$. Substances Dissolved by Dilute Soda, not Precipitated by Alcolul.- - The filtrate and washings from the precipitate obtained in 103 are eraporated to diyness, and the calculated amount of acetate of soda deducted from the dried residue. (See \$ 237.) The remainder represents the substances soluble in dilute catustic sonda, not precipitated hy acetic acid and alcolobl. It the residue dissolves completely in a feiw cc. of water it may be concluded that no substance allied to phlohiphene, soluble in alcohol, is present. In that case the orgamic matter (apart from the acetate

1 See the dissertations, etc., subsequently quoted.

2 Dissertation. Dorpat, 1881. 
of sorla) is sometimes a necomposition maturt of meteratic aciel or of allierl mucilaginous substances. The action of caustic soda on the latter often results in the formation of products that are not precipitable by alcohol. But this borly that thus remains in solution on atding alcohol will he more often formel to belong to the albuminoids. (See § 235.)

$\$$ 108. Phlobuthene.-A brown residue insoluble in water would frequently consist of phlobaphene. (See also \$ 18.) It should be collected on a tared filter, washed, dried, weighed, and deducted from the eraporation-resilue in 106 hefore the weight of the substances derived from mucilage, cascine, etc., can be arrived at. (See also § 246.)

The polyporic acid, isolated by Stahlschmidt, ${ }^{1}$ may also be mentioned here. It is insoluble in water, ether, benzene, bisulphicle of carbon, and glicial acetic acid, sparingly soluble in warm chlorofom, alcohol, and amylic alcohol, but dissolved by dilute ammonia, forming a violet liquil, from which it is precipitated hy hydrochloric acid. It crystallizes in rhombic jlates, and melts at about $300^{\circ}$.

'Humus.' - I am convinced that the 'humus' mentioned in old plant-analyses was in reality partly phlohaphene and its decomposition-products. In the majority of vegetable substances humus is not to be found, unless they are already in a state of decomposition. Perhapss some thick harks anct lignified fungi might yich substances with characters resembling those possessesl by humus. To solvents such substances would, it is true, show a

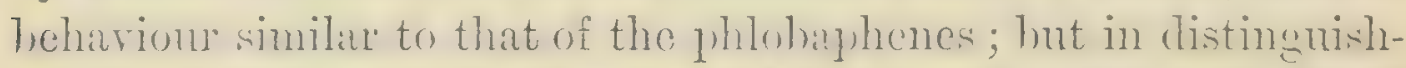
ing them we may take artrantage of the faet that the majority of the so-callerl humic sulsstunces contain hydrogen and oxysen in the proprertion in which ther exist in water, and that hmuns does not yield the decomprosition-products mentioned in 42 when acted upon by fused caustic potash.

1 Annal. d. Chem. und Pharm. clxxxrii. 177 (1S77) (Journ. Chem. Soc. xxxii, 620). 


\section{VII.}

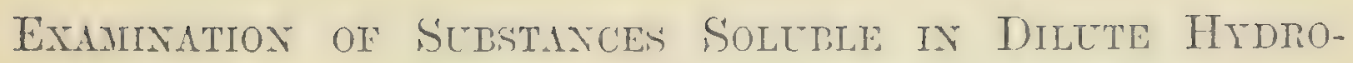
chloric Acid ; Pararabix, Oxalate of Calcicar, etce, AND STARCH.

\$109. Methat of Entraction.-The insoluble residne from \$10:3 is washed with water (which is lost accomplished either by decantation or as directed in $\S 71$ ), and suspended in water containing 1 per cent. of hydrochloric acid. It is advisable to allhere to the same proportion of menstrum to material as alrealy recommended. The method of procedure now depends minly upon the presence or absence of statch and of pararabin (or allied substance). The former may he recognised under the microsenpe by the hlue colour the granules assume when treated with an aqueous solution of iodine. ${ }^{1}$

$\$ 110$. Estimation of Oxalate of Calcium. - The simplest case rould be that in which neither starch nor pararabin is present. The only object in digesting with dilute hydrochloric acil would then he to extract oxaliste of calcium. To effect this the digestion should be continued for alout twenty-four hours at a temperature of 30 . A measured quantity of the filtrate may he nentralized with ammonia, or mixed with a known quantity of acetate of solia sufficient to convert all the hydrochloric acil into chloride of sodium. The oxalate of calcium, which. sejarates ont insolutle

1 If large quantities of mucilaginous (? albuminous) substances are present, this colouration is not perceptible on directly moistening a transverse section with iodine water. The mucilage (or albumen) must be first removed by treatment with a dilute (0.1 per cent) solution of caustic soda. A stronger solution should not be employed, as it might act upon the starch itself. If the residue from $\S 103$ is examined, the treatment with alkali is of course unnecessary. For a classification of starches, according to the shape of the granule, see Nïgeli's 'Monographie der Stirkekïrner,' Haisel, 1S5S; and Vogl, Zeitschr. d. österr. Apoth. Ver. 1866, pp. 290, 310. 
in acetic acid, is allowed to settle, and when the supernatant liquid is perfectly clear it is poured off, and the precipitate transferred to a fine filter, washed and dried. It may then be converted either into carbonate by gentle, or into oxide by strong ignition, and from the weight of either the amount of oxalate calculated. The filtrate and washings are evaporated to dryness, and the residue weighed. As the amount of chloride of sodium and undecomposed acetate is known, it will thus be ascertained if other sulstances (albuminoids, $\$ 223$ ct seq.) have been dissolved by dilute hydrochloric acid.

Instead of estimating the oxalate as carlonate or oxide, the washed precipitate may be dissolved in dilute sulphuric acid, and the oxalic acid determined by titration with jermanganate of potassium. (Cf. $\$ 81,219$.

Microscopical Examination.-Oxalate of calcium is always deposited in plants in the crystulline condition, and its presence may therefore be confirmed by microscopic examination. The crystals must be insoluble in water, alcohol, and ether, but solulble in dilute hydrochloric acid.

It should also he ascertained, by means of the microscope, if all the oxalate has been dissolved by the treatment directed in $\$ 109$. If that is not the case, the maceration with dilute aciel should be repeated.

$\$ 111$. Estimation of Oxalate of Calcium and Pararabin.-If the oxalate of calcium is accompranierl hy prararabin, but not by starch, the maceration is continued for twenty-four hours as before; hut previous to filtering, the whole is rapidly raised to the boilingpoint in a flisk provided with an upright condenser. A measured quantity of the filtrate (filtered whilst hot) is nentralized with ammonial, and mixed with 2 to 3 volumes of 90 jer cent. alcohol. The precipitate, which contains oxalate of calcium and frararabin, is collected on a tared filter, washed with 60 to 70 per cent. alcohol, dried, and weigherl. It is then incinerated, the ash calculater to oxalite of calcium, and deducted from the weight of the precipitate. The remainter is the weight of the pararallin.

The filtrate and washings from the precipitate may be eraporated to dryness as directed in $\$ 110$, in order to ascertain if other sulstances have been dissolved. Here, too, albuminous sulstances may possibly be found, and they may also be present in the precipitater pararabin. Should that lie the case, they may be 
estimater by determining the nitrogen in a portion of the precipitate. (Cf. § 233.)

\$112. Estimation of Pararabin ulone.-If pararalinin ${ }^{1}$ alone is present, the estimation may be conducted as described in $\$ 111$, with the exception, of course, that the determination of calcium is unnecessary. After precipitation with alcohol, pararabin swells in contact with water, but does not dissolve unless an acil be added. It is precipitated by alkalies, and does not yield arabinose under the influence of dilute sulphuric acid. (Cf. \$215.)

\$113. Estimation of Starch and Oxalate of Calcium.--If pararabin is absent, but oxalate of calcium and starch are present together, the material under examination may be boiled (not digested on a water-bath) with 1 per cent. hydrochloric acid for four hours in a flask prorided with an upright condenser. The flask is weighed before and after boiling, and any water that may have been lost by eraporation replaced. In one portion of the filtered liquid the oxalate of calcium may be determined as directed in $\$ 110$, and in another the glucose produced from the starch estimated by titration with Fehling's solution (§83).

The modification necessary when starch alone is present needs no special description.

\$11. Estimation of Oxalate of Calcium, Starch, and Pararabin.The following is the method I have adopted when oxalate of calcium, starch, and pararahin are present together. Water is added to the substance under examination in the proportion of $10 \mathrm{cc}$. for every gram, and the whole brought to the boiling-point. After cooling to $40^{\circ}$ or $50^{3}$, a centigram or more of gool, active diastase is arlded, and the maceration continued at the same temperature until the starch-paste is completely liquefier. The residue, after filtering and washing, is treated accorling to $\$ 111$. $A$ measured quantity of the filtrate containing the maltose and dextrin prodneed from the starch is acirlified with hydrochloric acid and hoilerl as directed in $\$ 113$, the glucose being finally estimated with Fehling's solution and calculated into starch.

\$ 115. Estimation of Starch alone.-If a vegetable substance, especially one rich in mucilage, metarahic acirl, pararalin, glucosides, etc., is to he examined for starch without previous treat-

${ }^{1}$ Compare Reichardt, Ber, d. d. Chem. Ges. viii. 807 (1875) (Journ. Chem. Soc. xxviii. 1179). 
ment with various solvents, a method that I pulblished in $1861^{1}$ may be adopted by which the substances that accompany the starch are removed. The powdered material is mixed with 30 parts of a 4 per cent. solution of caustic potash in alcohol, and heated to $100^{\circ}$ for a day or two in a well-closed flask. After filtering ancl washing with spirit till free from alkali, the substance on the filter is exhausted with water; and to effect this it is alvisal)le to transfer it to a beaker. The residue insoluble in cold water is hoiled with dilute hydrochloric acid, and treated as directed in $\$ 113$. The caustic potash acts upon the forcign substances which interfere with the direct estimation of the starch, ronclering them solyble pritly in alcohol, partly in water, whilst the starch itself is not attacked. (See $\$ 243$.

1 Journ. f. Landwirthsch (May, 1862), and Pharm. Zeitschr. f. Russland, i. 41. For the estimation of starch as glucose after the action of dilute sulphuric acid, see Musculus, Chem. Centralbl., 1860, p. 602 (Am. Journ. Pharm. xxxii.433); and Philipp, Zeitschr. f. anal. Chem. N. F. iii.400. Sachsse (Zeitschr. f. anal. Chem. xvii.231, 1878; Year-book Pharm. 1878, 97), has shown that the inversion is better effected by hydrochloric acid-1 per cent. of the weight of the liquid. Both Sachsse and Nägeli found that the analyses of $\therefore$ starch were more accurately expressed by the formula $6 \mathrm{C}_{6} \mathrm{H}_{10} \mathrm{O}_{5}+\mathrm{H}_{2} \mathrm{O}$, than by that usually adopted, viz., $\mathrm{C}_{6} \mathrm{H}_{10} \mathrm{O}_{5}$. 


\section{VIIT.}

\section{Deterifination of Lignin and Alimed Substances and of Celdulose.}

\$110. Lignin, Incrusting and Cuticular Substances.-The residue of the powder insoluble in all the foregoing menstrua, after treatment as directed in $\S 109$, is washed with water, dricd, and weigher. After haring been again fincly powdered, it is macerated in freshly prepared chlorine-water (in the proportion of about $100 \mathrm{cc}$. for every gram of substance), until the colour changes to a pale yellow. If 2 to 3 diays do not suffice, the chlorinewater must be drawn off and replaced by fresh, and this treatment repeated if necessary. It is finally collected on a tared filter, and wished first with water, then with rery dilute $(0.3$ per cent.) solution of caustic potash until the washings are colourless, the alkali being ultimately remored by pure water. The loss in weight after drying represents the amount of lignin, the so-called incilstiny substances, the majority of the suberin and cuticular substance. (Cf. § 247.) Bromine-water has been proposed in the liace of chlorine-water, but it does not act so energetically.

With regard to the microchemical extmination, I may olserve that lignified tissues absorb fuchsin from its arpueous solution, and retain it so tenacionsly that they apnear stained deep-red eren after maceration in glycerine, which remores all the colouring matter from non-lignified tissue. Russow ${ }^{1}$ recommends the object to be placed on a slide with a drop of dilute aqueous solution of aniline-red. A drop of glycerine is then brought into contact with the edge of the coverslip on the slide, and left for twentyfour hours. Stiles ${ }^{2}$ macerates in a dilute solution of chlorinated lime ( 1 in 60), then transfers for an hour to a solution of hypo-

1 Sitz-ber. d. Dorpater Naturf. Gesellsch. 1880, p. 419.

2 Pharm. Journ, and Trans. [3], vi. 741. 
sulphite of solla (1 in 32), washes with alcohol, and finally removes to a dilute alcoholic solution of acetate of rosaniline ( 1 in 960), the excess of which is washed out with spirit. Aniline-blue is said to impart a fine blue or violet colour to the parenchyma of the medullary rays, etc. The solution is made by dissolving 0.0325 gram of aniline-l)lue in 3.88 gram of water, adding 0.5 gram of strong nitric acid and spirit to 48 grams. After staining red as directed by Stiles, the section may be immersed for a few minutes in the solution of aniline-blue, washed with spirit and finally treated with cajeput oil or turpentine.

Wiesner ${ }^{1}$ has described a qualitative reaction for woody tissue, which consists in moistening the section with a 0.5 per cent. solution of phloroglucin, and subsequently treating with hydrochloric acid. The lignified tissue assumes a reddish or violet colour.

\$117. Estimation of Cellulose.-The residne, after treating as rlirected in $\$ 116$ and weighing, is a mixture of cellulose, intercellular substance, remains of the cuticular substance, etc., together with a little ash (and possibly also sand). It may be removed from the filter (which should be reserved), powlered, and introduced into a flask containing 50 to $100 \mathrm{cc}$. of nitric acid (sp. gr. $1 \cdot 16$ to $1 \cdot 18$ ) ; 1 to 2 grams of chlorate of potash are then addecl, and the mixture allowed to stand in a cool place with occasional agitation until the insoluble matter appears almost white. If this is not effected in a day or two the mixture may he warmed for one or two hours to about $40^{\circ} \mathrm{C}$. (not higher), and again allowed to stand. If this is not successful the strength of the nitric acid may be increased mitil it reaches a specific gravity not excecling 1.20. After the artion of the acid has hecn continued long enough, it may he diluted with water and filtered, taking care to pour the supernatant liquid on to the filter, leaving the insolulle matter as long as possille in the flask. After washing free from acid, it is treated with dilute ammonia ( 1 in 50 of water) as long as that is coloured brownish, and finally with alcohol and, if necessary, with ether. The residue is dried and weigherl. The loss in weight usually represents intercellular substance and certain carlohlydrates allied to cellulose, but less resistent (hydrocellulnses), rte. (See \$\$ 245, 246.) The residue on the filter consints of cellulnse with a little ash (silica, sand, etc.), that may be estimated and deducted. (See also § 248.)

1 Zeitschr. f. nnal. Chem. xvii. 511, 1878 (Journ. Chem. Soc. xxxiv. 612). 


\section{CONCLUDING REMARKS.}

$\$ 118$. In compiling the foregroing method of analysis, one object that I had in view was to show how, when working upon a small quantity of material, say 30 to 50 grams, an insight into its composition might be grained, so that at least the presence or absence of the more important constituents of plints might be ascertained. I wished to show further how the constituents actually present might be estimated, even if no more than the abore-mentionel quantity was availal)le. I had therefore to devise a combination of qualitative and quantitative analysis, and the fact that a consilerable number of the same constituents occur in the majority of plants justified me in making the attempt.

Neans have also been indicated by which attention would be drawn to the presence of substances that occur only in single plants or in snialler groups of the vegetable lingrom. In this respect the foregoing method is of course hut an introrluction, the special application and perfection of which for each separate case must be left to the investigator himself. Processes for the quantitative estimation of certain substances, and especially such as are of consideral)le practical importance in medicine, agrieulture, etc., have alrearly been recommended, and will be followed hy others in the second part of the work.

$\$ 119$. It must be admitted that miny of the proposed methods of detection and estimation cannot boast of the accuracy attainable in the analysis of some inorganic substances. For this reason I advise beginners to refrain from calculating their analyses, as is frequently clone, to the fourth and even fifth place of decimals. Such calculations often misleurl reulers less acyuainted with the sulvect to attach to the separate determinations an importance to which they are not entitled. I consider it ample to carry the calculations to the second decimal place.

To those who ask of what use analyses are, the accuracy of which I have myself this moment questionerl, I reply that the object of analyzing a regetable substance, as for instince ergot, is not so much to ascertain the exact composition of a fungus produced on a certain ear of rye in a certain ficld, but to obtain information as to the approximate composition of ergot in general, the specimen under examination heing taken as a representative of the drug. Attention must be specially drawn to the fact that 
in different years and different localities the proportions in which the constituents of ergot occur present certain variations.

If, on the other hand, an approximate analysis is not required, but in its stead a fairly accurate comparison of specimens gathered in different fields, then it must be borne in mind that only certain practically valuable constituents have to be taken into account, for the estimation of which more accurate methods may not unfrequently be devised. This we are generally able to accomplish, for we are in a position to elaborate the necessary mode of treatment, to determine the extent of the errors involved, and the corrections to be made for them, and to make several estimations from the same material from which a mean may be calculated. 
IX.

Special Metiods for the Estmifation of crertain Constituents of Plants, Suppleanentary jotes to the PreCEDING EXPERIMENTS.

FATS AND THEIR CONSTITUEATS CHOLESTERA, IILICIN, ETC.

\$120. Estimation of Fixed Oils.-For reasons given in $\$ 8, I$ recommended the use of benzene some twenty year's ago ${ }^{1}$ for extracting fixed oils. Petroleum spirit, which I sulssequently introduced for the same purpose, has the advantige orer benzene of being more rolatile and possessing a lesser solvent power for resins, etc. (Cf. \$36.) The use of benzene was afterwards arlvocated by Hoffmamn also, who give it the preference over ether and bisulphide of carlon. Other methods for estimating fixerl oils have been described by Mïnch. ${ }^{3}$ Various forms of apparatus that may he used have former the suljects of communications from Storch, ${ }^{4} \mathrm{~W}^{\mathrm{i}} \mathrm{unner},{ }^{5}$ Simon, ${ }^{6}$ Tollens, ${ }^{7}$ Schulze, ${ }^{\mathrm{S}}$ Tschaplowitz, Medieus, ${ }^{10}$ Siewert, ${ }^{11}$ Hirschsohn, ${ }^{12}$ Keyser, ${ }^{13}$ and others.

The apparatus represented in Fig. 5 is that last devised by Tollens. It consists of a weighed flask, A, holling about $100 \mathrm{cc}$, to which is tightly fitted, by means of a perforated cork, a glass tube $\mathrm{B}$; the latter is about $30 \mathrm{~mm}$. in diameter at its upper, and

1 Pharm. Zeitschr. f. Russland, i.44, 1862 ; Anm. Zeitschr. f. anal. Chen. i. 490 .

2 Zeitschr. f. anal. Chemie, vi. 368, 1867.

${ }^{3}$ N. Jahrb. f. Pharm. xxv. 8, 1866.

4 Zeitschr. f. anal. Chemie, vii. $68,1868$.

${ }^{6}$ Ibid. xii. 179, 1873 (Journ. Chem. Soc. xxvii. 293).

7 Ibid. xiv. 82, 1875, and xvii. 320, $1878 . \quad{ }^{8}$ Ibid. xvii. 174, 1878.

5 Ibid. xviii. 441, 1879.

${ }^{10}$ Ibid. xix. 163, 1880.

11 Landw. Versuchsst. xxiii. 317, 1879 (Journ. Chem. Soc. xxxvi. 558).

12 Archiv d. Pharm. [3], x. 486, 187\%. ${ }^{13}$ Farm. Tidskr. 1880, Nos. 9 and 19. 


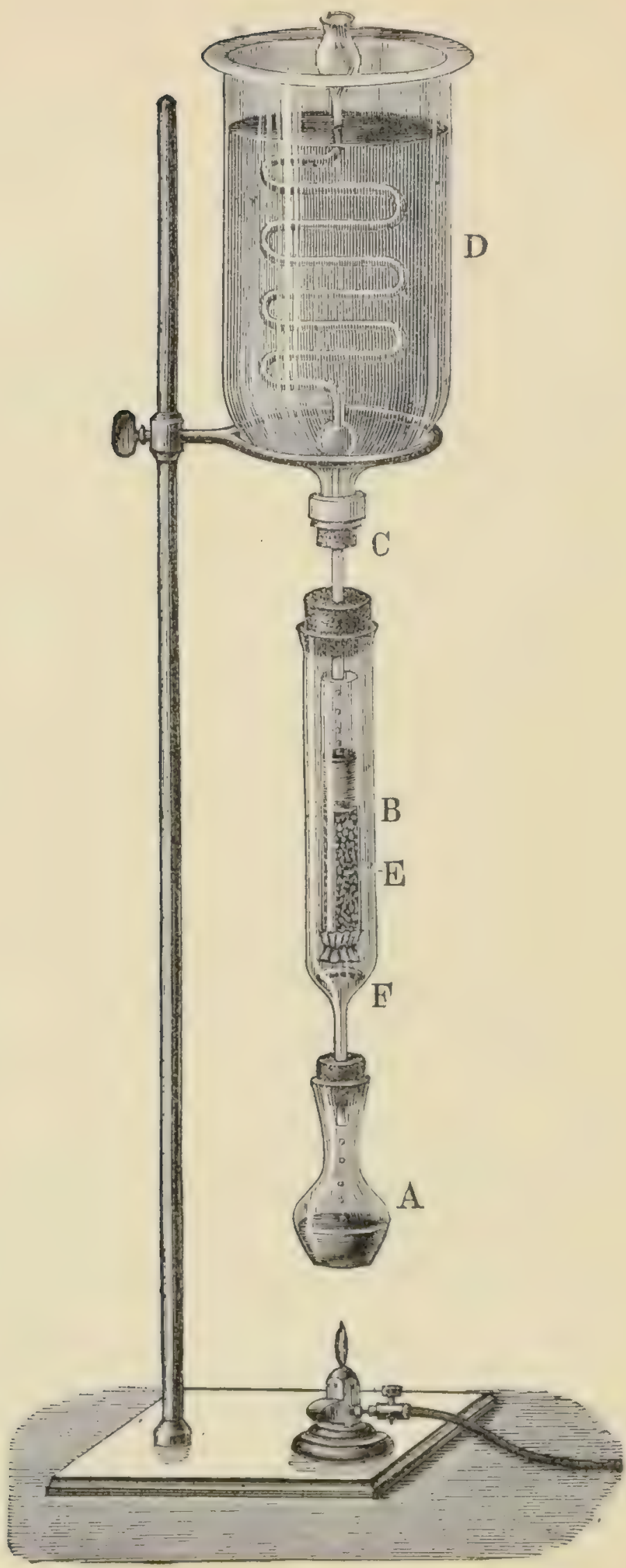

Fig. 5. 
If to 7 at its lower extremity ; the former communicates by means of perforated corks with the contenser D. A glass tube, li, about $20 \mathrm{~mm}$. in diameter, is supported upon a bent glass rod, $\mathrm{F}$, in such a manner that the condensed vapour from $\mathrm{C}$ irops directly into it. In this tube, E, the substance to be examined is carefully packed ; a piece of filtering-paper is then tied over the lower end, and a small circular filter laid upon the surface of the packed substance. During the extraction the heat is so regulated that the material is constantly covered by a layer of ether 1 to $2 \mathrm{~cm}$. thick.

$\$ 121$. Resinifucation. - The rapiclity with which an oil resinifies may be ascertained by exposing it to the air in thin layers and noting the daily increase in weight. Parallel experiments should be made with almond and linseed oil under precisely similar conditions. The oil used should be quite free from any trace of petroleum spirit.

$\$ 122$. Eluidlin Test. - This test $(\$ 12)$ consists in passing nitrous acid into a few cc. of the oil and observing the length of time that elapses before solidification takes place. Another method is to introduce copper turnings or a little mereury, together with nitric acid, into a test-tube, and pour a few cc. of the oil upon the mixture. The colour also of the elaidin produced may be characteristic of the oil under examination.

Using 5 grams of nitric acid, sp. gr. $1 \cdot 4$, and 1 gram of merculy to 10 grams of oil, Massie ${ }^{1}$ observed the following reactions:

On agitating the oil with the nitric acil alone for two minutes and allowing the liquids to separate, the following colourations were observed : almond, hazelnut, sunflower-seed oil, colourless or slightly greenish; olive oil, greenish, white. or slightly yellourish-ypeen, or distinctly green; ground-nut oil and poppy-seed oil, reldish; castor and sesame oil, yellurish or yeltourishorenge; oil of white mustard, apricot, walnut, camelinil, beech, rape and linseed oil, cheriy-ted or reddish-orenge; oil of 1,1ack mustard, cotton and hemp-seed oil, brown or brounish-red.

The acid was coloured yellowish by olive oil (occasionally), saffron-yellow by sesamé, light hrown with cotton, and slightly reddish or greenish by hemp oil.

After the addition and solution of the merenry, the mixture is

${ }^{1}$ Journal de Pharm. et de Chim. [4], xii. 13, 1869. 
shaken at intervals and finally set aside. The following observations were made:

\begin{tabular}{|c|c|c|}
\hline Almond & $\begin{array}{l}\text { After } 20 \text { to } 30 \text { mins. } \\
\text { white or pale-greenish }\end{array}$ & $\begin{array}{l}\text { After } 1 \mathrm{hr} \text {. } \\
\text { white. }\end{array}$ \\
\hline Hazelnut & & \\
\hline Sunflower-seed & lemon-yellow & lemon-yellow. \\
\hline Olive & ale yellowish & pale yellowish-green. \\
\hline Ground-nut & pale reddish & pale reddish. \\
\hline Poppy & red & red. \\
\hline Castor & rose & yellow. \\
\hline Sesamú́ & yellowish-orange & yellowish-orange. \\
\hline Apr & red & rose. \\
\hline White mustard & yellowish-orange & reddish-yellow. \\
\hline ina sativa & & recldish-orange. \\
\hline Walnut & cherry-red & reddish-y ellow. \\
\hline Beech & orange & reddish-orange. \\
\hline Rape & reddish-yellow & orange-yellow. \\
\hline Colza & pale reddish & pale yellowish-orange. \\
\hline Linseed & reddish-brown (effervesces) & reddish-brown. \\
\hline Black mustard & pale reddish & reddish-yellow. \\
\hline n-seed & dark orange-red or reddish & pale orange-red or red. \\
\hline Hemp & brown & reddish-brown. \\
\hline
\end{tabular}

The following oils solidify : almond in 1 1 hr., hatzelnut in $1 \mathrm{hr}$, olive oil in $1 \mathrm{hr}$, ground-nut in 13: hr., sesamé in 2.1. hr., apuricot in $1 \frac{3}{4} \mathrm{hr}$, beech in $6 \mathrm{hr}$, rape in $3 \mathrm{hr}$, colza in $3 \frac{1}{2} \mathrm{hr}$, cotton in $1 \frac{3}{4} \mathrm{hr}$. ; the remainder do not solidify at all.

123. Behaviour to Sulphuric Acid.-Casselman ${ }^{1}$ obscrved the following rise in temperatume when .50 ce. of the oil were mixed with 10 cc. of conc. sulphuric acid :

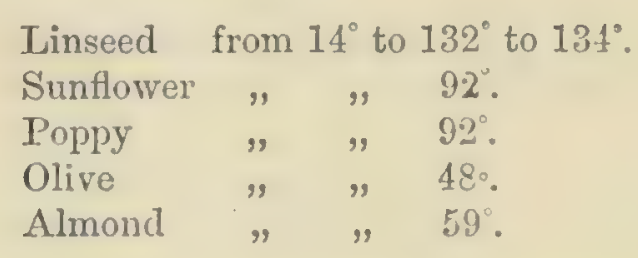

With the oil from peony-seed Stahre and myself " olserved a rise to $68^{\circ}$, whilst almond oil rose to $48^{\circ}$.

$\$ 124$. Behaviour to linengents nirmtioned in 1 12.-Casselman has made the following ohservations with the reatgents mentioned in $\$ 12$ :

${ }^{1}$ Pharm. Zeitschr. f. Russland, 299, 1867 ; Zeitschr. ¡. anal. Chemie, vi. 479. See also Chateau.

3 Archiv d. Pharm. [3], xiv. 412, 531, 1879 (Journ. Chem. Soc. xxxvi. 1043). 


\begin{tabular}{|c|c|c|c|c|c|c|c|}
\hline 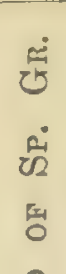 & $\underset{\stackrel{\leftrightarrow}{i j}}{\stackrel{i}{-1}}$ & $\stackrel{\ddot{0}}{\stackrel{0}{0}}$ & 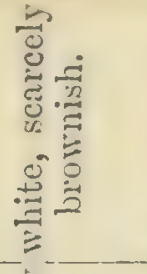 & 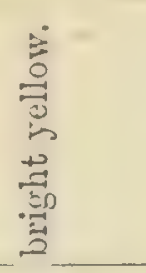 & 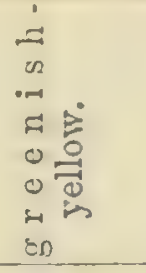 & 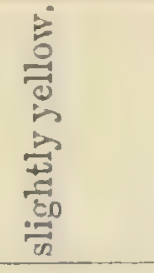 & $\stackrel{0}{0}$ \\
\hline 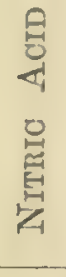 & $\begin{array}{l}\dot{0} \\
0 \\
0 \\
\end{array}$ & $\stackrel{3}{3}$ & 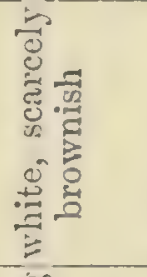 & 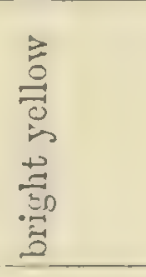 & $\begin{array}{l}\dot{z} \\
\therefore \\
\approx \\
\approx \\
0 \\
0 \\
0 \\
0 \\
=0\end{array}$ & 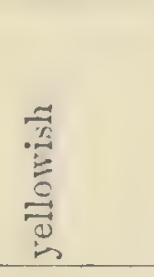 & 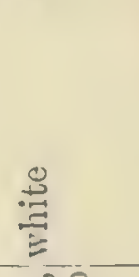 \\
\hline \multirow{2}{*}{ 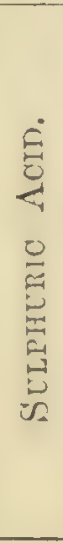 } & 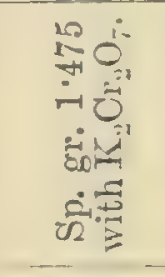 & 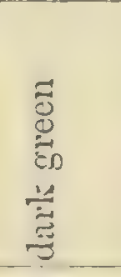 & 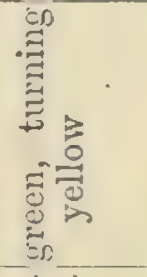 & 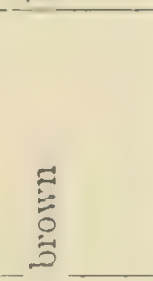 & 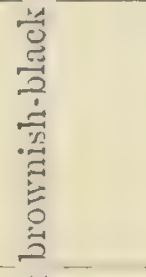 & & 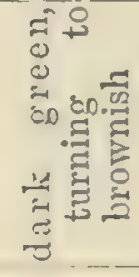 \\
\hline & 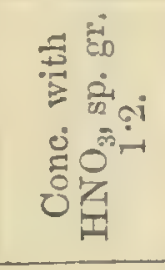 & 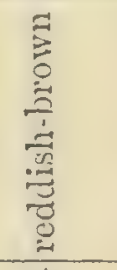 & 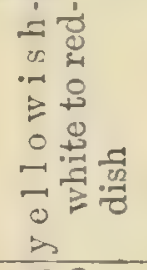 & בี & 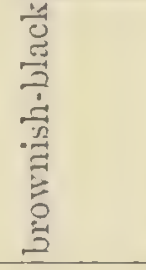 & 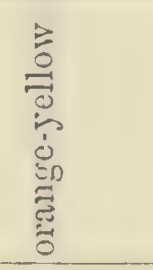 & 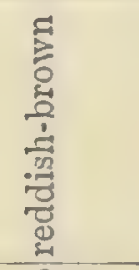 \\
\hline \multirow{3}{*}{ 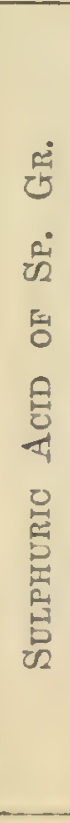 } & 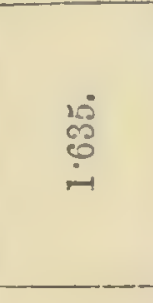 & 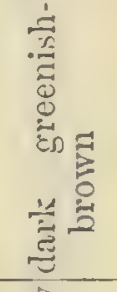 & 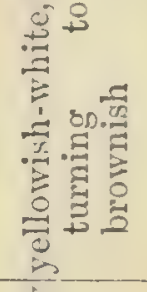 & \multirow{2}{*}{ 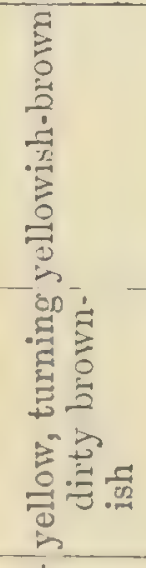 } & 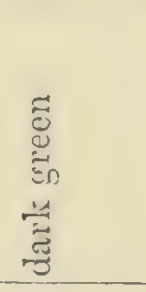 & 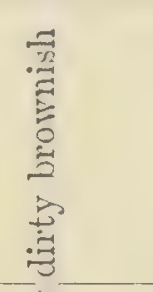 & 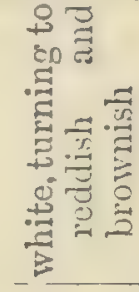 \\
\hline & 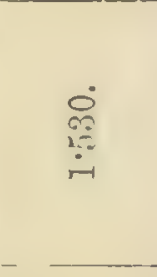 & 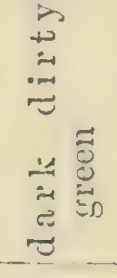 & 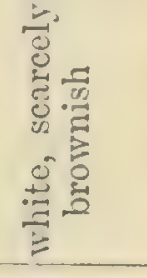 & & 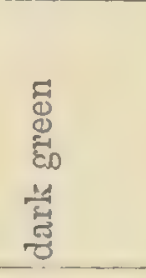 & 章 & 蒫 \\
\hline & $\begin{array}{l}10^{\circ} \\
\frac{10}{14} \\
\dot{11}\end{array}$ & 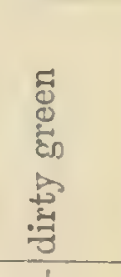 & 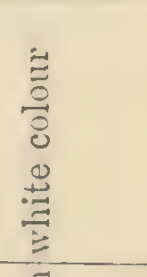 & 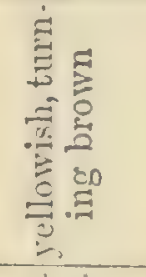 & 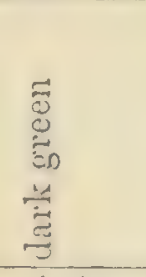 & 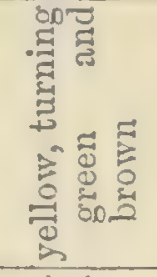 & 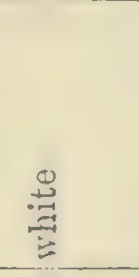 \\
\hline \multirow[t]{2}{*}{ - } & \multirow[t]{2}{*}{ כ2 } & 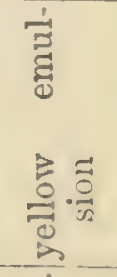 & 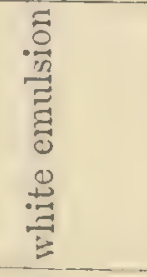 & 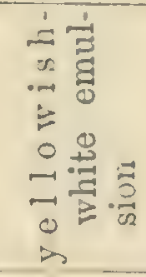 & 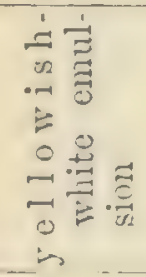 & 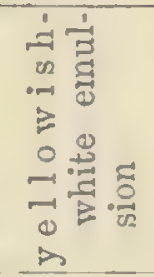 & 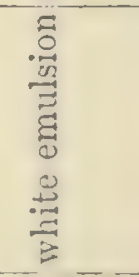 \\
\hline & & 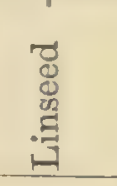 & 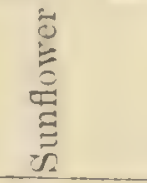 & 宕 & 离 & : & $\underset{\Xi}{\Xi}$ \\
\hline
\end{tabular}


Stunnic chloride produces the following changes in colour: linsech, dirty yellow, passing to green; sunflower, white, turning brown; polpy, greenish ; hemp, yellowish-green; olive, bright yellow; almond, scarcely yellowish. On warming with chloride of winc linseed oil becomes green, and hemp oil assumes a fine green colour, while the remainder undergo no change. Symuy juosphoric acid forms a sort of emulsion with linseed and poppy oil, but not with the others.

Warming with mercuric nitrate colours linseed oil from dark green to brownish-red; sunflower, bright yellow; poppy and hemp oil, green, turning brown; olive, dark yellow, passing to orange red; almond, deep chrome.

Bieber ${ }^{1}$ used nitric acid of sp. gr. $1 \cdot 4$, and also a cooled mixture of equal parts of conc. sulplunic and fuming nitric acid in the proportion of 1 volume of reagent to 5 of oil.

Hauchecorne ${ }^{2}$ has published reactions of oils with peroxide of hyllingen, but without specifying the strength of the reagent. He states that on shaking 1 volume of solution of peroxide of hydrogen with 4 of oil, olive assumes an apple-green; poppy, a flesh colour ; sesamé, bright red ; ground-nut, greyish-yellow ; and becch-nut oil, an ochre red. According to Cohné, drying oils may be distinguished from non-llyying by their behaviour to peroxide of hyolrogen. The former are said to be quickly decomposed with separation of fatty acids, whilst the latter resist such treatment.

Basoletto" observed that sesamé oil, when shaken with an equal volume of hydrochloric acid (23 to 24 per cent) containing 2 per. cent. of cene-sugur, assumed a reddish tinge, pussing to cherry-red, whilst olive oil was not colourerl. On agitating with nitric acid containing sugar, sesame oil was coloured cimmann, whilst the acid became yellowish-green. Cotton-seed oil turns yellow with the same reasent (the acid becoming pale rose coloured), but

1 Apotheker Zeitung, xii. 161, 1877 (Journ. Chem. Soc. xxxiv. 343). For the action of nitric acid on fatty oils, see also Hauchecorne, Zeitschr. f, anal. Chemie, iii. 512, 1864, where, however, the strength of the acids employed is not mentioned. Tanglies (il)id. ix. 5.34, 1870) recommends mixing nitric acid specific gravity 1.4 with $\frac{1}{3}$ of its volume of water, and warming 1 part of this reagent with 3 of oil in the water-bath. Sesamé oil is said to yield a red mass by this treatment.

2 Zeitschr, fo anal. Chemic, ii. 442, 1863.

${ }^{3}$ Bulletin della Soc. Adriatic, i. 178, 1875. 
almond and castor oil produce no alteration. Accorling to Vilian ${ }^{1}$ hydrochloric acid containing sugar changes the colour of castor oil to orange-yellow, poppy oil yellowish-hrown, grommlnut oil intense yellow, olive oil yellowish-orange, ritpe oil dark brown, and almond oil yellowish-orange.

For the use of chloride of antimomy as a reagent see Zabludowski" and Walz. ${ }^{3}$ The latter foumd that on adding a few drops of the reagent, which should be of a syrupy consistence, to 2 or 3 cc. of the oil to be examined, olive oil formed a whitish emulsion, gradually turning dark, without any rise in temperatture, whilst with cotton-seed oil a considerable amomnt of heat was evolved, the mixture becoming solid and of a chocolate-brown colour.

Concentrated solution of chlorinated lime is said to form an cmulsion with \& times its rolume of poply oil, but not with almond oil.

C'unstic socte of specific gravity 1.33 , heated to boiling with 4 or 5 times its volume of oil, yields a white liquid mixture with castor oil, yellowish-white with sesamé, colza, poppy, and walnut, and yellow with linseed, whilst olive oil and hemp) yield respectively brownish and hrownish-yellow solid masses. ${ }^{4}$ Some oils, such as rape and colza, may be contaminated with sulfurur comprume, which may he detected by nitro-purusside of sodium after treatment with caustic soda.

For the use of the spectroscope in identifying fixed oils see Cilmour, ${ }^{5}$ of the polviliscope sce Buignet, ${ }^{6}$ of cohesion figures see Tomlinson, ${ }^{7}$ Kate Crane, ${ }^{8}$ and Moffat. ${ }^{9}$

$\$ 125$. Free Fat-acid.-The presence of free fatacid may be

1 Journ. de Pharm. et de Chim. xxii. 30, 1875 (Journ. Chem. Soc. xxix. 111). Compare also Jahresb. f. Pharm. 288, 1875. The hydrochloric acid and sugar reaction was recommended by Camoin as early as 1860. Compare Choulette, 'Observations prat. de Chim. et de Pharm,' Fasc, i. 130.

2 Pharm. Zeitschr. f. Russland, ii. 233, 1863.

3 Amer. Journ. Pharm. xlvi. 25, 1874.

"Compare Hager, 'Untersuchungen' (Giinther Leipsic, 1874), vol. ii. 510.

5 Pharm. Journ. and Trans. [3], vi. 981, and Jahresb. f. Pharm. 362, 1876.

". Tourn. de I'harm. et de Chim. xl. 252, 156:) (Amex. Jumn. I'harm. xxxiv. 110).

7 Pharm. Journ. and Trans. [2], v. 387, 495.

8 Ibid. [3], v. 243, and Jahresb. f. Pharm. 289, 1874.

' Chem. News, xviii. 473. 
detected, according to Jinobson, ${ }^{1}$ by shaking with powderes rosaniline. Oil containing free fat-acid is coloured red.

Rimpler.2 employs carbonate of solla, which does not emulsify oils containing no free fat-acid.

Geissler ${ }^{3}$ estimates the free fat-acid by diluting with 2 or 3 volumes of ether and titrating with alcoholic potash, using an alcoholic solution of rosolic acid or phenol-phthalcin as an indicator:

\$ 126. Cholesterin. Detection and Estimation.-Hoppe-Seyler ${ }^{4}$ detects and estimates cholesterin in vegetable substinces by extracting with ether, distilling, boiling the resicute for a few hom's with alcoholic potash, exaporating, redissolving in water, and shaking with ether. If the cholesterin obtained by eraporating the ethereal solution is not pure, the treatment with alcoholic potash is repeated. If sufficient alkili is present neither fat nor soap will be taken up by the ether.

Schulze ${ }^{5}$ directs attention to the fact that the estimation is inaccurate if the material contains vegetable wax yielding an alcohol (\$14) on decomposition with an alkali, on account of the influence the latter exercises on the solubility of cholesterin in spirit. Schulze recommends the conversion of the impure cholesterin into benzoate of cholesteryl by heating with benzoic acid in sealed tubes. This compoumd may be freed from many foreign sul)stances by hoiling with al,solute alechol, in which it is almost insoluble. After recrystallization from ether the cholesterin may be liberated by heating with alcoholic potash.

C'erilesterin is soluble in petrolem spirit as well as in ether, and is therefore extracted by the former, together with the fixed oil. If an accurate estimation is requirer, large quantitics of material must be worked upon, as cholesterin occurs in only small proportions in regetable substances. (Beneke obtainer 1.5 gram from 2,500 srams of grey leals.) It is insoluhle in water, crystallizes from alcohol in silky needles and plates (lolonging to the rhombic system), melts at $137^{\circ}$, and is, in alcoholic solution, lxvo-rotatory $\left(\alpha_{D}=36 \cdot 61^{\circ}\right)$. Warmed with a mixture of 1 vol.

${ }^{1}$ Chem.- tech. Tepert. i. 81 ; Zeitschr. f. anal. Chemie, xvii. 387, 1878.

2 Keitschr. f. anal. Chemic, ix. 417, 1870.

3 Ibid. xvii. 387, 1878 (Journ. Chem. Soc. xxxiv. 334).

4 Merl.-chem. Unters. Heft i. 143. Weitschr. f. annl. Chemie, v. 422, 1866.

5 Zeitschr. f. anal. Chemic, xvii. 173, 1878. (Journ. Chem. Soc. xxxiv. 612.) 
conc. sulphuric acid with 1 of water, a red colouration is produced, whilst 4 of acid with 1 of water develops a blue, and 3 with 1 a violet tinge. If a mixture of concentrated hydrochloric acid and solution of ferric chloride (3 in 1 ) is evaporated with a little cholesterin, a reddish-riolet or hluish-violet colour makes its appearance. Similar treatment with sulphuric acil imrl furric chloride leares a carmine residue, which gradually passes to riolet and becomes scallet on treating with ammonia.? After trituration with sulphuric acid cholesterin is coloured red by the addition of chloroform.

Phyfesterin, a substance allied to and probably homologous with cholesterin, was discorered by Hesse ${ }^{2}$ in the Calalbar hean. Its solubility is, on the whole, similar to that of cholesterin, with which it hats occasionally been confounded. It melts at 13:3', and is somewhat less powerfully levo-rotatory $\left(\alpha_{D}=34 \cdot 2^{\circ}\right)$.

Filicin is another substance soluble in petroleum spirit; it is extracterl, therefore, together with the fixerl oil, and is partially deposited in crystals on evaporating such a solution; an aprureciable quantity, however, remains dissolved in the fixed oil. Experinent, mate at my instance by Kunse, with the object of derising a ruantitative separation of filicin from fixed oil, were montecsiful; all the liquids employed (acetone, acetic ether, ethcr, heavy petrolem oils, bisulphide of carbon, etc.) dissolverl both sulistances. Attempts to separate the fixed oil from the filicin by dissolving in a hot aqueous solution of carhonate of socla and fractionally precipitating with hyctrochloric acid, as well as the same treatment of an alkaline alcoholic solution, were attended with negative results.

The liosin: contained in cousso is soluble in petrolem spirit, especially when warm. It is more easily solut,le in ether, benzene, or bisulphicle of carlon, somewhat sparingly in alcohol and glacial acetic acirl. Ferric chloride colonrs the alcoholic solution red, and

1 Zeitschx. f. anal. Chemie, xvii. 173, 1878, and Ritthausen, 'Eiweisskörper,' 98.

-Annal. d. Chem. und Pharm. cxcii. 175, 1878 (Journ. Chem. Soc. xxxiv. 850). For paracholesterin, see ibid. ccvii. 229, 1881. Hesse, ibid. ccxi. 283; Schulze and Barbieri, Ber. d. d. Chem. Ges. xv, 953, 1852.

${ }^{3}$ Archiv d. Pharm. [3], ix. 24, 1876 (Journ. Chem. Soc. xxxi. 336). See also Luck, Annal. d. Chem. und Pharm. liv. 191, 1851, and Grabowski, Chem. Centralbl. 409, 1867.

+ Tliickiger and Buri, Archiv d. Pharm. [8], v. 193, 1874 (Pharm. Journ. and Trans. $[\ddot{\bullet}]$, v. 562). 
an alkiline arpueous solution also gradually assumes a rerl tinge. It is decomposed by fusion with potash, yielding, amongst other substances, butyric acid (the same is the case with filicin).

Einthorbun is liliewise soluble in petroleum spirit, and freely so in ether, benzene, chloroform, acetone, and grlacial acetic acid, but not in aqueous alkalies. It dissolves in concentraterl sulphuric acil, with the production of a brownish tinge, which is changed to violet by nitre or nitric acid. It melts at $113^{\circ}$ to $114^{\circ}$, and resembles, in many of its properties, lactucon or lactucerin (rariuns species of Lactuca), echicerin (dita bark), and perhaps also cynanchocerin (Cynanchum vincetoxicum and acutum).

Itelenin is easily soluble in petrolem spirit, alcohol, and ether, but insoluble in water, even in the presence of a little alliali; it is dissolved, however, by hot concentrated solution of potash. Helenin melts at $110^{\circ}$, crystallizes in colourless neerles, and dissolves in conc. sulphuric acil, with production of a red colouration. Hydrochloric acid-gas is also said to colour helenin red. ${ }^{2}$

Coumerin may be recognised by its odlour and by its colourless rhombic crystals. It is sparingly soluble in coll, more easily in hot water, and is also dissolved by ether and by alcohol. Amongst the sulsstances it yields when fused with potash is salicylic acid (\$26). For the allied melitotic acid compare Zwenger: ${ }^{3}$

Styjol also is characterized by its aromatic odlour. It is a colourless liquid convertihle hy long heating in sealed tulues into solid metastyrol. It is almost insoluble in water, but casily soluble in alcohol, ether, and bisulphide of carbon. Heated with chromic acid it yields benzoic acid and other prorlucts of decomposition $(\S 26)$.

For myrotoctrpin, see Stenhouse and Scharling ; for dimsmin, Landerer ${ }^{5}$ and Fluckiger ; for lï̈mpferid, Brandes and .Jahns $;^{7}$ for aseron (which is soluhle at least in warm petroleum spirit),

x Hesse, Annal. d. Chem. und Pharm. clxxx. 352; clxxxii. 163, 1876 ; cxcii, 193, 1878 (Amer. Journ. Pharm. 1. 552). See also Alberti and Dragendorff, Pharm. Zeitschr. f. Russland, ii. 215, 1863; and Fliickiger, N. Jahrb. f. Pharm. xxix. 135, 1868.

2 See Kallen, Ber. d. d. chem. Ges. vi. 1506, 1873 (Pharm. Jnurn, and Trans. [3], vii. 156).

3 Annal. d. Chem. und Pharm. Suppl.v. 100, 1867.

4 Ibid. Ixxvii. 306, 1851, and xcvii. 69, 1856 (Amer. Journ. Pharm. xxiii. 144).

5 Repert. f. Pharm. lxxxiv. 62.

6 Ibid. xxiii. (New Series), 102, 1874 (Amer. Journ. Pharm. xlvi. 235).

7 Archiv d. Pharm. 1viii. 52; Ber. d. d. chem. Ges. xiv. 2385. 
C. Schmilt ; for angelicin, which has becn proved to be identical with hyllourutin, see Brimmer ;' for curotin, see Husemann." The last-named sulstance forms red crystals, soluble in benzene anrt bisulphicle of carbon. It dissolves in conc. sulphuric acid, with a purplish-blue colour, and is also coloured blue by sulphurous-acielgas.

Anemenol, which occur's in many Ranunculacex, may also be mentioned here. It is an oily acrid liquid, volatile with the vapour of water, and gradually changing in aqueous solution to crystalline anemonin. The latter can be isolated by shaking the arneous solution with ether or chloroform, and like anemonol, actis as an irritant when applied to the skin. ${ }^{4}$

For cupsicin and cupsaicin see Thresh ; for amyrin and bryourtin see Buri. ${ }^{0}$

$\$ 127$. Caoutchouc.-Petroleum spirit extracts only a trace of cantchoue, which remains undissolvel on treating the residue after evaporation with warm alosolute alcohol. If a consilerable quantity of cautchone is present the majority is left in the sul)stance after exhaustion with petroleum-spirit, and may be extracted by lisulphide of carhon containing 6 to 8 per cent. of alcohol, or by chloroform. From these solutions it may be precipitated hy the arldition of more alcohol, whilst resinous substances and the like generally remain dissolved. (See also § 46.)

\$1ㄹ. Estimetion of Glycerin (\$13).--For details of the determination of this substance see Iicichardt, ${ }^{7}$ and Neubaner and Borgmann.s The latter authors point out the fact that etheralcohol removes other substances besiles glycerin from wine, etc., amel that the estimation may accordingly he too high. They therefore recommend dissolving the glycerin residue in alcohol, adding 3 volumes of ether, filtering and craporating. Pasteur advises the evaporation of the solution to be conducted as quickly

1 Annal. d. Chem. und Pharm. liii. 156, 1845.

2 N. Repert. f. Pharm. xxiv. 665, 1874 (Pharm. Journ. and Trans. [3], vii. 91).

${ }^{3}$ Annal. d. Chem. und Pharm. cxvii. 200, 1861.

${ }^{4}$ Compare Fehling, Annal. d. Chem. und Pharm. xxxviii. 278, 1841; Miuller, Chem. Centrlb. 618, 1850 ; Erdmann, Journ. f. prakt. Chem. Ixxv. 209. See Amer. Journ. Pharm. xxxiv. 300 ; xxxi. 440.

${ }_{5}^{5}$ Pharm. Journ, and Trans. [3], vi. 941, vii. 473.

${ }^{6}$ N. Repert. f. Pharm. 220, 1875 (Pharm. Journ. and Trans. [3], vii. 157).

7 Archiv d. Pharm. [3], x. 408 ; [3], xi, 142, 1877.

8 Zeitschr. f. anal. Chemie, xviii. 442, 1878. See also Pasteur, Annal. d. Chem. und Pharm. Iviii, 330, 1864. 
as possille, as glyecrin loses weight even in a vacum. Compare also Griessmeier and Clausnitzer. ${ }^{1}$

$\$ 129$. Wax -Cetyl alcohol (\$14) molts at $48^{\circ}$ to $49^{\circ}$, and at $54^{\circ}$ is miscible with splinit of specific gravity 0.812 in all proportions. Cerotyl ulcumel melts hetween $79^{\circ}$ and $81^{\circ}$, melissyl alcolul at $85^{\circ}$. The latter is scarcely soluble in cold alcohol, benzene, petroleum spirit, or chloroform, but dissolves on boiling.

Lïnig and Kiesow found a substance in mealow-hay which they considered to be cerotene, or a 'paraffin' of the composition $\mathrm{C}_{20} \mathrm{H}_{42}{ }^{2}$

Hirschsohn has endeavoured to find distinctive characteristics for certain vegetable waxes that find application in the arts, ${ }^{3}$ with the follorving results:

Wex from Myricu quercifolia. - Soluble in 10 parts of boiling chloroform; the solution remained clear on cooling. Completely soluble in ether: 9.5 per cent. spirit dissolvel 16.16 per cent. at the ordinary temperature; petroleum spirit 5.3 to 62 per cent. The alcoholic solution gave a precipitate with alcoholic-ferric chloricie ( 1 in 10), which did not dissolve on warming.

Wax from another sp. of Myrica yielded 19.88 per cent. to alcohol, $68 \% 0$ per cent. to petroleum-spirit. Ferric chloride coloured the alcoholic solution black.

II ux from IIyricu cerifere yielded $7 \cdot 16$ per cent. to alcohol and 41.62 per cent. to petroleum spirit. Ferric chloride coloured the alcoholic solution brownish.

IV (u, from lihus sercerduned (Japan wax) resembled the three forergoing waxes in heing completely soluble in chloroform, but was only partially soluble in ether. Alcohol dissolved 14 per cent., petroleum spirit $69 \cdot 8$ per cent. Boiling with 10 parts of 10 per cent. alcoholic potash saponified it ; the soap wats completely solulle in 100 parts of water, whilst that from hecswax was only partially dissolved.

Wax from Aleurites laccifera. - The solution in chloroform became turbir on cooling; the addition of an alcoholic solution of acetate of lead to a similar solution of the wax caused a cloudiness on standing. Boiling alcohol left a pulverulent substance undissolved.

1 Ber. d. d. chem. Ges. xi. 292, 1878 (Journ. Chem. Soc. xxxiv. 449), and Zeitschr. f. anal. Chemie, xx. 58, 1881 (Journ. Chem. Soc. xl. 470).

${ }^{2}$ Ber. d. d. chem. Ges. vi. 500, 1874. For vegetable wax see also Ludwig, Archiv Pharm. [3], i. 193.

${ }^{3}$ Pharm. Journ, and Trans. [3], x. 749. 
Cerrecelice wear behaved similarly to chloroform and alcohol, but acetate of learl caused no cloudiness. It was partially soluble in ether; the ethereal solution became turbid on the addition of alcohol. Cold alcohol dissolved 3.2.5 per cent., petroleum-spirit 5.04 per cent.

Buhia une resembled carnauba wax in most of its properties, but the aldition of alcohol did not render the ethereal solution turbid. Cold alcohol dissolved $9 \cdot 7$ per cent., petroleum spirit $3 \cdot 32$ per cent.

For cerosin from the sugar-cane see Avequin, ${ }^{1}$ Dumas, ${ }^{2}$ and Lewy. $^{3}$

Wax may be recognised microchemicully as a solid exudation on the surfice of the cells, insoluble in witer and partially or wholly soluble in ether. (See also $\$ \$ 14,15,145$.

$\$ 130$. Oleic and Linoleic Acids-Oulemanst has adopted the following method for the estimation of oleic acid. The soap obtained ly saponifying about 10 grams of the fat with potash is decomposed with sulphuric acid; the fat-acils are washed with water, mixerl with excess of carbonate of soda and dried. The dry mass is exhausted with boiling alcohol, filtering whilst hot; to the alcoholic solution a little water and an excess of acetate of learl is added. The lead precipitate i, collected and dried ; and from a weigher portion the oleate of lear is extracted by boiling with ether: The oleic acid may lie calculated from the weight of the residue obtained by evaporating the ethereal solution.

Linoleic acid has not yet been isolated in a state of purity, as the free acid when exposed to the air oxidizes even more rityilly than the corresponling glyecryl compouml. Nulder estimated it approximately by separating it, together with oleic, palmitic and myristic acid, from the soap, dissolving the mixed fat-acids in alcohol, carefully evaporating, allowing the palmitic and myristic acids to crystallize out, and finally converting into the lead salts. Extraction with ether then remores oleate and linoleate of lead. By repeated evaporation in contact with air and re-solution in ether, the linoleate of lead gradually becomes insoluble, whilst oleate of lead does not change. ${ }^{5}$

1 Annales de Chimic et de Physique, lxxv. 218.

2 Ibid. 238 ; Annal. d. Chem. und Pharm. xxxvii. 170, 1841.

${ }^{3}$ Ibid. (New Series), xiii. 451.

4 Journ. f. prakt. Chem. xcix. 407, 1877.

${ }^{5}$ Compare Zeitschr. f. Chem. ii. 452, 1866 (Amer. Journ. Pharm, xl. 249) ; Schiiler, Jahresb. f. Pharm. 155, 1857. 
Of lunic acid, Oudemans observes that it is easily volatile with the rapour of water, which is not the case with myristic and oleic acill $(\$ 15)$. (Myristic and other fat-acids may however be distilled in vacuo.)

Oleic and steuric uciels may loe separated, according to David, ${ }^{1}$ by precipitation from alcoholic solution with glacial acetic acir (1 volume to 3 of 95 per cent. spirit). Oleic acid is not thrown out even by the adilition of $2 \cdot 2 \mathrm{cc}$. of a mixture of equal volumes of glacial acetic acid and water to 3 cc. of alcoholic solution. Under these circumstances stearic acid would be completely separated. (See $\$ 16,131$.

$\$ 131$. The separation of resins from fat-acids in soap-analysis has formed the subject of communications from Jean, ${ }^{2}$ Barfoed $^{3}$ and Gladding. ${ }^{4}$ The following particulars are taken from Barfoed:

a. Stearic and palmitic acids are soluble in hot 70 per cent. spirit, but separate out on standing twenty-four hours in a cool place. Coniferons resin (al)ictic acid) dissolves in 10 parts of cold spirit of the same strength, but is nrecipitated on adding water containing hydrochloric acid.

b. If a mixture of the same fat-acids with resin is boiled with 7 volumes of 30 per cent. spirit, to which 1 volume of an aqueons solution of carbonate of sorla ( 1 to 3) has been adiled, both resin and fat-acid dissolve. On cooling, the soap produced from the fat-acirls separates out, whilst the resinate of sorla remains in solution. The fat-acils may be obtained from the precipitate by filtering ofi, washing with alcoholic carhonate of soda solution and decomposing with hydrochloric acil, whilst the filtrate yichls the resin on treatment with an acid and shaking with ether.

c. On adding a solution of 1 part of chloride of calcium in 15 of 80 per cent. spirit to a hot solution in spirit of the same strength, and cooling, the calcium salts of hoth fat-acids seprarate out, whilst that of the resin acid remains in solution.

d. If stearic and palmitic acid and resin are disolved in soda, the solution evaporated to dryness, powhered and extracted with a

1 Zeitschr.f. anal. Chem. xviii. 622, 1879 (Journ. Chem. Soc, xxxiv. 1011).

2 Polyt. Journ, ccvii. 1873 (Joum. Chem. Soc. xxvi. 195).

3 Zeitschr. f. anal. Chem. xiv. 20, 1875 (Journ. Chem. Soc. xxix. 771). Compare also Gottlieb, Poliz. chem. Skizzen, Leipzig, 1853 ; and Sutherland, Chem. News, 1866, 185.

${ }^{4}$ Chem. News, xlv. 159, 1882. 
mixture of 1 volume of 98 per cent. spirit to 5 of ether, the resin compound alone passes into solution.

Giarding's method depends upon the insolubility of the silver salts of fat acids in ether, in which resinate of silver dissolves both easily and abundantly. For working details of the process reference must be made to the original paper.

If oleic acid is present, the separation by $a$ and $b$ will be inaccurate, as the resin will be contanimated with oleic acid. These methods might, however, he employed to separate oleic from stearic and palmitic acid in absence of resin. If only a small quantity of oleic acil is present, the resin may loe estimated lyy e. On decomposing the lime salt with an acid, a little oleic acid may be precipitated with the resin, hut the former remains suspended in the liquid, whilst the latter agghutinates into lumpes. After separating the resin, the oleic acid may be removed by shaking the liquid with ether.

The estimation of resin in the presence of oleic acil is, howerer, best accomplished by $d$. The mixture must be well dried and the ether-alcohol made from anhydious spirit and ether; 1 part hy weight of oleate of soda dissolves in 9:3.5, 1 of resinate of sodia in 7.9 parts of ether-alcohol.

\section{CHLOROPHYLL AND ALLIED SUBSTANCES.}

\$ 132. Chlorophy77.-Notwithstanding that the chemical nature of chlorophyll is still involverl in consideralle olscurity, I treater it in $\$ 20$ as a homogencous body, and at the same time pointed out that the chlorephyll-gramules observable mider the microsepre contain solid albuminous substances, starch, etc., in addition to chlorophyll.

It has been satisfactorily proved by Fremy ${ }^{1}$ and other's that chlorephyll may he segatrated by treatment with hychochloric acid and ether or benzene into two colouring matters, one of which, cyanophyll or phyllocyanin, is blue and soluble in ether and

${ }^{1}$ Comptes Rendus, 1. 405, 1860, 1xi. 188, 1865; Journ. f. pralt. Chem. lxxxvii. 319, 1862. See also Kromayer und Ludwig, Archiv d. I'harm. clvi. 164, 1861 ; Aé, Archiv d. Pharm. cxcii. 163, 1870; Kraus, 'Zur Kenntniss des Chlorophyllfarbstoffes,' Stuttgart, 1872; Wiesner, Chem. Centralblatt, 353, 1874; Jilhol, Comptes Rendus, lxi. 371, lxxix. 612, 1874; Hartsen, Annal. der Phys. cxlvi. 158, 1874; 'Neue chemische Untersuchungen,' Forstemann, 1875; Archiv d. Pharm. [3], vii. 136, 1875. 
benzene, the other, xanthophyll or phylloxanthin, yellow and insoluble.

These two substances exist, according to Fremy; sicle by side in chlorophyll. In this opinion, howerer, he is opluosed hy Pringsheim and others, ${ }^{1}$ who assert that they are only products of its decomposition. Sorby, again, does not consirler the existence of a chlorophyll, a phyllocymin, or phylloxanthin of definite chemical composition to he probable, but rather anticipates in them representatives of whole series of such compounds. Which of these opinions may be correct it is impossible at the present time to decide.

Whether the green colouring matters isolated by Filhol, Sachsse, ${ }^{2}$ and others, and said to differ spectrosenpically from ordinary chlorophyll, are of artificial origin, or whether they cin be produced by the plant itself; what relation probally exists between chlorophyll, 'purified chlorophyll,' or chlorophyllan anrl cyanophyll ; between xanthophyll, Hartsen's crystalline chrysophyll and Pringsheim's hypochlorin, are questions involved in still greater obscurity.

I restrict myself, therefore, here, to stating that 'chlorophyll' can be extracted from vegetable substances by boiling alcohol after exhaustion with water; a little, however, is retained by the residue insoluble in alcohol, as benzene still extracts a green colouring matter possewsing all the characters of chlorophyll. "

${ }^{1}$ Chem. Centralblatt, 299, 316, 331, 1880.

I Ibid. 121, 1878.

3 'That the chlorophyll exists in different states of combination is rendered probable by the fact that if vegetable substances are exhausted with petroleum spirit, benzene, ether, etc., in succession, each of these solvents removes chlorophyll, so that when petroleum spirit fails to dissolve more of it, appreciable quantities can still be extracted with benzene. This combination might be conceived to be simply mechanical, the protoplasm acting in a similar manner to hydrate of aluminium which, as is well-known, has the power of mechanically retaining chlorophyll. Thut the question may also be raised whether chlorophyll, which, in the opinion of many authors, possesses the characters of a weak acid, does not exist in plants in combination with different bases, and whether soluble (basic) allali-compounds, such as those artificially produced by Fremy, do not occur ready-formed in some plants. Every nne that has been frequently engaged in plant-analyses must have observed that well-filtered aqueous extracts of leaves, etc., when acidified and shaken with benzene or ether, yield to those solvents substances which on evaporation assume a green tinge and possess all the characteristic properties of chlorophyll. The assumption of the presence in the aqueous extract of a colourless chromogene converted during the successive operations into chlorophyll would, it is true, be possible, but I cannot as yet regard the first view as untenable. The whole subject, indeed, appears to me deserving of further investigation. 
After acidulating the aleoholic extract with hychochloric acid and diluting with a little water, the chlorophyil may he removed by shaking with benzene, xanthophyll remaining in the alcoholic licquicl. Under these circumstances, however, the chlorophyll is unfortunately always accompanied by fatty matter, etc.

133. Estimution of Chlorophyll.- Should it alpear desirahle to isoliate the chlorophyll for the purpose of weighing (cf. 37 ), achantage might possibly be taken of an olservation made by Sirchsse, ${ }^{1}$ viz, that a henzene solution of chlorophyll, on standing for a few days over metallic sodium, deposits a green mass capable of being filterel off from the golden-yellow solution. With the exception of its containing sodium, it agrees with chlorophyll in most of its more important characters, although, of course, it no longer represents that substance in an unaltered state. It dissolves in water, but is completely precipitated by sulphate of copper. The copper compound thus formed may, lowerer, be contaminated with carbonate. From it the colouring matter may le isolated by suspending in aleohol, passing a current of sulphuretterl hydrogen through the mixture, and eraporating the alcoholic filtrate. The residue may be weighed.

\$ 134. Erythrophyll, Chlorophyllan, ctc.-By first freeing grass from wax by treatment with ether, and then exhausting with alcohol, Hopre-Seyler² succeeded in isolating from unaltered chlornphyll a sreenish-white colouring matter, sparingly solulble in alcohol, erystallizing in four-sided plates, and alpyearing red ly transmitted light. This sulstance seems to be illentical with Bongarel's" erythrophyll. Hopre-seyler also separated a second substance, which was more easily soluble in hot aleohol, crystallizerl in necelles, and appeared dark green loy reflected, but hrown by transmitted, light. This bouly, which he terms chloronthyllun, agrees with the so-called chlorophyll in most of its properties, especially the spectrum, in which, however, the bands in the yellow and green are somewhat deeper than they are in the ordinary chlorophyll-spectrum (\$S 148 and 20). Hoppe-seyler thinks it poscible to make approximate estimations of chlorophyll by titration with spectroscupic culd-reaction. ${ }^{4}$ (Gautier has also

I Chem. Centralblatt, 121,$1878 ; 741,1880$.

2 Ber. d. d. chem. Ges. xii. 1555, 1879 ; xiii. 1244, 1880 (Journ. Chem. Soc. xxxviii. 53, 894).

${ }^{3}$ Bulletin de la Soc. Chim. xxvii. 442, 1879 (Journ. Chem. Soc. xxxii. 790).

${ }^{4}$ For the chlorophyll contained in certain Florider, see Pringsheim, loc. cit.; 
isolated from the leares of dicotylectonous flants a crystalline chlorophyll, ${ }^{1}$ which Hopese-Seyler suspects to be a mixtme of erythrophyll, chlorophyllan and wax. Giantier's analyses agree tolerally well with those of Hoppe-Seyler's chlorophyllan.

\$135. Xenthophyll (phylloxinthin), the yellow colouring matter. to which the antumnal tint of many leaves is ascriber, appear's to be insoluble in water, sparingly soluble in cold ether, petroleum spirit, or benzene. Alcohol dissolves it more readily, and it is soluble also in ether-alcohol. It may be obtained as a yellow gramular deposit contaminated with fatty matter by evilyorating an alcoholic extract (Berzelius). Dilute acid and dilute potash and ammonia are said to dissolve it but sparingly; the latter may, therefore, be employed to effect a partial separation from fat, etc. Sulphuric and hydrochloric acils colour it only faintly blue. If the alcoholic extract has been shaken with henzene, as directed in $\$ 132$, the residue ol,tained on evaporating the benzene solution may be purified lyy suitable treatment with the foregoing liquids, especially petroleum spinit. ${ }^{2}$ Hartsen thinks that his chrysophyll is possibly identical with phylloxanthin.

Irypochlorin.-Pringsheim ${ }^{3}$ states that hypochlorin separates from the chlorophyll granules in the form of yellow drops, which gradually become crystalline. It is insoluble in water, dilute acids and solutions of salts, but is easily dissolved by ether, benzene, bisulphide of carbon and ethereal oils. In concentrated and dilute alcohol it is at one time easily, at amother difficultly, soluble. Possibly it is volatile with the vapour of water.

It would be premature, on the basis of the facts that have as yet been established, to assert the identity of hylochlorin with xanthophyil ; the latter is certainly not identical with etiolin, the yellow coloning matter of etiolated plints, which in alcoholic solution assimes a green tinge, amel, after the linse of some time, is coloured blue by hydrochloric acid.

for the colouring matter of certain Algre, see Sachsse, 'Chem. und Phys. d. Farbstoffe, Kohlehydrate und Proteinstibstanzen,' Leipzig, 1877.

${ }^{1}$ Bulletin de Ia Soc. Chim, xxviii. 147, 1879 (Journ. Chem. Soc, xxxviii. 266).

2 For the relation that xanthophyll (etiolin) bears to chlorophyll, see Wiesner, Annal. d. Phys. und Chem. cliii. 622, 1874, and Chem. Centralblatt, 353, 1871; also 'Die Enstehung d. Chlorophyll's in der Pflanze,' Wien, Hölder, 1874.

${ }^{3}$ Chem. Centralblatt, 9, 27, 299, 316, 331, 1880. Compare also Jahresb.

f. Wissensch. Bot. 1874. Sec Quarterly Journ. Mic. Soc. 1881. 
Antheimethin, the yellow colouring mat ter in the peetats of many flower's, also differ's from ximthophyll. It ocents in tho vallieties, one of which (anthochlor, xanthein) is soluble in wate!', whilst the other (xanthin, lutein) is dissolved only hy ether and alewhol. The latter turns green and blue on the addition of hydrochloric acid.

\section{ETHEREAL OILS, VOLATILE ACIDS, ETC.}

$\$$ 136. Fistimution.- - The following estimations are taken from Osse, and given here in illustration of the methor recommended in $\$ 22$ :

I. 0.277 gram of oil of turpentine wis: diluted with petrolenm spirit to $10 \mathrm{cc}$; $1 \mathrm{cc}$. of the solution was evaporated as described in $\$ 22$. The weight of the resilue was 0.046 gran, which, after exposure to the air for 1 minute, decreased to 0.026 gram (difference, 0.0 .5 ) ; after a second minute's exposure, 0.020.5 gram (difference, $0.00 \%$.5) ; after a third, 0.015 sram (difference, 0.0035); after a fourth, 0.0135) (difference, 0.0035). The weight of the turpentine taken is calculater from the thind weighing, 0.020 .5 gram, to which is arked $2 \times 0.003 .5 \mathrm{gram}$, making a total of 0.027 .5 gram from $1 \mathrm{cc}$, or $0.275 \mathrm{gram}$ from $10 \mathrm{cc}$., instead of 0.277 gram. A second estimation gave 0.267 gram; mean 0.271 gram.

II. $0.1268 \mathrm{gram}$ of oil of lemon was diluted to $5 \mathrm{cc}$. witl petroleum spirit, and $1 \mathrm{cc}$. taken for evaporation.

$$
\begin{aligned}
& \text { 1st weighing }=0.0505 \\
& \text { 2nd ", }=0.0250 \text { diff. }=0.0255 . \\
& \text { 3rd },=0.0185, \quad=0.0065 . \\
& 4 \text { th }, \quad=0.0165, \quad=0.002 . \\
& \text { 5th }, \quad=0.014 .5,,=0.0(1) 2 .
\end{aligned}
$$

To the third weighing, 0.0185 gram, there is to be added $2 \times 0.002$ gram, giving a total of 0.0225 gram from 1 cc., or $0.1125 \mathrm{gram}$ from $5 \mathrm{cc}$, instead of $0.1268 \mathrm{gram}$. A repetition of the estinution gatre 0.1275 gram ; mean 0.1200 gram instend of $0.1268 \mathrm{gram}$.

III. 0.166 gram of oil of cimmamon diluted to $10 \mathrm{cc}$; $1 \mathrm{cc}$. taken for evaporation.

$$
\begin{aligned}
& \text { 1st weighing }=0.0317 \\
& \text { 2nd ," }=0.0171 \text { diff. }=0.0146 . \\
& \text { 3rd },=0.0163, \quad=0.0008 . \\
& \text { 4th },=0.0160, \quad=0.0003 . \\
& \text { 5th },=0.0157,=0.0003 .
\end{aligned}
$$

The third weighing, $0.0 \bar{i} 63$, represents the quantity of oil present, since no correction hats to he made, as the co-cllicient of 
evaporation is less than $0.001 .10 \mathrm{cc}$. would, therefore, contain 0.163 gram instead of 0.166 gram.

137. Estimation with Bisulphide of Carbon.-Instead of petrolemm spirit, Osse also trier bisulphide of earbon, as recommended by $\mathrm{Hager}^{1}$ for the yuantitative estimation of camphor, as well as mixtures of hoth liquids, without attaining hetter results. Ihe hils therefore decided in fitvour of petroleum spirit alone, which, however, should not contain any oils boiling at a temperature higher than $40^{\circ} \mathrm{C}$.

In analyzing vegetable sulstances such a petroleum spirit is preferatble to mixtures of the sime with bisulphide of cartion, ats it has a lesser solvent power for resins, etc. Ethereal oils may be extracter from their aqueous solutions by petrolem spirit, ${ }^{2}$ and may therefore be estimated in the aqueous portion of the distillate (\$24) by shaking with that solvent and evaporating a measured quantity of the solution after separation from the arpeous liquid. I hare also cmployed this method for cstimating the essential oil in the official aromatic waters.

$\S$ 138. Influence of Fixed Oil.-O Osse also made experiments with the view of ascertaining whether the presence of fixed oil conld affect the determination of ethereal oil, either by it:elf increasing in weight during the exposure to the air or hy preventing the eratporation of the ethereal oil at $110^{\circ} \mathrm{C}$. He found that a pretty close approximation to the truth might generally be arrivel at by deducting 0.09 to 0.1 per cent. from the weight of the fat after heating to $110^{\circ}$. No appreciable error would be caused by the oxidation of the fixed oil cluming the eralpmation of the petrolem spirit, as the presence of the latter, even in small quantities, prevents or delays such change.

0.875 gram olive oil was mixed with 0.051 gram oil of turpentine and heated for an hour to $110^{\circ} \mathrm{C}$. 'The weight of the residue was 0.45. gram, which did not alter if the heating were continued two hours longer.

1.46 .5 gram olive oil and $0.0 .575 \mathrm{gram}$ oil of cimmanon weighed after

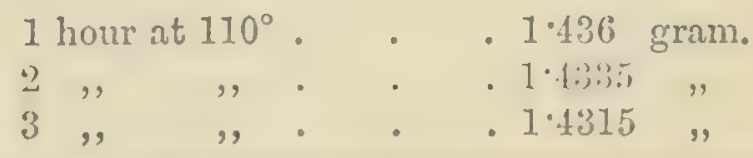

1 Pharm. Centralblatt, xiii. 449.

2 Dragendorff, paper read at a meeting of the German 'Apothekerverein' in Cologne, 1873; 'Ermittelung der Gifte,' 2nd ed., 46, 1876. 
I obtained similar results in experiments with cacao butter. Lesili could he almost completely freed from ethereal wil at $190^{\circ}$ to $110^{\circ}$, and it was only in the case of oils prone to widation, such as oil of cloves, that the residual resin was somewhat heavier than was expected. (See also \$146.)

Drying oils would, of course, increase very appreciably in weight. The evipolation and heating would have to be conducted in an atmosphere of carbonic acid (\$9).

The following experiment will serve as an example of the estimation of ethereal oil in a vegetable substance ${ }^{1}$

Five grams of sarvin leares were finely powdered and digested with 25 cc. of petroleum spirit; 1 cc. of the solution was eraporated. The residue weighed 0.0265 gram (corr.), which decreased to 0.0175 gram on heating to $110^{\circ}$. $1 \mathrm{cc}$. contained, therefore, 0.009 gram ethereal oil and 0.0175 gram resin, or 4.5 per cent. of ethereal oil and 8.75 per cent. of resin.

139. Sequidion of Tolutile Acils. - Angelic acid melts at $45^{\circ}$ and boils at $155^{\circ}$; methyl-crotonic acid at $65^{\circ}$ and $198^{\circ}$; crotonic acid, $16^{\circ}$ and $160.5^{\circ}$; capric, $30^{\circ}$ and $268^{\circ}$ to $270^{\circ}$; caprylic, $16^{\circ}$ to $165^{\circ}$ and $236^{\circ}$ to $237^{\circ}$; wnanthic boils at $223^{\circ}$ to $224^{\circ}$; caproic, $204^{\circ}$ to $206^{\circ}$; valerianic at $175^{\circ}$; trimethyl acetic, $163.7^{\circ}$ to $163.8^{\circ}$ (melts at $35.3^{\circ}$ to $355^{\circ}$ ); butyric at $163^{\circ}$; isobutyric, $154^{\circ}$; propionic, $140^{\circ}$; acetic, $118^{\circ}$ (solidifies at $167^{\circ}$ ); formic, $105^{\circ}$. This difference in the boiling points of fat-acids permits of their separation from one another by fractional distillation.

Fractional precipitation by salts of silver, etc., may also be forme neful in separating several of the foregoing volatile acids from one another; certain differences in the solubility of the salts can also sometimes be turned to account. Isobutyric acid, for instance, may be separated ly the former methorl, whilst the - fraring soluhility of the silver salt ( 1 in 100) enaliles nis to irolate acrylic, butyric, acetic acid, etc. The barium, calcium, and lead salts of some of the acids may be similarly employed; thus the birium salt of caprylic acirl is solul,le in 164 prirts of cold water ; 2 formate of calcium is insoluble in alsolnte alcohol; the lear salt dissolves in 6.j parts of water, whilst mereurons formater reyures.500 parts at the ordinary temperature. Thasice formate of learlohtamed

\footnotetext{
I See Osse's work previously referred to.

- For the estimation of valerianic acid, sec Zavatti and Sestini, Zeitschr. f. anal. Chemie, viii. $388,1869$.
} 
hy heating formic acirl with oxirle of learl is insolulle in alcohol, whilst basic acetate of lead prepared in a similar way is soluble (the heating should be contimed until the reation is allialine, but not longer, as otherwise an acetate insoluhle in alcohol might he produced). Basic butyrate of lead is also soluble in alcohol, but hoth the neutral and basie silt are greasy and springly soluhle in cold water. The same is the case with the ferric compound obtained by precipitating an alkaline butyrate with a forric salt (avoiding an excess). (See also \$ 34.)

$\$ 140$. Identification. - The suturating power of a fatty acid, a knowledge of which may be of assistance in identifying it, can be ascertained by titration with normal soda solution, or by estimating the sodium, barium, lear or silver contained in the corresponding salts. In certain cases a determination of the water of crystallization may prove useful.

By distilling the sorlinm salts with concentriterl sulphuric acid and alsolute alcohol, the ethyl-salts of the acids may he prepared; they are not unfrequently of characteristic odour (acetate, butyrate, valerianate of ethyl, ete.), by which, as also by their boiling points, they may sometimes be identified.

\$141. Optical Tests; Solubility in Alcohol.-For information with regard to the optical testing of rolatile oils sec Buignet, ${ }^{2}$ Franch,", Fliickiger, ${ }^{4}$ and Symes. ${ }^{5}$

I have ascertained that alcohol must possess the following strengths to be miscille with certain ethereal oils in erery propontion : oil of turpentine, 96 per cont.; fir, 96 per cont. ; juniper, 95 per cent.; savin, 92 per cent. ; lemons, 97 to 98 per cent. ; bergamot, 88 per cent. ; bitter orange, 98 per cent. : caraway, 88 per cent.; peppermint, 86 to 87 per cent. ; oleum menthæ crispx, 86 per cent.; lavender, 88 per cent. ; rosemary, 82 per cent. ; sweet marjoram, 82 per cent.; cajeput, 91 per cent. ; sage, 85 per cent.; cloves, 74 per cent. ; cinnamon, 78 per cent. ; cubebs, 90 per cent. ; fennel, 93 per cent. ; anise and rose, 93 to 94 per cent.; balm, 90

1 'Barfoed, Lehrbuch der organischen qual. Analyse,' Kopenhagen, 1880.

2.Journ. de Pharm. et de Chim. [3], xl. 252, 1862 (Amer. Journ. Pharm. xxxiv. 140).

:N. Tahrb. f. Pharm. xxvii. 131; xxix. 28. See also Mierzinski, 'Die Tabrik. iith. Oele,' Berlin, 1872, and Fliickiger's 'Pharm. Chemie,' Berlin, 1879, where the specific gravities of certain ethereal oils will also be found.

Archiv d. Pharm. [3], x. 193, 187t (Aner. Joum. Pharm. Ixxvi. 309).

5 Pharm. Journ. and Trans. [3], x. 207. 
per cent. These figures are true for fresh oils only, and for temperatures ranging from $20^{\circ}$ to $22^{\circ}{ }^{\circ}$

I fouml the following proportions of wealer alcohol necessury to form clear mixtures with the foregoing oils :

\begin{tabular}{|c|c|c|c|c|c|c|c|c|}
\hline \multirow{2}{*}{ Oil o } & \multirow{2}{*}{\multicolumn{2}{|c|}{$\begin{array}{l}\text { Cinnamon . } \\
\text { Cloves }\end{array}$}} & \multirow{2}{*}{. } & \multirow{2}{*}{$\begin{array}{l}\text { Vols. } \\
.3 \\
.2 \cdot 7\end{array}$} & \multicolumn{4}{|c|}{$\begin{array}{l}\text { Strength of Spirit. } \\
\text { f } 65 \text { per cent. (Tralles). }\end{array}$} \\
\hline & & & & &, & 60 & ", & ," \\
\hline ," & Sage. & . & . & . $3 \cdot 1$ & ", & 65 & $"$ & , \\
\hline , & Cajeput & . & . & .25 & $"$ & 65 & $"$ & $"$ \\
\hline , , & Marjoram & & . & . $1 \cdot 45$ & $"$ & 78 & $"$ & , \\
\hline , & Rosemary & & - & . 1.4 & , & 78 & $"$ & , \\
\hline , & Lavender & & . & $\cdot 2 \cdot 3$ & , & 65 & $"$ & , \\
\hline , & Mentha cr & rispar & . & $.2 \cdot 7$ & " & 65 & $"$ & , \\
\hline , & Peppermin & & . & $.2 \cdot 2$ & $"$ & 70 & $"$ & , \\
\hline , & Caraw:ty & & . & .0 .5 & " & $\therefore t$ & $"$ &,, \\
\hline , & Bitter orar & nge & . & .0 .9 & , & 94 & , & , \\
\hline , & Bergamut & & . & $.1 \cdot 15$ & , & is & , &, , \\
\hline , & Lemon (di & ist.) & . & $.4 \cdot 0$ &, & 91 & ", & , \\
\hline , &,$\quad$ (pr & ressed & & $.2 \cdot 8$ & ", & 92 & , & , \\
\hline , & Savin & . & . & $.1 \cdot 3$ & , & $\$ 0$ & $"$ & , \\
\hline ," & Juniper & . & . & $.3 \cdot 0$ & ", & 93 & $"$ & , \\
\hline , & Turpentin & & • & . 3.75 & " & 92 & & ", \\
\hline , & Fennel & . & • & $2 \cdot 9$ & , & 85 (at: & $21^{\circ} \mathrm{C}$.) & \\
\hline , & Anise & . & . & $.6 \cdot 3$ & , & 85 (at & $\left.17 \cdot 5^{\circ} \mathrm{C}.\right)$ & \\
\hline
\end{tabular}

\$142. Colour-reactions.-I have observed the following colourreactions with certain ethereal oils : ${ }^{2}$

Solution of bromine in chloroform ( 1 in 20), in the proportion of 10 to 1.) drops to one of oil, gives colourless mixtures with oils of turpentine, callaway, lemon, corianter ant cardamoms; yellow with bergimot, litter orange and neroli ; storly turning green with "loves, ginger, livender, cajeput, cascarilla ; slouly turniny greenishh., with ol. menth. crispe, oils of juniper, pepper and gialangal ; greenish-broun or broun with sweet marjoram, dill, cummin and valerian; a more or less fine rose, red, or reddish-violet tint is grathully produced by rosemary, fennel, anise, star-anise, cimmamon, nutmeg, thyme, pepuermint, myrth and parsley ; linumisleviolet with mace; blue or bluish-violet with cubebs, copaiba, amomum, laturel, sandal-wood and sweet Hag; wrenge with oil of worm-seed, oil of cedar-rwood; and with camphor.

${ }^{1}$ N. Tepert. f. Pharm, xxii, 1, 1872; Pharm. Journ. and 'Trans. [3], vi. 541 et sec. See also Godeffroy und Ledermann, Zeitschr. d. allgem. oestery. Apotheker Ver. xv. 381 et sery. ; Jahresb. f. Pharm. 394, 1877.

"Pharm. Journ. and Trans. [3], vi. 681; Archiv d. Pharm. [3], xii. 289. See also Hager, Pharm. Centralblatt, 137, 169, 195, 1870; and Flickigger, Sichweiz. Wochenschr. f. Pharm, 261, 1870. 
Impure Chloral Hydrate ${ }^{1}$ (2 drops to 1 of oil), resembles the foresoing reagent in the colouration it pnoduces with nnany oils. It differs, however, in its hehaviour to oil of lemon and hergamot, with which it assumes a reddish colour' cloves, which turns red on wanning; mace (fine rose-red), pepper (reddish-riolet), copraila (dark-green), valerian (stecnish), cummin (fine green), cimnamon (green, with violet margin), and myrrh (reddish-violet).

Alcoholic hydrochloric acid varies in its action with the amount of acid it contains. A dilute solution is to be preferred, as the colourations appear more slowly, but are purer. Dilute alcoholic hydrochloric aciel in the proprortion of $1510: 20$ drops to 1 of oil yields colourless mixtures with oil of turpentine, caraway, coriander, cardamoms (conc. acil, cherry-red), cloves, rosemary (conc. acid, deep cherry-red); yellow mixtures with bergamot. (conc. acid, orange to olive-green), mace (conc. acid, reidish-brown), dill (conc. acid, cherry-red), bitter orange, cummin (conc. acid, deep violet); brounish-red with oils of calscarilla, lavender, swect marjor:m, worm-seed, juniper (cone. acid, red); rwse to deep red or reddisterinlet with oils of culvels, pepper, copaiba, cctar wood, cinnamon, nutmeg, thyme, laturel, sweet-flag and myrrh ; red, tuming blue, with oil of peppermint.

Concentrated sulphuric acid (2 or 3 drops to 1 of oil) assumes with most cils a yellow colour, furning lnown, and frequently passing finally to a fine red. The latter colouration is observalule with oils of caraway, mentha crispa, sweet marjoram, star-anise, mace, rill, juniper, culches, copraiba, sage, winter-green, lavender, amonimn, cascarilla, mutmeg, thyne, samblal-worre, ferpermint, myrrh, and parsley. Oils of cardanoms, cloves, fennel, anise, cajeput and laurel produce a violet, cinnamon a green and blue colouration.

If a drop of the oil is mixed with 1 cc. of chloroform and 2 drops of conc. sulphuric acir atderl, similar colours are produced² and imparted to the chloroform.

1 Jehn was the first to observe that this reagent produced a currant-red colour with oil of peppermint. Its use is, however, open to objection, as it is not yet known what impurity causes the colouration, and it is therefore impossible to prepare a reagent of constant composition. If $100 \mathrm{cc}$. of alcohol are saturated with chlorine, mixed with sulphuric acid (after partially separating the hydrochloric acid by evaporation) and the resulting metachloral distilled, a very satisfactory reagent will be obtained, but its activity diminishes on keeping.

2 But not if petroleum spirit is used instead of chloroform. 
Fridule's lieugent' resembles sulphuric acirl in its action; lint the colours are purer and make their appearance more rapidly. Tery characteristic colour's are produced with some oils by sulphuric acid mixed with $\frac{1}{6}$ th of its rolume of a 5 per cent. aqueous solution of ferric chloride.

The oils should be dissolved in chloroform, in which the colouring matter is also soluble and thus seen to advantage.

Uils of pennyroyal, parsley, cortinder, fennel, anise, savin and turpentine canse no colueretion in the chloroform, eren after the lapse of some time; with oils of ledum and peppermint it assumes a icd tinge; with ledum-camphor, and oils of thyme, cijeput, gralungal, pepuer, cubebs, copaiba, juniper, viulet or thluist-rivlet; with serpyllum, sweet marjuram, roscminy, caraway, dill, nutrieg, cloves, worm-seed, cinnamon, green or bluish-green; with oil of bergamot, etc., olire-green.

Fuming nitric acid (5 drops to 1 of oil) gives specially characteristic colourations with oils of mace and nutmeg (blood-reel), cubebs (green), copailar (bluish-violet), gaultheria (cherry-red), cimnamon (carmine), myrrh (reddish-riolet), pimento (1,lood-red), and pennyroyal (violet).

Picric acid $(0.05$ gram to 5 to 6 drops of oil) is easily dissolved by some oils in the cold (caraway, cardamoms, cloves, rosemary, mentha crispa, sweet marjoram, anise, star-anise, dill, valerian, cummin, gaultheria, cinnamon, sweet flag); by others only on warming. Some of the solutions deposit crystals on standing (turpentine, lemon, bergimot, sweet marjoram, mace, dill, salangal, bitter orange, worn-seed, ralerian, cenlar-woorl, livender, cajeput, nutmeg, thyme, laurel and sandial-wood) ; other's gradually assume characteristic colourations: thus oil of mentha crispa becomes olive-green; cloves, sweet mirjoram, anise, star-anise, nntmeg, cinnanon, cummin, amomum and thyme, orange; fennel and myrrh, blond-red ; dill, citscarilla and galangal, brown; worn-seed, rechlish-brown; sweet-flag, deep brown; peplermint, deep grass green.

Fliickiger ${ }^{2}$ recomments acting upon a solution of the ethereal

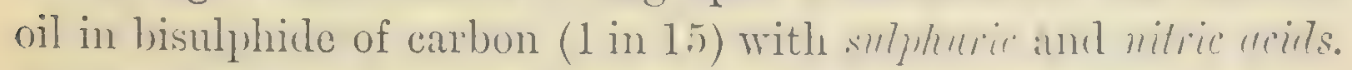
With oil of valerian and nitric acid (specific gravity, 1.2) he observed a green colouration of the bisulphide, and red of the aciel

$11 \mathrm{cc}$. conc. sulphuric acid with $0.01 \mathrm{gram}$ molybdate of soda.

${ }^{2}$ Schweiz. Wochenschr, f. Pharm. 261, 1870. 
layer; with a mixture of both acids, blue. Gurjun-balsam oil behaved similarly, and oil of cubcbs also turned blue with a mixture of both acids.

Solid ioctine acted to ethereal oils prouluees somewhat varying effects. With some oils, especially ter"penes of the formula $\mathrm{C}_{1,1} \mathrm{H}_{1 \dot{1}}$, the action is very energetic, and accompanied hy evolution of both light aml heat, whilst with other's nothing of the kind is olservahle. Chromic acid also reacts explosirely with certain oils. Some oxygenater oils (carrol of emmin oil) yield crystalline sulluhly liates when mixed with alcoholie solntion of sulphide of cmmonium, from which the oil may he separated ly decomposition with putash. ${ }^{1}$ If hydrochloric acid gas is passed through ethercal oils, crystalline or liquid hydivelulurutes are not unfrequently protueerl, which mily be characteristic of the oil actel upon. The $\mathrm{YOCl}$ group sometimes combines with hydrocarbons of the terpene series to form compounds of the formula $\mathrm{C}_{10} \mathrm{H}_{10} \mathrm{NOCl}$, and, accorting to Tilden, this reaction also maty be employed in dis. tinguishing ethereal oils. Tiliten ${ }^{2}$ ohtainerl crystalline compoumd: with French and American oil of turpentine, with oil of juniper, sage, caraway, bitter orange, bergamot, and lemon.

For the use of cohesion figures in identifying the various. ethereal oils see Kate Crane $^{3}$ and Tomlinson. ${ }^{4}$

\$ 143. Fractional distillation.-Linnemann's apparatus ${ }^{5}$ (fig. 6). is very servicealle in fractionally distilling ethereal oils (s: 30 ). $A$ is a tube of about $40 \mathrm{~cm}$. in length and $1 \mathrm{~cm}$. in diameter; at about $32 \mathrm{~cm}$. from one end a second tube, $B$, is fused on at an angle of about $80^{\circ}$, so that it can be commected with a condenser. Just beneath the junctiven, and at a distance of 20 and $2.5 \mathrm{~cm}$. from the end, bulbs are blown. At the upper end a thermometer is introduced, the bulb of which should be in C. In the lower part of the tube about 8 cup-shaped pieces of platinum gauze are inserted. These are intended to receive the condensing vapour from the linguils of higher boiling points and wathe ats it were, the vapour of more easily volatile liquids. Smaller apparatuses of 30 or $25 \mathrm{~cm}$. in height may be used for special purposes.

For distillation in a prevtiul vucum the apparatus represented in

${ }^{1}$ Compare Jahresb. f. Pharm. 468, 1867.

2 Pharm. Jomrn, and Trans. [3], viii. 188.

3 Pharm. Journ. and Trans. [3], v. 242.

${ }^{4}$ Ibid. v. $2 S 0$.

5 Annal. d. Chem. und Pharm. clx. 195, 1972. 
lig. 7 hits been recommended hy 'Thiriner. ${ }^{1}$ The methorl of using it is sufficiently intelligible from the figmre, and recpuires no special description.

$\$ 144$. Further Eruminution of Ethereul Oils.-For lletails of the analysis of ethereal oils by fractional clistillation, I refer to the examination of eucalyptus oil by Faust and Homeyer, ${ }^{2}$ of parsley

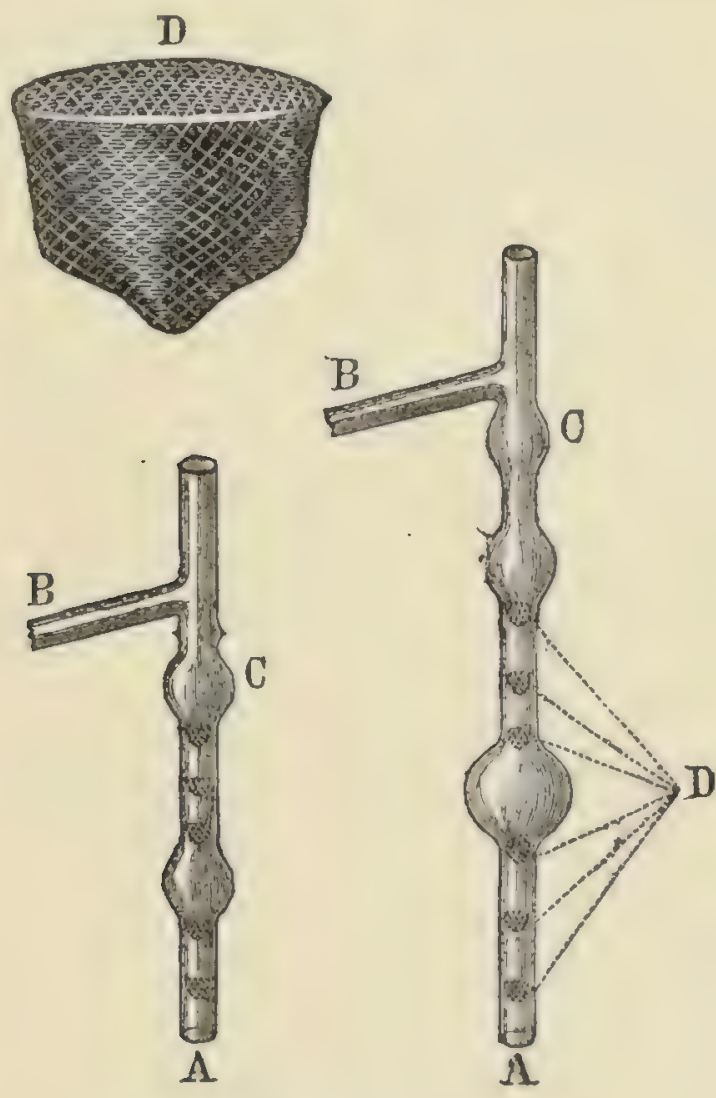

Fig. 6.

oil by Gerichten, ${ }^{3}$ and oil of sage by Mnir and Suguira. ${ }^{4}$ In the investigation of oil of dill by Nictzky, of oil of valerian by Bruylants (see below) and of arnica by sigel, the fatty aciuls rresent in the oil are includul. Jithereal salts were found hy

${ }^{1}$ Ber. d. d. chem. Ges. ix. 1868, 1876. See also Bevan, Chem. News, xxxviii. 183, 1879. $475)$.

Ber. d. d. chem. Ges. vii. 63 and 1429, 1874 (Journ. Chem. Soc. xxvii.

${ }^{3}$ Ber. d. d. chem. Ges. ix. 258 and 14\% $\%$, 1876 (Journ. Chem. Soc. xxx. 78.)

4 Pharm. Journ. and Trans. [3], vii. 265, 1876; viii. 191, 1877.

5 Archiv d. Pharm. [3], iv. 317, 1874 (Journ. Chem. Soc. xxvii. 892). $377)$.

'Annal d. Chem, und Pharm. clxx, 345, 1873 (Journ. Chem. Soc, xxvii. 
Renesse ${ }^{1}$ in the oil of Pastinaca satival and hy Möslinger² in that of Heracleum sphondylium.

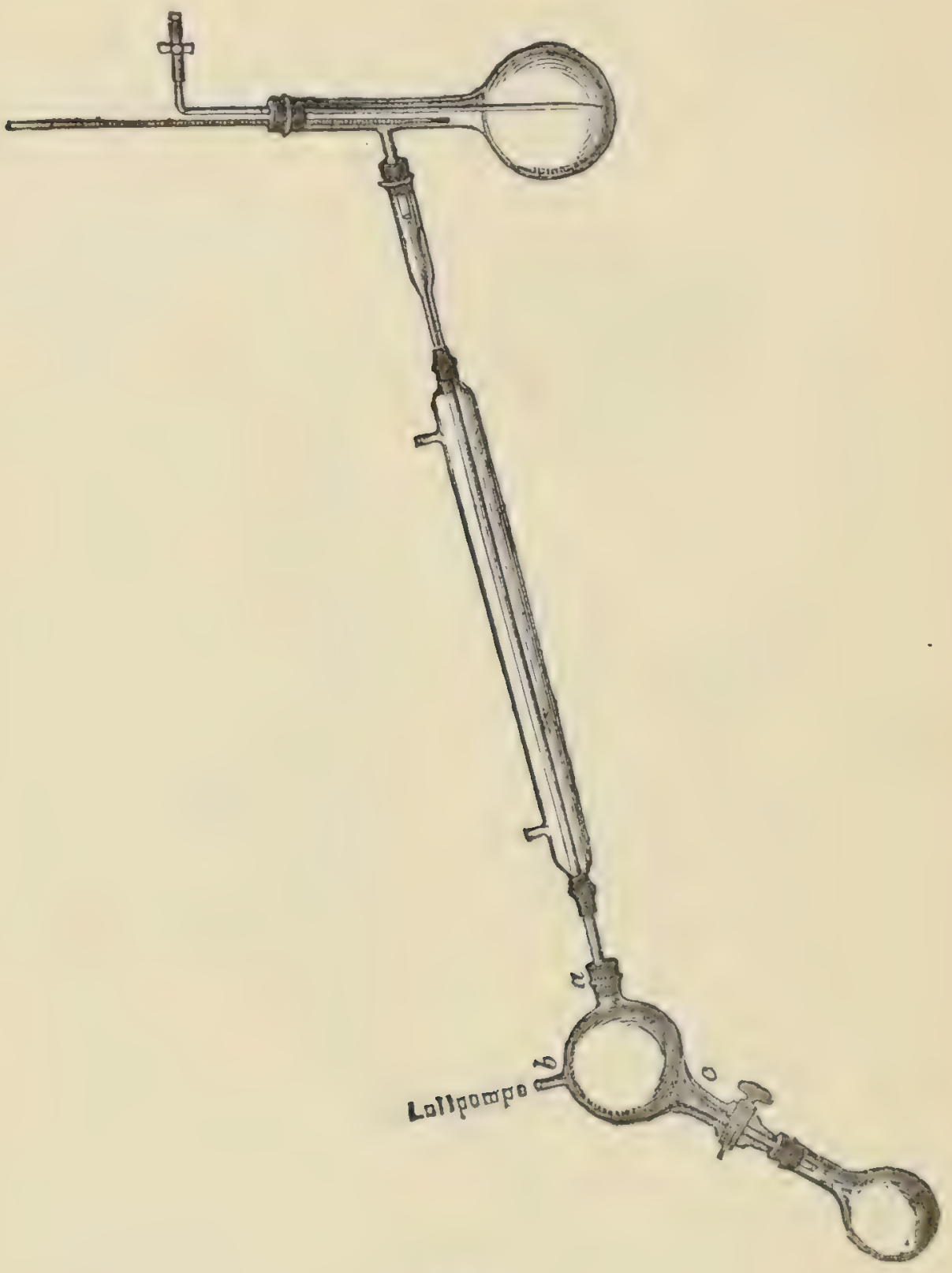

Fig. 7 .

Bruylants includerl aldehyclal substances in his examination of oil of tansy. ${ }^{3}$

1 Annal. d. Chem. und Pharm. clxi. 80 ; clxxi. 380 (Journ. Chem. Soc. xxvi. 642 ; xxvii. 1145).

2 Ber. d. d. chem. Ges. ix. 998. See also Zincke, Annal. d. Chem. und Pharm. clii. 1, 1869 ; Ber. d. d. chem. Ges. iv. 822, 1872. See also Gutzeit, ' Ueber das Vorkommen des Aethylalkohols im Pflanzenreiche,' Jena, Dufft, 1875 (Journ. Chem. Soc. xxviii. 1245).

${ }^{3}$ Ber. d. d. chem. Ges. xi. 449, 1878 (Journ. Chem. Soc. xxxiv. 157). 
RESINS, ANTHRLQUINONE-DERIVATIVES, BITER PRINCIILES, ETC'.

$\$ 145$. Pesin-ucids and the more importent methouls for therir selunil. tion.

With regard to the coniferous lesin-acids, the observations marle in $\$ 131$ may be supplemented by the following:

Abietic acid ${ }^{1}$ occurs in lamellar crystals, softening at $129^{\circ}$ and melting at $144^{\circ}$, soluble in alcohol and ether, and forming salts with most bases. Prolonged heating converts it into its anhydride, which is soluble in absolute alcohol, and was formerly known as pinic acid. The alcoholic solution of this substance yields no crystals on evaporation; it is gradually reconverted into abietic acid by the continued action of 70 per cent. alcohol.

Pimaric acid, from Pinus pinaster, forms granular crystalline masses melting at $149^{\circ}$, difficultly soluble in cold, but casily in hoiling alcohol, and soluble in ether. It resembles albietic acid in most of its properties, but differs in possessing a bitter taste.

For podocarpic acid see Oudemans ${ }^{2}$ gardenin, Stenhouse and Groves; ${ }^{3}$ phyllic acid, Bougarel.4

In isolating resin-acids one of the following methods will be frequently found successful :

a. Successive treatment uith spirit of different strengths, finally adding water and shaking with ether. It will be observed that resin acids are, as a rule, more casily solul)le in dilute spirit than resin-anhydrides, wax, etc. It was by this method that I succeeded in isolating mongumic acid from a bark imported from Madigascar. 5 The residue olstained on eraporating the ethereal extract was treated with 85 per cent. spirit, which left a wax undissolved. The spirituous solution was evaporated, and the

${ }^{1}$ Maly considered the acid formerly known as sylvic acid to be abietic; Duvernoy regards it as a modification of pimaric acid.

2 Ber. d. d. chem. Ges. vi. 1122; Annal. d. Chem. und Pharm. clxx. 213 (Journ. Chem. Soc. xxvii. 72).

3 Annal. d. Chem. und Pharm. cc. 311 (Journ. Chem. Soc. 1878).

4 Union Pharm. xviii. 262, 1877 (Journ. Chem. Soc. xxxii. 905). A substance similar to that clescribed under the above name is often met with in the analysis of herbaceous and leathery leaves. It is soluble in boiling alcohol, and separates from such solution, after the wax, on evaporating and cooling. It crystallizes in colourless scales, dissolves with difficulty in water and glycerin, is soluble in ether and chloroform, and also in warm potash, but precipitated by an excess of the latter.

${ }^{5}$ Pharm. Journ. and Trans. [3], ix. 816 (1870). 
mass treated with 50 per cent. spirit, in which a little brown. resin was found to he insoluble. To the alcoholic solution ether was added, and then sufficient water to cause separation. On well shilking the ether dissolved the whole of the mongrimic acid, the addition of a few drops of acetic or hydrochloric acid facilitating solution. The mongrumic acid was then ohtaned by eraporating the ethereal liquid.

b. Treatment of the mixed resins with a solution of soda or potash in dilute spirit, and recovery of the resin by the addition of acetic or hydrochloric acid and filtering, or, if very finely suspended, shaking with ether. I atopted this method in separating a resinacid from pæony-seed. ${ }^{1}$ The mixed resins were treated with boiling 8.5 per cent. spirit, and the liquid kept at $0^{\circ}$ for some time, to allow of the separation of a little resin anhydride that had been carried into solution. To the filtrate water was added till the spirit was reduced to a strength of 50 per cent., by which the resin was precipitated. The mass was then dissolved in a solution of soda in 50 per cent. spirit, again precipitated by the addition of acid, and finally decolourized in alcoholic solution by animal charcoal. In adopting this method the requisite strength of the spirit must be ascertained by preliminary experiments.

c. Treatment of the mixed resins with aqueous soda or potash.Any resin dissolved by the alkaline liquil may be generally recovered by acidification with acetic or hydrochloric acid. (Compare also $\$ 45) .^{2}$ It is, moreover, not unfrequently possible to uhtain sparingly soluble combinations of the resin with silver, lcarl, barium, calcium, etc., by adding salts of those metals to the solution of resinate of soda. This method is sometimes successful in cases of mixtures of several resin-acids or of a resin-acid with other resinous substances soluble in solution of soda. The resins present may be separated by fractional precipitation; or it may happen that only one is precipitated by the salt used, in which case, of

1 Archiv d. Pharm. [3], ix. 126, 1879 (Joum. Chem. Soc. xxxvi. 1043).

2 Chrysin, discovered by Piccard in the buds of the poplar (Ber, d. d. chem. Ges. vi. 884, 1873; Journ. Chem. Soc. xxvi. 1236) might be isolated by this method. It is precipitated yellow by acids, is somewhat sparingly soluble in ether and alcohol, and almost insoluble in petroleum, bisulphide of carbon, chloroform, and benzene. 'The latter, when warm, romores the so-called tectochrysin. An alcoholic solution of chrysin is coloured violet by ferricchloride, and gives with neutral acetate of lead a yellow precipitate, soluble in excess and in glacial acetic acid. 
course, the other's remain in solution; or finally a mixture may be precipitated, in which, however, a separation nilay he effecterl by treatment with solvents or by decomposition with carbonic aciel, etc. Hirschsohn met with a case of this clescription in his examination of gulbunum. ${ }^{1}$ The resinous portion of the drug was digested with soda, and to the solution chlorile of bariun was added till no further precinitate was produced. From the dried barium precipitate boiling alcohol dissolved a rather large amount, which separated argain on cooling, and contained only 1.07 per cent. of baryta. This portion must have been carried down either mechanically or in so loose a state of combination that boiling spirit sufficed to effect a decomposition into acid and hase. The alcoholic solution contained a second resin-acid, which was partly precipitated on passing carbonic acid through the liquirl, and partly, in masses of fibrous crystals resembling asbestos, on the subsequent aldition of water. Boiling 9.5 per cent. alcohol extracted it from the dried precipitate. The dilute alcoholic liquid, after treatment, with carbonic acid, was acidulated with hydrochloric acid, which threw down a flocenlent precipitate, soluble in ammonia. In addition to these three resins a fourth had escaped precipitation with chloride of barium. It could be separated by passing a current of carbonic acid through the alkaline solution.

In fractionally precipitating with silver or lead salts attention should be directed to the percentage of the metal and the melting point of the resin acid containerl in the precipitates. These two points are frequently of service in identifying acids.

d. The mixerl resins may finally be separated by dissolving them in spirit and fructionally precipituting with alcoholic solution of acetute of lead.

$\$ 146$. Resins and Gum-resins of Commerce.-The cxamination of conmercial resins and gum-resins, which generally consist of ethereal oil and various resinous substances frequently accompanicel by mucilage, sugur, etc., was at my suggestion undertaken and carried out by Hirschsohn. The following is an alstract of his results : ${ }^{2}$

${ }^{2}$ Pharm. Zeitschr. f. Russland, p. 225 ct seq., 1875 (Pharm. Journ. and Trans. [3], vii. 369 et seq.).

2 Pharm. Zeitschr. f. Russlandi, 225 et seq., 1875; 1 et seq., 1877. 'Beitrïge zur Chem. der wichtigerén Harze, Gummiharze und Balsame, Diss. Dorpat, 1877. Archiv d. Pharm. [3], x. 481 et seq. ; xi. 54 et seq. ; xiii. 288 et seq. Pharm. Journ. and Trans. viii. 389 et seq. 
1. For the determination of the chereal oil petroleum spirit may be used as a solvent. ${ }^{1}$ (See $\$ 9,22,23,138$.) Put, as elsewhere observed, part of the resin will also be dissolved; the residne obtained by evaporating at the ordinary temperature till the weight is constant must therefore he heated to $110^{\circ}$ or $120^{\circ}$, and the percentage of ethereal oil calculated from the loss. The amount of resin dissolved by the petroleum spirit, which is thus simultaneously ascertained, may be of use in estimating the value of different varieties of a resin or in detecting adulterations (in the case of copal, the better the quality of the resin the smaller the percentage of non-rolatile substances soluble in petroleum spirit). The mixture (of ethereal oil and resin) obtained by evaporating the petroleum-spinit solution frequently yields colour-reactions with the reagents mentioned in $\S 142$.

2. The residue insoluble in petroleum spirit is treated with ether and the substances dissolved estimated. It should be ascertained if ether takes up all the resin insoluble in petroleum spirit or if a further portion is removed by subsequent treatment with alcohol. Gum-resins will of course always leave a residue insoluble in ether, consisting of sugar, gum, salts, etc. The ethereal solution should be tested as to its miscibility with alcohol and the residue after craporation for colour-reactions as mentionel in 1.

3. The estimation of substances soluble in alcohol, both in the original drug and after treatment with ether, together with the qualitative cxamination of the solution, may likewise yield results of some value. In the case of gum-resins sugar is one of the principal substances extracted by alcohol. (See 50,83 et se $\% ; 200$ et seq.) It should be ascertained whether a turbidity is produced by adding ammonia, ether, or alcoholic solution of acetate of lead to the spirituous extract from the original resin.

4. If a gum-resin is under examination, water will remore gum (s. 73 et seq.; and 193 et seq.) and certain salts from the residue after treatment with alcohol. Note should be taken if a gum swelling, but not dissolving, in water is present. (See 103 and 193 et seq.)

5. Important results may also be oldtained by treating the original resin with chloroform, ether, or saturated aqueous solution

1 The resin should be rubbed down as fine as possible with powdered glass, and then macerated with petroleum spirit. 
of carbonate of socla. The latter may cause a colouration or take up cinnamic acirl (detecterl by the permanganate of potash reaction

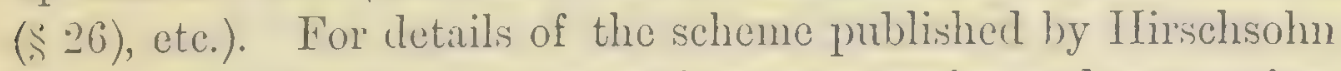
for the identification of the more important resins and gum-resins, reference must be midde to the original papers, etc., already quoted.

$\$ 147$. I'eonio-fluorescin.-If agitation with ether (\$44) removes any substance from solution in caustic alkali it should be ascertained whether the same can be extracted from a solution in a carbonated alkali. It wals found that pronio-fluorescin' ${ }^{1}$ could be ohtained much purer by using a carbonated rather than a caustic alkali, as the latter partially decomposes it, whilst the former does not. WThether the seeds of other plants contain in their testa a body allied to, or identical with, prennio-fluorescin, and possessing, therefore, a strong fluorescence in ethereal solution, is a matter for investigation.

Pronio-fluorescin is sparingly soluble in chloroform, benzene, and cold water (somewhat more freely in warm), but insolul)le in petroleum spirit. It is precipitated from a warm $\left(50^{\circ}\right)$ aqueous solution by gelatine, but not by acetate of lead or copper. On boiling with very dilute hydrochloric acid an intense green colour is developed, which can be extracted by agitation with ether, and changes to a reclish-violet in contact with acetate of soda. Its solution in very dilute lime-water, extremely weak ammonia, or even challiy spring-water, gradually assumes a fine red colour when exposed to the air.

\$ 148. Anthrutquinone-derivatives.-In treating the substances soluble in ether (\$S 36 and 46) with alkaline liquids, any change of colour, especially to red, should be carefully noted. If such is the case there is reason to take into consideration the possible presence of certain anthraquinone derivatives, such as chrysophanic acil, emodin, frangulic acid, alizarin, purpurin, etc. They are soluble in very dilute alliali, and are precipitated by hydrochloric acid from the deeply-coloured (generally red) solutions. It frequently happens that these borlies do not occur readyformed in the fresh sulsstances, or in material that has been carefully dried, hut are present in the form of ghlucosides ${ }^{2}$ (chrysophan, frangulin, ruberythric acid).

The following are some of the characteristic properties of the foregoing anthraquinone derivatives.

1 Archiv d. Pharm. [3], xiv. 412.

2 Compare my paper un Analyses of Rhubarb; Pharm. Zeitschr. f. Russland, 
Chrysophanic acid, as obtained from rhubarb, senna, ${ }^{1}$ etc., is almost insoluble in water, hut if in combination with a base it can be extracted from aqueous solution by arlding a strong aciel and shaking with ether. The solubility in alcohol and acetic acid varies directly with the strength of the solvent (1 cc. of $86 \mathrm{per}^{2}$ cent. alcohol dissolves 0.00017 gram at $20^{\circ} ; 1$ cc. glacial acetic acid dissolves 0.00046 gram).

Chrysophanic acid is sparingly soluble in petroleum spirit, lut is dissolved hy benzene and chloroform, especially when warm. It can be sublimed in flat rhombic prisms, which melt at $16: 2^{\circ}$, are yellow in colour, and strongly dichroic. It is easily dissolved by alkaline liquids, both aqueous and alcoholic, with production of a fine red colour, for particulars of the slectrum of which reference must be made to Kreussler's dissertation. This colouration in contact with alkali serves as a means of detecting chrysophanic acid and allied substances microscopically, but it is preferable to employ haryta- or lime-water, as with these bases compounds are formed which are insoluble in water.

Emodin agrees with chrysophanic acid in most of its properties, but may be distinguished by its insolubility in benzene, and greater solubility in ether and alcohol. It melts at $24.5^{\circ}$ to $250^{\circ}$, and crystallizes in needles from glacial acetic acid.

Eirythoretin and Pheeretin maty also be ohtained from rhubarh; they are both sparingly soluble in ether, freely in alcohol: the former is coloured purple-red by alkalies, the latter recldishbrown. ${ }^{2}$

Chrysarobin occurs in Goa powder ${ }^{3}$ it is soluble in boiling benzene, and forms a yellow solution with conc. sulphuric acirl (chrysophanic acid, red). It is not dissolved by dilute potash, but with concentrated it yielis a yellow solution with a green fluoresence. On shaking this liquirl with air for some time it turns red, and then deposits chrysophanic acid after acidulation.

65, 97, 1878 (Pharm. Journ. and Trans. [3]. viii. 826), and the continuation of the paper by Greenish, Pharm. Journ. and Trans. [3], ix. 933.

1 Compare Keussler, 'Unters. d. chrysophansiureart. Subst. der Sennes. blïtter und der Frangulinsiure,' Diss. Dorpat, 1879, and Pharm. Zeitschr. f. Russland, 257 et seq., 1878. See also Kubly, 'Ueber das wirksame Princip und einige andere Best. d. Sennesblätter,'Diss. Dorpat, 1865, and Pharm. Zeitschr. f. Russland, 429 et ser., 1866 (Amer. Journ. Pharm. xxxvi. 374).

${ }^{2}$ Compare Kubly, Pharm. Zeitschr. f. Russland, vi.6 6־3, 1867.

${ }^{3}$ Compare Liebermann und Seidler, Ber. d. d. chem. Ges. xi. 1603 (Journ. Chem. Soc. xxxvi. 326). 
Frangulic ucid can be obtained as an orange-red powder, consisting of small acicular (? hexagonal) crystals, which melt at $255^{\circ}$ and are not dichroic. At a temperature of $18^{\circ} 1 \mathrm{cc}$. of glacial acetic acil dissolves 0.00235 gram, 1 ce. of 36 per cent. spirit 0018 gram. The solutions of this substance in arueous or alcoholic alkalies are atso of a fine red colour, but prove to be somewhat different from those of chrysophanic acil when examined spectroscopically. Kenssler made the following ofservations with aqueous solutions in caustic potash, under the conditions mentioned in $§ 22$ :

$\begin{array}{lcccc} & \begin{array}{c}\text { Diminished } \\ \text { Intensity. }\end{array} & \begin{array}{c}\text { Undiminished } \\ \text { Intensity. }\end{array} & \begin{array}{c}\text { Diminished } \\ \text { Intensity. }\end{array} & \begin{array}{c}\text { No colours } \\ \text { observable. }\end{array} \\ \text { Chrysophanic acid } & .0^{\circ}-13^{\circ} & 13^{\circ}-34^{\circ} & 34^{\circ}-38^{\circ} & 48^{\circ} \text { to end. } \\ \text { Frangulic acid. } & \cdot 0^{\circ}-18^{\circ} & 18^{\circ}-38^{\circ} & \text { From } 38^{\circ} \text { to end gradual dimini- } \\ & & & & \text { tion of intensity to completedark- } \\ & & & & \text { ness. }\end{array}$

Compare Plate I., 1 and 2. ${ }^{1}$

Alizarin forms orange-red prisms, which are also almost insoluble in cold water, but soluble in alcohol, ether, benzene, and aqueous alkalies. They melt at $215^{\circ}$, and can be sublimed without decomposition. Its allaline solutions are violet, and yield 1)urple precipitates with salts of calcium, barium and learl. Togel states that the absorption-spectrum of a solution of alizarin in dilute alcoholic potash shows two dark bands, one of which is exactly divided by the line $d$, whilst the other begsins a little before $D$, and may be traced some distance past that line. (Compare Plate I., 3.) An alcoholic solution of alizarin, after adilition of ammonia, shows an absorption spectrum with a single illdefined band in the green between $D$ and $F$. (Plate I., 4).

Purpurin shows under the last-named conditions two ill-defined ahsorption bands to the right and left of $E$ (Plate I., 5), whilst an alcoholic solution mante allialine with potash absorbs dark hine powerfully, and shows two rery decp bands between $F$ and $E$, and $E$ and $D$, and one weak one at $d$. (Plate I., 6.) The difference between the spectra of alizarin and purpurin is so great thit an almixture of 1 jer cent. of the latter can be detected with facility in the former. The direct detection of small ynuntities of alizarin in purpurin is, however, impossible, but, according to

${ }^{1}$ For frangulin and frangulic acid, see also Faust, Archiv d. Pharm. clxxxvii. 8, 1869 (Pharm. Journ. and Trans. [3], iii. 1033).

2 'Prakt. Spektralanalyse,' Nördlingen, Beck, 1877 ; and Ber.d.d. chem. Ges. x. 157. See also ibid. 175 and 550 (Journ. Chem. Soc. vol. xxxii.). 
Schunk and Römer, indirect proof may he oftained ly taking advantage of the unequal affinity of the two sulsstances in alkaline solution for atmospheric oxygen. $A$ solution in caustic sorla is exposed to the air until it has become almost colourless and ceases to show the spectrum of purpurin after the addition of more alkali. By acidifying with hydrochloric acid and agitating with ether, the alizarin can be extracted, redissolved in alcoholic potash, and tested spectroscopically.

The scale on Plate I. corresponds to that described in \$20. I shall subsequently come to speak of the spectra of chlorophyll, hrmatoxylin, and some other colouring matters (partly taken from Vogel) also figured on the same plate.

Purpurin forms orange-red needles, melting at $253^{\circ}$, and soluble in boiling water and alcohol, but more freely so in ether, hisulphide of carbon, and boiling benzene. Aqueous solutions of alum dissolve it, forming yellow liquids with green fluorescence; with dilute aqueous alkalies purple solutions are obtained; it dissolves with difficulty in alcoholic soda, and is precipitated by lime- and baryta-water.

The erythrosclerotin, or sclererythrin, isolated by Porlwissotzky and myself ${ }^{2}$ from ergot is, I think, possibly identical with, or closely allied to, purpurin.

Alizarin is generally considered to be produced from a glucoside, melerythric acid, and not to occur ready-formed in the malder plant; ruberythric acid is possibly itself a product of the decomposition of rubian. The latter is said to be soluble in hot water and in alcohol; from aqueous solution it is not precipitater by solution of alum or lead salts, but probably it has not yet been obtained in a state of purity. Boiling solutions of alkalics dissolve rubian with production of a red colouration and formation of alizarin, rubiretin, rerantin, ruliadin and sugar. Boiling dilute acids induce a similar decomposition, whilst with cold dilute alkali it yields rubianic acid.

liuberythric acid is freely soluble in hot water, in alcohol, and in ether. It crystallizes in yellow silky prisms, and forms bloodred solutions with alkalies. Basic acetate of learl precipitates it as a vermilion-red powder. Boiling with dilute acid resolves it

${ }^{1}$ Ber. d. d. chem. Ges. x. 175, 1877 (Journ. Chem. Soc. xxxi. 664).

2 Archiv f. exper. Patholog. und Pharmakologie, vi. 154, 1876 (Pharm. Journ. and Trans. [3], vi. 1001, viii. 106). Sitz-Ber. d. Dorpater Naturf.Ges., $392,1877$. 
into sugar and alizarin. According to Stenhouse, morindin is identical with ruberythric acid, morindon with alizarin (which is doubted by Stein), and munjestin with purpurin.

With regard to the constituents of madder that have been here mentioned, and some others that accompany or can be obtained from them, I refer in particular to the investigations of Schunk, Rochleder, Stenhouse and others, for an account of which Gmelin's 'Chemistry' may be consulted.

For rhamnin, xunthorhannin, chrysorhumnin, and their allies, see Fleury and Biswanger, ${ }^{1}$ Ortlieb, Liebermann, and Hörmann. ${ }^{2}$

Rhinacanthin, discovered by Liborius in Rhinacanthus communis, appears to possess some of the properties common to anthraquinone-derivatives. ${ }^{3}$ It occurs in the intercellular spaces in the rootbark, is soluble in ether, alcohol and dilute alkali, but insoluble in pure and acidulated water. Alkalies produce a deep red colouration, which is discharged or changed to greenish by acids.

Alkiannin is insoluble in water, but yields fine red solutions with ether, alcohol, bisulphide of carbon, fixed and ethereal oils. The spectrum is figured on Plate I., 11. Alkannin is uncrystallizable, dissolves in concentrated sulphuric acid (violet), in alkalies (blue), and in alcoholic ammonia.

Bixin behaves similarly to water, alcohol and ether. It dissolves in aqueous alkalies also (but the compounds thus produced are sparingly soluble in alcohol), and is coloured blue by concentrated sulphuric acid. ${ }^{4}$

Curcumin ${ }^{5}$ is also insoluble in water, but is dissolved yellow by ether and alcohol, brown by alkalies. Boracic acid colour's it red, changing to dark blue on the addition of an alkali. (For its spectrum see Plate I., 12.)

For cambogic acid, which is dissolved yellow by concentrated sulphuric acid, see Johnstone ${ }^{6}$ and Büchner. ${ }^{7}$

${ }^{1}$ Journ. de Pharm. et de Chim. xxvii. 666 ; Repert. f. Pharm. civ. 54.

2 Bull. de la Soc. de Mulhouse, xxx. 16 ; Ber. d. d. chem. Ges. xi. 1618. See also Lefort und Stein, Jahresb. f. Pharm. 145, 1867; 127, 1868; 123, 1869 (Journ. Chem. Soc. xxxvi.).

${ }^{3}$ Sitz-Ber. d. Dorpater Naturf, Ges. 277, 1879 (Pharm. Journ. and Trans. [3], ix. 162).

${ }^{4}$ Compare Stein, Chem. Centralblatt, 939, $186 \%$.

${ }^{5}$ See Linda und Daube, Journ. f. prakt. Chem. ciii. 474, and New Series, ii. 86, 1870 (Journ. Chem. Soc. xxiv. 152).

${ }^{6}$ Phil. Mag. 281, 1839.

7 Annal. d. Chem, und Pharm. xlv. 72, 1843 (Amer. Journ. Pharm. xv. 129). 


\section{For grönhartin or taigusic acid see Stein and Arnaudson. ${ }^{\text {I }}$}

Pipitzahoic acid also probably belongs to this group. ${ }^{2}$

$\S 149$. Detection of Anthraquinone-derivatives.-To prove that these substances, or others that hare been separated with resins, or resins themselves, are entitled to be considered as anthracenederivatives, they may be heated dry with zine dust in a glass tube in the same way as in ultimate analysis (i.e., a mixture of zinc dust with the substance at the end of the tube, followed by a layer of pure zinc), the products of decomposition being led into a cooled receiver. ${ }^{3}$ Anthracene and methylanthracene should be specially looked for; both of them are obtained in the form of crystalline sublimates. The former melts at $213^{\circ}$, possesses a blue fluorescence, is insoluble in water, sparingly soluble in alcohol, but more easily in ether, benzene and bisulphide of carbon. When dissolved in benzene it forms a compound with picric acid, which separates out in red crystals. The action of bichromate of potash and sulphuric acid converts it into anthraquinone. If anthracene alone is obtained, a derivative of that body would be indicated; methylanthracene alone or together with anthracene would arouse suspicion of the presence of a methylanthracene derivative. The latter possesses, like anthracene, a powerful blue fluorescence; it melts at $200^{\circ}$, forms with picric acid a compound crystallizing in dark red needles, yields with bichromate of potash, sulphuric and glacial acetic acids, anthraquinone-carbonic acirl, which is sparingly soluble in excess of potash and melts at $278^{\circ}$. Methylanthracene is only slightly soluble in ether, alcohol and glacial acetic acid, but freely in bisulphide of carbon and benzene.

$\$ 150$. Homatoxylin, etc.-Treatment with alkali also reveals the presence of hematoxylin ; but it must be observerl that this substance can be removed by pure or acidulated water from the evaporation-residue of the ethereal extract (\$3\&).4 With alkalies

'Journ. f. prakt. Chem. xcix. 1 ; Jahresb. f. Pharm. 165, is66.

2 Compare Weld, Annal. d. Chem. und Pharm. xcv. 188, 1855 (Amer. Journ. Pharm. xxx. 446).

${ }^{3}$ Compare Liebermann und Graebe, Ber d. d. chem, Ges. i. 49, 104, 1868 (Journ. Chem. Soc. xxт. 139).

${ }^{4}$ The extraction of hematoxylin with ether free from alcohol and water is generally incomplete, as it is somewhat sparingly soluble in that menstruum ; a part, therefore, will probably be removed on subsequently treating with alcohol. 
hilmitoxylin proluces a heantiful violet colour; it reluces allsaline copper-solution as well as silts of silver and mereury, and camnot be sublimed.

The best methor of extracting hematoxylin from regetable sulustances (such as logwood) is to macerate first with water containing a little sulphurons acid and then exhanst with ether saturated with water. (For the spectrum, see Plite I., 7 and 8.)

Bruillin resembles hematoxylin, and, like it, is solul,le in ether, alcohol and water. Alkalies produce a carmine-red colouration, which disapnear's when the licuid is warmed with zinc dust, but returns on exposure to the air. The spectrum is shown on Plate I., 9. On boiling with peroxide of lead and water a strong fluorescence is developed.

S'antulin is soluble in ether (yellow), and alcohol (red), but not in pure water. With dilute potash it yields a violet coloured solution, from which chloride of barium precipitates a violet 1arium-compound. It differ's from alizarin in its melting-point $\left(104^{\circ}\right.$ ), in not sulliming, and in yielding no anthracene. (For spectrum see Plate I., 10.)

\$151. Detortion and Estimation of Gallic Acil, Cutechin, etc.-In addition to the foregoing sulstances gallic acirl, catechin and lyrocatechin are extracted by water from the evaporation-resirlue of the ethereal cxtract (\$38). They are deposited in acicular crystals on evaporating an aqueous solution over sulphuric acid at the ordinary temperature, or may be remored hy shaking with ether, or preferably, acetic ether. If in sufficient ruantity, gallic acid or catechin may be purifich liy re-erystallization from hoiling water, the former being soluble in 3 parts of boiling and about 100 of cold water, the latter in 4 and 16,000 respectively. Heated hetween watch-ghlasses, gallic acid yields a white sulnlimate of pyrosallol, together with hlack non-rolatile melangallic acil. Catechin yields pyrocatechin. (Cf. $\$ \S 38$ and 42.) Conc. sulphuric acid dissolves gallie acil colourless in the cold, hut on warming the liquid heeomes wine-red and crimson. The arlition of water now canses the separation of rufigallic acirl, which is coloured transient blue loy conce potash. If only traces of the latter acid are present they may be extracterl, according to Barfoed, ${ }^{1}$ from the arpueons liquirl by agitation with acetie ether containing spirit, and the residue olitained on crapnation treated with potash.

${ }^{1}$ Barfoed, Lehrb. d. org. qual. Analyse. Lief, 1, 63. 
Under the influence of alkalies gallie acid turns rapidly green, red and reddish-l)rown. Like tamic acid, it yields inky mixtures with ferrous and ferric salts, but is not precipitated by gelatine from aqueous solution. It recluces nitrate of silver and allialinecopper solution. Gallic acid is precipitated by acetate of lead, and is partially removed from aqueous solution hy digestion with the hyclrate of that metal. The precipitates are, howerer, neither quite insoluble nor of constant composition, so that they camnot be recommended as a means of estimating gallic acid except under certain conditions. If a solution of hyclrate of lead in potash is boiled with very dilute solution of gallic acil, a rose or violet colour is developed, which is persistent for some time, especially in the presence of alcohol (Klunge).

Catechin colours conc. sulphuric acid, on warming, purple, changing to black. Solutions in aqueous potash, ammonia or carbonated alkalies gradually absorb oxygen and become rose-red, scarlet, passing to dark red and finally black. The alkaline solution produces at first no colouration with ferrous sulphate, but a green tinge is subsequently developed; acetate of socla is said to turn the colourless mixture instantly violet-blue, and cause the separation of a bluish-black precipitate. A very small quantity of ferric chloride colours solutions of catechin green, but excess causes decolourization and formation of a brown precipitate. Like gallic acid, catechin does not precipitate gelatine, and acts as a reducing agent. The lead salt obtained by precipitation is not suited for the quantitative determination of citechin, as it casily decomposes (turning red on exposure to the air).

A better method for estimating both catechin and gallic acid consists in agitating with ether or acetic ether and weighing the evaporation-residuc, or preferahly, titrating it with permanganate of potash. (Cf. \$52, VII. ; \$5 53 and 165.)

Pyrocatechin is also casily soluble in alcohol, melts at $112^{\circ}$, and can be sublimer. Exposed to the air in alkaline solntion it turns green and black; ferroso-ferric salts colomr it dark green. It rerluces gold and silver salts and alkaline-copper solution. With acetate of lead a precipitate is formed, which is soluble in acetic acid; solution of gelatine is not precipitated.

$\$ 152$. Quercitrin, Quecetin, ctc-Duercitrin and quercetin, if present in the material under examination, might be partially extracted with ether (\$36), by which, howerer, they are not very 
easily dissolved. They are both very slightly soluble in cold water; quercetin even in hot. They dissolve in the fixed and rolatile allkalies, and in alcohol, crystallizing from the latter in yellow needles. Ferric chloride colours the alcoholic solutions green (quercetin red, on warming); acetate of lead produces orange-red and brick-red precipitates respectively. Both quercitrin and quercetin reduce solutions of gold and silver salts, and also alkaline-copper solution after prolonged boiling. Heating with mineral acids resolves quercitrin into isodulcite and quercetin (Lüwe contradicts this, and asserts that water alone is given off). It may be extracted from aqueous solution by agitation with amylic alcohol. ${ }^{1}$ It melts at $130^{\circ}$ to $133^{\circ}$, and is insoluble in benzene, petroleum spirit, chloroform, and bisulphicle of carbon.

In close relation to, but not identical with, quercitrin or rutin stands the violaquercitrin recently isolated by Mandelin ${ }^{2}$ from Viola tricolor. It was deposited in yellow acicular crystals on saturating the aqueous solution with benzene. Boiling with dilute acids lecomposed it with production of glucose, quercetin, and a third body as yet not further investigated.

A body allied to quercetin appears to occur in the rhizome of Podophyllum peltatum. ${ }^{3}$ According to Podwissotzky, the other important constituents of this drug are podophyllotoxin, which melts at $115^{\circ}$ to $120^{\circ}$, is sparingly soluble in water, soluble in ether and chloroform, and precipitated from chloroformic solution by petroleum spirit; picropodophyllin, which is easily crystallizable, and soluble in 95 per cent. spirit, ether and chloroform, but insoluble in milk of lime and ammonia ; and prodophyllic acid.

Gentisin is said to require 2,000 parts of cold ether for solution, and must therefore be looked for in the alcoholic extract. It forms pale yellow silky needles, which can be partially sublimed without decomposition, requires 5,000 parts of cold, 3,850 of hot water, 455 of cold and 625 of hot absolute alcohol for solution. Ferric

'Compare Johanson, 'Zur Kenntniss einzelner chemischer Bestandtheile der Weiden,' etc. Archiv d. Pharm. [3], xiii. 110, 1878 (Pharm. Journ. and Trans. [3], viii. 69). For Löwe's paper see Zeitschr. f. anal. Chemie, xiv. 233, 1875 (Journ. Chem. Soc. xxix, 108). See also Liebermann and Ham. burger, Ber. d. d. chem. Ges. xii. 1178, 1879 (Journ. Chem. Soc. xxxvi, 944).

2 Sitz-Ber. d. Dorpater Naturforscher, Ges. 1882, p. 343.

${ }^{3}$ Compare Podwissotzky, Archiv f. Pharm. und exper. Pathologie, 29, 1880 (Pharm. Journ. and Trans. [3], xii. 217, 1011). 
salts precipitate it reddish-hrown from alcoholic solution. Fused with potash it decomposes, yichling acetic acid, phloroglicin and gentisic acid. The latter is isomeric with protocatechuic acid (\$42), and is coloured deep bhe hy ferric chloride. An alkaline solution of gentisic acid becomes red on exposure to the air'; when heated it yields hydroquinone, melting at $169^{\circ} .1$

For thujin, see Rochleder and Kawalier ; ${ }^{2}$ for rutin (insoluble in ether), and robinin, Zwenger and Dronke ; ${ }^{3}$ for luteolin, Moldenhauer, ${ }^{4}$ Schïtzenberger, Paraf and Rochleder. ${ }^{5}$

\$153. Julupin and Allied Substances.-To the group of substances that are soluble in ether, and can be removed by dilute alkali, but not by pure water, from the evaporation-residue of the ethereal extract, there belong further some glucosidal resins (\$58), of which the julupin of Ipomoa orizabensis may be taken as a representative.

Jalapin is readily dissolved by alcohol, and in alcoholic solution is resolved by hydrochloric acid into sugar and jalapinal; the latter is soluble in ether, but only sparingly soluble in water. The action of aqueous solution of sola converts jalapin into jalapic acid; the latter, after liberation with a strong acid, is soluble in water, but only sparingly soluble in ether.

Jalapinol appears to occur ready-formed in scammony, and possibly in scammony-root also.

Tempicin of Tampico-jalap reseml,les jalapin in most of its properties, but differs in composition. ${ }^{\circ}$ The same may be said of

1 Compare Hlasiwetz and Habermann, Annal. der Chem. und Pharm. clxxv. 62 ; Ber. d. d. chem. Ges. viii. 684 (Journ. Chem. Soc. xxviii. 572). The actual gentian-bitter is not identical with gentisin. The former is easily soluble in water, is not thrown down by neutral acetate of lead, but precipitated by ammoniacal acetate and liberated from the precipitate hy sulphuretted hydrogen. It can be extracted with difficulty by agitation with benzene, but with ease by chloroform ; ferric chloride does not precipitate it. It is sparingly soluble in ether, and is said to dissolve in conc. sulphuric acid with red colouration, and to be decomposed by dilute sulphuric acid with production of sugar. (Compare Kromayer, loc. cit.).

${ }^{2}$ Chem. Centralblatt, 449, 1858.

3 Ibid. 766, 1862. Annal. d. Chem, und Pharm. Supplement, i. 257 (Amer. Journ. Pharm. xxxv. 32).

4 Annal. d. Chem. und Pharm. c. 180, 1856.

${ }^{5}$ Comptes Rendus, lii. 92, 1861; Journ. f. prakt. Chemie, xcix. 433, 1867.

${ }^{6}$ Compare Spirgatis, N. Repert. f. Pharm. xix.452, 1870 ; Köhler und Zwicke, N. Jahrb. f. Pharm. xxxii. 1, 1869 (Pharm. Journ. and Trans. [3], i. 444). 
the convolvulin of true jaliep, which is distinguished by its insolubility in ether, and of turpethin, ${ }^{1}$ which is insoluble in ether, but, differs in composition from convolvulin.

All these gilucosidal resins dissolve in conc. sulphuric acid with purple colour.

\$15. Estimation of Sintonin.-The following method may he arlopted for the quantitative estimation of santonin (5.5) in worm-seed : ${ }^{3}$

15 to 20 grams of the material are digested on a water-hath for 2 hours with 15 to $20 \mathrm{cc}$. of a 10 per cent. caustic sodir solution diluted with about $200 \mathrm{cc}$. of water, filtered and washed. The filtrate and washings are concentrated to 30 or $10 \mathrm{cc}$, cooled, nentralized with hydrochloric acid, and at once filtered. The precipitate is washed first with 15 to $20 \mathrm{cc}$. of water, and then with an 8 per cent. soda solution, and any crystals of santonin that may thus be separated subsequently added to the principal portion. The filtrate from the hydrochloric acid precipitate is acidified and shaken with 3 successive portions of 15 to $20 \mathrm{cc}$. of chloroform. The chloroformic solutions are washed with water and evaporated to dryness; the residue is dissolved in the smallest possible quantity of sola, filtered if necessary (washing the insoluble portion with a very little water), and acidified with hydrochloric acid. After standing for 2 or 3 days in a cool place the santonin is filtered off, washed with 10 to $15 \mathrm{cc}$. of 8 per cent. solution of sorla, dried at $110^{\circ}$, and weighed. A col'rection must be made of 0.002 gram for every $10 \mathrm{cc}$. of motherliquor, and $0.003 \mathrm{gram}$ for every $10^{\circ} \mathrm{cc}$. of washings.

Sintonin can also be extracted hy boiling with milk of lime. 15 to 20 grams of worm-seed are digesterl with $200 \mathrm{cc}$. of milk of lime diluted with $400 \mathrm{cc}$. of water on the water-bath for 6 hours, boiler for half an hour and filtered. The residue is again boiled with $10 \mathrm{cc}$. of milk of lime diluted with $200 \mathrm{cc}$. of water. The filtered decoctions and washings are evaporated to ahout $30 \mathrm{cc}$, excess of hydrochloric acid added, and at once filtered (the precipitate being treated with soda as before). The filtrate must stand for 5 or 6 days in a cool place, when the santonin may be collecter and washerl with sodit-solntion. The small amomut that

${ }^{1}$ N. Repert. f. Pharm. xiii. 97, 1864 (Amer. Journ. Pharm, xxxi. 374).

"Compare Archiv d. Pharm. [3], xiii. 306, 1878 (Amer. Journ. Pharm. 1. 296). 
remains dissolved in the mother-liquor and washings may be removed by shaking with chloroform.

Santonin is almost insoluble in cold water, but is rissolverl hy ether, allialies and boiling alcohol. It melts at $169^{\circ}$, turns yellow on exposure to light, produces no colouration when dissolved in conc. sulphuric acid, but colours alcoholic potash transiently carmine. If a solution of santonin in sulphuric acirl is heated to $150^{\circ}$, and a drop of a dilute solution of ferric chloride subsequently added, the mixture assumes a red tinge, gradually changing to violet.

\$55. Picrotorin, etc-Amongst other substances to be looked for in the ethereal extract the following may be mentioned:

Picrotoxin.-Soluble in 150 parts of cold, and 25 of boiling water, as well as in alcohol, chloroform, and amylic alcohol. From aqueous solution (\$5.5) it may be extracted by the last two solvents, and also by ether, but not hy benzene. ${ }^{1}$ It crystallizes with facility from water and alcohol in four-sided prisms, reduces alkaline copper solution, and dissolves yellow in conc. sulphuric acid. If dry picrotoxin is mixed with 6 parts of nitrate of potash, and sufficient conc. sulphuric acid to form a pasty mass, a brickred colour is developed on adding a solution of soda ( 1 to 3 ) in excess. The reaction succeeds better if the picrotoxin is moistened with nitric acid, dried on the water-bath, mixed with a very little sulphuric acid, and then with solution of soda.

Digitulin.-According to Schmiedeberg, ${ }^{2}$ this glucoside is insoluble in water and dilute soda, but soluble in warm dilute acetic acid. Alcohol, alone or mixed with chloroform, dissolves it easily, but in pure cther or chloroform it is more sparingly solulle. It is a colourless crystalline glucoside, yielding glucose and digituliresin by decomposition with hydrochloric acid in alcoholic solution. It dissolves yellowish green in boiling hydrochloric acid, brown in sulphuric acid, the latter solution becoming violet on the addition of bromine water $(\S 55)$.

I)igiturin accompanies digitalin in forglove; it crystallizes in pearly plates and needles, is not rery soluble in ether, and insoluble in water and benzene. Chloroform and hot alcohol

1 See also Gaabe, 'Unters iiber einige Derivate des Picrotoxins.' Diss. Dorpat, 1872.

2 Archiv f. exper. Patholog, und Pharm, iii. 16, 1874 (Pharm. Journ, and Trans. [3], v. 741). 
dissolve it frecly. Boiler with dilute acids in alcoholic solution, it is transformer into toxiresin (soluble in ether) without the simultaneous proluction of sugar. With hyrlyochloric acid it gives a reaction resembling that of digitalin, but is not coloured violet by sulphuric acid and bromine water. I)igitalin, digitoxin and toxiresin are all characterized hy very energetic physiological action that may be of use in their identification. ${ }^{1}$

I take this oplortunity of referring to three other constituents of foxglore, which, however, are insoluble in ether. They are the following:

Digitulën.-This sulsstance agrees in its physsiological action with digitalin and digitoxin, but differs from them in its solubility in water and cold absclute alcohol. It is sparingly soluble in chloroform, and is precipitated from alcoholic solution by the addition of a large quantity of ether. Boiling with dilute acids decomposes it into glucose and digitaliresin. Sulphuric acid and bromine produce the same colouration as with digitalin. Tannic acid and basic acetate of lead precipitate it from aqueous solution (\$55).

Digitonin is, as alrearly obscrved (\$ 79), allied to saponin; it is amorphous and soluble in water, to which it imparts the property of frothing. Fither precipitates digitonin from alcoholic solution more easily than it does digitalein. Baryta-water, tannic acid, and basic acetate of lead precipitate it from its concentrated aqueous solntion. Boiling with hydrochloric acid resolves digitonin into glucose, digitoresin and digitonein, with a gradual development of a garnet-red colouration. Cone. sulphuric acid colours it brownish red, which is not changed to redelish violet by bromine.

Digitin is a resinous substance that can be obtained in warty crystals from alcoholic solution. It is insoluble in water, ether, benzene and chloroform, and possesses no marked physiologrical action.

\section{For coriamyrtin compare Riban. ${ }^{2}$}

For cricalin, which is decomposed by hot dilute sulphuric acid, yielding glucose and ericinol, see Rochleder and Schwartz. ${ }^{3}$

I Compare my 'Ermittelung d. Gifte,' 2nd ed. 272 et seq.

2 Bull. de la Soc. chim. de Paris, vi.87, 1864; vii. 79. 1865 (Amer. Journ. Pharm. xxxvi. 114).

3 Annal. d. Chem. und Pharm. Ixxxiv. 366, 1552, and Chem. Centralblatt, 61, 1853. Compare also my 'Ermittelung d. Gifte,' 2 nd ed., 300 et seq. 
Ericinol is characterized hy its olour. (Compare also 5.5 and 167.)

Vanillin (cf. $\$ 167$ ), the aromatic constituent of vanilla, is very sparingly soluble in cold petroleum spinit, but might he partially carried into solution in the presence of fixerl or ethereal oil ; as a rule, however, it may be found in the ethereal extract. It is colourles, crystalline, possesses the pleasant oulour of ranilla, and is soluble in 183 parts of water (at $18^{\circ}$ ), in 4.4 parts of alcohol (specific gravity 0.803 ), and in 6.24 parts of ether. It melts at $82^{\circ}$, and is soluble in dilute sorla ; feric chlurite colours the aqueous solution dark bluish-violet. Being an alluhycle of methylprotocatechuic acid, it combines with acid sulphites (53), and it is upon this property of vanillin that the following (Thiemann and Haarmann's) method of estimation is based :1

The ethereal extract of ahout 30 grams of ranilla is eraporated to $150 \mathrm{ce}$, and thoroughly shaken for 10 to 20 minutes with a mixture of water and saturated aqueous solution of bisulphite of soda. The ethereal sulution is separated and again shaken with $100 \mathrm{cc}$. of the bisulphite mixture. The aqueous solutions are nuited and washed with pure ether to remove impurities. To every $100 \mathrm{cc}$. there are then gradually added 150 cc. of a mixture of 3 vols. of pure sulphuric acid with 5 vols. of water. The sulphurous acid evolved is received into solution of soda, the reminder being expelled by prising a current of steam throngh the linuid. After cooling, the vinillin, which has been liherated, is extracted hy shaking with 3 to 4 successive portions of ether, and can be weighed after evaporating the ethereal solution.

Ostruthiin, which resembles ranillin in being sparingly soluble in petroleum spirit," is not precipitated by that liquid from ethereal solution. It crystallizes in delicate, pale yellow necelles, molting at 9l'; is insoluble in cold water, sparingly solul)le in boiling water and benzene, freely in alcohol amel in ether. The alcoholic solution possesses a feeble blue fluoresecnee, which is increased by the auldition of water. With aqueons allialies it forms strongly fluorescent solutions, from which carbonic acil precipitates the ostruthiin maltered. It gives no characteristic reactions

1 Zeitschr. f. anal. Chemie, xv. 350, 1875 (Journ. Chem. Soc. xxix. 112).

2 Compare Gorup-Besanez, Annal. d. Chem. und Pharm. clxxxiii. 321, 1876 (Pharm. Journ, and Trans. [3], vii. 984). 
with metallic salts, nor does it yield angelic acid or allied substances when acted upon by alkalies.

I'encelunin ${ }^{1}$ is allied to, but not identical with, ostruthin. It rields no vilerianic or angelic acid, but is decomposed by the action of acids into oreoselon and methyl-compounds; it is, in firct, dimethyl-oreoselon. Peucedanin melts at $76^{\circ}$, is colourless, crystalline, insoluble in cold water, but freely soluble in alcolool and ether.

Oreostun can be obtained from peucedanin; it is almost insoluble in cold water, but soluble in alcohol, ether and benzene. Bisulphide of carbon, ammonia and dilute alkalies dissolve it only when warmed, and the latter solution reduces alkaline copper-salts. The alcoholic solution is not altered by ferric chloride. A blue fhorescent solution is yielded by conc. sulphuric acid, but not by allialies. Fused with an alkali, it yields acetic aciel and resorcin $(\$+2)$.

Athumanthin. ${ }^{2-}$-The statement that this substance is divalerylreosclon requires further investigation. It crystallizes in colourless neelles melting at $79^{\circ}$, is insoluble in water, but dissolves in diluted alcohol and in ether.

Luserpitin ${ }^{3}$ forms colourless prisms, melting at $111^{2}$, and is spraringly soluble in water and alkalies, but freely in alcohol, ether, chloroform, benzene, and bisulphide of carbon. Conc. sulphuric and fuming nitric acid dissolve it with red colouration; boiling with alcoholic potash is said to decompose it into angelic acid and laserol.

Cubebin can also be obtained in colourless crystals, melting at $1: 0^{\circ}$, difficultly soluble in cold, more easily in willm water, and soluble in 26 parts of ether, 76 of cold and 10 of boiling alcohol. It can he remored from aqueous solution by shaking with benzene (n) chloroform. Conc. sulphuric acid is coloured red by cubebin. Aqueous alkalies do not dissolve it. ${ }^{4}$ (Cf. § 55.)

Butulin is likewise tolerably freely soluble in ether and boiling

${ }^{1}$ Compare Hlasiwetz und Weidel, Annal d. Chem. und Pharm. clxxiv. 67 ; Heut, ibid. clxxvi. 70 (Journ. Chem. Soc. xxviii. 258, 772).

"Compare Schnedermann und Winkler, Annal. d. Chem. und Pharm. li. 315,1844 ; Hlasiwetz und Weidel, ibid. clxxiv. 67.

3 Compare Feldmann, 'Ucber das Laserpitin.' Diss. Göttingen.

4 For an analysis of cubebin compare Schmidt, Jahresb. f. Pharm. 51, 1870 (Pharm. Journ. and Trans. [3], ii. 270). For cubebin see TVeidel, Jahresb. f. Pharm. 68, 1877 (Amer. Journ. Pharm. 1. 257). 
alcohol, but insoluble in water and petroleum spirit. It dissolves in conc. sulphuric acid, from which it can be precipitaterl ly water. Betulin forms white crystals, which melt at about $200^{\circ}$, and are not attacked by aqueous alkalies. ${ }^{1}$

Anacardic acid can be obtained as a white crystalline mass, melting at $26^{\circ}$, freely soluble in alcohol and ether, and dissolving in conc. sulphuric acid with blood-red colouration. ${ }^{2}$

C'aritul is a colourless oil accompanying anacardic acid in the cashew nut. It is soluble in alcohol and in ether, but not in water, and possesses powerful resicant properties (not shared hy anacardic acid). It can be removed from suspension in water by agitation with chloroform. Contact with dilute potash for a short time does not result in the loss of the resicant property of cardol, as is the case when the alkali is concentrated and the action prolonged. The tough mass thus produced becomes red on exposure to the air, and gives with basic acetate of lead a precipitate that shows the same peculiarity.

156. Absinthiin, etc.-The following bitter principles are also soluble in ether : absinthiin ${ }^{3}$ (dissolves in conc. sulphuric acid with brown colour, passing to violet. See also § 55), adansonin, ${ }^{4}$ alchomin," anthemic acid," antirin, ${ }^{7}$ aristolocthe-yellou, ${ }^{\mathrm{S}}$ arnicin, ${ }^{9}$ asclepindin, ${ }^{10}$ beberic acid, ${ }^{11}$ cailcedrin, ${ }^{12}$ carymonteyllin ${ }^{13}$ (coloured bloodred by concentrated sulphuric acid, cf. $\S 55)$, cascarillin 14

${ }^{1}$ Compare Hausmann, 'Beitrïge zur Kenntniss des Betulins,' Göttingen, 1878.

2 See Stïdeler, Annal d. Chem. und Pharm. lxiii. 137, 1847 (Amer. Journ. Pharm. xx. 139).

${ }^{3}$ Compare Kromayer, Archiv d. Pharm. cviii. 129, 1868.

${ }^{4}$ Compare Walz, Jahrb. f, prakt. Pharm. xxiv. 100, 242; xxvii. 1; IVittstein, Vierteljahressch. f. prakt. Pharm. iv. 41.

5 Compare Frenzel, Archiv d. Pharm. xxiii. 173, 1829 ; Biltz, ibid. xii. 46, 1826.

${ }^{6}$ Compare Jahresb. f. Pharm. 51, 1867 ; 46, 1871.

7 Compare Walz, Jahrb. f. prakt. Pharm. xxvii. 74, 129 (Amer. Journ. Pharm. xxxy. 295).

${ }^{3}$ Compare Frickinger, Repert, f. Pharm. [3], vii. 12.

${ }^{9}$ Compare Walz, N. Jahrb. f. Pharm. xiii. 175; xiv. 79 ; xv. 329, 1860, 1861 (Amer. Journ. Pharm. xxxiii. 451).

10 Compare List, Annal. d. Chem. und Pharm. Ixix. 125, 1849.

11 Compare Maclagan, Annal. d. Chem. und Pharm. xlviii. 106, 1843 ; lv. 105, 1845 (Amer. Journ. Pharm. xix. 113).

12 Compare Caventou, N. Jahrb. f. Pharm. xvi. 335, 1861.

13 Compare Bonastre, Jahrb. f. Pharm. xi. 103; and Jahn, Annal, d. Chem. und Pharm. xix. 333, 1837.

14 Compare Trommsdorf, N. Journ. f. Pharm. xxvi. 2, 142; and Duval, N. Jahrb. f. Pharm. viii. $95,1857$. 
(the same), chimuphitin, ${ }^{1}$ chirutin ${ }^{2}$ and onthetic acid, cicutin," columbin. 4

('otoin ${ }^{5}$ crystallizes in quadratic prisms, is sparingly soluble in cold water, freely in alcohol, ether and chloroform. It melts at 130. Ferric chloride colours the alcoholic solution dark brown. Warming with nitric acid colours cotoin blood-reel, juracotoin. brown. The litter melts at $152^{\circ}$ (uncorrected). A description of leucotin, oxyleucotin and hydrocotoin will be found in the researches on cotoï and paracotoïn above referred to.

Eiluterin is sparingly soluble in ether, and is colomed yellow by conc. sulphuric acid. 1 to 2 drops of carbolic acid produce a red tinge, which changes to crimson on the addition of the same quantity of conc. sulphuric acid. (See also $\$ 55$. )

I may mention further, enyfhrocentun ${ }^{3}{ }^{7}$ euputorin, ${ }^{\mathrm{S}}$ guacin, ${ }^{9}$ hop-bitter. ${ }^{10}$ (To isolate the hop-bitter Isleib exhausts hops with coll water, al)sorbs the bitter principle with charrcoal, extracts it from the same with 90 per cent. alcohol, distils, and, after separating the resin, shakes the resulting liquid with ether. $\mathrm{He}$ confirms the statement that hop-litter is not a glucoside, but, on boiling with dilute acirls, combines with a molecule of water yielding sparingly soluble lupuliretin. Part of the hop-resin may he removed from arqueous solution by shaking with petroleum

${ }^{1}$ Compare Fairbank, Vierteljahresschr. f. prakt. Pharm. ix. 582, 1860 (Amer. Journ. Pharm. xxxii. 256).

2 Compare Kemp, Pharm. Journ. and Trans. [3], 1, 251, 1870 ; Höhn, Archiv d. Pharm. clxxxix. 229, 1869.

${ }^{3}$ Compare Wikszemski, ' Ein Beitr. z. Kenntniss der giftigen Wirkung d. Wasserschierling.' Diss. Dorpat, 1875, and Jahresb. f. Pharm. 493, 1875.

${ }^{4}$ Compare Boedecker, Annal. d. Chem. und Pharm. lxix. 37, 1849 (Amer. Journ. Pharm, xx. 324).

${ }^{5}$ Compare Hesse, und Jobst. Neues Repert. f. Pharm. xxv. 23, 1876 ; Ber. d. d. Chem. Ges. x. 149, 1877; Annal. d. Chem. und Pharm. cxcix. 17, 1879 (Pharm. Journ. Trans. [3], vi. 764; vii. 495, 1019 ; x. 521, 541).

${ }^{6}$ Compare Zwenger, Annal. d. Chem. und Pharm. xliii. 359, 1842; Walz, N. Jahrb. f. Pharm. xi. 21, 178, 1859 ; Köhler, N. Repert. f. Pharm, xviii. 577,1869 .

${ }^{7}$ Compare Méhu, Jahresb. f. Pharm. 70, 1866; 92, 1870; 56, 1871 (Amer. Journ. Pharm. xxxviii. 303).

${ }^{8}$ Compare Righini, Journ. f. Pharm. xiv. 623.

${ }^{9}$ Compare Pettenkofer, Repert. f. Pharm. Ixxxvi, 311 ; Fauré, Jahrb. f. Pharm. xxii. 291.

${ }^{10}$ Compare Lermer, Vierteljahresschr. f. prakt. Pharm. xii. 504, 1863 ; Bissell, Amer. Journ. Pharm. xlix. 582, 1877 ; Griessmayer, Ber. d. d. Chem. Ges. xi. 292, 1878 (Journ. Chem. Soc. xxxiv. 449); Isleib, Archiv d. Pharm. [3], xvi. 345, 1880 (Journ. Chem. Soc. xl. 101) ; Cech, Zeitschr.f. anal. Chem. xx. 180, 1881 (Journ. Chem. Soc. xl. 946). 
spinit. Criessmayer has availed himself of this property of hopresin in the examination of beer. Cf. $\$ 55$.) Other bitter principles are hurin, ${ }^{1}$ jerewic ucid, ${ }^{2}$ juniperin, ${ }^{3}$ liriudendrin, ${ }^{4}$ lycopin, merrulin, ${ }^{6}$ menyostin, muserpin ${ }^{8}$ and meconin. ${ }^{9}$ The last-named is soluble in hot water, and cim be extracted from aqueous solution after acilification with sulphuric acil, by shaking with benzene, chloroform, or amylic alcohol. With benzene it can be obtained fairly pure, and can be letected by conc. sulphuric acir, in which it dissolves withont at first producing any colouration; but the solution grarlually assumes a greenish, and in the course of twentyfour hour's a recldish tinge. If the liquid is then warmed, the colour changes to enerald-green, blue and violet, and becomes finally red.

Meconin is accompanied in opium by meconic acid, which is sparingly soluble in water and ether, but more easily in alcohol. Boiling with water or dilute acils decomposes meconic acid; with ferric chloride it strikes a blood-red colour, which is not discharged by a little hydrochloric aci or chloride of gold. It can. be removed from arueous solution hy shaking with amylic alcohol. Meconate of calcium is soluble, but the magnesium salt onlysparingly so. Chelidonic acid from Chelidonium majus is sparinglysoluble both in cold water and in alcohol. ${ }^{10}$

There may be further mentioned here, methysticin ${ }^{11}$ (which is slightly soluble in cold ether and dissolves in pure conc. sulphuric acid with fine redilish-violet, in commerciul with blood-red colouration), Raucuïn, ${ }^{12}$ nuthecin, ${ }^{13}$ mucin ${ }^{1.4}$ (coloured jurple by alkalies),

1 Compare Boussingault and Rivero, Annal, de Chim. et de Phys. xxviii. 430 (Amer. Journ. Pharm. ii. 346).

2 Compare Weppen, Jahresb. f. Pharm. 31, 1872 (Journ. Chem. Soc. xxvi. $906)$.

3 Compare Steer, Wiener Acad. Anz. B. xxi. 383.

${ }^{4}$ Compare Emmet, Repert. f. Pharm. Ixxv. 88 (Amer. Journ. Pharm. iii. 5).

5 Compare Geiger, Repert. f. Pharm. xv. 11.

${ }^{6}$ Compare Kromayer, Archiv d. Pharm. cviii. 257, 1862.

7 Compare W. Schmidt, Annal. d. Chem. und Pharm. xciii. 83, 1854 (Amer. Journ. Pharm. xxvii. 331).

${ }^{8}$ Compare Gentl, Annal. d. Chem. und Pharm. xlvi. 126, 1843.

${ }_{9}$ Compare Pelletier, Annal. d. Chem. und Pharm. Ixxxvi. 190, 1853, and Anderson, xcviii. 44, 1856. See also my 'Lrmittel. d. Gifte,' 2nd ed., 238.

10 See Lerch, Chem. Centralblatt, 449, 1846.

11 Compare Nölting and Kopp, Nonit. scientif. [3], iv. 920, 1874 (Pharm. Journ. Trans. [3], vii. 149).

1.2 Ibid.

${ }^{13}$ Compare Walz, N. Jahrb. f. Pharm. xiv. 345, 1861.

14 Compare Vorrel and Reinschaner, N. Repert. f. Pharm. v. 106 (1556); vii. 1 (1858). 
plumbergin ${ }^{1}$ (coloured cherry-red by small quantities of allaties), pulygonic ucid, ${ }^{2}$ quessin"3 (which is soluble in water, can he remored by shaking with benzene or chloroform. See also 5 5.), vottlerin ${ }^{4}$

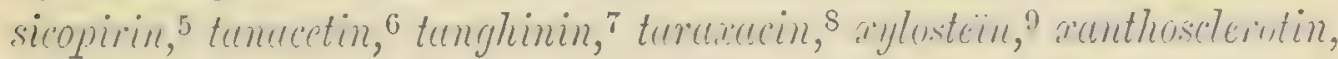
or scleroxanthin. ${ }^{10}$

\$157. Lichen Acils amb allied, Substances.-Amongst the constituents of plants that are solulble in ether a number occurring in lichens may finally be mentioned here. Some of them possess the characters of acids, as, for instance :

Roccellic acid, which is itself insoluble in water, but forms soluble alkaline salts. It can be detecterl in the gonidia by alkamna. ${ }^{11}$

Others are characterized hy yielding beautifully coloured compounds when acted upon by alkalies, ferric chloride or chlorinated lime, properties that would inclicate some relation to orein and allied bodies. Others, again, possess the chemical characters of ethereal salts, being resolved by allialies into stronger acids and alcohols. To the former group belong the following:

Lecenoric ucir (diorsellic acid), which is colourerl deep red by chlorinited lime (avoiding an excess), and is decomposed at $153^{\circ}$ into orcin and carbonic acid. ${ }^{12}$

Orsellic acid, which undergoes a similar decomposition at $176^{\circ}$,

${ }^{1}$ Compare Dulong, Jahrb. f. Pharm, xiv. 441.

2Compare Rademacker.

${ }^{3}$ Compare Wiggers, Annal. d. Chem. und Pharm. xxi. 40, 1837 ; Goldschmidt und Weidel, Ber. d. Wiener Akad. Ixxiv. 389, 1877 (Journ. Chem. Soc. xxxiv. 80). See also my 'Ermittelung d. Gifte,' 2nd ed., 300 et. seq. ; and Jahresb. f. Pharm. 619, 1878. Also Christensen, Archiv d. Pharm, xvii. 481, 1882.

${ }^{4}$ Compare Anderson, Chem. Centralblatt, 372, 1855 (Amer. Journ. Pharm. xxxii. 325); Groves, Jahresb. f. Pharm. 161, 1873 (Pharm. Journ. Trans. [3], iii. 228).

${ }^{5}$ Compare Peckolt, Zeitschr. d. Oesterr. Apotheker-Ver. 289, 1876 (Pharm. Journ. Trans. [3], vii. 69).

'Compare Leroy, Journ. de Chim. med. xxi. 357 ; Leppig, 'Chem. Unters. d. 'Tanacetum vulgare,' Diss Dorpat, 1882.

${ }^{7}$ Compare Henry, Journ. de Pharm. x. 52 (Amer. Journ. Pharm. viii. 102).

${ }^{8}$ Compare Kromayer, 'Die Bitterstoffe,' 97 ; and Polex, Archiv d. Pharm. xix. 50,1840 .

'9 Compare Hübschmann, Pharm. Vierteljahresschr. v. 197 ; and Enz, ibid. 196, 1856.

${ }^{10}$ Compare Dragendorff and Podwissotzki, loc. cit.

${ }^{11}$ Compare Schunck, Annal. d. Chem. und Pharm. 1xi. 66, 78 ; also Hesse, cxvii. 332, 1861 (Journ. Chem. Soc. iii. 153).

12 Schunck, Annal. d. Chem. und Pharm, xli. 157, 1842 (Journ. Chem. Soc. i. 71) ; liv. 261, 1845; lxi. 64, 1847 ; Stenhouse, ibid. Ixviii. 57, 1848; cxxv, 353, 1863 (Journ. Chem. Soc. xx. 221) ; Hesse, cxxxix. 22, 1866. 
and with alkaline solutions at a temperature as low as the boilingpoint. ${ }^{1}$ Both this and the foregoing acid form salts of ethyl when boiled with alcohol.

Gyrophoric acid, which is sparingly soluble in ether, yields orcin on decomposition with alkali, and turns red on exposure to ammoniacal air. ${ }^{2}$

Purellic acill, which is only slowly coloured under the same conditions. ${ }^{3}$

Ceratoplugllin, which strikes a violet colour with ferric chloride and blood-red with chlorinated lime. ${ }^{4}$

Putellaric acil, which, in alkaline solution, turns red when exposed to the air. Ferric chloride colours it blue; chlorinated lime, blood-red. ${ }^{5}$

Evernic acid yields orcin by dry distillation, is coloured darkred by ammoniacal air, but only yellow by chlorinated lime. ${ }^{6}$

Everninic ucid (oxyusnetinic acid?) is also coloured yellow by chlorinated lime, but does not change when exposed to ammoniacal air.

Lsnic acid behares in a similar manner, but an alkaline solution turns red on exposure to air, and the acid itself yields betaorcin by dry distillation. ${ }^{7}$

Curlusnic acids (is sparingly soluble in ether) gives no colour reactions.

Vulpinic acid (chrysopicrin), which is more easily soluhle in bisulphicle of carbon and chloroform than in ether, is olitainalble in yellow crystals and forms yellow salts with alkalies. Boiling: with baryti-water resolves it into alphatoluic acid, oxalic acil, and methyl-alcohol. ${ }^{9}$ It may therefore be placed in the grrony of

I Schunck, Annal. d. Chem. und Pharm. xli. 157, 1842 (Journ. Chem. Soc. i. 71) ; liv. 261, 1845; lxi. 64, 1847; Stenhouse, ibid. lxviii. 57, 1818; cxxv. 353, 1863 (Journ. Chem. Soc. xx. 221); Hesse, cxxxix. 22, 1866.

${ }^{2}$ Compare Stenhouse, ibid. 1xx. 218, 1849.

${ }^{3}$ Compare Schunck, ibid. liv. 274, 18t5; Strecker, lxviii. 114, 1848.

${ }^{4}$ Compare Hesse, ibid. cxix. 365, 1861.

${ }^{5}$ Compare Weigelt, Journ. f. prakt. Chem. cvi. 28, 1869.

${ }^{6}$ Compare Stenhouse, ibid. Ixviii. 86, 1848 ; Hesse, ibid. xlvii. 297, 1861.

7 Compare Knop, Annal. d. Chem. und Pharm. xlix. 103, 1843 ; Rochleder and Held, ibid. xlviii. 1, 1843 ; Stenhouse, ibid. lxviii. 97, 114. Knop and Schnedermann, Journ. f. prakt. Chem。xxxvii. 363, 1843; Hesse, Annal. d. Chem. und Pharm. cxvii. 343, 1861.

8 See Hesse, ibid. exxxvii. 241, 1866 ; Ber. d. d. chem. Ges. x. 1324, 1877 (Journ. Chem. Soc. xxxii. 896).

${ }^{9}$ Stein, Chem. Centralblatt, 556, 186t; 432, 1865. See also Spiegel, Ber. d. d. chem. Ges. xiii. 1629, 1880. 
ethereal salts previously mentioned. The same is the case with cryfluric ucil (sparingly soluble in ether), which is regarled as diorsellinate of erythrite, ${ }^{1}$ picroeryflerin (orsellinate of erythrite), and betecryfleric acid ${ }^{2}$ (orsellinate of betapicrocrythrin).

For picrolichenin compare Alns, Stenhouse, and Groves ; ${ }^{3}$ for cetiuric and lichenosteuric acid, Schmedermann and Knop ; for. ruriolinin, Robiquet $;^{5}$ stictic acid, Schnedermann and Knop $;^{6}$ loburic acid, Knop; ${ }^{\top}$ atranoric acid (hydrocarbo-usnic acid?), zeorin, sordidin, Paterno ; calycin, Hesse. ${ }^{9}$

Microscopical examination shows that the majority of these acids adhere in the form of minute granules to the exterior of the hyphe, in heteromerous lichens almost exclusively in the cortical portion of the upper surface, or, in old specimens, on the margin of the thallus (Physicia parietina). ${ }^{10}$

To test for a lichen-acid yielding orcin as a product of decomposition, the substance under examination, or part of the lichen itself, may be heated with dilute potash, chloroform aclded, and the warming continued for some time in the water-bath. If such an acid is present, homofluorescin will be produced, and the solution will appear redish-yellow by transmitted, and show a fine yellowish-green fluorescence by reflected light. Usnic acid is said not to give this reaction, which is yielded by lecanoric, erythric and evernic acid (by the list-named after continued boiling with milk of lime).

Eingthric and lecunoric acid are extracted from the lichen by digestion with ammonia, and are precipitated by acetic acid. On warming, erythric acid passes into solution, whilst lecanoric acid remains undissolved.

${ }^{1}$ Compare Heeren, Schweiz. Journ. lix. 313 ; also Schunck, Stenhouse, Strecker, Hesse, already quoted.

2 See Menschutkin, Bullet. de Ia Soc. chim. [2], ii. 424, 1864. Lamparter, Annal. d. Chem. und Pharm. cxxxiv, 243, 1865.

${ }^{3}$ Annal. d. Chem. und Pharm. i. 61, 1832 (Amer. Journ. Pharm. xvi. 262) ; ibid. clxxxv. 14, 1877 (Proc. Roy. Soc. 1x. 68).

* Annal. d. chem. und Pharm. Iv. 144, 159, 1845.

5 Annal. de chim. et de Phys. xlii. 236.

"Jahresb. f. Pharm. 76, 1845.

${ }^{7}$ Chem. Centralblatt, 173, 1872 (Journ. Chem. Soc. xxv. 639).

${ }^{8}$ Ber.d. d. chem. Ges. x. 1100 and 1382, 1877 (Journ. Chem. Soc. xxxi. 89 ; xxxii. 270).

9'Ber.d. d. chem. Ges. xiii. 1816, 1880 (Pharm. Journ. Trans. [3], xi. 471).

${ }^{10}$ Compare Schwartz in Cohn's 'Beitriige zur Riologie d. Pflanzen,' iii. Part II, and Archiv d. Pharm. [3], xix. 124, 1881. 
Usnic acid, which occurs in yellow crystals, yields a colourless ammonium salt.

\$158. Orcin and Betaorcin. Estimation of Orcin.-Orcin and betaorcin, which have alrearly been inentionerl-as prorlucts of the decomposition of certain constituents of lichens, and which sometimes occur ready formed in plants, can be obtained in colourless acicular crystals soluble in water, alcohol, and ether. Exposure to light colours them reddish; alkalies, chlorinated lime and ferric chloride, violet. By the action of ammonia and air orcin yields a blue colouring matter, whilst, under the same conditions, betaorcin gradually turns red. Orcin melts at $58^{\circ}$, betaorcin at a temperature above $109^{\circ}$.

Reymann estimates orcin in lichens by titrating with brominewater, ${ }^{1}$ by which monobromorcin is first produced and subsequently converted into tribromorcin. To the solution of orcin in a stoppered bottle titrated bromine-water is added till the precipitate has assumed a yellowish colour and excess of bromine is present, which is then estimated by iodide of potassium and hylosulphite of socla. The amount of orcin present is calculated from the equations:

and

$$
\mathrm{C}_{7} \mathrm{H}_{8} \mathrm{O}_{2}+\mathrm{Br}_{2}=\mathrm{HBr}+\mathrm{C}_{7} \mathrm{H}_{7} \mathrm{BrO}_{2}
$$

$$
\mathrm{C}_{7} \mathrm{H}_{7} \mathrm{BrO}_{2}+2 \mathrm{Br}_{2}=2 \mathrm{HBr}+\mathrm{C}_{\uparrow} \mathrm{H}_{5} \mathrm{Br}_{3} \mathrm{O}_{2} \text {. }
$$

TANNIC ACIDS.

\$159. Constitution.-In estimating tannic acids an error has generally been committer in overlooking too completely the chemical differenes existing between the various substances that have receiverl this name. It has usually been considered sufficient to deternine quantitatively the ralue of a reargent in terms of gallotannic acid, the tamnin most casily procuralule, and to apply the results thus obtained to the estimation of other tannins. This would be artmissible muler the assmuntion that all tamins possessed approximately identical equivalent weights and 1noduced nearly identical chemical effects. Thut it hats already heen shown in $\$ 52$ that such is not the case. It will be sufficient here to repeat that tannins exist which do not allow of comparisons with one another, even with resarel to their constitution.

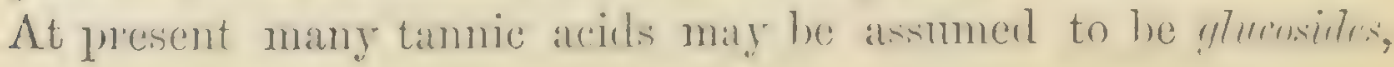

1 Ber. d. d. chem. Ges. viii. 790,1875 (Journ. Chem. Soc. xxvii. 1293). 
splitting up under the influence of dilute acils into glucose and some second sulsstance, but of a number it must be denied that they possess any such glucosidal characters.

$\$ 160$. Glucosidal nature. - In enumerating the characters of a newly-discorered tamic acid, it is, therefore, important to state whether it has been found to be a glucoside or not (\$61). The examination maly be made by heating weighed quantities of the tannin with 1 to 2 per cent. arueons hydrochloric acis in sealed tulhes to $100^{\circ}$ for several hours, allowing them to stand for some time after heing opener, in order to observe whether any sparingly soluble decomposition-product separates ont in the cold. If this is the case, the substance may be filtered off, but at the sume time it is adrisable to ascertain whether any portion that may remain in solution cannot be removed by shaking with ether, acetic ether or chloroform. After warming to expel dissolverl traces of those liquids, the solution may be examined for glucose (\$S 61, 83, et seq.; 200, et seq.).

The decomposition-products that are thus obtainer, together with glucose, are sometimes crystulline, as, for instance, gallic acid, from the tamnin of galls, sumach, myrobalans, divi-divi (cf. $§ 151$ ), and the yellow ellagic acid from the tannic acid of the pomegranate and bablah fruits. But they are generally amorphous, difficultly soluble in pure or acidified water and in pure ether; soluble in water containing ammonia, and frecly soluble in spirit ; they are, as a rule, deep in colour, and agree in all essential properties with the phloburhenes mentioned in ss 48 and 108. Some are so sparingly soluble that they may he of use in the quantitative estimation of the respective tamnins. This is especially the case if, after the action of the acil, the liquid is evaporaterl to dryness and treated with water, when they often remain behind almost entirely insoluble.

Sulstances of this description are yielded by the decompnsition of the tamic acid of oak, willow, elm, fir, birch, and acacia-lark, as well as hy that from rhubarb, male-fern, ledtum, wine, and by many others. Chemically the moluephenes approach many resins, with which they share the solubility in aleohol and slight soluhility in water, differing from them in their solubility in dilute ammonial, but resembling them again in the sulstances they yield when

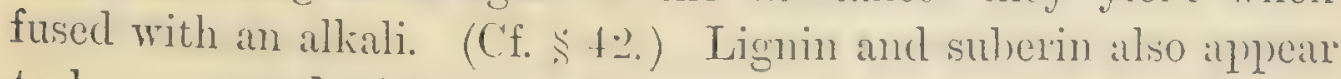
to be connected with the phlobaphenes. 
The phlobaphenes mentioned in $4 \$$ may, as stated, have been rrouluced from tamins during manipulation, whilst those in $\$ 108$ will probably have existed ready-formed in the material under. examination.

But, although phlohaphenes are insoluble in pure water, they are dissolved by solutions of tamnic acid, sugar, and other substances, and small quantities may therefore have been extracted by water.

$\$ 161$. Proneness to Decomposition. - The determination of the grlucosidal or non-glucosidal nature of a tamin is sometimes a matter of considerable difficulty, because, on the one hand, it is not always easily separated from any glucose with which it mily be contaminated, and, on the other hand, many tannins readily decompose, yielding bodies resembling their mother-sulbstances in possessing a similar action on hide, gelatine, etc. A decomposition of this lind is olsserval,le with gallotamic acid, which, especially on prolonged heating in aqueous solution, apparently melergoes dissociation into a polygallic acid and sugar. Some tamnins, too, from barks, etc., appear to be capable of parting with a portion of their glueose without completely losing their action on gelatine, etc., which, however, rapidly diminishes, even at the ordinary temperature, on allowing the aqueous solution to stand. It is not surprising, therefore, that very varying statements are met with as to the glucosidal nature of a tamnin, and especially the amount of glucose certain members of the class can be made to yicld. And yet it is most important to determine whether slucose can be olutained from a tamnic acid or not. The production of a sparingly soluble and possibly crystalline body from an casily soluble amorphous tammin by the action of hydrochloric or sulphuric acid (\$ 160) is insufficient proof of its glucosidal nature, since ron-glucosidal tammins undergo a similar decomposition.

As a rule the action of dilute acids on a tannin results in the formation, apart from glucose, of a single decomposition-product belonging to the aromatic series (sallic acid, ellagic acil, phlobaphenes, etc.), but the researches on the tannic acids of the Nymphacea recently carried out in my laboratory by Griining prore that two or more decomposition-products can be olitimed from one tamnin. From Nymphira alha and Nuphar luteum non-ghlucosidal tannic acirls were isolated, undergoing no further s'paration by fractional precipitation with lead, and yiclding, 
when warmed with a dilute acid, gallic and ellagic acils together with a phlobaphene. ${ }^{1}$

$\$ 162$. I'urificution.-The ease with which tamnins decompose renders their preparation in the state of purity desirable for accurate investigation a matter of considerable difficulty, and we may confidently assert that this has not been attained with the majority of the sulustances belonging to this class that have hitherto been described.

In preparing pure tannins the following hints mily be useful, in addition to those given in $\$ \$ 49$ to 51 and 60 :

1. If a tamnic acil is to be separated from the alcoholic extract it is very advisalble, after evalporating, to mix at once with a considerable ciuantity of water. Aleohol dissolves phlobaphenes and resinous substances, together with tamic acid, and strong aqueous solutions of the latter are known to be capable of taking up the former, even if otherwise insoluble in water ( $\$ 160)$.

2. In precipitating the aqueous filtrate with acetate of lead, it is arlvisable to add the reagent in successive portions, rejecting the first (generally more deeply coloured) and last precipitates, as they are usually contaminated with foreign substances to a considerable extent.

3. The lead precipitates should he washed and treated with sulphuretted hydrogen as rapidly as possible, to aroid decomposition of the tannate of lead.

t. The filtrate from the sulphinle of lead should he eraporated, if possible, in a partial vacumm, and only to the consistence of a thin syrup. The remiander of the water may be craporated over sulphuric acid and lime at the ordinary temperature, the operation being completed in vacuo.

It will frequently be found arlvantageous to shake the filtrate, before evaporating, with ether or acetic ether, which would remove any gallic acid that might be present.

Many tamnins may be purified lyy dissolving in water, alding chloride of sodium, and removing the tamnic acid by shaking with acetic ether or a similar solvent. This method has been strccessfully used by Loewe for stmach-tannic acid and some others, ${ }^{2}$ and by Rialabe for thatania-tamnic acid.." It should he

1 Beiträge zur Chemie der Nymphaceen, Diss. Dorpat, 1881.

"Zeitschr.f, anal. Chem. xii. 128 ; xiv. 35, 44 (Journ. Chem. Soc.xxvii. 171 ; xxviii. 75).

${ }^{3}$ Pharmo. Zeitschr. f. Russland, 577, 1880. 
observed that gallic acid must be remored by shaking with ether hefore chloride of sorlium is addecl, and that certuin tanmins are partially precipitated by saturating their arqueous solutions with salt; some also can be precipitater from their arpueous solutions by sulphuric or other mineral acil, but this method seldom yields them in a sufficient state of purity for our purpose.

$\$ 163$. Tannins insoluble in IVater.-The tannic acids of alder ${ }^{1}$ and hol, ${ }^{2}$ togrether with some others, are stated to be insolulle in water after isolation. In some instinces the tamnin may possilly have been partially decomposed during the process of isolation (s.5 48, 161). In any case in which tamins sparingly soluble in water are anticipated, the lead precipitate should be decomposed in the presence of spirit.

There are also a number of bodies which resemlle one or other of the tamnins in certain of their properties (as, for instance, in being precipitated by acetate of leal), but are insoluble in cold water. Pæniofluorescin might be placed in this class. ${ }^{3}$.

$\$ 164$. It not mufrequently occurs that a single plant contains two or more tannins: for example, in addition to their own peenliar tamnins, both oak and willow bark contain a little gallot:mnic acid ; myrobalans and divi-divi contain gallotamic and ellagotannic acid. ${ }^{5}$ If the presence of more than one tamnin is anticipated, the methorl of fractional precipitation shonld he tricel, or, if that is unsuccessful, the examination of the products olntained by warming with acils may afford the information requirerl, as was the cisse in the investigation of oak and willow bark; gallic: acid can be removed by shaking with ether, whereas oak-red cannot.

$\$ 165$. Notes on some of the more important I'annins.-In the following notes those tamins will be mentioned first that are not

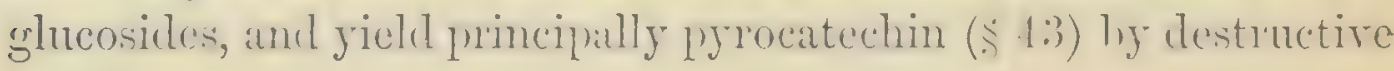
distillation.

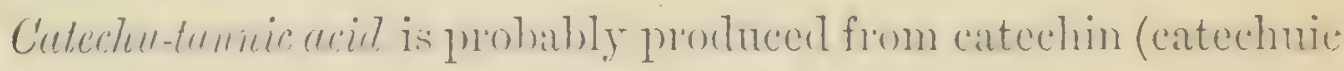
acid) by loss of the elements of water. ${ }^{6}$ In estimating catechu-

${ }^{1}$ Compare Reichardt, Chem. Centralblatt, N. F. i. 12.

See Etti, Polyt. Journ. cclxxxviii. 354, 1878 (Journ. Chem. Soc. xxxir. 797) ; Bissell, Amer. Journ. Pharm. [4], xlix. 582, 187\%.

$3 \$ 44$ and 147.

${ }^{4}$ Compare Johanson, loc. cit.

${ }^{5}$ Compare Loewe, Keitschr. f. anal. Chem. xiv. 35, 44, 1575.

${ }^{6}$ Compare Etti, Annal. d. Chem. und Pharm. clxxxvi. 327, 1878; Zeitschr. f. anal. Chem. xii. 285, 1873; xiii. 113, 1874 ; Journ. f. prakt. Chem. cv. 32. 
tannic acid goor resnlts can be obtained by using a 1 per cent. solution of gelatine in saturated solution of chloride of ammonium ats inclicater in \$.5, xii. ; chloride of ammonimm shonld be arterl to the tamnin solution also. I Lehmann has shown that the liquirl may be diluted within certain limits without affecting the result to any notable extent, and that it is advisable to promote the subsidence of the precipitate hy adiling powitererl slass and vigorously stirring. He determines the ent of the experiment by removing a clrop with a filtering tule and testing it with solution of gelatine on a watch-gliss with dark backigrouml. The tamnin solution should be mixed with an equal volume of saturated chlorille of ammonium solution. Each cc. of the reagent indicates 0.0139 gram catechu-tannic acid. No other constituents of catechu are precipitated by gelatine.

Catechuic acid (\$151), which is easily converted into catechutannic acid, should not be neglected in determining the value of a catechu. Lehmann endearoured to estimate it from the difference in the amount of permanganate of potassium required (cf. $\S 52$, vii.) before and after precipitation with gelatine (by which catechu-tannic acid alone is removed). The results he obtained were, however, somewhat too high, since an infusion of catechu contains other substances besides catechuic and catechutamic acids that act upon permanginate of potassimn. A more successful process consisted in removing the catechuie acid by shaking with ether, as directed in \$ 151 , and then titrating it with permanganate of potassium, reckoning 4.84 parts of catechuic acid for every 16 parts of oxygen consumed.

Rhateniu-tanni: uril, like the two precerling sulstances, yields phloroglucin and protocatechuic acid when fused with potash." For this tamin also Gïnther recommends the estimation with solution of gelatine, calculating 0.01:302 to 0.01:32:3 gram rhatania-tannic acid for every ce. of gelatine solution. The leat precipitate, which is tolerably stable but not quite insoluble in water, contains, according to Giinther, $31: 26$ per cent. of oxide of learl.

1 Lehmann, 'Vergl. Unters. einiger Catechu und Gambier-Proben,' Diss. Dorpat, 41, 1880 ; Pharm. Zeitschr. f. Russland, No. 18, 1881.

2 Compare Raabe, loc. cit. Raabe contests the glucosidal character of rhatania-tannic acid, and is of opinion that it simply loses water when converted into rhatania-red. See also Chem. Centralblatt, xii. 467, 1867; Annal. d. Chem. und Pharm. cxliii.274, 1867, in which Grabowski, like Wittstein, still maintains the production of glucose in the decomposition. 
Tiaabe found $3.3 \cdot t$ per cent. of oxide of lead in the leal-salt, and 16.64 of oxide of copper in the copper-salt. ${ }^{1}$

MIorintennic urit, which occurs together with morin and muclurin in fustic, also yields phloroghlucin and protocatechuic acirl by fusion with potash. Boiling water extracts morin from the wood in the form of a calcium-compound, which is sparingly soluthle in cold water, and is deprosited, therefore, from the decoction on cooling. Alcohol acidified with sulphurie acid decomposes the compound, dissolving the morin ; the latter crystallizes from alcoholic solution in yellow neclles, which are sparingly soluble in cold, but more freely in boiling water. With acetate of lead the boiling alcoholic solution gires an orange-red precipitate containing 58.4 per cent. of oxide of lead.

According to Loewe, an aqueous solution yields both morintannic acid and maclurin to acetic ether. By dissolving the eraporation-residue in cold water and adding chloride of sorlium an amorphous precipitate of the former is obtained, whilst the latter crystallizes out on standing. Maclurin is insoluble in a mixture of equal rolumes of water and saturated solution of salt, whereas morintannic acid is dissolved. Morintamnate of lear contains $6+\cdot 2.3$ per cent. of oxide of learl. No accurate methor of estimation is known.

The dount that has recently been thrown upon the slucosidal nature of rhatania-tannic acid renders it rery desirahle that lino-, tormentil- and histort-tannic acils shonld be examined afresh." These tannins yield similar prorluets when fused with potash. Kino-tannic acid is characterized hy the disposition its alcoholic solution shows to gelatinize. According to Giinther both kinoand tormentil-tamnic acids can he estimated by selatine-solution (see above, and also $\$ 52$, xii.), 1 cc. of which indicates 0.0130 gram kine, and 0.0168 gram tormentil-tannic acid.

For ellago-tannic acid see below.

The tamnin of the horse-chestmut," which is likewise non-ghlueosidal,

1 Possibly there is another copper-salt containing 22 to 23 per cent. $\mathrm{CuO}$; that would, at least, appear probable from some experiments of Giinther.

2 For the tannin of kino see Eisfeldt, Annal, d. Chem. und Pharm. xcii. 101, 1854; for its crystalline decomposition-product, kinoin, see Etti, Ber. d. d. chem. Ges. xi. 1879 (Journ. Chem. Soc. xxxvi. 159). Tormentil-tannic acid is discussed by Rembold, Annal. d. Chem. und Pharm. cxlv. 5, 1868 (Amer. Journ. Pharm. xl. 311).

${ }^{3}$ Compare Chem. Centralblatt, x. 318 ; xii. 513. 
is partially precipitated from arpucous solution by chloride of sodium, and by acid sulphite of potassium. The aqueous or alcoholic solution turns dark cherry-red when warmed with hychrochloric or sulphuric acid, and deposits red flocks ; bichromate of potassium prorluces a dark colouration and brown precipitate; with ferric chloride it strikes a green, or, if the solution is ammoniacal, a violet colour; it is not precipitated by tartir emetic. No method is known by which it can be accurately estimated.

Amongst the gluerabilul tuminis those may be mentioned first which, when boiled with dilute acids, yield, in ardition to glucose, crystal-line decomposition-products. The most important of them is -

Gallotaminic acin, the decomposition-product of which, gallic acid, has heen already alluled to (\$1.)1). Its cuantitative estimation is comparatirely easy, as fairly accurate results can he obtained both volumetrically by titration with gelatine-solution or with permanganate of potassium, and gravimetrically by precipitation as tin (stimnous), copler, or lead-salt. A few sources of error must, however, be here alluded to. In the first place, if the tamic acid has been extracted by water, mucilage and gallic acid may also have passed into solution; the latter is preeipitahle by gelatine in the presence of mucilage. That is aroided by extracting with spirit. In the second place, gallic acid, as already pointed out, acts upon permanganate of potassium. In titrating with a solution of that substance, therefore, either the gallic acid must be removed by shikking with ether, or, as surgested by Löwenthal, and mentioned in $\$ S 52,5.3$, two estimations must be marle, the one before, the other after, precipitating the tannic acid with gelatine, the calculations heing made from the difference. In precipitating with acetate of lead or copper (but not with ammonio-chloride of tin), gallic acil is also partially carried down, and should therefore be previously removed. From a solution containing about 2 per cent. of tamin the tin precipitate will contain 19.77 to $19 \cdot 79$ per cent. of stamnous oxile, the lead $50 \cdot 00$ per cent. of oxide of lear, and the copper :3.28 per cent. of oxide of copper.

Hammer's method ( $\$ 52$, xi.) may, as already stated, be best applied to the estimation of gallo-tannic acid.

The tamnins of sumach,', linoppern gatls, ratlonia and algatro-

'Compare Guinther, 'Beitr. zur Kenntn. der im Sumach, etc., vork. Gerbs.,' Diss. Dorpat, 1871 (Journ. Chem. Soc, xxiv. 602); Loewe, Zeitschr. f. anal. 
billa ${ }^{1}$ correspond exactly to gallotamic acid, and all that has been said of the liatter is equally true of the former. They are alway's accompanied by gallic acid in the materials that yield them.

Some of these also contain the so-called ellago-tannic acid, which is foume in notable quantities in myrobalans, divi-divi and bablah fruits. ${ }^{2}$

This ellago-tannic acid, which, as far as Loewe's experiments show, is not a glucoside, differs from gallotannic acid in yielding clligic in the plice of gallie acirl, a change thist can be hrought about by water alone at a temperature of $108^{\circ}$ to $110^{\circ}$. Ellagic acid can he obtainerl in sulphur-yellow crystals, which are almost insoluble in boiling water or in ether, and spritringly soluble in alcohol. Notwithstanding, howerer, its slight solubility in ether, small quantities can be removed from arueous solution lyy shaking with that liquid. Ferric chloride produces first a green, then an inliy colouration. It is soluble in potash, and is precipitated by acetate of lead from an alcoholic solution in the form of learl- silt, continining 63 per cent. of oxide. The dry substance heated with zine dust yields the hydrocarbon ellagene $\left(\mathrm{C}_{14} \mathrm{H}_{10}\right)$, which cannot be combined with picric acid.

Whether ellago-tannic acid has been prepared in a state of purity, and whether it is identical with pumico-tannic acil, ${ }^{3}$ are questions which we may for the present leave out of consideration. According to Ricmbold, the latter aliso yields cllagic acid. Special methorls for the estimation of these two substances have not as yet been published.

For nymphra-tannic acid see $\$ 161$.

Gallotannic and gallic acils also oceur in teu, accompanied by quercetin (possil)ly present in sumich also, 5152 ), and by the socalled boheic acil. ${ }^{4}$ The latter is not thrown down when acetate of lead is added to a hot infusion of tea, but is precipitated on

Chem. xii. 128, 1873 (Journ. Chem. Soc. xxvi. 748); xiv. 46 (tannin of knoppern-galls).

1 Compare Godeffroy, Zeitschr. d. Oesterx. Apoth.-Ver. 132, 1879 (Year-book Pharm. 215, 1879).

2 Compare Giinther, loc. cit. Also my observations in the Jahresbericht $\mathrm{f}$. Pharm. 192, 1875; and Loewe, Zeitschr. f. anal. Chem. xii. 128 ; xiv. 35, 44.

3 Annal. d. Chem. und Pharm. cxliii. 285, 1867. I may observe that in the pomergranate bark also the substance yielding ellagic acid is accompanied by sallotannic acid, and that Rembold obtained sugar by the decomposition of the former.

${ }^{ \pm}$Compare Hlasiwetz, Annal. d. Chem. und Pharm. cxlii. 233. 
adding ammonia. It is pale yellow, amorphous, and easily soluble in alcohol.

Cunfjetunnir acid yields sugut and crystalline caffeic acid. Caffeic acid is casily soluble in alcohol, sparingly in cold water, and strikes a dark green colour with ferric chloride, which is turnerl red by sorla. It reduces silver salts on warming, but not alkaline colper solution. Like caffea-tannic acid, caffeic acid yiells pyrocatechin by dry distillation. The former is also coloured wreen by ferric chloride. Its ammoniacal solution turns green when exposed to the air (viridic acid). According to Güinther's experiments, it camnot be (puintitatively determinel hy precipitation with copper, lead, or gelatine. Titration with permanganate of potassium might possibly yield approximate results.

The following tamins are provisionally considered by many chemists to he glucosides (see note); they yield amorphous decomposition-products resembling phlobaphenes. (Cf. \$ 160.)

Quercitamir acir, which is probably irlentical with the tamnic acids of willow and elm bark, ${ }^{2}$ is one of the less stable tamnins, and is, therefore, extremely difficult to purify and to estimate (\$161). The copper and lead salts seem specially liable to be decomposed by the combined action of air and water, whilst even the tannic acid itself in arpeous solution rapidly undergoes change. To have any value, therefore, estimations by gelatine or permanganate of potassium must be mirle with perfectly fresh infusions. But the mucilaginous and other substances that are simultancously dissolver by water from the oak-bark, also act upon the reagents and render the estimation inaccurate. By extracting with alcohol such foreign substances are exchuler ; but the cstimation cannot he marle in alcoholic solution, and distillation can scarcely be effected without partial decomposition of the tamnin.

1 See Hlasiwetz, Annal. d. Chem. und Pharm. cxlii. 220, 1867 (Amer. Journ. xxxviii. 504); also Mulder und Olaanderen, Jahresb. f. Chem. 261, 1858.

- Compare E. Johanson, 'Beitr. zur Chem. d. Eichen-, Weiden-, und Ulmenrinde,' Diss. Dorpat, 1875 ; Grabowski, Annal. d. Chem. und Pharm. cxlı. 1, 1868. For oak-red see also Böttinger, ibid. ccii. 269, 1880. Lnewe has recently contested the ghensidal mature of fuercitamnic acid. Compare \%citschr. f. anal. Chem. xx. 208, 1881 (Journ. Chem. Soc. xl. 901). Loewe believes oak-red to be a kind of anhydride produed from the tamnic acid loy loss of $4 \mathrm{nr}$ 3 molecules of water. Büttinger (Ber. d. d. Chem. Ges. xiv. 2390 ; Journ. Chem. Soc. xl. 1041) considers quercitannic acid itself to be a glucoside, and points out the difference between that substance ancl another constituent of oak-bark also soluble in water and capable of tanning. The latter was the body isolated by Loewe. 
The best results would probably be olntained by extracting directly with alcohol, eraporating the tincture in a partial vacuum, treating the residue with water, quickly filtering and estimating at once with gelatine or permanganate of potassium. (Cf. $\$ 51,52$, VII. and XII.) In standardizing the solutions, it may be useful to remember that, according to Cxünther's experiments, quercitannic acid, though differing greatly in other respects from gallotannic acid, possesses the same quantitative action on permanganate of potassium. It must be observed that tamic acid is deposited when its solution is completely saturaterl with chloride of ammonium; it is advisable, therefore, when precipitating with gelatine, to follow the directions given for titrating catechu-tannic acid. Quercitamic aciel is sparingly soluble in ether; ferroso-ferric salts produce inky mixtures with its aqueous solution; other of its properties are mentioned in $\$ 549,51$. The lead salt obtained by precipitation with a slight excess of the acetate contains 56 to 57 per cent. of oxide, the copper salt 29.5 per cent. The oak-red produced artificially from the tannic acid is identical with the phlobaphene that occurs naturally in the bark. It is likewise coloured black by iron salts, yields protocatechuic acid and phloroglucin when fused with potash, and possesses the properties of a phlobaphene as enumerated in $\$ 108,160$.

The tannins of the pine, ${ }^{1}$ biret, many species of acaciu, etc., which have been but little investigater, may possibly resemble quercitannic acid in many of their essential characters.

Filix-tunnic acid" is resolved, on boiling with acids, into glueose and red flocks of filix-red; the latter closely resembles cinchonared.

Cinchona-tannic acid ${ }^{3}$ undergoes a similar decomposition with production of cinchona-red. Its lead salt is somewhat easily soluble in acetic acid.

${ }^{1}$ Compare Kawalier, Wiener Akad. Ber. xi. 354 et ser.; Rochleder und Kawalier, ibid. xxix. 22 \&.t s\%. : Wittstein Vierteljahresschr. f. pract. Pharm. iii. $14,1854$.

2 See Malin, Chem. Centralblatt, xii. 46S, 1867. For tamaspidic acid and jteritannic acid, the former of which Malin believes to be impure filix-red, see Luck, ibid. 657, 676, 1851. Compare further Grabowski, Annal.d. Chem. and Pharm, cxlii. 279, 1867.

3 Compare liembold, Annal. d. Chem. und Pharm. cxliii, 270, 1867, and Schwarz, Chem. Centralblatt, 193, 1852. 


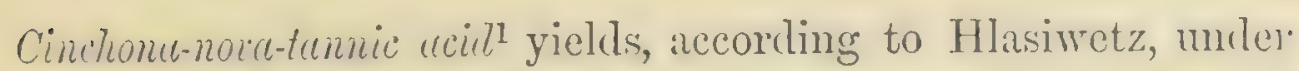
the sime conditions, sugar and cinchona-nova-red; the latter is easily soluble in ether.

For ipecacuante-tunnic acid ${ }^{2}$, see Willigh and Podwissotzki; for. leditcunic acid, Willigh" and Rochleder and Schwarz; ${ }^{4}$ for mucitannic aciu, Phipson;" for the tannin of maté, Arata; for celastius-tumic acid, Dragendorff.' Information concerning some other tannins may be gained from Gmelin's 'Chemistry.'

\section{OTHER GLUCOSIDES.}

\$166. Cyclopin, Rhinenthin, etc.-C'yclopin, which, however, camnot, without some consideration, be classed with the tannins, is a glucosidal substance found by Greenish, ${ }^{8}$ in the so-called Cape or Bush tea. It is freely soluble in water, and is precipitated from solution by acetate of lead, as well as by digestion with the oxyhydrate of that metal; from the combinations with lead thus obtained, it can be liherated by sulphuretted hydrogen. Ether precipitates it from alcoholic solution. Boiled with 4 per cent. hydrochloric acid, cyclopin decomproses into glucose and cyclopiared, which latter is insoluble in ether. Writh strong hydrochloric acid, the solution turns rapidly red. Cyclopin is not precipitater by gelatine or tartar emetic, and does not possess an astringent taste. In the plant producing it, it appears to he easily converted into oxycyclopin, which is insoluble in alcohol, and undergoes a similar decomposition to cyclopin itself.

Another glucoside that yields a deeply coloured decompositionproduct when boiled even with very dilute acids, is the rhincuthin, occurring in various species of Rhinanthus, Alectorolophus, anil Melampyrum.? It can be obtained in colourless acicular crystals, soluble in water and alcohol, insoluble in ether, and not preci-

1 See Hlasiwetz, Annal. d. Chem. und Pharm. lxxix. 130, $185 \%$.

2 Journ. f. pract. Chem. li. 404; Pharm. Zeitschr. f. Russland, xix. 1. Pharm. Journ. 'Trans. [3], x. 642.

${ }^{3}$ Chem. Centralblatt, $790,1852$.

4 Zeitschr.f. anal. Chem. v. 668, 1869.

Ibid. p. 812.

6 Jahresb. f. Pharm. 164, 1878. Compare also Byasson, ibid.

7 Archiv d. Pharm. [3], xii. 113, 1878.

8 Sitzb. d. Dorpater Naturforscher-Ges. 345, 1880 (Pharm. Journ. and Trans. [3], xi. 543). It is accompanied by the crystalline cyclopic-fluorescin, which is soluble in cther and alcohol but sparingly soluble in water. Potash dissolves it with yellow colour and production of a fine green fluorescence.

${ }^{9}$ Compare Ludwig, Archiv d. Pharm. cxlii. 199, 1870. 
pitated by acetate of lear. Boiled with dilute 'hydrochlonic acid it yields rhinanthogenin, which is of at driti bluish-yreen culour, and. insoluble in water.

Some alkaloils, too, possess the proprerty of yielling, nuler similar conditions, recply colourel decomposition-proulucts, as for instance, rhoadine, thebaine $(§ 189)$.

$\$ 16 \%$. Other important Glucosides; Solubility.-A remarkable peculiarity of the ahove, as well as a number of other glucosides, is thit, although more or less easily dissolverl hy alcohol, they are sharingly or not at all soluble in ether. Certain glucosiles that liave been mentioned, where necessary, in the foregoing chapters show a similar insolubility in ether (compure convolvulin, 1.53 ; digitalein and digitonin, 1.5 .5 ; chrysophim, 14 , etc.); in fact, this negative property may be sail to he characteristic of the majority of glucosides.

Nitiogen enters into the composition of sonc fer of the members of this class, and certain of them, when acted upon by ferments or actils, yield in artlition to sugar a rolutile decompusition-protuct of characteristic olon' ; lut this is not the case with most of them.

The following are some of the better-7noun glucosides that are suluble in alcohul, contain nitrugen, and yield a culetile decompusitionjroduct.

Limygdelin and leneroceresin ${ }^{2}$ are both tolerably casily soluble in water (amygdalin in 12 parts), and in boiling alcohol of sp. gr. $0 \cdot 819$, but more sparingly in coll. They are insoluble in petroleun sirit, and are precipitated hy cther from alcoholic solution. Amyodalin crystallizes with facility in hitter scales helonging to the monoclinic system. Laurocerasin has not yet been obtained in crystals. They are both levo-rotatory. Conc. sulphuric acid dissolves them with pale redilish-riolet colour. Emulsin easily resolves them into shluense, oil of hitter almomels, and hydrocyanic acid, the latter hody being profuced in larger quantity from amygolalin than from laurocerasin. The reason for this is to be found in the fact that in laurocerasin half of the eymogen in the amyodialin aroup, has hecur already converted into formic acid, so that lamecerasin mat le regatried as amygelalite of amysgdalin. On boiling amygedalin and lanwocerasin, therefore, with biryta-water, the foriner will yieln one molecule of ammonia for every molecule of

'Compare Lehmann, 'Ueber das Amygrdalin der Kirschen, PHaumen,' etc., Diss. Dorpat, 1874. 
harimn salt formerl, whilst from the latter only one of the formor. can be olstained for every two of the latter. ${ }^{1}$

Methods for the quantitative estimation of amygclalin have hec'n proposed by Rieckher" and Felelhaus. ${ }^{3}$ That of the latter is based upon the rlecomposition of the amygrtalin by emulsin in arpucons solution and estimation of the hydrocyanic acirl produced. Almonds are freed from oil, powered and macerated with water for twenty-four hours. The hyrlrocyanic acid is then dictilled oft in a current of stcan, received in ammoniacal water, and estimated as cyanicle of silver. Anyone that has ristilled litter-almonil water, or hrought hydrocyanic aciel into contact with powerful alkalies, will know that this method is very faulty. To obtain even approximate results I think it must he necessary that (") the flaskis in which the maceration is conducted should be completely filled with the mixture, and $(b)$ the use of ammonia or other powerful base should be avoided.

In Rieckher's methor the anygdalin is decomposed by hychate of barium, a reaction which, according to Lehmam, takes place tolerably smoothly. One reason for preferring this process to FeldInaus's is, that the result can he checked hy estimating on the one hand the ammonia liberited, and on the other the amygrdalate of harium producerl. The latter can he determined in the solution after expulsion of the ammonia ly removing the excess of bariun with carbonic aciel gas, and then decomposing with sulphuric acid the amygralate of that metal which has heen left in solution. From the sulphate of barium thus obtained the amount of amysdalin acted upon can he calculated. This methorl cannot, however, I think, he applied directly to almond meal deprived of fat, but only to the impure amyordalin obtained hy exhausting with boiling alcohol and precipitating with ether.

Ilyionute of prolessimn crystallizes in rhombic primm, which are frecly soluble in water, spraringly in cold alcohol, but are dissolven by warm $\left(500^{\circ}\right.$ to $\left.60^{\circ}\right)$ 8.5 per cent. spirit. Myronic acid itself is also) soluble in cold strong spirit, but rapidly decomposes. In arpueons solution myronate of potassium is easily resolved by ferment", especially by the myrosin of white and black mustard (but nut

\footnotetext{
${ }^{1}$ It is remarkable that Lehmann could find cane-sugar in the seeds of the anple, pear, cherry, plum, peach, and litter almond, which contain crystallizable amyodalin, whilst sweet almonds yielded ghense only.

2 N. Jahrb. f. Pharm, xxiv, 65. 3 Archiv d. Pharm, clxvi. 52.
} 
by emulsin) into volatile oil of mustarl (sulphocyanide of allyl, $\$ 29)$, characterized by its extreme pungeney, glucose and bisulphate of potassium. A quantitative estimation might possibly be made by freeing the finely-powdered seerls from oil, exhansting with warm 85 per cent. spirit, and digesting the tincture for some time with carbonate of barium. From the filtrate the alcohol might be recovered by distillation, the residue dissolved in water, and digested with myrosin at a temperature of about $40^{\circ}$, the barium being finally precipitated as sulphate by the addition of hydrochloric and sulphuric acid. One molecule of stzlphate of barium indicates one of myronic acid. ${ }^{1}$

White mustard contains no myronic acid, but in its stead another glucoside, to which the name of simulbin has been given. Like myronic acid, it dissolves in hoiling 8.5 per cent. spirit, separating out again to a great extent on cooling. It is crystalline, insoluble in ether and hisulphide of carbon; sparingly solul)le in cold, freely in hot alcohol, and in water. Alkalies colour it yellow, nitric acid transiently blood-red. It reduces alkaline copper solution, and is precipitated by mereuric chloride and nitrate of silver. Warm solution of caustic sodil converts it into sulphate and sulphocyanide of soda; myrosin into glucose, acicl sulphate of sinapine and sulphocymate of acrinyl $\left(\mathrm{C}_{7} \mathrm{H}_{7} \mathrm{O}, \mathrm{NC}\right.$ 's).

Sulphocyunate of sinupine, which also occur's in white mustark, is not ghlucosidal, and differs from 'sinalbin in being more easily soluble in cold alcohol, and in yielding the sulphocyanide reaction directly with ferric chloride. ${ }^{2}$

Ericolin and menyentlein." are glucosides containing no nitrogen, but yielding casily rolutile decomposition products. The former hats been described in \$15\%. Menyanthin is frecly soluble in warm water and in alcohol, but insoluble in ether. Conc. sulphuric acid dissolves it with the grarlual prorluction of a reshishviolet colonration. Warming with dilute sulphuric acid resolves it into gheose and menyanthol, the latter posiessing a penetrating odour. Menyanthin is mecinitaterl by tamnic acid, hut not by acetate of lead.

${ }^{1}$ Compare Will und Körner, Annal. d. Chem, und Pharm. cxxv. 25\%, 1863. (Am. Journ. Pharm. xxr. 323.)

a Compare Will und Laubenheimer, Annal. d. Chem. und Pharm. cxcix. 150, 1879 (Pharm. Journ. and Trans. [3], x.918). Babo und Hirschbrum, ibid. Ixxxiv. 10, 1852.

${ }^{8}$ Compare Kromayer, Toc. cit.; Liebelt, Jahresb. f. Pharm. 119, 1877. 
I'iniputin is described by Kitwalier ${ }^{1}$ as being freely soluble in water and alcohol, insoluble in pure ether, and not precipitable ly hasic aretate of lead. Its decomposition-products resemble thowe of ericolin.

Of ghucosides which yield cither fured or difficultly rolutile decrin. position-products not possessing any characteristic orlour, the follow ing may be mentioned.

cuniferin is sparingly dissolyed by cold, but freely by wamm water and hy alcohol. It crystallizes in glistening needles, and melts at $185^{\circ}$ (uncorr.). With conc. sulphuric acid it forms a violet solution, and when moistened with hydrochloric acid aml. phenol develops a blue colonration. Dilute acids resolve coniferin into sugar and a resinous substance; with emulsin it yields a crystalline decomposition-product. The latter, which is sparingly solul,le in water and alcohol, can he removed by ether from it. anpeouls solution. Its melting-point lies between $73^{\circ}$ and $7 t^{\prime}$. Coniferin, when exposed to the air, gradually acquires a ranillitlilic orlour, al change rapidly brought about by witrming with dilute sulphuric acid and bichromate of potassium, and caused by the lecomposition of the coniferin with the prouluetion first of the methyl-ethyl ether of protocatechuic aldehyle, and finally of renillin: (15.5). The reaction with hydrochloric acid and phenol may be used in testing for coniferin microchenicully in the camlium of conifers.

The illentity of this sulstance with the coniferin of Tangel," detected in sections of conifers hy the red colonration producer? by cone. sulphuric acid and phenol, must he left for the present an open ruestion. Mïller ${ }^{-1}$ has shown that the latter also occur. in most indigenons trees (Sialix, Popmlus, I'runus, Acer, Querens, etc.), and is to be met with in abumlance, especially in the autumn, in the hard hast and alburnum. According to Miëller, the pheneI only hastens the appearance of the red colour.

dibutin is sparingly soluble in cold alcohol, ether, and cold

I Chem. Centralblatt, 705, 724, 1853.

- Compare Tiemann und Haarmann, Ber. d. d. chem. Ges. vii.609, 1874 (Journ. Chem. Soc. xxvii. 895). Sec also Kubel, Journ。 f. pract. Chem. xcvii. $243,1866$.

${ }^{3}$ Florn, 1vii. No. 15, 1874.

Ibid. No. 25.

¿Compare Kawalier, Chern. Centralblatt, 761, 1852; Strecker, Annal. d. Chem. und Pharm. cvii. 288, cxviii. 292, 1861; Hlasiwetz and Habermann, ibid. clxxvii, 334, 1875 (Journ. Chem. Soc. xxix. 7S, xxx. 29S). 
water, but the latter solvent dissolves it with facility when wirmed. Dilute sulphuric acid resolves it into gluense, hyrlroquinone and methyl-hydroquinone. Both of the latter can he extracted by shaking with ether, and, when wamed with dilute sulphuric acil and peroxide of manganese, yield quinone, recosnisable by its characteristic iodine-like odlour. Acetate of learl does not precipitate arbutin.

Daplenin ${ }^{1}$ differs from arbutin in being precipitated by acetate of lead. It is sparingly dissolved by cold, but freely by warm. water and by alcohol, and is insoluble in ether. Alkalies colour it yellow. Acids and ferments resolve it into sugar and daphnetin; the latter can be partially sublimed without recomposition. Certain other constituents of mezereon bark yichl umbelliferone $(\$ 27)$ by dry distillation.

Sulicin crystallizes in colourless needles and scales, which hare a powerful action on polarized light, and are freely soluble in boiling water and alcohol, but much less so in colit. It is insoluble in ether. From aqueous solution it can be extracted by :mylic alcohol (56). Hydrate of learl does not combine with it. Boiling with dilute acids decomposes salicin into sugar and saligenin or saliretin, both of which substances can be remored by shaking with ether. If an aqueous solution of salicin or saligenin is boiled with dilute sulphuric acid and bichromate of potassium, salicylous acid is produced. (Cf. \$25.) Conc. sulphuric acid elissolves salicin, saligenin, and saliretin with production of a fine red colour. Salicin strikes a beautiful violet with Fröhle's reagent. These reactions can also be employed for the miciochemicul detection of salicin.

l'opulin yields benzoic acid in ardition to the abore-mentioned recomposition-products when acted upon by dilute acids (ef. \$ 26), and salicylous acid when wamed with chromic ateil. With conc. sulphuric acid a red colouration is developed, and with Fröhde's reagent a violet, which, however, is somewhat less intenice than that yielded by salicin moler similar conditions. It is consirleralily less solulle than the latter in water and in alcohol, and can be remover from arpueous solution not only hy amylic alcohol (like salicin), lut also by chloroform and (with difliculty) by

${ }^{1}$ Compare Zwenger, Annal. d. Chem. und Pharm. xc. 63, 1858 (Amer. Journ. Pharm. xxxiii, 325). 
benzene (5.55). Populin decomposes with far greater facility than salicin.

Bencchelicin, ${ }^{1}$ detecterl by Johanson in willow Tark, forms colonusess crystals, soluble in water and alcolnol. With cone. sulphuric acid it tums yellow. Fröhle's reagent roes not produce a violet colouration. Boiling with not over-dilute hydrochloric acil resulves benzohelicin into glucose, henzoic acil, ant it resinous substance that dissolves blood-red in conc. sulphuric acid.

Philyrin 2 is much less soluble in water and alcohol than is salicin, and yields umler the influence of dilute acids, ghrose and philysenin, a polymer of saligenin. Both philyrin am philyenten dissolve in conc. sulphuric acid with red colouration.

Ihlorkinin ${ }^{3}$ crystallizes in colonrless neerles sparingly soluble in cold water, easily in hot. Fthyl and methyl alcohol dissolve it with facility, ether with difficulty. Dilute acids resolve it into glucose and phlorrhetin. Conc. sulphuric acid forms red solutions srith both phlorrhizin and shlorrhetin; with Fröhde's reagent a splendid royal-blue colouration is rapidly developed. Moistened with ammonia and exposerl to the air, phlorrhizin tuns yellow, red, and finally blue.

- Tsculin can likewise be obtained in colourless needles solulle in 125 parts of boiling, 672 of cold water; in 24 of boiling, and 120 of cold absolute alcohol. Chloroform removes it from aqueous solution (5.5). Boiling with clilute acids resolves it into glucose and iesculetin. The latter yields a yellow solution with alkalies; it is also soluble in bisulphite of ammonia, and if such a folution be mixed with ammonia and shaken with ail, at first b) horl-red and subsequently a deep blue colour is developerl. The very characteristic blue fluorescence of resculin is increasen $1 \mathrm{y}$ alkalies and destroyed by acids.

Frarin possesses a similar fluorescence, and can also be whtained in colourless crystals. It is more sparingly solulle in water and alsolute alcohol than resculin, but more freely in ether, to which it imparts its fluoresence. Ferric chloride is silil at furst to strike

I See Johanson, loc cit. Piria, Annal. d. Chem. und Pharm. 1xxxi. 215, 1852; xcvi. 375, 1855 (Amer. Journ. Pharm. xxiv. 241, xxviii. 259).

2 Compare Campona, Annal. d. Chem, und Pharm. Ixxxi. 245, xcvi. 375.

3 For isophlorrhizin, see Rochleder, Journ. f. pract. Chem. civ. 397, 1868 (Amer. Journ. Pharm, xli, 119). 
a green colour and subsequently yield a yellow precipitate. Fraxin is thrown down by acetate of lead. ${ }^{1}$

Syringin (5) crystallizes in colourless necdles, dissolves with difliculty in cold water, more easily in hot water and alcohol, but is insoluble in ether. Basic acetate of learl does not precipitate it from arqueous solution. Conc. sulphuric acid dissolves it with (leep) blue colouration; Fröhde's reagent, blood-red passing to violet; conc. nitrie acid, deep reel. Chloroform extracts syringin from aqueous solution. ${ }^{2}$

For globulcurin see Walz; for coriamyrtin compare $\$ 155$; for pittosporin see v. Müller ; ${ }^{4}$ for samaderin see de Trij. ${ }^{5}$

Culocynthin can be obtained in yellowish crystals which dissolve in conc. sulphuric acirl with the gralual production of a fine red colour ; Frihde's reagent produces a cherry-red. It is extremely bitter, casily soluble in water and alcohol, but insoluble in ether: Benzene (5.5), or better, chloroform or amylic alcohol, extracts it from anneons solution; it is precipitated by basic acetate of leal and by tannin.

Bryonin is also precipitated by the latter reagent. ${ }^{6}$

For onomin, which gradually assumes a cherry-red colour with conc. sulphuric acid, see Hlasiwetz. ${ }^{7}$

Apiin crystallizes in shining silliy needles soluble in hot water. or, more easily, in hot alcohol. Ether does not dissolve it.

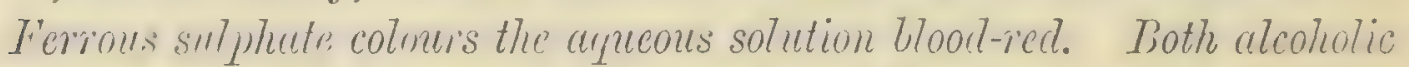
und apneous sulutions gelutinize on cooling. In dilute alkalies apuin dissolves with yellow colouration.

For datiscin, which is also coloured yellow by alkalies, see Bracomots and Stenhonse." Ferric chloride precipitates it green;

1 For a number of other glucosides and allied substances (argyrescin, aphrodæscin, etc.) discovered by Rochleder in horse-chestnuts, see Journ.f. pract. Chem. Ixxxvii. 26, 1863 (Amer. Journ. Pharm. xxxv. 290).

-For the nearly allied ligustrin, see Kromayer, Archiv d. Pharm. cv.9, 1861 ; for syringopicrin (easily soluble in water), ibid. cix. 26, 1862.

3 N. Jahrb. f. Pharm. vii. 1, 1857 ; xiii. 281, 1860.

4 "The Organic Constituents of Plants,' Melbourne, 1878.

"Chem. Centralblatt, 92, 1859 ; Jahresb. f. Pharm. 208, 1872. See Blume, Amer. Toum. Pharm. xxxi. 342.

${ }^{6}$ N. Jahrb. f. Pharm, ix. 65, 217, 1859 (Amer. Journ. Pharm. xxxi. 249).

- Chem. Centralblatt, 449, 470, 1855.

${ }^{8}$ Annales de Chimie et de Physique [2], iii. 277, 1816.

9 Annal. d. Chem. und Pharm. xcviii. 166, 1856 (Journ. Chem. Soc. ix. 226). Tor helianthic acid compare Ludwig und Kromayer, Archiv d. Pharm. [2], xcix. 1, 1818 (Amer. Journ. Pharm. xxxii. 135). 
arectite of learl, yellow. T/ander 1 has recently foumd a glucoside: allierl to datiscin in the seeds of Xanthimn strumarimu. Fur 1)hysulin, which can casily be extracterl by shaking with chlor: form (\$5), see Dessilgnes and Chautard ; for dulcumuriu, sec Gicissler:3 The latter is soluble in acetic ether, insoluble in ether', chloroform, bisulphide of carbon, and henzene. It is precipitater hy tamin, and by basic acetate of lear. Conc. sulphuric acid dissolves it with red colouration luassing to rose; with alkalies it forms reddish-brown solutions.

Hesperilin shows a disposition to form sphrero-cystals. It is sparingly soluble in water and cold alcohol, freely in warm alcohol and acetic acil, but insoluble in cther. Ferric chloride colours it brownish-red ; conc. sulphuric acid gradually hright red (limonin the same). Acetate of lead produces no precipitate. If a solution in dilute potash is evaporated to dryness, the residue is coloured red, passing to violet when warmed with excess of dilute sulphuric acil. Hesperidin can be recognised under the microscope as sphæro-crystals soluble in warm alcohol.

Crocin (polychroite) forms a dark red powder sparingly soluble in ether and water, more easily in alcohol. Conc. sulphuric acid colours it blue. Dilute acicls resolve it into glucose and crocetin (insoluble in water), a saffron-like orlour heing (leveloped during the lecomposition. Basic acetate of lear precipitates crocin."

Glycyrahive is deposited from glacial acetic acid in spharocrystalline masses of prismatic needles. After purification with atcetic acid it is almost insoluble in water (forming a jelly with it), lout may nevertheless be cxtracted (in combination with bases) from liquorice-root by that menstrum. It contains nitrogen, is sparingly soluble in atssolute, more easily in boiling 90 yer cent.

1 'Chem. über die Samen von Xanthium strumarium,' Diss. Dorpat, 1880.

" న. Repert. f. Pharm. i. 216, 1851 (Amer. Journ. Pharm. xxv. 135, 136).

${ }^{3}$ Archiv d. Pharm. [3], vii. 289, 1875 (Pharm. Journ. and Trans. [3], vi. 1010).

${ }^{4}$ Compare Hoffmann, Ber. d. d. chem. Ges. ix. 250, 685, 1876 (Joum. Chem. Soc. $\mathrm{xxx} .420,421)$; for aurantiin, murrayin, limonin, ibid.; also Hilger, ibid. 26 (Journ. Chem. Soc. xxix. 709). For naringin, see Archiv d. Pharm. [3], xiv. 139, 1879. See also Dehn, Zeitschr. f. anal. Chem. ii. 103, 1866 ; and Tiemann und Will, Ber. d. d. chem. Ges. xiv. 946, 1881.

5 See Weiss, Joum. f. pract. Chem. ci. 65,1868 ; Stoddart, Pharm. Journ. and Trans. [3], vii. 238, 1876.

"Compare Habermann, Annal. d. Chem. und Pharm. cxevii. 105, 1879 (Pharm. Journ. and Trans. [3], x. 45, 1879). Habermann changes the name to glycyrrhizic acid. 
:leohol, and is almost insoluble in ether. Conc. sulphuric acid precipitates it from arpueous solution; acetate of learl and chloride of calcium, from alcoholic. Teese's method for the quentitutice dreimination of glycyrrhizin is based upon the precipitation hy sulphuric acid.

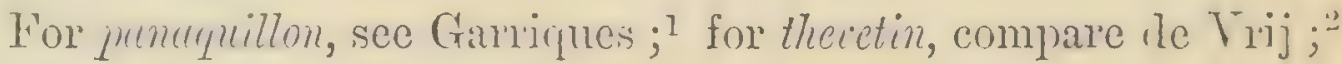
for chamcetirin, see Greene. ${ }^{3}$

('yrtemin. (Primulin) is crystalline and dissolves freely in water'; the solution froths when shaken. It is casily soluble in dilute aleohol also, but sparingly in absolute, and insoluble in ether." It is waid to hear a close resemblance to saponin. (Cf. St it et s\%.; $\$ 167$.

For gretiolin, see Marchand "s and Walz; ${ }^{6}$ for portulin, Walz ${ }^{7}$ and Delffs. ${ }^{s}$

For convallarin and convallamarin, see $\mathrm{WaI}_{\mathrm{*}}{ }^{9}$ The former is sparingly soluble in water', but imparts to it the property of frothing; it is frecly soluble in alcohol, but insoluble in ether. The latter dissolves more casily in water, is precipitated by tamin, aml tums gradually violet when exposerl to the air in contact with sulphuric acil. Warming with hydrochloric acid colnurs it rerl. Convallamarin can be extracted by shaking with chloroform $(\S 55)$.

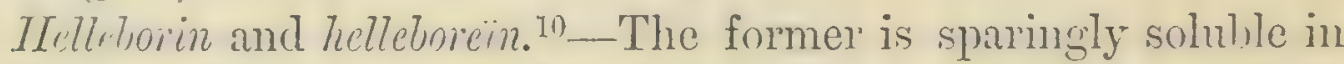
cold water, freely in alcohol and chloroform; the latter easily in water, more sparingly in alcohol, and insoluhle in ether. It cim be extracterl by shaking with chloroform (5.5). Both dissolve

${ }^{1}$ Chem. Centralb]att, 721, 1554 (Amer. Journ. Pharm. xxvi. 511).

2 N. Jahrb. f. Pharm. xxxi. 1, 1869. Compare also Jahresb. f. Pharm. 112, 1877 ; Blas, Amer. Journ. Pharm. xli. 310.

3 Amer. Journ. Pharm. 1. 250, 1878.

4 Compare MIutschler, Amnal. d. Chem. und Pharm. clxxxv. 214, 1875 (Year-book Pharm. 145, 1878). See also Luca, Compt. Rend. Ixxxvii. 297, 1878 (Pharm. Journ. and 'Trans. [3], vii. 876, 187\%).

5 . Tourn. de Chim. méd. xxi. 517 (Amer. Journ. Pharm, xvii. 281).

6 Jahrb. f. Pharm. x. 317, xiv. 70, 1852, xxi. 1, 1863, where certain other constituents of gratiola are also treated of. (Amer. Journ. Pharm. xxxi. 340).

7. Tahrb. f. Pharm. iv. 3, T. 2S4, vi. 10 ; N. Jahrb. f. Pharm. xiii. 174, 1860.

${ }^{8}$ Ibid. ix. 25, 1858.

9 Ibid. x. 145, 1858 (Amer. Journ. Pharm. xxi. 57 7 ).

II) Compare Husemann and Marmé, Annal. d. Chem, und Pharm. cxxxv, 5í, 1865 (Tharm. Tonrn, and Trans. [룽, vii. 621, 1866). 
in conc. sulphuric aciel, with immerliate production of a finc rect colouration.

For digitatin and digitalein, see $\$ 155$.

S'illuin, a glucosicle obtained from Ścilla maritima, resembles digitilin in physiological action. It is sparingly soluble in cold water, but freely in alcohol, and when boiled with dilute hydrochloric acid is decomposed into sugar and a second sulistince, soluble in ether. Concentrated hydrochloric acid is coloured red. when boiled with scillain, and this is followed by the separation of a greenish flocculent deposit. Concentrated sulphuric acirl dissolves it brown, with green fluorescence, and the solution is coloured bluish-red by bromine. Basic acetate of learl does not precipitate scillaïn. ${ }^{1}$

Suponin and digitunin are likewise ghucosides; they have ahearly been described in $\$ \$ 77,78,79,155$, where mention has been male of their insolubility in absolute alcohol. My object in referring to them again here, is to draw attention to the resemhlance they bear, in many respects (frothing of the solution, etc.), to the preceding glucosides (cyclamin, etc.). The following sul)stances are also allied to saponin:

Senegin-which, however, is possibly identical with saponinwas found by Christophsolm" to differ from that hody only in the rapidity with which the violet colouration was producen by sulphuric acid. It can be estimated by the methods detailed in $\leqslant$ :

C'mistophsohn also proved that both saponin and scnesin are accompanied in the dlugs yielding them by another substance that has a much more porverful action on the heart than either of those principles themselves. This other substance remains in solution after separation of the saponin ly haryta-mater, but could not be obtained in a state of purity.

Melunthin, found by Greenish ${ }^{3}$ in the seeds of Nigcllat sativil, is not precipitated by ether from alcoholic solution. It resemhles saponin in being freely soluble in weak spirit, but may be ristinguished by its slight solulility in water, and in the catic

${ }^{1}$ Compare Jarmerstedt, Archiv f. exp. Pathol, und Pharmacol. xi. 22, 18 79 (Amer. Journ. Pharm. lii. 91).

Loc. cit.

3 Sitzb. der Dorpater Naturf. Ges. 240, 1879; 91, 1881. Pharm. Journ. and Trans. [3], x. 909, 1013, xii. 6s1. 
with which it splits up into sugar and melanthigenin when boiler with a dilute acid.

The so-called smilacin was also formerly regarded as allied to saponin, but the researches of Fliickiger ${ }^{1}$ have shown that under this designation a mixture of substances has been described, the principal constituent of which was named parillin. This body stands in close relation to sapogenin, the decomposition-product of saponin; and as the latter is contained in sarsaparilla, ${ }^{2}$ it is probable that parillin is procluced from it during the life of the plant. According to Flïckiger, parillin is not soluble in cold water to any appreciable extent, but dissolves in 20 parts of boiling. It is taken up by spirit of sp. gr. 0.83 more easily than by stronger or weaker alcohol. ${ }^{3}$ Its reaction with conc. sulphuric acid resembles that of saponin. Boiled with 10 per cent. sulphuric acid it decomposes into sugar and parigenin, with production of a green fluorescence. $A$ similar fluorescence is also observed when hydrochloric acid gas acts upon a solution in a mixture of chloroform and alcohol.

Serpogrnin resembles parillin in most of its properties. Rochleder is of opinion that it still retains a little sugar, and is therefore really the result of an incomplete decomposition of saponin. The violet colouration gradually produced when sapogenin is dissolver in conc. sulphuric acid serves to distinguish the body from digitoresin, which, according to Schmiedeberg, yields a yellow solution. (See § 155.)

Indiecen may also be mentioned here, as, although it is not a sullstance that can be unconditionally ranked as a glucoside, it may nevertheless be compared with them as regards its constitution. By the decomposition of indican indigo-blue is produced, together with a kind of sugar called indiglucin. I leave it, however, an open question whether the formation of indigo-blue is preceder by that of indigo-white, which, it is true, rearlily yields that substance by absorption of oxygen. Indican appears to occur in many plants (leaves, etc.), but to undergo a prartial decomposition when they are slowly dried, and the black or blue

${ }^{1}$ Compare Fliickigrer and Hanbury, 'Pharmacographia,' 646.

"Otten, 'Iistiol. Unters. der Sarsaparillen,' Diss. Dorpat, 1S76. Otten estimated the saponin by the methods given in $\$ 78$.

${ }^{3}$ Archiv d. Pharm. [3], x. 535, 1877 (Pharm. Journ. and Trans. [3], viii. 488). 
colouration of the leaves produced thereby would aronise a suspicion of its presence. Cold spirit extracts indican ; the solution is hest evaporated in a current of dry air at the ordinary temperature. Foreign bodies may be removed from the arpueous solution by shaking it with freshly precipitated hydrate of copper, but the copper that simultaneonsly passes into solution must be subseuluently removel by sulphuretted hydrogen. The arjueons solution must also be evaporated at the ordinary temperiture, the residue dissolved in cold alcohol, and the indican precipitaterl by ether. Dilute acids decompose this unstable body, as above hescribed, with production of indigo-blue.

The latter is characterized by its insolubility in water, alcohol, and ether and solubility in carbolic and fuming sulphunic acids. It can be sublimed, and yields indigo-white (solnhle in water) when boiled with glucose and an alkali. Adrantage might be taken of the latter property testing for inclican in dried regetable substances. The residue of the material after exhaustion with water might be boiled with an alkali and glucose; from the solution thus obtained the indigo-blue would be again precipitated by passing a current of air through it.

$\$ 168$. The following bifter principles have not as yet been shown to he glucosides; but they are likewise sparingly solulhe in ethei, more freely in alcohol: Antiarin, ${ }^{1}$ aristolochio-bitter, ${ }^{-}$calendulin ${ }^{3}$ (gelatinizes with water), californin ${ }^{4}$ (appears to be a mixture of alkaloids, of which loturin, which is strongly fluorescent in acid solution, is especially interesting); carapin,${ }^{5}$ eratargin, ${ }^{6}$ cusparin ${ }^{7}$ (coloured green by nitric acid, red by mercurous nitrate); quinorins (quinovic acid, obtained by boiling quinovin or quinova-bitter with acids, is said to resemble cholic acid in gradually turning red with

1 See de Vrij and Ludwig, Zeitschr. d. oesterr. Apoth. Ver. 9:2, IS6S (Amer. Journ. Pharm. xxxv. 474).

2 See Walz, Jahrb. f. Pharm. xxvi. 73. Gmelin's 'Organic Chemistry.'

${ }^{3}$ See Stoltze, Ber. Jahrb. f. Pharm. 1820.

${ }^{4}$ See Mettenheimer, N. Jahrb. f. Pharm. i. 341, 1870. Hesse, Ber, d. d. chem. Ges. xi. 1542, 1878 (Journ. Chem. Soc. xxxvi. 73).

5 See Caventou, Vierteljahresschr. f. Iract. I'harm. x. 42.2, 1861 (Amer. Journ. Pharm. xxxi. 231).

"See Leroy, Journ. de Chim. méd. xvii. 3.

'See Saladin, ibid. ix. 388 (Amer. Journ. Pharm. v. 346).

8 Compare Gmelin, 'Handbook of Organic Chemistry.' Staceler's method of rstimating quinovic acid in certain cinchona barks (N. Tijdschr. voor de I'harm, in Nederl, 152, 1878) was pronounced unsatisfactory by de Vrij (ibid.
306 ). 
sulphuric acid and surgr); cnicin $^{1}$ (is said to dissolve green in conc. hydrochloric, red in sulphuric acid. It can be extracted by shaking with henzene (5.5), but is partially precipitated from aqueous solution ly basic acetate of lead); geranizin," lactucin and its allies,"

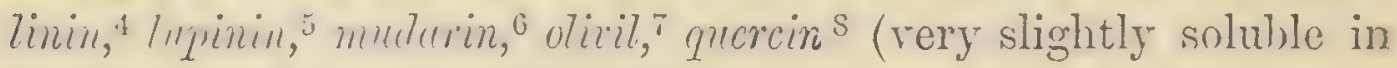
absolute alcohol); sparattospermin. ${ }^{9}$

\$169. Aloins.-There is another group of non-gincosidal bitter principles to which I should like to direct attention ; viz., that of the uloins-a series of closely allied but not identical chemical inclivichia. All the member's of the group are soluble in water and alcohol, sparingly only in ether; but it must he olserver that the separate aloins show notable differenees in their behaviour to water. That obtained from Tiatal aloes is the most difficultly soluble, whilst the aloin of Cape aloes, which is possibly isomeric witlo nataloin, is comparatively freely dissolved. ${ }^{10}$

All the aloins can be obtained in yellow crystals, but show a sreat clisposition to form supersaturated apueous solutions in which, perhaps, they exist in an amorphons state and free from water of crystallization. From such solutions the aloin can he

I See Nativelle, Journ. de Chim. méd. xxi. 69, and Scribe, Comptes rendus, $x$ x. 802. See also my article on the detection of foreign bitters in beer in the Archiv d. Pharm. [3], iv. 293, 1874; also 'Kubicki, 'Beitr. zur' Ermittel. fremder Bitterstoffe im Biere,' Diss. Dorpat, 1874 (Pharm. Journ. and 'Irans. [3], v. 566, 1875), and Jundzill, 'Ueber die Ermittel. einiger Bitterstoffe im Biere,' Diss. Dorpat, 1873.

'See Miiller, Archiv d. Pharm. [1], xxii. 29, 1828.

${ }^{3}$ Compare Ludwig and Kromayer, Archiv d. Pharm. cxi. 1, 1862; also IKromayer, 'Bitterstoffe.'

* See Schroeder, N. Repert. f. Pharm.x, 11, 1861.

5 Compare Landerer, ibid. i. 446, 1854. This lupinin must not be confounded with the glucoside of the same name discovered by Schulze and Barbieri in 1878. Compare Ber. d. d. chem. Ges. xi. 2200 (Journ. Chem. Soc. xxxvi. 467).

Compare Duncan, Phil. Mag. x. 465.

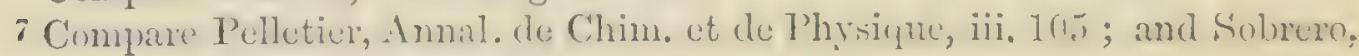
N. Jahrb. f. Pharm, iii. 286, 1855.

${ }^{8}$ See Gerber, Archiv d. Pharm. xxxiv. 167, 1831.

9 See Peckolt, Zeitschr. d. allgemoinen ocster. Apoth. Ver. 133, 1878 (Pharm. Journ. and Trans. [3], ix. 162, 1878).

J" Accorlingr to 'Tremmann's researches ('Bcitr. z. Kenntniss der Aloei,' This:. Dorpat, 1880) the following are the formulie of the rarious aloins (contrining water of crystallization) calculated to the same number of atoms of oxygen. Barbadoes aloin $=\mathrm{C}_{48} \mathrm{H}_{58} \mathrm{O}_{20}, 6 \mathrm{H}_{2} \mathrm{O}$; Cape aloin $=\mathrm{C}_{46} \mathrm{H}_{58} \mathrm{O}_{20}, 6 \mathrm{H}_{2} \mathrm{O}$; Socotra

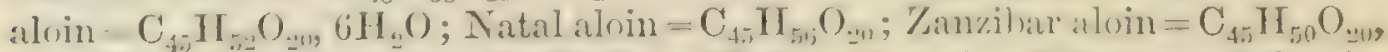

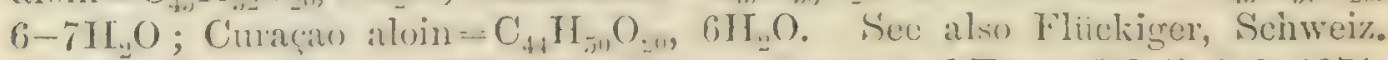
Wochcnschr. f. I'harm. 331, 1870 ; Iharm. Journ. and Trans. [3] ii. 193, 1871. 
gradually olutaned by diffusion, lunt it is often long before they deposit crystals (nost catsily obtained from Natal aloes). Ferric hlorile colour's them, without exception, greenish-black (Natal aloin rery slowly); they are all gratually precipitated hy basic acctate of lead; perchloride of plitinum colours Barbacloes and Curaçan aloin by degrees red to violet, Socotra and Cape aloin greenish-hrown, Natal aloin yellowish-brown; chloride of gold proiluces a more or' less fine raspherry-rerl, passing generally into riolet; with strong hydrochloric acid, Natal aloin alone becomes violet; mercurous nitrate colours Barbadoes and Curarao aloin reeldish. All the aloins are precipitated from arqueous solution by brominewater, in the form of sparingly soluble brominated compounds, which contain frequently, but not invariably, 40 to 44 per' cent. of lromine. The opinion expressed in my 'Chemische Werthbestimnumg starkwirkender Droguen,' that these bromine-precipitates might be used in determining the ralue of the different varieties of aloes, Was hased npon some experiments of Kondracki's ; ${ }^{1}$ but since Tremmann has shown that one and the same aloin can yield more than one sulstitution-prorluct, I have been shaken in this opinion. The applicalility of another method of estimating the value of an aloes liy ascertaining how much tamin is necessary to precipitate and reclissolve one of the constituents, has also been rendered doubtful. I was convincel that this body precipitalle by tamin was a decompusition-product of aloin, or possibly an amorphous morlification, and that it acted directly as a purgative; Kondracki's experiments confirmed this supposition ly showing that the more active an aloes wat, the greater was the amount of tammin solution requirerl in titrating. But as more recent experiments have. prover that the aloins themselves when taken in sufficient quantity hive a purgative action? (whether direct or indirect, I am mable to say), and the attempts to comprare the amount of aloin in an aloes with that of the substance precipitater hy tammin have not met with snceess, I feel myself compellerl to retract for the present the statements marle in my 'Werthlestimmung' on this subject.

The aloin is accompranied in aloes by a resinous substance which does not diswlve when the aloes is treater with about 10 prarts of Water, lut which is soluble in concentrater ayneons aloin-solutions, in hot water, and in aleohol. Anether hody, probahly non-purgative, aloo wecurs in dried aloe-juice; it is freely roluble in cold

1 Bcitr, z. Kenntniss der Aloe, Diss. Dorpat, 1874. 
water, and is possibly an oxyaloin. Bromine does not aplear to precipitate it from aqueous solutions.

170. Curthumin, etr.-Some sulstances, more freely solnble in alcohol than in ether, and characterized by their yellow colour, have been already mentioned in $\$ 152$, in connection with rnercitrin (rulin, rolinin, lutedin, ete.), and whilst refering to them here, I will also allude to carthamin, the colouring matter of safflower. I It has been olotined in the form of an amorphous powder, of an orange-green colour and metallic lustre. It is sparingly dissolved by water, hut easily liy aquenus alkalies and alcohol; from alkaline solution it is precipitated by acids. It dissolves in ether, and stains silk rose- or cherry-red.

\section{ALKALOIDS.}

$\$ 171$. Colour-recctions. - The following reagents may be recommended for producing colour-reactions with alkaloids: Pure sulphuric acil ; sulphuric acid, containing a little nitric acid (1 in 200); sulphuric acil, containing 0.01 gram of molybdite of sodil in each ec. (Fröhtle's reagent); sulphuric acid and sngar; sulphuric acid and bichromate of potash; nitric acid (sp. gr. 1·3); conc. hychrochloric acid; ferric chloride. The reactions are best observel when a few drops of a solution (in alcohol, ether, chloroform, etc.) are allowed to eraporate in a small clish and a drop or two of the reagent added to the residue. In testing with sulphuric acirl and sugarr, it is generally better to mix the allialoid as intimately as possible with s parts of sugar and add the sulphuric acisl to the mixture. Delphinoidine should be mixed with as concientrated a solution of sugar as possible before the addition of sulphurie acil. If hichromate of potash and sulphurie acis are to be nserl in combination, it is alvisalle to dissolve the alkaloid in the acid and drop a crystal of hichromate into the solution. Sulphurie acid and nitrate of potash may he employed in the same way in place of the mixed sulphuric and nitric acids. Ferric chloride shonld be used in arpueous solution, and he as nentral as posisile."

Srome of these reactions might be reed in testing for alkaloids microchemically. The following talile contains a few of the reactions of the more important alkaloids.

${ }^{1}$ Compare Schlieper, Annalen der Chemie und Pharm. Iviii. 357, 1816.

2 All these reactions are described at greater length in my 'Ermittel. d. Ciifte.' 


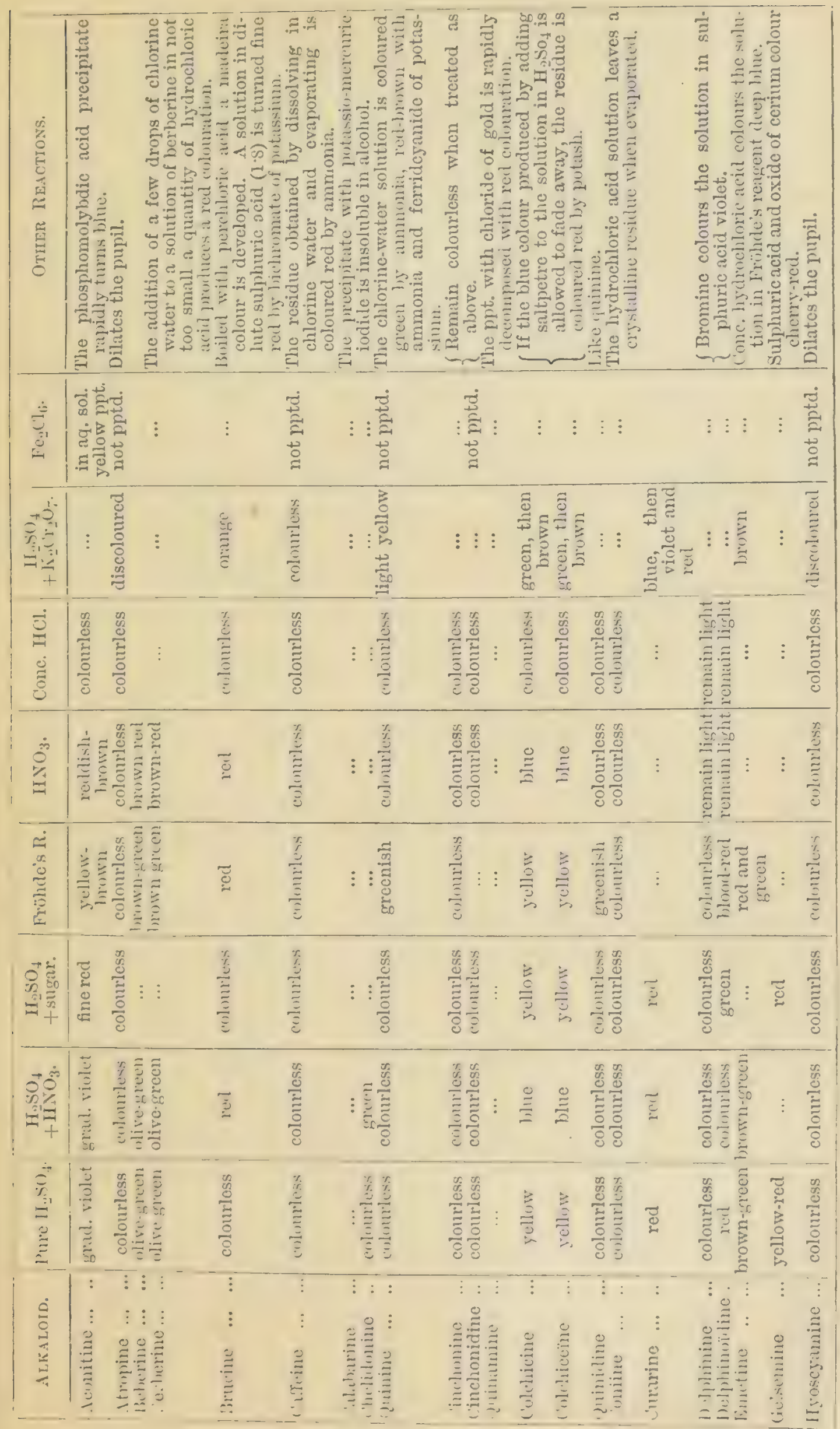




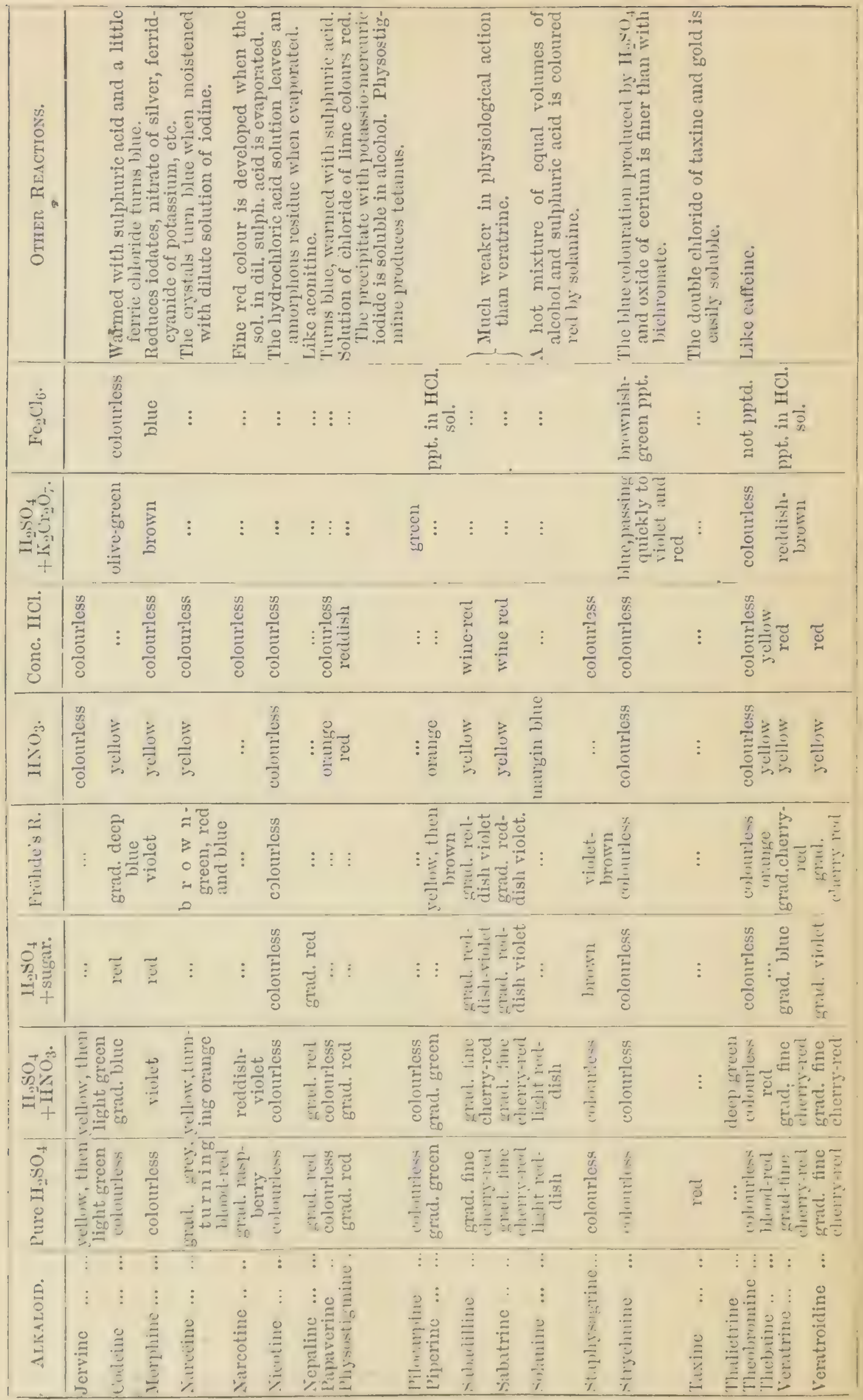




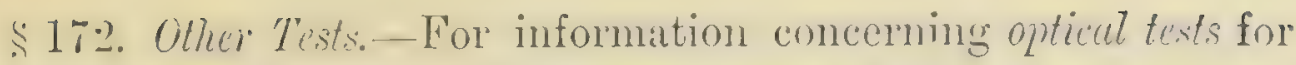

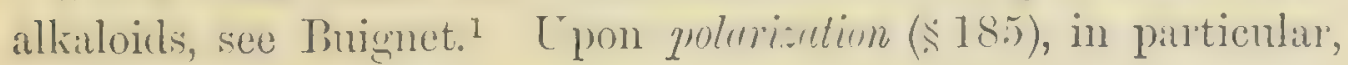
see Hesse. ${ }^{2}$ For the absorption spectra observable in colour-reactions of alkaloids, sce Meyer ${ }^{3}$ and Poehl. ${ }^{4}$

The temperature at which alkaloids sublime has been determined by Armstrong, in an apparatus similar to that described in $\$ 17$ for ascertaining the melting-point of fats. The alkaloid is placed on a coverslip, to which a glass ring $\frac{1}{3}$ to $\frac{2}{3}$ inch high is cemented, and on which a second coverslip is laid. As soon as a cloud is observer on the latter, the temperature is noter. The sublimate is subsenuently examined microscopically as to its crystalline or amorphous chatracter. Mercury or easily fusible alloys miry he userl to heat the alkilloid. For the appearances olservalule during the miemsublimution of allkaloids, see Helwig, Guy, Waddington, and others. ${ }^{5}$

The crystulline form of alkiloids has heen closely investigated hy Erhard. ${ }^{6}$

173. Pletimum uml Gold-alts.- The following list contains the percentage of platinum and gold in the louble chlorites of those metals with some of the more importint alkaloids (dried at $\left.100^{\circ}\right)$

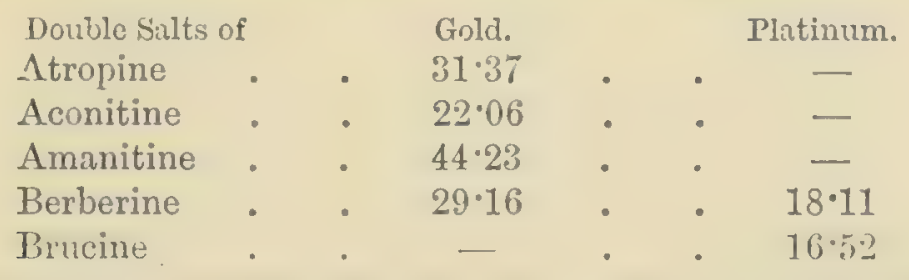

${ }^{1}$ Journ. de Pharm. et de Chim. [3], xl. 252, 1862 (Amer. Journ. Pharm. xxiv. 140):

"Annal. d. Chem. und Pharm. clxxvi. 89, 1875 (Pharm. Journ, and Trans. [3], vii. 191), and cxcii. 161, 1878. See also Oudemans, ibid. clxxxii. 33, -1877 (Year-book Pharm. 75, 1878); Arch. Néerland. des Sciences exactes et naturelles, x. 193, 1875; and amongst older works that in particular of Bouchardat, Annales de Chimie ct de Physique [3], ix. 213. See also Poehl's paper subsequently quoted.

${ }^{3}$ Archiv d. Pharm. [3], xiii. 413, 1878.

${ }^{4}$ Pharm. Zeitschr. f. Russland, 353, 1876.

"Compare Helwig, 'Das Mikioslop in der Toxicologie' Mainz; Cruy, Pharm. Journ. and Trans. [2], viii. 718 ; ix. 10, 58, etc. ; Waddington, ibid. [2], ix. 266t, 409 ; Stoddart, ibid. 173; Brady, ibill. 23:1; Ellwood, ibid. [2], x. 152 ; Ledgewick, Brit. Rev. lxxxi. 262.

${ }^{6} \mathrm{~N}$. Jahrb. f. Pharm. xxv. 129, etc.; xxvi. 9, etc., 1866. Amongst the older works are Huilnnefeld's 'Chemie der Rechtspflege,' Berlin, 1823; Anderson, Chem. Centralblatt, 591, 1848; Taylor, 'On Poisons ;' Guy, 'Principles of Forensic Medicine;' Brand et Chaudé, 'Médecine légale,' Paris, 3858. 


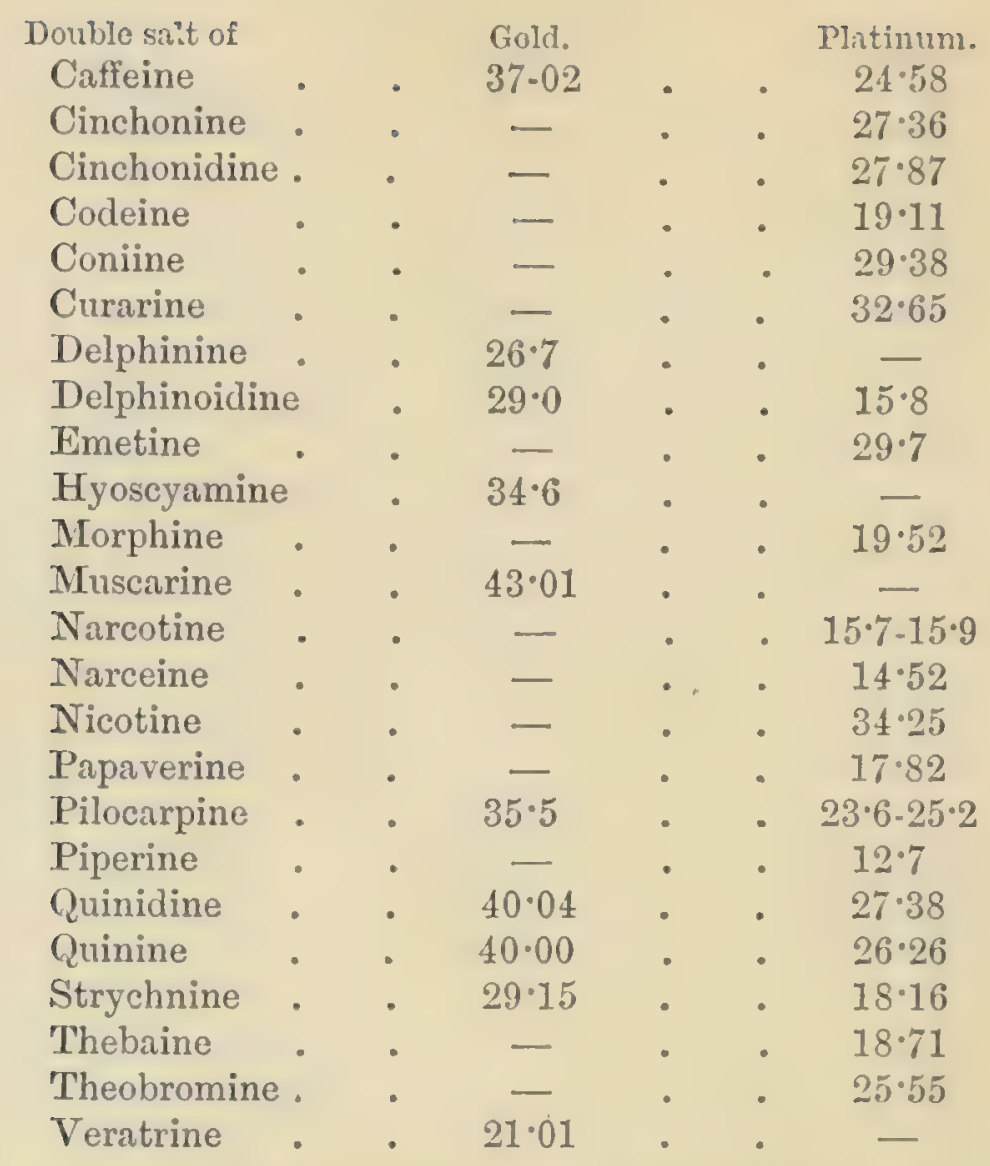

$\$ 17$. Estimatim of Alloloids.-In estimating the alkaloid in leaves or easily pulverizable stalks, it will frequently be foumd practicalble to exhaust the powitered substance with spirit, evilporate the tincture, and extract the residue with acidulated water. The solution thus obtained may then be titrated with potassio-mercuric iorlide, as directed in 56.$)$. But if the material contains much stirch, or is difficult to powrter (as, for instance, aconite root), it is better to allow it to soak in about twice its weight of dilute sulphuric acirl (1 in :30) before extracting with alcohol, as, otherwise, larger fragments of the substance are not uniformly penetrated by the spirit.

In estimating clionine, the drop-test (that is, the aclitition of a drop of the precipitating solution to a filtered clrop of the liquirl to be precipitated) cannot be used. It will be found advantageous to add at once sufficient of the reagent to precipitate the greater part of the alkiloil ; after stamling several hours, mutil the supermatant liquirl has hecome clear, more of the reagent may be added, and so on as long as a precipitate is produced. The lignid clear's more rapidly as the end is aproroached, till at last an interval of five to ten minutes is sufficient.

Atropine may also he estimated grarimetrically by achling 
excess of potassio-melende ionlide, dissolving the precipitate in alcohol of 90 to 95 per cent., evaporating the filtered solution, and weighing the residuc, which contains 40.9 per cent. of atropine.

For hyoscycmine the same precautions are necessary as for atropine. 1

In cotimating aniune gravimetrically with potassio-neremic ioclide, I obtained results that were far below the truth; the compomel precipitated is somewhat freely soluble. (See also) $\$ \$ 175,180$.

Nux Vomica and St. Ignatius' beans contain two alkaloids, stryehnine and brucine, which differ in the intensity, at least, of thcir action on animals, and this fact must not he lost sight of in determining the value of those drugs by titration with potassiomercuric iodirle. I have therefore proposer the following indirect method of determining both alkaloids: "2

1.) to 30 grams of the finely lasped seeds are exhausted hy boiling three times in succession with dilute sulphuric acirl (1 in 50), pressing the residne each time. The decoctions are united (about. 700 ce.), nearly (but not quite) nentralizerl with magnesia and evaporated to a syrup in the water-bath. To the residue $2 \cdot 4$ times its volume of 90 per cent. spirit is added, and after standing, the precipitater mucilage is filtered off and washed. The filtrate and wishings are evaporated to abont :30 to 50 ce. and, whilst still acid, well shaken with chloroform. The chloroform is then separater, the aryeous liquid marle allialine with ammonia, and the agitation with chloroform lepeaterl as long as any alkaloid is removed. The alkaloidal residne obtained by evaporating the chloroformic solution is dhierl, weighed and hissolver in hydrochloric acid; the excess of acid is removed hy evalporation, and the solntion titrater with potassio-nerenic iolide. The weight of strychnine can be calculated from the expression $x=5.566(0.0197 \times c-m)$ and that of brucine from $y=6.566$ $(m-0.0107 \times c)$, where $c$ is the number of cc. of reagent used and wh the woight of the mixel alkiloids. It is still luetter to weigh the hydrochlorates of the alkilloids and calculate the strychnine. salt from the expression $x=6.1733(0.02152 \times c-m)$, and the

${ }^{I}$ Compare my 'Werthbestimmung,' 32, and Thorey on the 'Distribution of Nitrogen in black and white henbane,' Diss. Dorpat, 1869, and Pharm. Zeitschr. f. Russland, 265, 333, 1865 (Pharm. Journ. and Trans. [3], xii. 874).

"See my 'Werthbestimmung,' 64. Compare also Pharm. Zeitschr. f. Russland, 233, 1866 . 
brucine salt from $y=7 \cdot 173:)(m-0 \cdot 018.5 \times c), c$ being the sanc as in the previons expressions and m denoting the weight of the mixerl hydrochlorates.

Titration of miphine and nacotine with potassio-mercuric iodide serves only as a check on the weight of the alkaloids after

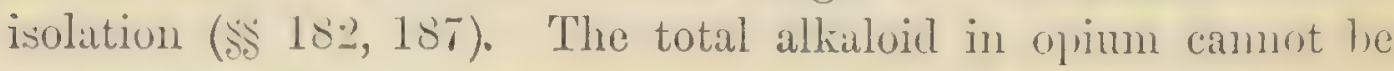
estimated volumetrically with that reagent.

For a methor of examining chelidonimm compares 6.5 amel my ' TVerthbestimmung,' 1) 98.

The presence in cecuctilla sects of three alkiloirls, all of which act upon potassio-mereuric iodide, renders it impossible to do more with this reagent than compare the extracts of two or more difterent samples of seeds with one another: ${ }^{1}$ If an apporoximate separation of the three alkaloids is desined, it must he remembered that, accorting to the investigations of 11 eigelin, ${ }^{2}$ atl three are removed together by shaking with chloroform; that sabarlilline is almost insoluble in ether, hut is dissolved by 150 parts of water at the ortinary temperature ; that sabatrine is frecly soluble in ether and soluble in 40 parts of cold water: and finally that relatrine is said to be taken up by 10 parts of ether and 1,000 of cold water.

The researches of Harnack and Witkowski have proved ${ }^{3}$ that the culuber been also contains two alkaloids (calaharine and physostigmine), differing from one another in physiolowical action. For this reason the estimation of the total allialoil hy titration with potassio-mercuric iodide has only a limited ralue, but the alkaloirls might possibly be separited, aml estimaterl grarimetrially, as the calabarine presipitate is insoluhle in aleohol whilst that produced by physostigmine is soluble.

\$175. Coniine, pilocapine, ctc-Zinofisky has shown that comime can the atecurately estimater by phosphomolylulic aced in solutions free from ammoniacal salts. ${ }^{*}$ 'The strength of the reagent was such that $1 \mathrm{cc}$. precipitated $0.05 \mathrm{gram}$ of conine.

${ }^{1}$ Compare E. Masing, Archiv d. Pharm. [3], ix. 310, 1876 (Journ. Chem. Soc. xxxii. 367).

2 Compare Weigelin, 'Unters. ïber die Alkaloïde der Sabadillsamen,' Diss. Dorpat, 1871 (Journ. Chem. Soc. xxv. 828). See also P. G. A. Masing, 'Beitr. \% gerichtl. chem. Nachw. des Strychn ins 1. Veratrins,' Diss. Dorpat, 1.רis.

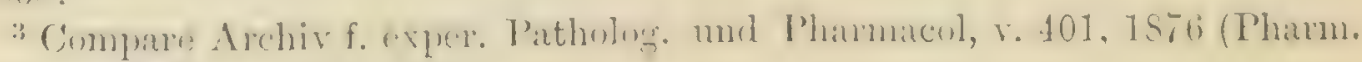
Tourn. and Trans. [3], viii. 3).

4 'Die quant. Best. d. Emetins, Aconitins und Nicotins,' Diss. Dorpat, 1872 (T'harm. Journ. and 'l'rans. [3], iv. 442'. 
The same reagent has been employed by Poehl ${ }^{1}$ for the gravimetric estimation of pilocarpine, but that chemist admits that the results obtained are only approximate. By his methor 10 Grams of jahorandi leaves are extracted with 100 ce. of water containing 1 per cent. of hydrochloric acid; the infusion is precipitaterl with acetate of leal, the excess of which is remover by hydrochloric acid, and then, after filtration, phosphomolybdic acid is added. The precipitate is collected, washerl with water containing a little hydrochloric acid, dhied at 100', and weighed. It is said to contain $45 \cdot 66$ per cent. of pilocarpine.

In estimating the allialoid in solutions of the pure sulstance, phosphomolyblic acid would probahly in many cases yield better. results thim potassio-mercuric iodide; but there is a certain danger attending its use, and that is the possibility in many cases of ammonia and amidic compounds being precipitated with and calculated as alkaloid. Of pilocarpine in particular it must be observed that, according to Christensen, the composition of the phosphomolybulic acid precipitate, as given hy Pochl, requires revision.

I'hosphomolythute of quinine (dried below T0') contains, accordings to Prescott, $27 \cdot 3$ per cent. of quinine.

For cases in which phosphotungstic acid may be employed see $\$ 17 \%$

Attempts have also been marle to estimate alkaloids by means of tunnic acid,, 2 by cither drying the precipitate prouluced or: lilserating the alkaloir from it with oxide of learl or other base, drying and weighing. My objection to the former of these two methods is that the tammates of the alkaloids are searcely crer constant in their composition. The latter might be arlopter in certain cases proviled that the precipitated tamnate is sufficiently springly soluble, and that the allialoil itself is not attackerl, as curarine is, by the oxide of learl userl to decompose its timmate $(\$ 64)$.

1 'Unters. d. Blaitter des Pilocarpus officinalis,' St. Petersburg, 1877 (Year. book of Pharm. 28, 141, 1881). See also Harnack and Meyer, Annal.d. Chem, und Pharm. cciv. 67, 1880 (Pharm. Journ. and 'Trans. [3], xi. 551, 587, 608) ; and Christensen, Pharm. Zeitschr. f. Iutussland, xx. 1881 (Pharm. Journ. and Trans. [3], xii. 400).

-Compare, for instance, Lefort, Journ. de Pharm. et de Chimie, ix. 117, 241, 1869 (Pharm. Journ. and Trans. [3], ii. 10.29; iii. 63). See also my 'Werthbestimmung,' 10. 
Hatger ${ }^{1}$ and Hielbig ${ }^{2}$ have both experimenterl on the estimation of certain alkiloids hy precipitation with pirric ucinl. I have no doubt that in many cases very satisfactory results might be olstained by combining precipitation by picric acid with extraction hy agitation with solvents, and in this opinion I have recently been confirmed by experiments pulblished by Hager on the quantitative determination of nicotine. Hager recommends precipitation with picric acid at a temperature of 15 , washing with an aqueous solution of the precipitant, and finally drying at a temperature not exceeding $40^{\circ}$ to $50^{\circ}$. He foum the nicotine precipitate to contain 27 per cent. of alkaloid.

\$176. Estimation of Caffeine.-I may supplement the method given in $\$ 66$ for the estimation of this alkaloid by the following remarls: : Ether" extracts the alkaloid in a state of greater purity than chloroform, and yields therefore a correspondingly better result; but the mass must be very finely powdered, and the treatment with ether repeated several times to be certain of dissolving the whole of the caffeine. I have also used a mixture of 3 parts of ether with 1 of chloroform with success.

In estimating the alkaloid in grarcenc it is not advisable to extract with acilified water, nor is it necessary in determining the theine in tea.

Lieventhal ${ }^{4}$ extracted the powdered tea directly with chloroform, by which, however, far less than the total quantity of theine was dissolver. I must make the same objection to Clans's methor, which consisted in extracting with ether, shaking the ethereal extract with dilute sulphuric acisl, neutralizing the anpeous solution with magnesia, eraporating to dryness, and again extracting with ether. Moreover, it would he difficult to remove the whole of the theine from ethereal solution liy shaking with acidified water. ${ }^{6}$

1 Tharm. Centralblatt, x. 137, 145, 1871. Compare also Medin and Almèn, Jahresb. f. Pharm. 1871.

$\because$ Loc. cit.

${ }^{3}$ Compare Wurthner's investigations, Pharm. Zeitschr. f. Russland, 711, 1872; and Weyrich, 'Ein Beitr. z. Chemie des 'Ihees und Kaffees,' Diss. Dorpat, 1872 (Journ. Chem. Soc. xxvi. 1235).

4 Pharm. Zeitschr. f. Kussland, 369, 1872 (Year-book of Pharm.239, 1873).

"Pharm. Zeitschr. f. Russland, 357, 565, 1862.

"For the less recent methods of Péligot and 'Zïllner, see my 'Chem.

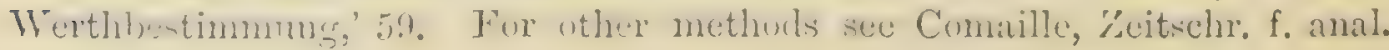




\section{Thembromine.-Trojanowsky found that the theobromine} in cacio-seeds might he estimated ly the following lnocess ${ }^{1}$ : 5 grams of the powdered seed are freed from fat by treatment with petroleum spirit, dried, rulbed down with powdered glass and water to a thin paste, mixed with an equal weight of calcined magnesia, and dried in the water-bath at 60 to 70 C'. 'The residne is again finely powdered, and exhausted by hoiling with 80 per cent. spirit. The rlecoctions are filtered whilst hot, and craporated to dryness in a beaker. From the dry extract petroleum spirit will dissolve a little more fat; after haring been again dried, the mass is thrown on to a tared filter, and washed with cold spirit till nearly colourless. It is then dried and weigherl, and to the weight of theobromine thus obtained 0.0007 gram added for .every cc. of wash-spirit.2

Wolfram estimates theobromine in cacao-seeds lyy precipitating with phosphotungstic acid" (\$4), and sulsequently separating.

Chem. xv. 474, 1876 (Year-book of Pharm, 20, 1876) ; Markownikoff, ibid. xvi. 127, 1877 (Year-book of Pharm. 104, 1877); Cazeneuve and Caillol, ibid. xvii. 221, 1878. 'The latter replace the magnesia in the above method with lime, and the ether with chloroform; Markownikoff also uses chloroform. In working upon coffee-beans it will be found very difficult to reduce them to the fine powder necessary to ensure the success of the estimation. This may be best accomplished after the beans have been thoroughly dried at $100^{\circ} \mathrm{C}$.; Weyrich, however, has shown that the amount of caffeine contained in a sample of coffee is no criterion of its quality, and even the estimation of the ash, potash and phosphoric acid in addition to that of the caffeine does not furnish data free from objection. Levesie estimated (Archiv d. Pharm. [3] viii. 298, 1876 ; Journ. Chem. Soc. xxxi. 752) fat, mucilage, tannin and cellulose, but with unsatisfactory results. 'The determinations of the theine, substances soluble in water, ash, etc., in tea, made by Weyrich, shewed the possibility of detecting adulterations, but not of judging of the quality.

1 'Beitr. zur pharmacog. und chem. Kenntniss des Cacaos,' Diss. Dorpat, 1875. This work also contains estimations of the other more important constituents of cacao (fat, ash, starch, etc.) in various samples.

2 According to determinations made at my request by Treumann, theobromine dissolves in 148.5 parts of water at $100^{\circ}$, and in 1,600 at $17^{\circ}$; in 422.5 parts of boiling absolute alcohol, and 4284 parts at $17^{\circ}$, and in 105 parts of boiling chloroform. It differs in its solubility from caffeine, with which, however, it shares the reaction with chlorine and ammonia. Shaking with benzene does not remuve theobromine from aqueous solutions (\$55). See Archiv d. Pharm. [3], xiii. 1, 1878 (Year-book of Pharm. 71, 1879). Basic acetate of lead does not precipitate theobromine from aqueous solution.

3 Keitschr. f. anal. Chem. xviii. 346, 1879 (Year-book of Pharm. 48, 1879). He prepared his reagent by dissolving 100 grams of tungstate and 60 to 80 of phosphate of soda in $500 \mathrm{cc}$. of water acidulated with nitric acid. For the use of phosphotungstic acid as an alkaloid-reagent, see also Scheibler, Journ. f. pract. Chem. 1xxx. 211, 1866. 
the alkiloil from the precipitate. Ten rams of the substance are rubbed down with water to a fine paste, then exhausterl hy boiling with the same menstrumm, filtered and washerl with hoiling water (700 to $800 \mathrm{cc}$.), as long as alkaloil can be detecterl in the washings. The mixed anneous solutions are precipitaterl with ammoniacel acetate of leal and filtered. The filtrate is made alkaline with caustic sola, evaporated to .0 cc., acillified with sulphuric acid, and again filtered. From the acid solution, which should contain about 6 per cent. of free sulphuric acid, the theobromine may be precipitated ly waming with phosphomolylulic acirl. The precipitate is collected when cool, washed with water acilified with sulphuric acil, and decomprosed hy warming with caustic barytil; the excess of the latter is remorerl by sulphuric acid and the sulphuric acid ly carbonite of harium. The mixture is then filtered whilst hot, evaporated to dryness, and weigherl. By deducting the ash the amount of pure theobromine is found.

$\$ 178$. Estimation of Piperine.-The following is Cazeneuve and Caillot's method: 10 grams of finely-ground pepper are mixerl with 20 of slaked lime, and enough witer to form a thin paste, boileil for fifteen minutes, and then evaporated to dryness on a water-1)ath ; the residue is finely powdered and exhausterl with ether. The piperine olstained ly evaporating the ethereal solution is recrystallized from alcohol and weighed. It would, I think, be better if the powdered pepler were first freerl from fat by treatment with petroleum spinit. Possibly the allialoid might then be jurifien hy washing with petroleum spirit and water instead of recrystallizing from alcohol. (Compare also $\$ 64$.

179. Acintimetric Listimutiun of Nicutine.-Schloessing's process, mentioner in $\$ 6$ s, consists in extracting the nicotine by passing the raprour of ether and ammonia through the tobaceo, condensing the distillate, allowing the ether and ammonia to erilporate, and titrating the recidual nicotine with rlilute sulphuric acid. But the alkaloid retains ammonia, and the amomt fomm is conseynently too high. (Compare Kinsutany and my "Werthlestimmung.')

Wittstein, Brandl, and Liecke, all extract the tobacco with water acidified with sulphuric acid. Liecke evaporates to a syrup, precipitates with ¿2 rolumes of alcohol, washes, and again evaporates. The residue is made alkaline with excess of potash,

1 Zeitchr. fo anal. Chem. xrii. 379, 1978 (Year-book of Pharm. 42, 1878). 
and ristilled (finally at a temperature of 2260) into at meatimed quantity of volumetric sulphuric acid, the excess of which is then determined by solution of soda. Wittstein and Bramll distil the acid extract direct with caustic potash, and note the amount of sulphuric acid necessary to neutralize the distillate. They then evaporate to dryness, extract with alcohol, which dissolves the sulphate of nicotine, and determine the sulphuric acid in the insoluble portion. This is then denlucter from the guantity nsed, and from the difference the nicotine present is calculated.

Kosutany treats the leaves, previously soaked in water, with milk of lime until free from ammonia, then extracts with water, and shakes the filtered solution with petroleum spirit. From the latter, after separation, the alkaloid is removed hy agitating with a known quantity of volumetric sulphuric acid, the excess of which is determined by haryta water. (Compare my " Werthlestimmung;' p. 55.)

\$180. Coniine.-Similar methods have also been proposed for the estimation of conime. I have alrealy expressed my opinion of them in my 'Werthbestimmung;' 1. 42, where I have at the sime time pointed out that those processes which involve the craporation of a solution of chloride of conine, and detemination of the alkaloid from the amount of chlorine in the resilue, are open to oljection on the gromel that chloride of coniine is easily volatilized (SS 174, 65).

\$ 181. Separation of tuo Allialoids. Attention has already been drawn in $\$ 69$ to cases of the occurrence of two alkaloids in regetable substances. The remarlis made in that section may he supplemented here with a few examples so talien as to include. cletails of processes of more freprent applicillility, and to wive hints for the raluation of diugs in general use. Some such instances have already been described in $\$ 174$, and I propose following these here with the risensiom of a fer more methorls. for the separation of only tuo allicloids.

Let us first assume that the two alkaloids to be separated differ in their behaviour to acids, as, for instance, jervine and veratroildine, alkitoids that oceur in Teratrum allowm, lobelianum and virile.:

${ }^{1}$ Compare Harger, 'Untersuchungen,' ii. 250.

"See 'Lobien, 'Beitr. z. Kenntniss der Veratrum Alkaloide,' Diss. Dorpat, 1877 (Pharm. Journ. and Trans. [3], viii. S08); Bullock, Amer. Journ. Pharm. xlvii. 451 , and xlix. 453 ; Wormley, ibid. xlviii. 4 . 
Sulposing, then, both these alkiloills to have been extracted together ly shaking with chloroform, and to have been redissolved in silute (-2 per cent.) acetic acid, the arldition of dilute sulphurie aciel to such a solution would cause the precipitation of the majority of the jervine as sparingly soluble aciel sulphate (Simon's vegetable baryta). According to Bullock this salt requires ter parts of cold water for solution, and the precipitate contains 15.5 per cent. of sulphuric acid $\left(\mathrm{H}_{2} \mathrm{SO}_{4}\right)$. The hydrochloric acid precipitate $(6 \% 5$ per cent. H('l) is more soluhle; the most adrantageons method of all is to precipitate nitrate of jervine (soluble in 1,200 parts of cold water) by adding nitrate of potassium to acetic acid solution. Veratroidine remains in the filtrate, from which it can be extracted by shaking with chloroform. In a similar manner pericine may be separated from other cinchona alkaloids in the form of a sparingly soluble nitrate.

The behaviour of two alkaloids to bases will more frequently be found to present differenees, of which adrantage may be taken. Here two cases are to be distinguished: viz., either one alkaloid is precipitated, and the other left in solution; or, both are precipitaterl, hut one is redissolver lyy an excess of the precipitant, whilst the other is not. As an instance of the first of these two cases, the separation of narcotine from narceine may be cited; the former is almost completely precipitated hy ammonia, whereas the narceïne remains in solution. Morphine and codeine serve to exemplify the second 'ase, which is of more frecuent ocemrence; excess of ammonia precipitates the former tolerally completely, but the codeine remains dissolved in the filtrate, from which it may be extracted by shaking with benzene. On the other hand, an excess of lime-water causes the separation of narcotine, but does not precipitate morphine. But nearly the whole of the latter alkialois is thrown down if chloride of ammonium be adderl to the solution in caustic lime (\$187).

This methor of precipitation with exeess of allall is, howerel', unclialle in some cases, in which farourable results might hate been anticipated. Strychnine can be separated from an acid solution very satiffactorily ly the ardition of excess of ammonia; brucine under the same conditions remains in solution until the

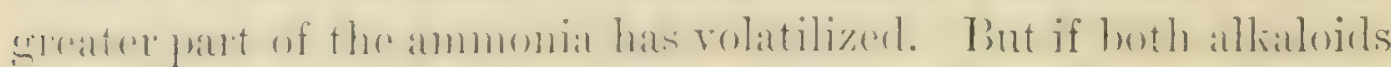
are present together, part of the brucine will separate with the strychnine on the arddition of ammonia. ${ }^{1}$

1 See my 'Frmittelung von Giften,' 2nd edition, 259. 
Carbonited allialies may occasionally he used instead of canstie. For the separation of some alkiloills bicarbonates have also been recommenterl, as it was fouml that under certain conlitions one alkialoid wonld form a soluble cartonnate, whilst the other was immediately precipititer in the free state. In this waty paricine can be separated from the other bark allialoids by hicarbonate of sorlat.

1s.. Jefurionr to solvents.--Separation mily be aceomplishert in this way, either lyy treating the dry alkilnids with the solvent, or by shaling it with the liquid containing the alkaloils in solution.

An instance of the first case may be found in the separration of brucine and strychnine from a mixture of the two alkiloids precipitated by ammonia. Alsolute alcohol dis:olves brucine with toleralle facility, but takes up only a minute proportion of strychnine. ${ }^{1}$ Another method, which I formerly employed for the separation of these two alkiloids, may also find a place here. It consisted in allowing the benzene solution of the mixed allialoids to evaporate until the majority of the strychnine lad separated, then quickly pouring off the mother liquor, washing with henzene, and evaporating to dryness; the brucine was thus obtainerl, mixed with a little strychnine $(0.0683 \mathrm{gr}$. for every cc.). I have succeeder in separating the two alkaloids tolerably completely by both of these methorls, lut as they occasionally fail I camnot further recommend either of them; the first is, however, the more preferable of the two.

Siy treatment with water colchirim may be separated from the colchiceine, which sometimes accompanies it in colchicum eorms. The cuantity of solvent used must not, howerer, be too small, as colchiceine is more soluble in concentrated apueous solutions of colchicine than in pure water, which dissolves it but very sparingly. ${ }^{2}$

Moens, ${ }^{3}$ Stoeder, ${ }^{4}$ and Hielbig, ${ }^{5}$ found 40 per cent. spirit adrapted for' the separation of the cinchonine and "amophous

${ }^{1}$ Compare my ' Werthbestimmung,' 66. Even if the greater part of the free ammonia present be allowed to evaporate, the complete precipitation of brucine is a matter of difficulty; that portion of the alkaloid that remains in solution must therefore be removed by shaking with benzene.

"See Hertel, Pharm. Zeitschr. f. Russland, Nos. 13 to 18, 1881 (Pharm. Journ. and Trans. [3], xii. 498).

${ }^{3}$ Nicuw Tijdschrift voor de Pharm. in Nederl., 322, 1869; 7, 1870; 161, 1875.

"Archiv d. Pharm. [3], xiii. 243, 1878 (JJurn. Chem. Soc, xxxvi。 281).

5 Kritische Beurth. der Method. zur Trennung und quant. Best. d. Chinaalkaloide,' Diss. Dorpat, 1880. 
allialoil' of cinchona bark. 'The latter found 1 part of cinchonine dissolve in 1, 100 parts of spirit of that strength, but, as the solution obtained in the separation of the alkaloids is not a saturated one, he recommends the addition of 0.0002 gram cinchonine for every ce. of such spirit used. He also found pure ether (free from water and alcohol) rery suitable for the same purpose, as it dissolves so little cinchonine that a correction is scarcely necessary. The mixture of both alkaloids mist be completely dried in the water-luath, and then very carefully powitered.

The separation of two allialoils by means of ether may also he accomplisher by allowing the ethereal solution of hoth to evaporate

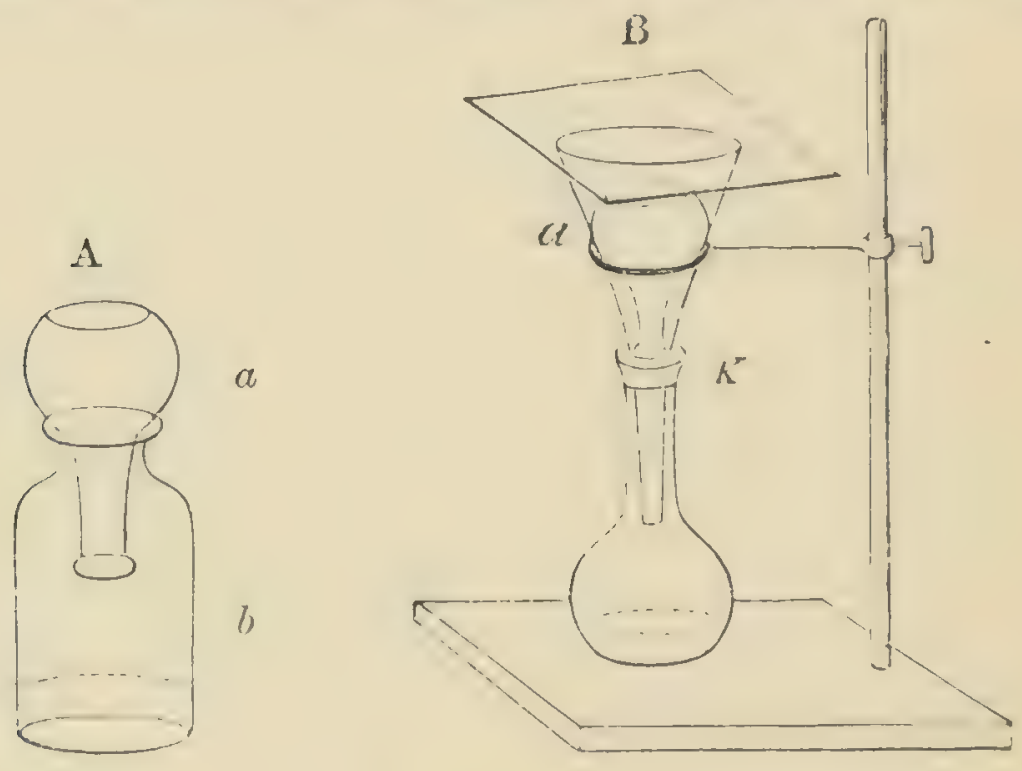

Fig. 8.

grarlually, ancl, if one should separate in crystals, remoring the other loy slow washing with ether in the form of rapour. By this methorl I sucecerted with Marquis ${ }^{1}$ in separating delplinime fom delphinöidine in perfectly colourless crystals.

The flask a, containing the mixed alkaloids (Fig. 8, A), was inverted in the wide-mouthed bottle, $b$, into which about $10 \mathrm{cc}$. of pure ether harl been pourer. The alplitatus was then allowed to stand for several days at the ordinary temperature, during which ether-rapour from l, was continually comblensing in a, and dropping back into $b$, saturated with delphinoïdine.

The apparatus figured in S B, allows of the process being, to a certain extent, resulated ; the fumel ", containing the flask, can be raised or lowered at pleasure.

1 Archiv f. exper. Pathol, und Pharmacol, vii. 55, 1877. 
For the separtation of morpline from uncotine by ether; see \$187. Ether and chloroform (free from alcohol) can also be userl to separate the former from codeine and thereine. Morphine can be separated from thebaine, codeine, and nareotine, hy the method of agitation; the last three are remored by benzene from ammoniacal solution, whilst searcely traces of morphine are dissolved.

In a similar manner delphinine and delphinoüdine may be separated from stephisugrine by agitation with ether, in which the latter is insoluble; ${ }^{1}$ after removing the first two, staphisagrine may be extracted with chloroform.

\$183. Use of Sults, ete.; Sepuration of Quinine and Cinchonidine, etc. ${ }^{2}$ - Instances of the use of salts in the separation of alkaloids may be found in the employment of tartrates for the quantitative estimation of quinine and cinchonidine in the presence of quinidine and cinchonine (cf. \$18t, I.) ; by means of iodide of potussium or sodium, quinidine can be separated from cinchonine and 'cmorphous alkulvill' (cf. \$184, IV.). Wittstein recommended conversion into oxalates in alcoholic solution for separating strychnine and brucine; ${ }^{3}$ quinine may be freed from cinchonidine by precipitation as herctpathite $^{4}$ (cf. $\S 184$, II.).

The separation of calaburine from physsostigmine by potassiomereuric iodide, has already been described in $\$ 174$; the same method might perhaps be feasible with chelidonine and senguincrine. ${ }^{5}$

Chloride of gold can be userl in separating muscurine from cimanitine, as the double salt of the former is more soluble in water than that of the latter: ${ }^{6}$

Perchlorid of pletimum was the salt used in separating poytine from the other bark alkaloids, as the double salt of platinum with that alkaloid is very sparingly soluble in water. By means of the same salt, ammonia may be separated from those alkaloids and amides that yielil double salts of greater solubility (\$98). It must, however, be borne in mind that certain allsaloids undergo

1 See the paper by Marquis and myself previously quoted.

2 Comp. Moens, loc. cit.; Johanson, Archiv d. Pharm. x. 418, 1877 ; Hielbig, loc. cit.

3 Vierteljahresschrift f. pract. Pharm. viii. 409, 1859.

${ }^{4}$ Compare Herapath, Pharm. Journ. and Trans. [1], xi. 448; xii. 6; de Vrij [3], vi. 161; N. Tijuschr. vour de Pharm. 18s1; Hielbig, lor. rit.

5 See my 'Chem. Werthbestimmung,' 102.

' Compare Harnack, Archiv f. exper. Pathol, und Pharmacol. iv. 82, 1875. 
rapid decomposition when precipitated in combination with chloride of gold and platinum (e.g. curarine).

$\$ 184$. Quantitutive Separation of Several Alkaloids from one another.-Such cases occur in the examination of cinchona barlis. Although several of the many alkaloids in these barks are present in such minute quantities that they may generally be neglected, there are at least five the detection and estimation of which are of importance in valuing samples. These are quinine, cinchonitine, quinidine, cinchonine, and the so-called amorphous ulkuloid. The mixed alkaloids are extracted and estimated as directed in $\$ 67$. For their quantitative separation from one another, I propose using Moens' method, which has been recognised by Hielbig, after numerous experiments, as suitable for the purpose. ${ }^{1}$

I. The mixed alkaloids just referred to are dissolved in acetic acid, ${ }^{2}$ without the application of heat, and the solution evaporated to dryness, care being taken that the residue does not turn brown. This is then dissolved in the smallest possible quantity of water and filtered. From the solution, which should not he evaporated, quinine and cinchonidine are precipitated together by (about $\cdot 5$ of a gram of) tartrate of ammonia and soda, which is preferable to the Rochelle salt usually used. After standing twenty-four hours the precipitate is filtered off, washed, dried at $110^{\circ}$, and weighed. $1 \cdot 6$ gram of mixed alkaloids would yield about $30 \mathrm{cc}$. of filtrate, and require about the same quantity of wash-water. A correction must be made of 0.000746 gram of quinine and 0.000441 gram of cinchonidine for each cc. of filtrate and washings, provided that both alkaloids are present together. If the bark contains quinine alone, $0.00102 \mathrm{gram}$ must be added for each cc.; or if cinchonidine alone, $0.000543 \mathrm{gram}$. The apparent discrepancy in these figures is caused by the influence exercised by the presence of either tartrate on the solubility of the other. 100 parts of precipitate indicate 79.41 anhylrous quinine or 76.8 cinchonidine.

II. To separate quinine from cinchonidine the mixed tartrates are dissolver in 90 to 92 per cent. spirit containing 1.6 per cent.

1 Loc. cit.

2 Hielbig has also experimented with hydrochloric and tartaric acids, but obtained the best results with acetic. 'The chlorides formed by the hydrochloric acid appear specially liable to cause crrors when subsequently precipitating with tartrute. Whichever acid, however, be chosen, the excess must in some way be removed. 
of sulphuric acid; the filter used in the previous operation is also extracted with spirit of the same strength. One part of precipitate should yield ahout 20 parts of solution; from this the quinine is best precipitated by the reagent recommended by de Vrij, ${ }^{1}$ which is prepared as follows: To a solution of 2 parts of sulphate of quinoidine in 8 of 5 per cent. aqueous sulphuric acid, a solution of 1 part of iodine and 2 of iodide of potassium in 100 of water is gradually added with constant stirring. The flocculent precipitate thus produced is slightly warmed till it agglomerates into a resinous mass, which is then washed with warm water, dried, and dissolved with application of heat in 6 parts of 92 to 94 per cent. spirit. After cooling the liquid is filtered off and evaporated to dryness, the residue redissolved in 5 parts of spirit, again filtered, and the filtrate used as the reagent. During the precipitation of the herapathite with this reagent, the liquid must be vigorously stirred to prevent the partial separation of cinchonidine in the form of orange flocks. If that has taken place the mixture must be warmed until the precipitate disappears. According to de Vrij, sufficient of the reagent has been added when an intense yellow colouration makes its appearance in place of a green precipitate of herapathite; the mixture is then heated to incipient ebullition, cooled, and its weight ascertained to allow of a correction for dissolved herapathite being subsequently made. Finally, the precipitate is collected on the filter previously used in separating the tartrates and washed with a saturated alcoholic solution of quinine-herapathite. After draining; the funnel is weighed with the filter, dried, and again weighed; the difference is the amount of herapathite solution retained by it, for each sram of which, as well as of mother liquor (not washings), a correction must be made of 0.00125 gram of quinine. 100 parts of herapathite dried at $100^{\circ}$ indicate 58.22 of anhydrous quinine. To ensure the success of the experiment, it is absolutely necessary that the herapathite should separate in the form of green glittering crystals, as otherwise the solubility differs from that here stated; amorphous herapathite, as well as some of the quinine compounds richer in iodine prepared hy Jörgensen, are far more easily soluble. Unfortunately it sometimes happens, when working upon the mixed alkaloids separated from hark, that it is impossible to obtain the precipitate in this crystalline condition even 
after three or four days. In this case a different correction must be made from that above mentioned, viz. 1 in 465 , as determined by Hielbig, instead of $1 \mathrm{in} 600$. It is more arlvantageous to separate the quinine from the greater part of the cinchonicline by ether, then precipitate in the cold and filter off at once. ${ }^{1}$

III. The amount of quinine thus found is calculated into tartrate, and deducted from the weight of the mixed tartrates determined in $\mathrm{I}$.; from the difference the amount of cinchonidine present can be calculated.

IV. The filtrate and washings from the tartrate-precipitate are mixed with iodide of sodium (in the proportion of 0.5 gram for each gram of mixer alkaloids), evaporated to $20 \mathrm{cc}$. cooled, and then vigorously stirred. After standing twenty-four hours, the iodide of quinidine, etc., that has separated, is collected on a small tared filter, transferred to a small beaker, and triturated with $10 \mathrm{cc}$. of 95 per cent. spirit, returned to the same filter, and again treated with the same quantity of spirit. The residue is finally washed with $20 \mathrm{cc}$. of water, ${ }^{2}$ dried and weighed. 100 parts of precipitate correspond to 71.68 parts of anhydrous quinidine, to which a correction of 0.002481 gram has to be added for each cc. of filtrate and washings.

V. To the filtrate and washings from the last operation hydrochloric acid is added until perfectly clear, then considerable excess (2 to 3 grams) of carbonate of soda, and the mixture evaporated to dryness on the water-bath. The residue is reduced to the finest possible powder, transferred to a small dry flask, and extracted by maceration with pure ether, in successive portions of 10 to $20 \mathrm{cc}$. each, as long as any colour is removed. The ethereal filtrates are evaporated, the residue dried and weighed as amorphous rllicloid after deducting the guinine that has escaped precipitation as tartrate.

VI. The portion insoluble in ether is freed from that liquid by warming, and treater with water to remove sorla, etc.; the cinchonine is then filtered off, washed, dried at $110^{\circ}$, and weighed. Traces of that alkaloid adhering to the filter used in filtering the ethereal solution and to the sides of the flisk, may he dissolved

${ }^{1}$ Compare Christensen, Tharm. Keitschr. f. Tiussland, 1881 (Tharm. Journ. and Trans. [3], xii. 441; de Vrij, ibid. 601).

"The ohject of washing with spirit is to redissolve any iodide of cinchonine or amorphons alkaloid that may have separated ont. It is important that the relative proportions of liquid, wash-spirit, and wash-water should be observed. 
in hydrochloric acil, alded to the aquenus filtrate containing soda, etc., and removed from solution by shalking with chloroform. The alkaloid thus isolated must he weighed and added to the amount previously found, from which sum, however, the cinchonidine and quinidine left in solution must be deducted if great accuracy is required.

Hielbig also describes a second process for determining quinidine, cinchonine, and amorphous alkatoid, as follows:

VII. The filtrate and washings from the precipitated tartrates are evaporated to $20 \mathrm{cc}$, and for each gram of mixed alkaloids 0.5 gram of iodide of sollium, dissolved in 5 cc. of water and 15 of 90 per cent. spirit, is added, and the whole allowed to stand for twenty-four hours in a cool place. The iodide of quinidine is then collected on a tared filter, washed with a little water, dried at $100^{\circ}$, and weigherl. (No correction is necessary for the alkaloid left in solution.)

VIII. The filtrate from the last operation is treated as in V., but the precipitate produced by the soda solution is here filtered off and the alkaloid still retained by the liquid extracted by shaking with chloroform. Both portions are then transferred to a beaker, and macerated with 40 per cent. spirit to remove amorphous alkaloid. It is best to cool the mixture and agitate, repeating the treatment as long as the spirit becomes coloured. The cinchonine is finally filtered off, dried, and weighed, 0.000202 gram being added for each cc. of spirit used.

IX. The alcoholic solutions are evaporated to dryness at 110', and from the weight of the residue the quinine, cinchonidine, and cinchonine, previously reckoned as 'correction,' deducted. The remainder is to be regarded as amorphous alkaloid.

If the bark contain so little quinine and cinchonidine that after the addition of tartrate only single crystals are deposited on the sides of the heaker where touched hy the glass rod, in quantity too small to allow of their heing weighed, it may be assumed that the liquid contains at least the amount of alkaloid equal to the correction to be made. The actual presence of quinine may be detected by the thalleioquin reaction (\$171): if that yield a positive result, the presence of cinchonidine must remain a matter for conjecture; but if the result he negative, the precipitate may be assumed to consist of cinchonidine, and its quantity calculated from the correction to be made. 
The same course may be pursued when only traces of quinidine are precipitated.

$\$ 185$. Belueviour to I'ulcrized Light.-Attempts have also been made in examining barks to take advantage of the differences the alkaloids show in their behaviour towards polarized light, but the requisite accuracy does not seem to have been yet attained. ${ }^{1}$ In working with mixtures of the pure alkaloids, the results are, it is true, very satisfactory; but as soon as the mixed alkaloids separated from barks are examined the errors increase, as even small quantities of contuminating impurity can exercise a considerable influence on their action on a ray of light.

The most feasible is Oudemans' method of estimating quinine and cinchonidine. The alkaloids are precipitated as tartrates, and redissolved in hydrochloric acid (to 0.4 gram precipitate about $3 \mathrm{cc}$. normal acid, and water to $20 \mathrm{cc}$.). Such a solution of quinine shows a rotation $[\alpha]_{D}=-215 \cdot 8^{\circ}$; of cinchonidine $[\alpha]_{\mathrm{D}}=-131 \cdot 3^{\circ}$. The calculations may therefore be made according to the formula:

$$
215 \cdot 8 x+131 \cdot 3(100-x)=100(a)^{m}
$$

where $x$ is the percentage of tartrate of quinine, and $(a)^{m}$ the specific rotatory power of the mixture.

$\$ 186$. Other Cinchona Alkuloids. - The following are some of the cinchona alkaloids of less frequent occurrence:

Aricine, ${ }^{2}$ the sulphate of which swells up to a jelly in chloroform.

Cusconine," the neutral sulphate of which gelatinizes in aqueous solution, and does not dissolve in more sulphuric acid. Acetate of cusconine is also gelatinous.

Quimmine. This alkaloid occurs notably in Cinchona succirubra, and generally remains associated with the 'amorphous alkaloid'

1 Compare the papers quoted in $\S 172$ by Oudemans, Hesse and Hielbig. For the application of fluorescence, see Kerner, Zeitschr. f. anal. Chemie, ix. $135,1870$.

${ }^{2}$ Compare Hesse, Annal. d. Chem. und Pharm. clxxxi. 58, 1876 (Pharm. Journ. and Trans. [3], vii. 331, 1876).

${ }^{3}$ See Hesse, Ber. d. d. chem. Ges. ix. 742, 1876 (Year-book Pharm. 226, 1880).

${ }^{4}$ Compare Hesse, Ber. d. d. chem. Ges. x. 2152, 1877 (Year-book Pharm. 62, 1875); Anmal. d. Chem. und Pharm. cxcix. 333, 1880 (Year-book Pharm. 34, 1880); de Vrij, N. Tijdschr. voor de Pharm. en Nederl. 69, 1877. Oudemans, Annal. d. Chem. und Pharm. cxcviii. 135, 1879 (Year-book Pharm. 57, 1879; 34, 1880). 
isolated in the examination of the bark. It may be separated as follows: The mixed alkaloids are dissolved in dilute acetic acid, and to the solution sulphocyanide of potassium is added until the colour is only pale yellow. After standing till perfectly clear it is filtered, the filtrate made alkaline with ammonia and shaken with ether. The residue obtained by evaporating the ethereal solution is then recrystallized from alcohol. Quinamine dissolves in 32 parts of ether, and is also soluble in boiling petroleum spirit. The precipitate produced with chloride of gold rapidly decomposes with production of a red colouration.

For paricine, see $\$ 181$; puytine, $\$ \$ 183,189$. Hesse states of the latter that it is coloured purplish-red by chloride of gold, and red passing to blue by chlorinated lime.

For other cinchona alkaloids, see Hesse in the papers, etc., already quoted. ${ }^{1}$

\$187. Estimution of Opium.-Many methods have already been proposed for the estimation of the more important opium alkaloids. I have criticized them at length in my 'Chemische Werthbestimmung,' and restrict myself, therefore, here to recapitulating the modification of the Guibourt-Schacht's process there recommended, adding a few remarks on methods that have appeared since the publication of that work.

I. Five to ten grams of powdered opium are triturated with water to a very thin paste, macerated twenty-four hours and filtered. The residue is again treated in the same manner, and finally washed on the filter until the washings are colourless. When dried the insoluble portion should not amount to more than 40 per cent. of the opium employed. It still contains narcotine, which may be estimated according to VI.

II. The aqueous infusions and washings are evaporated in the water-bath until reduced to about five times the weight of the opium employed, cooled, filtered if necessary, and mixed with the slightest possible excess of ammonia. ${ }^{2}$ It is then vigorously stirred,

${ }^{1}$ Compare also Ber. d. d. chem. Ges, xi. 1938, 1878 (Pharm. Journ. and Trans. [3], xi. 839, 1881); Annal. d. Chem. und Pharm. ccv. 194, 211, 1880 (Year-book Pharm. 24, 27, 28, 1879; 42-44, 1881).

2 See Cleaver, Amer. Journ. Pharm. xlviii. 359, 1876 (Pharm. Journ. and Trans. [3], vii. 210), and my remarks in the Jahresb. f. Pharm. 175, 1876. Cleaver, who also employs a modification of MIohr's process, recommends the opium to be previously exhansted with bisulphide of carbon, which removes substances that interfere with the subsequent operations. 
and allowed to stand exposed to the air, with occasionat agitation, until the excess of ammonia has disappeared (not longer). The precipitated mixture of morphine, narcotine, and meconate of calcium is filtered off and dried. It should amount to not less than 14 per cent. of the opium used. Filtrate and washings are treated according to $\mathrm{V}$.

III. The precipitate is removed from the filter, reduced to the finest possible powder, and macerated with pure ether in a dry flask as long as nareotine is removed. The ethereal solutions are filtered through the same filter, evaporated to dryness at $110^{\circ}$, and weighed, or instead of weighing the residue may be dissolved in water acidulated with sulphuric acid, and titrited with potassiomercuric iodide $(55)$. The weight is noted as the amount of narcotine soluble in water.

IV. The residue insoluble in ether is dried and exhausted with boiling alcohol of specific gravity 0.81 , which removes morphine, and leaves meconate of calcium undissolved. The alcoholic solutions are filtered through the filter already used in the extraction with ether. The weight of the alkaloid can be ascertained either by evaporating to dryness, redissolving in acidulated water, precipitating with ammonia, and weighing, or by evaporating, redissolving in dilute sulphuric acid, and titrating according to $\$ 65$. Good opium contains at least 8 per cent. of morphine.

$\mathrm{V}$. If the morphine is reprecipitated for gravimetric estimation the filtrate may be mixed with the filtrate from II., made alkaline with ammonia, and shaken with amylic alcohol. All the morphine in solution is thus removed, and the amount which escapes precipitation in II. is sometimes very considerable. The amylic-alcohol solutions are evaporater to dryness, the residne dissolved in a little acidulated water, precipitater with a slight excess of ammonia, drierl, weighed, and noted as morphine. A correction of 0.001 gram for each cc. of mother-liquid may be made if desirable.

VI. If the sample under examination is an opium of good quality the insoluble residue from I. will contain narcotine, but no morphine. The former may be estimated by extracting with water acidulated with sulphuric acid, precipitating with ammonia, filtering, washing, redissolving in dilute sulphuric acid, and titrating with potassio-mercuric iodide ( $(65)$.

$\$ 188$. Other Methods.--Weak spirit was also formerly employed 
in the place of water for exhausting the opimm, and Proctor ${ }^{1}$ has recently proposed triturating the opium (13 grams) with water (15.5 gram) to a paste in a warm nortar, adding methylated spirit ( 16 grams) by degrees, and exhausting by percolation with the latter menstruum. The solution is eraporated to a syrup, mixed with water (63 grams), and filtered. The filtrate is again eraporated (to 6 cc.), mixed with an equal rolume of methylated spirit and slight excess of ammonia, allowed to stand twelve to eighteen hours, filtered and the precipitate washed, first with a mixture of equal quantities of methylated spirit and water, and finally with the latter alone (about 31 grams). Proctor removes narcotine with benzene.

For the approximate estimation of the morphine Prollius recommends extracting the opium with 10 parts of 3.1 per cent. spirit, mixing the solution with 5 parts of ether and 0.2 of ammonia, allowing to stand twelve to twenty-four hours, filtering off, drying and weighing the morphine, which separates at the line of demarcation; narcotine is said to be dissolved by the ether.

Fliickiger ${ }^{2}$ exhausts 8 grams of powdered opium by agitation for twelve hours with 80 grams of water, and filters the infusion through a filter $12.5 \mathrm{~mm}$. in diameter. 42.5 grams of the filtrate are mixed with 12 grams of alcohol of sp. gr. $0.812,10$ grams of ether, and $1 \%$ caustic ammonia in a tared flask, and set aside for a day or two. The crystals of morphine that have separated are then collected on a donble filter 4 inches in diameter'; both flask and residue on the filter are washed, first with a mixture of 6 grams of spinit with 5 of ether, and afterwards with 10 grams of ether. The crystals are finally gently pressed, returned to the flask, dried, and weighel. To the amount thus obtained Flückiger adds $0 \cdot 1$ gram (Mylius 0.088) for loss in precipitating and washing.

For the rotatory porver of opium alkaloids, see Hesse. ${ }^{3}$

$\$$ 189. Other Allaloils.-In treating of the more important

1 Pharm. Journ, and Trans. [3], vii. 244, 1876; viii. 211, 1877.

2 Pharm. Zeitung, Nos. 57, 59, 1879 (Pharm. Journ. and Trans. [3], x. 254, 1879). See also Van der Burg, Pharm. Weekbl. No. 26, 1879; Mylius, Archiv d. Pharm. [3], xv. 310, 1879 (Year-book Pharm. 22, 23, 1880).

${ }^{3}$ Annal. d. Chem. und Pharm. clxxvi. 189, 1875. See also Yron, Journ. de Pharm. et de Chim. xxix. 372, 445, 1879. A paper on the rarer opium alkaloids was published by Hesse in the Amnal. d. Chem. und Pharm. cliii. 47, 1870 (Pharm. Journ, and Trans. [3], i. 205, 1870). 
alkaloids, I have described such of their properties only as are of importance for the object of this work, and refer students that may desire more minute details to any good text- or hand-book of chemistry. I may be permitted to give a few literary references, and make a few observations on some of the alkaloids with which we are less familiar, and about which little or no information is to be found in text- or hand-books, in case it should be necessary in the course of an analysis to compare a substance with any one of them.

For ergotinine and picrusclerotine, compare Tanret ${ }^{1}$ and Blumberg. ${ }^{2}$ Two volumes of conc. sulphuric acid colour an aqueous solution of the former, first red, then bluish-violet, of the latter violet. With an equal volume of Fröhde's reagent, both are coloured violet, passing to blue. Both can be extracted from solution by agitation with ether. The latter, which is resinous and very sparingly soluble in water, is possibly a decompositionproduct of the former.

For curcuine, which is freely soluble in water, see Preyer ${ }^{3}$ and Sachs. ${ }^{4}$ This alkaloid cannot be removed from solution by shaking with ether, etc. Its reactions are described in $\S 171$. Chloroform extracts small quantities (sufficient for the reactions and physiological experiments) of the alkaloid from the resiaue (finely powdered) obtained by evaporating its aqueous solution. (Compare also $\$ § 64,68,182$.)

For eiythrophlocine see Gallois and Hardy. ${ }^{5}$ It is soluhle in water, can be extracted by shaking with acetic ether, and is coloured violet by sulphuric acirl and permanganate of potassium.

Lobeliine, see Lewis and Richardson. ${ }^{6} \quad$ (Cf. $\left.\$ 56.\right)$

1 Repert. de Pharm. N. Sér. iii. 308, 1875 ; v. 226, 1877 (Pharm. Journ. and Trans. [3], vii. 249. 1876 ; vi. 522, 1875).

2 Ein. Beitr. z. Kenntniss d. Mutterkornalk. Diss. Dorpat, 1878 (Pharm. Journ. and Trans. [3], ix. 23).

${ }^{3}$ Zeitschr. f. Chem. vi. 382, Compt. rend. 1. 1828, 1865. See also Koch, 'Vers. iiber die Nachweisbarkeit d. Curarins in thier. Fliissigk. und Geweben,' Diss. Dorpat, 1870, and my 'T3eitr. z. gerichtl. Chem.' 170, St. Petersburg, 1871.

4 Annal. d. Chem. u. Pharm., cxci. 254, 1878 (Journ. Chem. Soc. xxxiv. 517). See also my observations in the Jahresb. f. Pharm. for the same year.

${ }^{5}$ Union Pharm. xvii. 202, 1876 (Pharm. Journ. and Trans. [3], vii. 77, 1876), also xix. $359,1878$.

6 Amer. Journ. Pharm. 293, 1872; Pharm. Journ. and Trans. [3], viii. 561, 1878. See also my 'Beitr. z. gerichtl. Chem。' 18. 
Conessine or urightine, see Ifaines ${ }^{1}$ and Stenhouse. ${ }^{2}$ It is very sparingly soluble in alcohol, ether, and hisulphide of carbon.

Incrmuline and hurmine, compare Fritsche. ${ }^{3}$ The former yields yellow salts with acids-the latter colourless. Both are somewhat sparingly soluble in alcohol.

Surimumine is also sparingly soluble in spirit. (Compare Hüttenschmidt and Winkler. ${ }^{4}$ )

Aribine, see Rieth. ${ }^{5}$ It is sparingly soluble in ether, as is also

Athero.permine, compare Zeyer ${ }^{6}{ }^{6}$ and liharuline, compare Hesse. ${ }^{7}$ The latter is colourless, but is converted by dilute acids into deep red rhoagenine.

Violine, compare Boullay; ${ }^{8}$ for beberine, see Maclagan ${ }^{9}$ (cf. § 171); for bellulonnine, see Hübschman ; ${ }^{10}$ for cocuïne and hyyrine, compare Niemann, Wühler, and Lossen. ${ }^{11}$ Concentrated hydrochloric acid decomposes cocaine into benzoic acid, and the alkaloidal ecgonine.

For chlorogenine and porphyrine see Hesse. ${ }^{12}$ Chlorogenine in acid solution shows a powerful blue fluorescence.

Coryduline, compare Wackenroder, Müller and Leube, Boedecker and Wicke. ${ }^{13}$ The alkaloid dissolves in conc. sulphuric acid, with dark red colouration.

\section{Cytisine, compare Husemann and Marmé. ${ }^{14}$}

1 Pharm. Journ. and Trans. [2], vi. 432.

2 Ibid. [2], v. 493; Schweizerische Wochenschrift f. Pharm. 172, 174, 1865.

${ }^{3}$ Chem. Centralblatt, 1847-49, 1853, 1854. See also Goebel, Annal. d. Chem. und Pharm. xxxviii. 363, 1841.

4 Gmelin's ' Handbook of Chemistry.'

${ }^{5}$ Chem. Centralblatt, 903, 1861 (Amer. Journ. Pharm. xxxiv. 395).

6 Vierteljahresschr. f. pract. Pharm. x. 513. 1861 (Amer. Journ. Pharm. xxxiv, 166, xxxv. 453).

${ }^{7}$ Annal. d. Chem, und Pharm. (Suppl.) iv. 50 ; cxl. 145, 1866 ; cxlix. 35, 1869 (Amer. Journ. Pharm. xxxviii. 568, xxxix. 122, xlii. 396).

8 Repert. f. Pharm. xxxi. 37.

9 Annal. d. Chem. und Pharm. xlviii. 109, 1843; Iv. 105, 1845 (Pharm. Journ. and Trans. [1], iii. 177 ; v. 228).

10 Viertel jahresschr. f. pract. Pharm. viii. 126, 1859.

11 Ibid. ix. 489, 1860 ; Annal. d. Chem. und Pharm. cxxi.372, 1562 (Amer. Journ. Pharm. xxxii. 450, xxxiii. 122, xxxiv. 406).

${ }_{12}$ Annal. d. Chem. und Pharm. (Suppl.) iv. 40. Muiller's alstonine from Alstonia constricta is probably a mixture of these two alkaloids (Hesse).

13 Archiv d. Pharm. xlix. 153, 184\%. Vierteljahresschr. f. pract. Iharm. viii. 536, 1859; ix. 521, 1860. Annal. d. Chem. und Tharm. cxxxvii. 274, 1866. (See Bentley, Pham. Journ. and Trans. [2], iv. 343, 1862; Amer. Journ. Pharm. xxxiii. 112).

14 Chem. Centralblatt, 781, 1865; and N. Jahrb. f. Pharm. xxxi. 193, 1869 (Pharm. Journ. and Trans. [3], i. 682, 1871). 
Ditemine (echitamine), see Gorul) Besanez, and Hesse ; 1 for ditcïne see Harneck. ${ }^{2}$ The latter is glucosidal, like solanine, and assumes a Hesh-colour when treated with conc. sulphuric acid, whereas ditamine turns splendid purple.

Geissospermine and aspidospermine, compare Fraude. ${ }^{3}$ The latter yields a deep violet solution when warmed with excess of perchloride of platinum; heated with dilute sulphuric acid and a little chlorate of potash, or with perchloric acid of sp. gr. 1.13, it turns deep red; with sulphuric acid and peroxide of lead, brown, changing to cherry-rerl. If not quite pure, in the latter case a violet colour is produced. At a temperature of $14^{\circ}$ aspidospermine dissolves in 6,000 parts of water, 48 of 98 per cent. spirit, and 106 of ether.

Dulcamerine, see Wittstein ; alkaloid in Eschscholtrich, sce $\mathrm{WTalz}^{\top}{ }^{5}$

${ }^{1}$ Annal. d. Chem. und Pharm. clxxvi. 88, 326 ; clxxviii. 49, 1875 (Pharm. Journ. and Trans. [3], vi. 142, 1875). Ber. d. d. chem. Ges. xiii. 1841, 1880 (Year-book Pharm. 171, 1881).

2 Archiv f. exper. Pathol. und Pharmacol. vii. 128, 1877. Ber.d. d. chem. Ges. xi. 2004, 1878 (Year-book Pharm. 188, 1878); ibid. xiii. 1645, 1880 (see also Pharm. Journ. and Trans. [3], viii. 803, 1878; xi. 331, 1870). Scharlée's alstonine (Hesse's alstonanine) from Alstonia spectabilis appears to be closely allied to ditamine, but crystallizes with facility.

${ }^{3}$ Ber. d. d. chem. Ges. xi. 2189, 1878 (Year-book Pharm. 193, 1879) ; ibid. xii. 1558, 1560 (Pharm. Journ. and Trans. [3], x. 712, 1880). See also my observations in the Jahresb. f. Pharm. 120, 1878; and Hesse, ibid, 115, 1877 (Pharm. Journ. and Trans. [3], viii. 648, 1878). The name geissospermine appears to have been applied to two different alkaloids, of which the one discovered by Hesse yields reactions closely resembling those of aspidospermine (red colouration with nitric acid, etc.). Hesse's geissospermine produces a splendid red colour with sulphuric acid and bichromate of potassium, blue with sulphuric acid and ferric salts, deep blue with Fröhde's reagent, and changes the colour of chloride of gold solution to a deep red. It can be removed from solution by shaking with benzene or chloroform, and is accompanied by an alkaloid which is easily soluble in ether and turns reddishviolet with sulphuric acid. The identity of aspidospermine and paytine already alluded to $(\S 186)$ is contested by Hesse. 'The same chemist has also lately discovered a second alkaloid in quebracho, which he calls quebrachine; it is coloured blue with sulphuric acid and peroxide of lead (Ber. d. d. chem. Ges. xiii. 2308; see Pharm. Journ. and 'I'rans. [3], xii. 704). In examining quebracho bark, I noticed that chloroform extracted from acid solutions (\$ 5i) a small quantity of an alkaloid giving the reaction of aspidospermine. Solutions renclered alkaline with ammonia yielded to petroleum spirit and benzene a mixture that reacted like aspidospermine with sulphuric acid and chlorate of potash, lout was coloured splendid violet ly Frohde's reagent, and behaved like strychnine to sulphuric acid and bichromate of potash. Compare also Arata, Actas de la Acad. nac. in Buenos Aires, 1881; Hesse, Annal. d. Chem.u. Pharm. ccxi. 249, 1882.

${ }^{4}$ Pharm. Vierteljahresschr. i. 371, 495, 1850. Cf. § 167.

5 N. Jahrb. f. Pharm. viii. 223, 1857 (Amer. Journ. Pharm. xxxiv. 329). Compare also my 'Ermittelung d. Gifte.' 
Ilunuine, see Probst; fumurine, see Pommicr, IImmon, and Prenss;- gelsemine, see Robbins" (cf. So 5.), 171); luyltastine, see I'errins ; jurubeline, see Greene; loturine, see \$168; nenispermine and purancuispermine, see Szteyner; ${ }^{\circ}$ olecundrine, see Leukowstiy ; orlyucunthine, see Polex;'s pelletierine (1)unicine), see Tamet. ${ }^{\circ}$

I'teirine, see Goos. ${ }^{10}$ It dissolves with purple colour in nitric acid.

Sivurteine, see Mills (cf. S J5);11 tuxine, see Narmé (cf. SS 55, 171) ; ${ }^{12}$ lycopodine, ${ }^{13}$ mupharine. ${ }^{14}$

190. Amiles. - The following are amides of less complex constitution occasionally met with in plants :

Amenitine, which may be distinguished from muscarine loy the properties of the gold salt $(\$ 183)$ and by the negative results of physiological experiments. ${ }^{15}$ It is isomeric, but not identical with choline (neurine, sinkaline), and is converted into muscarine by the action of nitric acid, whereas, under similar conditions, choline yielils letuine (= butylalanine and oxyneurine). Muscarine differ's from betaine in being more powerfully alkaline. ${ }^{16}$

${ }^{1}$ Annal. d. Chem. und Pharm. xxix. 120, xxxi. 250, 1838 (Amer. Journ. Pharm, xxxiii, 9).

${ }^{2}$ N. Repert. f. Pharm. ii. 469, 1853 ; Vierteljahresschr. f. pract. Pharm. iii. 68,1852 ; Zeitschr. f. Chem. ii. 414, 1866.

${ }^{3}$ Jahresb. f. Pharm. 152, 1876 (Amer. Journ. Pharm. 191, 1876). Robbins identified the so-called gelsemic acid with aesculin.

¿ Pharm. Journ. and Trans. [2], iii. 546, 1862. See also Mahla, Journ. f. pract. Chem. xci. 248 ; Prescott, Amer. Journ. Pharm, xlvii. 481, 1875; Hale, ibid. 247.

5 Amer. Journ. Pharm. xlix. 506, 1877.

${ }^{6}$ Jahresb. f. Pharm. 141, 1878.

7 Ibid. xlvi. 397.

${ }^{8}$ Archiv d. Pharm. [1], vi. 271, 1824 (Amer. Journ. Pharm. xxxiii. 455).

'Journ. de Pharm. et de Chimie, xxviii. 168, 1878 (Pharm. Journ. and Trans. [3], ix. 450).

${ }^{10}$ Chem. Centralblatt, 610, 1839. Compare also Peretti, Journ. de Chim. med. xxvi. 162.

11 Annal. d. Chem. und Pharm. cxxv. 71, 1862.

12. Jahrest. f. Tharm. 93, 1876; compare also 636, 1879 (Pharm. Toum. and Trans. [3], 893, 1877).

13 Ammal. d. Chem. und Pharm. ccviii. 363, 1851 (Phamn. Joum. and Trans. [3], xii. 280, 1881).

14 Gruining, loc. cit.

15 Compare Sehmiedobers, Ber. d.d.chem. Ges. iv. 633, 1571, and Harnack, loc. cit. (Pharm. Journ. and Trans. [2], xi. 365, 1869).

${ }^{16}$ For letane see Scheiblex, Ber. d. d. chem. Ges. ii. 292, 296, 1869 ; identity with oxyneurine, ibid. iii. 155; with lycine see Iluseman, Schweiz. 
Choline and amanitine are also tolerably strongly alkaline. The double salt of platinum and choline is precipitated hy alcohol from aqueous solution (contains 31.75 to 33.27 per cent. Pt.); the gold double salt is sparingly soluble in cold water, more freely in boiling (contains $44 \cdot 25$ to $44 \cdot 9$ per cent. Au.). The gold and platinum double salts of betaine are freely soluble in water, and especially so in alcohol, but more sparingly in ether.

$\$ 191$. Asparagine.-This sulistance requires 40 parts of cold and 4 of warm water for solution, and is insoluble in absolute alcohol and in ether. It crystallizes in colourless rhombic prisms. Boiling with hydrochloric acid resolves it into aspartic acid and ammonia, a reaction upon which Sachsse ${ }^{1}$ based the following method for the quantitative estimation :-10 grams of the powdered substance are boiled for a quarter of an hour with $200 \mathrm{cc}$. of a mixture of equal volumes of alcohol and water, in a flask provided with an upright condenser; 5 cc. of a cold saturated alcoholic solution of mercuric chloride are diluted with $5 \mathrm{cc}$. of water, and added to the mixture whilst still hot, the whole thrown on a filter, and washed first with hot 50 per cent. spirit, and finally with cold water. The filtrate and washings are eraporated to dryness, the residue redissolved in the smallest possible quantity of water (not more than 50 cc.), from which solution the mercury is precipitated with sulphuretted hydrogen. The sulphide of mercury is filtered off and washed with hot water until filtrate and washings measure 110 to $120 \mathrm{cc}$. This liquid is then mixed with $10 \mathrm{cc}$. of hydrochloric acid and boiled for an hour (with upright condenser), by which the asparagine is decomposed into ammonia and aspartic acicl; it is then cooled in an atmosphere free from ammonia, and made slightly alkaline with pure potash. The ammonia produced may be estimated gasometrically by Knop's method; 14 parts hy weight of nitrogen indicate 132 of anhydrous asparagine. For asparagine, see also $97,210$.

The microscopicul detection of asparagine may be effected by taking arlvantage of its insolubility in absolute alcohol. Crystalline deposits of that substance are usually formed when fresh sections of plants containing it are placed in alcohol. After beings dried they are insoluble in a cold saturated aqueous solution of

Wochenschr. 1875 (Amer. Journ. Pharm. 209, 1875). Compare also Annal.

d. Chem. und Pharm. (Suppl.) ii. 383, iii. 245, 1864.

1 Journ. f. pract. Chem. vi. 118, 1873 (Journ. Chem. Soc. xxvi. 652). 
asparaugine, and melt at $100^{\circ}$ to a homogeneous mass easily soluble in water. Should the addition of alcohol not be followed by the immediate formation of crystals, Borodin recommends covering the object with a coverslip, allowing the spirit to evaporate, and then again looking for crystals.

Schulze and Ulrich detected glutamine in beet-juice by precipitating with a slight excess of basic acetate of lead and filtering. To the filtrate which contains the glutamine, hydrochloric acid is adder in the proportion of $25 \mathrm{cc}$. to a litre; on boiling for two hours the glutamine is decomposed, like asparagine, into ammonia and the corresponding acid (glutamic acid). The greater part of the hydrochloric acid is now removed by concentrated solution of acetate of lead, and to the filtrate basic acetate of lead is added until the precipitate first formed is redissolved, with the exception of the remainder of the chloride of lead. The lead salt of glutamic acid is then precipitated from the filtered solution by the addition of alcohol. It is collected, decomposed with sulphuretted hydrogen, and filtered from the sulphide of lead. After expelling the excess of sulphuretted hydrogen from the liquid, oxide of silver is added to remove any hydrochloric acid present, the solution freed from silver by sulphuretted hydrogen, and evaporated to crystallization. The glutamic acid thus obtained may be purified by conversion into a copper salt and regeneration by sulphuretted hydrogen. The presence of glutamic acid was confirmed by converting with nitrous acid into the corresponding oxy-acid, from which pyrotartaric acid was obtained by the action of hydriodic acid.

The last portion of glutamic acid from the crystallization of the crude product was found to contain aspartic acid. ${ }^{1}$

Glutamine may be cstimated quantitatively in the same manner as asparagine.

For the quantitative determination of asparagine, leucine, tyrosine, etc., see also $\S 241$.

\$ 192. Leucine.-This substance has also been detected in certain plants. ${ }^{2}$ It may be separated from albuminous substances by dialysis, and if present in solution with asparagine, will be found in the mother-liquor after the crystallization of the latter.

1 Compare Zeitschr. f. anal. Chem. xvii. 104, 1878.

2 Compare, for instance, Gorup Besanez, Ber. d. d. chem. Ges. vii. 146, 569, 1874 (Journ, Chem. Soc. xxvii. 494). 
It is characterized loy crystallizing in sphero-crystals, by its hehilviour to water and alcohol (dissolves in 27 parts of cold, and easily in warm water, in 1040 of cold 96 per cent. spirit, and 800 of boiling 98 per cent.), by its power of dissolving oxide of copper, and by yielding leucic acid when acted upon by nitrous acid.

I have alrearly directed attention to the identity of the chenopodine obtained from decomposing yeast with leucine. ${ }^{1}$ Gorup Besanez has made the same assertions of the chenopodine from Chenopodium album.

Tyrusine, as well as leucine, has lately been detected in plants, especially in germinating seeds." Aqueous extracts of the material under cximination are concentrated, precipitated with alcohol, filtered, freed from alcohol by distillation, eraporated to a syrup, and allowed to stand, when the tyrosine separates out in groups of warty crystals. By recrystallization from ammoniacal alcohol it may be olutained in acicular crystals. Solutions of the latter develop a rose-colour with mercuric nitrate and a little nitrous acid. Warmed to $50^{\circ}$ with concentrated sulphuric acid (half-hour), and saturated with carbonate of barim, it yields a mass which assumes a fine violet with ferric chloride.

liutuntin agrees with tyrosine in most of its reactions, especially the two just described. It is almost insoluble in cold water, alcohol and ether, sparingly solul,le in boiling water, but freely in ammonia. Suspended in water, and then warmed with a little nitric acid, it dissolves, passing, as it does so, from rose to rubyred and blue, turning finally green with red fluorescence. ${ }^{3}$

\section{VEGETABLE MIUCILAGE.}

\$193. Veyctulle Muciluye, I'ectin, ch-The sulnstances lesignated by these names are a source of much inconvenience to the analyst, due probalbly to their occurring in varions modifications

${ }^{1}$ Compare Bergman, 'Das putride Gift,' Dorpat Gliser. Soe also lieinsch, N. Jahrb. f. Pharm. xxvii. 123, 1867.

${ }^{2}$ Compare Schulze and Barbieri, Ber. d. d. chem. Ges. x. 199, xi. 710 (Journ. Chem. Soc. xxxiv.663).

${ }^{3}$ It is notorious that ratanhin does not occur in rhatany-root, and that its presence in certain samples of commercial extract of rhatany is due to adulteration. Compare also Kreitmair, Jahresb. f. Pharm. 136, 1874 (Year-book Tham. 30, 185.). (rintl believes ratanhin to be identical with angelin from Ferreira spectabilis (Zeitschr. d. österr. Apoth. Ver, 32, 1869). 
differing greatly from one another in solubility, cte. The majority of them are characterized by a certain disposition to combine with lime, potash, cte., and this has led to their classification with the weak organic acids (arabic acid, etc.); in fact, some of the differences in solubility, etc., seem occasionally to depend directly upon the quantity and quality of the bases with which they are combined. ${ }^{1}$

But other substances, such as albumen, tannin, etc., that simply accompany the pectin and mucilage, can also exercise an influence on the behaviour of the latter to solvents. On this account, and because, as a rule, such matters as mucilage diffuse but slowly, it is not always possible, in extracting regetalle sulsstances with water according to $\$ 1$, to be certain that all the mucilage (arabin, etc.) soluble in water has really passed into solution. If heat were employed, the amount dissolved would certainly be increased, but at the same time other and more serious errors would be introduced.

One such source of error is to be found in the presence of carbohydrates closely allied to soluble mucilage, but differing from it in only swelling (not dissolving) in cold water (metaralic acid, etc.). These carbohydrates are of frequent occurrence in plants. Prolonged heating with water gradually dissolves them. Error would also be caused by carbohydrates like lichenin, caraghin, starch, etc., hot solutions of which gelatinize on cooling, as well as by other substances.

$\$ 19$ t. Modified, Methon of Errminution for Mucilage, etr.-For the reasons given in $\$ 193$, I think it is preforalle to extract with cold water, and estimate the mucilage and albumen in the solution prepared according to $\$ 71$. The washings mentioned in that section should be evaporated to a syrup, in which a similar determination of mucilage and albumen should be made. If the material has been macerated with exactly $100 \mathrm{cc}$. of water, and 65 ce. of filtrate have been obtained (used for the first determination of albumen, ete.), then 3.) cc. must be retained by the residue and filter, and these 35 cc. must be extracted by the washing. If the

1 This was clearly the case in peony-seed (Archiv d. Pharm. [3], xiv. 426, 1879 ; Journ. Chem. Soc. xxxv. 1043). Treatment of the seed with alcoholic tartaric acid rendered far more arabic acid soluble in water than it was possible to extract by direct treatment with the latter menstrum. It had evidently been liberated from combination by tartaric acid, and rendered soluble in water. 
extraction has been complete, the amount of albumen, etc., in the washings must be the same as that in 35 ce. of the first filtrate (which may be calculated from the first estimation); but should the washings contain more than the corresponding quantity of filtrate, the excess must be alded to the total of the analysis.

$\$ 195$. Churucters of Soluble Aluciluge.-A part from their being dissolved by water and precipitated by alcohol from aqueous solution, vegetable gum, arabin, arabic or gummic acil, is also characterized by being converted into glucose when boiled with a dilute acid. It must, however, be observed, that the various arabic acids, according to their origin, yield glucoses differing to a certain extent from one another, some being more powerfully dextro-, others læro-rotatory; some crystallizing with facility, others again not at all, or only with difficulty, or passing first through an intermediate stage as dextrin (according to Kirchner with simultaneous production of cellulose). By means of these properties, vegetable mucilages of particular origin can sonetimes be accurately described. Some years ago it was shown by Scheiller ${ }^{1}$ that the aral,ic acid of beet-root yielded, on inversion, a considerable quantity of dextro-rotatory arabinose, which crystallizes with such facility that it was at first thought to the mannite.

Kiliani has recently asserted the identity of arabinose with lactose. Nany varieties of gum arabic also behare like arahic acid, whilst some which are not otherwise distinguishathe from good grum, differ in yichling levo-rotiatory non-crystallizable glucose. In arldition to these, Bhechamp' 2has recently discovered a 'gummicose' which appears to be allied to galactose (\$205). I am almost incined to think that a minute investigation of these properties might enahle us to distinguish between the valious forms of vegetable mucilage soluble in water. ${ }^{3}$

The examination of the oxidation-products obtained by the

1 Ber. d. d. chem. Ges. vi. 612, 1873 ; Journ. f. pract. Chem. ciii. 458, 1868 (Journ. Chem. Soc. xxvi. 1124). Sce also Neubauer, Jahresb. f. Pharm. 6, 1854, and Græger, ibid. 218, 1872.

${ }^{2}$ Compare Béchamp, Journ. de Pharm. et de Chim. xxvii. 51, 1878.

${ }^{3}$ In general it may be said that the action of dilute acids must be continued for a longer time to convert vegetable mucilage (arabin) into glucose than is necessary for dextrin, triticin, etc. But it must be left for further experiments to show to what extent the amount of glucose produced may be taken as an indication of the quantity of arabin originally present. 
action of nitric acil may also result in the discovery of distinctive properties. Sprecial attention should be directed to the presence among these oxidation-prorlucts of mucic acid, and to the quantity in which it is yielded.

The action of aqueous solutions of these mucilaginous suthstances on pulurized light also requires further investigation. It is at all events certain that some arabins are powerfully lævorotatory (cf. \$146), others feehly so, whilst some again are dextrorotatory.

By the action of hydrochloric, or tolerably dilute sulphuric acil, or spirit containing 10 per cent. of the latter, aralbic acid is converted into metarabic acid (\$226) which is characterized lyy only swelling in water. This modification can be converted into arabje acid by boiling with a very dilute non-oxidizing acid, a little sugar' being simultmeously produced. A similar change to arabic acir talies place when metarabic acid is triturated with suffieient lime or baryta water to dissolve it, a lime or baryta salt of araljic acid being formed.

Aralice acil agrees in its essential properties with metapectic acid, and apuroaches pectic acid in such a manner as to allow of the conjecture that the latter, when examined in a state of purity, will prove identical with it; in fact, I am of the same opinion as Reichardt ${ }^{1}$ and others-riz, that the so-called peetin substances are nothing else than the various forms of regetal)le mucilage and its nearest allies.

The insolulility of these mucilaginous and 'pectinous' substances in alcohol and ether, and the property they possess of swelling in contact with water, allow of their detection miresirnfirmlly. They are generally coloured yellow by iodine water' (for allied substances coloured blue with iodine, see $\$ 244$ ). Aniline violet colours vegetable mucilage red.

196. Vurieties of Gum Arabic.-Masing ${ }^{2}$ has published commmications on the beharion to reagents (S $7: 3)$ of arahic acir, amel different ralicties of gum arabic, and its more important, surrogates. It appears that 10 per cent. aqueous solutions of these substances ate not precipitaterl by cold situraterl solution of acetate of colper, 10 per cent. alcetate of learl solution, or liy ferric

${ }^{1}$ Archiv d. Pharm. [3], x. 116, 1877 (Journ. Chem. Soc. xxxii. 502).

2 Archiv d. Pharm. [3], xv. 216, 1879; xvii. 34, 1880 (Year-bouk Pharm. 191, 1881; Journ. Chem. Soc. xl. 212). 
chloride of sp. s1. 1.2 ; a cloudiness or precipitate produced in some samples (e.g. Feronia elephantum) is probably due to contamination. Silicate of potash (1 part of thick soluble glass diluted with 20 parts of water) produces in solutions of gmu arabic, and most of its surrogates, a cloudiness or precipitate which partially or wholly redissolves on adding excess. Aralic acid remains clear, or becomes only slightly turbil. The same reagent does not precipitate the partially soluble gum from species of Cactus, Cedrela, or Rhizophora, or solutions of the gum from Acacia catechu, A. leucophloea, and species of Albizza, Azedirachta, Odina and Conocarpus. A 2 per cent. solution of stannate of potash yields reactions resembling in general those of silicate of potash, but produces in solutions of arabic acid a precipitate that redissolves in excess. A 10 per cent. solution of neutral sulphate of aluminium gives, as a rule, a precipitate, and this is in many cases soluble in caustic potash of sp. gr. 1.13. Basic acetate of lead also produces a precipitate, which is generally partially or wholly soluble in excess.

$\$ 197$. Separation from Dextrin, etc.-The behaviour of the mucilaginous substances soluble in water to hasic acetate of learl furnishes us with the means of getting rid of them, should we wish to make optical or chemical experinents with extracts of vegetable substances for the detectim of glucuse, suchurose, dentrin, triticin, etc. (cf. $\S \S 76,83$ ) ; care must be taken; however, not to add any large excess of the precipitant. If this precaution is olserved, such substances as arabin and dextrin can, I think, be more completely separated than hy the precipitation with alcohol, recommeniler in 55,75 . In the latter, ethylic alcohol can, as I showed some years since, be replaced by methylic. ${ }^{1}$

\section{DEXTRIN, TRITICIN, SINISTRIN, LEVULIN.}

\$198. Cherrecter-These carloohydrates are all casily converted. into glucoses (\$ 76$)$ by rlilute acids. Jurtion may he distinguished by its yielding grape-suga", whilst triticin, sinistrin and levulin are converted into levulose, and are also characterized by their hehaviour to baryta-water (see also 57 ). Tucrulin? is optically

1 Pharm. Zeitschr. f. Russland, iv. 152, 1866 (note).

2 Compare Weyher v. Reidemeister, 'Beitr. z. Kenntniss d. Levulins, etc.' Diss. Dorpat, 1880. 
inactive; sinistrin and triticin ${ }^{1}$ differ from one another in the extent to which they deviate a ray of polarized light. Triticin reduces Fehling's solution rapidly, but levulin and sinistrin require long boiling before cuprous oxide separates out (levulin, $1 \frac{1}{2}$ hour). These three carbohychrates also differ in the rapidity with which they are converted into glucose when heated with pure water in sealed tubes. Triticin is here the first to undergo a partial transformation into sugar. Levulin is more casily converted by yeast into carbonic acid and alcohol than is either triticin or sinistrin.

$\$$ 199. Alenholutes of the foregoing Curbohydrates, Comprosition, (Uuntitative Estimation, ete.-The precipitates of Icvulin, triticin and sinistrin produced by spirit retain notable quantities of alcohol in such a manner as to necessitate the inference that distinct alcululutes hare heen formed. Even after standing for three months over sulphuric acid the levulin compound had not lost all its alcohol, whilst in a partial vacum it had disappeared in the course of two months. Prolonged heating to $110,^{\circ}$ a temperature at which the alcoholate melts, is sufficient to cause the gradual expulsion of the alcohol.

In estimating the four carbohydrates in question by calculation from the amount of sugar yielded by the action of dilute acids, it must be remembered that the composition of dextrin, sinistrin and levulin, dried at $100^{\circ}$, has been found by analysis to correspond to the formula $\mathrm{C}_{6} \mathrm{H}_{10} \mathrm{O}_{5}$, but that triticin dried at $110^{\circ}$ has the same composition as cane-sugar: viz., $\mathrm{C}_{12} \mathrm{H}_{22} \mathrm{O}_{11}$.

In these cases the glucose ( 76$)$ is better estimated by Fehling's solution (\$.5) than by polarization (\$208). Solutions of levulin, triticin and sinistrin, although inverted with dilute acids only, do not always show an angle of rotation $=106^{\circ}$ to $107^{\circ}$ (\$ 205), even if the solution be neutralized, evaporated to dryness, redissolved in cold water, and tested immediately. On cooling the solution after inversion and examining at once, levulin yiclded, in the most favourable instances, a sugar with a rotatory power of $81^{\circ}$, triticin, $94^{\circ}$, and sinistrin, $96^{\circ}$; and it was only by conducting the inversion in sealed tubes that Reidemeister obtuined for triticin-sugar a rotation of $106.5^{\circ}$, indicating the presence of pure levulose. ${ }^{2}$

${ }^{1}$ For mycodextrin and mycinulin see Ludwig and Busse, Archiv d. Pharm. clxxxix. 24, 1869.

2 Compare Reidemeister, loc. cit. 
For the complete inversion of 1 to 1.3 grams of carbohydrate dissolved in $35 \mathrm{cc}$. of water, 5 to 6 drops of hydrochloric acid (33 per cent.) were found sufficient; in the case of levulin, two to two and a half hours' boiling is required, whilst triticin is completely converted in twenty-five to thirty minutes (Reidemeister).

To obtain accurate results the acid must he as dilute as possible, and the action stopped as soon as the inversion is complete. Here, as in many other instances, hydrochloric acid seems to be preferalble to sulphuric; consideral,le quantities of sugar (20 to 30 per cent.) may otherwise be lost by secondary decompositions, and in consequence the estimation of the carbohydrate be attencled with results inaccurate in the extreme.

For the estimation of glucose by titration, see $\$ \S 83,84$.

For dextrin, see also $\$$ 200, 201, 202.

GLUCOSES, SACCHAROSES, ETC.

$\$ 200$. Detetion of Grepe-sugar.-To detect grape-sugar (\$ 70 , 8.3 to 88), Mulder ${ }^{1}$ makes use of its reducing action on indigo. The solution to he cxamined is rendered faintly blue with sulphinrligotic acid; carbonate of soda is then added until the reaction is allialine, and the whole boiled for a few seconds. If grape-sugar is present, the colour passes from blue to violet, and then disappears; the liquid should not, however, be shalien, as the action of the air results in the rapid return of the blue colour. ${ }^{2}$

Tincture of litmus, sulstituted hy $\mathrm{V}^{\mathrm{T}} \mathrm{ggel}^{3}$ for indigo, is less sensitive.

Brann ${ }^{4}$ directs attention to the reaction between gluense and picric aciel, and recommends this reagent for distinguishing between grape-and cane-sugar. In the presence of caustic soda picric aciel is converted hy boiling with grape-sugar into blool-red picramic acirl. Fruit-and milk-sngar exert a sinilar action, which is not shared by mannite or cane-sugar.

For the action of grape-sugar on ferridcyanicle of potissium, see Gentele ${ }^{5}$ and Lenssen. ${ }^{6}$ The latter also discusses the reduc-

${ }^{1}$ Chem. Centralblatt, 176, 1861 (Pharm. Tourn. and Trans. [1], xviii. 421).

a Compare Neubauer, Zeitschr. f. anal. Chem. i. 378, 1862.

3 N. Repert. f. Pharm. xi. 62, 1862.

4 Zeitschr. f. anal. Chem. iv. 185, 1865.

5 Chem. Centralblatt, 91, 1861; Stahlschmidt, Ber. d. d. chem. Ges. 141, 1861 (Amer. Journ. Pharm. xxxii. 81).

${ }^{6}$ Zeitschr. f. anal. Chem. ix. 453, 1870. 
tion of cyanide of mercury by glucose as recommended by Knapp ${ }^{1}$ (S4), and shows that by neither method can saccharose be accurately distinguished from glucose.

O. Schmidt distinguishes between grape- and cane-sugar by adding basic acetate of lead and ammonia, and warming. The white precipitate that first appears turns red if grape-sugar is present; cane-sugar does not yield this reaction. ${ }^{2}$

$\$$ 201. Esstimution of Gluruse in Presence of Surcherose.--In titrating glucose in the presence of saccharose, it is arlvisable, according to Rumpf and Heinzerling, ${ }^{3}$ to conduct the experiment with the ntmost rapidity, as the error caused by the dextrin is then but very small.

Barfoed detects grupe-sugar in the presence of dertrin by means of an aqueous solution of crystallized acetate of copper ( 1 in 15), containing 1 per cent. of acetic acid. To the liquid under examination a few drops of the reagent are added, the whole hoiled for an instant and cooled. If grape-sugar is present, cuprous oxide gradually separates out. ${ }^{4}$ Canc-sugar, milk-sugar, and gum hehave like dextrin. These statements have been confirmed by Müller. ${ }^{5}$

\$20?. Detection of Dextrin in. Presenre of C'ene-singur:-Scheilnler ${ }^{6}$ has shown that a 20 per cent. aqueous solution becomes cloudy on the ardition of 4 volumes of 90 to 95 per cent. alcohol if the sugar is contaminaterl with as little as even '5 per' cent. of dextrin. A second test of Scheibler's, rlepending upon the use of iodine, may be passerl over here, as it succeeds with impure dextrin only. The presence of dextrin and cane-sugar in solution together may often he inferred if, after inversion, Fehling's solution shows less grape-sugar than could have heen anticipated loy calculation from the rotatory power before inversion; or if the rotatory power after inversion is less than that before inversion (taken as due to pure cane-sugar) would have led us to expect. (See § 207.)

\$203. Crurimetric Estimatim of Glucuse-MIulder recommends

1 Annal. d. Chem. und Pharm. cliv. 252 (Pharm. Journ. and Trans. [3], i. 301, 1870).

2 Annal. d. Chem. und Pharm. cxix. 102, 1861.

3 Zeitschr. f. anal. Chem. ix. 358, 1870. Compare also Barfoed, ibid. xii. 29, 1873 (Year-book Pharm. 176, 1874).

Z Zeitschr. f. anal. Chem. xii. 27, 1873 (Journ. Chem. Soc. xxvi. 1163).

5 Zeitschr. f. anal. Chem. xviii. 601 (Year-book Pharm. 74, 76, 1879).

6 Zeitschr. f. anal. Chem. x, 372, 1871. 
for this purpose heating for an hour to $60^{\circ}$ with excess of alkaline copper solution, filtering off, and weighing the cuprous oxide precipitated (\$3). The errors involved by this method, which at the best of times can yield only approximate results, have been the sulject of communications by Fresenius ${ }^{1}$ and Gratama. ${ }^{2}$

$\$ 20$ t. Fermentution Test $(\$ 85)$. - - To detect glucose by this test a little of the suspected solution is evaporaterl until it cortains at least 5 per cent. of sugar. After cooling a few drops of tartaric acid solution are added, and a little good yeast, previously washerl with distilled water; 1-2 cc. of this mixture are then introduced into a endiometer standing over mercury. If glucose is present

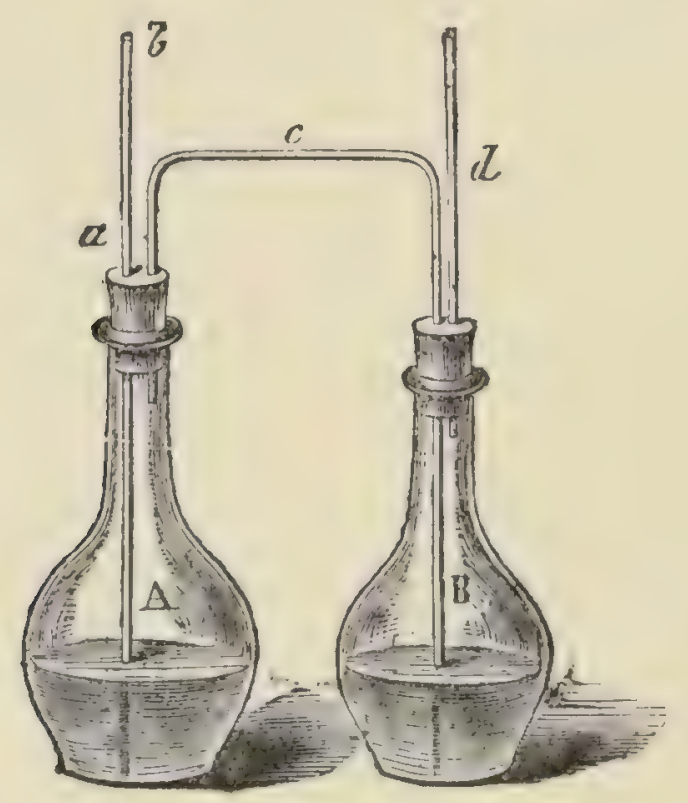

Fig. 9.

an cvolution of carbonic acid will soon begin, and should, in a few hours, displace a considerable amount of mercury (\$61). By means of a blank experiment with distilled water, and the same quantity of yeast, it may he ascertained whether any carbonic acir has been produced by the yeast itself alone.

The alsence of any evolution of carbonic acid is not necessarily a proof that the liquicl is free from glucose. Certain constituents of plants, such as salicylic acil, thymol, ctc., may occasionally the present, and prevent any fermentation taking place. ${ }^{3}$

1 Anleit. zur quant. Analyse, 5th edition, 833.

2 Zeitschr. f. anal. Chem. xvii. 1875, 1878 (Journ. Chem. Soc. xxxiv. 611).

${ }^{3}$ Compare Werncke, 'Ueber die Wirkung einiger Antiseptica auf Hefe.' Diss. Dorpat, 1879. 
If this is the case, such a method cannot of course be employed for the quantitutive determination of the glucose. But if the solution soon passes into a state of fermentation, and a tolerably large quantity of gas is produced, an estimation of the amount of glucose present may be made in the following manner: The glucose solution is preprared as directed for the qualitative test, and a measured quantity of it introduced into the flask $A$ (Fig. 9). The sccond Hask $\mathrm{B}$, shown in the figure, contains sulphuric acid, as for the determination of carbonic acid according to the method of Fresenius and Will. The whole apparatus is wiped dry, accurately weighed, and exposed to a temperature of $20^{\circ}$ to $30^{\circ}$. The carbonic acid evolved in A, passes through c, and is clried by the sulphuric acid in B, before being expelled through $d$. After the lapse of about two days, when the evolution of gas has ceased, the carbonic acid in the apparatus is driven ont by aspirating at $l$. The difference in weight is the amount of carbonic acid produced, 100 parts of which are equivalent to 204.54 of glucose. ${ }^{1}$

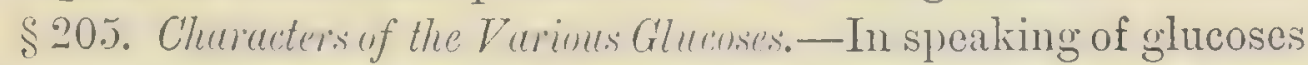
in the preceding paragraphs, I referred principally to grape-sugar, fruit-sugar, and the combination of hoth known as invert-sugar. Girlpe-suyur (dextrose) possesses the following characters: it can be obtained, by gradual deposition from solution, in prismatic crystals ${ }^{2}$ containing one molecule of water (cf. \$89); an aqueous solution, prepared fresh and without heat, in which the sugar is present in the crystalline modification, shows a rotatory power for $(\alpha)_{\mathrm{D}}+9181^{\circ}\left(\nu^{\prime}-1\right)$; whereas a solution that has been heated, in which the sugar has passed into the amorphous condition, possesses for $(\alpha)_{D}$ a rotatory power of $49 \cdot 54^{\circ}$ to $50 \cdot 00^{\circ}$, and $46 \cdot 34^{\circ} 3(\mu)=12$ ). Hoppe Seyler. found the rotatory power of amorphous grapesugar to he $(\alpha)_{\mathrm{D}}=564^{\circ}$, from which he obtained the constant quantity $\Lambda^{\prime} \mathrm{I}=1773.0$; this may be used for calculating the

1 Another method that has been suggested of estimating glucose consists in determining the specific gravity before and after fermentation (for 20 to 21 hours) and calculating 0.219 per cent. of glucose for each 0.001 in the difference. Manassein has shown that the method yields good results with the sugar in urine (Med. Centralblatt, 551, 1872).

2 Similar crystalline deposits, especially sphærocrystals, have been occasionally observed in the microscopic examination of dried drugs. Compare Braun, Zeitschr. d. öesterr. Apoth. Ver. xvi. 337, 1878.

${ }^{3}$ Compare Hesse, Annal. d. Chem. und Pharm. clxxvi. 89, 1875 (Pharm. Journ. and Trans. [3], vii. 191 et seq.).

4 Zeitschr. f. anal. Chem. xiv. 303, 1875. 
amount of grape-sugar present from the rotation observed. For imhydrous dextrose Tollens and v. Grote ${ }^{\mathrm{T}}$ ascertained $(\alpha)_{\mathrm{D}}=5.5 \cdot 10^{\text {, }}$, and the constant quantity $=1883 \cdot 3$. Hesse has shown that the prolonged heating of aqueous solutions of dextrose reduces the angle of rotation still further.

Biot has asserted the existence of glucoses, agreeing with grapesugar in all important properties, but differing from it in their rotatory power; and the truth of this assertion has been proved by Hesse. An instance may be citer in sulicin-sugar, the crystalline modification of which possesses a rotatory power $(\alpha)_{\mathrm{D}}=100^{\circ}(p=1)$, and the amorphous $(\alpha)_{\mathrm{I}}=50^{\circ}$ (populin-sugar is said to correspond to ordinary lextrose); the rotatory power of phlinine from phloricin is five-sixths that of glucose. ${ }^{2}$

Fruit-sugur (levulose) has recently been obtained in acicular crystals; $;$ a freshly prepared solution shows a rotatory power $(\alpha)_{D}=-106^{\circ}$ (constant 943.4 ; see also note to $\$ 209$ ), which slowly diminishes, on boiling, to $-56^{\circ}$. Levulose dissolves more easily in alcohol than crystalline dextrose, which may therefore, to a certain extent, he freed from the former by washing with spirit. The disposition to form a sparingly soluble compound with lime is very characteristic of levulose, and forms, at the same time, a means of separating this from grape and other sugars. Like dextrose, levulose is fermentable; lut when both sugars are present together, the former is the first to undergo alcoholic fermentation.

Sugars allied to levulose, differing from it only in the rotatory power, will probably he fouml in certain plants (Jerusalem artichokes, etc.; see also \$199).

Invert-sugar (see also $\$ 209$ et seq.) shows as a rule a rotatory power for $(\alpha)_{1)}$ of -18 . The majority of chemists resart it as a mixture of grape- and fruit-sugar, molecule for molecule; but Maumenet differs from then, and maintains that he has found in it, in arlition to these two constituents, arother, optically inactive, unstable sugar.

${ }^{1}$ Ber. d. d. chem. Ges. 487, 616, 1531, 1876. See also Hesse, Annal. d. Chem. und Pharm. cxcii. 169, 1879.

a Compare Hesse, Annal. d. Chem. und Pharm. cxcii. 173, 1878.

3 Jungfleisch and Lefranc, Comptes rendus, xciii. 547.

4 Journ. d. Pharm, et de Chim. xxii. 47, 1875. The name of chylariose has been given by Mauméné to the lævo-rotatory constituent of invert-sugar. 
According to the researches of Scheibler, ${ }^{1}$ a freshly prepared solution of arabinose possesses a rotatory power $(\alpha)_{D}=+121^{\circ}$, diminishing, after heating, to $+116^{\circ}$. It crystallizes, far more easily than dextrose, in rhombic crystals; but is not directly fermentable. Its action on Fehling's solution resembles that of grape-sugar. As alrealy observed Kiliani maintains that arabinose, when treated with nitric acil, yields mucic acid, and is identical with lactose. (This is contradicted by Clæsson.)

For caragheen-sugar see Benté. ${ }^{2}$ It is said to be optically inactive, and to reduce Fehling.

Guluctose, regarded by Fudakowski" as a mixture of lactose and another glucose, also belongs to this group. It differ's from most other glucoses in yielding mucic instead of oxalic acid when treated with nitric acid. (See also \$195.)

\$206. Surlin, Innite, ete-Corbin, inosite, and encalyn differ considerably in their properties from the foregoing sugars, but correspond to the glucoses in formula.

Surbin can he obtained in colourless crystals, which are frecly soluble in water, sparingly in cold spirit. It reduces Fehling, possesses a rotatory power $(\alpha) j=-46.9^{\circ}$; but is not fermental)le. Sorbin must not be confounded with the sorbite belonging to the mannite group ( $\$ 212$ ).

Innsite, or phusemunumite, forms colourless rhombic plates melting at $210^{\prime}$, soluble at $19^{\prime}$ in 6 parts of water, insoluble in cold absolute alcohol and ether. It is not fermentable, does not reduce Fehling, and is optically inactive. ${ }^{4}$ When warmed with nitric acid and dried, inosite is said to leare a residue that is colomed purple or blue by ammonia and chloride of calcium.

Euculyn has been obtained, up to the present time, only in the form of an uncrystallizable, non-fermentable syrup. It possesies for $(\alpha)_{r}$ a dextro-rotatory power of $65^{\circ} .^{5}$

${ }^{1}$ Ber. d. d. chem. Ges. vi. 612, $187^{\prime}$.

I Ibid. ix. 1157,1876 .

Ibid. viii. 599, 1875 ; ix. 42, 1876.

${ }^{4}$ On the occurrence of inosite in the vegetable kingdon (grape-juice) see Hilger, Annal. d. Chem. und Pharm. clx. 333, 1871 (Year-book Phamn. 156, 1872) ; also Neugebauer, Zeitschr. f. anal. Chem. xii. 39, 1873. Neugebauer has found inosite in vine-leaves also, and at the same time discusses the detection of quercetin, quercitrin, etc. Nucite, which has been discovered in hazelleaves, appears to be very similar to inosite (Jahresb. f. Pharm. 167, 1877).

5 For some other saccharine bodies that have been hitherto but little investigated, such as dambose, etc., see Ber. d. d. chem. Ges. vi. 1314, 1873. 
\$207. Sactuaroses.-Cane-sugar differ's from the glucoses in composition ; its formula, $\mathrm{C}_{12} \mathrm{H}_{2.2} \mathrm{O}_{11}$, is the same as that of certain carrohydrates of the vegetable gum group, triticin, etc. It crystallizes with tolerable facility in anhychous monoclinic crystals, is frecly soluble in cold water, insoluble in ether, and in cold alssolute alcohol; the latter, when heated to hoiling, dissolves abont 1.25 per cent. An aqueous solution is dextro-rotatory. Hesse ${ }^{1}$ found the rotatory power for $(\alpha)_{\mathrm{D}}$ to be $+67.95^{\circ}(p=1)$ and $+66.50^{\circ}$ $\left\langle p^{\prime}=10\right) ; ;^{-2}$ Tollens, ${ }^{3}+66 \cdot 6 \pm 9^{\prime}$, and $+66.475^{\circ}\left(p^{\prime}=10\right)$; and Schmitz, $+66.527^{\circ}$. Heated for some time to about $160^{\circ}$, cane-sugar is converted into dextrose and levulosan $\left(\mathrm{C}_{6} \mathrm{H}_{10} \mathrm{O}_{5}\right)$; at a higher temperature it is decomposed into caramel and other products. It does not reduce alkaline copper solution in the cold; prolonged boiling, however, causes the gralual separation of cuprous oxide. Cane-sugar is only indirectly fermentable, being first graunally converted into glucose by the invertin of the yeast (\$230). It has already been observed ( 86,88 , etc.) that a similar change is casily brought about by the action of clilute acids; the principal means of clistinguishing canc-sugar from the more important glucoses have also been mentioned (see $\$ 200$ to 204 and $\$ 206$ ).

The following saccharoses are isomeric with cane-sugar and classed with it.

Milli-sugyi, which has not yet been detected with certainty in the regetalble lingdom, forms rhomlic crystals containing 1 molecule of water of crystallization and soluble in $\overline{7}$ parts of water at $10^{\circ}$. Its rotatory power (in solutions that have been previously leated $)$ is $(\alpha)_{\mathrm{D}}=+53.63^{\circ}(p=2)$; Hesse found for freshly prepared cold solutions $(\alpha)_{D}=+80.68^{\circ}$. It is not directly fermentable, but, like cane-sugar, is gradually inverted by yeast. The action of dilute acids results in the production of galactose (S.). $)$; by oxidation with nitric acid it yields large quantities of mucic acid. Mlilk-sngar reduces ammoniacal silver and alkiline copler solution in the cold, hut the extent to which reduction is cflecterl when boiled with the latter reagent is less than is the case with dextrose. When converterl into gialactose the rerlucing power

1 Loc. cit. Calderon found $(\alpha)_{\mathrm{D}}=67 \cdot 09^{\circ}$ (Journ. de Pharm. et de. Chim. xxiv. 437,1876$)$.

2 For the decrease in rotatory power caused by the presence of certain salts see Muntz, Ber. d. d. chem. Ges. ix. 962, 1876.

${ }^{3}$ Ber. d. d. chem. Ges. x. 1403, 1877 ; xi. 1800, 1878. Sce also Schmitz, ibid. x. 1414. 
is allout the same as that of invert-surgar; so that after inversion 10 cc. of Fehling indicate about 0.0475 gram milk-sugar. ${ }^{1}$

To Mulfwes, produced together with dextrin ly the action of diastase on starch, Schulze" assigns the formula $\mathrm{C}_{12} \mathrm{H}_{2,2} \mathrm{O}_{11}+\mathrm{H}_{22} \mathrm{O}$. It reseml)les milk-sugar in its behaviour to alkaline copler solution. Boiling with dilute acids converts it entirely into dextrose, and, as with milk-sugar, it is advisable to invert maltose before estimating it with Fehling's solution. Its lotatory power is greater than than that of dextrose $;(\alpha)_{D}=149 \cdot 5-150 \cdot 6^{\circ}$. Maltose is said to be (? directly) fermentable. With nitric acid it yields no mucic acid.

Idituse crystallizes in needles containing 3 molecules of water. It is soluble in 9 parts of cold water, and is dextro-rotitory $\left(+102^{\circ}\right)$. Boiling with dilute acids converts it into glucose and encalyn, the latter of which is not fermentable. Ieast also acts in a similar manner (\$206), in which case the glucose prodneed ferments. With nitric acid melitose yieldsabundance of mucic acid.

Meleaiture crystallizes in rhombic prisms with 1 molecule of water of crystallization. It is freely soluble in water, insoluble in alcohol and in ether. An arpueous solution is dextro-rotatory $\left(94.45^{\circ}\right)$, and indifferent to Fehling's solution; it is converted into slucose when hoiled with a lilute acid; yields with nitric acid no mucic acid, and is slowly decomposed by yeast.

1Iyrue (trehulw') forms rhombic prisms containing 2 molecules of water. Boiling spirit dissolves it tolerably freely; in aqueous. solution it is powerfully dextro-rotatory $\left(+220^{\circ}\right)$, only slowly and incompletely fermented hy yeast, and converted into dextrose when boiled with dilute acid for several hours. It does not reduce copper solution, and yichls no mucic acid with nitric acid.

20s. Estimatim ly I'uluriontion.-This is possible when the glucose or saccharose is not accompanied hy any other similar carbohydrate, and when the solution contains no other substance (asparagine, etc.) that has an action on polarized light, or when all such substances present cim be completely lenoverl, cither by boiling (as albumen), or by precipitation with hasic acetate of lead (organic acids, gum, etc.) $(520)$. Of comse the rotation-

1 Compare Rodewald and Tollens, Ber. d. d. chem. Ges, xi. 2076, 1878 (Year-book Pharm. 77, 1879).

Ber. d. d. chem. Ges, vii. 1047, 1874 (Year-book Pharm. 85, 1875), and Journ. f. Landwirthschaft, xxvi. 67, 187 S. See also O'Sullivan, MIoniteur scient. March, 1874; and Ber. d. d. chem. Ges. ix. 281, 1876 (Journ. Chem. Soc.). 
constant of the carbohydrate in question must lie known. The results are generally calculated from the equation

$$
\mathrm{C}=\mathrm{A}_{\mathrm{L}}^{\varrho}
$$

where $\mathrm{C}$ is the weight of the sulustance (expressed in grams) contained in a litre of solution, A the rotation-constant of the sulustance to lie estimated, " the observed rotation, and $\mathrm{L}$ the length of the column of solution in millimetres. If the concentration of the solution has an influence on the optical activity, then 1 , the weight of substance in grams in $100 \mathrm{cc}$. of the solution, must also be taken into account. 1 The same must be done for the temperature when that exerts any influence on the rotatory power (invert-sugar) (cf. § 199).

Suppose for instance a solution of grape-sugar in a tube 0.1 metre long to have shown a rotatory power $+3^{\circ}$, then (using Tollens and Grote's constant),

$$
\mathrm{C}=1883.2 \times \frac{3}{100}
$$

For a solution of levulose with rotatory power $-3^{\circ}$,

$$
\mathrm{C}=943.4 \times \frac{3}{10} \mathrm{U}
$$

For a solution of cane-sugar with rotatory power $+3^{\circ}$ (using Wild's constant),

$$
\mathrm{C}=1505 \cdot 6 \times \frac{3}{100}
$$

In the first instance the solution would contin 56.496 grams of rlextrose per litre; in the second, $25: 3112$ grams of levulose in the third, $45 \cdot 168$ grams of cane-sugar. See also $\$ 210$.

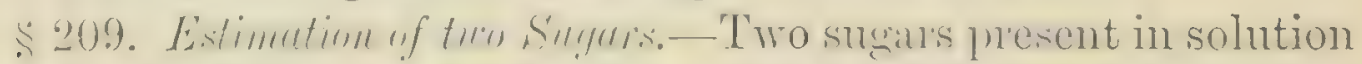
torether may he accurately estimaterl, providerl that the rotatory power of each is known, and the other conditions in $\$ 208$ are fulfilled. This is frepuently the case with solutions of dectrose

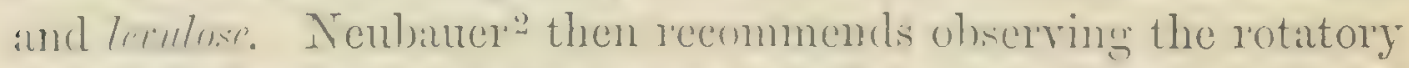
power, and estimating the sugar with Fohlings solution. If the latter inclicates 15 jer eent. of sugar, then if levuluse alone were fresent, the rotatory power (hy sorlimulight, in a tube $0 \cdot 1$ metre

${ }^{1}$ Sec Hesse, Annal. d. Chem, und Pharm. clxxvi. 95, 1875, and Tollens, Ber. d. d. chem. Ges. xi. 1800.

2 Ber. d. d. chem. Ges. x. $827,1877$. 
long) should be $-15^{\circ}(=15 \times 1 \cdot 0),{ }^{1}$ and for dextrose alone $7 \cdot 96^{2}$. Supposing now the angle of rotation olserver to hatve heen $-5 \cdot 202^{\circ}$, that is $-9.798^{\circ}$ less than levulose alone, the amount of the litter present can be calculated from the statement

$$
2883 \cdot 3: 1883 \cdot 3:: 9 \cdot 798: x
$$

where $288.3 \cdot 3$ is the difference hetween the rotation-constants of srape- and fruit-sugar $\{1883 \cdot 3-(-1000 \cdot)$, and $1883 \cdot 3$ the constant of grape-sugar; multiplying out

$$
\begin{aligned}
x & =0.65317 \times 9.798 \\
& =6.4
\end{aligned}
$$

which is the percentage of levulose, leaving $15 \cdot 0-6 \cdot 4=8 \cdot 6$ per cent. of dextrose.

\$210. C'une- and Inert-sugur.-A similar course may be pursued in other cases involving the simultaneous estimation of two sugars. For cane- and invert-sugar, as they occur for instance in beet-juice, it is usual to determine the rotatory power both lefore and after inversion with a dilute acil. If cane-sugin is present, more invertsugar will be found than would correspond to the rotatory power first observed.

According to Haughton," the rotatory power of mixtures of cancand invert-sugar camnot le correctly determined unless the excess of the basic acctate of leal, nser to clarify the solution, is first removed. He thinks that the lead forms a dextro-rotatory compound with levulose. Snch solutions containing lead are also said to yichd inaccurate results with Fehling's solution.

If the use of basic acetate of lead alone is insufficient to rentere such linpuits as beet-juice, etc., clear and colvurless enough for examination in the polariscope, it may sometimes be arlvantageonsly combined with solution of alum. It is frequently mulesirable to decolourize with charcoal, as that is calualle of retaining some of the sugar.

The presence of usperergine can be the sonuce of considerable crror: firstly, hecanse that substance is itself optically active; and secondly, hecause its rotatory power varies as the sulntion is acid or alkiline. Noreover, it is resulved, by hoiling with hydrochloric

${ }^{1}$ Calculated from equation $a=\frac{10}{10 \cdot 0}$. Neubauer takes the rotatory power of levulose to be $-100^{\circ}$ instead of $-106^{\circ}$.

"Journ. Chem. Soc. ix. 85; Zeitschr. f. anal. Chem. x. 490, 1871. 
acid, into aspartic acid and ammonia; the former of which is l:evo-rotatory in alkaline solution, but dextro-rotatory in acid.

Asparagine is not precipitated by hasic acetate of lead, by lime, or by baryta; and although aspartic acid is thrown down by lead salts, yet the precipitate is redissolved by an excess. ${ }^{1}$

\$211. Estimation of three Sugars.-Dupré2 and Apjohn ${ }^{3}$ have made the estimation of cone-, grape-, and fruit-sugar in the same solution, the subject of investigation. As their methods, however, involve a combination of optical and volumetric determinations in which accuracy is reppired in ascertaining the amount of srape-and fruit-sugar present, especially in titrating, I am afraic their processes will at present yield only approximate results. I have alrealy shown (\$5) that the rolumetric estimation of shlucose in the presence of cane-sugar is not so accurate as might be wished.

\$212. Mennite.-Of mannite (cf. \$91) it may be here olsserved that one part dissolves in $6 \cdot 14$ to 6.21 of water at $15^{\circ}$, and in $5 \cdot 12$ to 5.38 at 20 . One part requires also 1515 of absolute alcohol at $17^{\circ}$ for complete solution. Although optically inactive, as previonsly stated, it is dextro-rotatory when dissolved in a concentrated solution of borax. It melts at $166^{\circ}$, and is converted at $200^{\circ}$ with loss of water into mannitan. With moderately strong nitric acid it yichds principally mucic and saccharic acids; with the strongest acid, nitro-mannite. It is said (according to liescl) to reduce gold and silver salts, but not alkaline colper solution, when warmed for a short time. Mannite prevents, howerer, the precipitation of hydrate of copper.

1 On saccharometry, and especially the estimation of invert-sugar when accompanied by cane-sugar, as in beet-juice, crude sugar, etc., see Ventzke, Journ. f. pract. Chem. xxv. 65, xxviii, 101 ; Kleinschmidt, Dingler's polyt. Journ. clxxxi. 306, 1867 ; Anders, ibid. clxxxii. 331; Bodenbender, Zeitschr. f. Chem. N. F. ii. 222, 1867 ; Sostmann, ibid. 480. The latter authors draw special attention to the influence that lime exercises on the results of optical determinations of cane-sugar. The influence of asparagine and aspartic acid has been observed by Dubrunfaut (Dingler's polyt. Journ. cxxi. 305) and Scheibler, ibid. clxxxi. 415). Communications by Scheibler on the errors in optical estimations have appeared in the Zeitschr. f. Chem. N. F. iii. 617, and Zeitschr. f. anal. Chem. viii. 211, 1869. See also Stammer, Dingler's polyt. Journ. clxxxii. 160 ; Dubrunfaut, ibid. cxxi. 299, clxxxv. 231; Landolt, Zeitschr. f. anal. Chem. vii. 1, 1868. On the influence of asparagine, see lastly also Champion and Pellet, ibid. xvi. 120, 1877.

2 Chem. News, xxi. 97, 1870.

${ }^{3}$ Ibid. p. 86. Sec also Zeitschr. f. anal. Chem, ix. 499, 501, 1870. 
Dulcite, or melcmpmrite, is isomeric with mamnite, and shares most of its important properties. The crystals of the former belong to the monoclinic system, those of the latter to the rhombic. Dulcite dissolves in three parts of cold water, is optically inactive, does not ferment, and melts at $182^{\circ}$.

Ieodulcite (rhamnodulcite) is also isomeric with the foregoing. Crystals of isodulcite melt at $93^{\circ}$ to $94^{\circ}$, dissolve in 2.09 parts of water at $18^{\circ}$, and also in absolute alcohol. It is not fermentable, but reduces Fehling's solution, and is dextro-rotatory, $(\alpha) j=8 \cdot 4^{\circ}$.

Hesperidin-sugar and sorlite are also said to be isomeric with mannite. The former crystallizes in the monoclinic system, is dextro-rotatory, sparingly soluble in hot absolute alcohol, but more easily in hot 70 per cent. spirit. It melts at $70.5^{\circ}$ to $76^{\circ}$, and slowly reduces Fehling. Anhydrous sorbite melts at about $110^{\circ}$, and does not reduce Fehling. ${ }^{1}$

\$213. Quercite, ete-Quercite and pinite are isomeric with mannitan and dulcitan and are sweet to the taste.

Quercite crystallizes in the monoclinic system, dissolves in 8 to 10 parts of cold water, is dextro-rotatory $\left(+33.5^{\circ}\right)$, and melts at $235^{\circ}$.

Pinite is indistinctly crystalline, freely soluble in cold water, and somewhat soluble in dilute spirit; it melts at $150^{\circ}$, and has a dextro-rotatory power of $58 \cdot 6^{\circ}$.

Abiotite differs from the foregoing in containing the elements of a molecule of water less; it has heen the subject of communications by Rochleder. ${ }^{2}$

\section{ACIDS.}

$\$ 214$. Detection of Acids.-In arldition to the reaction of mulir "rill mentioned in \$ $\$ 1$, Barfoed ${ }^{3}$ describes another depending upon the conversion of the acid, at a temperature of $160^{\circ}$ to $170^{\circ}$, into maleic and fumaric acirls, with production of a crystalline sul)limate. A third is the lime-reaction; malate of lime requires the addition of at least 1 to 2 volumes of spirit for precipitation; and when thus

${ }^{1}$ Compare Bonssingault, Journ. de Pharm. et de Chim. xvi. 36, 1872 (Pharm. Journ. 'Trans. [3], iii. 28).

2 Journ. f. pract. Chem. cv. 63, and Apoth.-Ver. viii. 363, 1868. For catharto-mannite, see Kubli and Dragendorff, Pharm. Zeitschr. f. Russland, iv. 167,1865 , and Keussler, ibid. xvii. 363,1878 . For burgenite, see Morelle, Chem. Centralblatt, 758, 1881 (Comptes rendus, xciii. 646).

3 Zeitschr. f. anal. Chem. vii. 403, 1868. 
thrown out of solution, softens on warming and agrgregates to a mass, which becomes granular and crystalline on cooling. The magnesia-reaction, mentioned by the same author as a new one, consists in converting into malate of magnesia either by saturating the acid with oxide or carbonate of magnesia, or by mixing a concentrated solution of an alkaline malate with chloride of magnesium. The salt is precipitated by spirit from a hot solution, as a tenacious mass hardening on cooling. (Citrate of magnesia behaves in a similar manner.)

Barfoed separates mulic from ormlic (\$219) and turtaric (\$217) acids by precipitating the last two from neutral solution by chloride of calcium, and throwing out malate of calcium from the filtrate by the addition of alcohol. If tartaric acid is present, it must be remembered that the calcium-salt of this acid separates but slowly. (See also §218.)

In separating citric (\$215) from malic acid the same chemist takes advantage of the fact that citrate of calcium requires less spirit for precipitation than malate.

If mulic acid is in solution with oreulic, tarturic, and citric aciel, Barfoed advises the precipitation of the last three as neutral ammonium salts by the addition of $r$ to 8 volumes of 98 per cent. spirit; after standing twelve to twenty-four hours the precipitate is filtered off, and the malic acid thrown down in the filtrate with acetate of lead.

Surrinir acid (\$220) can be separated from melir acid, according to Burfoed, lyy converting into neutral alkaline silts, precipitating: with acetate of learl, dissolving the precipitate in acetate of ammonia solution, and then separating the malate of lead by the ardition of 2 volumes of spirit; or the concentrated arueous solutions of the neutral potassium, or solium-salts, may he mixed with about 6 volumes of spirit, when the succinate remains in solution.

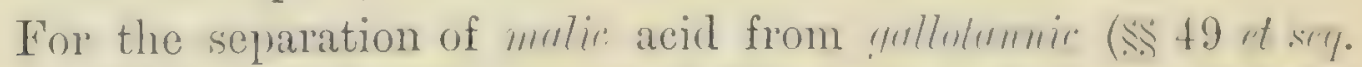

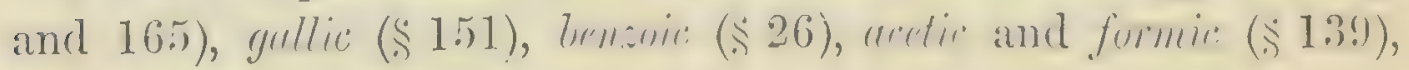
acid, reference must be made to the original work.

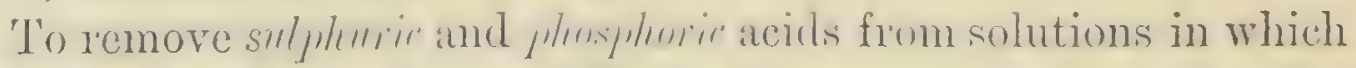
malic acir is to be detected, Barfoed recommends separating the first two by the ardition of chloride of barimm to the hot solution, and precipitating the malate of barium from the tiltrate by the addition of alcohol.

\$215. Estimulim of Citrit: Acirt. - In estimating citric eciel, Creuse 
takes alvantage of the insolubility of the harium-salt in spirit. T'u a neutral solution of the citrate a solution of acetate of harium and 2 volumes of spirit are alded. The precipitate is filtered off', ignited, converted into sulphate by sulphuric acid, and weighed as such. The composition of citrate of barium is said to be $\mathrm{Ba}_{3} \mathrm{C}_{12} \mathrm{H}_{10} \mathrm{O}_{14}$. (Compare Zeitschr. f. anal. Chem. xi. $\left.+46,1871.\right)^{1}$

Precipitation hy barium had heen previously recommended by Kïmmerer as a means of detecting citric acid. 2 If to a solution of a citrate excess of acetate of barium is added, a voluminous precipitate is obtained, which gradually becomes crystalline (prisms) when heated for several hours on the water-bath. The presence of other fruit-acils does not interfere. If the solution is very dilute it must be concentrated after the adilition of the barium salt, as otherwise only acicular crystals are produced. See further $\$ 218$ to 220 .

216. Dunclitutice Reartions of Citrie Acir.-Darandinaki has drawn attention to the fact that the triethylic ether of citric acid decomposes when heated in sealed tubes to $110^{\circ}$, with separation of a blue powder; ${ }^{3}$ and that an aqueous solution of citrate of ammonium, similarly treated for six hours, also deposits a blue decomposition-product on subsequent exposure to air and light in a flat dish. Sabanin and Laskowskyt have shown that neither tartaric, malic, nor oxalic acid interferes with the reaction which succecds with 0.01 gram of citric acicl. Aconitic acid comports itself like citric. If the juice of a fruit or a vegetable infusion is under examination, the eitric acid can be precipitated as citrate of lead, the latter converterl into citrate of barium, and finally into citrate of ammonium, which can be tested as above descriled.

It may also be olserved that an aqueous solution of citric acid is optically inactive. According to Roemnefahrt, 100 parts of ether dissolve 10 parts of the crystallized and 13 of the anhydrons acid, and can remove as much as $: 3 \cdot 6$ parts when shaken with an arpleous solution; farts scarcely in accordance with the statement

1 For quantitative estimation of tartaric acid, see also Inette, Comptes rendus, 1xvi. 417, 1868.

"Annal. d. Chem. und Pharm. cxlviii. 294, and Zeitschr. f. anal. Chem. viii. $298,1869$.

${ }^{3}$ Ber. d. d. chem. Ges. 1100, 1872. Compare also Kümmerer, ibid. 736, 1875 (Journ. Chem. Soc. xxix. 496, xxviii. 1178).

4 Zeitschr. f. anal. Chem. xvii. 73, 1878 (Year-book Pharm. 165, 1878). 
formerly made to the effect that citric acid was difficultly soluble in ether.

\$217. Precipitution of Turturie Acid (\$82).-As early as 1864 , Berthelot and de Flemieu precipitated tartaric acid by converting it into acid tartrate, and adding 5 volumes of ether-alcohol. ${ }^{3}$ Jokisch and Bolley ${ }^{2}$ have shown that acid tartrate of calcium may be simultaneously thrown down.

For the estimation of the total acid in must, see Pasteur. ${ }^{3}$

Martenson ${ }^{4}$ precipitates tartaric acid from a 1 per cent. arineons solution of normal tartrate of potassium by the addition of chloride of calcium and lime-water. The sides of the porcelain dish in which the operation is performed should not he touched by the stirring-rod. On standing for several hours, the calcimm-salt separates in crystals, and can be filtered off, washed with 80 to 8.5 per cent. spirit, dried at $100^{\circ}$ and weighed ; its composition is then $\mathrm{CaC}_{4} \mathrm{H}_{4} \mathrm{O}_{6}, 4 \mathrm{H}_{2} \mathrm{O}$.

\$218. Estimution of Turtarie and Citric Acirl.-Fleischer recommends the separation of the former as acid tartrate of potassium, the precipitation being rendered complete by the addition to the solution of twice its volume of 95 per cent. spirit. The acid tartrate is filtered off, redissolved, and estimated by titration with normal alkali (\$82).

The citric acid is precipitater from the filtrate by nentral acetate of lead, washed with spirit of about 45 to 50 per cent., liberated by sulphuretted hydrogen, and estimated by titration with normal alkali.

This method is directly applicable if the acids are present in the free state, or in combination with alkalies. ${ }^{5}$

${ }^{1}$ Comptes rendus, Ixxvii. 394.

2 Dingler's polyt. Journ. clxxxiii. 47, 1867 (Amer. Journ. Pharm. xxxvi.60). See also Kissel, Zeitschr. f. anal. Chem. viii. 409, 1869.

3 Zeitschr.f. anal. Chem, viii. 86, 1869.

4 Pharm. Zeitschr. f. Russland, viii. 23, 1868 (Amer. Journ. Pharm. xli. 335).

5 See also Schnitzer, Dingler's polyt. Journ. clxiv. 132, 1862, on the separation of tartaric from citric acid as acid tartrate.

Should it appear desiralsle to estimate the citric acid directly, after remoral of the tartaric as acid tartrate of potassium, the filtrate may be mixed with chloride of calcium and concentrated by boiling. The citrate of calcium that separates after adding lime-water should be filtered off hot, washer with boiling water, dried and weighed $(255$ parts of the dried sult indicate 192 of citric acid). See also Allen, Zeitschr. f. anal. Chem. xvi. 251, 1877.

For distinctive characters of tartaric and citric acid, see Archiv d. Pharm. clviii. 206, 1861; Chapman and Smith, Laboratory, April, 186S; Wimmel, Zeitschr. fo anal. Chem. vii. 411, 1868. 
If the solution contains oculic and sulphuri, in addition to tartaric and citric acids, all of them must be rrecipitated with acetate of lead (which would also throw down part of any chlorine that may be present); the precipitate should be washed with dilute spirit and treated with ammonia (free from carbonate), which dissolves citrate and tartrate of lead and part of the chloride. The tartaric acid may be estimated in the solution by elecomposing the lead-salts with sulphide of ammonium and acetic acid, filtering, and precipitating with acetate of potassium as above described. If chloride is present, the citric acid must be subsequently precipitated from a lot solution, either as lear-salt by excess of acetate (washing with dilute spirit) or as calcium-salt in the presence of spirit; the latter must be redissolved in acetic acid, and precipitated with acetate of lead.

If lime and plesplutes are also present (in hydrochloric acid solution), they may be precipitated by acetate of ammonia as oxalate of calcium and phosphate of iron, and washed with solution of chloride of ammonium to avoid loss of tartaric acid as acil tartrate of calcium. The phosphoric acid may be subsequently precipitated as phosphate of lear, which is insoluble in ammonia. The residue of the leal precipitate, after treatment with ammonia, cim be decomposed by sulphide of ammonium, and in the filtrate from the sulphide of lead, phosphoric, sulphuric, and oxalic acids determined by the usual processes.

Malic aril if present would be precipitated together with the citric acid as calcium salt; the former, however, is soluble in boiling lime-water.

limemic acid would be thrown down with the tartaric acid, but could be separated by dissolving the acid tartrate and racemate in hydrochloric acil, supersaturating with ammonia and adding chloride of calcium, which, under these conditions, precipitates racemate of calcium only. ${ }^{1}$

Rilcenic acid is optically inactive, whilst tartaric acid is dextrorotatory $(\alpha)_{\mathrm{D}}=+14 \cdot 18^{\circ}(p=5)$, or $(\alpha)_{\mathrm{D}}=+12 \cdot 80^{\circ}(p=15)$. It is well-known, however, that racemic acil can be made to yield lavoracemic acid by suitable treatment.

For detection of tartaric acid in presence of malic, formic acids, etc., see Braun, Zeitschr. f. anal. Chem. vii. 349, 1868; Kïmmerer, viii. 300, 1869. See also Cailletet, xvii. 499, 1878 (Year-book Pharm. 150, 1S78).

${ }^{1}$ Compare Fleischer, Archiv d. Pharm. [3], v. 97, 1S74 (Journ. Chen. Soc. xxvii. 1181). 
Both tartaric and racemic acids are easily soluble in water and alcohol. See also $\$ 219,220$.

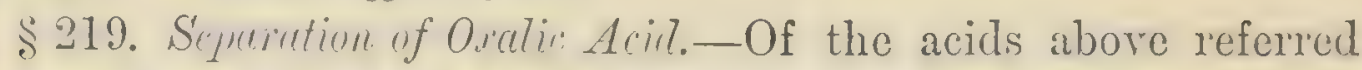
to, orali: acill (\$s $\$ 1,214,216,218$ ) splits up, when heated, into water, carbonic acid, and carbonic oxide without separation of carbon. It undergoes a similar decomposition when warmed with concentrater sulphuric acid. In addition to the reactions already described, it must be observed that a neutral solution of an oxalate throws down bright yellow erystalline ferrous oxalate, when warmed or allowed to stand, with a solution of a ferrons salt. According to Barfoed, ${ }^{1}$ the precipitate is soluble in about 4,000 parts of cold water, but tolerably easily in solutions of oxalates, tartrates, and citrates of the alkalies. The reagent must therefore be added in sufficient quimtity to convert the whole of the regetable acids present into salts of iron.

Turturic uid, if present, might also yicld a crystalline precipitate, but the colour would be dirty-white and the crystals would be distinguishable under the microscope; it might lie separated loy cold, very dilute hydrochloric acil, in which the oxalate is almost insolul)le. Citric acid delays the precipitation, and frequently prevents the formation of characteristic crystals, which, howerer, may be obtained by dissolving in a little warm hydrochloric acid and neutralizing with ammonia.

Oxalic acid can be isolated from wrelute of culcium (\$110) for the purposes of further identification by dissolving in hyclrochloric acil, and adding sufficient sulphuric acid to convert into sulphate, which can then be completely precipitater by the addition of an equal volume of spirit. Or the oxalate may be dissolver in the smallest pussible quantity of clilute nitrie acid, precipitated with nitrate of lead, and liberated from the learl-salt by sulphuretter hydrogen. (Cf. S51, 218, 220, where the estimation of oxalic acid is discusserl.) Oxalic aciel requires 10 piurts of cold water for solution, but only 2 parts of alcohol.

$\$ 220$. Succinic Acid (\$214) is also one of those organic compounds that are not blackened hy concentrated sulphuric acid, and leave no carbonaceous residue when heated on platinum foil, or in at test-tube. In the latter case the major part is rolatilized without decomposition. It differs from oxalic acid in being less soluble in cold water (about 1 in 15 at $20^{\circ}$ ), and in being spar-

1 'Lehrb. d. org. qual. Analyse', Copenhagen, 1880. 
ingly dissolved by alcohol, and to but a very slight extent hy ether. The occurrence of succinic acid is frequently mentioned in plant-analyses of less recent date, but in many instances confirmation of such statements is required. And eren if that were forthcoming, the question might be raised as to whether the acid had not been produced by a process of fermentation that might have taken place during the manipulation.

The following reactions may serve for the identification of succinic acid :

Chloride of birlium precipitates from a solution of an alkaline succinate (in presence of alcohol) a crystalline barium-salt, which is soluble in about 250 parts of water, but almost insoluble in alcohol. Hydrochloric acid (lissolves it, hut acetic acid takes up) only small quantities at the ordinary temperature. ${ }^{1}$

Chloride of calcium also throws down a crystalline salt from concentrated solutions of alkaline succinates. The precipitate clissolves, according to Barfoed, in about 50 parts of water, but is very sparingly soluhle in alcohol. If the precipitation takes place in the presence of alcohol the salt is at first amorphous, and subsequently assumes a crystalline condition. It dissolves in warm dilute acetic acid, and in boiling solution of chloride of ammonium. (Distinction from oxalic acid.)

Succinate of lead is likewise crystalline, but complete separation takes place very slowly. Basic acetate of lead throws down an amorphous salt. Ferric chloride produces brownish-red amorphous precipitates in solutions of normal alkaline succinates, but does not form insoluble compounds with oxalates.

In separating orulic from sucrimic acid advantage may be taken of the solubility of ammonium succinate in spirit. Barfocl separates turterir from surimir acid in the form of acid tartrate of potassium in the presence of hydrochloric acil and alcohol. Or' it maly be precinitated hy mixing the hot solution with chloride of ammonium, arlding chloride of calcium and cooling. Citrit urit. may be separated in a similar manner, hut in this case the mixture must be boiled until the whole of the citrate of calcium has been thrown down; or the solution may he boiled with chloride of barium and filtered whilst hot from the precipitaterl citrate of barium. The filtrate contains the succinate of barium, which can be thrown down by alcohol after cooling $(\$ 215)$.

'See Barfoed, loc. cit. 
For the separation of malic acid, see $\$ 214$.

$\$ 221$. Fumuric acid can also be sublimed, and, like oxalic and succinic acids, yields a precipitate with acetate of lead that gradually assumes a crystalline condition (\$\$ 81, 214). It differs from malic acid in its slight solubility in water (according to Lassaigne about 1 in 260 at $17^{\circ}$ ). It is much more easily soluble in hot water, and is also dissolved by ether and by cold spirit. The solubility of the silver-salt is extremely slight; manganous fumarate is also sparingly soluble in water, but freely in spirit. The acid potassium and acid ammonium salts are not very soluble in water, and scarcely at all in cold 80 per cent. spirit. Lime-water does not precipitate fumaric acid.

Nuleic acil is isomeric with the preceding, and, like it, is optically inactive and yiclds a crystalline lead-salt. It is freely soluble in water, but camnot be sublimed without decomposition.

Irinic acid may also be mentioned here. It is precipitated by ammoniacal, but not by normal acetate of lead; and when situraterl with milk of lime, yields at first a calcium-salt soluble in water.

Many other vegetalle acids can be separated from linic aciel by precipitation with normal acetate of lear; the filtrate, after removal of the excess of lead as sulphide, can be freed from sulphuretted hydrogen, boiled with milk of lime, concentrated, and allowed to stand, when a crystalline deposit of kinate of calcium will gradually separate, or more rapidly if spirit is added. The presence of kinic acid in the deposit may be demonstrated by heating with sulphuric acid and black oxide of manganese; the quinone thus produced is rolatile, crystallizes in yellow needles, and can be detected even in traces by its iodine-like odour (\$167, arbutin).

Kinic acid and its silver-salt are casily soluble in water. ${ }^{1}$

\$22. Lurtic Lirl.-Although the occurrence of lactic acid in living plints has not been placed beyond dount, we must derote a few lines to it here, as it is frepuently producerl from carbohydrates when vegetalle infusions are allowed to stand, and is therefore often met with in plint-amalysis. It can be detected by

${ }^{1}$ For rubichloric acid, which occasionally accompanies kinic acid and, like it, is only precipitated by alkaline acetate of lead solution, see Schwarz, Sitzungsber. d. Akad. d. W. in Wien Math. nat. Cl. 26, 1852. Rubichloric acid is decomposed with simnltaneons separation of sreen insoluble chlorruhin when its aqueous solution is boiled with dilute hydrochloris acid. 
shaking the aqueous liquid with ether. On evilorating the ethereal solution, it is obtained in the form of a syrup, easily soluble in water and in alcohol. Both the calcium and lead salts are freely dissolved l,y water, the former requiring about 10 parts at the ordinary temperature. Lactic acid can thus be separated from many other acids by precipitation with acetate, or, if free acids are present, hy digestion with carbonate of lear or calcium. Lactate of calcium is further soluble in boiling 8.5 per cent. spirit, and crystallizes from hot saturated spirituous and aqueous solutions on cooling.

From a spinituous solution of lactate of lime ether throws down an amorphous urecipitate, which gradually becomes crystalline. ${ }^{1}$

The magnesium and zinc salts are also crystalline; the former is best prepared by precipitating a concentrated solution of lactate of soda with chloride of magnesium in the presence of alcohol; the latter is frequently of use in detecting lactic acid. Lactate of magnesium requires about 30 parts of cold water for solution, of zinc about 60 ; both atre far more casily soluble in hot water. If the presence of lactic acid is suspected, the arweons solution should be concentrated, digested hot with oxide of zinc, cooled, and examined under the microscope. It should show bundles of needles and sphwrocrystalline masses, as well as four-sided prisms and wedge-shaped crystals. Puralactate (sarcolactate) of zine is much more easily soluble, requiring only about 6 parts of cold water. Acicular crystals are also obtained if carbonate of silver is used instead of oxide of zine; they are soluble in alcohol.

Air-dry lactate of calcium contains $29 \cdot 2$ per cent. of water and $18 \cdot 3$ per cent. of oxide of calcium.

The zinc-salt contains $18 \cdot 2$ per cent. of water and $27 \cdot 3$ per cent. of oxide of zinc.

2.23. Glycolic Acirl-C Glycolic acid is homologons with lactic acid, and resembles it in many of its properties. It has been found in the juice of mripe grapes. Ethereal solutions yield the acid in crystals which melt at $78^{\circ}$ to $79^{\circ}$, and are partially rolatile in the vapour of water without decomposition. Cilycolate of bariun dissolves in 7.9 parts of cold water, of calcium in s0.8, of zine in $31 \cdot 6$, of leal (normal salt) in $: 31 \cdot 17$. The last three can be obtained in erystals. The precipitate produced hy batsic acetate of lead is very sparingly soluble (albout 1 in 10,000), and

1 Compare Barfoed, loc. cit. 144. 
can therefore be made available for the separation of the acid; the basic lead-salt can be converted into the normal by the action of dilute nitric acid. Glycolic acid can he isolated by shaking with ether. Its calcium-salt contains 23.09 per cent. of oxide of calcium, its normal leal-salt $62 \cdot 48$ per cent. of oxide of lead.

\section{ALBUMINOIDS, ETC.}

\$22t. Estimation.-In $\$ 96$ the alluminoids have been estimated by multiplying the nitrogen found by 6.25. This calculation is based upon the assumption that allumminoid substances contain 16 per cent. of nitrogen. ${ }^{1}$ Attention has, howerer, been frequently drawn to the fact, that mostalbuminous sulsstances contain more than 16 per cent. of nitrogen; those of cereals, leguminous fruits, etc., can be estimated to contain at least 16.60 per cent. ; the factor 6.0 has therefore been recommended in such cases as preferable. But even then the results obtained will be too low if the material under examination contain much conglutin or gliaclin² (as, for instance, lupin seeds, almonds, brazil-nuts, wheat, etc.), as conglutin contains 18.4 , and glialin (\$2.35) 18.1 per cent. of nitrogen. When, therefore, large quantities of those bodies are present, Ritthausen advises multiplying by $5 \cdot 5$.

\$225. Iegmmin.-If the experiment descrihed in \$93 has shown the presence of legumin (vegetal)le cascin), the maceration should be repeated in the cold (best at a temp. of $4^{\circ}$ to $5^{\circ}$ ) for about five hours, the clear liquid decanted off, and the maceration

${ }^{1}$ It was formerly assumed that they contained 15.6 per cent. of nitrogen, and the amount of the latter was therefore multiplied by 6.33 . 'That the nitrogen found in alkaloids, albuminoids, etc., by the method of Varrentrapp and Will is too low has already been shown by V. d. Burg (Zeitschr. f. anal. Chem. iv. 322, 1865), Nowak (ibid.xi.324, 1871), and Seegen and Nowak (ibid. xii. 316, 1873; xiii. 460, 1874). Meusel expresses himself to the contrary (ibid. v. 197, 1866). Märcker has shown (Annal, d. Landwirthsch. xii. 619) that the error is not so large if the soda lime used is free from magnesia. See also Kreusler (Zeitschr. f. anal. Chem. xii. 354, 1873); Miircker (ibid 221); Märcker und Abesser (ibid. 447); Johnson (ibid. 446); Ritthausen (ibid. xiii. 240, 1874); Settegast (ibid. xvii. 501, 1878). On the estimation of nitrogen, see also Nowak (Keitschr. f, anal. Chem. xii. 102, 1873); Makris (ibid. xvi. 249, 1877); Habermann (ibid. xvii. 376, 1878); Pfliger (Archiv. f. ges. Phys. xviii. 117, 1879) ; Hanko (Ber,d. d. chem. Ges, xii. 451) ; Schiff (Annal d. Chem. und Pharm. cxcv. 293); Ritthausen (Zeitschr. f. anal. Chem. xviii.601, 1879).

"Compare litthausen, Die liweiskirper der Getreidearten, ILulsenfrichte etc., 237, Bonn, 1872. 
repeated once more. The legumin can then be precipitated as described. ${ }^{1}$

During all these manipulations, the exclusion as far as possible of the carbonic acid in the air is most strongly to be urged. It would he liable, in most cases, to cause an error by partially or completely precipitating albuminoids allied to (perhitps identical with) legumin, such as globulin, or vegetable vitellin.

If the material has not heen previously entirely freed from fixed oil (and this is not always possil)le with petroleum spirit) the precipitated legumin must be finally washed with absolute alcohol and with ether, to remove the oil mechanically retained lyy it.

\$226. Eitruction uith Dilute - Mhuli.-Ritthansen has observer that the strongly acid reaction of many freshly powdered secils decreases on liecping. Now strongly acid liquids are less suituhle for the extraction of legumin than neutral or alkaline; Weyl, ${ }^{2}$ moreorer, asserts that fresh seeds contain no legumin, and expresses it as his opinion that this substance is produced from ritellin and myosin during the manipulations. The differences that can thus arise are extremely inconvenient. It must also he olserved that pure water frequently extracts but rery small 'puantities of legumin from regetable substances containing that body, anc that the major part is remored only by dilute alkiali. This portion of the legumin (caseïn," glutencasein, conglutin, vegetal)le fibrin) will therefore be dissolved when the residue insoluble in water is treated with dilute $(0.1$ to 0.2 per cent.) sorla or potash (10:3 to 106). If the presence of legumin is suspected it is advisable to extract at a temperature of $4^{\circ}$ to $6^{\circ}$. (See also $\$ 2.33$.

Should moturulin: urid (\$ 195) and legumin he extracted together, a total estimation must first he mate, and the nitrogen then determined in a part of the precipitate, from which the amount of legumin present can be calculated.

A current of carlonic acid might be passer throngh the alkaline extract to ascertain whether ylululin (vitellin, myosin) can be thus precipitated (.5.9); should this prove to be the care, it might lee

${ }^{1}$ Compare Ritthausen, loc. cit. 144.

2 Beitr. z. Kenntniss d. thier. und pflanz. Eiweisskörper. Diss. 1877.

3 The substances here referred to agree in most of their properties, but exhibit certain differences; thus, glutencasein contains more sulphur, and is more easily soluble in acetic acid than legumin. Ritthausen advocates the use of the word 'caseïn' as a group-designation. 
rappilly filtered ofi with the help of a filter-pump, washed with 40 to 50 per cent. spinit, finally with absolute alcohol and with ether, dried and weighed.

$\$ 227$. Isolution of Vitellin, etc.-Grains of vitellin ${ }^{1}$ (aleurone, etc.) may be frequently isolated from substances containing them in large (quantities, by a process of elutriation with olive oil, ${ }^{2}$ or a mixture of oil and petroleum spirit. ${ }^{3}$ Freed from oil with petroleum spirit, vitellin dissolves in water at $30^{\circ}$ to $40^{\circ}$, and can be precipitated from such a solution by a current of carbonic acid. To obtain it in crystals the precipitate is digested with calcinerl magnesia at $35^{\circ}$, filtered whilst warm and cooled. Schmiedebergy considers these crystalloids, as well as aleurone itself, to be compounds of vitellin with alkalies or alkaline earths. The crystals are doubly refracting.

2.28. Sequeration of Vitellin fium MIyusin.-According to Weyl, ${ }^{4}$ reget:at)le ritellin may be distinguished from regetable myosin by requiring, in a solution containing 10 per cent. of common salt, a temperature of $75^{\circ}$ for coagulation, whilst myosin coagnlates at $5.5^{\circ}$ to $60^{\circ}$. The latter, which has also been found in potatoes, passes into solution when the residuc, after treatment with water, is macerated with 10 per cent. solution of salt. Small pieces of rock-silt suspended in such a solution (previously nentralized with carbonate of soda) cause the gradual precipitation of the myosin, which, howerer, can be redissolved by the allition of a little water. Myosin may be separated from vitellin by diluting the solution largely with water, precipitating both with carbonic acid, clissolving in dilute salt-solution and coagulating at the temperature stated.

\$2.29. Estimution.- Experiments made by Liborius, ${ }^{5}$ Girgensolnn, ${ }^{6}$ and Tiraskewicz, ${ }^{7}$ have shown that the alhumen of bloodserum, eggs, etc., can be estimated with tolerable accuracy by

1 A similar substance nccurs in the seeds of Pinus cembra. See Schuppe, Pharm. Zeitschr. f. Russland, 520, 1880.

$\approx$ Compare Maschke, Chem. Centralblatt, 864, 1858, and Sachsse, ibid. 583, 1876 (Journ. Chem. Soc. xxxii, 200).

${ }^{3}$ Compare Schmiedeberg, Keitschr. f. phys. Chem. i. 206 ; Ritthausen, Archiv f. die ges. Phys, xvi. 301 (Journ. Chem. Soc. xxxiv. 518).

+ Joc. cit.

"Beitr. z. quant. Eiweissbest. Diss. Dorpat, 1870.

6 'Beitr. z. Albuminometrie und z. Kenntniss d. Tanninverb. d. Albuminate. Diss. Dorpat, 1872.

7 Linige Methoden z. Werthbest d. Milch. Diss. Dorpat, 1873. 
means of the tannin reagent mentioned in \$9., and CramerDolmatow has found that extracts from one and the same plant yield concordint results when titrated with the same reagrent. It must be left, however, for further experiments to show what vergetable albuminoids can be estimated in this way.

\$230. Estimution comtinned. - I greurimetric estimution uth tunnin will generally yield higher results than can be obtained by cmennlation (\$94). The source of the difference is to lie looked for partly in the deficiencies of the latter method, and partly in the fact that a number of albuminous sulbstances soluble in water are not coagulated hy boiling with dilute acetic acid, but are nevertheless precipitated by tannin. For this reason the results obtained by the tamin-method will generally agree hetter with those yielded by precipitation with alcohol. Nevertheless, I do not recommend the omission of the estimation by coagulation, for if the difference is considerable, that is, if the estimation by the tannin-method yielils much higher results than that by coagulation, it proves that another albuminous substance is present, which is not coagnuated by boiling. It is only when the difference is small that the presence of regetalle albumen alone may be inferred ; it may then he estimated by precipitation by tamnin.

To render the coagulation-test as reliable as possible, I have recommended chloride of sodium to he adder, and the precipitate to be washed, first with hoiling water, and subsequently with dilute spirit. If the chloricle of sodium is omitter the precipitation is generally less complete, and prolonged washing, especially with cold water, is liahle to redissolve part of the alhumen.

Ferment. - Simultaneously with the albumen a number of other sulstances may be partially or wholly precipitated, which, although agreeing with allumen in many respects, have heen too little investigated from a chemical point of riew to justify their heing classed straightway ats alluminoirls. I refer to the so-cillerl forment.: Like allhumen, they contain nitrogen, and are precipitated by strong alcohol, ete. ; most of them, prohahly, are coagulated like, or together with, alhumen when boiled in arpueous solution. They are distinguished from albumen hy their fermentative action, which evinces itself in various ways. Diastase, like saliva, converts starch into sugar, whilst invertin changes saccharose into invertsugar. Vegetable ferments allied to pepsin (papayotin) peptonize albumen. Mryrosin decomposes myronic acid, emulsin amygdalin; 
but emulsin does not attack myronic acid, nor does invertin convert starch into maltose and dextrin, etc. It is easy, therefore, to detect diastase in malt, invertin in yeast, emulsin in almonds, etc., the presence of which is anticiputed. The liquefaction of starch-paste, the conversion of cane-sugar into invert-sugar, the development of hydrocyanic acid and oil of bitter almonds, are changes so striking and so promptly effected, that the qualitative detection of the ferments producing them leares nothing to be desired. But the varied nature of the ferments themselves and of their action render's it exceedingly difficult to detect them in vegetable substances that have not previously been examined, as a general reagent applicable in such a case is yet unknown. It must be admitted that attention has been clrawn to the fact that the ferments liberate oxygren from an aqueous solution of peroxide of hydrogen, to which a little tincture of guaiacum has been adred, and thus produce a blue colouration of the mixture. But it is hardly to be expected that this property should be shared by all ferments, or that it should be peculiar to them alone.

$\$ 231$. Estimation of total Allumen.-The total albumen soluble in water can be estimated by means of acetate of copper, provided that no tannin or other substance precipitated by the same reagent is present in solution. The precipitate produced by an excess of the acetate is filtered off, dried, weighed, and ignited, the resulting oxide of copper being deducted. ${ }^{1}$

If other substances are thrown down with the albumen the nitrogen in the precipitate may be determined, and from that the alloumen jresent calculaterl. Ritthausen "and Taraskewiez ${ }^{3}$ have prover experimentally that the precipitate contains the whole of the albumen, caseïn, etc.

§232. Estimation continued.-Sestini ${ }^{4}$ considers it advisable to precipitate with acetate of lead. In cases in which other nitro-

${ }^{1}$ In some instances it is necessary to add a considerable excess for complete precipitation of the albumen. In an experiment made by Taraskewicz with casein, 1 gram of oxide of copper (in the form of acetate) was found to precipitate 4.19 gram of casein; but for complete precipitation an amount of acetate corresponding to $4 \cdot 55$ grams of oxide had to be added.

2 Loc. cit. 34, etc.; Ritthausen and Settegast, Archiv f. d. ges. Phys. xvi. 293, 1877. See also Mörner, Upsala Läkarefören. Forhandl. xii. 475, 1877 ; Fassbender, Ber. d. d. chem. Ges. xiii. 1818, 1880 (Journ. Chem. Soc. xl. $205)$.

3 Loc, cit.

${ }^{4}$ Landwirthsch. Versuchsst. xx, 305, 1878 (Journ. Chem. Soc, xxxiv, 740). 
genous substances accompany the albumen in aqueous solution he alvises the determination first of the total nitrogen; a part of the orisinal sulsstance is then to be boiled with water for an hour, male distinctly acid with lactic acid, mixed with acetate of learl, and filtered ; the insoluble resilue is dried and the nitrogen in it estimated. He thus assumes that all the nitrogen not present in the form of alluminoids passes into aqueous solution, and the nitrogen in the insoluble residue after precipitation with leal indicates the total albumen, both soluble and insoluble.

In addition to the foregoing precipitants, some of the group' reagents for alkaloids-phosphomolybelic, phosphotungstic acil, potassionercuric iodide, etc.-also throw down albuminous sulbstances (\$ 6.3). Phosphotungstic acid precipitates peptones, and might therefore he used for their estimation in regetable infusions previously freed from albuminous substances by coagulation or precipitation with lead. ${ }^{1}$

1 See Schulze and Barbieri, Landwirthsch. Versuchsst. xxvi. 213, 230, 234, 1881 (Journ. Chem. Soc. xl. 312); Chem. Centralblatt, 714, 731, 747, 761, 1881; Defresne, Repert. de Pharm. viii. 453, 1881; Hofmeister, Zeitschr. f. phys. Chem. iv. 253, 1880.

From the results recently obtained by Schulze and Barbieri, it appears probable that peptones are of far more frequent occurrence than could have been anticipated. As plints contain peptonizing ferment.; the possibility must not be ignored of peptones being produced during the preparation of aqueous infusions; they are also occasionally found ready formed in plants. The following are the more important properties of peptones: They yield with water solutions from which they are precipitated by alcohol, and redissolved by the addition of water. Estimation, however, by precipitation with alcohol is said to yield unsatisfactory results. In aqueous solution they are not coagulated by warming, nor are they thrown down by nitric acid, alum, ferrocyanide of potassium, or acetate of lead, but they are precipitated by tannin; and in the presence of neutral salts (sulphate of magnesia, etc.) tho separation is often very complete. Peptones are precipitated, as above stated, by phosphotungstic acid, and this takes place in an acetic acid solution; a property that enables us to separate them from other nitrogenous substances thrown down by the same reagent from solutions containing a mineral acid. The most important reaction of peptones is the so-called biuret reaction. An aqueous solution of a peptone assumes a pure red colour on the addition of caustic soda and very dilute solution of sulphate of copper (avoiding excess); Fehling's solution produces the same effect. The following might temporarily be recommended as a suitable method for the detection of peptones: The (fresh) material to be examined is triturated with sand and water, strained, washed with water and pressed. The liquors are united, acidified with acetic acid, warmed and filtered from the coagulum. From the filtrate any albuminoids remaining in solution are precipitated by the addition of acetate of lead, or, better, by warmins with basic acetate and hydrate of lead, and filtered off. The clear liquid is then rendered strongly acid with sulphuric acid, and the peptone procipitated 
Precipitation by phenol and calculation from the nitrogen contained in the precipitate has been recommended by Church ${ }^{1}$ for the estimation of the alluminoids in vegetable infusions, in the presence of amides, etc.

My experience in precipitating albumen, ete, with phenol compels me to doult the possibility of always obtaining complete separation by this means. Sestini has also expressed himself to the same effect.

$\$ 2: 33$. Eirtraction uith Dilute Acil.-It has already been observed that the residue of a regetalle substance, after exhanstion with water, yields albuminous substances to dilute alkali. The same is the case with lilute acid $(2 \cdot 12$ per cent. $\mathrm{HCl})$, the sulstances extracted being gluten, filuin (\$235), gliadin, mucedin, etc. But the albuminoils brought into solution by these two solvents do not appear to be always identical; at leist Wagner found that the amount removed by dilute alkali (after exhanstion of the material with water) (liel not coincirle with that extracted by acirl. (Compare also 111, 106). It might nevertheless in many. cisses be desirable to ascertain to what extent the substances allicil to alloumen resist the action of water, dilute alkali (cf. $\$ 226$ ) and dilute acid respectively.

In estimating the value of certain regetalile sulsstances as foods, it will often be found desirable to determine what proportion of proteids are dissolved by the combined action of pepsin and hyrlrochloric acid after the material has been exhausted with water.

From experiments that have been made in this direction it would appear that hydrochloric acid and pepsin dissolve more than. the former alone. ${ }^{2}$ In making such estimations I should recommend 100 cc. of water, 1 gram of $: 3: 3$ per cent, hyrlyochloric acid, and $0 \cdot 1$

by phosphotungstic acid. The precipitate is filtereed off as rapidly as possillele, washed with 5 per cent. sulphuric acid and transferred whilst still moist to a mortar. It is then triturated with excess of hydrate of baryta, warmed for a short time and filtered. If the filtrate is colourless, the biuret-test can be applied; if yellow, it can frequently be decolourized by adding a little acetate of lead, and filtering off from the precipitate thus produced. Animal charcoal should not be used, as it absorbs peptone. Schulze and Barbieri, who proposed the foresoing method, have obtained aproximate quantitative results colorimetrically.

${ }^{1}$ Landwirthsch. Versuchsst. xxvi. 193 (Journ. Chem. Soc. xxxviii. 588). See also Sestini, loc. cit.

a See Kessler, Versuche über die Wirkung des Pepsins auf einige animal. u. vegretab. Nahrungsmittel. Diss. Dorpat, 1880. 
of good pepsin to be taken for every a grams of fincly powdered sulsstance. Starch, if present in large quantity, might with adrantage be previously converted into maltose and dextrin hy boiling, cooling to $40^{\circ}$, and digesting for four hour's at that temperature, after adding 0.005 gram of active diastase.

$\$ 234$. Ertraction with Spirit.-Some of the albuminoids insoluble in witer attract our attention by their solubility in sprivit, as, for instance, those known as glutenfibin, gliullin (or vegetable gelatine), and mucedin. In seels only hare these three substances been detected with certainty; they remain undissolved when the material containing them is treated with water, or, at most, the mucedin alone is partially taken into solution. They would be removed, however, by the dilute alkali used for the extraction of the glutencasein $(\$ 226)$, and it is advisable therefore, in looking for these substances, to treat the material with spirit previously to extracting the glutencasein with alkali. Part, however, of the glutenfibrin and a little gliadin would be left undissolved, and would be subsecpuently found with the casein (\$226). The spirit should be usecl cold, and should be of a strength of about 60 to 80 per. cent. 'The maceration must extend over' a considerable perior, and the spirit be renewed several times. The united extracts are distilled until the strength of the spirit is reduced to 40 to 50 per cent. (not less). On cooling, a clear slimy mass separates, consisting principally of glutenfibrin mixed with a few flocks of glutencasein and possibly fat (which is, however, better removed by petroleum spirit before treating with alcohol). If the majority of the spirit is distilled off from the clear liquor a second precipitate will form, consisting principally of glimtin and mucedin, and a further quantity of the same two sulsstances (impure) can loe obtained by neutralizing the filtrate with a little potash and concentrating.

All these precipitates are triturated with absolute alcohol until they hecome hard and solid. ${ }^{1}$ Fat, if present, is removed by treatment with ether.

We are as yet macquainted with any methor of separating the glutenfibrin, gliadin, or mucedin for quantitative determination. We must therefore content ourselves with making a total estima-

1 The spirit dissolves a little glutenfibrin, which can subsequently be precipitated by ether. 
tion, and applying a few qualitative tests to show the presence of one or more of the substances referred to.

\$235. Properties: Glutenfibrin. - Glutenfibrin is insoluble in water and in absolute alcohol, but dissolves easily in warm 30 to 70 per cent. spirit, separating again on cooling. ${ }^{1}$ It is also taken up by cold 80 to 90 per cent. spirit. Prolonged boiling with water converts it into a gelatinous substance insoluble in spirit, acids, or alkalies. Glutenfibrin dissolves with facility in cold dilute acids (acetic, citric, tartaric, hydrochloric), and in alkalies; with ammonia, lime- and baryta- water it gelatinizes. It is precipitated from both acid and alkaline solutions on neutralizing; and is also thrown down by acetate of copper. ${ }^{2}$

Gliadin is characterized by its tough, slimy consistency. It is sparingly soluble in cold water ; a considerable quantity dissolves on boiling, but, like glutenfibrin, it undergoes simultaneously a partial decomposition. Gliadin is insoluble in absolute alcohol, but dissolves in 60 to 70 per cent. spirit, both cold and warm (especially freely in the latter). In general it resembles glutencaseïn in its behaviour to dilute alkalies and acids, but ammonia, lime- and baryta- water dissolve it. Boiled with concentrated hydrochloric acid it yields a bluish-brown solution. It is precipitated by acetate of copper, but not by mercuric chloride. Attention has already been directed ( $\$ 224)$ to the high percentage of nitrogen in gliadin.

Mucertin is far less tough and elastic than gliadin, and is more casily soluble in 60 to 70 per cent. spirit. It is precipitated from a cold solution by 90 to 95 per cent. spirit in flocks or friuble masses (solutions of gliadin become milky); stirred up with water it yields a clondy mucilaginous liquid, which clears again on standing; but, if warmed, the aqueous solution becomes cloudy and remains so for a considerable period, till finally a flocky mass separates which is only partially soluble in acetic acid and spirit.

1 On concentrating such solutions the glutenfibrin forms a skin on the surface of the liyuids, which dissolves again on stirrings. Gliadin and mucedin do not exhibit this peculiarity.

2 Glutenfibrin agrees with maize-fibrin in most of its properties; the latter contains only 15.5 (instead of 16.9 ) per cent. of nitrogren, and is insoluble, or only partially dissolved, by dilute acetic, citric, tartaric and oxalic acids. Zander has recently reported on another albuminous substance soluble in spirit ('Chemisches iiber die Samen des Xanthium Strumarium.' Diss. Dorpat, 1881). 
In its other properties it agrees fairly well with gliadin. (Compare also $§ 237$.

\$236. Gluten.-Glutencasein, glutenfitrin, gliadin, and mucedin are the principal constituents of the so-called gluten which possesses such importance as a food. An estimation of total gluten is generally made by rubbing down 10 to 20 grams of the meal to a paste with water, transferring to a fine linen cloth, and washing with distilled or rain-water until the washings, on standing, deposit only traces of starch. The mass is then pressed, scraped from the cloth, and dried on watch-glasses, finally at a temperature of $115^{\circ}$ to $120^{\circ}$; it should then be powdered and dried again until the weight is constant. In this method of estimating gluten it will be found advantageous to add a weighed quantity (1 to 2 grams) of purified bran, the weight of which is afterwards, of course, to be deducted from that of the total gluten. ${ }^{1}$

According to Benard and Girardin, ${ }^{2}$ the amount of gluten found varies if the mixture is allowed to stand before washing with water. It would be advisable to begin washing about three hours after mixing the meal with water.

\$237. Sulstances dissolved by Dilute Alliali, not mecipitated by Acid and Spirit.-In estimating metarabic acid and albuminous substances sparingly soluble in water, as directed in $\$ 103$ and 206 , it will not unfrequently be observed that the total substances extracted by dilute alkali are considerably in excess of those precipitated by acid and alcohol. A part of the former, therefore, must still remain in solution, and will be recovered, together with acetate of sodium, by evaporating the filtrate $(\$ 10 \tau)$. We may expect to find here the constituents of gluten (including gliadin) and products of their decomposition. After distilling off the majority of the spirit, they might be precipitated with acetate of copper, and estimated as directed in $\S 231$.

The substances not precipitated by this reagent are probably allied to, or derived from, vegetable mucilage; they may be estimated by removing the excess of copper with sulphuretted hydrogen, evaporating to dryness and weighing, deducting the acetate of soda present.

With regard to the latter, I may observe that it camnot be calculated from the amount of soda used, hut must be estimated by

${ }^{1}$ Compare Archiv d. Pharm. cxcv. 47, 1871.

2 Journ. de Pharm. et de Chim. [5], iv. 127, 1881. 
incincrating a portion of the dried residue, and calculating from the carbonate of soda in the ash. In miny analyses made in my laboratory, the amount of soda in solution has been found to be much smaller than was expected from calculation; part of it was evidently retained in the insoluble residue.

\$238. Other Nitrugenous Sulstunces. - We possess hardly any lnowledge at all of the nitrogenous sulsstances that are not dissolved by water, alcohol, or allicli. I have already stated (\$231) that they may sometimes be extracted by hydrochloric acid and pepsin, but Treffner's researches on the chemical composition of the mosses, alluded to in $\$ 106$, prove that this is not always the case. I will here only remark that, in estimating the nutritive value of a plant, such substances cannot, without further consideration, be considered as albuminoids.

\section{AMINES AND THEIR COMPOUNDS.}

\$ 239. Monamines.-According to A. W. Hofmann, monamines may be distinguished from other amines by means of the isonitrilereaction, as the latter do not evolve the characteristic odour of that compound when warmed with alcoholic potash and chloroform.

Another reaction for monamines consists in warming an alcoholic solution with bisulphide of carbon, by which a sulphocarbamide of the base is produced. This compound, when heated with an arqueous solution of mercuric chloride (not in excess) develops an odour of oil of mustard. ${ }^{1}$

\$240. Fer the sejercution of ethylamine from diethyl-and triethylumine by means of anhydrous ethyloxalite, see A. W. Hofmam ;the author subsequently availed himself of the methor in separating the methyl bases. Carey Lea ${ }^{3}$ recommends picric acid for the ethyl bases.

In Hofmann's method the efluylemine is converted into diethyloxamide, which can be recrystallized from water, and yields ethylamine by distillation with potash.

Diethylumine yields moler the same conditions oily ethylic diethyloxamate, which can be purified by distillation (boils at $260^{\circ}$ ), and converted by potash into diethylamine.

1 Ber. d. d. chem. Ges. iii. 767, 1870.

2 Journ. f. pract. Chem. 1xxxiii. 191, 1861 ; Comptes rendus, Iv. 749, 1862.

${ }^{3}$ Chem. Centralblatt, 76, 1863. 
Triethylamine is not atticked by ethylic oxalate, and can be separated from diethyloxamide and ethylic diethyloxamate by distillation (B.P. $91^{\circ}$ ).

The three corresponding methyl bases behave in an exactly similar manner. Trimethylamine boils at $4^{\circ}$ to $5^{\circ}$ and can easily be separated from the crystalline methylethyloxemide and the liquid ethylic dimethyloxamate (B.P. $240^{\circ}$ to $250^{\circ}$ ) by distillation.

\$241. Estimation.-Sachsse and Kormann ${ }^{1}$ have published a method for the approximate estimation of amides, based upon their decomposition by nitrous acid with liberation of nitrogen; the

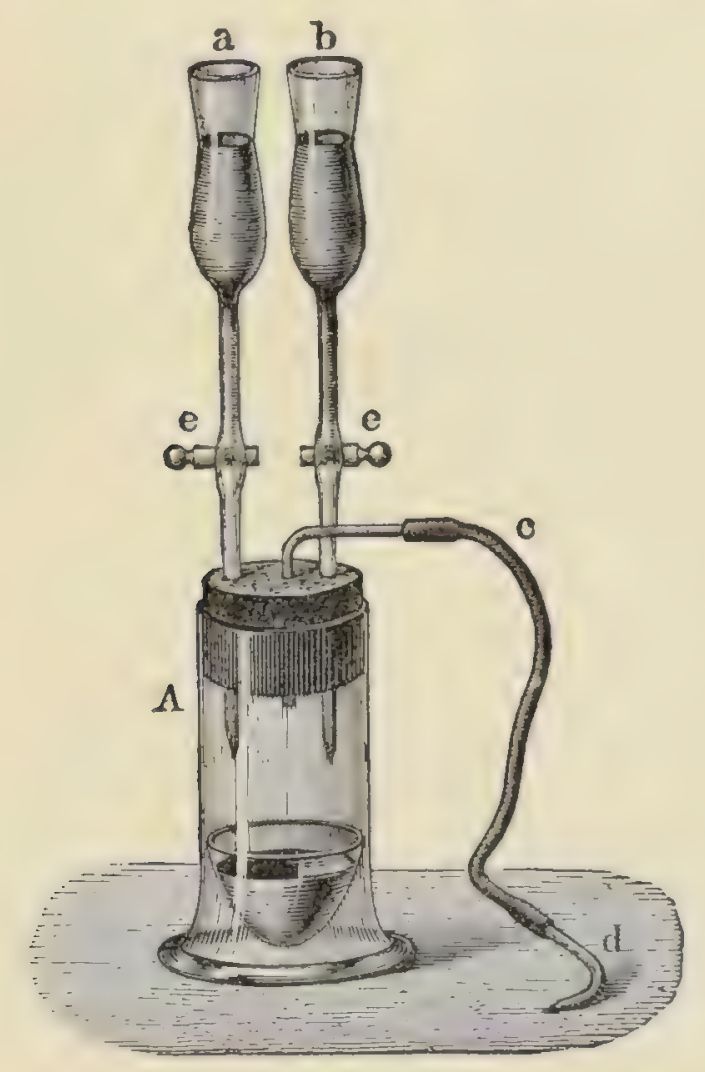

Fig. 10.

latter gas is collected and moasured, and from it the amount of amide originally present is calculated.

The apparatus usel for the estimation is shown in Figs. 10 and 11. The generating vessel $\mathbf{A}$ is of about 50 to 60 cc. capacity, and closed with an indiarubber cork bored with three holes; through these there pass two funnel-tubes, $a$ and $b$, and a bent delivery tube $c$, to which is attached, loy means of a long indiarubber tube,

1 Landwirthsch. Versuchsst. xvii. 321 (Journ. Chem. Soc. xxvii. 784); Zeitschr. f. anal. Chem. xiv. 380, 1875. 
a curved glass point $d$. About 6 cc. of a concentrated aqueous solution of nitrite of potassium (free from carbonate), together with nearly an equal quantity of water, is introduced into the generating vessel. The lower parts of the funnel-tubes, that is up to a little above the tap, say about $e$, are also filled with water, so as to displace the atmospheric air. Dilute sulphuric acid is now poured into one funnel, and a weighed quantity of the amide dissolved in water into the other, taking care not to alluw any bubbles of air to adhere to the sides.

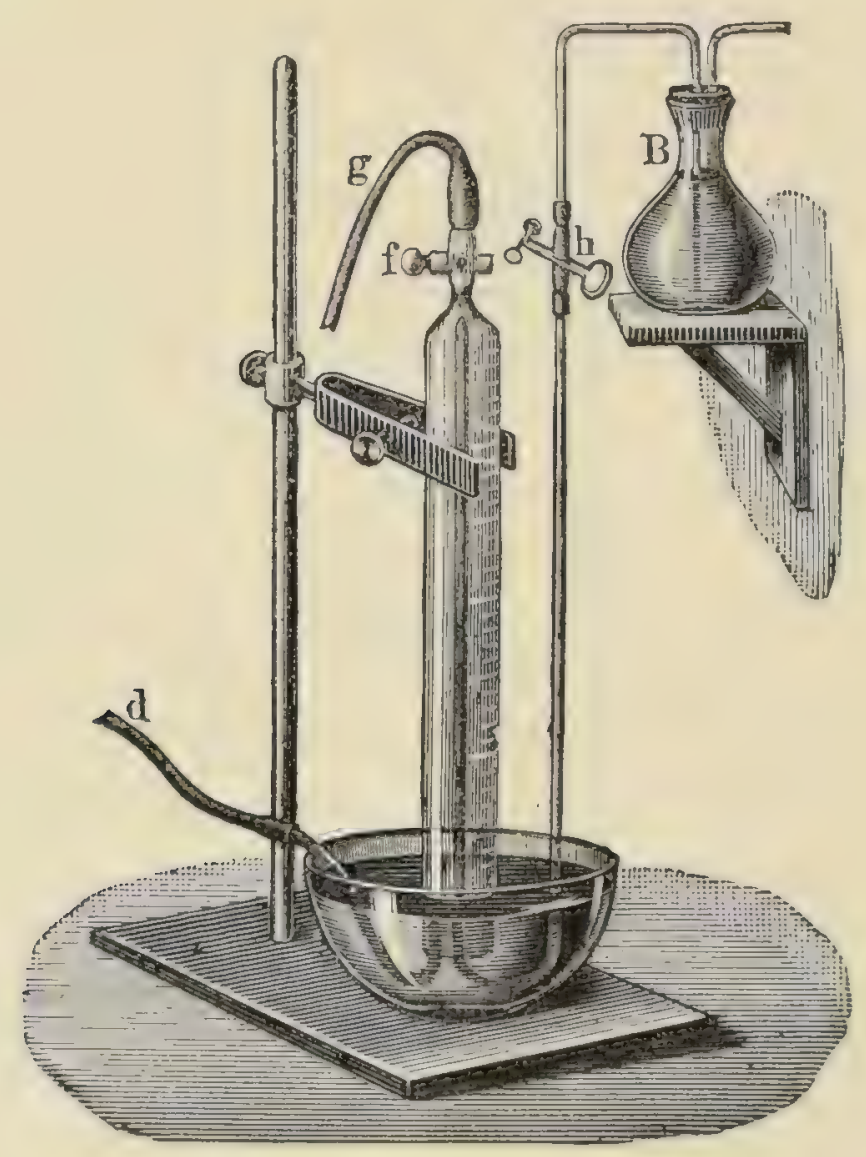

Figr. 11.

The atmospheric air in the apparatus has now to be displaced, and this is effected by running sulphuric acid, little by little, into the nitrite solution, by which nitrous acid and nitric oxide are evolved. To ascertain if the displacement is complete, 5 to $10 \mathrm{cc}$. of the gas from the generating vessel are allowed to pass into the measuring tube (Fig. 11) previously filled with solution of ferrous sulphate. Not more than $0.1 \mathrm{cc}$. should remain unabsorbed. Fresh ironsolution may be introduced, if necessary, from the flask B, as subscquently described. The apparatus is now rearly for the commencement of the actual experiment. The measuring-tube, stand- 
ing in a pneumatic trough, should be capable of holding 50 to 60 cc., and be graduated to $0.2 \mathrm{cc}$. It is filled with the iron-solution contained in B by opening the clip $h$ and blowing through the shorter bent tube in $\mathrm{B}$; by this means the solution can be run into the pneumatic trough; on opening $f$ and sucking at $g$ the solution rises in the tube until it reaches and passes $f$, which should then be closed.

After replacing the clip $h$, the bent point $l$ is introduced under the measuring tube and the solution of the amide allowed to run from the second funnel-tube into the generating vessel, rinsing with a little water, but keeping the tube from $e$ downwards full of liquid. Small quantities of sulphuric acid are allowed to run into the generating vessel from time to time, when the evolution of gas becomes sluggish, taking care that the measuring-tube always contains sufficient strong solution of ferrous sulphate; this can be ensured by frequently opening the clip $h$ and allowing the solution from $\mathrm{B}$ to run into the measuring-tube. The end of the decomposition is recognised loy the liquid in A assuming a permanent blue colour from excess of nitrous acid. The remainder of the gas is then driven out by filling the entire apparatus with water through the second funnel-tube until it flows into the measuringtube through $d$. The delivery-tube is now removed, and the whole of the nitric oxide absorbed by the introduction of fresh iron-solution. After closing the clip $h$, the delivery-tube from B is drawn out of the measuring-tube, and the latter transferred to a deep cylinder, where the iron-solution is removed as far as possible and replaced by caustic soda to absorb carbonic acid. When this has been effected, the measuring-tube is lowered in the cylinder until both liquids have the same level. The volume of gas is now read off, reduced to $0^{\circ}$ and from it the amount of amide originally present calculated, deducting 1 cc. as unavoidable error caused by the atmospheric air mixed with the nitrogen; 28 parts by weight of nitrogen indicate 150 of crystallized asparagine, 131 of leucine, and 181 of tyrosine. ( $\$ 191,192$ ).

§ 242. Amirlic Acids.-The amillic acids referred to in $\$ 101$ are freely soluble in water and 50 per cent. spirit, requiring considerable quantities of strong alcohol for precipitation, so that in this respect they resemble such substances as dextrin, levulin, etc. They are precipitated therefore with, or in the place of, dextrin and the like, but differ from these bodies in containing nitrogen. 
The precipitate obtained as dextrin (cf. ss $76,198,199$ ) must be tested for nitrogen, and if much is found, experiments must be made to ascertain whether any one of the following substances is present. It may sometimes be approsimately estimated, if found, by mixing the aqueous solution with alcohol till it contains about 50 to 60 per cent., filtering, eraporating the filtrate to a syrupy consistence, and now precipitating with 5 to 6 volumes of absolute alcohol. From the amount of nitrogen in the precipitate the quantity of amidic acid present may be calculated.

Cuthartic Acid occurs in senna, in the bark of Rhamnus frangula, and probably also in rhubarb. ${ }^{1}$ It is a glucoside, yielding by its decomposition sparingly soluble cathartogenic acid and 34.1 per cent. of ghcose. According to Kubly, cathartic acid ${ }^{2}$ contains 1.48 to 1.51 per cent. of nitrogen, cathartogenic acid 2.46 per cent. The latter is easily produced by heating an aqueous solution of cathartic acid with access of air; in fact, that substance decomposes with great facility in the presence of bases and air. In senna and rhubarl it is contained chiefly in combination with bases (the alcohol precipitate containing 4 to 5 per cent. of ash); but in Rhamnus frangula it appears to occur, partly at least, in the free state. It is a strong purgative.

Husson ${ }^{3}$ estimates the quality of a rhubarb by ascertaining the amount of iodine an infusion is capable of absorbing; but Greenish ${ }^{4}$ has shown that this method does not yield reliable results.

Selervitic Acid ${ }^{5}$ is a constituent of ergot, and contains about 4.2 per cent. of nitrogen, but no sulphur; its activity is not destroyed by acids, etc., if in contact with them for a short period only. In solubility it resembles cathartic acid. Its action, when injected subcutaneously into frogs and other animals, is that of a powerful

${ }^{1}$ Compare Kubly, 'Ueber das wirksame Princip und einige andere Best. d. Sennesblätter,' Diss. Dorpat, 1865, and Pharm. Zeitschr. f. Russland, iv. 429, 465. On Rhamnus frangula, see also Pharm. Zeitschr. f. Russland, v. 160, 1866. On rhubarb, ibid. vi. 603, 1867 ; xvii. 65, 97, 1878 (Pharm. Journ. and Trans. [3], ix. 813, 933, 1879).

"Probably also sulphur; cathartic acid from Thammus frangula bark contains less nitrogen.

${ }^{3}$ Union Pharm. 99, 1875 (Year-book Pharm. 344, 1875).

${ }^{4}$ Pharm. Journ. and Trans. [3], ix. 813.

${ }^{5}$ Compare Dragendorff and Podwissotzki, Archiv fo exper. Patholog. und Pharm. 153, 1876; Sitz-Ber. d. Dorpater Naturf. Ges. 109, 392, 1877 (Pharm. Journ, and 'Irans. [3], vi. 1001). 
poison. ${ }^{1}$ It is precipitated by tannin and basic acetate of learl, and from concentrated solutions also by chlorine-water and phenol. It does not share with albuminoids the reactions mentioned in $\S 92$.

On keeping ergot for any length of time, part of the sclerotic acid appears to be converted into an allied substance containing 6.6 per cent. of nitrogen, which has been named scleromucin. It can be extracted with warm water, but requires less alcohol for precipitation than sclerotic acid. Diffused in water whilst still moist, it forms a mucilaginous liquid; but once dried, it is not dissolved by cold water, and not with facility by warm. It resembles sclerotic acid in its action and other properties.

\section{STARCH, LICHENIN, WOOD-GUM, ETC.}

\$243. Starch.-Starch is not, as is well known, a homogeneous substance, but it is nevertheless usual, and very properly so, to estimate the whole of the carbohydrates of which it is composed as directed in $\$ 113$ to 115 . Formerly three principal constituents of starch were generally distinguished : first, one striking a blue colour with iodine, and passing into solution when starch is triturated with powdered glass and water-solutile starch, amidulin, \& amylon (Béchamp); secondly, a substance characterized by its insolubility in cold water, solubility in saliva, etc., and by the blue colouration it yields with iodine, gramulose, the principal constituent of all starch; and thirdly, cellulose, which, in the form of a membrane, gives to the starch grain its particular shape, is coloured yellow by iodine (after boiling with water, violet), and is converted by chloride of zinc into a substance that is tinged blue by the same reagent.

Some years ago Nägeli ${ }^{2}$ stated that in his opinion there existed two different modifications of amylon, which he called blue

1 From 0.03 to 0.04 gram produces in frogs a swelling of the skin and almost complete paralysis, commencing at the hinder extremities. Irritants produce no effect, and indeed the animal gives no other sign of life than an occasional feeble contraction of the heart. Although its condition may appear to improve in the course of five to seven days, it sometimes succumbs to a relapse.

2 Annal. d. Chem. und Pharm. clxxiii. 218, 1874 (Journ. Chem. Soc. xxviii. 55. See also Musculus, Annal. de chim. et de Phys. ii. 385, 1874 (Pharm. Journ. and Trans. [3], v. 3) ; Musculus and Gruber, Journ. de Pharm. et de Chim. xxviii. 308, 1878 (Journ. Chem. Soc. xxxiv. 778) ; Bondonneau, Repert. de Pharm. iii. 231, 1875 (Journ. Chem. Soc. xxix. 365); Journ. de Pharm. et de Chim, xxiii. 34, 1874; Béchamp, ibid. 141. 
and yellow, according to the colour they yielded with iodine. These two were connected by intermediate modifications striking violet, recklish and reddish yellow colours with iodine, differences which are probably referable to variations in the density. In accordance with this theory the several modifications vary in the resistance they offer to solvents and chemical agents. As the blue modification is the most easily attacked, it might be considered to be that of lowest density. It is followed by the violet, red, etc., in succession up to the yellow, the densest form of which shows a great resemblance to cellulose. When starch is boiled the blue modification passes into solution, carrying with it a little of the yellow. If the former is removed by allowing it to decompose, the yellow modification separates out. From a solution of the latter, prepared by prolonged boiling with water and concentrating, crystals of amylo-dextrin can be obtained, which are coloured yellow by iodine.

The bodies above referred to occur in different proportions in the different varieties of starch, and the amount of either present might possibly be found to be characteristic of the starch under examination. It might, for instance, be ascertained by comparative experiments how long the action of an acid of certain strength must be continued before the blue or red colouration with iodine ceases to be produced. For the isolation of the yellow modification, formerly called cellulose, $\gamma$ amylon (Béchamp), I have recommended digestion at a temperature not exceeding $60^{\circ}$, with 40 parts of a saturated solution of chloride of sodium containing 1 per cent. of hydrochloric acid, and washing with water and dilute spirit. I have thus obtained $3 \cdot 4$ per cent. from arrowroot, $2 \cdot 3$ per cent. from wheat-starch, and $5 \cdot 7$ per cent. from potato-starch.

$\$ 244$. IIydrocellulose.-A blue colouration of the cell-ucall. is frequently noticed when sections of vegetable substances are moistened with iodine water. It was probably this reaction that gave rise to the theory that a modification of cellulose could occur striking a blue colour with iodine.

I do not concur in this view; in fact, I am convinced that in such cases the cell-wall in question contains besides cellulose, which is characterized by its power of resisting the action of chlorate of potash and nitric acid, other carhohydrates (amyloid), probal)ly, at least in part, of the composition $\mathrm{C}_{12} \mathrm{H}_{22} \mathrm{O}_{11}$, agreeing therefore in this respect with araljic acid, pararabin, etc. Whether these 
carbohydrates are hydrocellulose's, such as are formed from cellulose by the action of concentrated sulphuric acid or chloride of zinc, is a matter for further inquiry. If the treatment with the above oxidizing mixture of chlorate of potash and nitric acid $(\$ 119)$ is continued long enough, such substances are always destroyed. Some of them are soluble in boiling water. This is the case with one contained in the asci of certain lichens (Cetraria), etc., from which it is extracted, together with lichenin, by boiling with water; hence the erroneous idea that the lichenin itself was coloured blue by iodine. ${ }^{1}$

Berg's researches have shown that if a decoction of the lichenin be allowed to gelatinize by cooling, cut into pieces and macerated in distilled water, the whole of the substance that strikes a blue colour with iodine passes into solution, from which it can be isolated by precipitation with alcohol, although impure and not free from ash. After drying it is to a great extent insoluble in water, and is converted into sugar by boiling with dilute hydrochloric acid ( $t$ per cent. of acid of sp. gr. 1.12) for a period of two hours, a change which is not effected by pure water. The glucose produced is dextro-rotatory, and as the decomposition takes place tolerably smoothly, the amount of the substance, which we may temporarily call lichen-sturch, can be determined by estimating the sugar thus formed. Lichen-starch dissolves tolerably easily in ammonia of sp. gr. 0.96 , and is precipitated from this solution by spirit. It appears to be more difficultly soluble in dilute alkalies, and is not converted into sugar by diastase or saliva.

\$245. Lichenin.--Lichenin is characterized by its property of gelatinizing, which is exhibited by a solution containing 1 in 60 . It is insoluble in cold water, alcohol, and ether; boiling water dissolves it, as do also ammonio-sulphate of copper and concentrated (20 to 30 per cent.) potash. From its solution in strong potash it can be precipitated by alcohol in the form of a potassium-compound containing up to 10 per cent. of alkali. Concentrated hydrochloric acid also dissolves it, but with simultancous (partial) decomposition. When boiled with dilute acid it is converted with even more facility than lichen-starch into a dextro-

${ }^{1}$ Compare Berg, 'Zur Kenntniss des in Cetraria islandica vork. Lichenins und indblizuenden Stoffes,' Diss. Dorpat, 1S72. From licrs's experiments it would appear that the formula $\mathrm{C}_{6} \mathrm{H}_{10} \mathrm{O}_{5}$ would indicate the composition of lichen-starch better than $\mathrm{C}_{12} \mathrm{H}_{22} \mathrm{O}_{11}$; the same is true of lichenin. 
rotatory fermentulle sugar, so that this method may be adopter for its estimation. Ammonia dissolves it with difficulty, and it undergoes but little change when heated with potash in sealed tubes (\$115).

Gelose, ${ }^{1}$ the gelatinizing constituent of many algre, agrees with lichenin in most of its properties, but is insoluble in ammoniosulphate of copper, and is less easily converted into sugar. By decomposition with dilute acids, arabinose (lactose) is produced in place of the glucose yielded by lichenin. The gelose appears to be accompanied, at least in Sphærococcus lichenoides, by a carbohydrate 2 soluble in dilute hydrochloric acid, but differing from pararabin ( $\$ 112)$ in yielding glucose when boiled with an acid.

\$246. Woolt-gum.-Thomsen ${ }^{3}$ found that when ligneous tissue, previously exhausted with water, spirit, and very dilute alkali, was macerated with caustic soda of sp. gr. $1 \cdot 1$, a substance was extracted, the composition of which he ascertained to be $\mathrm{C}_{6} \mathrm{H}_{10} \mathrm{O}_{5}$, and which he named wood-gum. It can be isolated from its solution in soda by acidifying and adding alcohol. When once dried, cold water will not redissolve it; this is, howerer, effected by boiling. It is precipitated by basic acetate of lead, is converted into glucose by boiling with a dilute acid, and is not coloured blue by iodine. An alkaline solution is levo-rotatory. It differs from lichenin in not possessing the power of gelatinizing, from metarabin in not being dissolved (when dry) by 0.1 per cent solution of soda.

A similar substance was ohtainer by Pfeil $^{4}$ from parenchymatous tissue (agrecing, however, in composition hetter with the formula $\mathrm{C}_{12} \mathrm{H}_{2,2} \mathrm{O}_{11}$, a hydrocellulose), by Treffner from mosses, and by Greenish from algx.

\section{CELLULOSES, LIGNIN, AND ALLIED SUBSTANCES.}

\$24. Celluloses, etc.-F'remy and Terreil ${ }^{5}$ assume that woody tissue is chiefly composed of three different sul)stances, which they distinguish as cellulose, incrusting substance, and cuticular sub-

1 Compare Morin and Porumbaru, Comptes rendus, xc. 924, 1081, 1880 (Year-book Pharm. 120, 121, 1881).

${ }^{2}$ Greenish, Archiv d. Pharm. [3], xx. 241.

3 Journ. f. pract. Chem. [2], xix. 146, 1879 (Year-book Pharm. 99, 1880).

${ }^{4}$ Loc. cit.

5 Journ, de Pharm, et de Chim, vii. 241, 1868. 
stance. The first is said to be the only one capable of resisting the action of chlorine-water; it can be isolated by the method detailed in $\$ 116$. The authors overlook the fact that several units per cent. of a substance probably isomeric with cellulose (? intercellular substance), removalole by chlorate of potash and nitric acid, are left associated with the cellulose.

The cuticulur substance alone is said to be insoluble in a mixture of $1 \mathrm{eq}$. of sulphuric acid with $4 \mathrm{eq}$. of water; it can be isolated by treatment with acid of that strength, followed by washing with pure water and dilute alkali.

The incrusting substances are estimated by difference.

In a more recent publication, the author's observe that the following are the principal substances they would expect to find in tissue previously exhausted with indifferent solvents:

Cellulose, soluble in ammonio-sulphate of copper.

Paracellulose, insoluble in the same until after it has been acted upon by acids.

Metucellulose (fungin) insoluble in ammonio-sulphate of copper.

All three modifications of cellulose are soluble in $\mathrm{H}_{2} \mathrm{SO}_{4}, 2 \mathrm{H}_{2} \mathrm{O}$. (Compare also \$248).

$V$ usculose, insoluble in $\mathrm{H}_{2} \mathrm{SO}_{4}, 2 \mathrm{H}_{2} \mathrm{O}$, and in ammonio-sulphate of copper; soluble in alkalies only under increased pressure, anit decomposed by treatment with chlorine-water, followed by washing with dilute alkalies.

Cutose, insoluble in $\mathrm{H}_{2} \mathrm{SO}_{4}, 2 \mathrm{H}_{2} \mathrm{O}$, and in ammonio-sulphate of copper, hut soluble in alkalies under the ordinary pressure.

Pectose, convertible by acids into soluble pectin. ${ }^{1}$

I would observe that the sulistance designated as vasculose (formerly called incrusting substance), agrees in the main with my lignin (116). Lignin camnot, unfortunately, be separated frem cellulose without decomposition, and it is therefore impossible to adduce direct proof that it does not consist of a mixture of sereral chemical inclividuals. Nevertheless, I think it probalsle that in some instances the cellulose is accompaniel by a single definite substance, 'lignin.' Stachmam² cxhausted regetable substances rich in lignin with the indifferent solvents already alluded to, as well as with dilute sorla and dilute acid, and then determined the approximate composition of the lignin by making

${ }^{1}$ Comptes rendus, 1xxxiii. 1136. (Journ. Chem. Soc, xxxi. 229).

2 'Studien iiber die Zusammensetzung d. Holzes.' Diss. Dorpat, 1878. 
an ultimate analysis of the material that had been thus treated, both before and after the action of chlorine-water. Several varieties of wood yielded tolerably concordant results. The lignin of dicotyledons appeared to contain between $53 \cdot 1$ and $59 \cdot 6$ per cent. of carbon, 4.4 and 6.3 per cent. of hydrogen, 34.1 and 38.9 per cent. of oxygen; the majority of his results agree very well with Fr. Schulze's ${ }^{1}(\mathrm{C}=55 \cdot 5, \mathrm{H}=5 \cdot 8, \mathrm{O}=38 \cdot 6)$; but German walnut and mahogany show a little variation, probably due to the larger amount of foreign substances they contain. All the dicotyledonous woods examined by Schulze and Stackmann must have contained at least one substance in notable quantity, viz. wood-gum, which was not discovered until after the publication of Stackmann's work. Experiments made by Schuppe, ${ }^{2}$ at my suggestion, showed that poplar wood contained 3.25 per cent. of wood-gum, mahogany $3 \cdot 37$, American walnut $4 \cdot 56$, German walnut, $6 \cdot 32$, oak $6 \cdot 03$, and alder $\mathbf{7} \cdot 09$. Deducting the wood-gum present, the average amount of lignin in the majority of woods is about 17 per cent. (mahogany 20.4), and its mean composition, 60.56 per cent. C, 4.66 per cent. H, and 34.80 per cent. O. In this respect it approaches catechin, many tannins and phlobaphenes, and agrees fairly well with the lignin of coniferous woods which contain no wood-gum. Stackmann found about the same quantity of lignin in the wood of grmnosperms as Schuppe did in that of angiosperms, viz. 16 to 17 per cent.

Koroll $^{3}$ found the lignin of sclerenchymatous tissue (hazel-nut, walnut) to contain from 51.5 to 54.2 per cent. of carbon, 4.8 to $5 \cdot 5$ per cent. of hydrogen, and $40 \cdot 1$ to $44 \cdot 7$ of oxygen, and estimated its quantity at 14.3 to $15 \cdot 7$ per cent. A substance resembling woorl-gum also occurs in the sclerenchymatous tissue of nut-shells. Bast-fibres (lime and elm) yielded him 14.5 to $15 \cdot 8$ per cent. of lisnin, containing 53.6 to 54.9 per cent. of carbon, 4.9 to 6.0 per cent. of hydrogen, and 40.1 to 40.4 per cent. of oxygen.

On the other hand, from the outer hirch-bark (rich in cuticular substance, chlorine-water extracter 11 per cent. of a substance of an entirely different composition; viz. $\mathrm{C}=72 \cdot 7, \mathrm{H}=7 \cdot 8$, $\mathrm{O}=19 \cdot 4 . \quad$ (Cf. $\S 250$.

1 'Beitr. z. Kenntniss d. Lignins.' Rostock, 1856.

2 Beiträge z. Chemie d. Holzgewebes. Diss. Dorpat, 1882.

3 'Quant. chem. Unters, uiber d. Zusammensetz.d, Kork-, Bast-, Sclerenchym, und Markgewebes.' Diss. Dorpat, 1880. 
The tissue of turnip, chicory-root, and elder-pith, which is principally parenchymatous, yielded hardly anything to chlorinewater. Pfeil also came to a similar conclusion with regard to the tissue of apples. ${ }^{2}$

The substance formerly known as suberin is in part the cuticular substance just alluded to ; it should, however, be observed that under this name less recent authors understood a mixture of fat, wax, tannin, etc. ${ }^{2}$ Siewert has published a minute inrestigation of the substances that accompany suberin, but not of the suberin itself; our lnowledge of that substance is but very insufficient, and I can only state that it is not dissolved by the usual solvents, that it is more easily attacked by certain oxidizing agents than lignin, but is more difficult to remove completely by digestion with chlorine-water. Nitric acid of sp. gr. 1.3 attacks it very energetically; and with an acid of sp. gr. 1.1 the action may be so violent as to cause ignition. It resists chromic acid more powerfully than lignin. Whether suberin really yields the ceric and suberic acids that have been obtained by the decomposition of cork is still a matter of uncertainty.

Siewert estimates the amount of suberin in cork at 90 per cent.; but I think this is too high. I feel convinced that the residue he speaks of as suberin must have contained a considerable quantity of true cellulose. (Koroll found 50 per cent. in the outermost parts of birch-bark.)

In my opinion, the hardening substance of many woody fungi is possibly identical with suberin. ${ }^{3}$

For the microchemicul churucters of cutin, lignin, ete., see also Vogl ${ }^{4}$ and Poulsen. ${ }^{5}$ (See also $\$ 249$. )

The remarkably constant proportion existing between the amount of cellulose and lignin, etc., present in varieties of wood, raises the question whether these two substances do not occur in combination with one another. The attempt has frequently been made to regard the substance of the cell-walls of liguified tissue

\section{${ }^{1}$ Loc. cit.}

${ }^{2}$ Compare Siewert, Zeitschr. f. d. ges. Naturw., xxx. 129; Journ. f, pract. Chem. civ. 118, 1868. See also Hïhnel, Sitz.-ber der phys. math. K. d. Akad. d. W. in Wien, 1877 ; Bot. Ztg. 783.

${ }^{3}$ Compare my 'Chem. Unters. eines an Betula alba vork. Pilzes.' Diss. Petersburg, 1864.

4 Zeitsch. d. österr. A potheker-Ver. 1867, 16, 34, 60.

5 'Botanisk Mikrokemi.' Kjöbenhavn, 1880. 
as a special chemical compound (gluco-lignose, gluco-drupose of Erdmann). Erdmann assumes that it is decomposed by hydrochloric acid with production of glucose, together with lignose or drupose, and that with nitric acid it yields cellulose, whilst the lignose or d'upose undergoes further decomposition. Bente, ${ }^{1}$ who doubts the existence of gluco-drupose, shows that wood-cells (? lignin) yield pyrocatechin when fused with potash.

\$ 248. Cellulose.-The cellulose obtained from various plants in the manner indicated does not appear to be invariably of the composition $\mathrm{C}_{6} \mathrm{H}_{10} \mathrm{O}_{5}$. That isolated by Stackmann from coniferous wood was represented by the formula $5\left(\mathrm{C}_{6} \mathrm{H}_{10} \mathrm{O}_{5}\right)+\mathrm{H}_{2} \mathrm{O}$, and the cellulose that certain sclerenchymatous and bast-tissues yielded to Koroll was of similar composition. The latter chemist also prepared it from parenchymatous tissues, and then it generally possessed a composition approximately indicated by the formula $5\left(\mathrm{C}_{6} \mathrm{H}_{10} \mathrm{O}_{5}\right)+2 \mathrm{H}_{2} \mathrm{O}$, whereas the wood of most dicotyledons contains, according to Stackmam, a cellulose of the formula $5\left(\mathrm{C}_{6} \mathrm{H}_{10} \mathrm{O}_{5}\right)+3 \mathrm{H}_{2} \mathrm{O}$. In these experiments the substance was exhausted with water, alcohol, dilute soda, dilute acid, a mixture of one part of sulphuric acid with four of water, and chlorinewater, previously to being treated with nitric acid and chlorate of potassium. Schuppe has shown that the action of the sulphuric acid, the use of which I recommend to be discontinued, results in the formation of a hydro-cellulose. If the treatment with sulphuric acid was omitted, the cellulose obtained from woods corresponded in composition to the formula $\mathrm{C}_{6} \mathrm{H}_{11} \mathrm{O}_{5}$. But the cellulose isolated from apples hy a process that did not include treatment with sulphuric acid showed a deriation in composition from the formula $\mathrm{C}_{6} \mathrm{H}_{10} \mathrm{O}_{5} .{ }^{2}$

The cellulose of fungi (cf. \$ 249) frequently shows a composition corresponding almost exactly to the formula $\mathrm{C}_{6} \mathrm{H}_{10} \mathrm{O}_{5}$.

$\$ 249$. Vurieties of Cellulose. - The variations observed in celluloses isolated from different plants is partly to he ascribed to the abovementioned difference in composition, and partly probal,ly to variations in density. For instance, the cellulose of most phanerograms

1 Annal. d. Chem. und Pharm. cxxxviii, 1, 1866, and Jahresb. f. Pharm. 9, 1867. Compare also Bente, Ber. d. d. chem. Ges. xiii. 476, 1875; Journ. f. Landwirthsch. 166, 1876. Compare also Bevan and Cross on the chemistry of Bastfibre, Chem. News, xlii. 77, 91, 1880.

2 Compare the dissertations of Pfeil and Treffner already quoted. 
is dissolved by ammonio-sulphate of copler, ${ }^{1}$ and reprecipitated in an amorphous condition by dilute acils; but that of many fungi is either insoluthle or taken up to a slight extent only; and then with great difficulty. Concentrated sulphuric acid and syrupy solution of chloride of zine render cellulose capathle of assuming a hue colour with iodine; ${ }^{2}$ but in some instances the reaction is found to fail, ${ }^{3}$ and Schulze's reagent for cellulose, which is not without its value ats a micro-chemical reagent, cannot therefore in such cases be employer for colouring the cell-wall. The facility, too, with which cellulose can he converted into glucose varies. Masing ohserves that fungus-cellulose undergoes the change more easily than flax-fibre. ${ }^{4}$

5 250. Cinde Fitre. - From what has heen said of the isolation of cellulose, it follows that the crude fibre of the physiologist and agricultural chemist cannot be exactly identical with that sulbstance. To estimate the crude fibre, the material is generally boiled for half an hour, first with 1 per cent. sulphuric acid, and then with 1 per cent. canstic potash. The residue is exhausted with cold water, alcohol, and ether in succession, dried and weighed. In this crude fibre we may anticipate the presence of a little undecomposed wood-gum, lignin, and sulperin, as well as part of the hydrocelluloses mentioned in $\$ \S 117,244$.

An apparatus that may be used with advantage in this determination has been described by Holdefleiss. ${ }^{5}$

${ }^{1}$ I prepare this reagent by precipitating hydrate of copper from a solution of the sulphate by dilute caustic soda, rapidly filtering off, pressing and dissolving in the requisite quantity of 20 per cent. solution of ammonia.

2 The reagent known as Schulze's can be prepared by dissolving 25 parts of dry chloride of zinc and 8 of iodide of potassium in $8 \frac{1}{2}$ of water, and adding as much iodine as the solution will take up when warmed for a short time with it.

${ }^{3}$ On cellulose of fungi, see Masing, Pharm. Zeitschr. f. Russland, ix. 385, 1870. Richter (Chem. Centralblatt, 483, 1881) has recently denied the existence of a special fungus-cellulose as the prolonged action of caustic alkalies converts it into ordinary cellulose. But is it not probable that such treatment actually produces a chemical change?

${ }^{4}$ On cellulose see Pajen, Annal. d. Sciences naturelles, xi. 21, xiv. 88; Fromberg, Annal. d. Chem. und Pharm. lii. 113; Heldt and Rochleder, ibid. xlviii. 8; Schlossberger and Dijphing, ihid. lii. 106 ; Schlosiberger, ihid. cvii. 24, 155s; Péligot, Comptes rendus, lxiii. 209, 1861 ; Ḱnop and schnedermann, Journ. f. prakt. Chem. xxxix. 363, xl. 389 ; Henneberg, Annal. d. Chem. unk I'harm. cxlvi. 180, 1969; Köni 5 , Zeitschr. f. anal. Chem. xiii. 242, 1879 .

${ }^{5}$ Compare Holdefleiss, Zeitschr. f, Anal. Chem. xvi. 498, 1877, and Landwirthsch. Jahrb. Supp, vi. 101. 
PERCENTAGE COMPOSITION OF THE CONSTITUENTS OF PLANTS MENTIONED IN THE FOREGOING WORK.

\begin{tabular}{|c|c|c|c|c|c|c|c|c|}
\hline \multicolumn{3}{|c|}{ NAME. } & FORMULA. & C. & H. & O. & N. & S. \\
\hline Abietic acid & - & . & $\mathrm{C}_{44} \mathrm{H}_{64} \mathrm{O}_{5}$ & $78 \cdot 57$ & $9 \cdot 52$ & $11 \cdot 91$ & & \\
\hline Absinthiin & . & . & $\mathrm{C}_{40}^{48} \mathrm{H}_{58} \mathrm{O}_{9}$ & $70 \cdot 38$ & $8 \cdot 50$ & $21 \cdot 12$ & & \\
\hline Acetic acid & . & . & $\mathrm{C}_{2} \mathrm{H}_{4} \mathrm{O}_{2}$ & $40 \cdot 00$ & $6 \cdot 66$ & $53 \cdot 33$ & & \\
\hline Achilleïne & - & . & $\mathrm{C}_{20} \mathrm{H}_{38} \mathrm{~N}_{2} \mathrm{O}_{15}$ & $43 \cdot 84$ & $6 \cdot 96$ & $43 \cdot 84$ & $5 \cdot 12$ & \\
\hline Aconitine & . & . & $\mathrm{C}_{33} \mathrm{H}_{43} \mathrm{NO}_{12}$ & $61 \cdot 39$ & $6 \cdot 67$ & $29 \cdot 77$ & $2 \cdot 17$ & \\
\hline Aconitic acid & . & . & $\mathrm{C}_{6} \mathrm{H}_{6} \mathrm{O}_{6}$ & $41 \cdot 38$ & $3 \cdot 45$ & $55 \cdot 17$ & & \\
\hline Adansonin & - & - & $\mathrm{C}_{48} \mathrm{H}_{72} \mathrm{O}_{33}$ & $48 \cdot 30$ & $5 \cdot 95$ & $45 \cdot 75$ & & \\
\hline $\begin{array}{l}\text { Aesculin } \\
\text { Albumin }\end{array}$ & ; & : & $\mathrm{C}_{21} \mathrm{H}_{24} \mathrm{O}_{13}$ & $\begin{array}{l}52 \cdot 07 \\
52 \cdot 45\end{array}$ & $\begin{array}{l}4 \cdot 96 \\
6 \cdot 81\end{array}$ & $\begin{array}{l}42 \cdot 97 \\
22 \cdot 21-\end{array}$ & $15 \cdot 65$ & 0.8 \\
\hline Albumin & & & $?$ & $\begin{array}{l}52 \cdot 42^{-} \\
53 \cdot 97\end{array}$ & $\begin{array}{l}0.71- \\
7.77\end{array}$ & $23 \cdot 50$ & $15 \cdot 92$ & \\
\hline Alizarin & - & - & $\mathrm{C}_{14} \mathrm{H}_{8} \mathrm{O}_{3}$ & $75 \cdot 00$ & $3 \cdot 57$ & $21 \cdot 44$ & & \\
\hline Alkannin & - & - & $\mathrm{C}_{15} \mathrm{H}_{14} \mathrm{O}_{4}$ & $69 \cdot 72$ & $5 \cdot 42$ & $24 \cdot 86$ & & \\
\hline Amanitine & . & - & $\mathrm{C}_{5} \mathrm{H}_{14} \mathrm{NO}$ & $57 \cdot 69$ & $13 \cdot 46$ & $15 \cdot 38$ & $13 \cdot 46$ & \\
\hline Amygdalin & - & - & $\mathrm{C}_{20} \mathrm{H}_{27} \mathrm{NO}_{11}$ & $52 \cdot 51$ & $5 \cdot 91$ & $38 \cdot 52$ & $3 \cdot 06$ & \\
\hline Amyrin & & - & $\mathrm{C}_{25} \overrightarrow{\mathrm{H}}_{42} \mathrm{O}$ & $83 \cdot 49$ & $11 \cdot 79$ & $4 \cdot 73$ & & \\
\hline Anacardic aci & & . & $\mathrm{C}_{44} \mathrm{H}_{64} \mathrm{O}_{7}$ & $75 \cdot 04$ & $9 \cdot 07$ & $15 \cdot 89$ & & \\
\hline Anemonin & - & - & $\mathrm{C}_{15} \mathrm{H}_{12} \mathrm{O}_{6}(?)$ & $62 \cdot 50$ & $4 \cdot 17$ & $33 \cdot 33$ & & \\
\hline Anethol & - & - & $\mathrm{C}_{10} \mathrm{H}_{12} \mathrm{O}$ & $81 \cdot 08$ & $8 \cdot 11$ & $10 \cdot 81$ & & \\
\hline Angelic acid & . & - & $\mathrm{C}_{5} \mathrm{H}_{5} \mathrm{O}_{2}$ & $60 \cdot 00$ & $8 \cdot 00$ & $32 \cdot 00$ & & \\
\hline Antiarin & . & . & $\mathrm{C}_{14} \mathrm{H}_{20} \mathrm{O}_{5}$ & $62 \cdot 68$ & $7 \cdot 46$ & $29 \cdot 85$ & & \\
\hline Apiin & - & - & $\mathrm{C}_{27} \mathrm{H}_{32} \mathrm{O}_{16}$ & $52 \cdot 9$ & $5 \cdot 2$ & $41 \cdot 9$ & & \\
\hline Arabic acid & - & - & $\mathrm{C}_{12} \mathrm{H}_{22} \mathrm{O}_{11}$ & $42 \cdot 10$ & $6 \cdot 43$ & $51 \cdot 47$ & & \\
\hline Arachic acid & - & - & $\mathrm{C}_{20} \mathrm{H}_{40} \mathrm{O}_{2}$ & $76 \cdot 92$ & $12 \cdot 82$ & $10 \cdot 26$ & & \\
\hline Arbutin & - & - & $\mathrm{C}_{25} \mathrm{H}_{34} \mathrm{O}_{14}$ & $53 \cdot 7$ & $6 \cdot 1$ & $40 \cdot 2$ & & \\
\hline $\begin{array}{l}\text { Aribine } \\
\text { Aricine }\end{array}$ & : & : & $\begin{array}{c}\mathrm{C}_{23} \mathrm{H}_{20} \mathrm{~N}_{4} \\
\mathrm{C}_{23} \mathrm{H}_{26} \mathrm{~N}_{2} \mathrm{O}_{4}\end{array}$ & $\begin{array}{l}78.43 \\
70.05\end{array}$ & $\begin{array}{l}5 \cdot 68 \\
6 \cdot 59\end{array}$ & $16 \cdot 25$ & $\begin{array}{r}15 \cdot 89 \\
7 \cdot 11\end{array}$ & \\
\hline $\begin{array}{l}\text { Aricine } \\
\text { Asclepin }\end{array}$ & 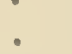 & . & $\begin{array}{c}\mathrm{C}_{23} \mathrm{H}_{26} \mathrm{~N}_{2} \mathrm{U}_{4} \\
\mathrm{C}_{20} \mathrm{H}_{34} \mathrm{O}_{3}\end{array}$ & $74 \cdot 54$ & $\begin{array}{r}6.59 \\
10.56\end{array}$ & $14 \cdot 90$ & & \\
\hline Asparagin & & . & $\mathrm{C}_{4} \mathrm{H}_{8} \mathrm{~N}_{2} \mathrm{O}_{3}$ & $36 \cdot 36$ & 6.06 & $36 \cdot 37$ & $21 \cdot 21$ & \\
\hline Aspidospermi & ine & . & $\mathrm{C}_{22} \mathrm{H}_{30} \mathrm{~N}_{2} \mathrm{O}_{2}$ & 74.57 & $8 \cdot 48$ & $9 \cdot 04$ & $7 \cdot 91$ & \\
\hline Athamantin & & - & $\mathrm{C}_{24} \mathrm{H}_{30} \mathrm{U}_{7}$ & $66 \cdot 98$ & $6 \cdot 98$ & $26 \cdot 04$ & & \\
\hline Atherospermi & ine & - & $\mathrm{C}_{30} \mathrm{H}_{40} \mathrm{~N}_{2} \mathrm{O}_{5}$ & $70 \cdot 87$ & $7 \cdot 87$ & $15 \cdot 75$ & $5 \cdot 51$ & \\
\hline Atropine & . & . & $\mathrm{C}_{17} \mathrm{H}_{2,3} \mathrm{NO}_{3}$ & $70 \cdot 58$ & $7 \cdot 95$ & $16 \cdot 60$ & $4 \cdot 84$ & \\
\hline Barbaloïn & . & . & $\mathrm{C}_{17} \mathrm{H}_{20} \mathrm{O}_{7}$ (?) & 60.71 & $5 \cdot 95$ & $33 \cdot 34$ & & \\
\hline Bassorin & - & . & $\mathrm{C}_{12} \mathrm{H}_{22} \mathrm{O}_{11}$ & $42 \cdot 10$ & $6 \cdot 43$ & $51 \cdot 47$ & & \\
\hline Beberine & . & . & $\mathrm{C}_{19} \mathrm{H}_{21} \mathrm{NO}_{3}$ & $73 \cdot 31$ & $6 \cdot 75$ & $15 \cdot 44$ & $4 \cdot 50$ & \\
\hline Benzaldehyde & & . & $\mathrm{C}_{7} \mathrm{H}_{6} \mathrm{O}$ & $79 \cdot 24$ & $5 \cdot 65$ & $15 \cdot 11$ & & \\
\hline Benzoic acid & . & - & $\mathrm{C}_{7} \mathrm{H}_{6} \mathrm{O}_{2}$ & $68 \cdot 85$ & $4 \cdot 92$ & $26 \cdot 23$ & & \\
\hline Benzohelicin & . & - & $\mathrm{C}_{20} \mathrm{H}_{20} \mathrm{O}_{8}$ & $61 \cdot 86$ & $5 \cdot 15$ & $32 \cdot 99$ & & \\
\hline Berberine & . & . & $\mathrm{C}_{20} \mathrm{H}_{17} \mathrm{NO}_{4}$ & $71 \cdot 64$ & $5 \cdot 08$ & $19 \cdot 10$ & $4 \cdot 18$ & \\
\hline Betaine. & . & . & $\mathrm{C}_{5} \mathrm{H}_{13} \mathrm{NO}_{3}$ & $44 \cdot 44$ & $9 \cdot 63$ & $35 \cdot 55$ & $10 \cdot 37$ & \\
\hline Betaorcin & . & . & $\mathrm{C}_{8} \mathrm{H}_{10} \mathrm{O}_{2}$ & $69 \cdot 56$ & $7 \cdot 24$ & $23 \cdot 20$ & & \\
\hline Betulin . & . & . & $\mathrm{C}_{36} \mathrm{H}_{60} \mathrm{O}_{2}$ & 82.57 & $11 \cdot 36$ & $6 \cdot 06$ & & \\
\hline Bixine . & . & . & $\mathrm{C}_{28} \mathrm{H}_{34} \mathrm{O}_{5}$ & $74 \cdot 66$ & $7 \cdot 55$ & $17 \cdot 78$ & & \\
\hline Boheic acid & . & . & $\mathrm{C}_{7} \mathrm{H}_{10} \mathrm{O}_{6}$ & $44 \cdot 21$ & $5 \cdot 26$ & $50 \cdot 53$ & & \\
\hline Borneol & 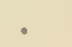 & . & $\mathrm{C}_{10} \mathrm{H}_{18} \mathrm{O}$ & $77 \cdot 92$ & $11 \cdot 69$ & $10 \cdot 39$ & & \\
\hline Brasillin & . & . & $\mathrm{C}_{16} \mathrm{H}_{14} \mathrm{O}_{5}$ & $6 \gamma^{\circ} \cdot 11$ & $5 \cdot 43$ & $27 \cdot 46$ & & \\
\hline Brucine & . & . & $\mathrm{C}_{23} \mathrm{H}_{26} \mathrm{~N}_{2} \mathrm{O}_{4}$ & 70.00 & $6 \cdot 64$ & $16 \cdot 26$ & $7 \cdot 10$ & \\
\hline Bryonin & - & - & $\mathrm{C}_{48} \mathrm{H}_{80} \mathrm{O}_{19}$ & $60 \cdot 00$ & $8 \cdot 33$ & $31 \cdot 66$ & & \\
\hline Bryoïdin & & - & $\mathrm{C}_{20} \mathrm{H}_{39} \mathrm{O}_{3}$ & $73 \cdot 62$ & $11 \cdot 66$ & $14 \cdot 72$ & & \\
\hline
\end{tabular}




\begin{tabular}{|c|c|c|c|c|c|c|c|c|}
\hline \multicolumn{3}{|c|}{ NAME. } & Formula. & C. & H. & O. & N. & S. \\
\hline Butyl alcohol & & $0^{\circ}$ & $\mathrm{C}_{4} \mathrm{H}_{10} \mathrm{O}$ & $64 \cdot 80$ & $13 \cdot 51$ & $21 \cdot 62$ & & \\
\hline Butyric acid & & $\bullet^{\circ}$ & $\mathrm{C}_{4} \mathrm{H}_{8} \mathrm{O}_{2}$ & $54 \cdot 55$ & $9 \cdot 09$ & $36 \cdot 36$ & & \\
\hline Caffeine & - & - & $\mathrm{C}_{8} \mathrm{H}_{10} \mathrm{~N}_{4} \mathrm{O}_{2}$ & $49 \cdot 48$ & $5 \cdot 15$ & $16.5 i$ & $28 \cdot 86$ & \\
\hline Caffeo-tannic & acid & . & $\mathrm{C}_{1 \downarrow} \mathrm{H}_{16} \mathrm{O}_{7}$ & $56 \cdot 75$ & $5 \cdot 41$ & $37 \cdot 84$ & & \\
\hline Caïlcedrin & - & . & & $64 \cdot 9$ & $7 \cdot 6$ & $27 \cdot 5$ & & \\
\hline Caïncin & . & - & ? & $58 \cdot 24$ & $7 \cdot 38$ & $34 \cdot 38$ & & \\
\hline \multicolumn{2}{|c|}{ Callutannic acid } & - & $\mathrm{C}_{14} \mathrm{H}_{14} \mathrm{O}_{9}(?)$ & $51 \cdot 53$ & $4 \cdot 30$ & $44 \cdot 17$ & & \\
\hline Camphor & - & - & $\mathrm{C}_{10} \mathrm{H}_{16} \mathrm{O}$ & $78 \cdot 94$ & $10 \cdot 53$ & $10 \cdot 53$ & & \\
\hline Cane-sugar & - & . & $\mathrm{C}_{12} \mathrm{H}_{22} \mathrm{O}_{11}$ & $42 \cdot 10$ & $6 \cdot 43$ & $51 \cdot 47$ & & \\
\hline Caoutchouc & - & . & $\mathrm{C}_{10} \mathrm{H}_{16}$ & $88 \cdot 24$ & $11 \cdot 76$ & & & \\
\hline Capaloïn & - & . & $\mathrm{C}_{16} \mathrm{H}_{20} \mathrm{O}_{7}$ (?) & $59 \cdot 26$ & $6 \cdot 17$ & $34 \cdot 57$ & & \\
\hline Capric acid & & - & $\mathrm{C}_{10} \mathrm{H}_{20} \mathrm{O}_{2}$ & $69 \cdot 76$ & $11 \cdot 62$ & $18 \cdot 61$ & & \\
\hline \multicolumn{2}{|c|}{ Capric aldehyde } & . & $\mathrm{C}_{10} \mathrm{H}_{20} \mathrm{O}$ & $76 \cdot 92$ & $12 \cdot 82$ & $10 \cdot 26$ & & \\
\hline \multicolumn{2}{|c|}{$\begin{array}{l}\text { Caproic acid } \\
\text { Capryl alcohoi }\end{array}$} & . & $\mathrm{C}_{6} \mathrm{H}_{12} \mathrm{O}_{2}$ & $62 \cdot 07$ & $10 \cdot 35$ & $27 \cdot 58$ & & \\
\hline \multicolumn{2}{|c|}{ Capryl alcohol } & - & $\mathrm{C}_{8} \mathrm{H}_{18} \mathrm{O}$ & $73 \cdot 84$ & $13 \cdot 84$ & $12 \cdot 32$ & & \\
\hline \multicolumn{2}{|c|}{ Caprylic acid. } & . & $\mathrm{C}_{9}^{\circ} \mathrm{H}_{16}^{10} \mathrm{O}_{2}$ & $66 \cdot 67$ & $11 \cdot 11$ & $22 \cdot 22$ & & \\
\hline \multirow{2}{*}{$\begin{array}{l}\text { Capsaïcin } \\
\text { Cardol. }\end{array}$} & - & - & $\mathrm{C}_{9} \mathrm{H}_{14} \mathrm{O}_{2}$ & $70 \cdot 00$ & $9 \cdot 29$ & $20 \cdot 71$ & & \\
\hline & - & s & $\mathrm{C}_{21} \mathrm{H}_{30} \mathrm{O}_{2}(?)$ & $80 \cdot 25$ & $9 \cdot 55$ & $10 \cdot 20$ & & \\
\hline Carotin & - & $0^{\circ}+2-2$ & $\mathrm{C}_{18} \mathrm{H}_{24} \mathrm{O}$ & $84 \cdot 37$ & $9 \cdot 37$ & $6 \cdot 26$ & & \\
\hline \multirow{2}{*}{$\begin{array}{l}\text { Carthamin } \\
\text { Carvol. }\end{array}$} & - & . & $\mathrm{C}_{14} \mathrm{H}_{16} \mathrm{O}_{7}$ & $56 \cdot 75$ & $5 \cdot 40$ & $37 \cdot 85$ & & \\
\hline & • & . & $\mathrm{C}_{10} \mathrm{H}_{14}^{20} \mathrm{O}$ & $80 \cdot 00$ & $9 \cdot 33$ & $10 \cdot 77$ & & \\
\hline \multicolumn{2}{|l|}{ Caryophyllin } & • & $\mathrm{C}_{10} \mathrm{H}_{16} \mathrm{O}$ & $78 \cdot 94$ & 10.53 & 10.53 & & \\
\hline \multicolumn{2}{|l|}{ Catechin } & & $\mathrm{C}_{19} \mathrm{H}_{18} \mathrm{O}_{8}$ & $60 \cdot 96$ & $4: 81$ & $34 \cdot 23$ & & \\
\hline \multicolumn{3}{|c|}{ Catechu-tannic acid } & $\mathrm{C}_{38} \mathrm{H}_{34}^{20} \mathrm{O}_{15}^{\circ}$ & $62 \cdot 46$ & $4 \cdot 66$ & $32 \cdot 88$ & & \\
\hline \multicolumn{2}{|c|}{ Cathartomannite } & • & $\mathrm{C}_{6} \mathrm{H}_{14} \mathrm{O}_{6}$ & $39 \cdot 56$ & $7 \cdot 69$ & $52 \cdot 75$ & & \\
\hline \multicolumn{2}{|c|}{ Cathartic acid } & - & ? & $57 \cdot 57$ & $5 \cdot 12$ & $34 \cdot 96$ & $1 \cdot 50$ & 0.85 \\
\hline \multirow{2}{*}{\multicolumn{2}{|c|}{$\begin{array}{l}\text { Cellulose } \\
\text { Ceric acid }\end{array}$}} & - & $\mathrm{C}_{6} \mathrm{H}_{10} \mathrm{O}_{5}$ & $44 \cdot 44$ & $6 \cdot 17$ & $49 \cdot 39$ & & \\
\hline & & . & $?$ & $64 \cdot 23$ & $8 \cdot 77$ & $27 \cdot 00$ & & \\
\hline Cerotic acid & & - & $\mathrm{C}_{27} \mathrm{H}_{54} \mathrm{O}_{2}$ & $79 \cdot 02$ & $13 \cdot 17$ & $7 \cdot 81$ & & \\
\hline Cerotyl alcoh & & . & $\mathrm{C}_{27} \mathrm{H}_{56} \mathrm{O}$ & $81 \cdot 81$ & $14 \cdot 14$ & 4.05 & & \\
\hline Cetraric acid & & . & $\mathrm{C}_{18} \mathrm{H}_{16} \mathrm{O}_{8}$ & $60 \cdot 00$ & $4 \cdot 44$ & $35 \cdot 56$ & & \\
\hline Cetyl alcohol & & - & $\mathrm{C}_{16} \mathrm{H}_{34} \mathrm{O}^{\circ}$ & $78 \cdot 68$ & $13 \cdot 95$ & $7 \cdot 37$ & & \\
\hline Chelidonine & & - & $\mathrm{C}_{19} \mathrm{H}_{17} \mathrm{~N}_{3} \mathrm{O}_{3}$ & $68 \cdot 06$ & $5 \cdot 08$ & $14 \cdot 32$ & $12 \cdot 54$ & \\
\hline Chelidonic ac & & - & $\mathrm{C}_{7} \mathrm{H}_{4} \mathrm{O}_{6}$ & $45 \cdot 65$ & $2 \cdot 17$ & $52 \cdot 24$ & & \\
\hline Chlorogenine & i & & $\mathrm{C}_{21} \mathrm{H}_{20} \mathrm{NO}_{4}, \mathrm{H}_{2} \mathrm{O}$ & $65 \cdot 97$ & $5 \cdot 75$ & $20 \cdot 95$ & $7 \cdot 33$ & \\
\hline & 1 & 37 P) & C $\stackrel{?}{H} \Omega$ & $73 \cdot 4$ & $9 \cdot 7$ & $9 \cdot 57$ & $5 \cdot 62$ & \\
\hline $\begin{array}{l}\text { Cholesterin } \\
\text { Cholin }\end{array}$ & - & : & $\begin{array}{c}\mathrm{C}_{30} \mathrm{H}_{52} \mathrm{O} \\
\mathrm{C}_{5} \mathrm{H}_{15} \mathrm{NO}_{2}\end{array}$ & $84 \cdot 11$ & $12 \cdot 15$ & $3 \cdot 74$ & & \\
\hline Chrysarobin & & & $\mathrm{C}_{5} \mathrm{H}_{15} \mathrm{NO}_{2}$ & $\begin{array}{l}49 \cdot 59 \\
72 \cdot 31\end{array}$ & $\begin{array}{r}12 \cdot 39 \\
5 \cdot 08\end{array}$ & $26 \cdot 44$ & $11 \cdot 57$ & \\
\hline Chrysorhamn & & & $\mathrm{C}_{23}^{30} \mathrm{H}_{20} \mathrm{O}_{17}$ & $\begin{array}{l}1231 \\
58 \cdot 23\end{array}$ & $4 \cdot 64$ & $\begin{array}{l}22 \cdot 48 \\
37 \cdot 13\end{array}$ & & \\
\hline Chrysophanic & acic & & $\mathrm{C}_{15} \mathrm{H}_{10} \mathrm{O}_{4}$ & 70.87 & $3 \cdot 94$ & $25 \cdot 19$ & & \\
\hline Chrysopicrin & & & $\mathrm{C}_{10} \mathrm{H}_{14} \mathrm{O}_{5}$ (?) & $70 \cdot 81$ & $4 \cdot 35$ & $24 \cdot 84$ & & \\
\hline Cinchonine, & Jinc & iidine & $\mathrm{C}_{19} \mathrm{H}_{22} \mathrm{~N}_{2} \mathrm{O}$ & $77 \cdot 55$ & $7 \cdot 48$ & $5 \cdot 44$ & $9 \cdot 53$ & \\
\hline Cinchona red & & & $\mathrm{C}_{12} \mathrm{H}_{14} \mathrm{O}_{7}(?)$ & $53 \cdot 33$ & $5 \cdot 19$ & $41 \cdot 48$ & & \\
\hline Cinchona-tan & nic : & icid & $\mathrm{C}_{42} \mathrm{H}_{60} \mathrm{O}_{35}(?)$ & $44 \cdot 84$ & $5 \cdot 33$ & $49 \cdot 83$ & & \\
\hline Cinchona-no & a re & d. & $\mathrm{C}_{12} \mathrm{H}_{12} \mathrm{O}_{5}$ & $61 \cdot 01$ & $5 \cdot 15$ & $33 \cdot 61$ & & \\
\hline Cinnameïn & ai $2+20$ & & $\mathrm{C}_{28} \mathrm{H}_{38} \mathrm{O}_{17}$ & $52 \cdot 01$ & $5 \cdot 88$ & $42 \cdot 11$ & & \\
\hline Cinnamic aci & & & $\mathrm{C}_{16} \mathrm{H}_{14} \mathrm{O}_{2}$ & 80667 & $5 \cdot 88$ & $13 \cdot 45$ & & \\
\hline Cinnamic ald & ehyd & & $\begin{array}{l}\mathrm{C}_{9} \mathrm{H}_{8} \mathrm{O}_{2} \\
\mathrm{C}_{0} \mathrm{H}_{8} \mathrm{O}\end{array}$ & $\begin{array}{l}72.97 \\
81.01\end{array}$ & $5 \cdot 41$ & $21 \cdot 62$ & & \\
\hline Citric acid & - & . & $\mathrm{C}_{6} \mathrm{H}_{8} \mathrm{O}_{7}$ & $37 \cdot 50$ & $4 \cdot 17$ & $\begin{array}{l}1210 \\
58 \cdot 33\end{array}$ & & \\
\hline Cnicin . & • & ( & $\mathrm{C}_{42} \mathrm{H}_{56} \mathrm{O}_{15}$ & $63 \cdot 00$ & $7 \cdot 00$ & 30.00 & & \\
\hline Cocaïne & . & . & $\mathrm{C}_{16} \mathrm{H}_{19} \mathrm{NO}_{8}$ & $66 \cdot 11$ & 6.57 & $22 \cdot 15$ & $4 \cdot 84$ & \\
\hline Codeine & • & . & $\mathrm{C}_{18} \mathrm{H}_{21} \mathrm{NO}_{3}$ & $72 \cdot 24$ & $7 \cdot 02$ & $16 \cdot 06$ & $4 \cdot 68$ & \\
\hline Colchiceïne & - & 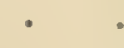 & $\mathrm{C}_{17} \mathrm{H}_{21} \mathrm{NO}_{5}$ & $63 \cdot 44$ & $6 \cdot 58$ & $25 \cdot 20$ & $4 \cdot 38$ & \\
\hline Colchicine & - & - & $\mathrm{C}_{17} \mathrm{H}_{23} \mathrm{NO}_{6}$ & 60.53 & $6 \cdot 82$ & $28 \cdot 50$ & $4 \cdot 15$ & \\
\hline Colocynthin & - & . & $\mathrm{C}_{56} \mathrm{H}_{84} \mathrm{O}_{23}$ (?) & $59 \cdot 78$ & $7 \cdot 47$ & $32 \cdot 75$ & & \\
\hline Columbin & & & $\mathrm{C}_{21} \mathrm{H}_{22} \mathrm{O}_{7}$ & $65 \cdot 28$ & $5 \cdot 69$ & 29.03 & & \\
\hline
\end{tabular}




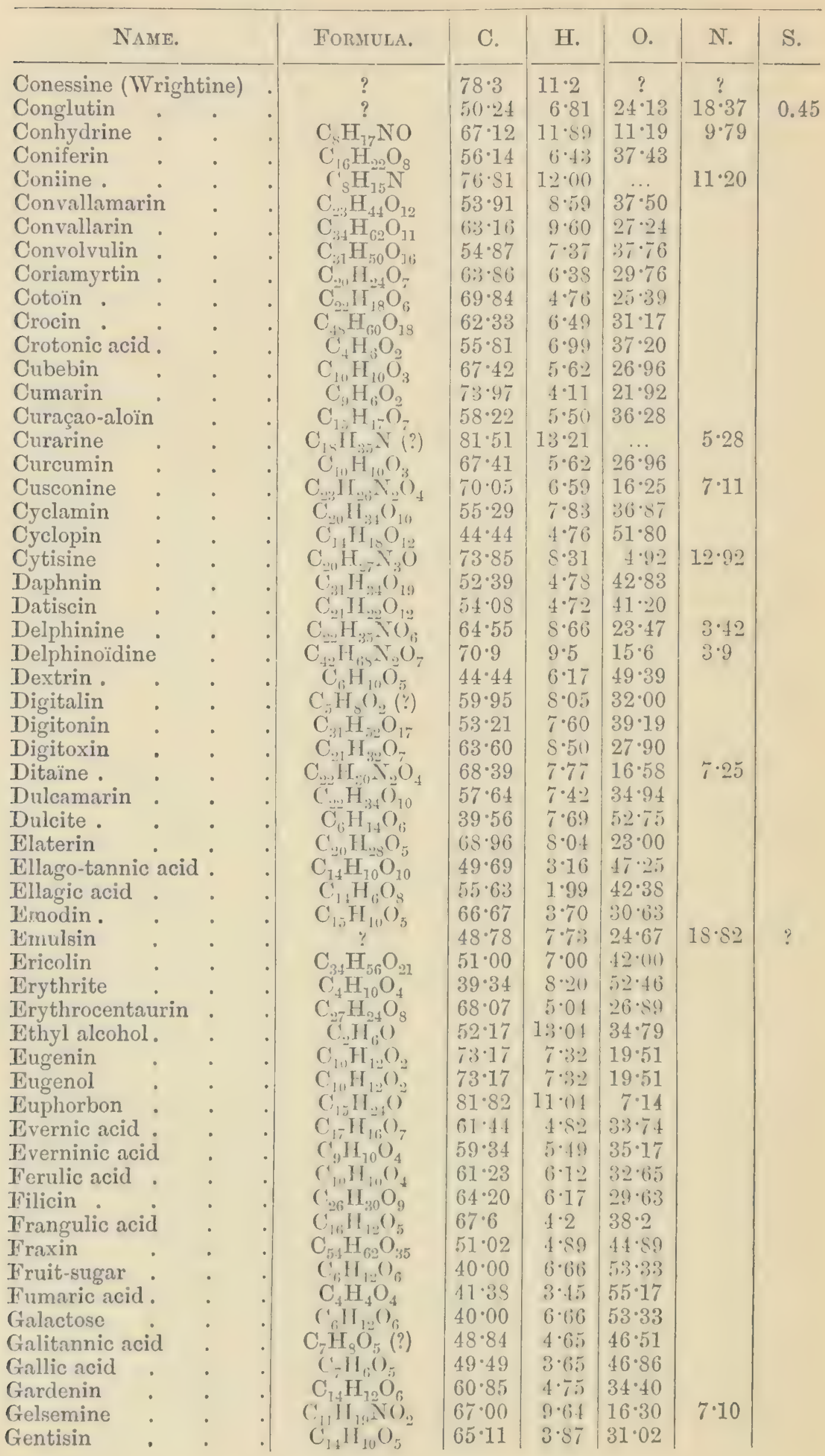




\begin{tabular}{|c|c|c|c|c|c|c|c|c|}
\hline \multicolumn{3}{|c|}{ NaMe. } & \multirow{3}{*}{ Forriura. } & \multirow{2}{*}{$\frac{\text { C. }}{52 \cdot 60}$} & H. & O. & \multirow{2}{*}{$\frac{N .}{18.06}$} & \multirow{2}{*}{$-\frac{S .}{0.85}$} \\
\hline Gliadin & - & . & & & $7 \cdot 00$ & $21 \cdot 49$ & & \\
\hline Globularin & - & - & & $\begin{array}{l}57 \cdot 32 \\
57 \cdot 0\end{array}$ & $7 \cdot 01$ & $35 \cdot 67$ & & \\
\hline $\begin{array}{l}\text { Glutencaseïn } \\
\text { Glycerin }\end{array}$ & - & - & $\mathrm{CH} O$ & $\begin{array}{l}51 \cdot 0 \\
30 \cdot 13\end{array}$ & 6.7 & $25 \cdot 4$ & $16 \cdot 1$ & 0.8 \\
\hline $\begin{array}{l}\text { Glycerin } \\
\text { Glycolic acid }\end{array}$ & $\dot{.}$ & : & $\begin{array}{l}\mathrm{C}_{3} \mathrm{H}_{8} \mathrm{H}_{4} \mathrm{O}_{3} \\
\mathrm{C}_{2} \mathrm{C}\end{array}$ & $\begin{array}{l}39 \cdot 13 \\
31.58\end{array}$ & $\begin{array}{l}8 \cdot 70 \\
5 \cdot 26\end{array}$ & $\begin{array}{l}52 \cdot 17 \\
63 \cdot 16\end{array}$ & & \\
\hline Glycyrrhizic a & acid & . & $\mathrm{C}_{44} \widetilde{H}_{63} \mathrm{NO}_{18}$ & $59 \cdot 12$ & $7 \cdot 05$ & $32 \cdot 66$ & $1 \cdot 17$ & \\
\hline Grape-sugar & . & - & $\mathrm{C}_{6} \mathrm{H}_{12} \mathrm{O}_{6}$ & $40 \cdot 00$ & $6 \cdot 66$ & $53 \cdot 34$ & & \\
\hline Gratiolin & - & - & $\mathrm{C}_{20} \mathrm{H}_{34} \mathrm{O}_{7}$ & $62 \cdot 17$ & $8 \cdot 81$ & $29 \cdot 02$ & & \\
\hline Grönhartin & & - & $\mathrm{C}_{30} \mathrm{H}_{26} \mathrm{O}_{6}(?)$ & $74 \cdot 6$ & $5 \cdot 3$ & $21 \cdot 1$ & & \\
\hline $\begin{array}{l}\text { Gyrophoric ac } \\
\text { Hæmatoxylin }\end{array}$ & cid & - & $\mathrm{C}_{36} \mathrm{H}_{36} \mathrm{O}_{15}$ & $\begin{array}{l}60.81 \\
63.57\end{array}$ & $\begin{array}{l}4 \cdot 90 \\
4 \cdot 62\end{array}$ & $\begin{array}{l}34 \cdot 29 \\
31 \cdot 70\end{array}$ & & \\
\hline & . & : & $\begin{array}{c}\mathrm{C}_{16} \mathrm{H}_{14} \mathrm{O}_{6} \\
\mathrm{C}_{13} \mathrm{H}_{14} \mathrm{~N}_{2} \mathrm{O}\end{array}$ & $\begin{array}{l}63.58 \\
72.90\end{array}$ & $\begin{array}{l}4 \cdot 63 \\
6.54\end{array}$ & $\begin{array}{r}31 \cdot 79 \\
7 \cdot 48\end{array}$ & $13 \cdot 08$ & \\
\hline Harmine & - & . & $\mathrm{C}_{13} \mathrm{H}_{12}^{14} \mathrm{~N}_{2} \mathrm{O}$ & $73 \cdot 58$ & $5 \cdot 67$ & $7 \cdot 54$ & $13 \cdot 21$ & \\
\hline Hederic acid & . & - & $\mathrm{C}_{15} \mathrm{H}_{26} \mathrm{O}_{4}$ & $66 \cdot 60$ & $9 \cdot 63$ & $23 \cdot 71$ & & \\
\hline Helenin & - & - & $\mathrm{C}_{21} \mathrm{H}_{28} \mathrm{O}_{3}$ & $76 \cdot 83$ & $8 \cdot 53$ & $14 \cdot 6 \pm$ & & \\
\hline Helleborein & - & - & $\mathrm{C}_{26} \mathrm{H}_{14} \mathrm{O}_{15}$ & $52 \cdot 35$ & $7 \cdot 38$ & $40 \cdot 27$ & & \\
\hline Helleborin & & - & $\mathrm{C}_{36} \mathrm{H}_{42} \mathrm{O}_{6}$ & $75 \cdot 78$ & $7 \cdot 37$ & $16 \cdot 85$ & & \\
\hline Heptyl-alcoho & & - & $\mathrm{C}_{7} \mathrm{H}_{16} \mathrm{O}$ & 72.41 & 13.79 & $13 \cdot 79$ & & \\
\hline Hesperidin & & - & $\mathrm{C}_{22} \mathrm{H}_{26} \mathrm{O}_{12}$ & $54 \cdot 77$ & $5 \cdot 39$ & $39 \cdot 84$ & & \\
\hline Hydrocarotin & . & & $\mathrm{C}_{18} \mathrm{H}_{30} \mathrm{O}$ & $82 \cdot 44$ & 11.41 & $6 \cdot 15$ & & \\
\hline $\begin{array}{l}\text { Hydrocyanic } \\
\text { Hydroquinon }\end{array}$ & $e^{\text {acid }}$ & $\cdot$ & CNH & $44 \cdot 44$ & $3 \cdot 70$ & 51.85 & & \\
\hline & & $\dot{0}$ & $\begin{array}{c}\mathrm{C}_{6} \mathrm{H}_{6} \mathrm{O}_{2} \\
\mathrm{C}_{17} \mathrm{H}_{33} \mathrm{NO}_{3}\end{array}$ & $\begin{array}{l}65 \cdot 45 \\
70 \cdot 58\end{array}$ & $5 \cdot 16$ & $\begin{array}{l}29 \cdot 09 \\
16 \cdot 16\end{array}$ & & \\
\hline $\begin{array}{l}\text { Hyoscine } \\
\text { Hyoscyamine }\end{array}$ & & . & $\begin{array}{l}\mathrm{C}_{17} \mathrm{H}_{23} \mathrm{NO}_{33} \\
\mathrm{C}_{17} \mathrm{H}_{23} \mathrm{NO}_{3}\end{array}$ & $\begin{array}{l}70.58 \\
70.58\end{array}$ & $\begin{array}{l}7 \cdot 95 \\
7 \cdot 05\end{array}$ & $\begin{array}{l}16 \cdot 16 \\
16 \cdot 16\end{array}$ & $\begin{array}{l}484 \\
4 \cdot 84\end{array}$ & \\
\hline Indican & . & - & $\mathrm{C}_{52} \mathrm{H}_{62} \mathrm{~N}_{2} \mathrm{O}_{34}$ (?) & $\begin{array}{l}0.58 \\
49 \cdot 60\end{array}$ & $\begin{array}{l}7 \cdot 95 \\
4 \cdot 92\end{array}$ & $\begin{array}{l}16 \cdot 16 \\
43 \cdot 26\end{array}$ & $\begin{array}{l}404 \\
2 \cdot 22\end{array}$ & \\
\hline Indigo-blue & - & - & $\mathrm{C}_{8} \mathrm{H}_{5} \mathrm{NO}$ & $73 \cdot 28$ & 3.82 & $12 \cdot 22$ & $10 \cdot 68$ & \\
\hline Inosite . & & - & $\mathrm{C}_{6} \mathrm{H}_{12} \mathrm{O}_{6}$ & $40 \cdot 00$ & $6 \cdot 66$ & $53 \cdot 31$ & & \\
\hline Inulin . & ton. & & $\mathrm{C}_{6} \mathrm{H}_{10} \mathrm{O}_{5}$ & $44 \cdot 44$ & $6 \cdot 17$ & $49 \cdot 39$ & & \\
\hline Ipecacuanha & $\tan$ & c acid. & $\mathrm{C}_{14} \mathrm{H}_{18} \mathrm{O}_{7}(?)$ & $56 \cdot 37$ & $6 \cdot 04$ & $37 \cdot 59$ & & \\
\hline Isodulcite & - & - & $\mathrm{C}_{6} \mathrm{H}_{14} \mathrm{O}_{6}$ & 39.56 & $7 \cdot 69$ & $52 \cdot 75$ & & \\
\hline Jalapin . & : & : & $\mathrm{C}_{34} \mathrm{H}_{56} \mathrm{O}_{16}$ & $56 \cdot 66$ & $7 \cdot 77$ & 35.57 & & \\
\hline $\begin{array}{l}\text { Jervine } \\
\text { Kämpferid }\end{array}$ & • & : & $\begin{array}{c}\mathrm{C}_{27} \mathrm{H}_{47} \mathrm{~N}_{2} \mathrm{O}_{8} \\
?\end{array}$ & $\begin{array}{l}61 \cdot 03 \\
64 \cdot 48\end{array}$ & $\begin{array}{l}8 \cdot 56 \\
4 \cdot 40\end{array}$ & $\begin{array}{l}25 \cdot 27 \\
31 \cdot 20\end{array}$ & $5 \cdot 14$ & \\
\hline Kinic acid & 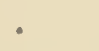 & . & $\mathrm{C}_{7} \mathrm{H}_{12} \mathrm{O}_{6}$ & $43 \cdot 75$ & $6 \cdot 30$ & $50 \cdot 19$ & & \\
\hline Kosin & - & - & $\mathrm{C}_{31} \mathrm{H}_{38} \mathrm{O}_{10}$ & $65 \cdot 26$ & $6 \cdot 66$ & $28 \cdot 07$ & & \\
\hline Lactic acid & - & - & $\mathrm{C}_{3} \mathrm{H}_{6} \mathrm{O}_{3}$ & 40.00 & $6 \cdot 66$ & $53 \cdot 34$ & & \\
\hline Lactucerin & . & . & $\mathrm{C}_{30} \mathrm{H}_{48} \mathrm{O}_{2}$ & $81 \cdot 81$ & $11 \cdot 04$ & $7 \cdot 14$ & & \\
\hline Laserpitin & & . & $\mathrm{C}_{24} \mathrm{H}_{36} \mathrm{O}_{7}$ & $66 \cdot 05$ & $8 \cdot 26$ & $25 \cdot 69$ & & \\
\hline Laurocerasin & & 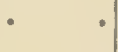 & $\mathrm{C}_{40} \mathrm{H}_{53} \mathrm{NO}_{23}$ & $52 \cdot 47$ & $5 \cdot 79$ & $40 \cdot 23$ & $1 \cdot 53$ & \\
\hline Laurostearic & acid & - & $\mathrm{C}_{12} \mathrm{H}_{24} \mathrm{O}_{2}$ & $72 \cdot 09$ & $12 \cdot 04$ & $15 \cdot 87$ & & \\
\hline $\begin{array}{l}\text { Lecanoric aci } \\
\text { Legumin }\end{array}$ & d & 1 & $\mathrm{C}_{16} \mathrm{H}_{?} \mathrm{H}_{4} \mathrm{O}_{7}$ & 60 & $4 \cdot 40$ & $35 \cdot 23$ & & \\
\hline $\begin{array}{l}\text { Legumin } \\
\text { Levulin . }\end{array}$ & : & : & $\mathrm{C}_{6} \stackrel{?}{\mathrm{H}}_{10} \mathrm{O}_{5}$ & $\begin{array}{l}51 \cdot 47 \\
41 \cdot 44\end{array}$ & $7 \cdot 02$ & $24 \cdot 29$ & $16 \cdot 82$ & $0 \cdot 40$ \\
\hline $\begin{array}{l}\text { Levulin . } \\
\text { Leucine . }\end{array}$ & . & - & $\mathrm{C}_{6} \mathrm{H}_{13} \mathrm{NO}_{2}$ & $\begin{array}{l}44.44 \\
54 \cdot 96\end{array}$ & $\begin{array}{l}6 \cdot 17 \\
9 \cdot 09\end{array}$ & $\begin{array}{l}49 \cdot 39 \\
24 \cdot 13\end{array}$ & & \\
\hline & & - & $\mathrm{C}_{6} \mathrm{H}_{10} \mathrm{O}_{5}$ & $44 \cdot 44$ & $6 \cdot 17$ & $\begin{array}{l}24^{\circ} 43 \\
49 \cdot 39\end{array}$ & 10.69 & \\
\hline Lichen-starch & & - & $\mathrm{C}_{6} \mathrm{H}_{10} \mathrm{O}_{5}$ & $44 \cdot 44$ & $6 \cdot 17$ & $49 \cdot 39$ & & \\
\hline $\begin{array}{l}\text { Lignin (cf. p. } \\
\text { Limonin }\end{array}$ & $256)$ & . & & & & & & \\
\hline $\begin{array}{l}\text { Limonin } \\
\text { Linin }\end{array}$ & & & $\mathrm{C}_{26} \mathrm{H}_{30} \mathrm{O}_{8}$ & $66 \cdot$ & $6 \cdot 48$ & $27 \cdot 23$ & & \\
\hline Lupinin (gluc & coside & & $\mathrm{C}_{29} \mathrm{H}$ & $62 \cdot$ & $4 \cdot 72$ & $32 \cdot 36$ & & \\
\hline Luteolin & . & - & $\begin{array}{c}\mathrm{C}_{39} \mathrm{H}_{52} \mathrm{O}_{16} \\
\mathrm{C}_{12} \mathrm{H}_{8} \mathrm{O}_{5}\end{array}$ & $54 \cdot 63$ & $5 \cdot 47$ & $39 \cdot 90$ & & \\
\hline Maclurin & - & - & $\mathrm{C}_{15} \mathrm{H}_{12} \mathrm{O}_{8}$ & $62 \cdot 07$ & $3 \cdot 45$ & $34 \cdot 48$ & & \\
\hline Maleic acid & 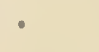 & - & $\mathrm{C}_{4} \mathrm{H}_{4} \mathrm{O}_{4}$ & $\begin{array}{l}56 \cdot 25 \\
41 \cdot 38\end{array}$ & $\begin{array}{l}3.75 \\
3.45\end{array}$ & $\mid \begin{array}{l}40 \cdot 00 \\
55 \cdot 17\end{array}$ & & \\
\hline Malic acid & - & - & $\mathrm{C}_{4} \mathrm{H}_{6} \mathrm{O}_{5}$ & $35 \cdot 82$ & $4 \cdot 48$ & $59 \cdot 70$ & & \\
\hline tose & - & . & $\mathrm{C}_{12} \mathrm{H}_{22} \mathrm{O}_{11}$ & $42 \cdot 10$ & $6 \cdot 43$ & $51 \cdot 47$ & & \\
\hline nite & & 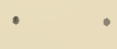 & $\mathrm{C}_{6} \mathrm{H}_{14} \mathrm{O}_{6}$ & $39 \cdot 56$ & $7 \cdot 69$ & $52 \cdot 75$ & & \\
\hline c acid & & - & $\mathrm{C}_{7} \mathrm{H}_{4} \mathrm{O}_{7}$ & $42 \cdot 0$ & $2 \cdot 0$ & $56^{\circ} 0$ & & \\
\hline Meconin & & - & $\mathrm{C}_{10} \mathrm{H}_{10} \mathrm{O}_{4}$ & $61 \cdot 85$ & $5 \cdot 15$ & $|33.00|$ & & \\
\hline
\end{tabular}




\begin{tabular}{|c|c|c|c|c|c|c|c|}
\hline \multicolumn{2}{|c|}{ NAME. } & FORMOLA. & C. & H. & 0. & N. & S. \\
\hline Melanthin & - & $\mathrm{C}_{301} \mathrm{H}_{33} \mathrm{O}_{7}$ & $62 \cdot 4$ & $9 \cdot 0$ & $28 \cdot 6$ & & \\
\hline Melezitose & & $\mathrm{C}_{12} \mathrm{H}_{22.2} \mathrm{O}_{11}$ & $42 \cdot 10$ & $6 \cdot 43$ & $51 \cdot 47$ & & \\
\hline Melissyl alcoh & hol & $\mathrm{C}_{30} \mathrm{H}_{62} \mathrm{O}$ & $82 \cdot 19$ & $14 \cdot 15$ & $3 \cdot 66$ & & \\
\hline Melitose & - & $\mathrm{C}_{1,}, \mathrm{H}_{22} \mathrm{O}_{11}$ & $42 \cdot 10$ & $6 \cdot 43$ & $51 \cdot 17$ & & \\
\hline Menispermin & & $\mathrm{C}_{18} \mathrm{H}_{21} \mathrm{~N}_{2} \mathrm{O}_{2}$ & $72 \cdot 00$ & $8 \cdot 00$ & $10 \cdot 65$ & $9 \cdot 35$ & \\
\hline Menthol & & $\mathrm{C}_{10} \mathrm{H}_{20} \mathrm{O}$ & 76.93 & $12 \cdot 82$ & $10 \cdot 25$ & & \\
\hline Menyanthin & $\therefore$ & $\mathrm{C}_{2.2} \mathrm{H}_{36}()_{11}$ & $55^{\circ} 46$ & $7 \cdot 56$ & 36.98 & & \\
\hline & $\begin{array}{l}\text { id } \\
\text { ol }\end{array}$ & $\mathrm{C}_{1 \%} \mathrm{H}_{22,2} \mathrm{O}_{11}$ & $42 \cdot 10$ & $6 \cdot 43$ & $51 \cdot 47$ & & \\
\hline $\begin{array}{l}\text { Methyl alcoh } \\
\text { Methylamine }\end{array}$ & & $\mathrm{CH}_{4} \mathrm{O}$ & $37 \cdot 50$ & $12 \cdot 50$ & $50 \cdot 00$ & & \\
\hline & e & $\mathrm{CH}_{5} \mathrm{~N}$ & $38 \cdot 71$ & $16 \cdot 13$ & $\ldots$ & $45 \cdot 17$ & \\
\hline & . & $\begin{array}{c}\mathrm{C}_{y} \mathrm{H}_{17} \mathrm{~N} \\
?\end{array}$ & $77 \cdot 69$ & $12 \cdot 23$ & & & \\
\hline $\begin{array}{l}\text { Methysticin } \\
\text { Milk-sugar }\end{array}$ & & $\mathrm{C}_{1}, \stackrel{?}{\mathrm{H}_{0.2}} \mathrm{O}_{11}$ & $65 \cdot 85$ & $5 \cdot 64$ & $28 \cdot 51$ & & \\
\hline & & $\begin{array}{l}\mathrm{C}_{1,2} \mathrm{H}_{22,2} \mathrm{O}_{11} \\
\mathrm{C}_{12} \mathrm{H}_{10} \mathrm{O}_{4}\end{array}$ & $42 \cdot 10$ & $6 \cdot 43$ & $51 \cdot 47$ & & \\
\hline Morphine & . & $\begin{array}{c}\mathrm{C}_{12} \mathrm{H}_{10} \mathrm{O}_{4} \\
\mathrm{C}_{17} \mathrm{H}_{19} \mathrm{NO}_{3}\end{array}$ & $\begin{array}{l}66 \cdot 0 \\
71 \cdot 58\end{array}$ & $\begin{array}{l}4 \cdot 6 \\
6 \cdot 67\end{array}$ & $\begin{array}{l}29 \cdot 3 \\
16 \cdot 54\end{array}$ & $4 \cdot 91$ & \\
\hline Morin : & . & $\mathrm{C}_{15} \mathrm{H}_{10} \mathrm{O}_{7}$ & $\begin{array}{l}11.58 \\
59 \cdot 61\end{array}$ & $3 \cdot 31$ & 37.08 & & \\
\hline Moschatine & - & $\mathrm{C}_{21} \mathrm{H}_{27} \mathrm{NO}_{7}$ & $68 \cdot 22$ & $6 \cdot 66$ & $27 \cdot 65$ & $3 \cdot 45$ & \\
\hline Mucedin & - & $?$ & $54 \cdot 11$ & $6 \cdot 90$ & $21 \cdot 45$ & $16 \cdot 63$ & $0 \cdot 88$ \\
\hline Muscarine & . & $\mathrm{C}_{5} \mathrm{H}_{13} \mathrm{NO}_{2}$ & $50 \cdot 42$ & 10.92 & $26 \cdot 89$ & $11 \cdot 77$ & \\
\hline Mycose & & $\mathrm{C}_{12} \mathrm{H}_{22} \mathrm{O}_{11}$ & $42 \cdot 10$ & $6 \cdot 43$ & $51 \cdot 47$ & & \\
\hline Myristic acid & & $\mathrm{C}_{14} \mathrm{H}_{28} \mathrm{O}_{2}$ & $73 \cdot 68$ & $12 \cdot 28$ & $14 \cdot 04$ & & \\
\hline Myronic acid & -・ & $\mathrm{C}_{10} \mathrm{H}_{19} \mathrm{NS}_{2} \mathrm{O}_{10}$ & $31 \cdot 83$ & $5 \cdot 04$ & $42 \cdot 42$ & $3 \cdot 72$ & $16 \cdot 98$ \\
\hline Narcëine & - & $\mathrm{C}_{23,3} \mathrm{H}_{2,4} \mathrm{NO}_{9}$ & $59 \cdot 63$ & $6 \cdot 28$ & $31 \cdot 09$ & $3 \cdot 02$ & \\
\hline Narcotine & - & C. ${ }_{2}^{-1,} \mathrm{H}_{2,3} \mathrm{NO}_{7}$ & $63 \cdot 92$ & $5 \cdot 57$ & $27 \cdot 12$ & $3 \cdot 39$ & \\
\hline Naringin & - & $\mathrm{C}_{23} \mathrm{H}_{26} \mathrm{O}_{12}$ & $55 \cdot 6$ & $5 \cdot 6$ & $38 \cdot 5$ & & \\
\hline Nataloïn & 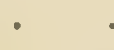 & $\mathrm{C}_{16} \mathrm{H}_{19}\left(\mathrm{O}_{7}(?)\right.$ & $59 \cdot 44$ & $5 \cdot 88$ & $34 \cdot 68$ & & \\
\hline Nepaline & - & $\mathrm{C}_{36} \mathrm{H}_{49} \mathrm{NO}_{12}$ & 63.09 & $7 \cdot 47$ & $27 \cdot 3: 2$ & $2 \cdot 12$ & \\
\hline Nicotine & - & $\mathrm{C}_{10} \mathrm{H}_{14} \mathrm{~N}_{2}$ & 74.08 & $8 \cdot 64$ & & $17 \cdot 28$ & \\
\hline Nucite & $\because$ & $\mathrm{C}_{6} \mathrm{H}_{12} \mathrm{O}_{6}$ & $40 \cdot 00$ & $6 \cdot 66^{\circ}$ & $53 \cdot 33$ & & \\
\hline Oak-bark tan & nic aci & $\mathrm{C}_{-16} \mathrm{H}_{16}()_{16}$ & $53 \cdot 85$ & $5 \cdot 13$ & $41 \cdot 02$ & & \\
\hline Oenanthic aci & id & $\mathrm{C}_{7} \mathrm{H}_{14} \mathrm{O}_{2}$ & $6.1 \cdot 12$ & $11 \cdot 44$ & $24 \cdot 4 t$ & & \\
\hline Oleic acid & - & $\mathrm{C}_{18} \mathrm{H}_{34} \mathrm{O}_{23}$ & 76.59 & $12 \cdot 06$ & $11 \cdot 35$ & & \\
\hline Ononin & - & $\mathrm{C}_{331} \mathrm{H}_{34}\left(\mathrm{O}_{13}\right.$ & $59 \cdot 80$ & $5 \cdot 64$ & $34 \cdot 56$ & & \\
\hline Orcin & 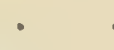 & $\mathrm{C}_{7}-\mathrm{H}_{8} \mathrm{O}_{2}$ & $67 \cdot 76$ & $6 \cdot 45$ & $25 \cdot \$ 1$ & & \\
\hline Orsellic acid & • & $\mathrm{C}_{4} \mathrm{H}_{4} \mathrm{O}_{4}$ & $57 \cdot 15$ & $4 \cdot 76$ & $38 \cdot 09$ & & \\
\hline Ostruthiin & 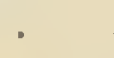 & $\mathrm{C}_{14} \mathrm{H}_{17}(\mathrm{O})(?)$ & $77 \cdot 07$ & $7 \cdot 95$ & $14 \cdot 99$ & & \\
\hline Oxalic acid & & C.... $\mathrm{H}_{2}()_{4}$ & $26 \cdot 66$ & $2 \cdot 2 \cdot 2$ & $71 \cdot 11$ & & \\
\hline Oxyacanthine & & $\mathrm{C}_{3,3}, \mathrm{H}_{46} \mathrm{~N},()_{11}$ & $60 \cdot 57$ & $7 \cdot 26$ & 27.76 & $4 \cdot 42$ & \\
\hline Pæoniofluores & $\operatorname{scin}$ & $\left.\mathrm{C}_{14} \mathrm{H}_{10}, \ldots, \mathrm{H}_{2} \mathrm{O}\right)$ & 71.38 & $5 \cdot \$ 9$ & $2.1 \cdot 73$ & & \\
\hline Palmitic acid & & $\mathrm{C}_{1 i} \mathrm{H}_{32} \mathrm{O}_{2}$ & $75 \cdot 00$ & 12.50 & $12 \cdot 50$ & & \\
\hline Papaverine & - & $\mathrm{C}_{-11} \mathrm{H}_{21} \mathrm{NO}_{4}$ & $70 \cdot 79$ & $6 \cdot 20$ & 15.45 & $4 \cdot 13$ & \\
\hline Pararabin & - & $C_{12}+H_{12} O_{11}$ & $42 \cdot 10$ & $(i \cdot 4)$ & $51 \cdot 17$ & & \\
\hline Parellic acid & . & ${ }^{-} \mathrm{H}_{6} \mathrm{H}_{4} \mathrm{O}_{4}$ & $60 \cdot 67$ & $3 \cdot 37$ & $33.5 \cdot 96$ & & \\
\hline Paracotoïn & . & $\mathrm{C}_{1 ! 3} \mathrm{H}_{1: 2} \mathrm{O}_{6}$ & $67 \cdot 85$ & $3 \cdot 54$ & $28 \div 8$ & & \\
\hline Paricine & . & $\mathrm{C}_{16} \mathrm{H}_{19} \mathrm{~N}, \mathrm{O}$ & $75 \cdot 59$ & $7 \cdot 09$ & $(i \cdot \cdot 29$ & $11 \cdot 02$ & \\
\hline Paridin . & . & $\left({ }_{16} \mathrm{H}_{2-x}()_{7}\right.$ & $57 \cdot 83$ & $8 \cdot 13$ & $333 \cdot 74$ & & \\
\hline Parillin . & . & $\mathrm{C}_{14} \mathrm{H}_{2,1}(\mathrm{)}$ & $60 \cdot 4$ & $9 \cdot 0$ & $30 \cdot 6$ & & \\
\hline Paytine. & . & $\mathrm{C}_{21} \mathrm{H}_{2,2} \mathrm{~N}_{23}(\mathrm{O}$ & $79 \cdot 74$ & $6 \div 3$ & $5 \cdot 06$ & $8 \cdot 86$ & \\
\hline Peucedanin & . & $\mathrm{C}_{1} \cdot \mathrm{H}_{1}, \mathrm{O}_{3}$ & 70.58 & $5 \cdot 88$ & $23 \cdot 5.4$ & & \\
\hline Philyrin & 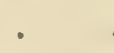 & $\mathrm{C}_{27} \mathrm{H}_{34} \mathrm{O}_{11}$ & $60 \cdot 67$ & $6 \cdot 37$ & $32 \cdot 96$ & & \\
\hline Phlorizin & - & $\left(\mathrm{C}_{3,1} \mathrm{H}_{1,4}()_{10}\right.$ & $56 \cdot 15$ & $5 \cdot \$ 1$ & $38 \cdot 0.4$ & & \\
\hline Phloroglucin & . & $\left({ }_{6} \mathrm{H}_{63}()_{3}\right.$ & $57 \cdot 13$ & $4 \cdot 76$ & $34 \cdot 11$ & & \\
\hline Physalin & & $\mathrm{C}_{11} \mathrm{H}_{116}\left(\mathrm{O}_{5}\right.$ & 63.64 & $6 \cdot(16$ & $30 \div 30$ & & \\
\hline Physostigmine & & $\mathrm{C}_{1} \mathrm{H}_{2,1}+\mathrm{C}_{3}\left(\mathrm{O}_{2}\right.$ & $65 \cdot 49$ & $7 \cdot 64$ & $11 \cdot 60$ & $15 \cdot 27$ & \\
\hline Phytosterin & & $\mathrm{C}_{-6} \mathrm{I}_{41}(\mathrm{)}$ & $83 \cdot 87$ & $11 \cdot \$ 3$ & $4: 30$ & & \\
\hline Picropodophy & yllin & & $67 \cdot 71$ & $5 \cdot \leq 8$ & $26 \cdot 47$ & 5.56 & \\
\hline Picroroccellin & he & 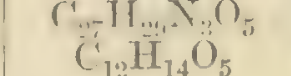 & $\begin{array}{l}68 \cdot 08 \\
60 \cdot 50\end{array}$ & $\begin{array}{l}6 \cdot 31 \\
5 \cdot 38\end{array}$ & $\begin{array}{l}17 \cdot 0.5 \\
33 \cdot 6 \cdot 2\end{array}$ & 5.010 & \\
\hline Picrotoxin & & $\mathrm{C}_{12} \mathrm{H}_{14} \mathrm{O}_{5}$ & 0 & & & & \\
\hline
\end{tabular}




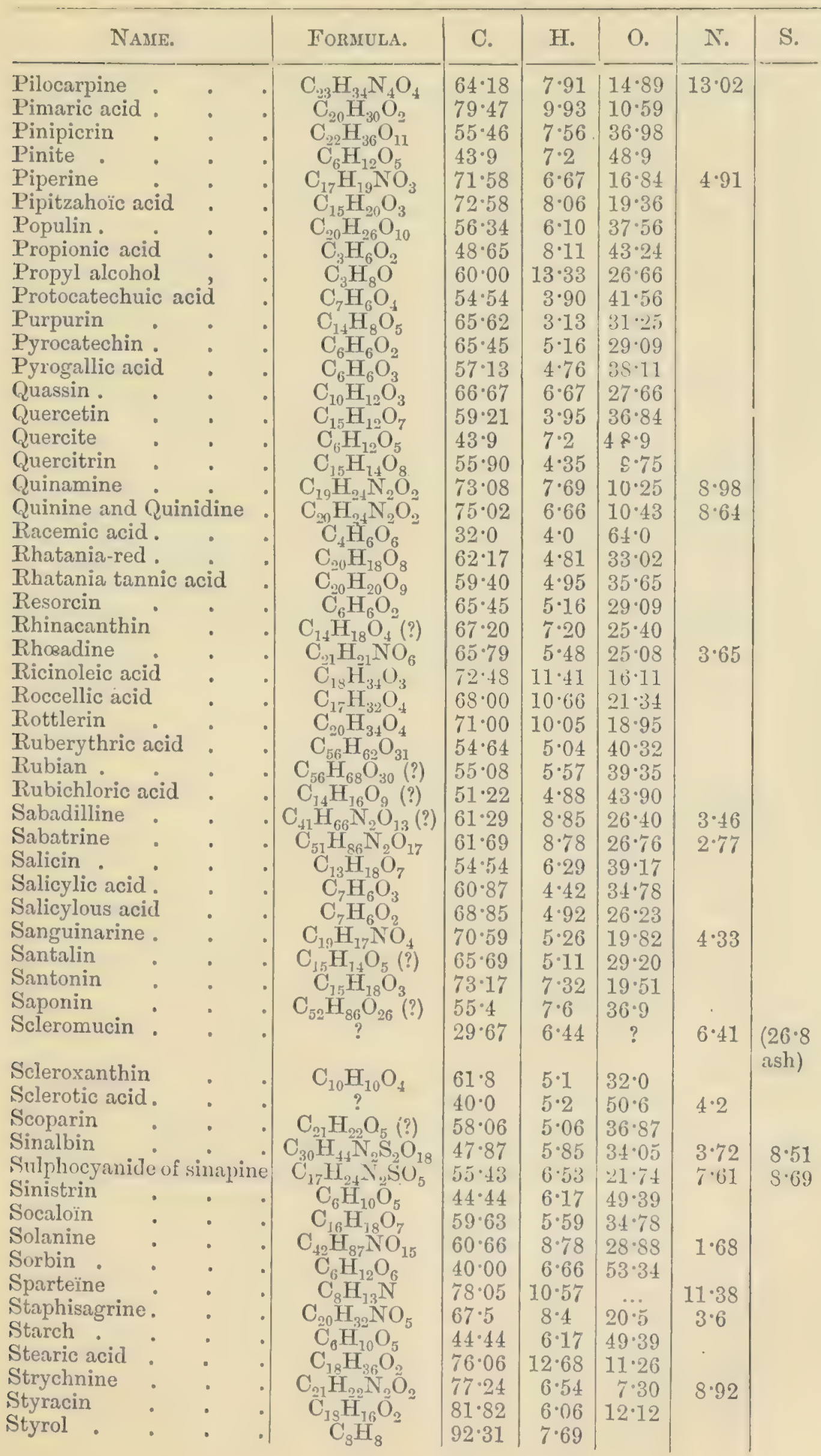




\begin{tabular}{|c|c|c|c|c|c|c|}
\hline Name. & Formula. & C. & $\mathrm{H}$. & O. & N. & S. \\
\hline $\begin{array}{l}\text { Succinic acid } \\
\text { Syringin } \\
\text { Tannaspidic acid } \\
\text { Tannin } \\
\text { Tartaric acid : } \\
\text { Terpene. } \\
\text { Thebaine } \\
\text { Theobromine: } \\
\text { Thevetin } \\
\text { Thujin : } \\
\text { Thymol } \\
\text { Trimethylamine } \\
\text { Triticin } \\
\text { Turpethin : } \\
\text { Tyrosin } \\
\text { Umbelliferon: } \\
\text { Usnic acid } \\
\text { Valerianic acid } \\
\text { Vanillin } \\
\text { Veratrine } \\
\text { Veratroïdine } \\
\text { Vitellin (Brazil nut) } \\
\text { Vulpic acid } \\
\text { Xanthorhamnin }\end{array}$ & 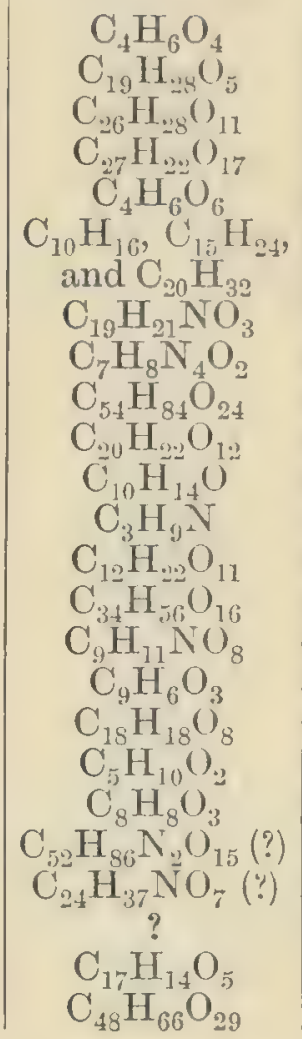 & $\begin{array}{l}40 \cdot 68 \\
54 \cdot 81 \\
60 \cdot 46 \\
52 \cdot 42 \\
32 \cdot 0 \\
88 \cdot 23 \\
73 \cdot 31 \\
46 \cdot 67 \\
58 \cdot 06 \\
52 \cdot 56 \\
80 \cdot 00 \\
61 \cdot 0 \cdot 2 \\
42 \cdot 10 \\
56 \cdot 66 \\
59 \cdot 66 \\
66 \cdot 66 \\
59 \cdot 39 \\
5 S \cdot 5 \cdot 2 \\
63 \cdot 13 \\
64 \cdot 4 \cdot 2 \\
63 \cdot 5 \\
52 \cdot 29 \\
70 \cdot 81 \\
51 \cdot 08\end{array}$ & $\begin{array}{c}5 \cdot 09 \\
6 \cdot 7 \cdot 3 \\
5 \cdot 42 \\
3 \cdot 56 \\
4 \cdot 0 \\
\\
11 \cdot 75 \\
6 \cdot 75 \\
4 \cdot 44 \\
7 \cdot 53 \\
4 \cdot 54 \\
9 \cdot 3 \cdot 3 \\
15 \cdot 25 \\
6 \cdot 43 \\
7 \cdot 77 \\
6 \cdot 07 \\
3 \cdot 71 \\
4 \cdot 94 \\
9 \cdot 80 \\
5 \cdot 26 \\
8 \cdot 70 \\
8 \cdot 2 \\
7 \cdot 24 \\
4 \cdot 35 \\
5 \cdot 83\end{array}$ & $\begin{array}{l}15 \cdot 44 \\
17 \cdot 75 \\
34 \cdot 41 \\
42 \cdot 30 \\
10 \cdot 77 \\
\ldots \\
51 \cdot 47 \\
35 \cdot 57 \\
26 \cdot 54 \\
29 \cdot 6 \cdot 3 \\
35 \cdot 36 \\
31 \cdot 37 \\
31 \cdot 58 \\
23 \cdot 97 \\
24 \cdot 9 \\
21 \cdot 06 \\
24 \cdot 94 \\
43 \cdot 09\end{array}$ & $\begin{array}{c}2 \cdot 91 \\
3 \cdot 1 \\
18 \cdot 09\end{array}$ & $1 \cdot 32$ \\
\hline
\end{tabular}


COMPOSITION OF THE MORE IMPORTANT CONSTITLENTS OF PLANTS, ARRANGED ACCORDING TO PERCENTAGE OF CARBON.

\begin{tabular}{|c|c|c|c|c|c|}
\hline C. & $\mathrm{H}$. & 0. & $\mathrm{~N}$. & S. & Name. \\
\hline $26 \cdot 66$ & $2 \cdot 22$ & $71 \cdot 11$ & & & Oxalic acid. \\
\hline $31 \cdot 5 \mathrm{~S}$ & $5 \cdot 26$ & $63 \cdot 16$ & & & Glycolic acid. \\
\hline $31 \cdot 81$ & $5 \cdot 04$ & $42 \cdot 4 \cdot 2$ & $3 \cdot 72$ & $16 \cdot 99$ & Myronic acid. \\
\hline $32 \cdot 00$ & $4 \cdot 00$ & $6+00$ & ... & ... & Tartaric and racemic acid. \\
\hline $35 \cdot 8 \cdot 2$ & $4 \cdot 48$ & $59 \cdot 70$ & & $\cdots$ & Malic acid. \\
\hline $36 \cdot 36$ & $6 \cdot 00$ & $34 ; \cdot 37$ & $21 \cdot 21$ & $\ldots$ & Asparagine. \\
\hline 3750 & $4 \cdot 17$ & $5: 3 \cdot 3: 3$ & .. & ... & Citric acid. \\
\hline $\begin{array}{l}37 \cdot 50 \\
35 \cdot-1\end{array}$ & $12 \cdot 50$ & $50 \cdot 00$ & & .. & Methylic alcohol. \\
\hline $\begin{array}{l}35 \cdot 71 \\
39 \cdot 13\end{array}$ & $\begin{array}{r}16 \cdot 13 \\
8 \cdot 70\end{array}$ & $52 \cdot 17$ & $45 \cdot 17$ & $\cdots$ & Methylamine. \\
\hline $\begin{array}{l}39 \cdot 13 \\
39 \cdot 31\end{array}$ & $\begin{array}{l}8 \cdot 70 \\
8 \cdot 20\end{array}$ & $52 \cdot 46$ & $\begin{array}{l}\cdots \\
\cdots\end{array}$ & $\begin{array}{l}\cdots \\
\cdots\end{array}$ & $\begin{array}{l}\text { Glycerm. } \\
\text { Erythrite. }\end{array}$ \\
\hline 3956 & $7 \cdot 69$ & 52.75 & $\cdots$ & $\cdots$ & $\begin{array}{l}\text { Dulcite, isodulcite, mannite, } \\
\text { etc. }\end{array}$ \\
\hline $40 \cdot 30$ & $6 \cdot 66$ & $5: 3 \cdot 3: 3$ & $\ldots$ & $\ldots$ & $\begin{array}{l}\text { Acetic and lactic acid, glu- } \\
\text { cose, etc. }\end{array}$ \\
\hline $40 \cdot 00$ & $5 \cdot 2$ & $50 \cdot 6$ & $4 \cdot 2$ & $\cdots$ & Sclerotic acid. \\
\hline 40.68 & 5.09 & $54 \cdot 2 \cdot 3$ & $\ldots$ & $\ldots$ & Succinic acid. \\
\hline $41 \cdot 38$ & $3 \cdot 45$ & $55 \cdot 17$ & .. & ... & Aconitic acid. \\
\hline 41.38 & $3 \cdot 45$ & $55 \cdot 17$ & $\cdots$ & $\cdots$ & Fumaric and maleïc acid. \\
\hline $\begin{array}{l}42 \cdot 0 \\
4 \cdot 10\end{array}$ & $\begin{array}{l}2 \cdot 0 \\
6 \cdot 43\end{array}$ & $56^{\circ} \cdot 0$ & $\cdots$ & $\cdots$ & Meconic acid. \\
\hline $42 \cdot 10$ & $6 \cdot 43$ & 1.76 & ... & $\ldots$ & $\begin{array}{l}\text { Arabic and metarabic acid, } \\
\text { pararabin, triticin, saccha. } \\
\text { rose, etc. }\end{array}$ \\
\hline 43775 & $6 \cdot 30$ & $50 \cdot 19$ & ... & $\cdots$ & Kinic acid. \\
\hline $4: 3 \cdot 9$ & $7 \cdot 2$ & $48 \cdot 9$ & $\cdots$ & .. & Pinite and quercite. \\
\hline $44 \cdot 21$ & $5 \cdot 26$ & $50 \cdot 5: 3$ & & .. & Boheic acid. \\
\hline $41 \cdot 14$ & $9 \cdot 6: 3$ & 35.55 & $10 \cdot 37$ & ... & Betaïne. \\
\hline 41.44 & $3 \cdot 70$ & & $51 \cdot 85$ & $\ldots$ & Hydrocyanic acid. \\
\hline $44 \cdot 44$ & 4.76 & $51 \cdot 80$ & $\cdots$ & $\cdots$ & Cyclopin. \\
\hline $44 \cdot \pm 4$ & $6 \cdot 17$ & $49 \cdot 39$ & .. & $\ldots$ & $\begin{array}{l}\text { Cellulose, dextrin, inulin, } \\
\text { levulin, sinistrin, starch. }\end{array}$ \\
\hline $\begin{array}{l}45 \cdot 65 \\
46 \cdot 67\end{array}$ & $\begin{array}{l}2 \cdot 17 \\
4 \cdot 44\end{array}$ & $\begin{array}{l}52 \cdot 24 \\
17 \cdot 79\end{array}$ & $3 \dddot{111}$ & ... & Chelidonic acid. \\
\hline $47 \cdot 87$ & $5 \cdot 85$ & $\begin{array}{l}17.75 \\
81.05\end{array}$ & 3.72 & $8: 51$ & 'Theobromine. \\
\hline $48 \cdot 65$ & $8 \cdot 11$ & $4: 3 \cdots 1$ & & ... & $\begin{array}{l}\text { Sinalbine. } \\
\text { Propionic acid. }\end{array}$ \\
\hline $49 \cdot 18$ & $5 \cdot 15$ & $16 \div 1$ & $28 \cdot 86$ & $\ldots$ & Caffeine. \\
\hline 4959 & $12: 39$ & $26 \cdot 41$ & $11 \cdot 57$ & $\ldots$ & Choline. \\
\hline $49 \cdot 60$ & $4: 92$ & $43 \div 26$ & $2 \cdot 22$ & & Indican. \\
\hline $50 \cdot 2 t$ & $6 \cdot 81$ & $21 \cdot 1: 3$ & $18 \cdot 37$ & 0.45 & Conglutin. \\
\hline $50 \cdot 12$ & $10 \cdot 92$ & $26 \cdot 89$ & $11 \cdot 77$ & $\ldots$ & Muscarine. \\
\hline $51 \cdot 0$ & $6 \cdot 7$ & $25 \cdot 4$ & $16 \cdot 1$ & 0.8 & Glutencaseïn. \\
\hline $51 \cdot 00$ & $7 \cdot 00$ & $+2 \cdot 00$ & $\cdots$ & $\cdots$ & Ericolin. \\
\hline $\begin{array}{l}51 \cdot 02 \\
51 \cdot 2 \cdot 2\end{array}$ & $\begin{array}{l}4 \cdot 89 \\
4 \cdot 58\end{array}$ & $\begin{array}{l}4.87 \\
4: 30\end{array}$ & & $\cdots$ & Fraxin. \\
\hline $51 \cdot 17$ & $7 \cdot 02$ & $21 .-2 ! 9$ & 16.82 & $0 \cdot 40$ & Legumin. \\
\hline $52 \cdot 01$ & $5 \cdot 88$ & $4 \cdot 2 \cdot 11$ & & & Cinchona-tannic acid. \\
\hline $52 \cdot 07$ & $7 \cdot 24$ & $21 \cdot 00^{\circ}$ & 18.09 & $1 \cdot 32$ & Vitellin. \\
\hline
\end{tabular}




\begin{tabular}{|c|c|c|c|c|c|}
\hline C. & $\mathrm{H}$. & O. & N. & S. & NAMIE. \\
\hline $52 \cdot 39$ & $4 \cdot 78$ & $42 \cdot 83$ & & ... & Daphnin. \\
\hline $52 \cdot 42$ & $3 \cdot 56$ & $44 \cdot 02$ & & & Gallotannic acid. \\
\hline $52 \cdot 45$ & $6 \cdot 81$ & $22 \cdot 21$ & $15 \cdot 65$ & 0.8 & Albumin. \\
\hline $52 \cdot 47$ & 5.79 & $40 \cdot 23$ & 1.53 & $\ldots$ & Laurocerasin. \\
\hline $52: 51$ & $5 \cdot 91$ & $38 \cdot 52$ & $3 \cdot 06$ & $\ldots$ & Amygdalin. \\
\hline 52.53 & $7 \cdot 38$ & $40 \cdot 27$ & 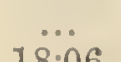 & oㅏ & Helleborein. \\
\hline $52 \cdot 60$ & $7 \cdot 00$ & $21 \cdot 49$ & $18 \cdot 06$ & 0.85 & Gliadin. \\
\hline $52 \cdot 9$ & $\begin{array}{l}4 \cdot 84 \\
5 \cdot 2\end{array}$ & $\begin{array}{l}42 \cdot 30 \\
41 \cdot 9\end{array}$ & $\begin{array}{l}\cdots \\
\ldots\end{array}$ & $\begin{array}{l}\cdots \\
\ldots\end{array}$ & $\begin{array}{l}\text { Thujin. } \\
\text { Apiin. }\end{array}$ \\
\hline $53 \cdot 21$ & $7 \cdot 60$ & $39 \cdot 19$ & $\begin{array}{l}\cdots \\
\cdots\end{array}$ & $\ldots$ & $\begin{array}{l}\text { Apmitonin. } \\
\text { Digitonin. }\end{array}$ \\
\hline $53 \cdot 33$ & $5 \cdot 19$ & $41 \cdot 48$ & ... & $\ldots$ & Cinchona-red. \\
\hline $53 \cdot 7$ & $6 \cdot 1$ & $40 \cdot 2$ & ... & $\ldots$ & Axbutin. \\
\hline $53 \cdot 85$ & $5 \cdot 13$ & $41 \cdot 02$ & ... & ... & Oak-bark tannic acid. \\
\hline $53 \cdot 91$ & $8 \cdot 59$ & $37 \cdot 50$ & $\ldots$ & $\ldots$ & Convallamarin. \\
\hline $54 \cdot 08$ & $4 \cdot 72$ & $41 \cdot 20$ & $\ldots$ & $\ldots$ & Datiscin. \\
\hline $54 \cdot 11$ & $6 \cdot 90$ & $21 \cdot 48$ & $16 \cdot 63$ & $0 \cdot 88$ & Mucedin. \\
\hline $54 \cdot 54$ & $3 \cdot 90$ & $41 \cdot 56$ & $\cdots$ & $\cdots$ & \\
\hline $\begin{array}{l}54 \cdot 55 \\
54 \cdot 54\end{array}$ & $\begin{array}{l}9 \cdot 09 \\
6 \cdot 29\end{array}$ & $\begin{array}{l}36 \cdot 36 \\
30 \cdot 17\end{array}$ & $\ldots$ & $\begin{array}{l}\ldots \\
\ldots\end{array}$ & $\begin{array}{l}\text { Butyric acid. } \\
\text { Salicin. }\end{array}$ \\
\hline $54 \cdot 63$ & $5 \cdot 47$ & 39.90 & $\begin{array}{l}\cdots \\
\cdots\end{array}$ & $\cdots$ & $\begin{array}{l}\text { Salicin. } \\
\text { Lupinin. }\end{array}$ \\
\hline $54 \cdot 64$ & $5 \cdot 04$ & $40 \cdot 32$ & $\cdots$ & $\ldots$ & Ruberythric acid. \\
\hline $54 \cdot 77$ & $5 \cdot 39$ & $39 \cdot 84$ & ... & $\ldots$ & Hesperidin. \\
\hline $54 \cdot 81$ & 6.73 & $38 \cdot 46$ & ... & ... & Syringin. \\
\hline $54 \cdot 87$ & $7 \cdot 37$ & $37 \cdot 50$ & 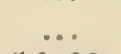 & $\ldots$ & Convolvulin. \\
\hline $54 \cdot 96$ & $9 \cdot 92$ & $24 \cdot 43$ & $10 \cdot 69$ & $\ldots$ & Leucine. \\
\hline 55.08 & $5 \cdot 57$ & $39 \cdot 35$ & $\cdots$ & $\cdots$ & Rubian. \\
\hline $55 \cdot 29$ & $7 \cdot 83$ & $36 \cdot 87$ & $\cdots$ & $\cdots$ & Cyclamin. \\
\hline $\begin{array}{l}55 \cdot 4 \\
55 \cdot 43\end{array}$ & $\begin{array}{l}7 \cdot 6 \\
6 \cdot{ }^{2}\end{array}$ & $\begin{array}{l}36.9 \\
21.74\end{array}$ & $\dddot{7} \cdot 61$ & $\ddot{8} 69$ & $\begin{array}{l}\text { Saponin. } \\
\text { Sulphocranate of sinapine. }\end{array}$ \\
\hline $55 \cdot 46$ & $7 \cdot 56$ & 36.98 & ... & $\ldots$ & \\
\hline $55 \cdot 46$ & $7 \cdot 56$ & $36 \cdot 98$ & $\ldots$ & $\ldots$ & Pinipicrin. \\
\hline $55 \cdot 6$ & $5 \cdot 6$ & $38 \cdot 8$ & $\ldots$ & $\ldots$ & Naringin. \\
\hline $55 \cdot 81$ & 6.99 & $37 \cdot 20$ & $\ldots$ & $\ldots$ & Crotonic acid. \\
\hline $55 \cdot 63$ & 1.99 & $42 \cdot 38$ & $\ldots$ & ... & Ellagic acid. \\
\hline $55 \cdot 90$ & $4 \cdot 35$ & $39 \cdot 75$ & ... & ... & Quercitrin. \\
\hline $56 \cdot 14$ & $6 \cdot 43$ & $37 \cdot 43$ & $\cdots$ & $\ldots$ & Coniferin. \\
\hline $56 \cdot 15$ & $5 \cdot 81$ & $38 \cdot 05$ & $\cdots$ & $\cdots$ & Phlorizin. \\
\hline $56 \cdot 25$ & $3 \cdot 75$ & $40 \cdot 00$ & ... & $\cdots$ & Maclurin. \\
\hline $56 \cdot 34$ & $6 \cdot 10$ & $37 \cdot 56$ & $\cdots$ & $\cdots$ & Populin. \\
\hline $56 \cdot 37$ & $6 \cdot 04$ & $37 \cdot 59$ & $\cdots$ & $\ldots$ & Ipecacuanha-tannic acid. \\
\hline $56 \cdot 66$ & $7 \cdot 77$ & $35 \cdot 57$ & $\ldots$ & ... & $\begin{array}{l}\text { Jalapin and turpethin. } \\
\text { Caffeo-tannic acid. }\end{array}$ \\
\hline $56 \cdot 75$ & $5 \cdot 41$ & $37 \cdot 84$ & $\ldots$ & $\cdots$ & $\begin{array}{l}\text { Caffeo-tannic acid. } \\
\text { Carthamin. }\end{array}$ \\
\hline $56 \cdot 75$ & $5 \cdot 40$ & $37 \cdot 85$ & $\ldots$ & $\begin{array}{l}\cdots \\
\ldots\end{array}$ & Carthamin. \\
\hline $57 \cdot 13$ & $4 \cdot 76$ & $38 \cdot 11$ & $\ldots$ & $\begin{array}{l}\cdots \\
. .\end{array}$ & $\begin{array}{l}\text { Phloroglucin, pyrogallol, etc. } \\
\text { Orsellic acid. }\end{array}$ \\
\hline $57 \cdot 15$ & $4 \cdot 76$ & $38 \cdot 09$ & $\begin{array}{l}\cdots \\
\ldots\end{array}$ & ... & $\begin{array}{l}\text { Orsellic acid. } \\
\text { Globularin. }\end{array}$ \\
\hline $57 \cdot 32$ & $\begin{array}{l}7 \cdot 01 \\
5 \cdot 7\end{array}$ & $\begin{array}{l}35 \cdot 67 \\
34 \cdot 96\end{array}$ & 1.50 & 0.85 & \\
\hline $\begin{array}{l}57 \cdot 57 \\
57 \cdot 64\end{array}$ & $\begin{array}{l}5 \cdot 12 \\
7 \cdot 42\end{array}$ & $\begin{array}{l}34.90 \\
34.94\end{array}$ & & $\ldots$ & $\begin{array}{l}\text { Cathartic acid. } \\
\text { Dulcamarin. }\end{array}$ \\
\hline $57 \cdot 69$ & $13 \cdot 46$ & $15 \cdot 38$ & $13 \cdot 46$ & $\ldots$ & Amanitine. \\
\hline $58 \cdot 00$ & $5 \cdot 06$ & $36 \cdot 87$ & $\ldots$ & $\ldots$ & Scoparin. \\
\hline $58 \cdot 06$ & $7 \cdot 53$ & $34 \cdot 41$ & $\ldots$ & ... & 'Thevetin. \\
\hline $58 \cdot 22$ & $5 \cdot 50$ & $36 \cdot 28$ & $\ldots$ & $\ldots$ & Curaçao-aloin. \\
\hline $58 \cdot 23$ & $4 \cdot 64$ & $37 \cdot 13$ & $\ldots$ & $\ldots$ & Chrysorhamnin. \\
\hline $58 \cdot 24$ & $7 \cdot 38$ & $34 \cdot 38$ & $\cdots$ & ... & Caïncin. \\
\hline $58 \cdot 82$ & $9 \cdot 80$ & $31 \cdot 37$ & $\cdots$ & $\cdots$ & Valerianic acid. \\
\hline $\begin{array}{l}59 \cdot 21 \\
59 \cdot 26\end{array}$ & $\begin{array}{l}3 \cdot 91 \\
6 \cdot 17\end{array}$ & $\begin{array}{l}36 \cdot 84 \\
34 \cdot 57\end{array}$ & $\begin{array}{l}\cdots \\
\ldots\end{array}$ & $\begin{array}{l}\ldots \\
\ldots\end{array}$ & $\begin{array}{l}\text { Quercetin, } \\
\text { Capaloin. }\end{array}$ \\
\hline & & & & & \\
\hline
\end{tabular}




\begin{tabular}{|c|c|c|c|c|c|}
\hline C. & $\mathrm{H}$ & (). & N. & S. & NaMe. \\
\hline $59 \cdot 34$ & 549 & $35 \cdot 17$ & $\cdots$ & $\cdots$ & Everninic acid. \\
\hline $59 \cdot 44$ & $5 \cdot 89$ & $34 \cdot 6 s$ & $\cdots$ & $\ldots$ & Nataloïn. \\
\hline $59 \cdot 40$ & $4 \cdot 95$ & $35 \cdot 65$ & $\ldots$ & $\ldots$ & Rhatania-tannic acid. \\
\hline $59 \cdot 39$ & $4 \cdot 9.4$ & $35 \cdot 36$ & .. & $\ldots$ & Usnic acid. \\
\hline $59 \cdot 63$ & 5.59 & $34 \cdot 78$ & $\ldots$ & $\ldots$ & Socaloïn. \\
\hline $59 \cdot 63$ & $6 \because 28$ & 31.09 & 3.02 & $\ldots$ & Narceine. \\
\hline $59 \cdot 66$ & 6.07 & 20.54 & $7 \cdot 73$ & $\ldots$ & Tyrosine. \\
\hline $59 \cdot 78$ & $7+7$ & $3 \cdot 2 \cdot 75$ & $\cdots$ & $\cdots$ & Colocỵnthin. \\
\hline $59 \cdot 80$ & $5 \cdot 64$ & 34.56 & & $\cdots$ & Ononin. . . \\
\hline $59 \cdot 92$ & $7 \cdot 05$ & $3 \cdot 2 \cdot 66$ & $1 \cdot 17$ & $\cdots$ & Glycyrrhizic acid. \\
\hline 59.95 & $8 \cdot 05$ & $\begin{array}{l}32 * 00 \\
3 * 00\end{array}$ & $\cdots$ & $\cdots$ & Digitalin. \\
\hline $60 \cdot 00$ & 8.00 & $32 \cdot 00$ & $\cdots$ & $\ldots$ & Angelic acid. \\
\hline $60 \cdot 00$ & $8 \cdot 33$ & $31 \cdot 67$ & $\cdots$ & $\ldots$ & Bryonin. \\
\hline $60 \cdot 00$ & $4 \cdot 44$ & 3556 & $\cdots$ & $\cdots$ & Cetraric acid. \\
\hline $60 \cdot 00$ & $1: 3 \cdot 33$ & $26 \cdot 67$ & $\ldots$ & $\cdots$ & Propylic alcohol. \\
\hline $60 \cdot 37$ & $4 \cdot 40$ & $35 \cdot 2: 3$ & $\cdots$ & $\cdots$ & Lecanoric acid. \\
\hline 60.40 & $9 \cdot 0$ & $\begin{array}{l}30 \cdot 6 \\
3.1 .7\end{array}$ & $\cdots$ & $\cdots$ & Parillin. \\
\hline $\begin{array}{l}60 \cdot 16 \\
60 \cdot 50\end{array}$ & $\begin{array}{l}5 \cdot 42 \\
5 \cdot 89\end{array}$ & $\begin{array}{l}34 \cdot 12 \\
3: 3 \cdot 6 \cdot 2\end{array}$ & $\cdots$ & $\cdots$ & Tamnaspidic acid. \\
\hline $60 \div 3$ & $6 \cdot 62$ & $25 \div 0$ & $\dddot{4} \cdot 15$ & $\begin{array}{l}\ldots \\
\ldots\end{array}$ & \\
\hline $60 \cdot 57$ & $7 \cdot 26$ & 27.76 & $4 \cdot 42$ & $\cdots$ & $\begin{array}{l}\text { Colchicine. } \\
\text { Oxyacanthine. }\end{array}$ \\
\hline $60 \cdot 66$ & $s \cdot 78$ & $28 \cdot 89$ & $1 \cdot 68$ & $\ldots$ & Solanine. \\
\hline 60.67 & $3 \cdot 37$ & $335 \cdot 96$ & $\cdots$ & $\cdots$ & Parellic acid. \\
\hline $60 \cdot 67$ & $6 \cdot 37$ & 3,3296 & $\cdots$ & $\ldots$ & Philyrin. \\
\hline $60 \cdot 71$ & $5 \cdot 95$ & $3: 3 \cdot 34$ & $\ldots$ & $\ldots$ & Barbaloïn. \\
\hline $60 \cdot 81$ & $4 \cdot 90$ & $34 \cdot 29$ & $\cdots$ & $\cdots$ & Gyrophoric acid. \\
\hline $60 \cdot 85$ & 4.75 & $34 \cdot 10$ & .. & $\cdots$ & Gardenin. \\
\hline $60 \cdot 86$ & $4 \cdot 42$ & 3.179 & $\cdots$ & $\cdots$ & Salicylic acid. \\
\hline $60 \cdot 90$ & $4 \cdot 81$ & $3+\cdots 2: 3$ & & $\ldots$ & Catechin. \\
\hline 61.02 & $15 \cdot 25$ & & $5 \cdot 1.4$ & $\cdots$ & Trimethylamine. \\
\hline $\begin{array}{l}61 \cdot 03 \\
61 \cdot 29\end{array}$ & 856 & $\begin{array}{l}25 \cdot \cdot \cdot 27 \\
24 \cdot 10\end{array}$ & 3.46 & $\cdots$ & Jervine. \\
\hline $\begin{array}{l}61 \cdot 2 ? \\
61.39\end{array}$ & $\begin{array}{l}8.55 \\
6.67\end{array}$ & $\begin{array}{l}24 \cdot 40 \\
29 \cdot 77\end{array}$ & $2 \cdot 17$ & $\cdots$ & Sabadilline. \\
\hline $61 \cdot 44$ & 4.82 & $33: 74$ & $\ldots$ & $\cdots$ & $\begin{array}{l}\text { Aconitine. } \\
\text { Evernic acid. }\end{array}$ \\
\hline $61 \cdot 69$ & 8.78 & 2676 & 2.7 & $\begin{array}{l}\cdots \\
\cdots\end{array}$ & $\begin{array}{l}\text { Evernic acid. } \\
\text { Sabatrine. }\end{array}$ \\
\hline $61 \cdot 8$ & $5 \cdot 1$ & $3: 2 \cdot 0$ & $\ldots$ & $\ldots$ & Scleroxanthin. \\
\hline $61 \cdot 85$ & $5 \cdot 15$ & $3: 3 \cdot 00$ & $\cdots$ & $\ldots$ & Meconin. \\
\hline 61.86 & $5 \cdot 15$ & $32 \cdot 99$ & $\cdots$ & $\ldots$ & Benzohelicin. \\
\hline $62 \cdot 01$ & $5 \cdot 15$ & $33 \cdot 64$ & $\ldots$ & $\ldots$ & Cinchona-nova-red. \\
\hline 62.07 & $10 \cdot 35$ & $27 \cdot 5.8$ & $\ldots$ & $\ldots$ & Caproic acid. \\
\hline $62 \cdot 07$ & $3 \cdot 45$ & $34 \cdot 48$ & $\cdots$ & .. & Luteolin. \\
\hline $62 \cdot 17$ & $\$ \cdot 81$ & $29 \cdot 02$ & $\cdots$ & $\cdots$ & Gratiolin. \\
\hline $62 \cdot 17$ & $4 \times 1$ & $3: 3 \cdot 02$ & $\ldots$ & $\ldots$ & Rhatania-red. \\
\hline $62 \cdot 33$ & $6 \cdot 49$ & $: 31 \cdot 17$ & $\cdots$ & $\cdots$ & Crocin. \\
\hline $62 \cdot 4$ & $9 \cdot 0$ & $2,-6$ & $\cdots$ & $\ldots$ & Melanthin. \\
\hline $62 \cdot 16$ & $4 \cdot(6)$ & 32.89 & $\ldots$ & $\ldots$ & Catechu-tannic acid. \\
\hline 62.50 & $4 \cdot 17$ & $3: 3: 3: 3$ & $\ldots$ & $\ldots$ & Anemonin. \\
\hline $62 \cdot 68$ & $7 \cdot 46$ & $29: 5,9$ & $\cdots$ & $\ldots$ & Antiarin. \\
\hline $62 \cdot 32$ & 472 & $: 2 \cdot 36$ & $\cdots$ & .. & Linin. \\
\hline $63 \cdot 00$ & 50 & $30 \cdot 0$ & & $\cdots$ & Cnicin. \\
\hline $63 \cdot 09$ & $5 \cdot 17$ & $27 \cdot 32$ & $2 \cdot 12$ & $\cdots$ & Nepaline. \\
\hline $\begin{array}{l}6: 3 \cdot 1: 3 \\
6: 3 \cdot 16\end{array}$ & $\begin{array}{l}5 \cdot 26 \\
0.60\end{array}$ & 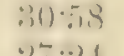 & $\ldots$ & $\cdots$ & Vanillin. \\
\hline $\begin{array}{l}\text { (1.). } 16) \\
63.14\end{array}$ & $\begin{array}{l}9.60 \\
6.58\end{array}$ & $\begin{array}{l}-27 \cdot 24 \\
25, \cdots 20\end{array}$ & & & Convallarin. \\
\hline 63.57 & $4 \cdot(6) ;$ & $31 \div 9$ & $\begin{array}{l}4.38 \\
\ldots\end{array}$ & & Colchiceïne. \\
\hline $63 \cdot 60$ & $8 \div 0$ & $2,-9 \cdot 90$ & $\cdots$ & & $\begin{array}{l}\text { Hrmatoxylin. } \\
\text { Uimitoxin. }\end{array}$ \\
\hline $63 \cdot 64$ & 6.06 & $30 \because 30$ & $\ldots$ & & $\begin{array}{l}\text { Phitoxin. } \\
\text { Physalin. }\end{array}$ \\
\hline
\end{tabular}




\begin{tabular}{|c|c|c|c|c|c|}
\hline C. & H. & O. & N. & S. & NAME. \\
\hline $63 \cdot 83$ & $6 \cdot 38$ & $29 \cdot 76$ & & & Coriamyrtin. \\
\hline $63 \cdot 8$ & $8 \cdot 2$ & $24 \cdot 9$ & $3 \cdot 1$ & $\ldots$ & Veratroidine. \\
\hline 63.92 & $5 \cdot 57$ & $27 \cdot 12$ & $3 \cdot 39$ & $\ldots$ & Narcotine. \\
\hline $64 \cdot 12$ & $11 \cdot 44$ & $24 \cdot 44$ & ... & $\ldots$ & Oenanthic acid. \\
\hline $64 \cdot 20$ & $6 \cdot 17$ & $29 \cdot 63$ & $\cdots$ & $\ldots$ & Filicin. \\
\hline $64 \cdot 23$ & 8.77 & $27 \cdot 00$ & 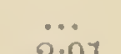 & $\ldots$ & Ceric acid. \\
\hline 64.42 & $8 \cdot 70$ & $23 \cdot 97$ & $2 \cdot 91$ & $\ldots$ & Veratrine. \\
\hline $64 \cdot 48$ & $4 \cdot 40$ & $31 \cdot 20$ & $\ddot{0}$ & $\ldots$ & Kämpferid. \\
\hline 64.55 & $8 \cdot 66$ & $23 \cdot 47$ & $3 \cdot 42$ & $\ldots$ & Delphinine. \\
\hline $64 \cdot 80$ & $13 \cdot 51$ & $21 \cdot 62$ & ... & $\ldots$ & Butylic alcohol. \\
\hline $64 \cdot 90$ & $7 \cdot 6$ & $27 \cdot 5$ & $\ldots$ & $\cdots$ & Cäilcedrin. \\
\hline $65 \cdot 11$ & $3 \cdot 87$ & $31 \cdot 02$ & $\cdots$ & $\ldots$ & Gentisin. \\
\hline $65 \cdot 26$ & $6 \cdot 66$ & $28 \cdot 07$ & $\cdots$ & $\cdots$ & Kosin. \\
\hline $65 \cdot 28$ & $5 \cdot 60$ & $\begin{array}{l}29 \cdot 03 \\
29 \cdot 09\end{array}$ & $\cdots$ & $\cdots$. & $\begin{array}{l}\text { Columbin. } \\
\text { Pvrocatechin, hydroqui- }\end{array}$ \\
\hline $65 \cdot 45$ & $5 \cdot 16$ & & $\cdots$ & & $\begin{array}{l}\text { Pyrocatecnin, } \\
\text { none, resorcin, etc. }\end{array}$ \\
\hline 65.49 & $7 \cdot 64$ & $11 \cdot 60$ & $15 \cdot 27$ & & Physostigmine. \\
\hline $65 \cdot 62$ & $3 \cdot 13$ & $31 \cdot 25$ & $\ldots$ & ... & Purpurin. \\
\hline $65 \cdot 69$ & $5 \cdot 11$ & $29 \cdot 20$ & $\because \ddot{6}$ & $\cdots$ & Santalin. \\
\hline 65.79 & $5 \cdot 48$ & $25 \cdot 08$ & $\begin{array}{l}3 \cdot 65 \\
\ldots\end{array}$ & $\cdots$ & Rhœeadine. \\
\hline $65 \cdot 85$ & $5 \cdot 64$ & $28 \cdot 51$ & $\dddot{7} \cdot 33$ & $\cdots$ & $\begin{array}{l}\text { Methysticin. } \\
\text { Chlorogenine. }\end{array}$ \\
\hline $\begin{array}{l}65.97 \\
66 \cdot 0\end{array}$ & $\begin{array}{l}5 \cdot 75 \\
4 \cdot 6\end{array}$ & $\begin{array}{l}20.95 \\
29.3\end{array}$ & $\begin{array}{l}7.33 \\
\ldots\end{array}$ & $\cdots$ & $\begin{array}{l}\text { Chlorogenine. } \\
\text { Mongumic acid. }\end{array}$ \\
\hline $66 \cdot 05$ & $8 \cdot 26$ & $25 \cdot 69$ & $\cdots$ & $\cdots$ & Laserpitin. \\
\hline $66 \cdot 38$ & $6 \cdot 38$ & $27 \cdot 23$ & & $\ldots$ & Limonin. \\
\hline $66 \cdot 44$ & 6.57 & $22 \cdot 15$ & $4 \cdot 84$ & ... & Cocaïne. \\
\hline $66 \cdot 66$ & $9 \cdot 63$ & $23 \cdot 71$ & $\cdots$ & ... & Hederic acid \\
\hline $66 \cdot 66$ & $3 \cdot 71$ & $29 \cdot 63$ & ... & $\cdots$ & Umbelliferon. \\
\hline $66 \cdot 67$ & 6.67 & $26 \cdot 66$ & $\cdots$ & $\ldots$ & Quassiin. \\
\hline $66 \cdot 67$ & $3 \% 0$ & $30 \cdot 63$ & $\cdots$ & $\cdots$ & Emodin. \\
\hline $66 \cdot 98$ & 6.98 & 26.04 & 7.10 & $\cdots$ & Athamanthin. \\
\hline $67 \cdot 00$ & $9 \cdot 64$ & $16 \cdot 30$ & $7 \cdot 10$ & $\cdots$ & Gelsemine. \\
\hline $67 \cdot 11$ & 5.43 & $27 \cdot 46$ & 0.70 & $\cdots$ & Brasillin. \\
\hline $67 \cdot 12$ & $11 \cdot 89$ & $11 \cdot 19$ & $9 \cdot 79$ & $\cdots$ & Conhydrine. \\
\hline $67 \cdot 20$ & $7 \cdot 20$ & $25 \cdot 40$ & $\cdots$ & $\cdots$ & \\
\hline $\begin{array}{l}67 \cdot 41 \\
67 \cdot 41\end{array}$ & $\begin{array}{l}5.62 \\
5.62\end{array}$ & $\begin{array}{l}29 \cdot 96 \\
29 \cdot 96\end{array}$ & $\begin{array}{l}\cdots \\
\ldots\end{array}$ & $\cdots$ & $\begin{array}{l}\text { Cubebin. } \\
\text { Curcumin. }\end{array}$ \\
\hline $67 \cdot 5$ & $8 \cdot 4$ & 20.5 & 36 & $\cdots$ & Staphisagrine. \\
\hline $67 \cdot 6$ & $4 \cdot 2$ & $28 \cdot 2$ & ... & $\ldots$ & Frangulic acid. \\
\hline $67 \cdot 71$ & $\mathbf{5} \cdot 88$ & 26.41 & $\ldots$ & $\ldots$ & Picropodophyllin. \\
\hline $67 \cdot 76$ & 6.45 & $25 \cdot 81$ & $\ldots$ & $\ldots$ & Orcin. \\
\hline $67 \cdot 85$ & $3 \cdot 57$ & $28 \cdot 58$ & & $\ldots$ & Paracotoïn. \\
\hline $68 \cdot 06$ & $5 \cdot 08$ & $14 \cdot 32$ & $12 \cdot 34$ & $\cdots$ & Chelidonine. \\
\hline 68.07 & $5 \cdot 04$ & 26.89 & 0.0 & $\cdots$ & Erythrocentaurin. \\
\hline 68.08 & $6 \cdot 31$ & $17 \cdot 05$ & $8 \cdot 56$ & $\ldots$ & Picroroceelline. \\
\hline $68 \cdot 22$ & $6 \cdot 66$ & $27 \cdot 65$ & 3.45 & . & Moschatine. \\
\hline $68 \cdot 39$ & $7 \cdot 77$ & $16 \cdot 58$ & $7 \cdot 25$ & $\cdots$ & $\begin{array}{l}\text { Ditaïne. } \\
\text { Salicylous and benzoic acid. }\end{array}$ \\
\hline $68 \cdot 85$ & 4.92 & 26.23 & $\cdots$ & 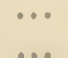 & $\begin{array}{l}\text { Salicylous and benzoic acid. } \\
\text { Elaterin. }\end{array}$ \\
\hline $68: 96$ & 8.04 & $\begin{array}{l}23 \cdot 00 \\
23 \cdot 20\end{array}$ & $\cdots$ & .. & $\begin{array}{l}\text { Elaterin. } \\
\text { Betaorcin. }\end{array}$ \\
\hline $69 \cdot 56$ & $7 \cdot 24$ & $\begin{array}{l}23 \cdot 20 \\
24 \cdot 86\end{array}$ & $\cdots$ & $\begin{array}{l}\cdots \\
\cdots\end{array}$ & $\begin{array}{l}\text { Betaorcin. } \\
\text { Alkannin. }\end{array}$ \\
\hline $\begin{array}{l}69 \cdot 72 \\
69 \cdot 76\end{array}$ & $\begin{array}{r}5.42 \\
11.62\end{array}$ & $\begin{array}{l}24.86 \\
18.61\end{array}$ & $\cdots$ & $\ldots$ & Capric acid. \\
\hline $69 \cdot 84$ & $4 \cdot 76$ & $25 \cdot 39$ & ... & $\ldots$ & Cotoïn. \\
\hline $70 \cdot 00$ & $9 \cdot 29$ & $20 \cdot 71$ & & $\ldots$ & Capsaicin. \\
\hline 70.05 & $6 \cdot 59$ & $16 \cdot 25$ & $7 \cdot 11$ & & Cusconine and aricine. \\
\hline $70 \cdot 38$ & $8: 50$ & $21 \cdot 12$ & & $\cdots$ & Absinthiin. \\
\hline 70.58 & $7 \cdot 95$ & $16 \cdot 60$ & $4 \cdot 81$ & $\ldots$ & Atropine, hy \\
\hline
\end{tabular}




\begin{tabular}{|c|c|c|c|c|c|}
\hline C. & HI. & O. & $N$. & S. & Nase. \\
\hline $70 \div 5$ & $5 \cdot \$ 8$ & $2: 3 \cdot 5 \cdot 4$ & & & Peucedanin. \\
\hline $70-5 !$ & $5 \cdot 26$ & $19: 2$ & $4: 3: 3$ & $\cdots$ & Sanguinarine. \\
\hline $70 \cdot 79$ & $6 \cdot 20$ & $18 \cdot s S$ & $4 \cdot 13$ & $\cdots$ & Papaverine, \\
\hline $50 \cdot 51$ & $4 \because 35$ & 24.84 & $5=$ & $\cdots$ & Chrysopicrin (vulpic acid). \\
\hline 70.57 & $7: 5$ & 1575 & $5 \% 1$ & $\cdots$ & Atherospermine. \\
\hline $\begin{array}{l}70 \cdot 57 \\
70 \cdot 9\end{array}$ & $\begin{array}{l}3 \cdot 94 \\
9 \div 5\end{array}$ & $\begin{array}{l}2.5 \cdot 19 \\
15 \cdot 6\end{array}$ & 399 & $\begin{array}{l}\cdots \\
\cdots\end{array}$ & Chrysophanic acid. \\
\hline $\begin{array}{l}70 \cdot ? \\
71 \cdot 00\end{array}$ & $\begin{array}{c}9 \cdot 5 \\
10 \cdot 05\end{array}$ & $\begin{array}{l}156 \\
15 \cdot 95\end{array}$ & $\ldots$ & $\begin{array}{l}\cdots \\
\cdots\end{array}$ & $\begin{array}{l}\text { Delphinoïdine. } \\
\text { Rottlerin. }\end{array}$ \\
\hline $71 \div 3$ & $5 \cdot 49$ & $2 \cdot 2 \div \div 3$ & & $\ldots$ & Pæoniofluorescin. \\
\hline $71 \div 5$ & $6 \cdot 67$ & $16 \cdot 54$ & $4: 91$ & $\cdots$ & Morphine and piperine. \\
\hline $71 \cdot 6+4$ & $5 \cdot 0.8$ & $1 ! \cdot 10$ & $4 \cdot 1.5$ & $\cdots$ & Berberine. \\
\hline $7 \cdot 2 \cdot 00$ & $S \cdot 00$ & $10 \cdot 65$ & 9.35 & $\ldots$ & Menispermine (?) \\
\hline $7 \cdot 2 \cdot 09$ & 12.04 & $15 \cdot 57$ & & $\cdots$ & Laurostearic acid. \\
\hline $7 \cdot 2 \cdot 21$ & $7 \cdot 02$ & $16 \cdot 06$ & $4 \cdot 68$ & $\cdots$ & Codeïne. . \\
\hline $72 \cdot 31$ & $5 \cdot 2 \cdot 2$ & $2 \cdot 2 \cdot 47$ & $\cdots$ & $\cdots$ & Chrysarobin. \\
\hline $72 \cdot 41$ & $1: 79$ & 1379 & $\cdots$ & $\cdots$ & Heptyl-alcohol. \\
\hline $7 \cdot 2 \cdot 18$ & $11 \cdot 11$ & $\begin{array}{l}16 \cdot 11 \\
16 \cdot 36\end{array}$ & ... & $\cdots$ & Ricinoleic acid. \\
\hline $7 \cdot 58$ & $8 \cdot 00$ & $\begin{array}{r}19 \cdot 36 \\
7 \cdot 45\end{array}$ & $13 \cdot 05$ & $\cdots$ & Pipitzahoic acid. \\
\hline $7 \cdot 2 \cdot 90$ & 6.54 & $\begin{array}{r}7 \cdot 45 \\
21 \cdot 62\end{array}$ & & $\cdots$ & Harmaline. \\
\hline $7.2 \cdot 0.2$ & $\begin{array}{l}5 \cdot 11 \\
7.69\end{array}$ & $\begin{array}{l}21 \cdot 62 \\
10 \cdot 25\end{array}$ & $8 \cdot 98$ & $\begin{array}{l}\cdots \\
. .\end{array}$ & $\begin{array}{l}\text { Cinnamic acid. } \\
\text { Quinamine. }\end{array}$ \\
\hline 73.17 & $7 \because 32$ & 19.32 & & ... & $\begin{array}{l}\text { Quinamine. } \\
\text { Santonin, eugenol, eugeni }\end{array}$ \\
\hline $7: 3 \cdot 2.3$ & $3 \cdot 5 \cdot 2$ & $1 \cdot 2 \cdot 2 \cdot 2$ & $10 \cdot 69$ & $\ldots$ & Indigo-blue. \\
\hline $7: 3: 31$ & 675 & $15 \cdot+4$ & $4 \cdot 50$ & $\ldots$ & Berberine and thebaine. \\
\hline $7: 3018$ & 567 & $7 \% 4$ & $13 \cdot 21$ & $\ldots$ & Harmine. \\
\hline $5: 3 \cdot 62$ & $11 \cdot 166$ & $14 \% 2$ & & ... & Bryoïdin. \\
\hline $7: 34 t$ & $13 \cdot 84$ & $12 \cdot 32$ & & ... & Caprylic alcohol. \\
\hline $7: 3 \cdot 55$ & $S \cdot 31$ & $1 \cdot 92$ & $12 \cdot 9 \cdot 2$ & $\ldots$ & Cytisine. \\
\hline 7:369 & $12 \cdot 28$ & $14 \cdot 0.4$ & $\cdots$ & $\cdots$ & Myristic acid. \\
\hline $\begin{array}{l}7: 3.97 \\
74.09\end{array}$ & $\begin{array}{l}4 \cdot 11 \\
8 \cdot 6 \cdot 2\end{array}$ & $21 \cdot 92$ & $17 \cdot 28$ & $\ldots$ & $\begin{array}{l}\text { Coumarin. } \\
\text { Nicotine. }\end{array}$ \\
\hline 7.4 .4 & $9 \cdot 7$ & 9.57 & $5 \cdot(02$ & $13 \ddot{7}\left(\mathrm{l}^{\prime}\right)$ & $\begin{array}{l}\text { Nicotine. } \\
\text { Chlorophyllan. }\end{array}$ \\
\hline 71.51 & $10 \div 6$ & $1+90$ & & $\ldots$ & Asclepin. \\
\hline $74 \div 7$ & $S \cdot 1 S$ & $9 \cdot 04$ & $7 \cdot 81$ & $\cdots$ & Aspidospermine. \\
\hline 546 & $5 \cdot 3$ & $21 \cdot 1$ & $\cdots$ & $\ldots$ & Grönhartin. \\
\hline 74.66 & 7.55 & $17 \cdot 78$ & $\cdots$ & $\cdots$ & Bixin. \\
\hline $55 \cdot 00$ & 354 & $21 \cdot 1 \cdot 1$ & $\cdots$ & .. & Alizarin. \\
\hline 7500 & $12 \div 0$ & $12 \div 0$ & & $\ldots$ & Palmitic acid. \\
\hline 7502 & 666 & $10 \cdot 43$ & $8 \cdot 61$ & $\cdots$ & Quinine and quinidine. \\
\hline 7501 & 9.07 & $15 \cdot 59$ & & $\cdots$ & Anacardic acid. \\
\hline $\begin{array}{l}7509 \\
75.75\end{array}$ & $\begin{array}{l}7 \cdot 09 \\
7 \cdot 37\end{array}$ & & $11 \cdot 02$ & $\cdots$ & Paricine. \\
\hline 76.06 & $12 \cdot 68$ & $\begin{array}{l}16 \cdot 85 \\
11 \cdot 26\end{array}$ & $\cdots$ & .. & $\begin{array}{l}\text { Helleborin. } \\
\text { Stearic acid. }\end{array}$ \\
\hline 7659 & 12.06 & $11: 35$ & & $\cdots$ & $\begin{array}{l}\text { Stearic acid. } \\
\text { Oleic acid. }\end{array}$ \\
\hline zt:S1 & $12 \cdot 00$ & & $11 \cdots 20$ & ... & Coniine. \\
\hline $76 \cdot 8: 3$ & $2 \div 3$ & $14 \cdot 64$ & $\ldots$ & $\ldots$ & Helenin. \\
\hline 76.0 .2 & $12 \cdot 2 \cdot 2$ & $10 \cdot 26$ & & & $\begin{array}{l}\text { Arachic acid, menthol, } \\
\text { capric aldehyde. }\end{array}$ \\
\hline $57 \cdot 07$ & $7 \cdot 05$ & $14 \cdot 9 \mathrm{~s}$ & & & Ostruthiin. \\
\hline & 6.51 & $5 \cdot 30$ & $8 \cdot(9) \cdot 2$ & & Strychnine. \\
\hline & $7 \cdot 48$ & $5 \cdot 14$ & 2... & & $\begin{array}{l}\text { Cinchonine and cinchoni- } \\
\text { dine. }\end{array}$ \\
\hline $77 \cdot 69$ & $12 \cdot 2 \cdot 3$ & & $10 \cdot 07$ & $\ldots$ & Methylconiine. \\
\hline $\begin{array}{l}7+0.2 \\
75.0 .5\end{array}$ & $\begin{array}{l}11 \cdot 69 \\
10 \cdot 57\end{array}$ & $10 \cdot 39$ & $11 \cdot 3$ & $\cdots$ & Borneol. \\
\hline 58.3 & $11 \% 2$ & $\dddot{m}$ & ? & $\cdots$ & $\begin{array}{l}\text { Sparteine. } \\
\text { Conessine. }\end{array}$ \\
\hline & $5 \cdot 68$ & $\cdots$ & $15 \cdot \$ 3$ & & Aribine. \\
\hline
\end{tabular}




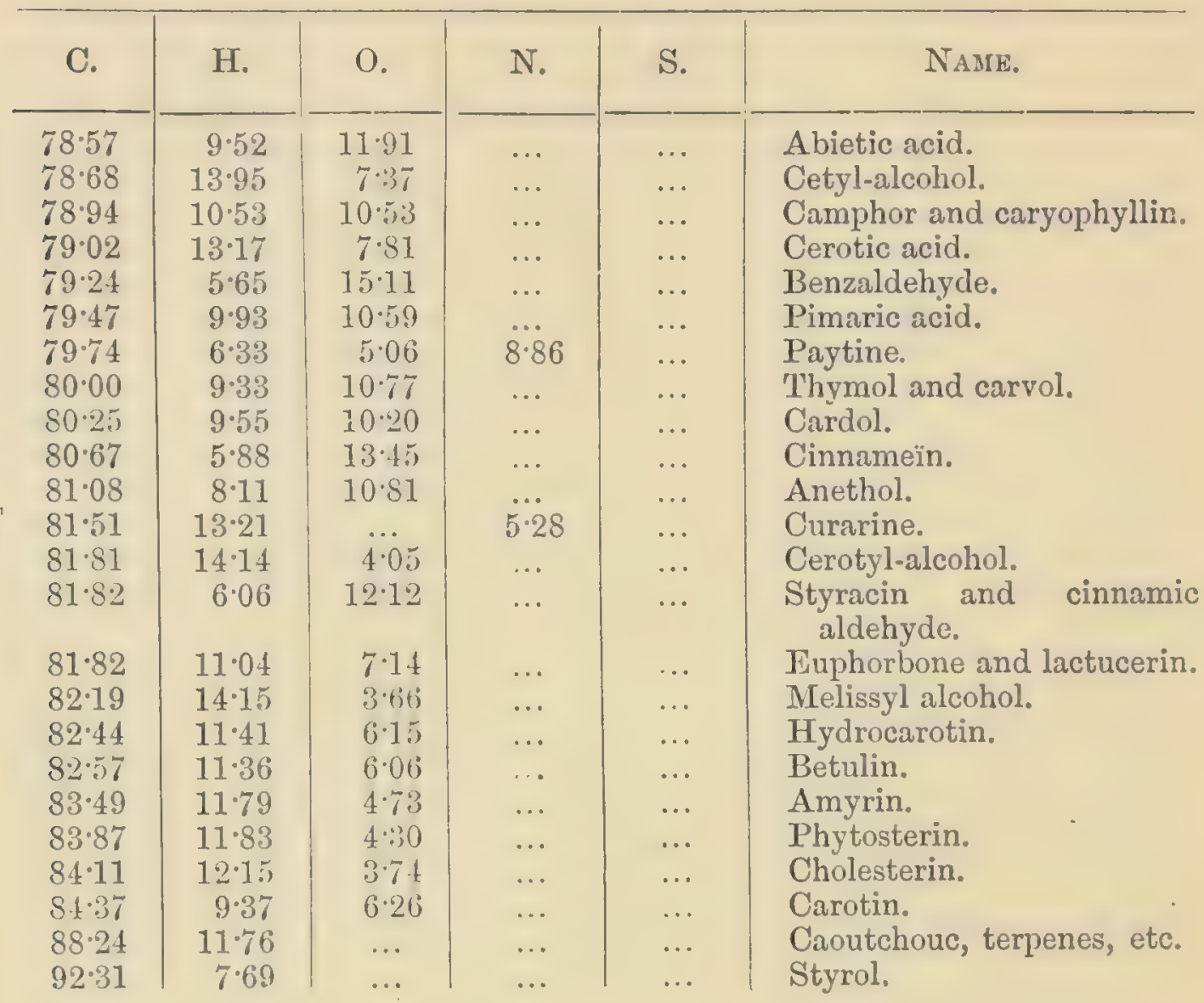




\section{N D E X.}

\section{Abietite, 225}

Absinthiin, 49, 146

Acacia, tannin of, 162

Acid, abietic, 127

acetic, 23, 24, 119, 226

aconitic, 70

acrylic, 24, 119

anacardic, 146

angelic, 13, 24, 119

anthemic, 146

arabic, $76,210,211,250$

arachic, 15

aspartic, 206

atranoric, 151

beberic, 146

benzoic, $32,33,35,49,226$

beta-erythric, 151

boheic, 160

butyric, 35, 119

caffeic, 161

caffeo-tannic, 161

cambogic, 135

capric, 13, 119

caproic, 13,119

caprylic, 13, 119

carbusnic, 150

catechuic, 41, 44, 156

, estimation, 157

catechu-tannic, 156

cathartic, 86,248

cathartogenic, 248

celastrus-tannic, 163

cetraric, 151

chelidonic, 148

chrysophanic, 36, 132

cinchona-nova-tannic, 163

cinchona-tannic, 162

cincho-tannic, 162

cinnamic, 25

citric, 70

" estimation of, 226,228

, reactions of, 226

crotonic, 119

diorsellic, 149

ellagic, 153
Acid, ellago-tannic, 160

erythric, 151

evernic, 150

everninic, 150

formic, $23,24,119,226$

filix.tannic, 162

frangulic, 133

fumaric, 70,232

gallic, 32, 133, 226

" detection and estimation, 47,137

gallo-tannic, 160; 226

gelsemic, 205 estimation, 159

glutamic, 207

glycolic, 233

glycyrrhizic, 171

gummic, 210

gyrophoric, 150

helianthic, 170

hydrocarbusnic, 151

hydrocyanic, 24, 29

isobutyric, 119

jalapic, 140

jervic, 148

kinic, 232

lactic, 232

lauric, 13, 112

lecanoric, 149,151

leditannic, 163

lichenostearic, 151

linoleic, 11

, estimation, 111

lobaric, 151

maleic, 232

malic, 70, 229, 234

, detection, 225

meconic, 148

melangallic, 137

melilotic, 108

metapectic, 211

metarabic, 88, 209, 211, 235, 243

metatungstic, 56

methylcrotonic, 13, 119

methylsalicylic, 30 
Acid, mongumic, 127

morintannic, 158

myristic, 15, 16, 112

myronic, 165

nitric, 78

, estimation, $83,84,85$

nucitannic, 163

octylic, see caprylic

œnanthic, 119

oleic, 11, 112, 113

"detection, 18

, estimation, 111

ophelic, 147

orsellic, 149

oxalic, 70, 91, 230

oxyusnetinic, 150

palmitic, 18, 112

para-oxybenzoic, 35, 36

parellic, 150

patellaric, 150

pectic, 211

pelargonic, 13

phosphomolybdic, 56

phosphoric, 226, 229

phyllic, 127

picric, 56

pimaric, 127

pinic, 127

pipitzahoic, 136

podocarpic, 127

podophyllic, 139

polygonic, 149

polyporic, 90

propionic, 119

protocatechuic, 35

pteritannic, 163

quercitannic, 161

quinic, see kinic

quinovic, 175

racemic, 70,229

rhatania-tannic, 157

ricinoleic, 19

roccellic, 149

ruberythric, 134

rubichloric, 232

rufigallic, 137

salicylic, 24, 32, 33, 49

salicylous, 24, 29, 168

santonic, 36 (see also 'santonin ')

sclerotic, 86,248

stearic, 18,112

stictic, 151

succinic, 230, 231

sulphuric, 226

sylvic, 127

taigusic, 136

tannaspidic, 162

tannic, 56

tartaric, 71

" estimation, 228
Acid, toxicodendric, 24

trimethylacetic, 119

usnic, 150, 152

valerianic, $13,24,35,119$

viridic, 161

vulpic, 150

Acids, 225

amidic, 247

estimation of in fruits, 71

examination for, 65,69

examination of substances soluble

in, 91

extraction with, 91

fatty, identification of, 120

, separation from resin, 112

lichen, 149

mineral, estimation of, 71

organic, estimation of, 69

produced by alkalies, 36

qualitative separation of, 70

resin, 32,127

tannic, estimation of, $41-47$

volatile, 23, 29, 117

Acolyctine, 58

, separation of, 119 .

Aconine, 58

Aconitine, 50, 179, 181

estimation of, 60

Acrinyl, sulphocyanate of, 166

Adansonin, 146

Aesculetin, 169

Aesculin, 49, 169

Agrostemma githago, saponin in, 68, 69

Albumen, estimation of, $79,80,238$

soluble in dilute soda, 88

vegetable, in mucilage, 66

Albumenoids, detection of, 78 estimation of, 231, 236, 237

examination for, 65,78

extracted by dilute acid, 240

extracted by pepsin, 240

extracted by spirit, 241

extraction of, 78

insoluble in dilute soda, 89

microchemical, detection of, 78

nitrogen in, 234

not precipitated by alcohol, 76

reagents for, 79

soluble in dilute soda, 88,235

Alchornin, 146

Alcohol, examination of substances soluble in, 38

extraction with, 38

amyl, 30

cerotyl, 13, 110

cetyl, 13, 110

melissyl, 13, 110

melyl, see melissyl 
Alcohol, octy1, 30

Alcohols, boiling points of, 30

Alcohols, primary, secondary, etc., 30

Aldehyde, angelic, 29

benzoic, 25

capric, 29

cinnamic, 25,29

methyl-capric, 29

pelargonic, 29

salicylic, 25, 29

Aldehydes, detection in ethereal oils, 29

Alder, tannin of, 156

Aleurites laccifera, wax from, 110

Aleurone, 236

Algarobilla, tannin of, 159

Alizarin, 133

Alkaloid, amorphous, separation from

cinchona, 194

of celandine, 50

of eschscholtzia, 204

of pimento, 50

Alkaloids, 178

colour-reactions of, $178,179,180$

confirmatory tests for, 57

decomposition by alkalies, 58

estimation of, 58,63, 182

examination for, 50,51

extracted in fixed oil, 19

extracted with alcohol, 38,48

extracted with ether, 33

extracted with petroleum spirit, 20

extraction from aqueous solution, 49

group-reagents for, 55

isolation of, 55

microsublimation of, 181

not separated by shaking, 57

of cinchona, 198

, rarer, 198

, separation, 194

platinum and gold salts of, 181

quantitative separation, 194

separation, 63,189

separation by precipitation, 193

separation by solvents, 191

tests for, 181

volatile, 50

Alkannin, 135

Almond, oil of sweet, 102

Aloe-resin, 177

Aloes, valuation of, 177

Aloins, various, 176

Alstonine, 203

Amanitine, 205

Amides, 205

Amido-compounds, 82

Amidulin, 249

Amines, 244

estimation of, 245

Ammonia, estimation of, 81
Ammonia, examination for, 78

Amygdalin, 164

Amylin, 253

Amylodextrin, 250

Amylum, see starch.

Amyrin, 109

Analysis, general method, 5

Anemonin, 109

Anemonol, 109

Angelicin, 109, 208

Anhydrides, action of alkalies on, 36

Aniline, 50

Anthochlor, 117

Anthoxanthin, 117

Anthracene, 136

Anthraquinone-derivatives, 127, 131, 136

Antiarin, 175

Antirin, 146

Aphrodrescin, 170

Apiin, 170

Apricots, oil of, 102

Arabin, 210

Arabinose, 218

Arbutin, 167

Argyræscin, 170

Aribine, 203

Aricine, 198

Aristolochia, bitter, 175 yellow, 146

Arnicin, 146

Asaron, 108

Asclepiadin, 146

Ash, estimation of, 7

Asparagine, 82, 206, $20 \%$

Aspidospermine, 50, 204

Athamanthin, 145

Atherospermine, 203

Atropine, 50 estimation of, 60,182

Bablah fruits, tannin of, 160

Beberine, 203

Beech-oil, 102

Belladonnine, 203

Benzohelicin, 169

Berberine, 49 estimation of, 62

Betaine, 205

Betaorcin, 152

Betapicroerythrin, orsellinate of, 151

Betulin, 145

Birch, tannin of, 162

Bistort, tannin of, 158

Bitter-almond oil, 29

Bitter principles, 127 extracted by alcohol, 38, 48 lead compounds of, 52

Bixin, 135

Brasillin, 137 
Brucine, 50 estimation of, 61,183

Bryoidin, 109

Bryonin, 170

Butylalanine, 205

Cacao, 187

Caffeine, 49 estimation of, 186

Cailcedrin, 146

Calabar Bean, estimation of alkaloid, 184

Calabarine, estimation of, 184

Calcium, oxalate of, 91 estimation, 91 microscopical detection, 92

Calendulin, 175

Californin, 175

Calycin, 151

Cane-sugar, 220

Caoutchouc, detection in fixed oil, 11 extraction of, 109

Capsaicin, 109

Capsicin, 109

Capsicum, 49 alkaloid of, 50

Caragheen-sugar, 219

Carapin, 175

Carbohydrates, see under respective names.

Carotin, 109

Cardol, 146

Caryophyllin, 49, 146

Carthamin, 178

Cascarillin, 49, 146

Casein, 235

Castor-oil, 102

Catechin, 32, 138 estimation of, 137

Catechu, tannin of, 156

Celandine, alkaloid of, 50

Celastrus, tannin of, 163

Cell-nucleus, 79

Cellulose, 252, 256 estimation of, 96 varieties of, 256

Ceratophyllin, 150

Cerosin, 111

Cerotene, 110

Cevadilla seed, 184

Chamælirin, 172

Chelidonine, estimation of, 62

Chelidonium, estimation of alkaloid in, 184

Chenopodine, 208

Chimaphilin, 147

Chiratin, 147

Chlorogenine, 203

Chlorophyll, 19, 113, 114 estimation of, 115
Chlorophyll, extraction of, 19, 32

Chlorophyllan, 114, 115

Cholesterin, 99 detection in fixed oil, 11 detection and estimation, 106

Choline, 205

Chrysarobin, 132

Chrysin, 128

Chrysophyll, 114

Chrysopicrin, 150

Chrysorhamnin, 135

Chylariose, 218

Cicutin, 147

Cinchona, amorphous alkaloid of, 191 tannin of, 162

Cinchona-alkaloids, estimation of, 62

Cinchona-nova-red, 163

Cinchona-red, 162

Cinchonidine, separation of, 194

Cinchonine, 49, 50 separation of, 194

Cinnamein, 25

Cinnamyl, cinnamate of, 25

Cnicin, 176

Cnicus benedictus, bitter principle of, 49

Cocaine, 203

Codeine, 50

Colchiceine, 49

Colchicine, 49 estimation of, 61

Colocynthin, 49, 170

Columbin, 147

Concluding remarks (to Part I.), 97

Conessine, 203

Conglutin, 235

Conhydrine, 50

Coniferin, 167

Coniine, 50 estimation of, $61,183,184,189$

Conquinine, see quinidine

Convallamarin, 49,172

Convallarin, 172

Convolvulin, 141

Coriamyrtin, 143, 170

Corydaline, 203

Cotoin, 147

Cotton-seed, oil of, 102

Coumarin, 108

Cratægin, 175

Crocetin, 171

Crocin, 171

Crude Fibre, 257

Crystalloids, 79

Cubebin, 49, 145

Curarine, 58, 179, 194, 202

Curcumin, 135

Cusconine, 198

Cusparin, 175

Cuticular substance, 95, 253

Cutose, 253 
Cyanophyll, 113

Cyclamin, 172

Cyclopiafluorescin, 163

Cyclopia-red, 163

Cyclopin, 163

Cynanchocerin, 108

Cytisine, 203

Daphnin, 49, 168

Datiscin, 170

Delphinine, 50

Delphinoidine, 50

Dextrin, 212

alcoholate of, 213

estimation of, $65,67,213$

estimation of in cane-sugar, 215

Dextrose, see glucose

Diastase, 237

Diethylamine, 244

Digitalein, 49, 143, 173

Digitalin, 142, 173

Digitaliresin, 142

Digitin, 143

Digitonein, 143

Digitonin, 143, 173 estimation of, 69

Digitoresin, 143, 174

Digitoxin, 142

Dimethyloreoselon, 145

Diosmin, 108

Distillation, fractional, 124

Ditaine, 204

Ditamine, 204

Divaleryloreoselon, 145

Divi-divi, tannin of, 156,160

Dulcamarin, 171, 204

Dulcite, 225

Ecboline, 202

Echicerin, 108

Echitamine, 204

Elaidin, test for oils, 102

Elaterin, 49, 147

Emetine, 50 estimation of, 61

Emodin, 132

Emulsin, 237

Ergotine, 202

Ergotinine, 202

Ericinol, 143

Fricolin, 49, 143, 166

Erythrite, diorsellinate of, 151 orsellinate of, 151

Erythrocentaurin, 147

Erythrophyll, 115

Erythrophloeine, 202

Erythroretin, 132

Erythrosclerotin, 131

Eschscholtzia, 204

Ethereal Oil, see 'Oil, ethereal'
Ethereal Salts, see 'Salts, ethereal'

Ether, direct extraction with, 36

estimation of substances soluble in, 32

examination of substances soluble in, 31

Etiolin, 116

Ethylamine, 244

Eucalyn, 219

Eupatorin, 147

Euphorbon, 108

Fat-acids, fixed, 14

fractional precipitation of, 14

free, 105

detection and estimation, 106

melting points of, 14,15

volatile, 13

Fats, see 'Fixed Oil '

Fehling's Solution, 72

Ferments, 237

Fibrin, vegetable, 235

Filix, tannin of, 162

Filicin, 99, 107

Fixed oil, composition of, 10

detection of, 10

elaidin test for, 10

estimation of, 10, 11, 99

estimation of glycerin in, 12

linoleic acid in, 11

oleic acid in, 11

qualitative reactions, 11

resinification of, 101

tests for, 101, 102

Fraxin, 169

Fresh plants, treatment of, 6,10

Fruit-sugar, 218

Fumarine, 205

Fungin, 253

Galactose, 219

Galls, tannin of, $156,159,226$

Gardenin, 127

Geissospermin, 49, 204

Gelose, 252

Gelsemine, 50, 205

General Remarks, 1

Gentian-bitter, 140

Gentisin, 139

Geraniin, 176

Glaucine, 205

Gliadin, 241 properties of, 242

Globularin, 170

Globulin, 235 estimation of, 79

Glucodrupose, $256^{\circ}$

Glucolignose, 256

Glucose, detection of, 214

estimation of, $72,73,7 \pm, 215,217$ 
Glucose, fermentation test for, 216 polarization of, 221

Glucoses, detection and estimation, 64,72 extracted by alcohol, 38, 48 various, 256

Glucosides, detection of, 53 direct examination for, 50 extraction of by ether, 33 extraction of from aqueous solution, 49 group-reagents for, 54 solubility of, 164

Glutamine, 82 detection of, 207 estimation of, 207

Gluten, 243

Glutencasein, 235

Gluten fibrin, 241, 242

Glutin, 241

Glycerides, 11

Glycerin, estimation of, 109

Glycyrrhizin, 171

Goa-powder, 132

Gold, chloride of, as alkaloid reagent, 56

Granulose, 249

Grape-sugar, see glucose

Gratiolin, 49, 172

Grönhartin, 136

Ground nut, oil of, 102

Guacin, 147

Guarana, 186

Guaranine, 186

Gum, 208

Gum arabic, varieties of, 211

Gum, see also 'Mucilage'

Gummicose, 210

Gum-resins, commercial, 129

Gypsophila struthium, saponin in, 69

Hæmatoxylin, 32, 33, 136

Harmaline, 203

Harmine, 203

Hazel nut, oil of, 102

Helenin, 108

Helianthus, oil of, 102

Helleborein, 49, 172

Helleborin, 172

Hemp, oil of, 102

Hesperidin, 171

Hesperidin-sugar, 225

Homofluorescin, 151

Hop-bitter, 147

Hop-resin, 49

Hop, tannin of, 156

Horse chestnut, tannin of, 158

Humus, 90

Hurin, 148

Hydrastine, 205

Hydrocellulose, 250
Hydrocarotin, 109

Hydrocotoin, 147

Hygrine, 203

Hyoscine, 60

Hyoscyamine, 50 estimation of, 60, 183

Hypochlorin, 114, 116

Incrusting substance, 95,253

Indican, 174

Indigo blue, 174

Indiglucin, 174

Indigo white, 174

Inosite, 219

Introduction, 1

Inulin, characters, 87 detection of, 66 estimation and extraction of, 86 examination for, 86

Inuloid, 87

Invertin, 237

Invert sugar, 218

Ipecacuanha, tannin of, 163

Isodulcite, 225

Isophlorrhizin, 169

Jalapin, 140

Jalapinol, 140

Jervine, 180

Juniperin, 148

Jurubebine, 205

Kämpferid, 108

Kawain, 148

Knoppern-galls, tannin of, 159

Kosin, 107

Lactose, 210

Lactucerin, 108

Lactucin, 176

Lactucon, 108

Laserol, 145

Laserpitin, 145

Laurocerasin, 164

Legumin, estimation of, 79,234

Leucine, 207 estimation of, 207

Leucotin, 147

Levulin, 212 alcoholate, 213 detection and estimation of, 67, 213

Levulosan, 220

Levulose, 218

Lichen-acids, test for, 151

Lichenin, 249, 251

Lichens, microscopical examination of, 151

Lichen-starch, 251

Lignin, 95, 252, 253 
Iignin, micro-chemical characters of, 255

Lignin, micro-chemical detection of, 95

Ligustrin, 170

Limonin, 171

Linin, 176

Linseed, oil of, 102

Liriodendrin, 148

Literature of plant-analysis, 3

Lobeliine, 50, 202

Loturine, 175,205

Lupinin, $176^{\circ}$

Iutein, 117

Luteolin, 140, 178

Lycine, 205

Lycopin, 148

Lycopodine, 205

Maclurin, 158

Maltose, 221

Mangostin, 148

Mannite, 77, 224

Marattin, 70

Marrubin, 148

Masopin, 148

Meconin, 148

Melampyrite, 225

Melanthin, 173

Melanthigenin, 174

Nelezitose, 221

Melitose, 221

Mrelting-points, determination of, 15

Menispermine, 205

Menyanthin, 49, 166

Mercuric chloride as allialoid reagent, 56

Metacellulose, 253

Methylanthracene, 136

Methylconiine, 50

Methysticin, 148

Milk-sugar, 220

NLoisture, estimation of, 5

MLonamines, 244

Morin, 158

ILorphine, 50 estimation of, $61,184,199$

MLorindin, 135

Morindon, 135

Mucedin, 241, 242

Mucilage, characters of, 210 estimation of, 65 examination for, 65 modified method of examination, 209 vegetable, 208

Mudarin, $176^{\circ}$

Munjestin, 135

Murrayin, 171

Muscarine, 205
Mustard, volatile oil of, $166^{\circ}$

Mycose, 221

Myosin, 235

separation from vitellin, $236^{\circ}$

Myrica cerifera, wax from, 110

quercifolia, ,, 110

species, " " 110

Myrobalans, tannin of, 156,160

Myrosin, 165

Myroxocarpin, 108

Narceine, 49,50

Narcotine, 50 estimation of, 61, 184, 199

Naringin, 171

Narthecin, 148

Nepaline, 60

Neurin, 205

Nicotine, 50 estimation of, 61,188

Nitriles, 27

Nitrogen, detection in ethereal oil, $2 \pi$ estimation of, 80

Nitrogenous substances, 244

Nucin, 148

Nucite, 219

Nupharine, 50, 205

Oil, ethereal, constituents of, 27 detection and estimation of, 21

detection of nitrogen in, $2 \bar{\tau}$

detection of sulphocyanogren in, 27

detection of sulphur in, 26

distillation of, 23

estimation of, 117

examination of, 25

examination for aldehydes, 29

fluorescence, 26

fractional distillation, $2 \overline{7}$, 124

optical tests for, 120

polarization of, 25

reactions of, $26,121,122$, 123

solubility in alcohol, 26, 120

specific gravity of, 26

stearoptenes in, 28

olive, 102

Oleandrine, 205

Olivil, 176

Ononin, 170

Operations, preliminary, 5

Opium, estimation of alkaloid in, 199

Orcin, estimation of, 152

Oreoselon, 145

Ostruthiin, 144

Oxyacanthine, 205 
Oxyaloin, 178

Oxycyclopin, 163

Oxyleucotin, 147

Oxyneurin, 205

Proniofluorescin, 36, 131

Panaquillon, 172

Papaverine, 49, 50

Papayotin, 237

Paracellulose, 253

Paracholesterin, 107

Paracotoin, 147

Paramenispermine, 205

Pararabin, 91 estimation of, 93

Paricine, 199

Paridin, 172

Parigenin, 174

Parillin, 174

Paytine, 199

Pectin, 208

Pectose, 253

Pelletierine, 205

Peptone, 239

Pereirine, 50, 205

Petroleum Spirit, estimation of substances soluble in, 8

Petroleum Spirit, extraction with, 8

Peucedanin, 145

Phæoretin, 132

Phaseomannite, 219

Philygenin, 169

Philyrin, 169

Phlobaphene, 88, 90

Phloroglucin, 35

Phlorose, 218

Phlorretin, 169

Phlorrhizin, 169

Phyllocyanin, 113

Phylloxanthin, 114, 116

Physalin, 49, 171

Physostigmine, 50 estimation of, 61,184

Phytosterin; 107

Picroerythrin, 151

Picrolichenin, 151

Picropodophyllin, 139

Picrosclerotine, 202

Picrotoxin, 49, 142

Pilocarpine, 50 estimation of, 184

Pimento, alkaloid in, 50

Pine, tannin of, 162

Pinipicrin, 167

Pinite, 225

Piperine, 49 estimation of, 188

Pittosporin, 170

Platinum, perchloride of, as alkaloid reagent, 56
Plumbagin, 149

Podophyllotoxin, 139

Podophyllum peltatum, 139

Polychroite, 171

Pomegranate, tannin of, 160

Poppyseed, oil of, 102

Populin, 49, 168

Porphyrine, 203

Potassiobismuthic iodide, as alkaloid reagent, 55

Potassiocadmic iodide, as alkaloid reagent, 56

Potassiomercuric iodide, as alkaloid reagent 55

Potassium, bichromate of, as alkaloid reagent, 56

Potassium, myronate, 165 tribromide, as alkaloid reagent, 55

Potassium, tri-iodide, as alkaloid reagent, 55

Powdering, 6

Preliminary operations, 5

Protoplasm, 79

Pseudaconitine, 60

Pseudamyl-alcohol, 30

Punicine, 205

Purpurin, 133

Pyrocatechin, 32, 33, 36, 138

Pyrogallol, 35, 36, 137

Quassiin, 49, 149

Quebrachin, 49

Quercetin, 36, 138

Quercin, 176

Quercite, 225

Quercitrin, 36, 138, 178

Quillaja saponaria, saponin in, 69

Quinamine, 198

Quinidine, 50 separation of, 194

Quinine, estimation of, 62, 185 separation from bark-alkaloids, 194

Quinovin, 175

Rape-oil, 102

Ratanhin, 208

Resin, detection in fixed oil, 11 extraction of, 31,38 micro-chemical detection, 33 separation from fat acid, 112

Resins, 127 acid, 34,36 "s separation of, 127, 128 action of potash on, 34 anhydrides, 34

behaviour to reagents, 34 commercial, 129 dry distillation of, 36 indifferent, $3 \pm$ 
Resins, micro $\cdot$ chemical examination, 33 oxidation-products of, 34 purification, 34

Resorcin, 35

Rhamnin, 135

Rhamnodulcite, 225

Rhatany-red, 157

Rhatany-root, tannin of, 157

Rhinacanthin, 135

Rhinacanthus communis, 135

Rhinanthin, 163

Rhinanthogenin, 163

Rhoeadine, 203

Rhœeaginine, 203

Rhubarb, Assay by Iodine, 248

Rhus succedanea, wax from, 110

Ricinus communis, oil of, 102

Robinin, 140, 178

Rottlerin, 149

Rubiadin, 134

Rubian, 134

Rubiretin, 134

Rutin, 140, 178

\section{Sabadilline, 50} estimation of, 61,184

Sabatrine, 50 estimation of, 61,184

Saccharose, Böttger's test for, 76 characters of, $76^{\circ}$ estimation of, 75 examination for, 65,72 inversion of, 75

Saccharoses, 220

Salicin, 33, 50, 168

Salicin-sugar, 218

Saligenin, 168

Saliretin, 168

Salts, ethereal, 29

Samaderin, 170

Sand, 7

Sangtuinarine, 62

Santalin, 137

Santonin, 36, 49 estimation of, 141

Saponaria officinalis, saponin in, 69

Sapogenin, 68

Saponin, 49, 173

estimation of, 68 examination for, 67

Sarracenia purpurea, alkaloid in, 50

Sarsaparilla, saponin in, 69

Scillain, 173

Sclererythrin, 134

Scleromucin, 249

Scleroxanthin, 149

Senegin, 49, 173

Separation, methods of, 3

Sesamé, oil of, 102

Sicopirin, 149
Sinalbin, 166

Sinapine, acid sulphate of, 166 sulphocyanate of, 166

Sinistrin, 212 alcoholate of, 213 detection and estimation, 67,213

Sinkaline, 205

Smilacin, 174

Soda, examination of substances soluble in, 88

Solanidine, 49

Solanine, 50

Sorbin, 219

Sorbite, 225

Sordidin, 151

Sparattospermin, 176

Sparteine, 50, 205

Special Methods, 99

Staphysagrine, 180, 193

Starch, 91, 249 estimation of, 93

Stearoptene in ethereal oil, 28

Styracin, 25

Strychnine, 50 estimation of, 61,183

Styrol, 108

Suberin, 95, 255

Sugar, estimation by polarization, 221

Sulphocyanogen, detection in ethereal oil, 27

Sulphur, detection in ethereal oil, 26

Sumach, tannin of, 159

Sunflower seed, oil of, 102

Surinamine, 203

Syringin, 49, 170

Syringopicrin, 170

Tampicin, 140

Tanacetin, 149

Tanghinin, 149

Tannin, constitution of, 152

decomposition of, 152, 153, 154, 156

detection of, 39

detection of glucose from, 153

ellagic acid from, 153

estimation of, 41.47

extracted by ether, 31

extraction of, 40 alcohol, 38

gallic acid from, 153

glucosidal nature of, 153

insoluble in water, 156

microscopical detection of, 40

purification of, 155

reactions of, 40

separation from alkaloid, etc., 52 various, $153,162,163$

Taraxacin, 149

Taxine, 50, 205 
Tea, $186^{\circ}$

tannin of, 160

Thebaine, 50

Tectochrysin, 128

Terpenes, 28

Thalictrin, 180

Theine, estimation of, 62

Theobromine, 49 estimation of, 187

'Thevetin, 172

Thujin, 140

Toxiresin, 143

Trehalose, 221

Triethylamine, 244

Trimethylamine, 245

Trimethylaniline, 50

Triticin, 212 alcoholate of, 213 detection and estimation, 67,213

Turpethin, 141

Tyrosine, detection of, 208 estimation of, 207

Umbelliferon, 36

Valonia, tannin of, 159

Vanillin, 167 estimation of, 144

Variolinin, 151

Vasculose, 253

Verantin, 134
Veratrine, 50

estimation of, 61,184

Veratroidine, 179, 189

Viola tricolor, 139

Violaquercitrin, 139

Violin, 203

Vitellin, 235

Vitellin, isolation of, 236 separation from myosin, 286

Walnut, oil of, 102

Water, examination and estimation of substances soluble in, 65 mineral matter dissolved by, 65

Wax, Bahia, 111

Carnauba, 111

microscopical detection, 111 vegetable, 13,110

Wood-gum, 249, 252

Wormseed, estimation of santonin in, 141

Wrightine, 203

Xanthein, 117

Xanthin, 117

Xanthophyll, 114, 116

Xanthorhamnin, 135

Xanthosclerotin, 149

Xylostein, 149

Zeorin, 151

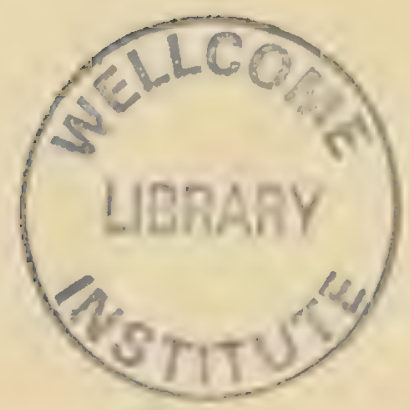





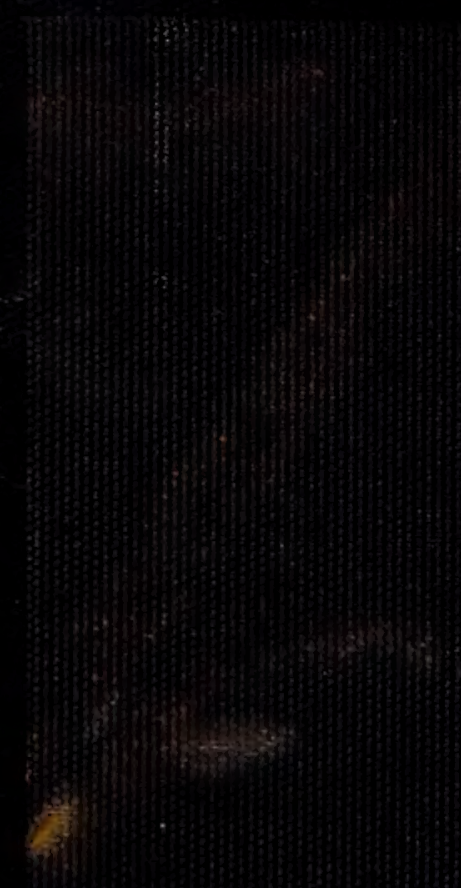

